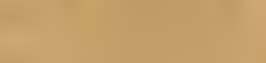

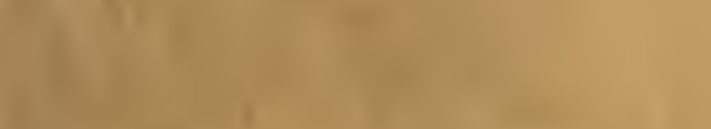

with
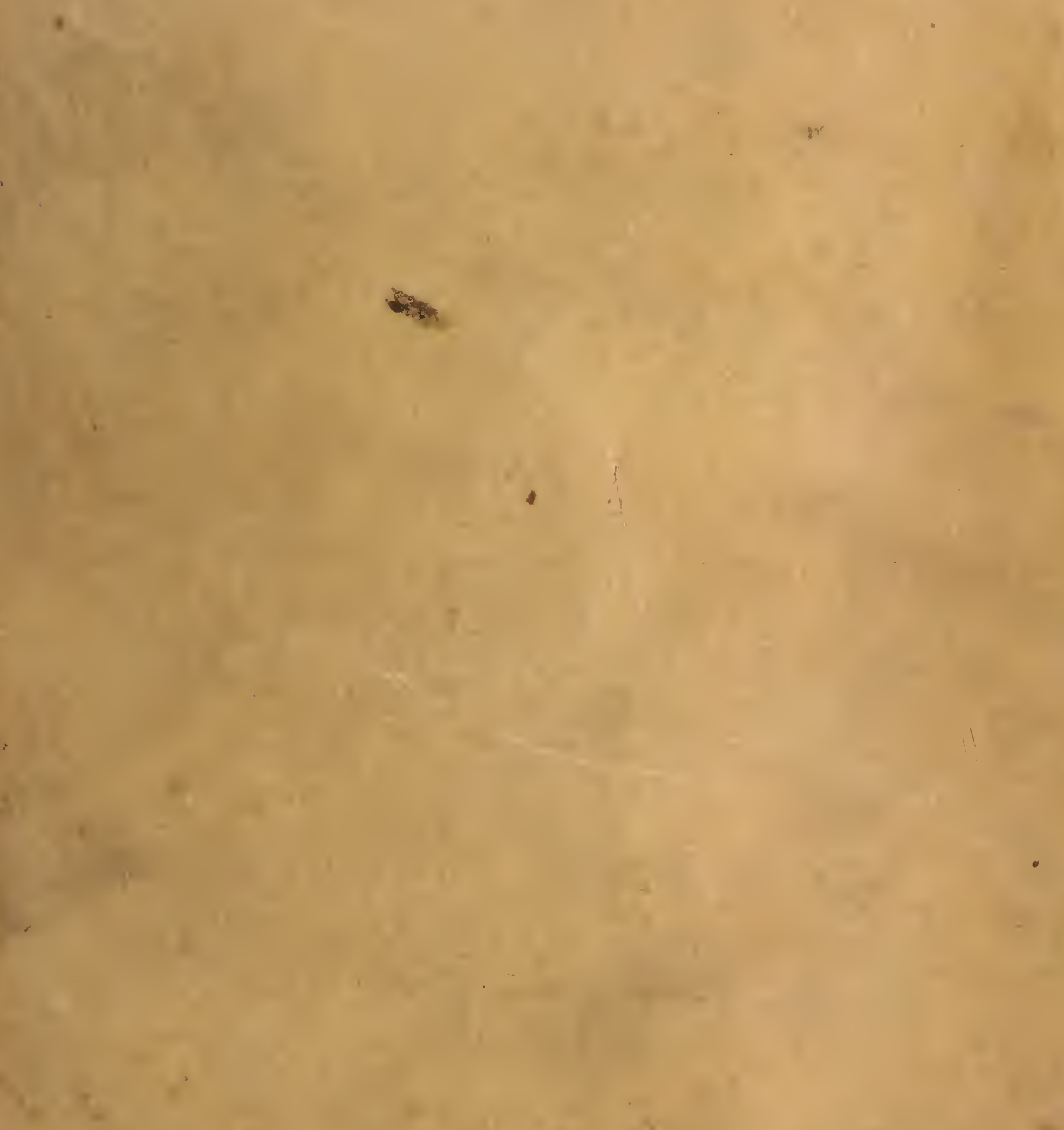

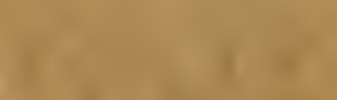

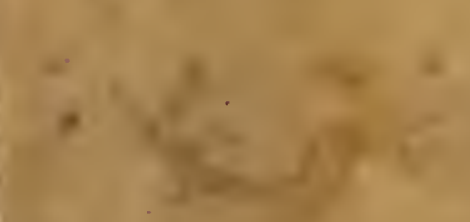
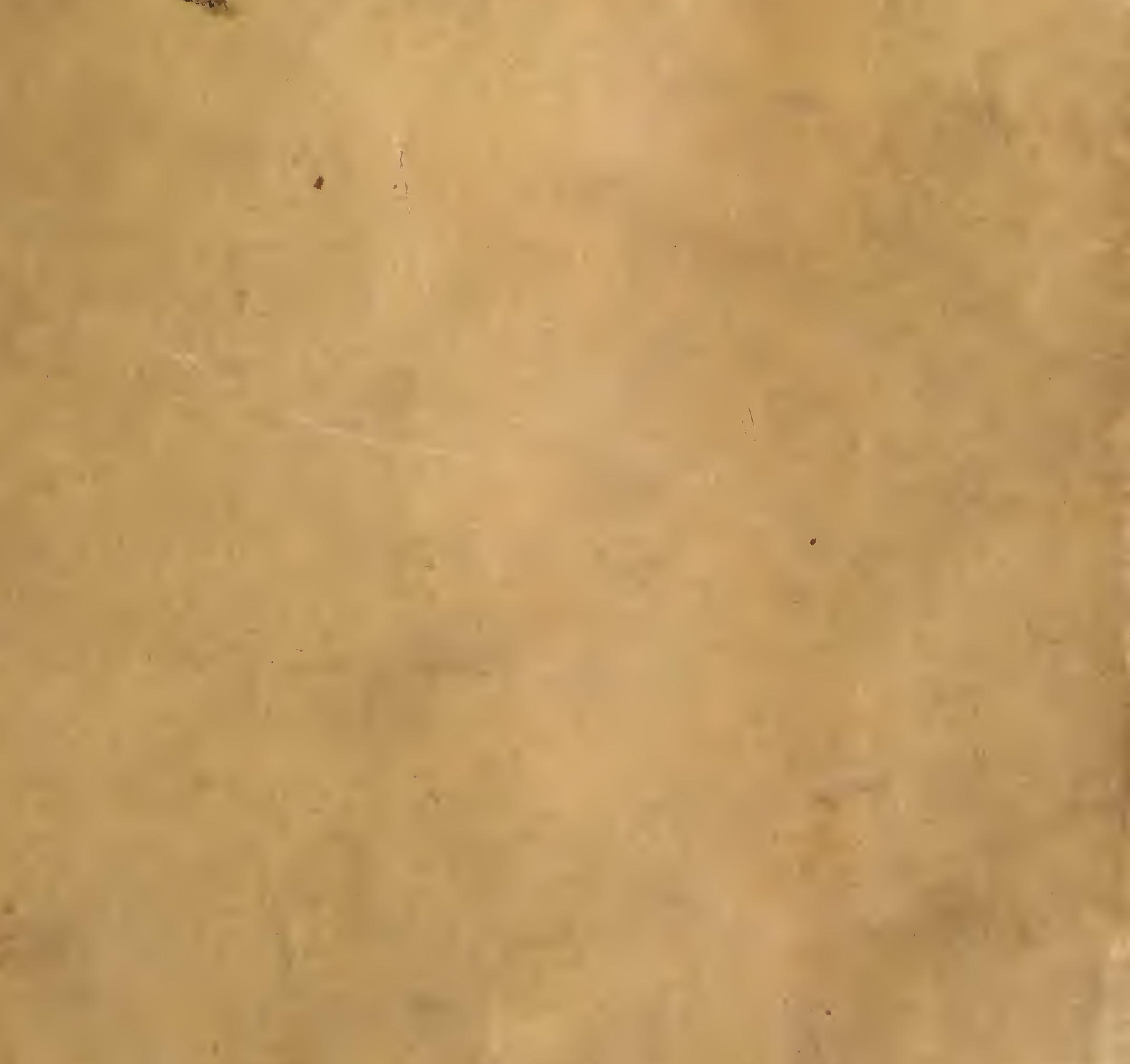
The Dibner Library of the History of

Science and Technology

SMITHSONIAN INSTITUTION LIBRARIES
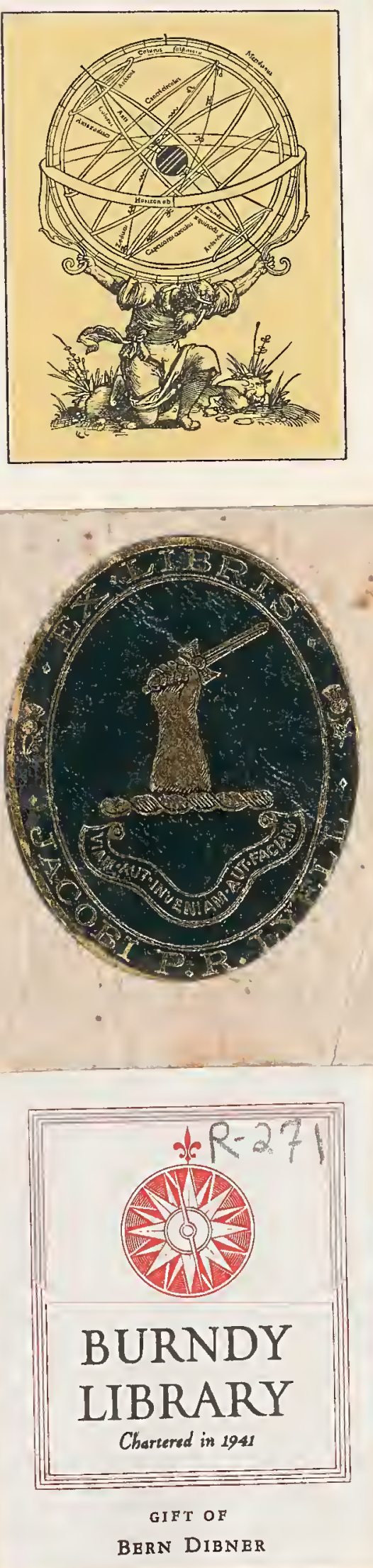


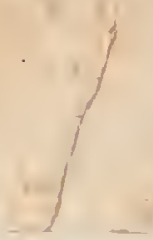

ROLFWINCK (W.) : FASCICULUS IEIVPORUM.

VENICE,ERHARD RATDOLT, I 485, Sept.8th.

Folio. no signatures. 8 unnumbered ff. \& 66 numbered ff

In two columns in part.

WITH IUANY IITERESTING CUTS OF TOWNS, DIAGRANS, \&C.

FAIN *6935; Br. Mus. Cat. V;/ Redgrave, No.52.

One of the most interesting of Ratdolt's illustrated books and containing one of the earliest views of Venice.

A good copy in which the first leaf of text(fol.9a cum num. i.) has been beautifully illuminated by a border of flowers and foliage in gold and other colours, extending on all four sides of the page and with a circular shield at foot for the insertion of Arms. Rubrouted throughout and the a cuts throughout the book have also been illuminated in colours by a contemporary artist.

There are contemporary notes of ownership in $\mathrm{ms}$. on the blank recto of folio i, and on the blank verso of the last leaf. The binding of old vellum has the cipher of the Collegium Germanicum et Vngaricum in Urbe and the Arms of Gregory XIII., stamped on the back. There is a similar binding in all respects in the British Museum on one of their Venice incundbula. (see IB20283)

As indicatine the clerical ownership of this copy, it is interesting to note that on fol.57, cum num. 49 , the reference to Fope Joan,"dictus Ioannes papa et fuit femia et meretrix (!)occulta et fuit de anglia natione" has been struck out with two lines of ink across the paragraph.

e. $\mathrm{V} \cdot \mathrm{IO} / 32$

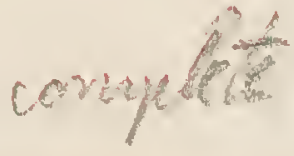




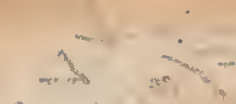 \\ $\cdots+4$}

1 $1+\cdots \cdot \cdots$

5
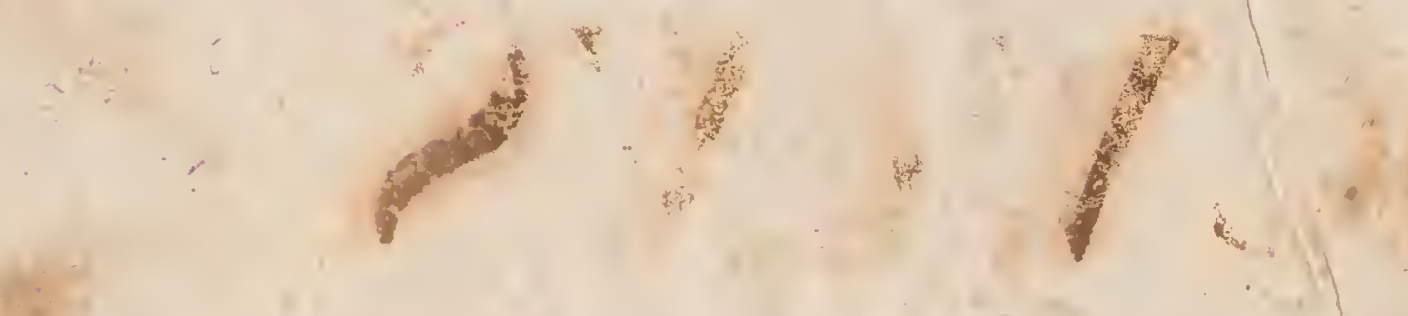

11

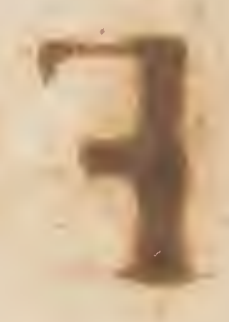

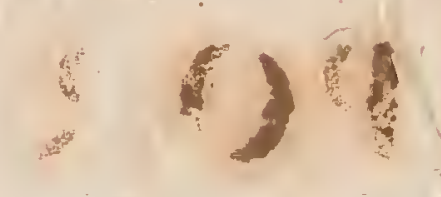
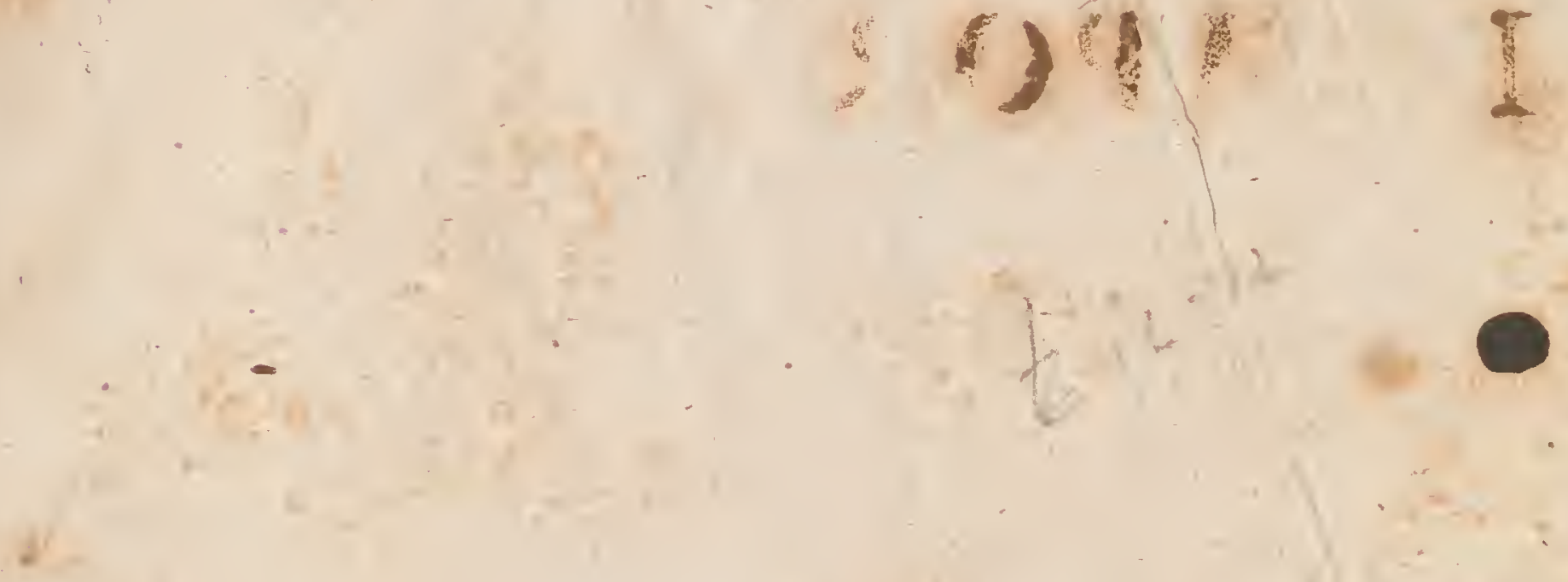

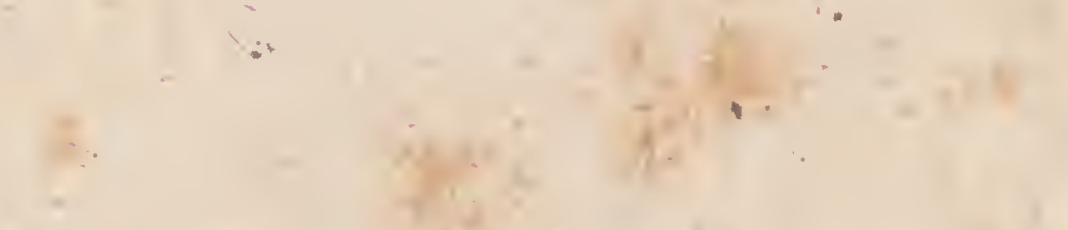

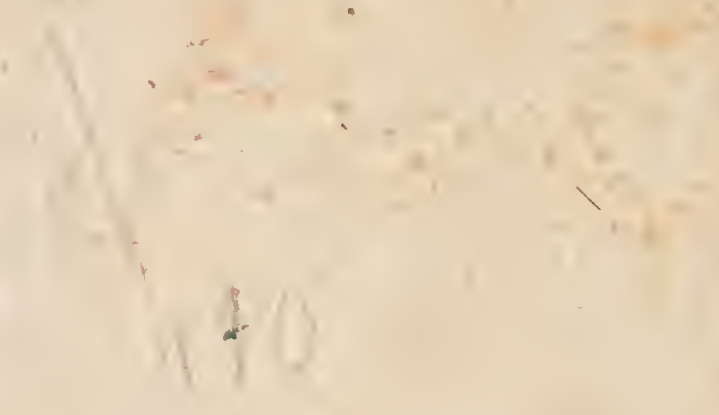


AASICVLVS

\section{TEMPORV M}

$=$

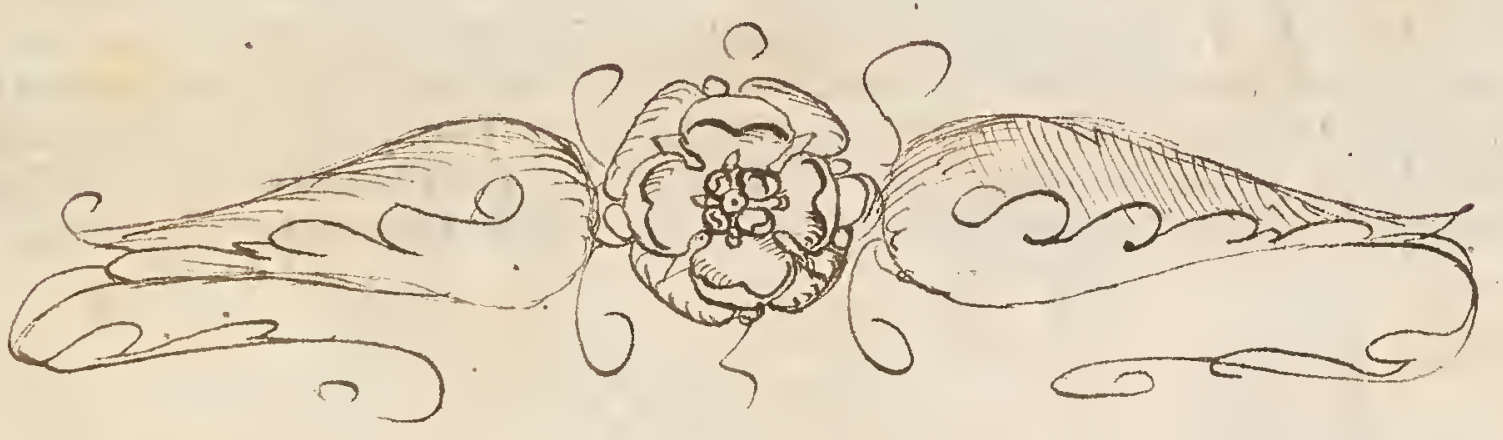




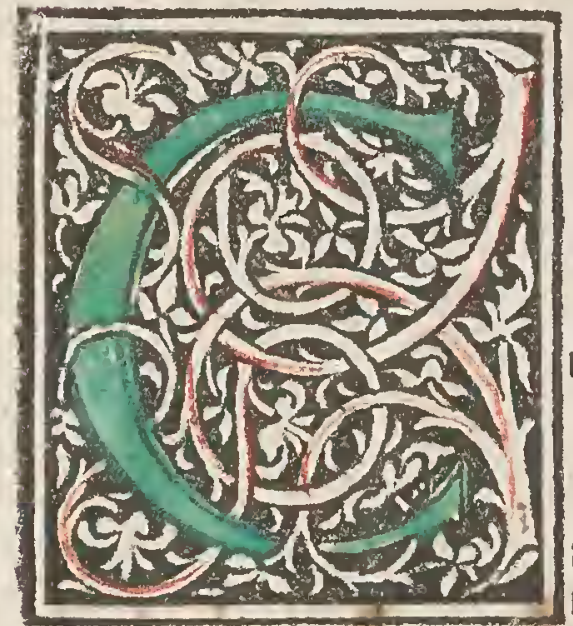

Dgitaui fępius Tlicolae magnifice: $r$ in litterarü ftudijs emi nentiffime: Quo tandë mun ere p noftra iam inueterata ami citia te o onare poffem. Auefiuig oiu rem:que nö fozet afper nanda: $z$ tuę imenfe o octrinę uô impar z condigna effe vide. retur:Eonfideranfos $\tau$ animovertens. Zuiro patricio rem nul lam eque cōducibilê foze; ac biltiozie ipfítus verä agnitionê: utpote quę vitę noftrę fit magiftra:veritatis lux:tempoz mi. niftra: $z$ que nos oeniq a moztalitatis îuria vendicet. fta tui imṕrentia cá tèpozú fafciculū qué äter folus ego bis i parti. bus italie impofitis ozdine fuo figuris r fignis ante bac im. pzeffi cura z opa oiligentiozi impzimendü fumpferim: opus ipfum labozefá meos tibi oicare:quo z beniuolentiā meã in te palam facerê:nofcerefq; maiozg etiả p te me fubiturü: qut " ptereg i eligendus eft qui ingento ooctri a qliave anipi in tute polleat : quétibi virtuti

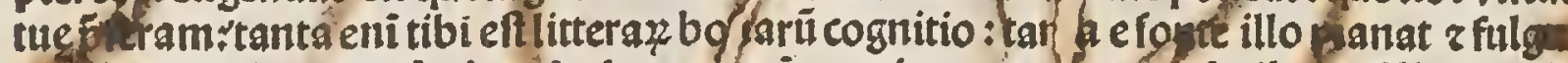
vîz eloquentię:tam admiranda renten arü grauitas:tam frar z fenile onfilium:ut ie dem qua es oecem r nouem annozü clateplura क̈ credi par eit. be te po ceri videaris:E nibil etiä pzęter bęc ad te eroznandun oefit:non opes:nö clientelę:nó cognati:nô amici: r Inp omnia accedit illa tua tam potens: vetus $r$ generofa gentilitas in vabe tam opulentiffi. ma:quid ut alios omittam pelariffimos inpatozes: Th bom petrum z ioannēeferam:tres bzeni interuallo in rep.fummosz ariftroc tie zinici es: [u quo adbuc feliciflime oegit:tu vo becc onnia quodâmodo ooctring tua bumanitate $r$ amicos liberalitate ac munificen tia fiuperas: quẹ fola pzęter iam oicta alia me ad boc agendü impellerêt : quare 2Docenice mi magnifice farciculum tempo tibi babe,quicad qualifüque fit ipfuz tibi oico:zp amv citia noftra mutuag inter nos beniu olentia tui rít volo:z fi quid etiá: qõ inemendatü fuer rit .caftig̊ueris: ¿eniä nö oepzecaboz:cī opus nô publicauerim necreiectiöi vllus ampli? extet locus:Din' 'nicolse te nominatim appellaui: z patrocinius meis verbis mibi ademi: Interim te rogare nô oefinã: velis interdum intermiffis pbilóopbię ftudijs:quę tua ppzia funt:an imü ad bẹc aliquantulü leuioza applicare: erunt enim tibi bęca longo zimenfo ftu diozü laboze veluti 'olatiolum quoddă: vbi cũ antiquozū tū maiozù tuozü etiam gefta in ferts inuenias ea ad magna omnia pzo rep.tua fubeunda magis accenderis. Ulale: 
CI Labula cómodifima fuper libzo requẽti qui farciculus oicit tempozü Zn âgdē vbicüq púctus añ numez apparet:gefta i pziozi folio za latere: bi vo poft ipolteriozi ut reperient oenotat.

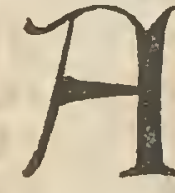
$\begin{array}{lr}\text { Sacucppliaminoz } & 15 \\ \text { Zbacuc martyr } & 32 \\ \text { Zbdiasppbeta . } 11 & 12 . \\ \text { Zbbdon iudex. } 9^{\circ} & 8 .\end{array}$ Zabdon z Tenmes martyres $\quad .32$ Zlbdoppbeta כ̄bieroboä 9. Zbel pzim'martyr inocens 2 . albeffon inder ifr'bonus 8. Zabyas rexiuda $\quad .10$ Ztbiatbar pontifex gloziótus 9 Zlbiuf filius garon Zlbymelecb iuder ifrl malus .s \&bymelecb pontifex .10 Zlbifue pontifer Zlbiutb oux fili'çozobabel .17

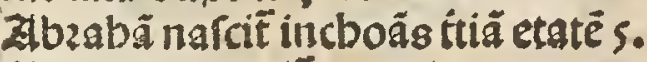
Zababam mozit 25

IIAcbaçrexiıda Zácbeluold'cṕs vintonieri. $\quad 52$. Alcbiss filonites ppbeta Zlaymags fili'\{adocb pötifer .9 Acbymelecb facerdo6 onii .9 Acbim rex 19. Acbis filuitts rexalban" 9 . Zlobitob pontifer $\quad .9$ Zlcbitob facerdos $\quad 9$ Zcbitob pontifex $\quad$.13 Zcies ignee rup bierufalę $\quad .21$ Zlcies ignee vifé fút in celo .40 Acbó cititas foztiflima capit 59. Z d

ZAda uel oda prozlamecb Zdoppbeta 10 zadam pzimus bö format 2. Zldam mozit Zldamarus pirfcüs . 51 Zldditio anuo zeçecbieregis 13. Zldeodatis papa 43. Zldelbertus vir ́cús $\quad .52$ Żdelberttis eps meteĩ. $\quad 53$. Zdo vir religiofus 42 . Zldolpbus impatoz $\quad .60$ Adrianus beliçeus impatoz $\quad .29$ Zdriants papa prim? $\quad .47$ Zdrianus papa fecĩdus 49. Zdrianus papa tertilis $\quad .49$ Zddriantls papa quartus 56. Zdrianuspapa quintus $\quad .59$ zildrian'cronograpb'r möacb' 54 . 교 $f$

CAffrican'icipio roman? .21

Zffricanus iulius

.32

$$
\text { 2 } 8
$$

dagamennon rex grecops. ägar famula fare 5 . Agapitus martyr 32. Zlgapitus martyr $\quad .33$ Agapes Zlgapitus papa prim? Zlitapitus papa fecúdus Ȧgeric ${ }^{0}$ virdunenfis epss Ziggeusppheta Zlggeus increpat populí .17

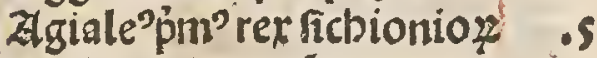
Zzgilis abbas feús 42 . Zligilolph'eṕs colonieri. 45. Zgatbo papa IIgatba virgo $2 \mathrm{martyr}$ Agnes vtrgo r martyr Agricola martyr ZI grippa filtui'rex italie Agrippina ciltitas 2. $b$

đatbab rer itrlidolatra

atbialon iuder

Zy padanus eps

Zlymundus rex anglie

$$
\text { z. } 1
$$

व) Alan'ooctor vnitierfal .60 allbafiluitis rex albanie 9 . zalbertus magnits 58. Zlbertus impato? $\quad .60$ Zllbertus impato2 63. Zllbert'p riar.bierofolymo 57. Zlbiutus martyr 33. Zllbinis vir rés 38. Albinus andegalteri.epss 45. Albo abbas floziacen. $\quad 52$. Alcbin'oe gîne facerdotali 21 . allcibiades focraticus 17. Zllcbozan'lexmacbumeti .\$2 Zlebuin'vir ooctifinus 46. Zllexius vir fanctus $\quad .35$ Zlletander narcit alexandria ciuitas 18. Zlerandermagn'regnat 19. Zllexãder uel Z̧ăne'pótifex. 22. Zlexandet rex fyrie $\quad .22$ Zllexandra in linea pon. $\quad .23$ alexander medicus $\quad .30$ Alexander mgĩ osigenis $\quad 30$. Zlerander mamee ipatoz 31 . Zllexander ep̧s bierofolpmo. rum martyr

Zlerander

.32

.33

Zllexander eṕs alexädrie $\quad .34$

zlexander oe balis ooctoz 53

Zlekander oe villa oei $\quad .59$ allexander papa pzim" 29 .
Zlexander papa recüdus

Zlexander papa tertius $\quad 56$.

Zlexander papa quart 59

Zlerander papa quint? 62 .

Alexandria martyr $\quad .36$

Almania

Almericus bereticus

.59

Zltinus oircipul'fci petri $\quad .270$

Amalecb oelet praul

żman'eṕs aureliaceit. $\quad 36$.

Żmandus vir fcús éps $\quad .40$

Amarias facerdos

Amarias pontifes 12.

Zmatbus exulat $\quad .44$

Amaçonü fíue maffagetarum

regnum ozitur 4ó

Almaçones funt mulieres 8.

Amaçias rexiuda $\quad .12$

Ambzofi"roman"ooctoz .35

Anelius comes aluertieii. 47.

Almic'zberican'martyres 47 .

Amict'rex aflyrio 7 . 7 .

Zminadab pzinceps iuda $\quad .7$

Aminius paratoz iudee $\quad .25$

Ztmitbus rexaffirio $\quad \sigma_{0}$

Ztmmon fitilis lotb

Zimmon monacbus $\quad .36$

Amos rexiuda 14.

Zlmouppbets 12.

ZImos p F. 3000.monacho 34. Amram filitis caatb 6 . $\begin{array}{lll}\text { Atmri rexifrael } & .10 \quad 10 .\end{array}$ z in

IZAnaclet'paparmartyr 28. Alnanias .15

Znaftalia virgo 33.

Anaftafius imperato? bere' ticus

Anaftafius impatoz $\quad .45$

Anaftafils papapiimus . .36

Znaftafius papa fecúdus . .38

Znaftafius papa tertius $5 \sigma$.

Zliaftalitis " 50.

Zlnatbolia pirgo r martrr 32.

Znatboli' ép 8 cốttantino. .37

Znaragozas $\quad .17$

Zntrelm"ep̧s cantuarieñ. 54.

Ancilla .36

Ancbifespater enee

Zncus rexromanoy is

ZAndreas aplins 27.

Andoen'rotbomageit. 44

Zneliutus martpr 31.

Znfridus epus trariecteri. $\quad j 2$.

ZAnglia q̃ $r$ bzitānia capit̃

Zanglia ad fidé côuertî́ 30 . 


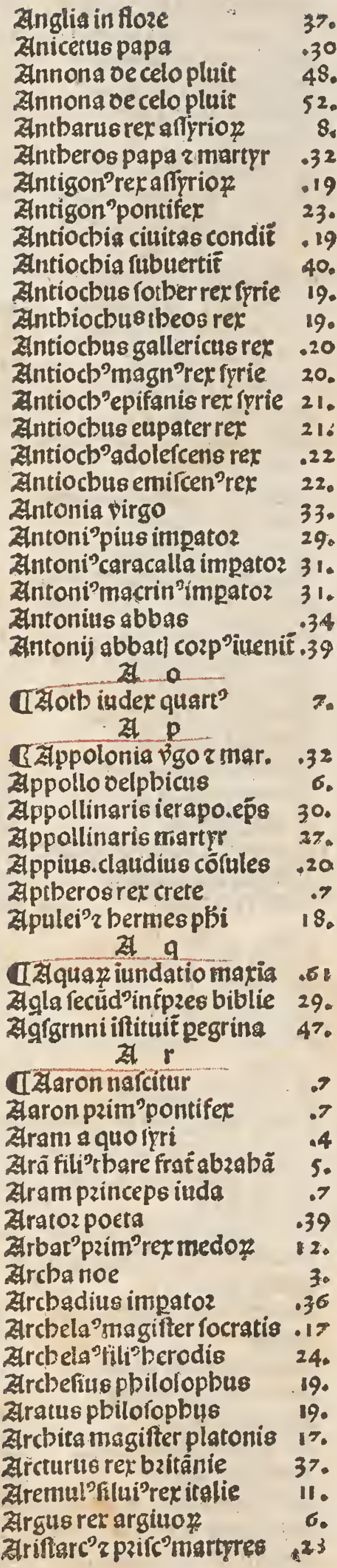

Ariftides pbiloropbus .29

Ariftoteles audit platone . Is

Ziriftoreles famoris babet is.

Ziriftobol'iudesperypa. 21.

Znriftobol "p̉n"rex facerdos 22.

Zarmamitre rex afprioz $\quad .6$

Armenia maioz a tburcis 46 .

Zarmili'filui'rexitalie $\quad 12$.

Ammulpb'éps turoneit. $\quad 38$.

Antulpb"ourlotbozingie .43

ZAmulpb'arcbieṕs slugdu. 54.

Arabarat fill'sem

Zrpbarat rex medo 16.

Arionmitbilene? $\quad .15$

Arrius rexalfpriog 5 .

Zlritus bereticus $\quad .34$

Arfamusgzargus rex is.

Zrtabas imenrura 19.

Zartaban'2experfarä 17.

Zarbakerfes rex perfay 17.

Arrbemoni'beretic

Artifices libzo impiffozes .64 Zi 1

प्याद .10

Zlapb 9

Zlica 33.

Aflcanius rex italie $\quad .9$

Zlcatadeo rex affyrio $\quad .7$

Afer filius iacob $\quad .6$

Zifaradon rex affirlox $13^{\circ}$

Affenes filius gomer 3 .

zafluerts rex perfari $\quad$ is

Zlfumptio beate virginis 26 .

Zfiura quo affrij

Zftozius martyr 310

Aftronomimaximi 60.

$$
\text { z. } t
$$

Tatbatia vxoziozm .11

Atbanafi"epsalexâdrine .34

Atbenas cicrops cōdidit $\sigma$.

Zthenienfes 18

Zabenienfes fub magiftratu .9

Ziblas aftrolog ${ }^{9}$ magn' $\sigma_{\text {. }}$

Zttalus fundantentur ecclie $: 30$

Zttila rex bino 2

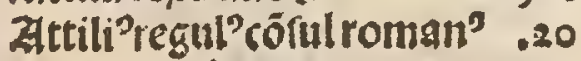
स 4

प2aluccius (ubaracon? .31

Zunentinus filut' rex italie . 12

Zuguftus impator 23.

żuguftin'ep̄us flozet 35.

Zuguftin'venerabilis .41

Zututus abbas aurelianeif. 38.

ztuitus abbas carnotein. $\quad .39$

Zuinionis cituitas capit 45 .

Zulus romanus $\quad .22$

zurea sbbatiffa fancta 42,
Aturelius impator

Aurelianus impatoz

31.

Zuftregiffl'eṕs lutburi.

Auftregifilins biturieri.

zuttria

\section{Z3}

daksabel rex fyrie

Zjarias filius obetb

Zzarias pontifex

Azarias uel ozias rex iuda

Ajarias pontifex

Zzzoriss ppbeta

Ajarias filius acbimags

2302 oe tribuiada

B 4

abara rexifrael

Babplon metropolis

Babylon veftruit

Babplonia nous condit

Babillis martyr

Balagm ppbetat r occiditur

Bala concubina iacob

Baleus rex affyrioz

Daltbaçar rex babylonie

Sarbara virgo z martir

Bardo vir fancuts

Barlagm eremita

Barnabas coaplits pauli

Bartolomeus aplus

Bartbolus r baldus legifte

Barucb ppbete

Eafilides

¿afilins củ feptëmar.

Bafilius magnus ooctor

Salolus abbas

Batbildis regina francie

"Batuel filitis nacboz 52

TIBeda venerabilis ooctor

Begardi multi cōbufti runı

Bella atbenienfiú

Bella focialia oziuni

Bella continua

Bella intefting

Bella cituilia incipiúr.

Sella plura in oituerfie ptib"

Bellü marcomānicui

Bellǘfranco z $z$ angloy

Bellifari'patritius comes

Belorus rex affrioz

Belus paimus rex affyrioze

Benadacb rex fyrie

Genadab filius açaelis rex

Benedictus pzimus papa

Benedictus fecüdus pap

Benedicus tertius papa

Benedictus quantuspaps 
Defilentia magna

Deftilentia grauis

- Petreitus re pfodit

Petronella filia fci petri

petronelle cozpus zë.

petronius éps

Petrus aplus r papa

Petrus

Detrus oamafcenue

Petrusoamianus

Detrus alpbonltus

Detrus abaelardus

Petrus Lombardus ep̉s

petrus comeftoz

Detrus tbarentafieñ.

Detrus oetbarentafia

Petrus nouts martp:

Petrus de eliaco

Petrusmanicus

D $i$

Tipilatus peurato 2 iudee

pbilemonplits

- Dbilemon

Pbilippus rer macedonú

Dóbilippus rex

Pbilippus rex frrie

Dbilippus aptus

Pbilippus epus

Dbilippus ṕfectus

Obilippus pimts impator

Dbilipp'fecúdus impatoz .45

Dbilippus tert!'impator 57.

Dbilo oifertifinus 26.

pbilometor rex .21

pbinees pontifex

pbinees filius beli

Pippin'p2im? rex francoz

Dippintus filius karoli

-Dícis marintus

Pitagozas plos primus

Ditus primuts papa

Dius recüdus papa

pius lodouicus ret is 1

I Placella vxoz theodoni 35.

plagabozzibilis 48.

Dlatopbiloropbus $\quad .18$

Dlautus eloquens 20.

Plinitus fecudus 02atoz 28.

plotius retboz

pluralitas beneficioni 53 .

Plures ciututates côfracte $\quad .55$

Plutarcus pbiloropbus 28. p 0

IT

pompeitus trogus

.30

Dompeins mareellus con rales

Pontionns martyr
Dontiantis papa r martyr 31. Dozpbirius plus $\quad .32$

Doztentü ignis in celo .61

Doffefio ecclefie

.01

Dotétion'oifcipul'fci petri 27 . is $r$

IPraredis virgo

Dzaredis quieuit

.27

Dzedfinatozú berefis

.30

Dzeiectus o marin'mar.

Dbriges

Driam'quidã nobilis 35.

primus z feliciante 33.

pifícillianus epss

Pzifcus tarquinus res

Pifcus martpr

Drifeus martyr

pzifcin' auto: grämatice .39

pziuatus martpr 31.

Szobus impatoz

Prochasfiluine $\quad 12$

Pzocefus martyr $\quad .27$

Drodigiamagna 19.

Prodigiaplura 27.

Pzorper epsaquitanie 37.

Drotbafitis martyr

Protbus riacinctus 30.

pzorimns pzeforter $\quad .32$

Prudentius poeta $\quad .36$

$$
\text { is to }
$$

I Ptolemets fotber ret 22

ptolemens alerander $22_{a}$

Dtolemetts cleopatra $\quad 22$.

prolemetis oionyfitus : 22.

Dtoleme? rex esgpti is

Diolemetrs pbiladelpb" 19.

Ptolemens suergetes $\quad .20$

Dtolemens pbilopater $\quad .20$ i 4

(T) Publitus roman" . 22 publius slucius romani 22 . Dudentiana virgo

Duella quedã.tí.annoy 49 puellababuit. s.vulnera .64 puer quidã iudens $\quad .40$ Dueri be almania 57. Puerifimicbatis $\quad .64$ - Dugna fancta ozitur $\quad .40$ - Sbul rex afirioz . 12. IOuadratus ep̃us $\quad .29$ Duattuoz cozonati $\quad .33$

Quintius reptus in rure 17.

Duintius romantus 23.

Quiriats martyr

Quiriacus ep̄s $\tau$ martpr .35

Quirinus martyr . 32.

Duirinus martyr
Quirintus martyrtribuntus .29 Quint'curcius pbilofopbs is. Duint'fcipio roman" .23

Quint'flamini'romantis 21 .

Auintus ennitus poets .20 $R \quad$

ARagb vroz falomon $\quad 7$.

Racbbodusourfri. 45 .

Fadeguadis reging 40

Raimundus 58.

Raglin rex fprie 2.

$$
\text { R }
$$

TRbedona ciuitas 48

Rbea virgo filia regis : is

Rebeccamater iacob 5 .

Reformatio pma rci brídicti.50

Reformatio mag̈ plinoz .64

Reges iuda incipiut $\quad .9$

Reges ifrtincipiunt . 9.

Regina faba 9.

Reginulpba virgorc $\ldots . .43$

Tegma

Regnú itudecreftituit 22.

Reguú tartarozú incepit .57

fiegulus ep̆us arelateit. : .28

Regufar rex babylonie . 16

Kegreffio iu.in biert. $\quad 16$.

Renigius eṕs remeñ. $\quad 37$.

Retbaredus ret gotboz 40.

Rerapbricerpianus 57.

TRicard'virduneĩ.abbas 53 .

Ricard"oelicó victoze 55.

Kipbat filius gomer 3.

$$
\text { R } 0
$$

IRobert'rexfrancie .53

Roboam rex iuda 9.

Rodoaldus ер̄แs $\quad .43$

Rbodusinfulacapit $\quad .60$

Foma in meroze

Roma deftruit a laracenis $4 \mathrm{~S}$.

Roma capit a gotbis $\quad .36$

Romanus papa

Romäi faracenos incfibiüt 44.

Rome ciuitan icolenuerati . 23

Rotbarilögobardozret 42 . B 4

RKuben p̉mogenit'iacob .6 Rupertus impato2 62 . $5 a$

U.Saba filius cbus

.4

Sabatba

Sabataca 4

Sabufardacb rexbaby, :..16

Sabellius bereticus ' 326

Sabingmartyr 298

Sabinus 33.

Sqdocb pontifert 


\begin{tabular}{|c|c|c|c|c|c|}
\hline Sadocb pontifer & 136 & Scifma.xip.ecelefie & 52. & Serapis rex & б. \\
\hline Sadocb oe tribuiluda & .19 & Scirma.xiij.ecclefie & .53 & Sergius pzimtus papa & .44 \\
\hline Safrus rex affiriog & .7 & Scifma.xiiij.ecclefie & .53 & Sergius fecüdus paps & 48. \\
\hline Salaberga abbatiffa & 41. & Silma.xp.ecclefie & .54 & Sergius tertius papa & 50. \\
\hline Salatbiel oux ifrael & 15. & Scirma.rvi.ecclefie & 54. & Sergius quart’papa & 53. \\
\hline Sale in linea xṕi & .4 & Scifma.xvij.ecclefie & .55 & \multicolumn{2}{|c|}{ Sergitus epus a oco plagatus } \\
\hline Salinus eṕs & .48 & Scifma.rviij.ecclefie & 55. & & 46. \\
\hline Salomon filius naafon & 7. & Scima.xip.ecclefie & .56 & Serotinus martpr & 27. \\
\hline Salomon rexpacis & 9. & Scima.xx.ecelefie & 56. & Sertuacius tungrop eps & 35. \\
\hline Salmanaçar rex alfyrio z & .13 & Scifma.xxj.ecclefie & 60: & Seraile bellü in fieilia & 22. \\
\hline Saluftius cripus & .23 & Scifma.xxij.ecclefie & .62 & Sertitus ppli írtlincipit & $\sigma$. \\
\hline Samaria condit & 10. & Scirma.xxiij.ecclefie & 63. & Seruitus tulli'troman ${ }^{2}$ & .16 \\
\hline Samarite & .4 & Scifms peffinü ozitur & .62 & Sertuius flascus romani & 226 \\
\hline Samnites & 18. & Scifing ozit̃ in impio & 57. & \multicolumn{2}{|c|}{ Seruus feruoz oci inftituif a } \\
\hline Samus & 9. & Scitarü regnù oziť & 4 & gregozio papa & .41 \\
\hline Simprna & 9. & Scotica gens oziț & 27. & Seuera abbatiffa & .43 \\
\hline Samproniudex & 8. & \multicolumn{2}{|c|}{ Scurrinus pzim?abbas vul } & Senerin’arcbieps coloñ. & 35. \\
\hline Sampfon eṕs & .40 & denfis vir fanctus & .46 & Setuerinus papa: & 42. \\
\hline Samuel iudex & .9 & $-5 e$ & & Setb filins adam & 2. \\
\hline Sanctin'ep̃s melderí. & .28 & ISebaftianus martyr & .33 & Setbçelo vir fanctus & 55. \\
\hline Sangarindex & .7 & Sebafte olim famaria & .13 & $5 i$ & \\
\hline Sanguis oe celo fluxit & .47 & Secta cbozífantiü & .62 & USibplls famia & 7. \\
\hline Sanguis oe imagine rë. & 46. & Secüdus pbilofopb? & .29 & Sibpllia oelpbica & .8 \\
\hline Earaballa fupftitiofum ten & & Sedecbias rex & .15 & Sibpllia frigia & .18 \\
\hline plumedificat & .19 & Sedecim milia martyrü & 34. & Sibỵlla ery̨tbzea & .13 \\
\hline Sarai vroz abzabam & 5. & Sedes cardinaliü rč. & 58. & Sibylla ramia & .15 \\
\hline Saraigs pontifex & .15 & Sela vroz lamecb & $3 i$ & Sibỵlla cumana & .14 \\
\hline Sardanapall?rex affyrioz & 12 & Sela filiusiude & .6 & Stbplla bellerpontia & 16. \\
\hline Saraceni de apbzica & 45. & Seleucia cilntas condit & 19. & Sibylla tiburtina & .24 \\
\hline Saracenipficiunt & 45. & Selencus rex fyrie & 19. & Siccitas magna & 55. \\
\hline Saraceniquitabane & 50. & Seleucus ceränes rex & 20. & Siclus magnus annoys & .54 \\
\hline Sarucb filits reu & .5 & Seleucus iners rex & .21 & Spdon argitus & 12. \\
\hline $59 g 9 g$ rex egypti & 9. & Sellizrerifrael & 12. & Sigdon velet & is. \\
\hline Saturnin?eps tbolofan" & .28 & Sellum pontifex & 14. & Sigibertus filius regis & .42 \\
\hline Saturn'rex italie & 7. & Sem filius noe & 3. & Signa bozzibilia & 39. \\
\hline Sauinianus ер́s & 27. & Semuyas dar babet & 9. & Signū crucis gpparuit & 47. \\
\hline Sauinianus papa & 41. & \multicolumn{2}{|c|}{ Seniramis affyrioy reging 5 . } & \multicolumn{2}{|c|}{ Signa multa p̃ceffetunt mozte } \\
\hline Saul paim?rexifrt & .9 & Sempzonian'martyr & .33 & karoli & .48 \\
\hline Squluspfternit & 26. & Sempzonius romain & .20 & Silegs apud macedoniă & 27. \\
\hline Saxonia conuertiē & .47 & Senpioni? palerius & 20. & Silla romanus & .23 \\
\hline & & Seneca floichs & .27 & Silueriuspapa & 39. \\
\hline IScacbozuludus repit & 15. & Senefius lugduneit. & .44 & Siluefterpzimpapa & 33. \\
\hline Sceptrü de iuda aufert & 23. & sennacberib rex affirioz & 13. & Siluefterfecüdus papa & 52. \\
\hline Scipio fäminius roman? & 20. & Seno impatoz & 37. & Siluefter tertius pqps & 53. \\
\hline Scipio,affricanus & .21 & Senopapa & .44 & Siltuitus rex italie & .9 \\
\hline Ecipionafica & .22 & \multicolumn{2}{|c|}{ Senones galli cum romanis } & \multicolumn{2}{|c|}{ Simacbus quartus interpzes } \\
\hline Scipio fetprï ithgulauit & 23. & pugnant & 17. & legis oiluine & 39. \\
\hline Scif́ma primú in ecclia oei & .32 & Sepultus karolus rex & .46 & Simacbus parritipmar. & 38. \\
\hline Scifme fecundü ecclefie & .35 & Septem macbabei & 21. & Symeon arcbieṕ & 3.40 \\
\hline Scifma tertiü ecclefie & 35. & Septem fapientes & 13. & Simillanus abbas & .40 \\
\hline Scifma quartũ ecclefie & 36. & Septem oormientes & .32 & Siminicus pzerbpter & .30 \\
\hline Scifma quintü ecclefie & 38. & Septē oozmiētes euigilät & .37 & Simifius eps & 27. \\
\hline Scirma retri ecclefie & 38. & Septugginta intpretes & 19: & Symmon comes & $57:$ \\
\hline Scifma reptimü ecclefie & 44. & Serapbis martyr z pir & 29. & Symon inftus pontifer & 19. \\
\hline Ecifma octauñ ecclefie & .48 & Serapion marţr & .32 & Symon filius onie & 20. \\
\hline Scifma noni ecclefie & .50 & Serapion & .33 & Symon fili'matbatbie & 226 \\
\hline Scifma oecimü ecclefis & 51. & Serapion pater ber & & Symon magus & 27. \\
\hline Ecifme,xj.ecclefie & 51. & monacbozü & .35 & Symon r indas apti & 27 \\
\hline
\end{tabular}


Smmon deopbe

Stmplicius papa

Sigírmúdus impator

Simpbozianus

Simpzonianus martpr

Sindulpbus pzelbyter

Sine undice

Sine rege

Synodus nicens

Synod'oftãtinopolitana

Synodus epbefins

Synodus calcedoneñ.

Synod'oftãtinopolitana

Synod?oftãtinopolitana

Synodus reptima

Synodus octaus

Sypontus ciuitas

Sppontusivaitataflauis

Erracula condiẗ

Siricius papa

Sifinnilts papa

Sixtus p̉mppapa rmar.

Sixtus fecudus papa

Sixtus tertitus papa

Sixtus quartus papa

$$
50
$$

asocrates pbusnarcit

Socrates pbius

Sol oecé lineis renertiẗ

Sol in celo imobilis ftat

Solobicurat

Solobrarat

Soles outo apparuerit

Solénis ep̃us

Solipus fidonius roctoz

Solira pericula plura

Sopbianobilis matrona

Sopbocles poeta

Sopboniasppbeta

Sozes pzim'rexegypti

Softratus pbari oftruxit

Sotberpapa $z$ martyr

TIspartani $5 p$

Speculü biftoziale

Spes virgo r martyr

Speufippusplís

Spines cozong oñ flozuit in manu karoli

Spís fcüs fup aplos

spüs gatidôis mitts retelat 60 .

$$
5 t
$$

Statius cecilius

Staninlaus ệs

$31:$

Stattia marmozea

58.

Gtellamagnain Oziente

Stepban'p̣mppapa zmar. 32.
Stepbart'recüdus papa

.46

.17

$$
\text { s } \mathfrak{u}
$$

TSte bro? ude

Sulpicius bitureri.

Stulpicius fetuerus

Süma occifo\% oe perfis

Stunderoldus eps

Supbene oeiapbet

Sufis

$$
I
$$

QIabernaculuppara

Zacitus impato?

Ialiarandus cardinat"

Ialmud iudeor

Ibarepater abzabam

Iarquinus fupbus

Iarris a quo cilices

Zartaripmiffione rec.

Zartari oellaftant

Zartari inuadüt

Ibauranus rex afiyrioz

Zarinus éps ebozacent.

Zarentü capiẗ

Tauramenia capiĩ

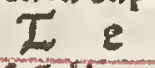

ILecla ică birgo

Ieglatpbalaffar rex

Zelexion rex ficbionioz.

Lempoza groffa ż̈.

Iempla paimí joftruunt

Zemplú falomôis incẽdit

Zemplü fundat

Iemplü purgat

Iemplū fopbie extruit

Eemplarijoeftruunt

Zẻplù oñi i egypto extruit Epa fanguinolents

Ipa crtenta
Ipa pecaminola

Ipa multú fupftitiofa.

61.

Ipa fatis turbulenta

61. Iempus effeminatü

Ibeodocion tertius interpes

$$
\text { oiune legis }
$$

Ibeodol'martyr roiacon" .29

Ibeodericus martyr $\quad .35$

Ibeodericus arriants $\quad .38$

Ibeodozicus ret francic $\quad 48$

Ibeoderic epps meteit. . .52

Theodardus abbas ..51

Zbeodebert' $\mathrm{Tex}$ francic 39.

Ibeodoza martyr $\quad .33$

Ibeodoza 33.

Ibeodozus epus fyrie - $\quad 37$.

Ibeodozus arcbieṕs $\quad .44$

Ibeodous paim'papa 42 .

Ibeodozus fecüdus papa 1.50

Ibeopbilus epus 30.

Ibeopbilus $\quad 33$.

Zbeopbilus eṕs 35

Ibeopbil'g fe oiabolo oedit 3\%.

Ibeodofia 33.

Ibeodofitus impato2 35.

Ibeodofitus impatoz $36 . .45$

Iberentius romanus .21

Iberentitus somicus .21

Ierra reäboctpe z $\tilde{c}_{0}$. $\quad .55$

Ierremotus maximus $\quad .37$

Zerremot'continui

Ierremotus magni $\quad .60$

Eerremotus maximi 61.

Tertuliants affricanus 30 I $i$

ULpberins filui'rexitalie 10.

Ipberi'pzeuign'octauiani :25

Ipberi'graccus romani 21 .

Ipberi? fecildus impato2 ...40.

Ipberanus fotts 38.

Iyburtius martpr 31 .

Iyburtius $\quad .33$

Zbimotbetts berettcus $3 \sigma_{\text {. }}$

Iimotbeus epss 28.

Eyrus capit a xp̉anis 55.

Titus oiaconus 27.

Zitus epus cretenfiti $\quad 27$.

Titus filius verpafiani $\quad .28$

Iit'liui?tragediaz feriptoz 20.

Zitus liutus biftozicus - 23.

Iitus publius romani , 17.

Litus Quintius romani is.

Tobias mozit ${ }^{0}$

14.

Togorma filitus gomer 3 .

Tola iudex 
Tbomas aplins

Zbonas oe aquino

27.

Tbomss eṕpus canoniçat

Ibomesantuarieñ.

Ioletum ciuitas bifpanie

$$
\tau r
$$

IIranquillinus .33

Iranilatio iciaugurtini 45 .

Irấlatio marie magdalene 46

Iranflatio fci inocentij .49

Irẩtatio fci mattbei eแā. 51.

Irâllatio triü martyrü $\quad .46$

Eranflatio plurimo $\quad .48$

Irantlatio fanctor $\quad .52$

Iranitatio imperij

Iranflationicbolai ep̃ $\mathbf{i} 54$.

Iranfmigratio

Lras a quo tbzaces

Irespueri pijciunt

Ires foles in celo

Ires foles vifi fït

Ireueris tota martpriçat

Iribuni oecem viri

Irifaritts curfus tempozü

Irifon puer

Iriginta milia martyrū

Zrigitafepté milla marțrü 33.

Iripolis capiż a faraceivis 59.

Iriphompditoz rexigrie $\quad .22$

Irimmpbi rome $\quad .21$

Iroia vaftat

Iroianú bellí

Zroianus imeatoz

Irois in oardania regnat

Iropbinus epus

Iropbonia vroz oecij

IIubal $\tau \|$

Inbalcbayn p̉m'malleato2

Inellinus rex vngaroz

Iunica oñi repit

Iurci de montib?carpijs

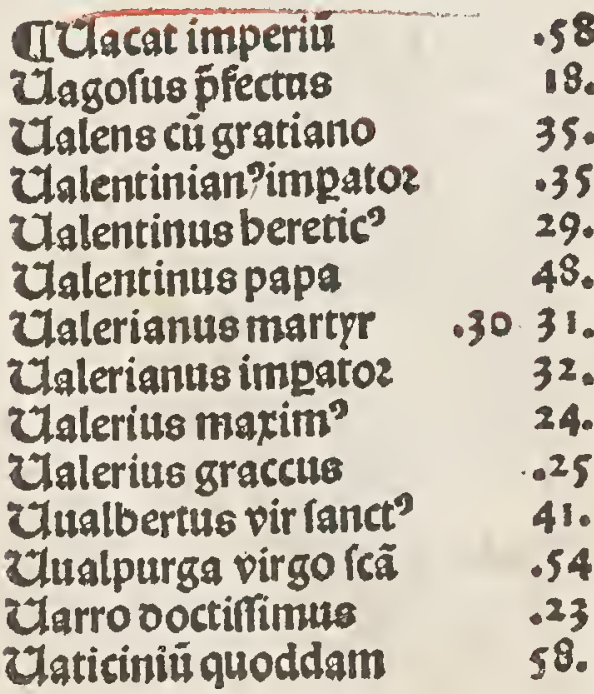

4

पUedaftus atrebateñ. 38.

Venetie rpaduarc̈.

.9

Ueneriarü ciuitas inclyta 37.

Uentus magnus fuit

Cleipafian"impatoz

$10 u$ ernberus puer fanctun 59.

Zluencela"p̉nceps bobemie 5

Utuençetans impator

Uueftpbalia incepit suerti 44 .

dUtibertus vir fels
Uictozints martyr

Ulictozinus

Victoziantus

Üictorian'pcöful

Uictozmiles

Uictor p̉mp papa z mar.

Uictoz fecüdus papa

Uictor tertius papa

Ulictor

Uicto2 martyr

Uicroz cii parentib?

Ulictoz cū pluribus

Uictor ep̃us capuan"

Uictozia virgo r marţ̧r

Uictozia miraculó́a

Uigilius antbifíodozeñ.

Uigoz boiaceñ. ép

Dilbelmus rex anglie

Dilbeimus beremita

Djilbelmus parienfis

Dilbelmus impatoz

Dilibzozdus cui.xij.

Ulincentius

Ulincentius oe valentina

Uincentitus fpeculatoz

Uincentius bifpanus

Uirgilius narcit

UUirgili'excellétiff.poetar

Uifiones tondali

Uifiones elifabetb

Uifiones bildegardis

Uifiobozzenda

Uifio flebilis

Uitalis martyr

Citalis

Uitellianns papa

Ulitus rmodeftus

27

đUlpian?iuriltegatis

$$
4 \mathrm{n}
$$

AUndecimmiliưtirginü

Unigari gens inclpts ozî̄

Ungari vaftantroma

Ungaria ouertit ad fidê
TUolfranus eṕts

$$
\text { U } r
$$

45.

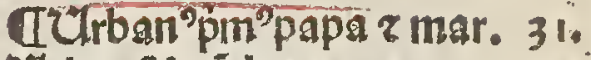

Uarban'fecüdus papa 54.

Urban'tertilis papa . 57

Zlrban"quart'papa . . 59

Urbanins quint?papa . 61.

Urban'rextus papa $\quad .62$

Urias ppbeta occidit it

Urfinarus pful fanctus 540

TEerfes rex affyrio

Xerres rex prarü 15.

X̄̃ofozuspapa $\quad .50$

Xp8 onis nafcit $\quad .24$

Tyuan a quo greci

yrad filitis enocb

TZabulon filitus iacob :6

Zacbarias z elizabetb .24

Zacbarias papa $\quad: 46$

Zacbarias rexifrl $\quad 12$

Zamrirex ifrael 10.

Zaroas

Zaria pontifes

Zelpba cốcubina iacob

Zenocrates plius

Zefixin'papa r martyr

Zeptineus oux bobemiead

fidem cô̆uer'tus

Zozoaftes paim 'rex bzar ctianoum

Zozobabel ret

Zolimas abbas

Zofimus papa (n)

2.

.6

18.

.31

.51

.5

.16

.34

36. 
Benedictus gntus papa S1: Benedictus fextus papa. $\quad .52$ Senedictus feptimpapa $\quad .52$ Benedictus octauPapa $\quad .53$ Denedictus nonuspapa .53 Senedictus oecimus papa .54 Benedictto.rj.papg $\quad .60$ Senedictus.xij.papa 60. Benedictus,xiij.papa $\quad .62$ Benedictus iunioz 39. Benedictus pater marim Beniamin filius iacob .6 Beneuentum $\quad .52$ Berengari? p̉nus impato2 50. Berengari? fecūd'impatoz so. Berengari'tertioimpatoz $5 \mathrm{i}$. Berengari' quart'impatoz 51 . Berengari'eps turoneri. . . 54 5 Sernardin'frater minoz 63. Bernardus incipit clarełce 55. bernardus canoniçat 56. Serta martyriz abbatiffa $\quad .44$ Bertuo abbas

Beruo angienfís $2 i \quad 53$

['Sayas vn'0e.7.fapiêtib" 13. Bigamia Biçantiü ciuitas condiẗ 14 . 250

Troccipontifet

Zoertius vir cófularis

¿obemia ad ftdé ouertit"

Bobemia fit regnui

Dobemia vaftat

Sobenie our ceptineus

Boleflaus fili"çeptinei

Bonifacius

Bonifaciº̀nus papa

¿onifacius fecuidus papa

Bonifacilis terti'papa

Bonifacius quart'papa

Bonifacitus gntus papa

Bonifacilts lextus papa

Bonifacius feptim?papa

'Bonifacius octan?papa

Bonifaciug nontepapa $\quad .62$

Bonifaci?arcbieṕs magútie 45.

Bon'uel oonn'fecund'papa.52

Bon'rṕpianus mozit

Sooc filitus falomon

Sos in egypto z $\vec{c}$. 34

TDulgaro क्ष regnü ozit Bulgarozü rex ž. Burgúdiones osti füt

Burgundi fiút xṕiani

Sus oe quo balaam

38.

56.

56.

.53

51.

33.

36.

.39

41.

41.

42.

43.

.50

$$
3 r
$$

C'Szandan'in feotia claret .40 Bzaulio epus 41. Bictius epss turoneit. $\quad .36$ Bzigida vidua 61 . Stigida claret in feotia $\quad$.3S Bzitannia 31 . Bzuno archieps s colonieñ. 51 . 'Szuno colonieñ.p̉m²artbu. 54. ¿zutus cóful romanus $\quad .17$ TLagthfiliusleut 6 .

Ealeucus vir $\quad .14$

Ealiftenes pbiloropbus $\quad .19$

Calixtus primpapa $3 \mathrm{i}$.

Lalittus recüdus papa 55.

Ealixtustertius papa $\quad .64$

Cbaldei

Calmana fozoz z $4 \times 0 z$ cayn 2 .

Laloceriusmartyr 29.

Ealopedius martyr, 31 .

Ebam filits noe 3 .

Cambifes filius cyrri

Eamillus roman'ooctoz is

Campanus ooctoz $\quad .53$

Cbanam filius cbam $\quad .4$

Lancian ${ }^{\circ}$ eps turoneri. $\quad .28$

Eapua

Ebaranus rex

Laput ioánis baptifte rč.

.52

2

Eaput fancti gregozij

Earannus martyr

Laritas virgo

Lbaritas refriguit valde

Carmentis filia enandri

Carpentus filut'rex italie

Larpofozus martyr

Lartbago prima condié

Lartbago iterĩ condit

Larthago Delé

Cartus impatoz

Lafaria regina perfarí

Caftiodoans gloziolius

Caftodozins gloziolts vip .39

Laffits namient.eps 39.

Laftozilis cin vroze 33.

Caftulus 33.

Eatafrige beretici ozitut 30 .

Latbena ralomonis 65.

Catbena anne 66.

Catbilina famofus tyränus .23

Eatbina condit 13.

Eatbmus condidit tbebas ?\%

Latbo noiatifimus 23.

49. Eaurabumanemalicie 61.

.24 Eagn filius adam malus 2. Le

Eecilia virgo z martyr 31. Ledarfilius ifmabel $3 \circ$

Celeftinus papa pzim? 36.

Eeleftinuspapa fecüdus . 56

Leleftinus papatertius $5 \%$

Celeftinus papa quart 58.

Eeleftinuspapa quintus $5 \%$

Lelits quintus romani 22 .

Eellum filitus mefraim

Eelfus martyr 27.

Eelüardere vifum eft 39.

Eenobii in caturcenfi $\quad .46$

Eerdo bereticus . 29.

Eberintbus bereliarcba $\quad .28$

Eefarims oiaconus $\quad 32$.

Eelaritts 33.

Eetbim filitsyauan

Eetbura vroz abzabe. 5.

$$
E \text { i }
$$

Teiceromarcus tullius .23

Ebilianus ep̄s berbipoleñ. .44

Ebyonia 330

Lipriantis docto2 gliortus .32

Eiprianus amfilieir.eṕs 37.

Eirus côftantinopolita.ep̉s 45.

Eyrus rex perfari $\quad .16$

Eyrillus eps alexandrie $\quad 36$.

Eprillus vir fanctus $\quad .49$

Eirilla virgo z martyr 32 '

Eituitas oei z müdi z:

$$
\text { E } 1
$$

EElaudia martyr

Elaudius impatoz

32.

Elaudianus

.$\quad .33$

Elandianuspoeta $\quad .36$

Elaudius martyr $\quad .33$

Elaudius eṕs vienneir. .39

Elemēspapa r martyr p̉mp .28

Elemens papa recüdus 53.

Llemenspapa tertius . .57

Elemeins papa quart? $\quad .59$

Elemens papa quintus $\quad .60$

Elemens papa fextus .б1

Elemens papa reptimus $\quad .62$

Elemës alexandrin ${ }^{\mathrm{p}} \mathrm{bs}, 30$.

Elementinapliber publicat 60 .

Eleobolus vnus oe reptē 13.

Eleopatra filiagntiocbi 20.

Eleopatra regina egypti 23.

Cletus papa r martpr .2S

Elodoald ${ }^{2}$ fili? regis fräcie .39

Elodoneus rex franco 4 43.

Elodone $x$ p̆pian $^{3} \mathrm{pm}^{3}$ rer frä. 38 .

Eluniacia möafteriä famofī .50 E 0

TEobares pbiloropbus

18. 
Loder editur

Codrus reratbenientiu .37

Cocbines rbodü cödiderūt

Eolonis conftruit 35 .

Colonie tempeftas ozit .49

Colofius cozzuit 20.

Coluban"pater venerabilis .40

Lolüba virgo z martpr $\quad .33$

Colüna lateritia tlapidea .3

Lomets apparuit 34.

Cometa appartit 41.45 .60

Lonseta apparuit 62.64

Eomes murieti. $\quad .56$

Eomitatus blefenfo ouit .50

Coniodus impatoz 30.

compoltelle ecciefir .48

Lomponi?peuratoz indes 24.

Lonciliú antiosbenú $\quad .33$

Eonciliu cartbaginenfe 36 .

Conciliú aurclianen re 39.

Conciliü generale 45 .

Eonciliülateranenre .58

Eonciliti lugdunenre .59

Eonciliu viennenfe $\quad .60$

Eonciliü pifanū 62 .

Xonciliu conftantienre .63

Consciliübafiliente 63.

Lonciliui turoneñ. 56.

Loncozdia martyr 32.

Concozdi'lubdiscon'? mar. 30

Eoncupi reentia auriü $\quad .3$

Eoncupifentia oculoy

Loncupircentia carnis $\quad .3$

Londitionē pabis tit?lui" .13

Konegüdis q̆ re in litterak . . 53

Eoffirmatio ordinis podicat). . s\$

Eöfirmstio carmelita

Eofirmatio 0z.mino . 5958.

Conoepsetretieroy 54.

Conradus thel bugo 50.

Conredus p̉mus impatoz $\quad .53$

Eouradus fecidus impatoz .56

Conftantia virgo z mar. .27

Eonftantia filia côftantini 34 .

Eonftantitus impatoz 33.

Lonftantin' filio cóftantini 34 .

Conftantius comes $\quad .36$

Eonftans fili 'conftantiui 34.

Köftantinopola far.obretra 45.

Eonftantinopolresupgt $57 \%$

Eonftantinopolis capit 63.

Conftantin magn'impato2 33.

Eōnâtin'idẻ fecit crucé auri 34.

Eonftantin'secüd'impato2 34.

Conftantin'tertioimpato2 43.

Conftantin' quart'impato2 .43

Conttantin'gntus impatoz .46

Lonftentin? fextus impator o47
Eonftantinus pomns papa 44.

Conftantin'fecuidus papa 46 .

Lötra pluralitaté brificio 58 .

Lboze filtis ifuar

Eboze perit cui. 300 .

cosizantes quida

.53

Lozintbus condit

Lozintbioz regnü ozit $\quad .9$

Eozintbus vaftatur

Eoznelius biftozicus

Lornelius gallius

Eozona oñi fpinea

Eozpa triū regü tranfferüt

Losp ${ }^{\circ}$ bartbolomei trälfert 47 .

Eorp'fci filueftritranffert .46

Lozp'ici calixti tranffert $\quad .50$

Iozpusgigantis iuenit 53.

Lofdras rex prarü

Colmas z oamianus

.41

Ebiprogonus

$$
L^{\prime \prime}
$$

19.

33.

C Cunibert'arebiéps coloin.4I. Ebunipt'longobardo ż rex 44.

Ebus filins cbam

$$
\text { E } r
$$

Lrates tbebantus

.4

. 17

Erefcentia virgo 33.

Erefcens ep̃egallaceñ. $\quad 27$.

Ibzifantus martgr z plis .33

Ebrifofoztts martyr 33.

Ebromacius .33

Lbzonicabieronymifinit 35 .

Cruxaureg conftan. $\quad .34$

IDadan filitis regma .4

Dagobertus virbonus $\quad .42$

Dagobertus idé qui $z \ddot{c}$. $\quad 42$.

Damafus pzimus papa $\quad .53$

Damafis fecidus paps $\quad 35$.

Dan filius bale

Dani idolatriâ poftponút .51

Daniel adbuc ituenis $\quad .15$

Daniel oucit in babplone .15

Daniel vir oefiderioz $\quad .16$

Dano r pbifis 16.

Daria martgr ₹ virgo $\quad .33$

Darius rerpiarü $\quad .16$

Darius irafpis rexplap $\quad .17$

Darius áilins arfami :is

Datban r abiron abrorbent .7

Dauid recüdus rex ifrael $\quad .9$

$$
D e
$$

UDecem miliú martyrú 29.

Decretales compilant $\quad .58$

Decius impato?

Dedicatio templi
Deditio pma apơ romanos .19

Delboza filia adam

Delboza oe effraim

Demetrins rex fyrie

Demetriug filitus oemetrij

Democrit'pbilolopbus

Demoftenes pom?0zatoz

Demus papa roman?

Defiderius

Defiderius vieñ.eṕs

.7

21.

.22

.17

18.

43.

33.

:4t

Denfdedítpapa romantis 41.

Deutronomiúf fribit

$$
\text { i) } i
$$

IDictatoz romantus

.18

Didimus cecus ooctor

.35

Digniffi mus z gozdianus 38 .

Diluniu in acbaia

Diluuiū oeucalıonis

Dina filia 1 acob

Difputatio famora

Diocles

Diocletianus impatoz

Diodozus feriptoz grecus

Diodozts martpr

Diogenes alexâdro potētioz 17.

Dionyfia cum filio $\quad 38$

Dionyrij fciooctozis libzi 48.

Dionnfius ficillus ret $\quad .18$

Dionprius ep̃s parifieñ. .28

Dionyfus eps cozintbioz 30.

Dionyfi'alexandrino zeps .32

Diontriopmus pak 2 rmar. 32.

Diolcozus martyr

$$
\text { D } 0
$$

.33

CDodanim filius yanan $\cdot 4$

Dolobella. Domici" cö́ttles 19.

Domicianus frudiacontus 27:

Domicianus frater titi $\quad .28$

Domicilla martyr 28.

Drícus ozdinis b́dicatore 57.

Donatianus 330

Donatifte beretici otiunt 34.

Donatus grä̀maticus $\quad .35$

Donatus martyr $\quad .35$

Donatus ер́

.36
Dozotbea virgo

Dozotbens

Dozotbeus

D 4

ISubzicius pmasanglie 37.

Ducenti 2.50 .clerici

Dulcinus berefiarcba

Durandus eṕpsleodieñ.

Duracbiü

Duxmediolani E b

QEbdomade onnieli: E 6

33.

33.

.36

34.60

.53

15.

.65

.32

9.
17. 
Ecctie feê marie noue

.49

Ecchis quattmoz cozonato .40 Ecclefia magdelburgeftis .52 Ecbilts patricius .37 Ed-

TEdgartureranglie .52 Ediltrudis regina anglie $\quad .44$ Ediffa ciutas condit $31 . \quad 19$ Edmundus rex vir fä́s 53. Edmūd'arcbiep̄s cătuarieri. 58. Eduardus rex anglie $\quad . \quad 54$ Eduinus reranglie $\quad 51$. $E$

Effraim filius iorepb $\quad .6$ Effrem z paribus monacbi .35 E 5

đEgelmot ${ }^{\circ}$ archiep̄ s cãtua. 53 . Egeripp'biftoziograpb? .30 Egidius abbas

Egyptuevaftata $\therefore 45$.

TElam q quo elamite 4 Elbertus abbas 53. Elburga filia eduardi $\$ 54$ Elcbias pontifex $\quad .14$ Eleaçar de tribu iuda $\quad .21$ Eleaçar filius aarou $\quad .7$ Eleaçarus pontifex $\quad 7.19$. Electio impatozis $57 \%$ Eliacbim oetribu inda i?. Eligius aurifer vir faus $\quad 42$. Eliud oetribu iuda $\quad .20$ Elifabet canonizat s8. Elpbegus cantuarieri.eps 52. Elpzedus reranglie $\quad .50$ Eltbeicanusrexanglie .5I E m

AEmplius fabius cốtules .20 Emplius côful romanus " 19. Empedocles pbilofopbus 17. E $n$

Q Eneas rex italie

Eneas filuius rex italie 8.

Enocb filius cayn

Enocb iuft'filius iaretb

Enos filitis fetb

$$
\text { E } O
$$

IEodald'oifcipul'ici petri 27. E P

UEpafozaseps colofeñ. 27: Epicurus Pozax

Epifanes rex egypti

Epifanius rex cipzi

17.

Epimacbus martpr

20.

Epatus.5. fiüt p karalí E $r$

.36

.35

48.

IEraquid fit .3
Eraponcipalis entebii

Erapncipalis grecor

.5

Erapncipalis fúdatiöis têpli 9 .

Erapncipalis romanoz 13.

Era pincipalis regni greco .19

Era xpiano? 24.

Eramabometi $\quad .42$

Era alpbonfi famoliffima .57

Eraclius impato2 41 .

Erafmuseps 33.

Ereneides rex perfay 16.

"Erictbonitus atbenieif: $\quad 7$.

Erubertus rex anglie $\quad 42$. E $r$

TEfaufilitis iacob 5.

Eldrasfacerdos de ftirpe $\quad 16$

Eldras vir fcüs 17

Efrom vetribu itda $\cdots \sigma$ E

UEtates mudi $\quad .68$

Etbbinus bzitanicts $\quad .40$

Etgbita filia etgari regis $\quad .56$ E. $\mathbf{a}$

GEua vrozadam 2 .

Euariftus papa rmartyr 28.

Eucbarius epsstreuerein. 27.

Eudorus aftrologus 17.

Euentius martyr $\tau$ p prbpter .29

Euergetes rex egypti 21 .

Eugenia r eunucbi ei $\quad 30$.

Eugenia martyr 32

Eugenitus primus papa ". 43

Eugenius fecidus papa $\quad .48$

Eugeniits tertius papa $\quad .56$

Eugenitus quart ${ }^{\circ}$ papa $\quad .63$

Eugenius toletaiimartyr .28

Euila

Euilmerodacb rexbaby' $1 \%$

Eunomius beretleus $\quad .35$

Euodius eps 27.

Eutodius titituenfis epss 39.

Euripiades pbiloropbus .17

Eufebius monacb' martyr 32 .

Eufebius papa r martir $\quad 33$.

Eurebitus cefarie ep̃s $\quad .34$

Eurebi ${ }^{2}$ difcipul'bieronymi 36 .

Euftacbi' $g$ r bonauen. $\quad 58$.

Enftacbius martyr $\quad .29$

Eutberius eṕs aureliaueri. 45.

Eutbices martyr $\quad \cdots \quad: 28$

Eutbicen abbas . .37

Eutropi eṕs aquitanient. $\quad 28$

Eutropius eṕs zancteri. . .28

Eutropius eps aurifitani: ..28

Eutropits pzerbyter $\quad .37$

Euualdi ouo fci propten 44.
E $\mathfrak{r}$
UExemplis fancto
TEcechiasrexiuda
Esecbielppbeta

Sabianus paps z martrr . .32

Sabioz gloziofífima fa. $\quad 17$.

Sabins romanus 22

Sabzicip vir oigne memozic is.

Sames magna in ifrael 10.

Sames incredibilis $\quad 39$

Eames validifima $\quad 39$.

Sauntis rexitalie . $\quad .8$

Ifeliciante

Selicifimus inartyr 3.2

Selícitas cum reptem filijs .70

Eelixmartyr

Sclix martyr 31.

Eelix martpr 32.

Selix z adauctis 33.

Selixprimpapa r martyr. 32.

Selir fecîdus papa $\quad 35$

Selit tertius papa $\quad .38$

Selix quartus papa $\quad . \quad 39$

Selixgntuspapa 63.

Semina papa $\quad 49$.

Serruncius eṕs .

Seftiuitas oius foỏytran 48.

Seftū oius fcổ inftituit 41.

Seftúpurifiçatióis $\quad 39$.

Feltü vifitatiöis btểmarie .62

Seftü venerabilis facraméti -59

Seftütranffiguratiöis $\quad \therefore .64$

Seftú fci petri ad vin.infti. 37

Seftü ättuoz enangeliftaz 59.

Seltus 33.

a Fides virgo r martpr 29. Silijifrti magna tribulatiōe. .7

Simbzia ilium valtat $\quad .23$

Sirminus epss 55.

IFormolus papa. $\quad .50$

Forreus cenobiüfüdauit . 43

Soztunatus poeta $\quad .40$

a Sulbert? eps carnotent. 53 :

Sulgentius eps rulperi. 37.

Fulgoz rönalis . 19.

Surfeus vir fcises . .41

Sutb filius cbus . $\quad .4$ $\xi$

Flacetus romants 22

Slaminius romanus 21 .

Slandria efficit́ comitatus 49. 


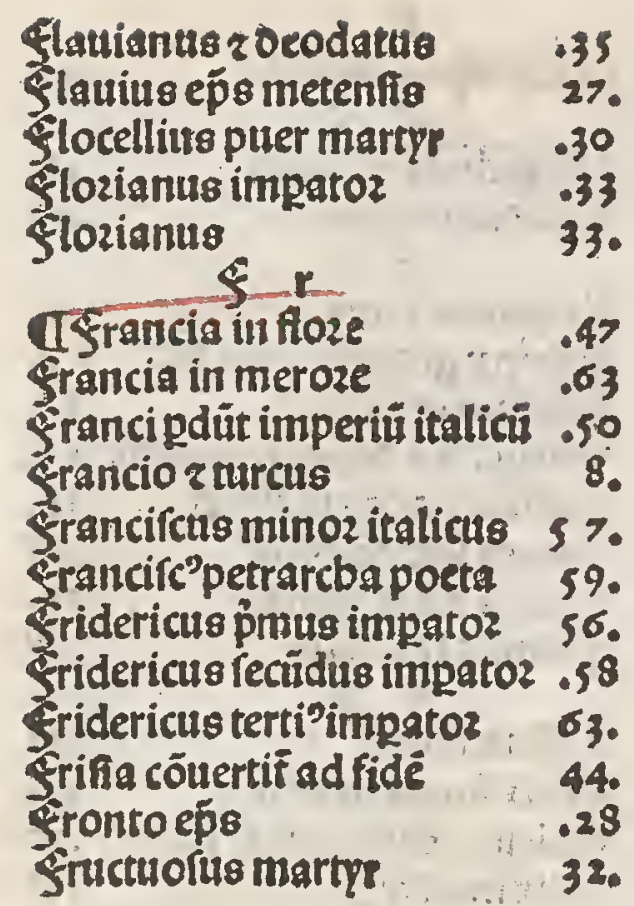

$\frac{6}{\text { GBad filius iacob }}$

Gadppbeta 9

Gains cólul roman 18.

Daius romenus .20

Baits romanus 20.

Baius manlius roman $\quad .23$

bains cefar 23.

Gaitus falcidits : 23.

Baius impatoz 26.

baius martyr : $\quad .30$

Baiuspapa z martyr $\quad .33$

5alba.ocbo. vitellius $z \vec{c} . \quad 27$.

Ealerius impatoz 33.

Balienus medicus 29.

Ballia pene tota paftar 49.

Ballia aüt fuit $r \tilde{c}$. $\quad . \quad 49$.

Ballicanus martyr . $\quad .35$

Sallus cu valufiano $3:$.

Bangeriecameraceil.eps .41

Baufericus rex puandalo 36.

Gafimunda regina francie 40 5 e

Thedeon iuder . . . . .

Beiafius pimus papa $\quad .38$

Belafius fecidus paps 55.

Benticius romanus , 19.

Beminianus 33.

Senebald ponus epolau. 38.

Bengulpbus martįr 46.

Benoutefa virgo $\quad .37$

Beozgius bellaceri. $\quad .28$

Beozgius martyr : : $\quad .33$

Selpbi z gebellini 59.

Bberardus bitureti.eps 55.

Bberardus oux bauarie : 47.

Bberardus groet. $\quad 62$.

Bereon martyr .33

Germanis adfidé cõuer'ต 45 .
Bermanus ep̄s antifio.

36.

Eermanus capuan'epss .39

Germantzs parilieii. $3 \%$

Eermanuts exulat

befron filius leui

Ébertrudis abbatifra

45.

bertafius martyr b $i$

बbigantes funt in terra

Éilgardus eṕs rotbomageñ. 139 .

Gilla virgo pzudētífima 52. 51

IElozialaus rễ, edit 48.

Enetsromanks

Enotbo vir \{́pū fan. 53.

$\frac{60}{\text { Ibomer filits iapbet }}$

Eozdianus impatoz :

Eordianus martyr : $\quad 35$

Eozgonills martyr 33.

botbozregnúceflat $\quad .47$

$\frac{5 r}{\text { ŪEraccus romanus }} 2 i$.

Eratian'ci valentiniano 35:

Grantus montacbsoecre.cōpl.. .\$6

Erando marima $\quad 35$

Ereci pereut miferabiliter 8 .

Éregozi ${ }^{\circ}$ pps lingonenfis $: 29$

Éregozius turoneñ. ‥40

Eregozi?filiug gozdiani $\quad .40$

Erregozius fpolis 33.

Éregozi'emiffenus epp $\quad \ldots .35$

Eregozills naçancenus .35

Erregozi" magn'p̉m papa .41

Éregozius fecúdus papa .45

Eregozills tertills papa. 45.

Éregozius quart papa 48.

Bregozitus gntuspaps $\quad .42$

Gregozius fextus papa 53.

Ëregozilis feptimi paps $\quad 54$.

Éregozius octauls papa .57

Éregozilis nonus papg $\quad .58$

Ǵregozius oecimus papa $\quad .59$

Eregozills vndecimus papa 61 .

Gregozins ouodecim'papa 62.

Groffa tha z rudis So S 4

Abueric ${ }^{\circ}$ epseçenonten. 45.

Euidomuficus in italia 53.

Builbelmus abbas oi. $\quad 53$.

Éuilbelmus puer cruci $\quad 56$.

Suilbelmus altifiodozeri. . .58

Euido ooctor . .61

Th
Thaitbanarius res
Danibal fenio?

banibal arrocifimu. 30 . of $e$

atbeber a quobebze

tobion berefiarcba

4

bector primogentit'priami

bectozis filij

bela rex ifrael : 10.

Delena rapif $a$ paride 8.

toelena regina abigeno 20.

Delena mater conftantini . 34

belena tranffert a ronta $\quad .49$

beli iudex 8.

belias tefbytes 10.

pelias colonieit abbas 53.

belimandus laudineñ.eṕs .5s

belimandus monacbus . 57.

beliodozus intrantit templü ;2i.

belifa a quo belifí

belíeus ppbeta

tjelifeus mozit

37.

benricus oux faronut .51

Denricus pzimus impatoz .53

benricus fecidus impato: 53 .

benricus tertius impatoz . 54

benricus quart'impatoz .55

benricus gntus impato2 .57

penrirus fextus impatoz 58.

Denricus feptimus impato2.60

benricus yota tbeologus 62 .

perricus oe baffia ooctoz 62.

ber filius iude

peraclitus cerebizofins

berafiftratus medicus ... 19.

Dercules anteum vicit ".7

bercules ilium vaftar , .8

berculanus ep s parufin $390^{\circ}$

berefis pbarifeoz $\quad .23$

Derefis nicolaitarí $\quad .28$

berefis acepbaloy 37.

Derefis vuicleff $z$ bus 62.

perefis adamitarí 62.

perefis imaginû. . ... $\quad .45$

berefis feliciana

Derefis magna berengarij .54

Derefis fabellij 32 .

Derefis pauli $\ldots 32$.

Derefis manicbeoz 32.

Derigerusabbas lobieñ. 52.

'Deribert'arcbieṕs colonieñ. 52.

Derliuius abbas

Dermes ooctoz

.54

Dermes trifmegiflus

Dermes tranflatus in galtia .49

Dermigildis filius regis 40.

perodes afcbolonita .24

berodotus biftoziograpb2 .17 
toarnintts eppolobieri. 45. Deftilins tragediograpb? .17 "Defaias nobilis ppbets" 12. Defaias martyrio cozonat .14 betguiga fancta canoniçá .59 berla auguriatrix Utbibernia cốtuertic 34 . Dieuppbets io Dilaria .33

bilarion $\quad .35$

Dilariuspaps 37.

Dilarius ep̃e pictanieri. $\quad 340$

Dilarius epss arelateit. $\quad .37$

Dildebertus cenomanen. .55

Dildericus rex monacb" - .46

Dyppolitus martre 32.

Dircanus pontifex . $\quad .23$

birenea 33.

bireneus eṕs $\quad .28$

bireneis eps $\quad 31$

Direneus 33

Diftozia ut cicero oicit

Diftuzia be idolo 7.

Diftozia libzí indican $\quad: 7$

biftozia rutb 8 :

biftozia pzimi libzi regü 8.

Diftozia libzi efdre $\quad$.16

biftozia tertijlibzirega 9.

Diftozia indith 16.

biftozia robie 13.

Diftoziabefter .18

biftozia libzi exodi 6.

Diftozia enangelica $\quad .24$

Dieronyin "p̈ppter boctoz .35

bieronymus obijt 36 .

Diertifalé pmittente Deo $\quad .57$

Dierufale capta fuit $41 . \quad .43$

bierufalem reftaurat 29 .

Dierufalem oeftruit $2 \%$.

Dierufalem reedificat 17.

bieremias.2"0e natozib" 14 .

bieremias in eggpto 15.

$\frac{b}{\text { IDolofernes priceps }}$

Domerus poeta 9

bonan filius iude $\quad .6$

bonoldus rex baptiçat .48

bonozarus z fabinus 35.

bonozilus pinus papa $\quad .42$

bonozius lecüdus papa 55.

bonozilss terius papa is

bonozitis qtiartus papa 59.

bonozius impatoz $\quad 36$

bozmifdapapa 38.

bozzibile fácti contigit $\quad 46$.

Dofpitius
Doftienfis cittitas contit is

đbubert'trantalit fedé 4.4 .

bugo cluniaceñabbas $\quad .55$

bugo pirfanctiffime vite 5.

Dugo de fancto victoze 55.

bugofolieti 56

bugo cardinalis 58.

bus a bitl filijaram $\quad .4$

Dus filiue nachos 5 . z) $a$

C.7̧gbel filius lamecb

Facintus martpr " $\quad$;2。

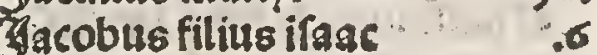

3acob mozit $\sigma$.

3acobus minoz aptus $\quad .27$

yacobils maioi aplits " 26 .

Facobus de vitriaco 57 .

3aduepontifer $\quad .19$

Ganuarius 33.

Fanus rex italie 7 .

Japber filitis noe 3 .

Glaretb filitus malalebel a

Yafonmartpr $\quad .33$

zafon oe genere facerdotali .21

Jauan

Gapriudex 8

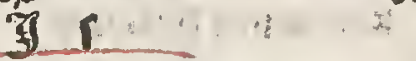

dTJfis regina egypti

Jjfuardus monacbus : 47.

zjlaac mozit

yracbar filitis lacob ' .6

Zfuar

đ\}dolatria $: 5$

Ayeconias filius iofic is

Jectan filitu beber: :

Gepte iudex $\quad$ s.

Gericbo extruit 10.

Geroboam rex ifrael : : $\quad .12$

jefus filius ioledecb $\quad .16$

Zlefus fyracb 20.

zelus ropsnafcit : $\quad 24$.

zebeu rex írmel 3 i

CIgnaci? Doctor gloziofus 29 . 37 in

IJ̈mperiü bipartitúfit 46. Ymperiütranifert $\quad .52$ 3 . $n$

d 3 nachus $\mathrm{pm}^{2} \mathrm{rer}$ argituo Znnocentius pmus papa . 36 IInnocentins Tecüdus papa 56. IInnocentius tertius papa $5^{7}$. Innocentius quart? papa 58. Znnocentitus quintus papa .59 Znnocentius lextus papa .68 3inocentills feptim papa 62.

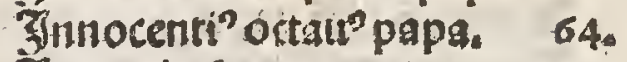
Intuentio fancte crucis 33. Inuentio fímicbaetis $\quad .38$ Znundatio pluuiaz 40. 35 :

T'zyoiada pontifex

Foachimfilius leconie is

Toacbim ranna clarent .24

Goabas rex ifrael it.

Togs rexiuda ..... I,

Joas rexifrael . 12

Zoatban oe tribu ind

zoatbas ocetribuliuda 14.

Job vir fainetus.

Tobitamartyr 29.

yoannes fille iude pontif. 19.

Zoannes bircanus $\quad .22$

joannies baptiftanalcit .24

yoãnes baptifta decolla $\quad .25$

Foannes euangelifta. .2S

zoanes z paulus martyres . 35

Toanes cbrpfoftom? claret .35

70anes cbryfoltom? exulat .36

Goannes beremita . $\quad 35$

toannes cafífinils 36.

Goantes damafcentooctoz .35

Tlannes oamalcentus fuit . 38

\%oannes elemorynarius 40.

Joannes tungrenfis $\quad 4 I_{\text {a }}$

Joannes anglic'natiöe $\quad 49$

乌loannes fcotte $49 \%$

3loannes gerfon tbeologns 62 .

Zoannes oiaconisis 49.

Yoänes oe tpibus mozit $\quad .56$

Zoannes andree iurifts .60

ఛ̧oãnes manidétuil medicus 60.

Joannes oe ruperciffa mino: 61 .

Foannes rurbrock 62.

Gloannes our burgüdie $\quad .63$

3̧oäner 8 capeltrano fr mioz 63 .

Toanna regina francie 61

Gloannes pmus papa $\quad \therefore 39$

zoantes fecidus pap : : $\quad 39$

Joannes tertitus papa $\quad .40$

'Goannes quart'paps $\quad 42$.

Joannes quintus papa $\quad 44$

Joannes fextus papa 44 .

Joannes feptim papa 44

Joannes octaulus papa 49.

Joannes nonus papa $\quad .50$

Joannes decimus papa 50 .

zoannes pndecimus paps : 21 .

\$loanes ouodecim²papa SI.

Foanues.riii.papa "- S1.

Zुoannes riiij:papg $\quad .53$

Joannes,xpipapa 58 . 
Tomnes.xti.papa $\ldots, 52$

Toannes.rviipapa 52.

zloannes.rviii:papa 52 .

Joannes.xix.papa 52.

Zुoannes.xx.papa $\quad .53$

foannes oxi.papa $\quad .59$

3ुoannes.xrij.papa $\quad .60$

Tonnnes.rxiil.papa $\quad .63$

Tobelppbeta 12.

Gonasppbeta 12

Zुonas mittit r $\vec{c}_{0} \quad 12$.

Zonadab filius recbab il

Gonatbar pontifer 21.

Gonicbus filius noe 3.

3ozdan'teutôic'soctoz fúo .58

zozam rexiuda $\therefore$.il

Zlozam rex ifrgel $\ldots$

Zorapbar reriuda 10.

3olapbarberemita rek . $\quad .35$

Foredecb pontifer . is

కlorepb filius iscob $\quad .6$

Torepb venditus eft 6.

乌lolepb mozit. 6.

Tolepb fp offus marienalcit 23.

Torepb'biftoziograpb" 27.

Fofias reriuda.

yotue iuder. $\quad \%$

Joumiantus impator a... 35

Goulus atbenievi. ṕfbrter $\quad .28$

$$
\text { I: } 1
$$

Jimsel filius abzabam . 5 .

3 frael in floze : ., 9.

yfrgel finerege $\quad 12$.

IIrael traniffer

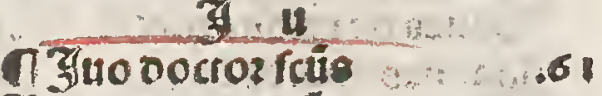

Zuba rex ingulat 23.

Hoal filius lamecb . .

Yubileus inftituit : ...6. 59 .

Yubileusmurat : .61 .64

Zubileus celebzat

Zudas filius iacob

Zud as macbabeus 21.

\&udea tributaria fit . $\quad 23$.

Gudei osuaftant puincias .29

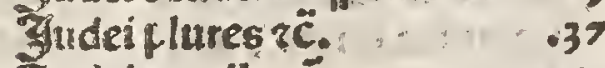

Zudriexpelluni $\quad .60$

zudei cöbuftifuerüt .6i

ऊudeus quidã $z c$. $\quad .40$

Tududeus quidã $\quad 58$.

Fudocus fil ilis regis . . . $\quad .43$

Zultans martyr $\quad, \quad .35$

3 yliung virgo r marty : 33.

Fulianus qui r frmon . . 8

Gultanus occifor parentí .28

Fulianus marty? 32 .

3ulianus tmpatoz apoitata .35
Zulita maripr

31.

Julitus cerar

23.

yllius papa

340

Guftina impatrix $\quad 35$.

Iuftinian'pm?impatoz - $\quad 39$

Tufturiau? recüdus impato2 44

- Juftinian" 2 "iterato impat 44.

Juftin" pintis impatoz $\quad 39$

Juftinus pbilofopbus : $\quad 29$

Fuftus leocadia 33.

Iutuenalis poera $\quad .27$

Gutuenalis eps.

.37

Trallinitus marinu ignem intenit

44

Rarilepbus vir fcüs 38.

karol'magn'pintus impato 47.

karolus fecudus impato2 49.

karolus tertius impatoz 49.

karolus quart'impato2 61

karolus rex francie : . . . 51

karolusmarcellus , .45

korolomänue frater pippini .46

karolus ret franco z _ _ . 46.

karclina firps 52

karolpbusmercioz 53.

katberina virgo z marty? 33 .

katberina oe fenis

61.

$$
2 \text {. } a
$$

I Laban frater rebecce 5.

Zacedemon conditur it

Lacedemoniozregni 9

Lacedemones füt fpartani 18.

Lambert'eṕs fili" comitis 44.

Lameco bigamus

Lamecb filus matburale

Lana oe celopluit $\quad .35$

Lantfrancus eṕe $\ldots . .54$

Lantonus 38.

Lancea oñi repperít $\quad .55$

Lapis grandis cecidit $\quad 58$

Laomedonter troie :S

Latro ep̃s

Laudo papa

38.

Laurentius bifpanus $\quad 32$.

$$
2 e
$$

.58

(1) eander gothos cöuertit .40

Zecroz quidã paulus . .61

Leoptimus papa $\quad .37$

Zeofecuduspapa $\therefore .44$

Leo tertius papa _. . 44.

Leoquartuspapa $\quad 47$.

Leoquintus papa .. .50

Zeofextuepspa , 51

Ieofeptimus paps .51
Zeo octaulupapa 516

Leononuspapa .... 53.

Leo primus impatoz $\quad 37$

Leo fecudus inpator 44.

Leodegariusauguftudu. .44

Leonardis louioceñ. $z$ c. $\quad 38$.

Leonardus beremita 40

Leoncius cöfulárie martyr 32.

Leoncius $\quad 33$

Leonida rexfpartanoz $\quad .17$

Leonides pater ozigents .31

Leonilla martyr.

Leonina ciuitas

Letania maioz inftituit : 41

Leui filius iacob. ... .6

Leui pater omniüleuitaz б.

Leupzand'lógobardon rex .46

Ler oat in monte fynga

$$
1 \text { i }
$$

Alia Droz iacob

Liberpater vina inuenit , .7

Liber leuiticus feribit .7

Liber numerozpmulgat $\quad .7$

Liberregú fecuidus

Libzaria.400, miliülibzozum comburit in egypto . .23

Ligurguspbiloiopbus 11.

Linus papa z martyr

27.

Lipbard'oircipul'remigi 38. 30

CLodoutcus pmmimpatoz .48

Lodouicus fecud'impatoz 49

Lodouicts tert? impatoz 50.

Lodouic"quart'impatoz 60.

Lodouicus filius regis : . $\quad .58$

Lodouicns ref francie $\quad 58$.

Lodouic?olim rexfrancie . .60

Zodouc'tbolotanus ep̧ 6 . 60 .

Lodouic'ouraturelian. $\quad 62$.

Lodouic"pater fí lodouici .48

Lodouicus ep̄s arelateñ. $\quad 63$.

Zondoaldus vir fcüs $\quad .43$

Longinus

.33

Lotb filius aram

Lotbarius pmus impato: 48 .

Lotbari"fecidus impatoz 5 i. 14

TLucanus poeta .27

Lucas difcipulus pauli 27.

Lucrecia feming nobilis 16.

Lucian'beluaceñ martyr $\quad .28$

Zucianus martyr 31 .

Lucia virgor antbeas rex 33.

Lucia vidua 33.

Zucius impatoz . . .30

Jucins rex butanie. 
Lucilts primpaparmar. $\quad 32$. Lucius fecüdus papa $\quad .56$ Lucius tertitus papa Ludgerus ер̆s Ludi fcenici inftituunt Ludolpbus cartbufieñ. Ludus feacboy reperit Lugdunü condit

Luna in fanguinëverfa

\section{on}

[2T)acedonü regnu: 2Dacrinus impatoz 2Dacbutes oifcipulue 2Dadan Dadap 20adian 2Dagog 2Daglozius ep̄s ooleñ. 201agniradus beremita maguntia affligif maiolus vir fanctus Malalebel 2Dalacbiasvir fanctus Malcbus martyr 20ailius tozquatus 20Damertints abbas 20Danaben rex ifrael Mananeel 27. anaftes filius iofepb DDanaftes rex iudo 2Danicbeoz berefis 2Danilius oecius romani 20 Darcus gneus romani 2Darcus valerius 2D arcus valerius coztuin? 2Darcus curius romani DDarcus catbo romani 2Darcus varro Darcus g gripp -Darcus antoni?impatoz .30 - DDarcus confeftoz DDarcus fecúdus papa marcella pediffequa 2Darcellianus 20 arcellin'papa z martrr 2 Darcellus papa r martyr 33. 2Darcialis eṕs lenoniceñ. 27. DDartialis eṕs çanchdoñ. .28 2 Darcionbereticus 29. 2Darculpbus abbas .41 mardocbeus in babplone 15 mordocbensindens . 18 DDargaretg virgo zmartyr 33. aparia ppbetifia 2Daria oei genitrix nassit PDaria magdalena maria egyptiaca
Mafilita

ZDaria oe ognies

. 12

marianus

2Darianus monacbus

2Darinus martpr

2Darinus eṕs epbefioz

DDarius romanus

2Daron martyj

2Darfus

martba 0202 magdalene

2Dartina martyt

zDartinianus

moartinus ṕmus papa

martinus fecúdus papa

2Dartinus tertius papa

Dartinus quart'papa

2Dartinus gntus paps

27Dartintus cardinalis

DDartyres infiniti

DDarucbasep̃s

matban filitis fadocb

Datatbias pontifer

MDatbeus aplins

matbias aptus

Datbildis comitifis

matbufale oe retb

maturabel oe cayn

DDauricius martyr

Dauycius impatoz

2Daurilius rotbomageit.

2Daturus

2Daturus oifcipul'brictict

maxentits abbas

mpaximinus eṕs

IDaximinus impatoz

Maximus eṕs

maximus martyr

2Daxim'pzébpter z martyr 32 DP $B$

Timbeander famarites :28

DDedericus abbas 52 .

mediolana condif́ .18

melania

Delanius cōfliarỉ - 38 .

melcba filis aram 5.

mpelcbiades pap a rmartyr 33.

melcbiledecb rer 5:

menander comicus $\quad .19$

menedemus pbiloropbus .19

menelaus .21

2Dennas 33.

moercurius

Deraiotb pontifet

2Derari filius leui

37.

merlinus oe incubo $\quad .37$

20Derodacb pimus rex baby. 1.3.

tDes filius aram
2Delraym

indeffala poeta

20

U2Dicbael impato:

47.

2Dicbaelis templü cöftruî́ 44.

Micbeasppbeta

micbeas cótrabiernfalé

2Dilo oe angler oux $\quad .49$

zoimenusrerbzitonü 49.

minerua

moinutia virgo

.6

mifael

mirabilia cötigerüt

2Ditridates rexponti $\quad 22$. ap a

Toporfesnarcit .7

2Doyles abbas $\quad .35$

mopres pzetopter zmar. .32

monarcbiaperfarí . .16

2Donarcbia grecoy $\quad .19$

monafteria Tolēnia $\quad 48$

200nafteriü fcibridicti 45 .

Dons quidã maximus $\quad .58$

2Dons gargants .38

2Donftü bris caput $\tau \ddot{c} . \quad 50$.

2Donftri in italia $\quad .52$

200nitrü oue mulieres 53.

2 Do2s fci onicici patr] p̈dica. 159

2Doztalitas maxima $\quad .53$

molog

Iobstres infiniti

n $\mathfrak{a}$

TThason princeps

Tabaiotb

17ibucbodonofor

Nabucbodonofor filius

Thacbozfrater abzabam 5 .

Thacboz oe fem $\quad$.5

Thadab filius aaron

Tadabretifrael $\quad .19$

Narbona ciuitas $\quad .46$

narcifius patriarcba 30.

Natbalia fancta mulier 33.

Tatbanad ,16

Matban filius fratris oguid .9

Taumppbeta .13

Nautaquidá

Naçarius martyr $\quad .27$

ITeemas vir benignth

nenrotb .4

nemrotb pinceps 4.

Tero impatoz .27

Nerug impato2 .28

Neltozi? ep̃ s ç̄ tantinopoli. 36 . n $i$

KThicbefozus impatoz

47. 
Titicofous marty

Ticbolausep̃s

Nicbolaus pinus paps

nicbolans fecidus papa

Tlicbolaus tertius papa

Nicbolaus quartuspapa

Thicbolatis oe lyra ooctoz

nicoftratus diaconus

- ninus pmus rex affyrio

'ninus quart? rex affirio

niniue oeftruit

niniue metropolis

$$
\text { in o }
$$

TThobilitas qũ incepit

Thobilis martyr

noe vir iuftus

- Noema

ทozmãdia cö̀tertî́

nozuegia conuertit

nouatus pzefbyter

nouatus martyr

$$
\text { in } 4
$$

CTluma pompilitis

Thumitoz rex italie

Tümiaurei

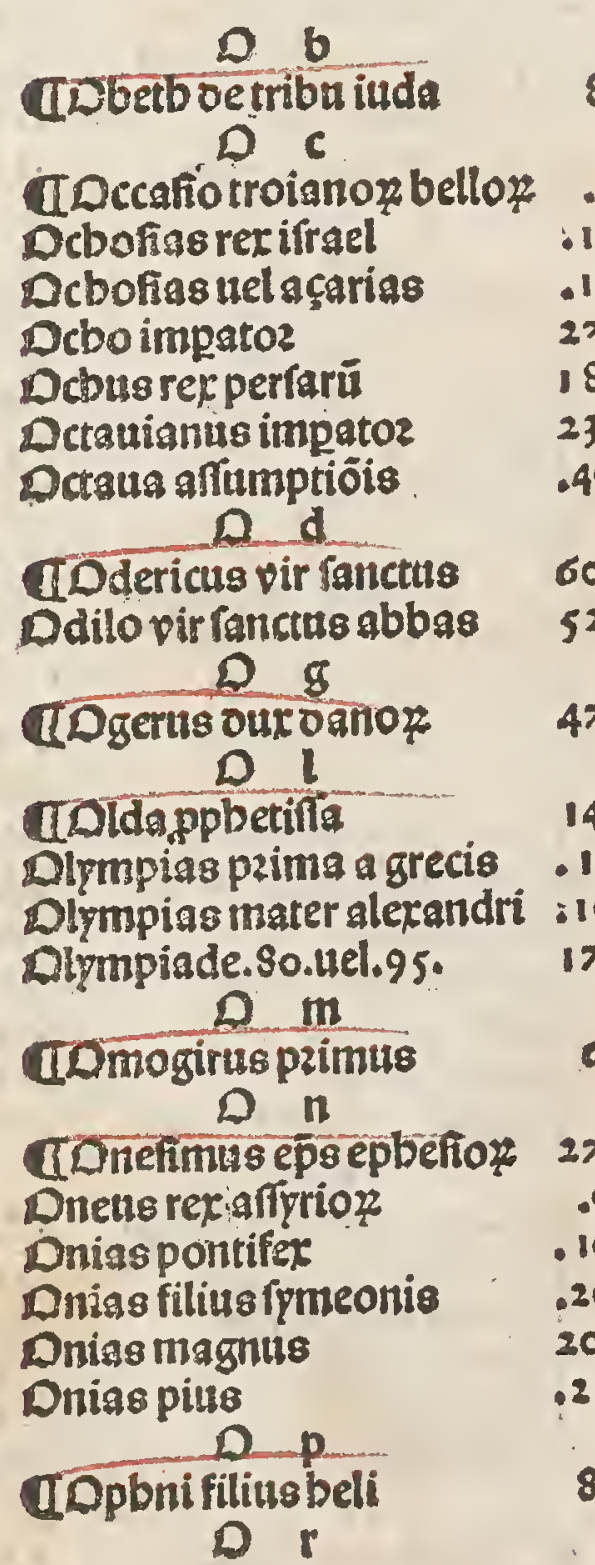

UD2acultiarcban.micbaet".38 D2scius flaccus poeta $\quad .23$

Dzbigoilivifo rê.

Dzdocluniscent. 50.

D2docartutieñ. 54.

Dzdo ciftelleii. $\quad .55$

D2dociftercieit. 55.

D2do templarioy 55.

Dido ici ioanis baptifte 55.

D2doguilbelmitar"

D2doonoztetubonico\% .57

Dido fancte trinitatis $\quad .57$

Didocruciferoy

Dido celeftinozí 59.

33. Didopzemonftrateĩ. 55.

3. Dzdocanonicus 54.

. 3 Didononozmilití 60.

49. Dido raluatozis uel brigide 61.

56. Drdines.4.mendicantiü .58

.32 Drigenes voctoz egregius 31.

.30

.14

.13

7.

$\varepsilon$.

.8

.11

.11

27.

18.

23.

.49

60.

52.

47.

14.

.13

.19

17.

$\sigma$

27.

.9

.19

20

20.

.31

8.
Dioncitts

.33

Dzofius

.36

TDs ufferni imedio vibis 17. Orberms abbas leodicent. 53. Dfrarmuelis jpete .36 Dreeppheta is.

Dreerexifral $\quad .13$

Díualdus e $\overline{\mathrm{p}} \mathrm{s}$

$$
0 t
$$

ILtbonilitider

Dito primus impatoz

Dtro recuadus impatoz

Dttotertits impatoz

Dito qusartus impatoz D 4

Duidius nalo poeta $23, \quad .27$

dDçipontifex

Dçias uel açarias

apacbomilis vir Teís

pacbonius monacbus

paculius

Pafnucits monacbus

"Dalmaci"martyr ciu vro.

palladius eṕs

- Dantbentis floicus

- Pantbalcon martyr

pantbeon oedicat

Dapias ioamis auditoz

Dapias

Dapirius romantis

parifîns miraculú cốtigit

percalis ptimpapa

Dafcalis fecüdus papa

- Daíchlís vir fanctus

opaffagiũ magnú
Daffegiti grande

- Daftozes pecozí

- Datricius ế 6 egpti

.59

Datricius filius fozozis

patricius magntus pater

- Patricius martyr

patroculus martyr

Paula fenatrix vidua

poutinus ep s treuereir.

Dautinuseps

Doulus z therentioramani 36 . Daulus apliss 27.

- Daulus pzin'eremita

Daulus fimplex

- Dauli ozarijbiftozig finit

- Daulus oiaconus

Daultas piimus papa

Daillus fecüdus papa

Daupes oelugduno

Pbaceererírael

Dacbeia rex ifrael

- pbaleg filius beber

- Dbara virgo fancta

- Dbaraonefres rer

opbarao amonopbis

- Dbarao bocchozis

- pbarao filitus iude

pbarocomes

- Pbarus turris in mari

- Pbaronelts rex arginoy

pax vituerialis totipozbis .27

Dar vniuerialis

parecclelle reddita

pax prima ecclefie

$$
\text { of } e
$$

Inselagius pzim papa

Delagius papa

Delagitns bereticus

Deregrinus eṕs

Dermenides philolophus i7. perpetuus eps $\quad 37$ Perfituspoeta 27. Derfettio tëpli falomonis 9. Derfecutio pzima peclefie 27. Derfecutio fecüda ecclefie . 28 Perfecutio tertia ecclefie $2 s$. Derfecutio quarta ecclefic 30 Derfecutio quinte ecclefie 30. perfecutio fexta ecclefie $\quad .32$ perfecutio feptima ecclefie .32 Derfecutio octana ecclefie 32. - Derfecutionona ecdefie $\quad 33$ Derfectutio becima ecclie 33. Derfecutio indecima ectie 34 . Perfecutio onodecina ecte.35 Derfecutio iterü inlapbzica .39 peftilentia maxima. 


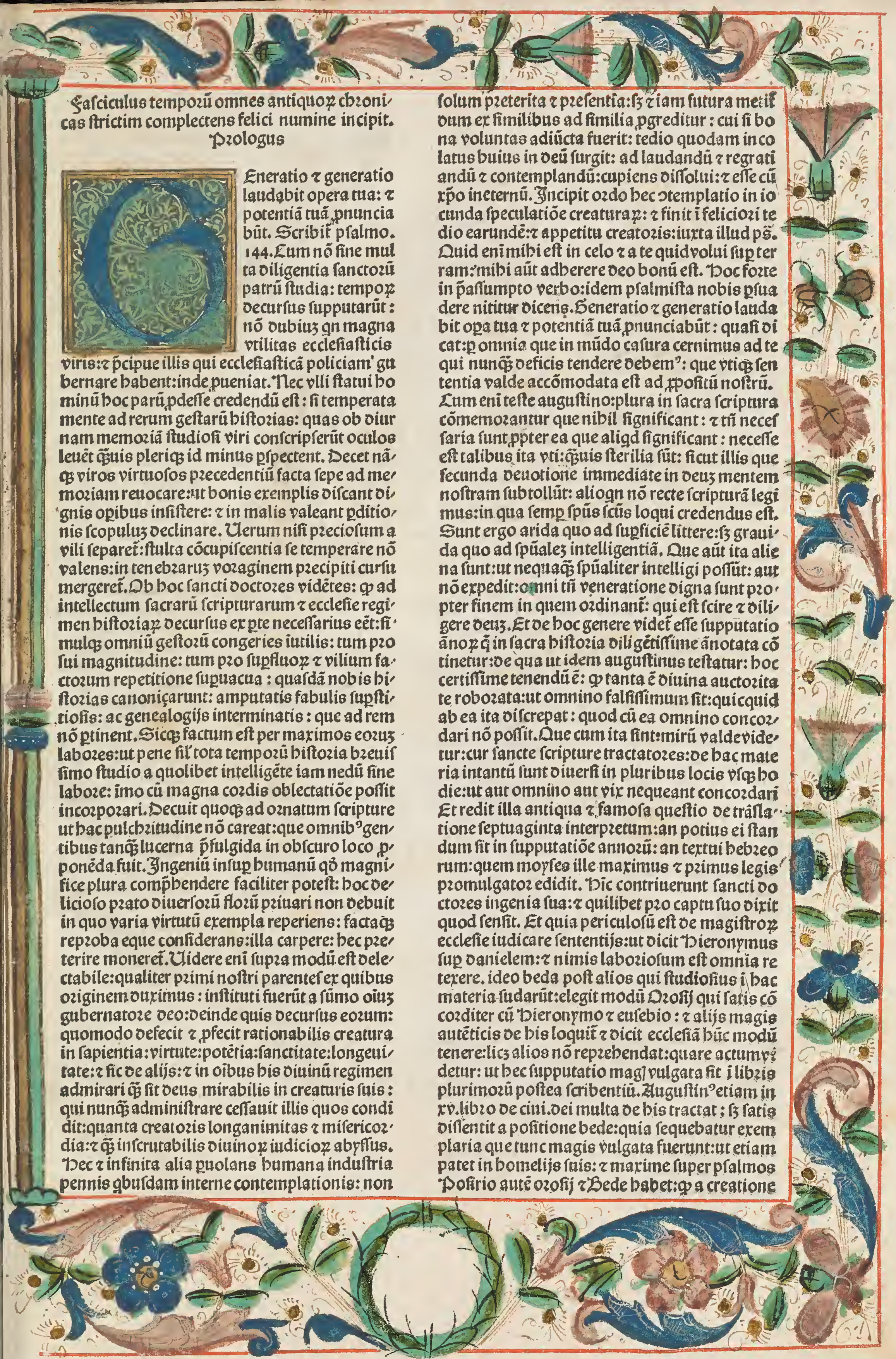


mundi vics ad natuitute abzabe fluxerunt anni $3184.5 \mathrm{~m}$ feptuginta. bebzei autẽ min? babent 1236 .quia 5im biblias cozzectas intrta bebzaicã veritatê:ab adam wiq ad natiuitatë abzabe: füt anni tanti. 1943. Deinde fatis conco?dant cum bebzeis feptuaginta interpzetes: pfo; ad oeftru. ctionem templi: que vocatur cõmuniter tranfmi gratio babplonis. Sequentia tempoza nom ba bentur ex canonica feriptura : fed er aliís bifto' rijs tam iudeozú (ึ̈gentiliu. Et iterum ibi eft oi. uerfitas: fad nö nimis magna. Simul igif colli. gendo fin ' 5 edam a mudi creatione vf natiuitatem veniut anni.5199. . bic eft modus ecclefie. vnde verfus. Unu tolle oatus:ađ milia quings oucentis. Harcenti oomino: Beda oat a pzotboplafto. De rlteriozi oifcuffiöe buius que, ittionis vide fi placet aluguftinu vbi fupza z bies ronynu $r$ alios locis fuis. Dic auté quia bzeui. tati ftudemus:pzolixitas ipfa nobis vitanda êt Colligere nà ó oifpoluinus ituante oomino ex pluribus libzis farciculum quendã tempozum:a mundi creatione vfas ad pzefens:in quo tam fa. crarü fcripturarü äß oiuerfarü aliarum biftozia rum facra tanö in memoziali quodam compen diofe religabinus. Saciã proinde iuxta fenten tiam flozi: quod folent qui cerrarí fitus in bzeai quafi rabella oepingüt: ita totam bumani gene ris imaginte: tempozüqzoccurfus in pauculis fo lijs complectar. Tee mibi confcius fum aliqaid meporuiffe:quod non in fidedignis biftoziis ba beat:aut aliis libzis ecclefiafticoz ooctozú: fitce quod nücex cozú oictis aperte fequat̃. Uloi antë oubiu fuerit:an fic uel aliter:boc ipfuz etiam it ut repperi pari modo annotani. Et me ip fa fupficies biftozie oeuotis tediofa effet:perfepe renten tias quardam flozidiffimas applicaui ex fancto, num oictis:que oeuotionem redolent:pariter ac ooctrinä. Zluctozitatem ergo oãtes bis qui ante nos labozacterunt:nos pzo modulo noftro in la boz2s eozi intrauimus: parfim bincinde carpe. tes quod potuim". Et ut fciat quo ozdine eos fe, cuti fumus:pzimo totü tempus veteris teftamé. ti. 5 169. annozũ in quinqzetates oiftinctuz repe rimus in quodam libello:qui Zfidero afcriptus videbatur:pbi multuz artificialiter pzocedit oe. ducendo annos mundi $\downarrow$ fos ad tempoza fua fcili cet eraclij:qui cepitregnare circe änos Dñi.6 12 .

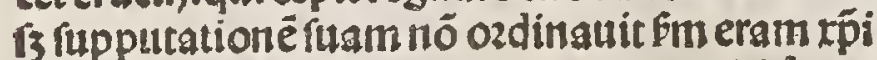
ficut nec 0zofius. Et bǘ requimur iouab? p̉mis etatibus: fimiliter $z$ in ouabus fequentibus: $e x$ ceptis paucis quia tertus $\mathrm{fm}$ bebaicam verita tem a natiuitate abzabev fa ad captiuitatem ba bylonicam:apud nos magis eft cozzectus: $z$ oili genrius explangtus: r ideo fequimur eum:parü tamen refert. In quinta etate maiozem labozes babuimus pzopter nimiã oiuerfitatem biftozia runi.z veniam pcoz: quia iam vnum iam alium prout melius putaui fecutus fum. Zૈn autë o ebi. te fingulos amnos fupparaui: lectozi iudiciü cö

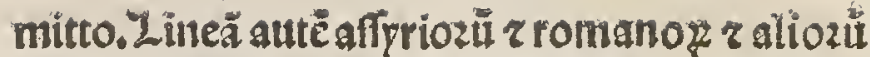
ex oituezirs biftozijs laboziofe fatis coaptauitro gans : ut fi cui tranforibere placuerit : oiligenter obreruet fpacia r numerĩ cozzefpondentemine longitus aut ftrictius ponat ố eremplar baber: alioquin $z$ laboz peribit $z$ fructi no repoztabit. Eritcs opus co mendofius quo compendiofits nifi boc oiligenter ftudeat obferuare. fi autë oe' bitequod facile arbitramur bec incozpozaterit nö modicã ei prebebit illuminationẽ ad intelligendam facram fcripturã: $r$ libzos zluguftini: bieronymi: 2 Dzofiti: ac alio ze zê.fi vera runt que in'pluribus libellis fcripta reperimus. Pozzo in ferta etate fequimur cbzonicã martini zvincen, ttj: qui compendiofe pzoceduntviog ad tempoza rua. Doft eos pannos fere oucentos: fequoz no rabilëlibzü quendam cuilus auctozèn eicio : qui pene viós tea rua extendiť. Que auté oepoft acta funt memozie oigna:ficut audiuimus z vidinus Fideliter pziosibus fuppoftuimus. Que omnis in requentibus funia bzeuitate patebunt. 2Dodus auté procedendi planiffimus eft : $r$ groffitudini rufticane adeo amicus:ut in pariete quidem be. pingi: poflit eo $q$ ilico fine omni bifficultate in. tuenribus fe offerat. Depinxi igit in medio folif circulos cum noibus pronaze oebitis p quolibet tempoze: z infra z fupza lineas ouas:quarum í perioz cum fuo numero oef́cendit ab adam vfog ad xp̃m iuxta feriem ṕdictozū fignificãs:ut quic. quid ex adnerfo illi? numeri feripti eft fiute rupe rius fiue inferius etià circalla tempoza factum verifimiliter credaŕ. Secuida linea id eft inferioz

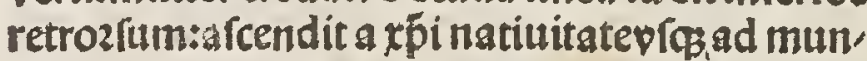
di creationez: ut eadem facilitate vnico numero firpecto fciat:quot annis boc aut illud factu; fit ante xp̄i natiuitatê:quod ideo fic ozdinauimus: quia bec era magiffolénis eft apud nos:z citits folet requiri. " poft xṕm fimul ambe oefcendunt Vfä ad tempoza noftra paulatim crefcendo : ita ut fupioz femp oftendat etatez mundi: $z$ inferioz etatem xpi:quod planiffime patebit locis fuis. $\tau$ quig ex multis libzis mendofe foriptis: modum büc nö leui laboze ad lineã veritatis cozzextm?: obrecramus pzo xp̄o lectozem:ne inciuiliter ma nù ad cozzigendü banc annozü fupputationem apponat:nifi pzius toto opere pípecto: quod nö ideo oicimus quafi nullibi errauerimus : fed ad auifandù oe nimia oiuerfitate ooctozum in bac materia.z frequenter pofitio pnitus eft inuolutio alterius: $\bullet$ bi autēe errozē intuenit:clementer igno reat $z$ cozzigat ex pzedictif quos requimur. facile enim in numeris errat: $z$ repe negligenter oeferi bunt:z negligentius emendantiut oicit Zuguti nuts, 15.libzo oe ciuitate dei. 

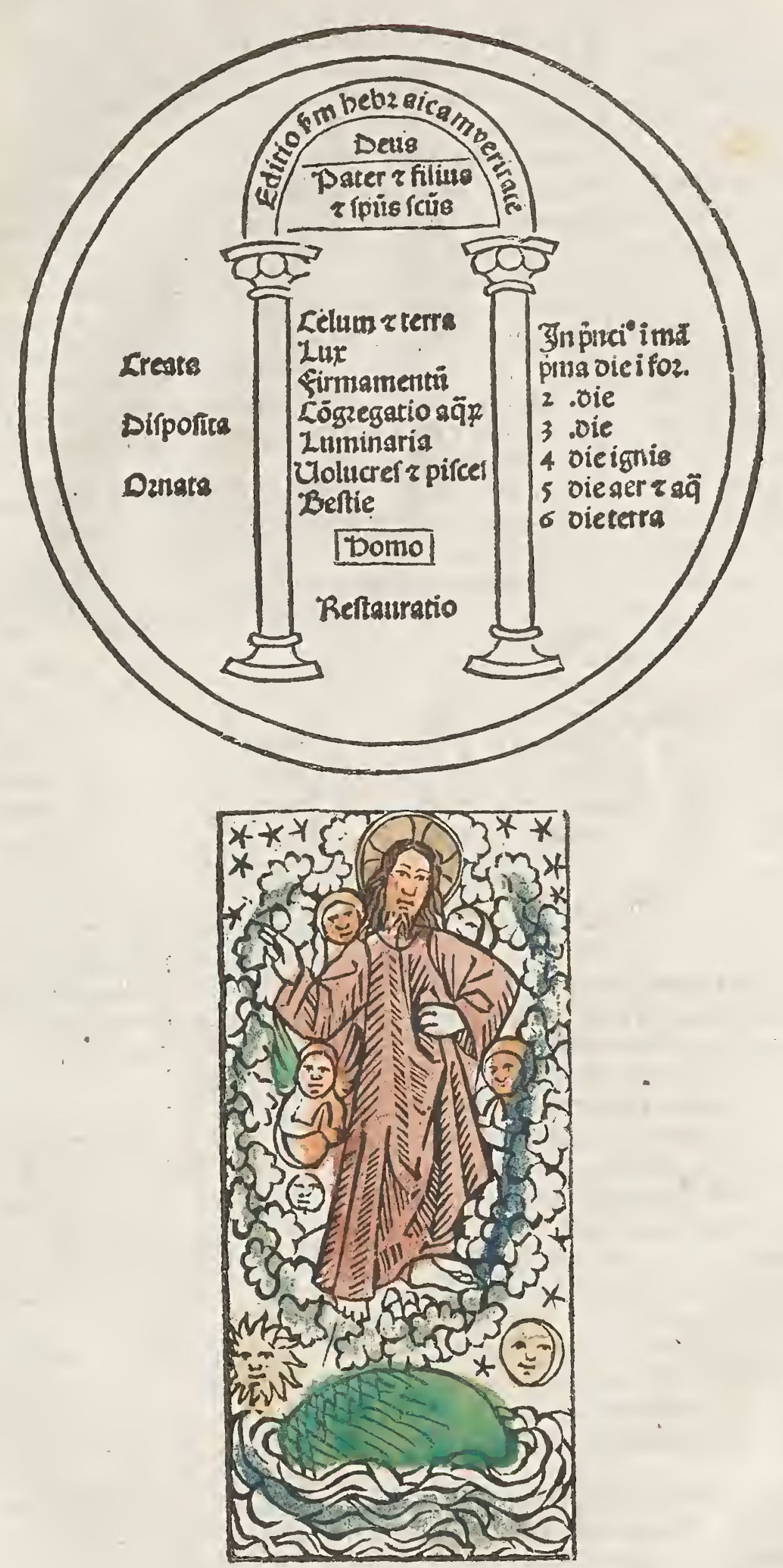


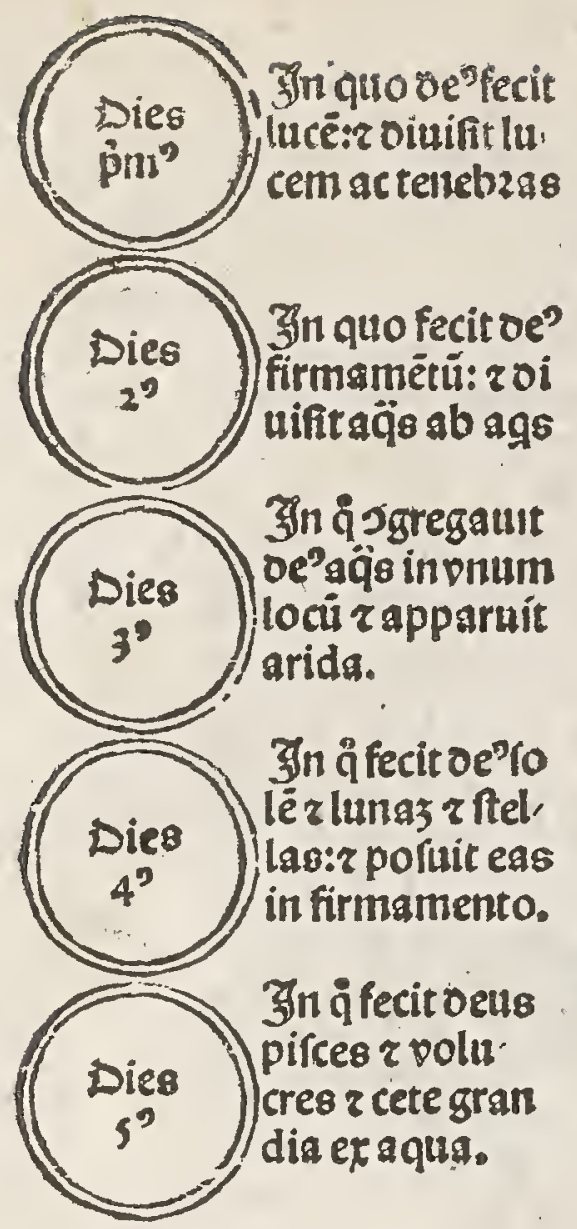

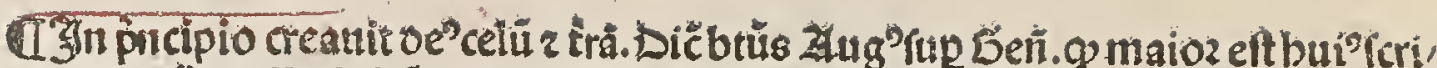

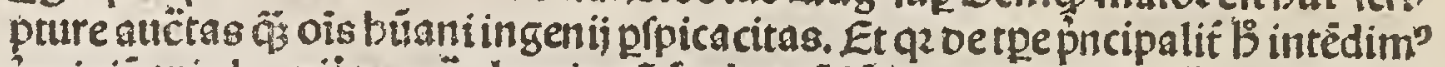

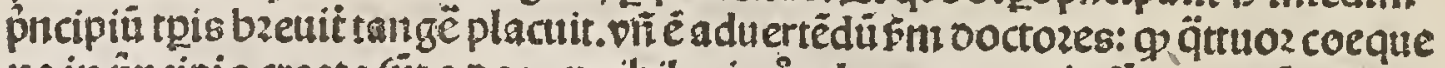
ua in partipio creata fut a deo cr nibilo: in q̊ relucet creatozis füma potêtia. bec aüt rüt celü empyreü: angelica nä:materia ğttuoz elementoz:z temp" Et bocto

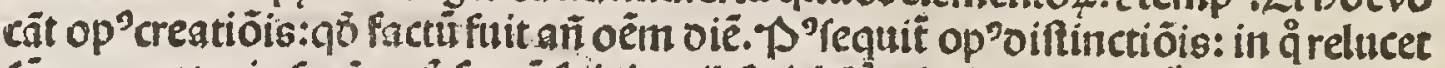

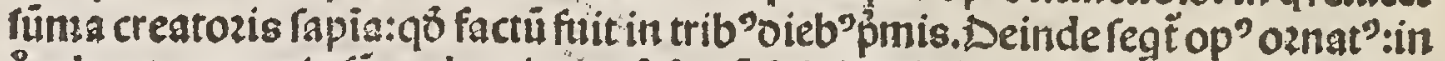

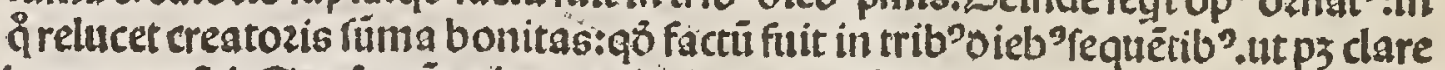
in textu geit.i. Septia aüt oie regenit ab oi ope qô patrarat:non ä́f opando laff?

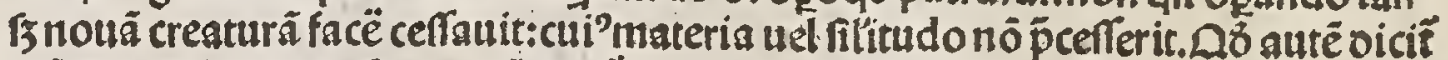

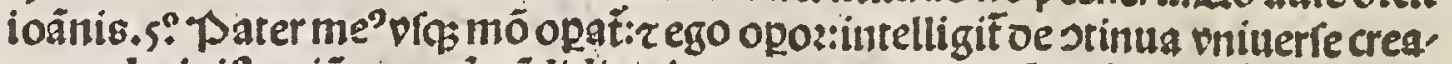
ture adminiftratiōe: qz qo cödidit otinere $z$ gubernare nö ceffat: 2 in boc relucet creatozis lüma pfectio:q2 fibi foli fufficit:nec eget creaturis:\{3 poti? ej: q2 virtus creatozis é cã rubriftẻdi oi creature. z bocé $q$ feptima oies véperã nö bร. De bis pleni" videmgr̈m, 2: miaz: zooctozes defup copiofe feribentes. Dozzo fequens

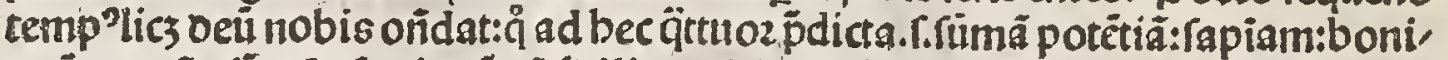

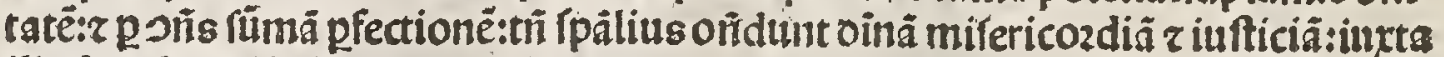
illud pral.2mifericozdiã z iudicium cantabo tibi one. Et iterī. Uniuerfe pie onii mifericozdia z veritas.2Moifericozdia tì feeptrü tenet:ä̉diupiatozes fumus:que nulli petenti veniä negat.

đDumanü genus io ex vno boie oeths inffituit: ut cỏmèdaret ö ei grata fit i plu

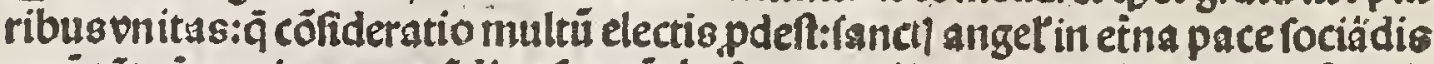

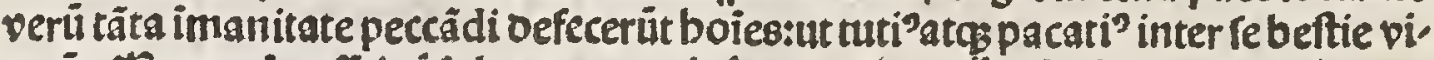

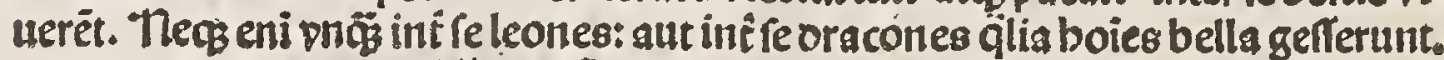
Ulinculü cōcordie oiligit oeus. 'bec aug? . kij:oe ciui.oei.
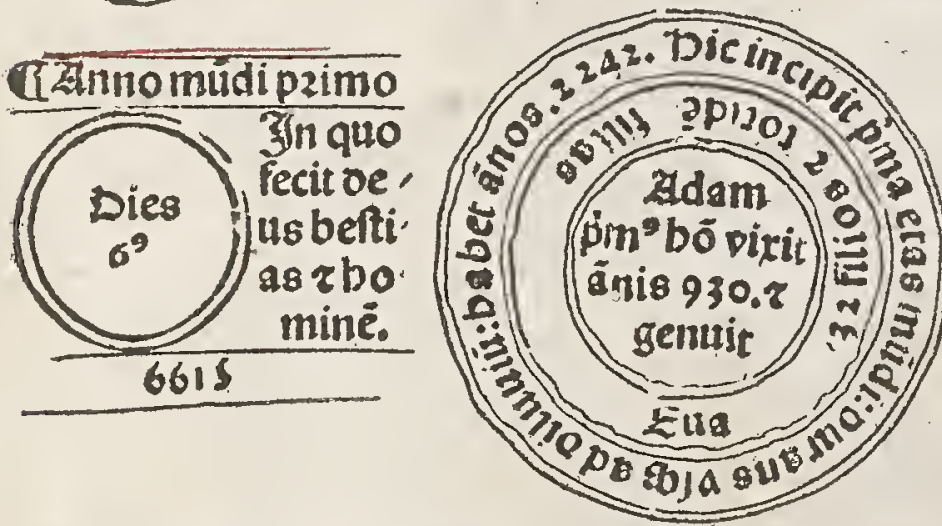

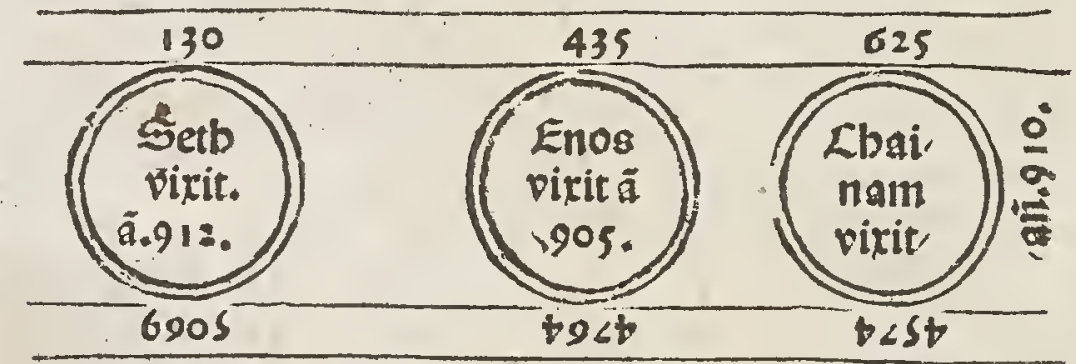

đIfle fetb nat? quož mopfes ṕtermifit centü gb? luxit abel in valle plozatiōisppe ebzon. Ijpre etiáp oleo míericoz die ipetrando paradifï adijt.

(

Delbo: rafoz: abel

Cदjfte enos cepitiuo care nomen onit: fozte aliqua b̉ba oépcatozia iuenit:aut imagines fe cit p colendo oeo: ficut modo fit in ecclia.

II The abel paim² martpr ecclefiă in. cboauit q2 in grã moztu? Puit.fi eni ab adam incboata fuiffet:nö fozet stinua Dic f́m augl.cinitatë oei odidit: cuni? pmus ciuis fuit: $\tau$ qz iuft? fuerat: oeus

abel

occir?

a.cain

oei.
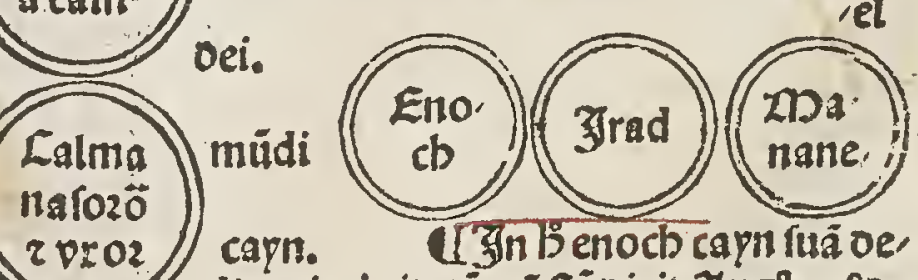

CInt benoch cayn fuã oe,

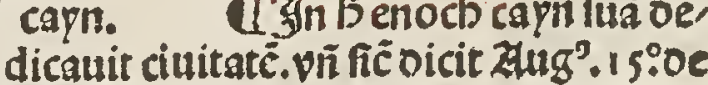
ciui.oèi: nō eft ablurdü $q$ capn edificauit ciuitatē cum vir ättuoz viros fcriptura oicat tüc fuiffe: $q 2$ nö oés Iumerauil: q tüc effe poterät: fed illos tū noiare neceffe putauit quos fufcepti operis ratio res ouo: terrenä. f.amoz ini vfas ad cötêptü bel. celeftem io amoz oei vfas ad stemptǘrui:oenicg illa in feipia:beci oño gloziat. Zlla querit ab boib'gloziä:buic aùt oe' J́cie teftis maxima ë ghta. Ad illä ptinet:cayn $q$ p̀mo nat?eft: $\tau$ ciuitatë cödidit.ad iftã ptinet abel g fecüdo nat ${ }^{2}$ eft $z$ ranç gegrinus bic cöuer fat"elt: q2 grä p̈dellinat? ciuis furfü erat. Deniq ut ciuitas oei fue aduer farie cōpatione clarelcat: aliqua facta repzobozü cömemozare necête fuit.

ILíitas terrena ab bomicida cagn incipit vfö ad bomi cidam lamecb.

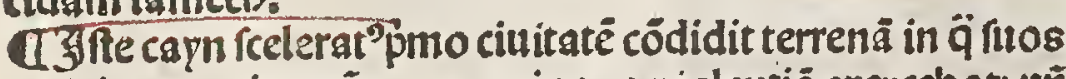
poluitppter timozé:eo g rapinas $\imath$ violentiä exercebat: vĭ furpicabat fibi talia reddenda qualia faciebat: ió in nuto fe recepit. 'bic fratrē fuuz abelppter inuidiä occidit: zpunit" ono vagus zppugus:0efpatufas tandē a lamecb occifus $\overrightarrow{\mathrm{E}}$.

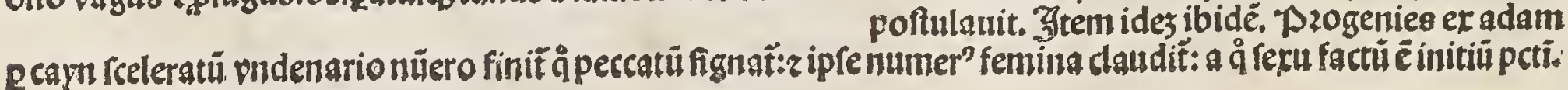
ei oblationé acceptauit. 


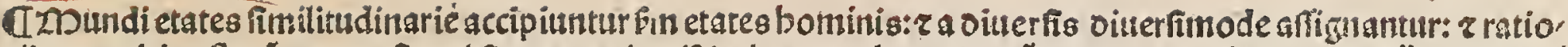

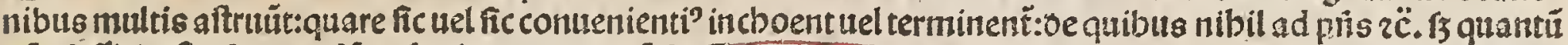

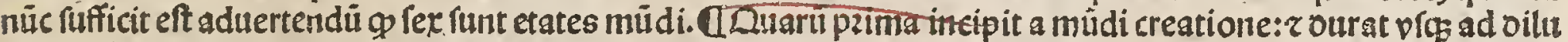

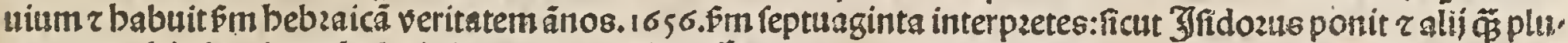
res: quos bic requimur.babuit åno .2242 . 2 fic oiffertunt in annis. $586 . q u 08$ bebzei min ${ }^{3}$ babent in bac etate. $\tau$

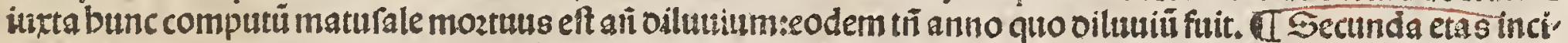

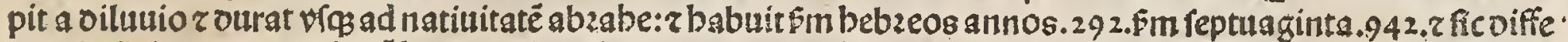
runt in ãnis.650.q10 iterü bebzei minus babent. Rue aute fit ratio tante oiuerfitatis iuenireno potui. I Ler.

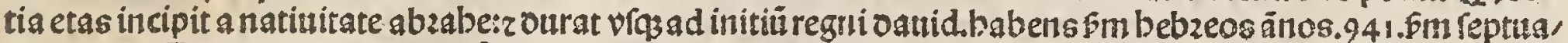

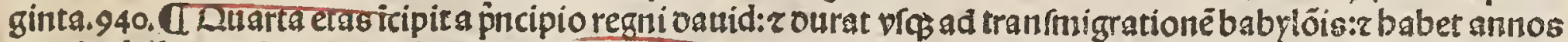

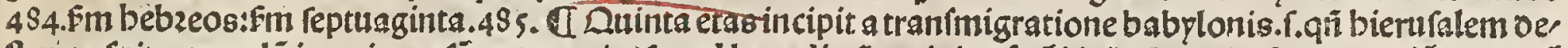
fructa fuit: $\tau$ templü in ea incenfú: $\tau$ ouraut québic fequimur. 590 . Et ficut ṕdictĩ eft: grandis eft altercatio oefupputatione annozủ buius ctatis:oiuerfi oi.

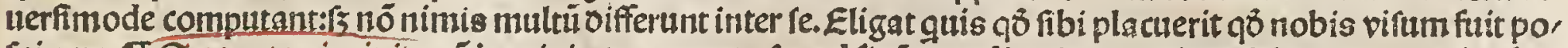

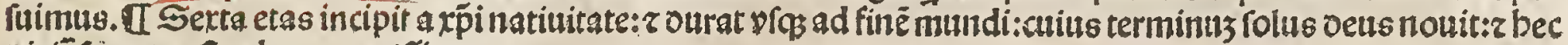
oicit fenectus fiue bo?̣a noutifima.

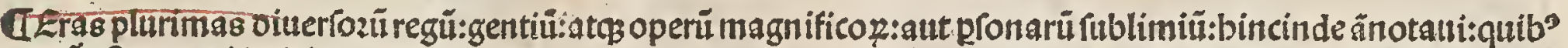

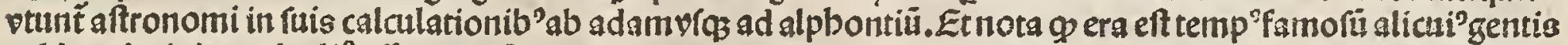
uel fecte incipiens a b aliå effectu g elt notabilis bonitatis uel malicie: $z$ vulgarit pör oici oatuz: iuxta gơ publice conicriptiones fiü. Unde r feüs leo bui"nois pzimts:frequenter boc termino era vtit in epiftolis fitis.

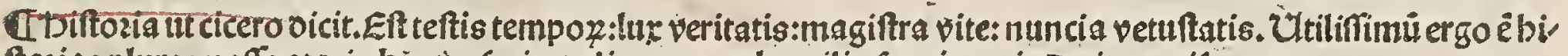

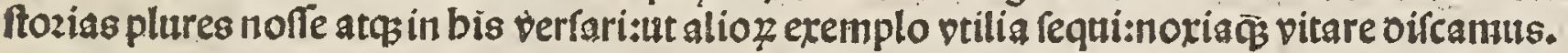

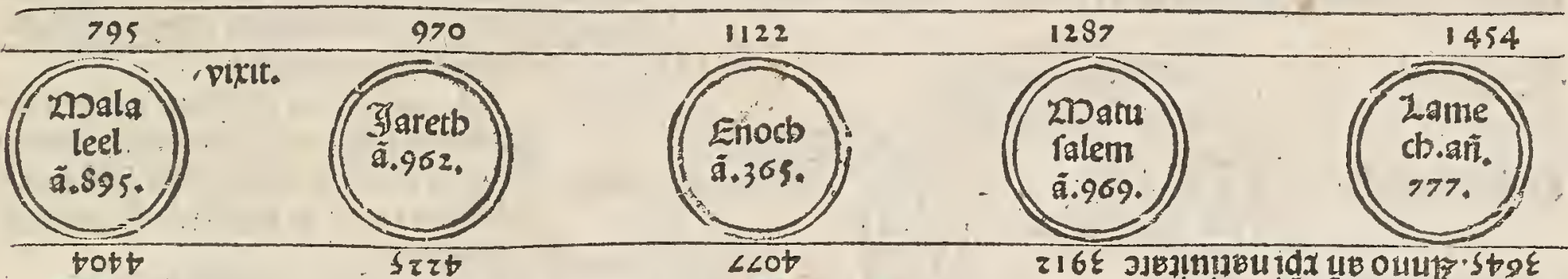

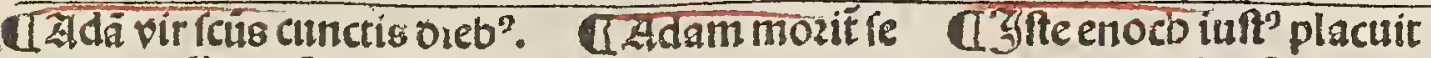

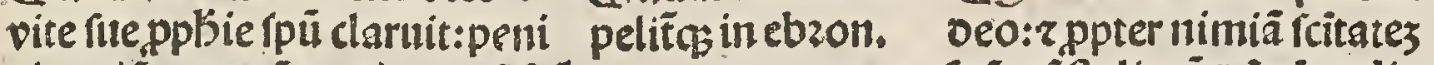
nitentiẫ magnã ac oiuturnã feé

filijs ftuis popta iufticie dedit:p̄cipiēs ut a orortio

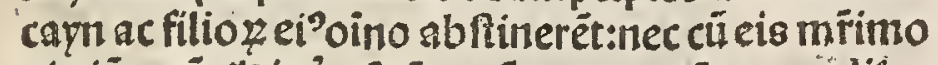

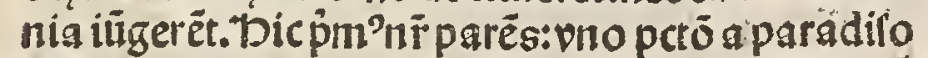
nos expulit:[s fcä ouerfatióefita acpnia:exemplì nobis oedit ad regni celeftis gaudia remeãdi:qui aüt bocnô requit̃:oe p̉mo cỏqueri iuftenö poterit.

$$
\text { Q Luriofitas. }
$$

Thota $\$$ oés artes uel fie feculares:liberales fitue me chanice uel pbificébüane curiofitati oefertuiêtes:a filijs lamecb legunť inuête: $z$ fic filì adultinin p̉mũ fubtiliozes alís fuert:z qz timebät futuz pi culü oilutuij"zignis.iótubalear Z Zda dea adbuc

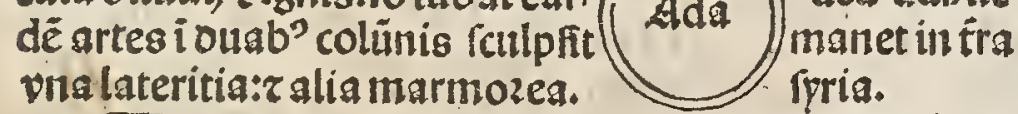

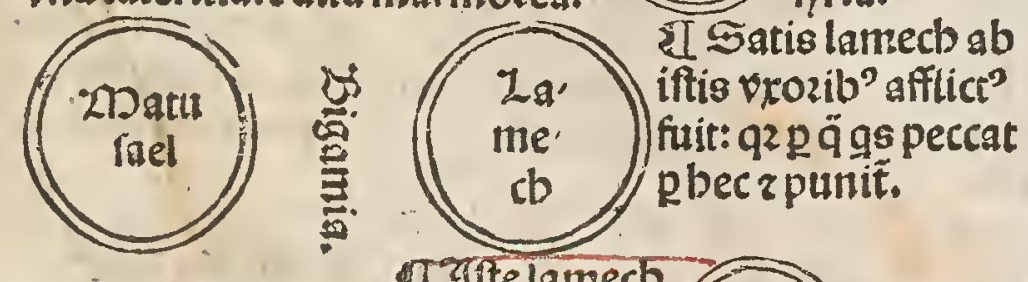

p̉m?วึnaturã r mozes bigamiä infti tuir adulteriü cönnittendo: ipłe etiał carn occidit nó tii volıntarie: red cii fenuifier z caligaffent ei’oculi: a puero oucebat̃: $q$ putãs 9) ferä vidiffer:ind icauit ei ut iagictaret : zficipum cayn

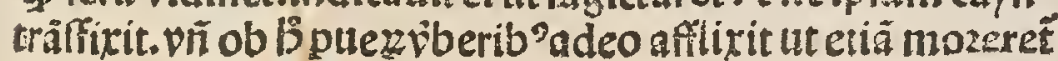

ruã trấftulit eủ oris i padí.

fü. vbi cu eliq viat in mä̈ cozpis a fuñ träquillirate vfo;ad antixpi adueritum túc eni exibütppi cóforta. tioné electozu1z z martyrio cozonabüt. Enocb fripta eligt:iuda aplo atteftãte.
I "Dic matuale fenifin" ă multiudine än fcriptura cōmēozat. Eún.11.500. ânos brët: oitit ei oño. Edifica vomin fi vis: giñ adbuc.500.9n

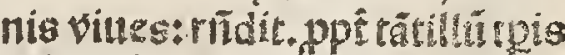
nó edificabo oomui:z tetb arbo rib" z circa vepzes oo mmituit ut pzitus cófuseuerat.

Cisultiplicant mala funtrã. Cbpgantes tunt in terta.

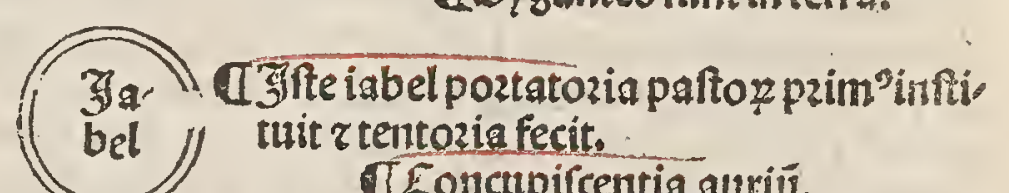
TEonctupifentia auriu.

UZfte iubal pater canentiü i citbaris z o2 Zlu, ganis a mufice artis inuentoz:ppoztiones bal quoqs fonozer malleors fonitu ppendit.

đConcupícentia oculozú.

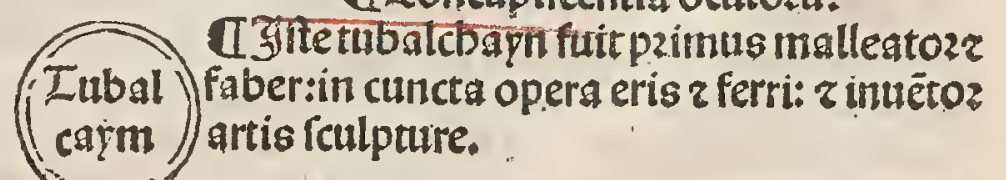

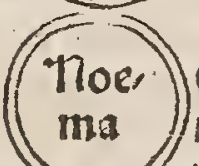

CLoncupircentia carni:.

Q. Ifte noenta iusnit artes varie oilierfeq; rexture: lanã z lina in fila traxit: $z$ pannun? texuit ppter leuitates. nä antea pellibus be ftiarip:o veftubus vtebant. 


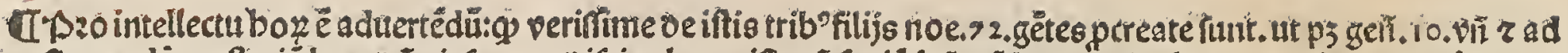

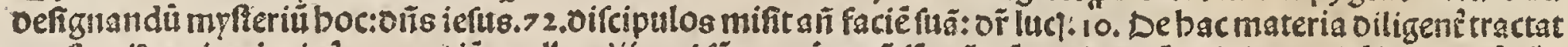

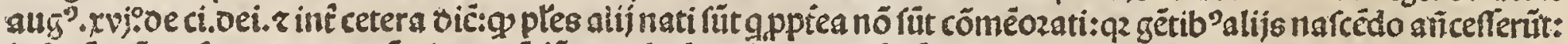

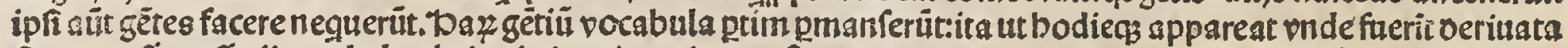
ficut ex afiur affyrij:z ex beber bebrei. Dartim tpis vetuftate mutata funt:ita ut vir boies ooctifimi antigfimas

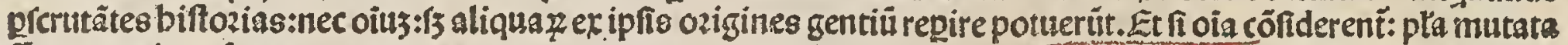
ถึ:manentia noia apparent.

UT Tota 1 m o octores oebitã penäboctpe müdo inflictã:ฤtia eni luxturia sbundauit: que cozpa polluit:iố $\mathrm{p}$ aquä terra lota rmü.

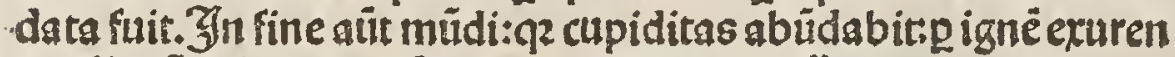
tur. Zૈurü eni zargentui igne purgari folent z 2 :

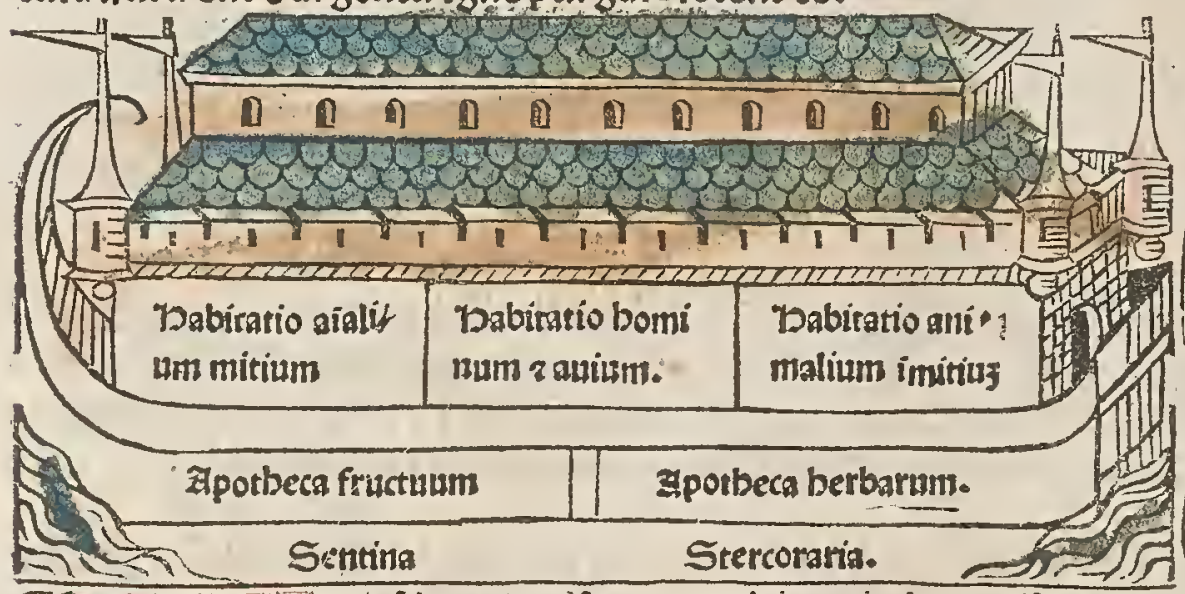

A Archa noebabut i longitudie. 300. cubitos.in latitudie.50. cubitos:i altimdie.30.cubitos ri fúmitate vnu cubin.geri.
điDoc fignu federis: 980 no inter me z pos z ad ommē animã.geñ.9.

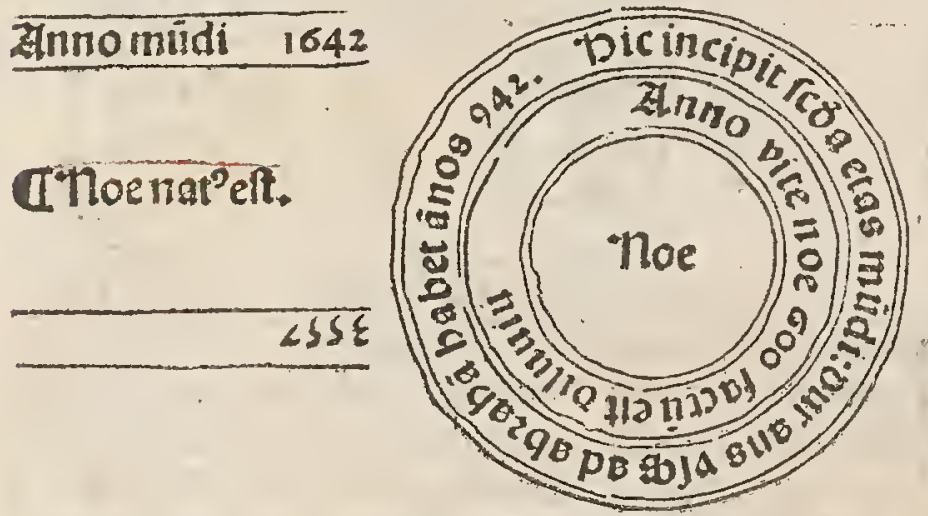

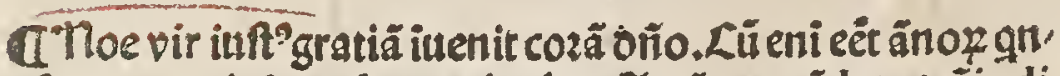
gêto\%: genuit fem:cbam r iapbet. Arcã oe mãdato oniti edi

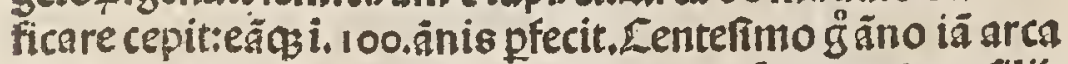
cōpleta:ite ž oñs apparuit ei:mãdâs:ut củ troze fua r filijg

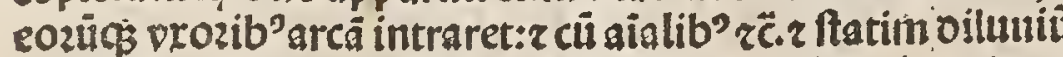

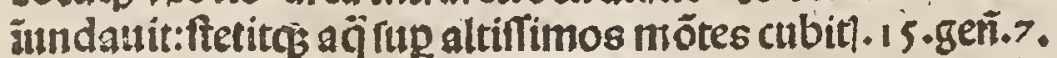
Et nota qu codéoic oritico i maio å ingref" fuit:año reuolu

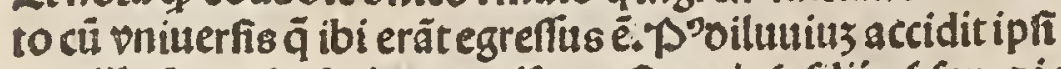
noe illa famofa ebzietas: cui? occafione ip fe filijs.f. fem $r$ ia pbetp bonoze prno z bonefta verecuidia bridixit. Silio vo fuo cbamp irrifiöe zirreuerêtia maledirit. Et bic fnn augl. fit p̉mg mentio oe fertutute: $z$ poppofitü oenobilitate:nec putandĩ é qués oe cbam dercédêtes fuerit ignobiles r im

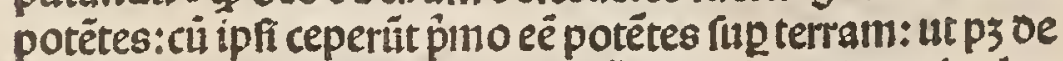

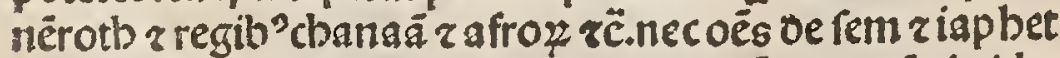
fuerüt virtuofí fiue nobiles aut potëtes: cü pene oẻs in ido latrie crimé ceciderür: $z$ ab alijs op prifi fepe fuerüt.jz bec ma

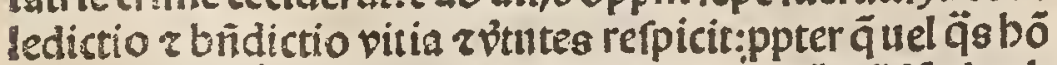
veraciter vicit ignobilis uel nobilis. "Pari niô g fidē abzabe

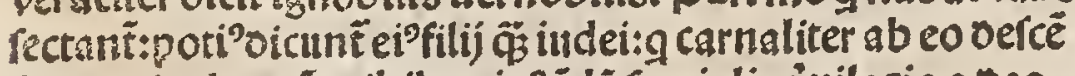

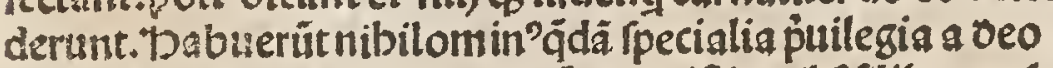
ppimerita patris acbuidictioné. Et ex iftis trib'filís noe. fem dban z ispbet:ip fo adbuc viuente iurta pbilonis biftoziã.24, miliü z centú virownati funt extra mulieres partulos:babentes fupza fe tres pzincipes:nemrotb:ietban z fupbente. lici:ediditaggenerationes.3.

\section{3̧oni.} cus fili us noe
Arcplutuialis fiue iris ouos colozes p̉ncipalit̃ babet:g ouo iudi cis reprität. Zqque oilutuiü ṕteritu figurat : ne.ampli? timeat Fygneus futup iudiciü fignificatp igně: ut certimdinaliter etpectet́.

IJfteionich'fuit fili?noc:oe â moy res tacet:fapiēs: pjmo poft oiluuiú aftrononiā üenit:z qudā futura $\bar{p}$. uidit: 2 maxie oe 02tu.4.regnorü reop occafu: cüas pr de dif́z ei mu nera:ituit îra â etban: rbitauit ibigentē Jftituës: bic fert כifliii oediffe nërotb quõ regnare poffet. bicfert ofiliü oedifienérotb quö

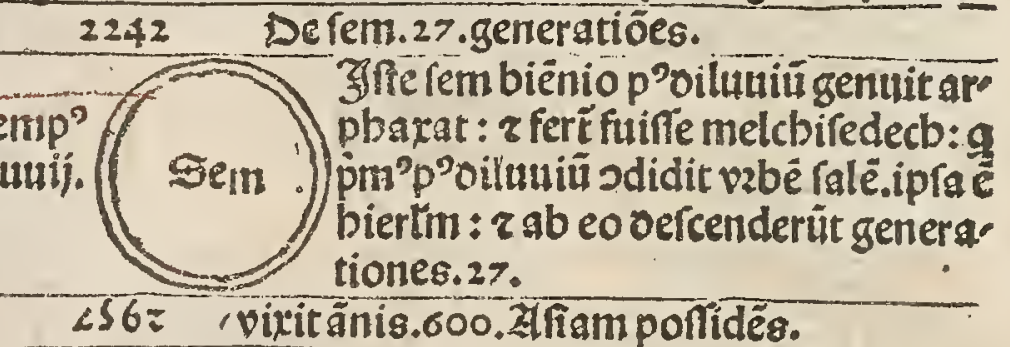

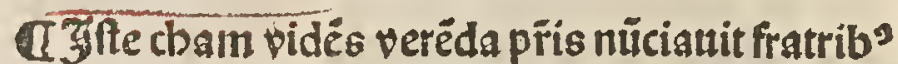

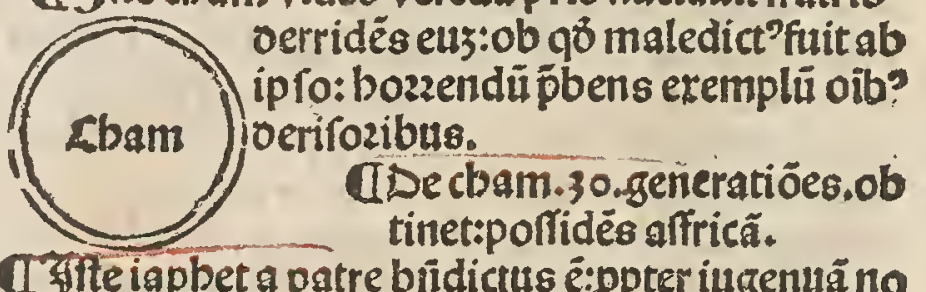

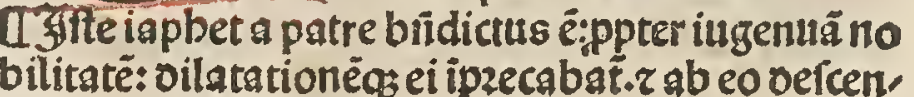
derunt generatiōes.1 5 .

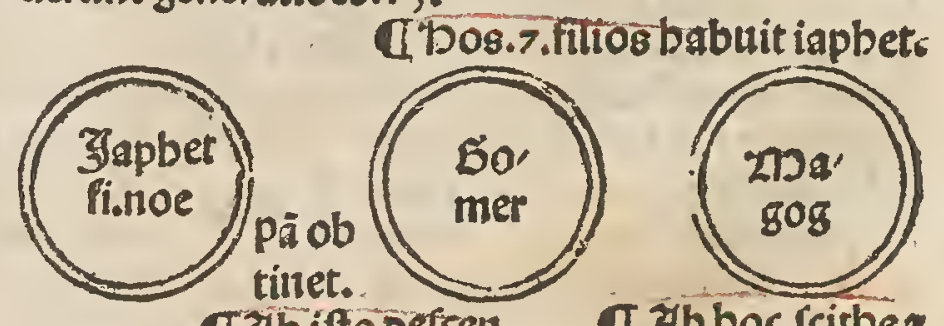

Taibifto oeften derútgalatbe r $p^{9} g a l$

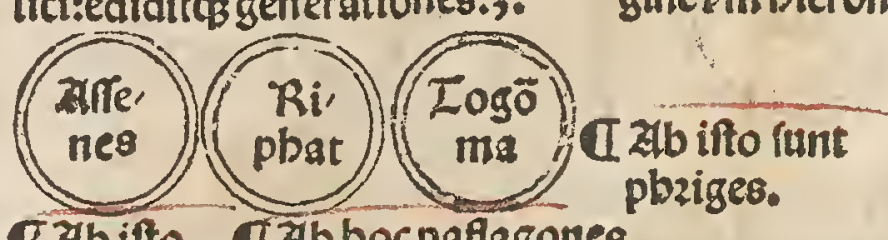

Gabifto a Abbocpaflagones. a Zlb boc reitbe? goti traxerüt ou ginéfmbierony. priges. affenes farmate venterüt:̨̊s greci regtos vocant. 
a 2 b boc arampgeniti funt fịri quosü metropolis oamafcus. indez in bebzeo Jrria oicit aram.
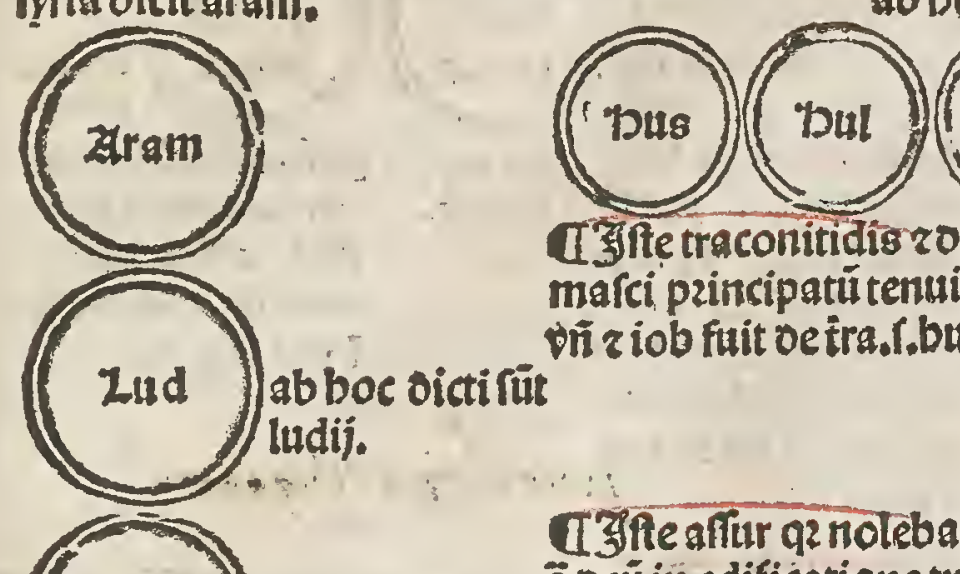

abboc rütrabei.i.arabeo.

Iffe traconitidis roa marci pzincipatí tenuit: dii z iob fuit oe tra. .bus.

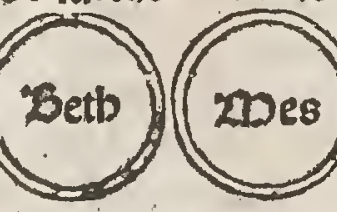

Ifte affur q2 notebat rebellare

\section{కెectå}

Xfilij cbus oecbam ab boc faba Zffti noiapdiderút?

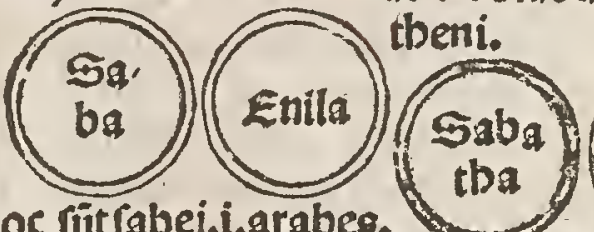
innt nobis ignoti.

ab B getuli

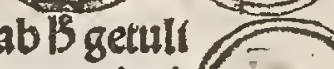
in remotiozi o'apbriceptil ba

b'beremoco

beren ab boc fabeos oicuit appellatos. tes.

\section{Zlfur} 5 oen in edificatione turris babel ab boc affiprij. cus nemrotb:io fugit oe terra len, naar:ad aliä regiones longinquä pri?nó babitatã que ex ei’noie vo caí affyria:z edificauit ciutatê qu

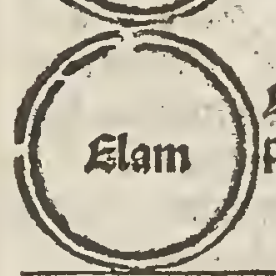
Elamite pzinci poltea vocata eft niniue ä fuit me pes pfidis. tropolis toti?regni affriozú. Żftee pplus femp crudelitatis infamiä. babuit.

I Gfle iectan exemplonemrotb accepit poncipatũ fup filios fem: $r$ babuit filiog tredecim : g oés fecernnt generatiōs pincipaleo is pplí ifti fm bieronymü:nó funt nobis noti: uel ppter terrarü longinquitatê: uel ppter mix. tationes pplo ₹ $z$ noninü:tiel cótriti guerris 2 fubuerfionib'uel alije oecallis ž̈.

Elmodad.falepb.farmoth.iare. filijiectan adburan.vfal. oedal.ebal.abp mabel.faba.opbir.enila iobab.

2244 2379 2509

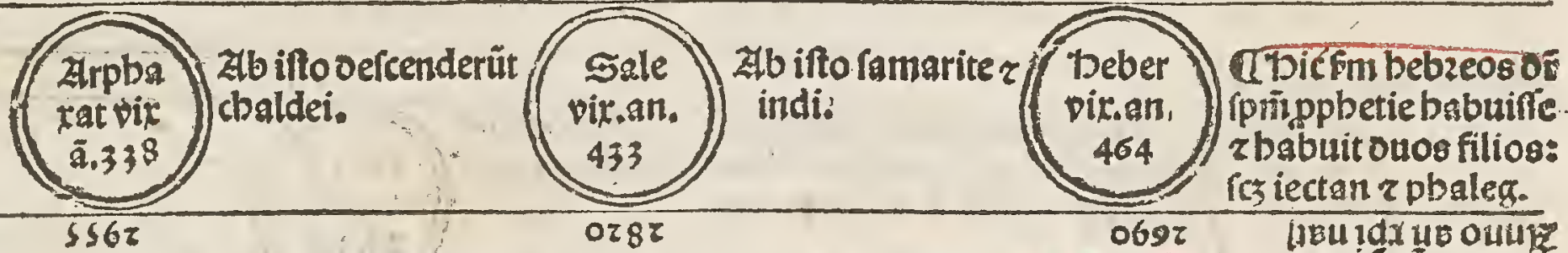

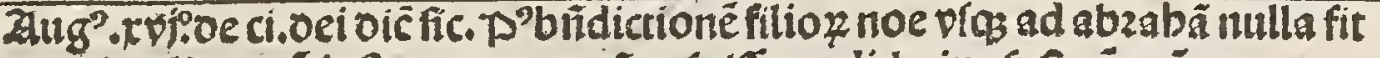
mentio aliquozú iuftož:nec cos tñ oefuiffe crediderim: fy fi oés cömemoza,

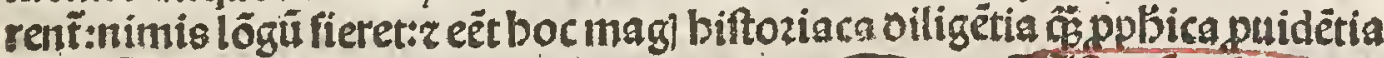

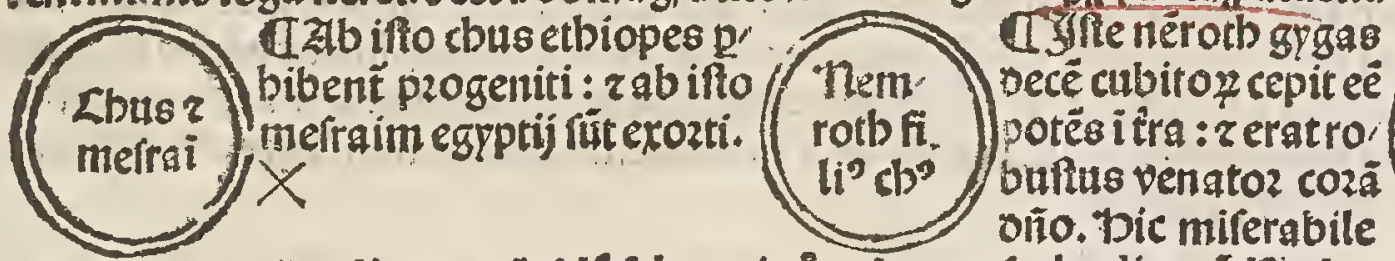
vitiü libidis oñandi per tyränidé icboauit:q̊ oeiceps vfás bodie müd"adeo

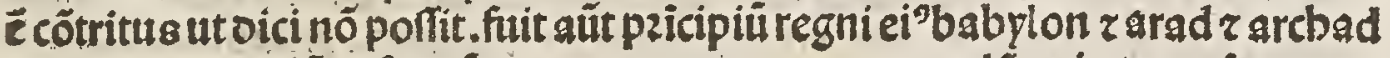
reptem generatiōes fecerüt.

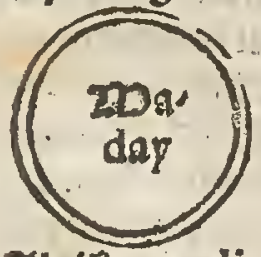

ab ifto medi veniffe putât Sepotetiflimi
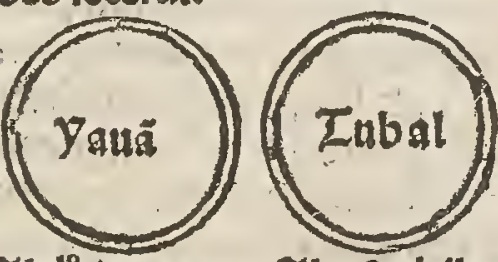

Zbbiotiesg

uit.pî zmare gdä ex eor ita ioutiu oictü é Xlos furpicant.
$X$ Etedidit generationes quattuoz:
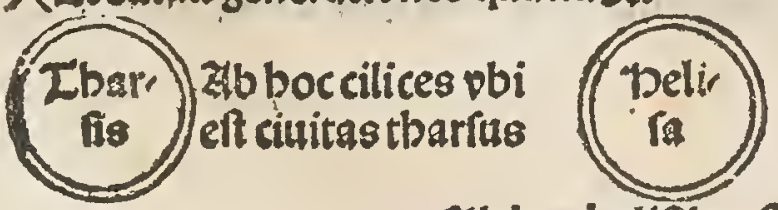

Z6 bocbelifiz rp'colides. z calầne in terra fennagr.

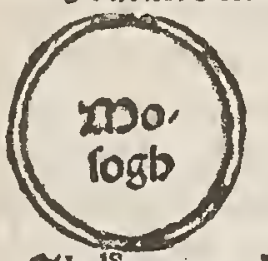

Zu É cappado

apud eosmaçe uel tbi cab oicitur. races. dazb ifto beber bebzei noiati fut: กส̃ i oomo illi"in oituifióe lingua rola bebzes lingua remanfiffe oe, Tcribit: ă antea buma Eana. na oicebatur:qua oës z futb cöiter vtebant. CSili chanan. Si. don.etbetts.iebuçus. cine". amozze". gergeçe". eratbe". cineus.aradius. Famarites. am a theus pplinoti. Zlb ifto cbanaan pgeniti füt gffri: $r$ fenices z cbang neoz gentes. Et ab ifto futb libies oicunt exozti. vnder mauritan'flu uius vfoz ad pins futb oicit:omế, circa eú regiones futbenfes.

ludim.anamyn. labim.neptuim. pbetrufitu.cellui If flij mefraim Debisegreffi füt philiftijim $r$ captu rim.alij ignoti fü nobis. 


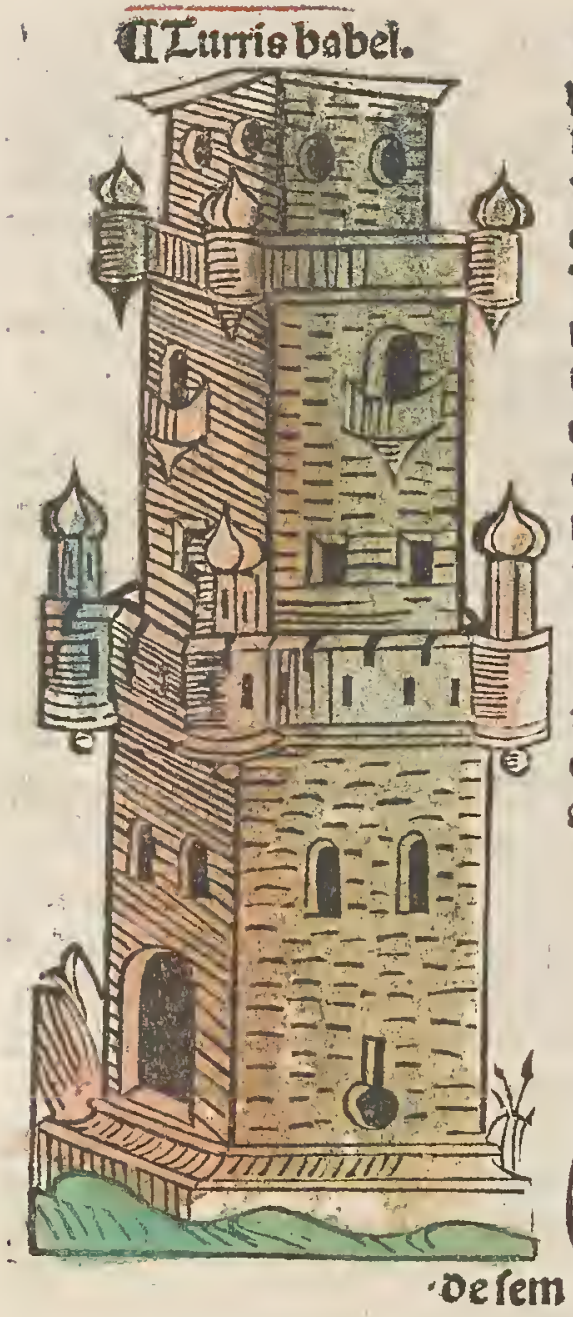

UDemaliciabaionerotb pleni funt libzi.fozte oino iudicio actüë:ut nero i ei vocabulo plane re offerat qui fimilé infamiā babuit Thá poft côfứnoné lingus rü ad pfas abijt:z 208 igne Docuit colere:babplöe reli etrafilio ftio belo:qui ei ruc ceflit:r fic oeinceps pofte ritge ei' regnü illud obti. nuit víg ad quartü cbilia dem:fm merbodiü $\tau \bar{c} . S \xi$ aug'oicit eú fugatü inde: $z \Phi$ filijaftur regní illud obtinuerüt r tentuerüt vio ad ann08.1305.zت्ن

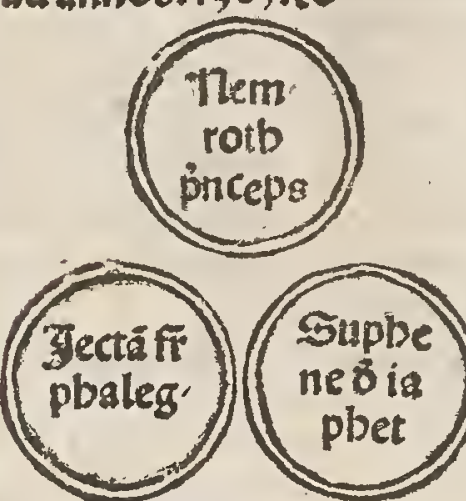

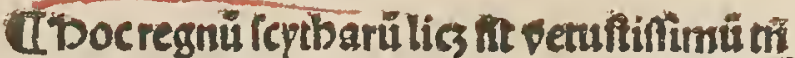
q2 barbarołé: inter paicipalia regna mime cōputat vii ppter illi ppli ieptitudinê fiuc groffitiē: regio illa ip oicta eft barba. rica:r émaguñ de: qs meotidis pa ludib'incipiés int oanubiū zoceanú reptentrionalé of ad germaniã pozzi git. Et é pzima pars

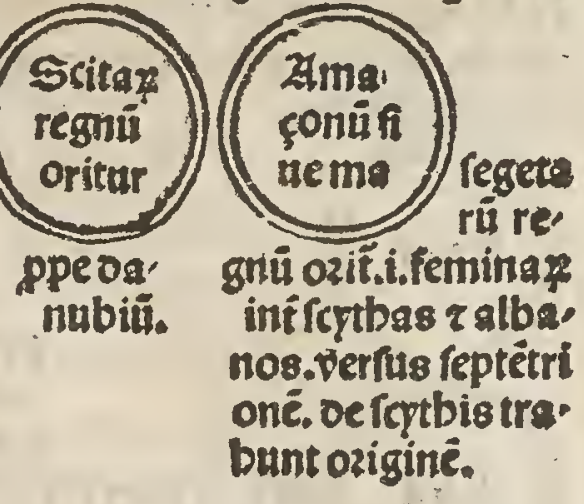
regnauit zanue oe ftirpeiapbet. Sotbi idêngarifut oe bis roani rc̈.

$$
\text { genealogia Vingarom?' }
$$

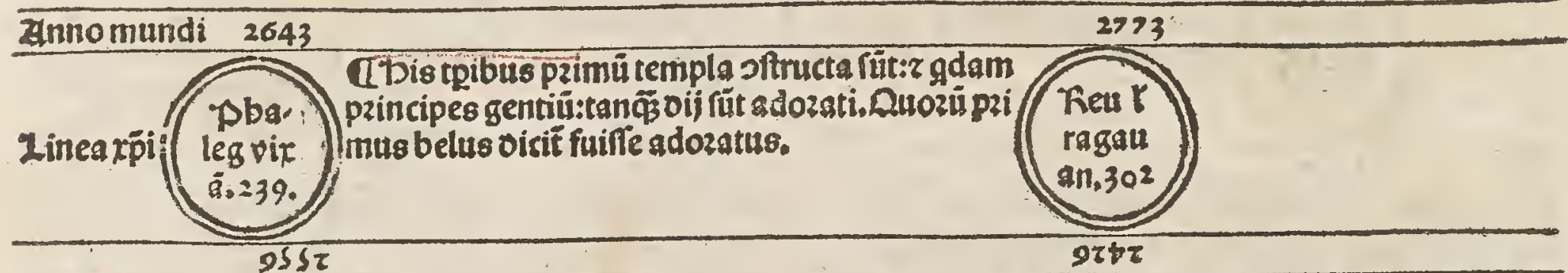

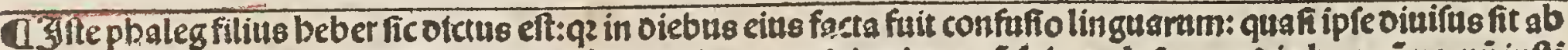
alip:quia in oomo fua manfit lingua paiftina:q2 in ea confpiratione nô fuit:mnde fm augl.in boc nō paruu iufti cie veftigium apparuit: ifta comus libers fuit ab bac pena:quafi nö fuerit pticeps in culpa. Et nota fm eúdem

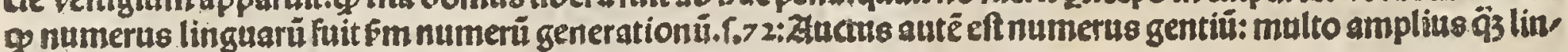
guarü:nam in vna lingua plurimas gentee nouimus.

ITlobilitas circa bectempoza fert introducta. Et nota $\phi$ pluribus oe caufs inftituta fuit. prima fuit neceffit tis.crécente enibumano genere:ciub omines ad malü pzoni effent: opoztuit pbibere infultus pzauozum aduer, (us bonos: $\pi$ ideo eligebat aliquis vir bonus iuftioz ceteris atq pzudentioz:qui cōmunitati pzefideret:pirtuofos pmoueret:mediocres oefenderet: 2 mal os coerceret:binc oictus eft nobilis quari pze alijs in virtutib'notabilis. 2Inde bieronfmtts. Thibil aliud video in nobilitate appetendü: nif 9 nobiles quadã neceffitate conftringantur

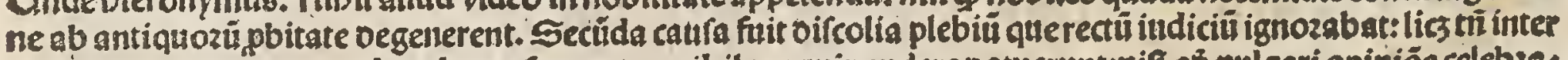
re pacate viuerent:nam a deo ebetes fuertunt: $q$ nibil magnipendere potuerunt:nifi qo vulgari opiniöe celebzar

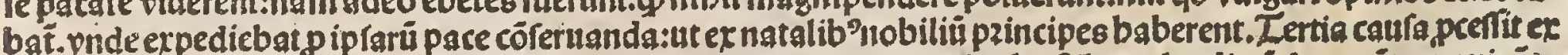

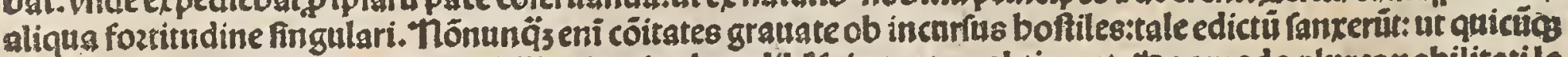
patriam a talibus liberaret:ius nobilitatis p fe z beredib"fuis apetuo obtineret. bocmodo plures nobilitatile

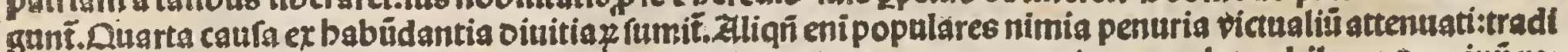
derüt fe r rus alicui oiuiti:utboc pacto malum inopie temperarent: $z$ eum oeinceps velut nobilem r vominú res cognorcerent. Inueniunt etiam quedam nobilitateo 2 oiuinú oraculü inftitute:liç pauce quarü aliqueper $X$ 


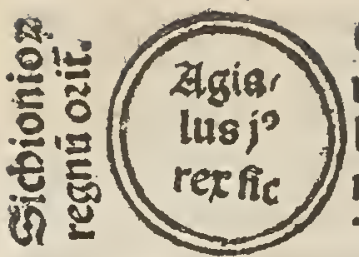

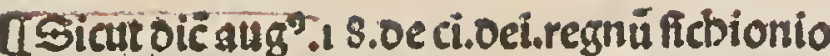

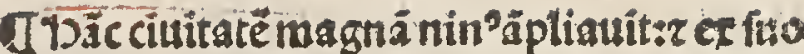
rü admodü puî erat:oe co octiffim² parro pe noieninitue appellauit:ă é metropol affrioz

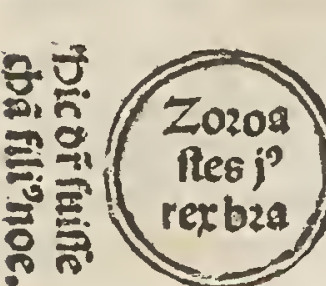
lut antig tpe eroz/us é:puenit tandes ad atbe niêres oeinde ad latinos:oeinde ad romanos buic fucceffit europs fecúd' rex ficbionio z: ? ourauit vlas ad tra beli facerdot? z iudid irrt.

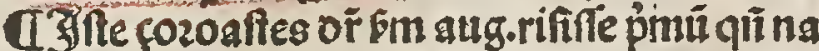
tus é:necaligd boni móftruor" ille rifus ptéde bat cü oib"cồ fít:flédo bür múdú intrare:artè crianop.

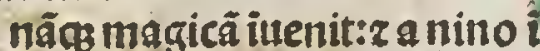
đErápncipalis etrąebij z gétiliu: qs antigo

: Belus I bocregnü pene nü pacati

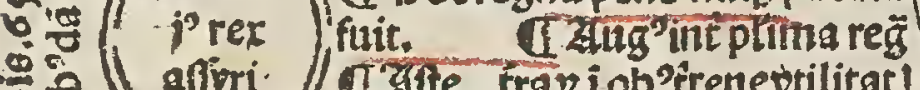
: anpri. bel'or uel cupiditatl éoinifa fo.

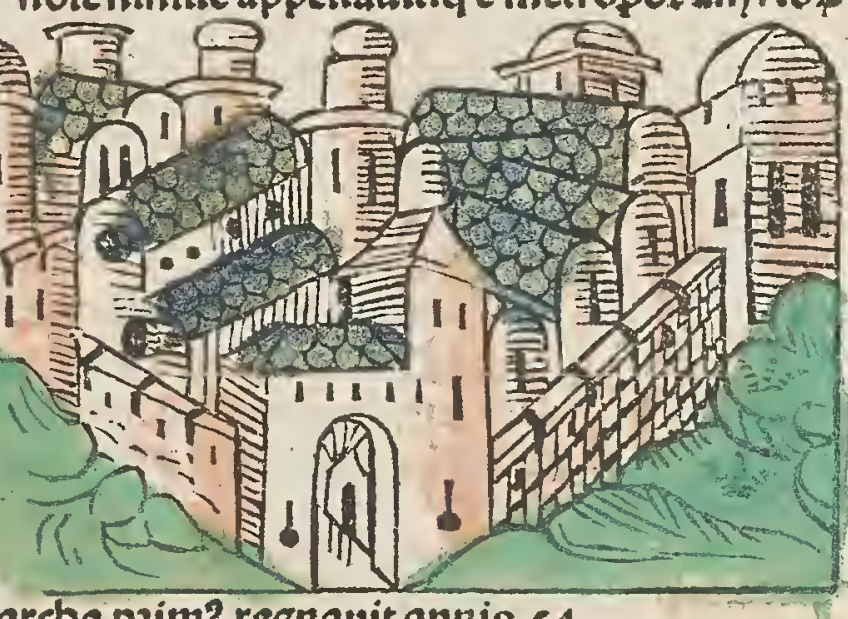
nirtus iprex mo' narcba p2im?.regnauit annis.54. lobicuroregnaffe: q: puü cietas quã bui?múdi citui buit onium. Et ifte fuitpai taté olivocsbulo nuicupa mus quẻ erroz ppli oeum mus:ous reğ cernim?lon fuife putatuit. vi oiuerre gë gepueniffe clarioza.affy' tes oiuerfimode ei noiant rioz p̉mú:beinde romsno r.bel.basl.bastim.beelpbe rü:uttpib'ita z locis int fe gor.beelçebub rč. Et ftetit ordinata atō̇oiftincta.

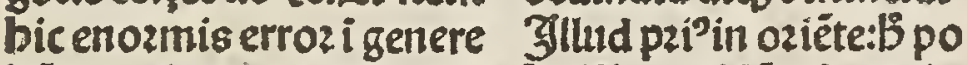
buno vitra ouo miliagn. fteri’in occidéte furrerit. Gyftelibidine oliandi pmot'ut lati? reg̈re por fet finitimis idé vicinis fuis bella intulit: 2 q pplus ad buc rudis fuit:nec bellädi: nec armo pitiä büit: cito pes

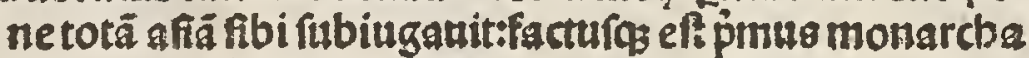
ozientaliü cúgnimis voleret oe mozte pris fui beli:fecit fibi in rolatiü fuñ imaginé ei": cui tantä reuerentiä exbir bebat:ut gbuicū́a reis ad ipfâ cófugiêtib’ pceret:s penā indulgeret. Dui"exéplo plares cbaris fuis moztuis ins gines vedicare ceperüt: vidétes aút maligni Ipús curioñ

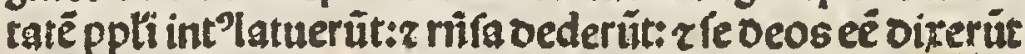
ac oinos bonozes fib! fieri oecreuerut : ficq; B infelicifi. nozí.

Zुn fine illi'initiū fuitb". mū idolatrie crimé introductú é: oine maieftati pmari, Regna cetera ceterofg's reges:velut appëdices oiteri. me offenfíuü: $z$ itantü bec vefania creuit:ut capirali fen,

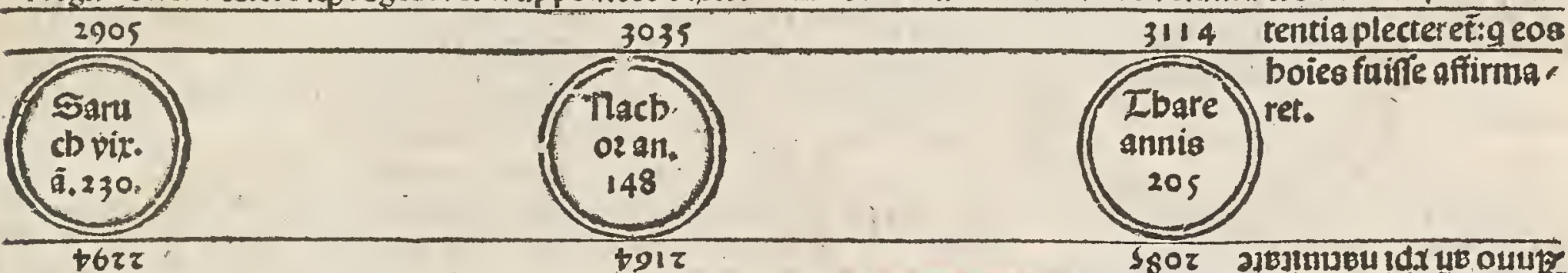

Xmanferitt:ut in oguid.alique cito oefecrunt:ut in faul z bieroboam:z quozudam aliozum. phrime quogle, gunt nobilitates $\mathrm{p}$ violentiā $r$ tyränidé introducte:qua. rîlimiliter alique ftatim oeftructe $z$ penit? oelete fuerit: aliāftabiles pmanferüt. Etnota $q$ Em veteres biftozias raro aut núç̄ i pagani ímo:nobiliü ftirpes ppentate fue

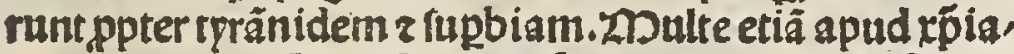
nos ppter candé caufâ oelete füt. frm illud ecclefiaftici.x: Sedes oucü fuperbo y oeftruxit onis:r redere fecit mites p eis. Tु tẽ nota 9 nemo vnö nobilitaté odio babuit: q2 eft bont p fe appetibile:ficut virtu 6 aut religio: 13 multi fancti eam fugierunt ob grande piculus quod in ea latet ppter difficultatē maximã ip fi annexâ.bos fatis i rancto ppbeta Danid apparuit:qué ipfernet oeuf tā peculiariter elegit. Relinquit ergo ap pix pauciflimi ad tantam fubli mitatem idonei fuermit. a 3ftetbare $p^{5}$ mozté filij fai aram:erinit oe pr cbal' deozu z pegrinat' eft i cbarra cil filije z neporib" fuis ferí g ppter iniurias illatas fíbi a cötribulib"fuis:co gu nollet adozare ignê: receffit $z$ oicit ab bebzeis cöit g nertnrotb ibi regnanit : g o ict? fut alio noie antra. pbel rex fennaar : quë oitu poft bec abzabam fugatuit z pecuffit.ut oicié geñ. $14^{\circ}$

Uद̧ Jolatria ozit́. Nota op fi bene reuoluas biftozias repies $\Phi$ tria pincipaliê boies ad idolatria indurertit T.effectio circa mozientes : timoz r adulatio apud re' ges:r oiligēti̊ artificĩ circa ́culpturã. Demones aũt in idolis latêtes:z réponfa oätes:buncerrozé conffir. mauerenimis:ita ut capitali pena plecteré̃: qui ei fe nó cöfirmaret. Acceffit infup fraudulenta poetarum laudatio: qui miferos oänatof́s boies in celü cōp ofi tis carminib'extulerunt. Et pulcbze eodé tpe cus oe' mones log boibus cepiffent: mifit clemês oñs anger los fuos: ut gburdã electis fuis etiã vifibilit loquerế ne filtota büanitatis mafla erroze peffimo oepiret. 


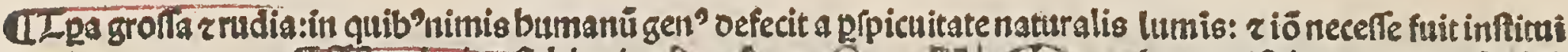
I Ifite telexion ficbionion s'pex fuit:å regnäte víg adeo ibi mi tia z leta tog furerit ut eù oefunctü ve Ieles lut oeuz colerêt.facrificando z ludos (i zion celebzâdo: ૧̊s ei pmitus fecerit. buic fucceffit tburiac":circa cuius fepulcbzi etiam fa

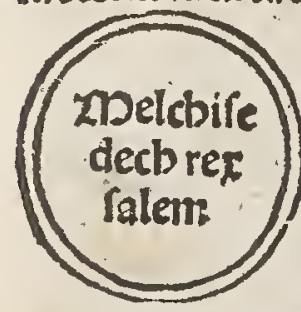
crificarefolebant.

II Jुte vulgarit oicebat rex in ftusppi eximiä rcitatē:panem 2 vinut obtulit abzabe in magnuz mp̣̂teriuz. fuitetiā facerdos oei exceifr.

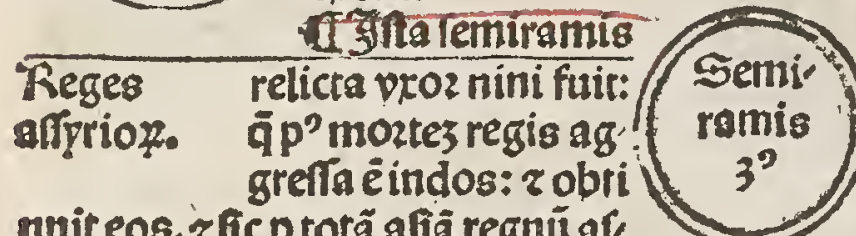

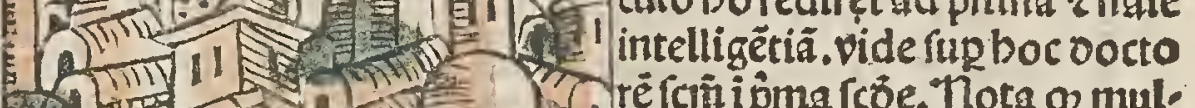

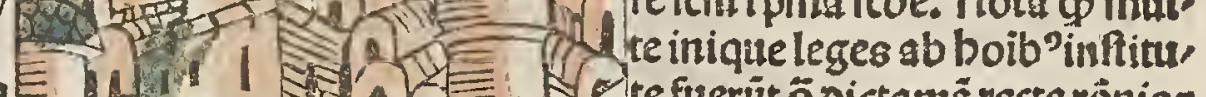

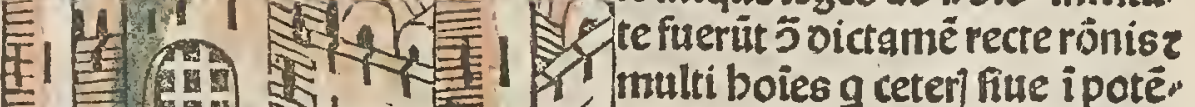
(1) res erät oij putabäț Déeni qő erat infolitu : reputabant quafi ourinū.

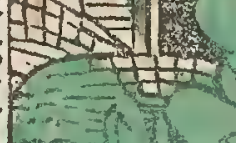

$\Leftrightarrow$ Dour

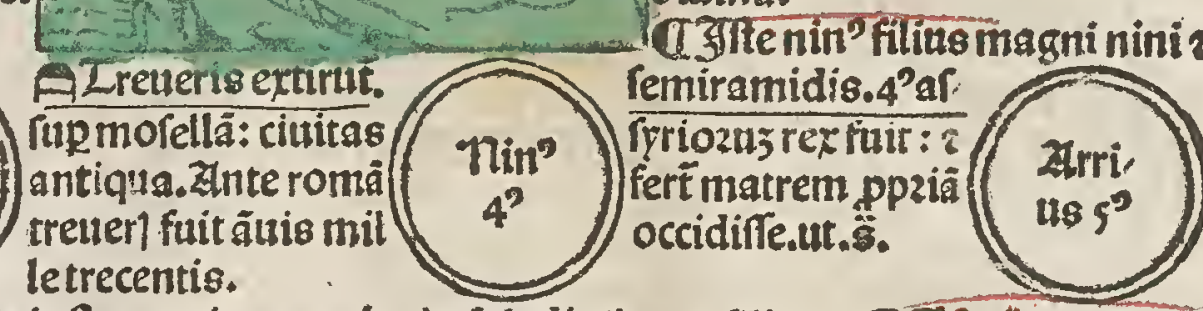

nuit eos.zfic p totã gfiã regnú al

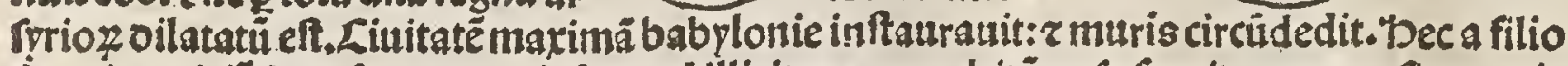

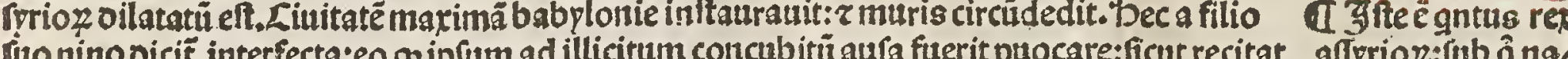

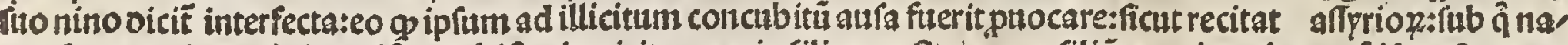

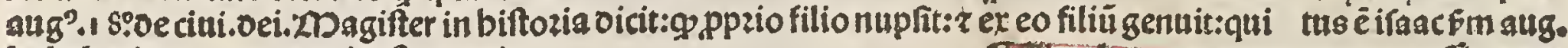
babyloniam caput regni inftaurauit.

Uदzbzabantquattuoz regespcunitppter

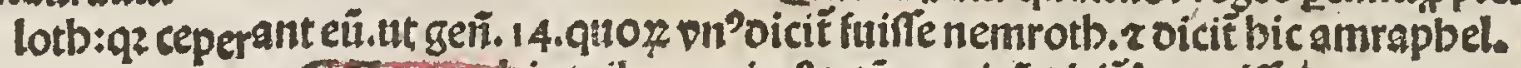

Znnomï

di 3184

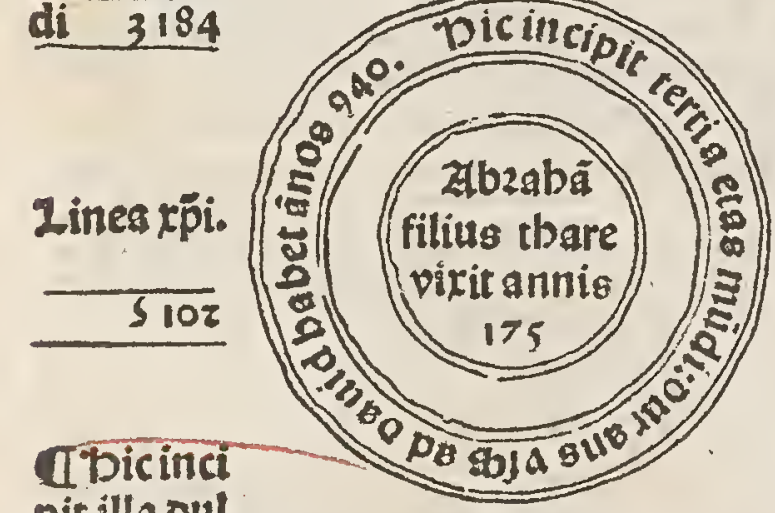

pir illa oul

cisz oetuota biftozia pĩiarchaznĩoł:gue

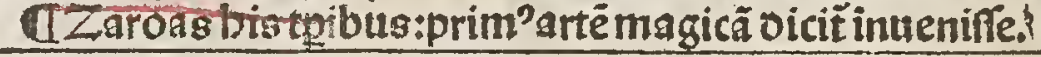

rú oeü coluerüt:z colendü pzedicauerunt. vide geti.xij:? $v$ f́s ad finé.

¿2magntisiteamic"

oeiabrabam:narcit anno.43.17ini regis.

QZुfte lotb cú exijifet oe çodomis gentit bos

onos. filio'o ouab'filiabus fuis ebzitts factus: vir inf?

z fcüs angelicã meruit vifitationé:fícut $r$ abzabam.

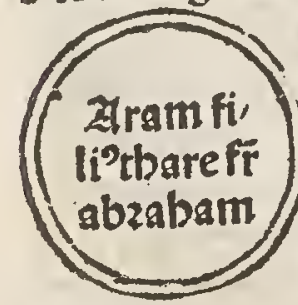

G J fte ara moztil" eft in or cbaldeozi.i. in loco g vr oi lecbat $D \delta$ aút oicit́ g iigné piect? fuit cĭ abzabã̃ zc̄. fa bule funtiudeo for magi ftrü in biftozije r alios.

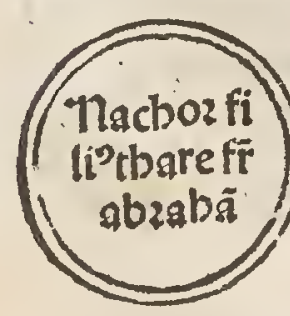

dI Zftenacbor exituit cum patre fino tbare oe chaldea z venit in carrã méropota. nie:ibiqs mozat?eft: 8 po fteritas eitus pmanfit. nota oiligêt $q$ ãno abzabe.75.0emagnifi co glia fúmi oei elapfü ể bü mĩe fun buma nü gen": q2 tunc ceperüt 02acula pmifitionü

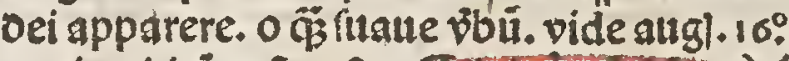
oeci.oei.ite geii.15: T'bic prnu ciă X 3284

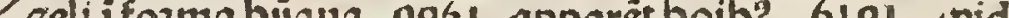

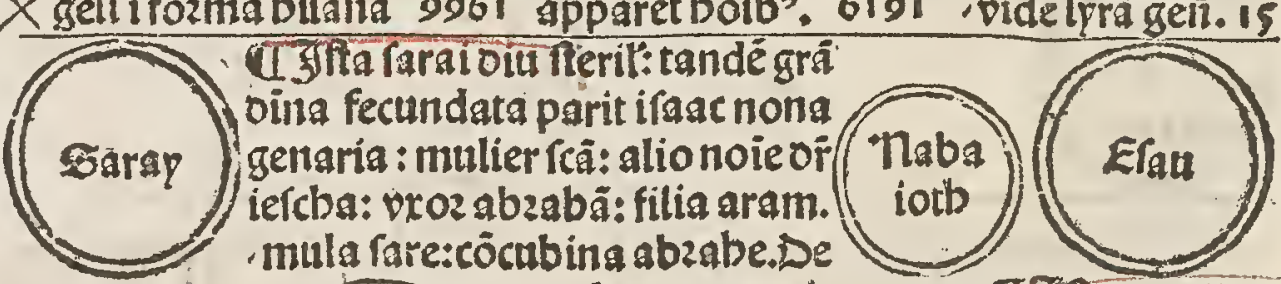
Ylage tiuitate ifage

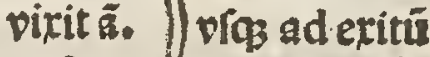
180 de egypto flu rerütsini.40.

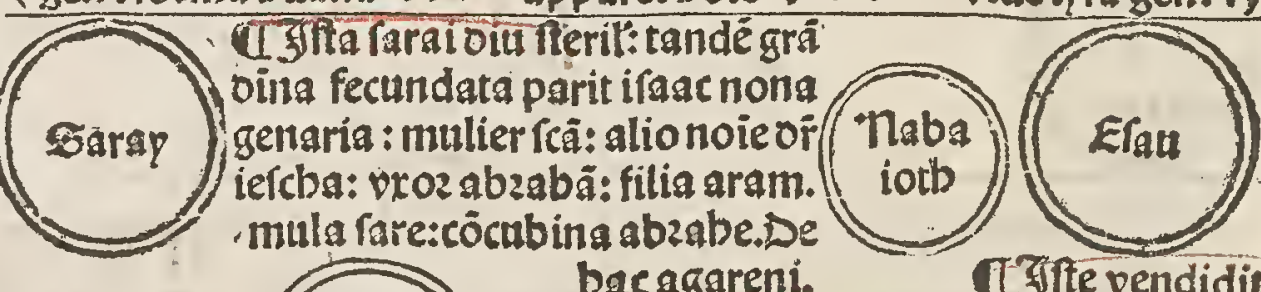
Agare bacagareni. donte vendidi

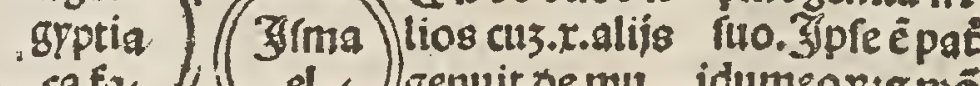
cafa. el ' genuit de nu idumsoz:rmó liere egyptiaca tē fezr polfedit
bomo ferus.

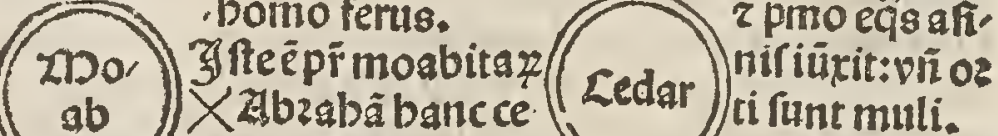

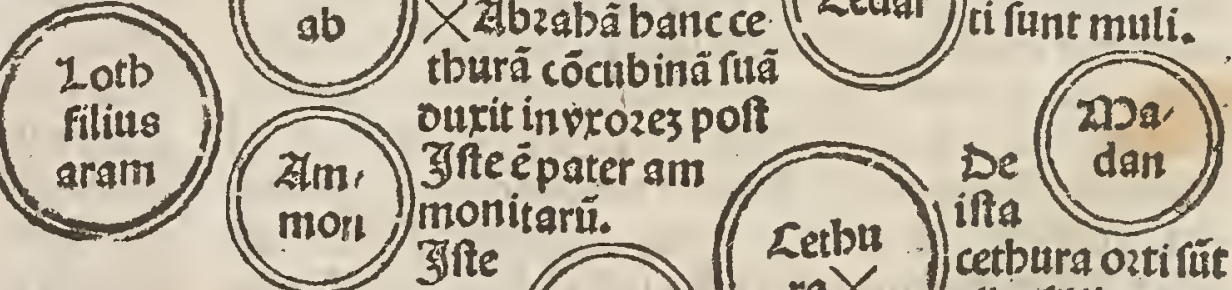
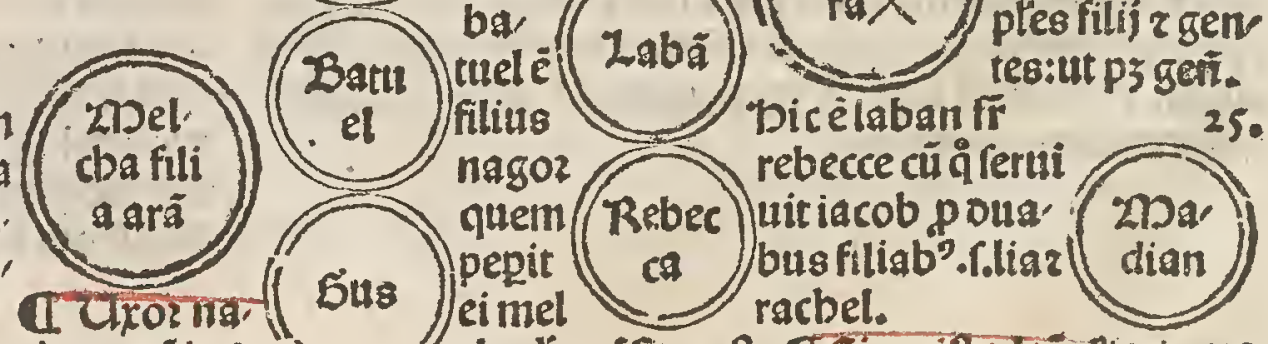
ba' $\bar{\varepsilon}$ (Labã $\mathrm{raX}$ cetbura oztifít
ples filij r gen el filius bicètaban fr eg:ut p3 geti. cboz geüit.s.

filiog.ut ps geñ. 22. fed oe vino.f.battuel fit pfecutio ppter rebeccam vrozem ifaac. Deboc oefendit iob fm quordā.<smiles></smiles>
cba.bmâfitpoft UEircaifud têp" lodoms mozté príis carrã z gomozza ppter pctã fua I Deboerểdit bozzibiliter rubuertuntur. balaā rbeliu. UTroz lotb retro refpiciēe falêrepẽte cōnería magno

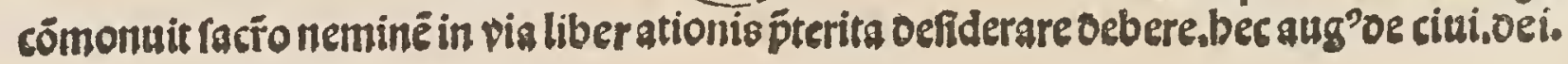




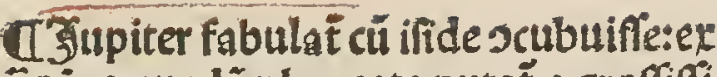
âoina quedã ples ozta putat a groffifi mis plebib?: boc ftudiu fuit quozudam malefico za talit ruia aut potentĩ ftupza

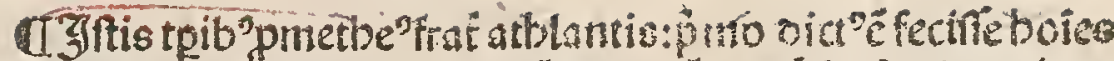

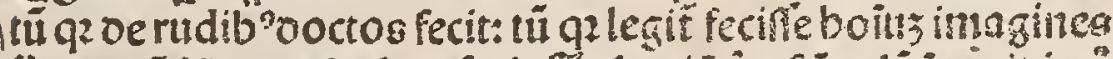

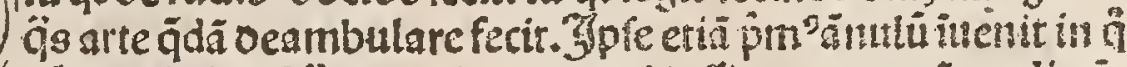
gëmâ iclufit:z iärto oı gito po ztari iufititppter venta cozdis ă. exculare.

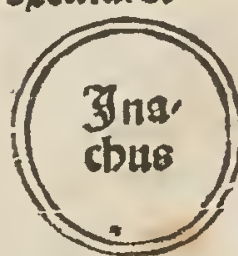
T'zjta pmo octa fuit 30 filia inacbi:\{ 3 in UTic ozit regnu egrptunauigans:ibil lräs oocuit zifts vo arginoz fille gre cozü: vbi pzimo inach'regnauit: zourauit pigad tpa oelboze.

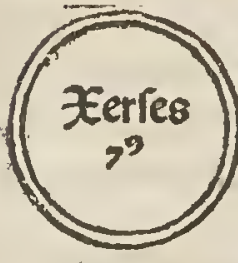
Itbic oicit xerles ant quits g $r$ bales vocat : fub å nat'elt iacob:re gnate túc apud ficbio. nios tburiaco qué gdã tburimacbù f́cribüt.

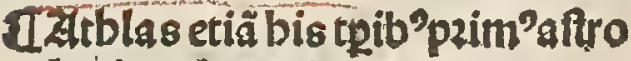 logiam inuenit.}

IApud egyptam fuit infolita fafti diendaq̄ $\bar{b}$ bertas.Deinde iugis $\tau$ intolerabilis fames:cui iorepb oíui na prouifionefubuenit.

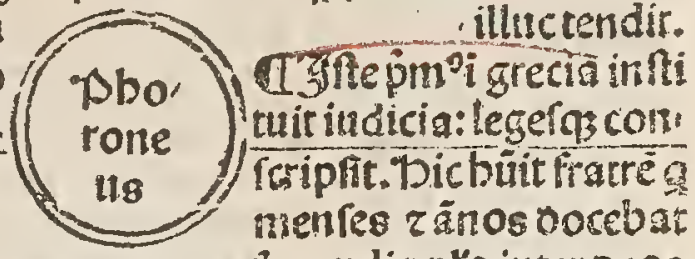

obfertuare z facellı cöftituit ad colëdos ocos:ppter qơ a rudi pplo inter ocos cönumeratus eft:tz ei boutes imolabant:sict? eft pbequus.

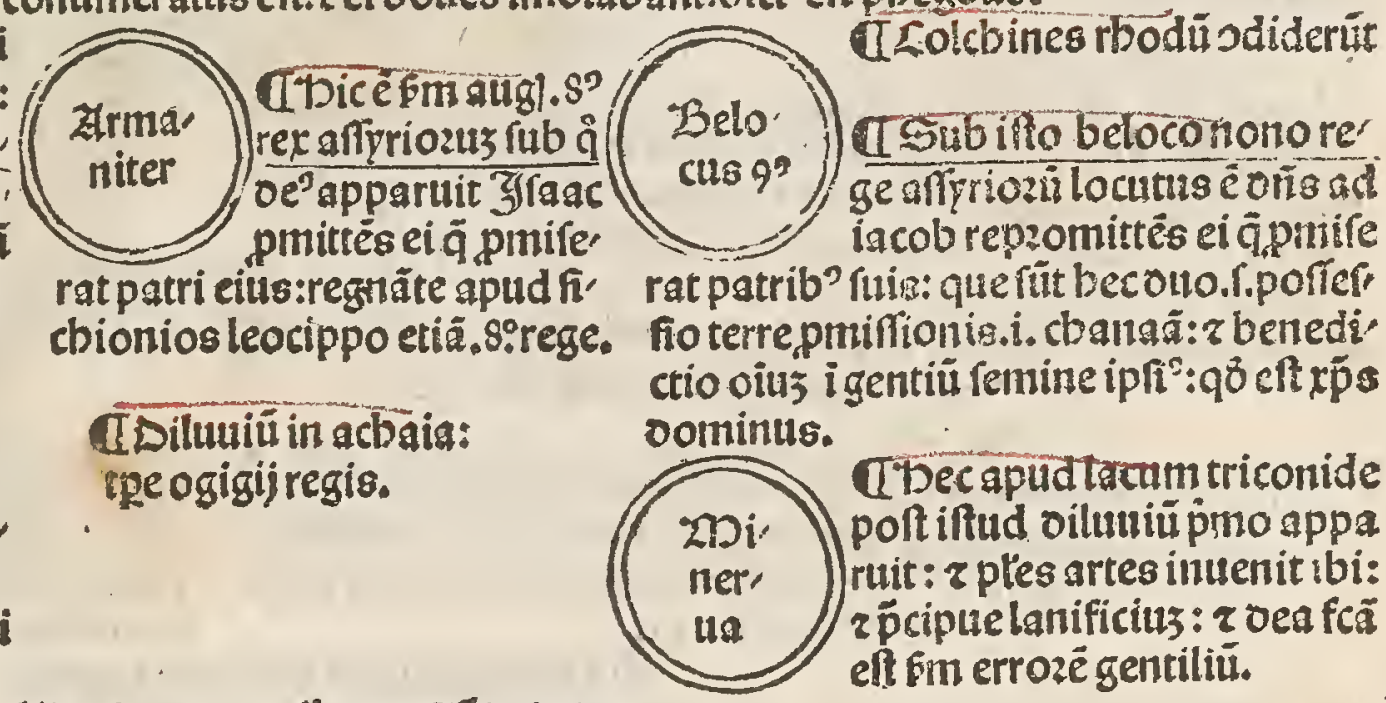

Zb:abam mozit r repelie in bebzon.

\begin{tabular}{|c|c|c|}
\hline 9581 & $99<1$ & 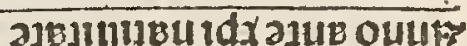 \\
\hline
\end{tabular}

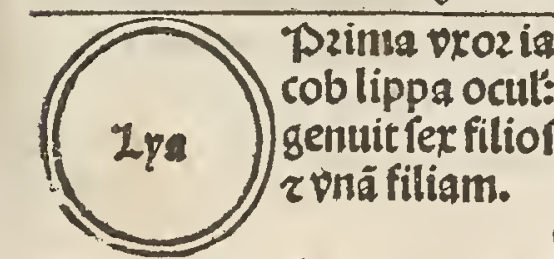

I la lie cốcubina iacob genuit oulos filios. 3olepb vir f́cie z glia oom'ifrt: ouplicem tribü facit.pzimo genita füt eius.
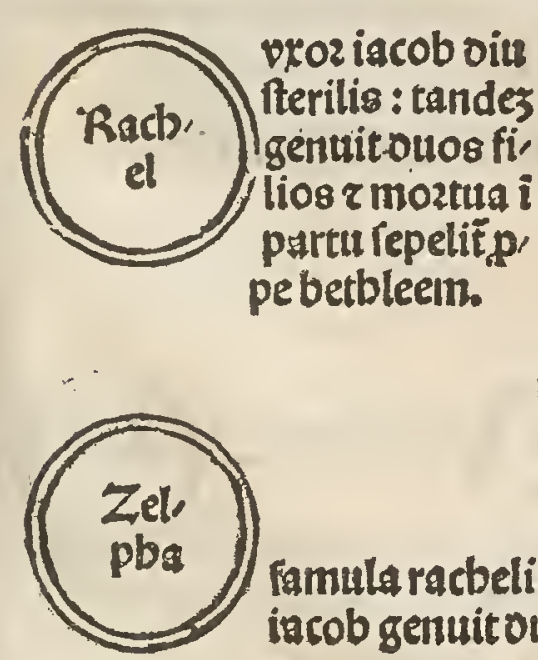

Famula racbelis concubing iscob genuitouos filios.

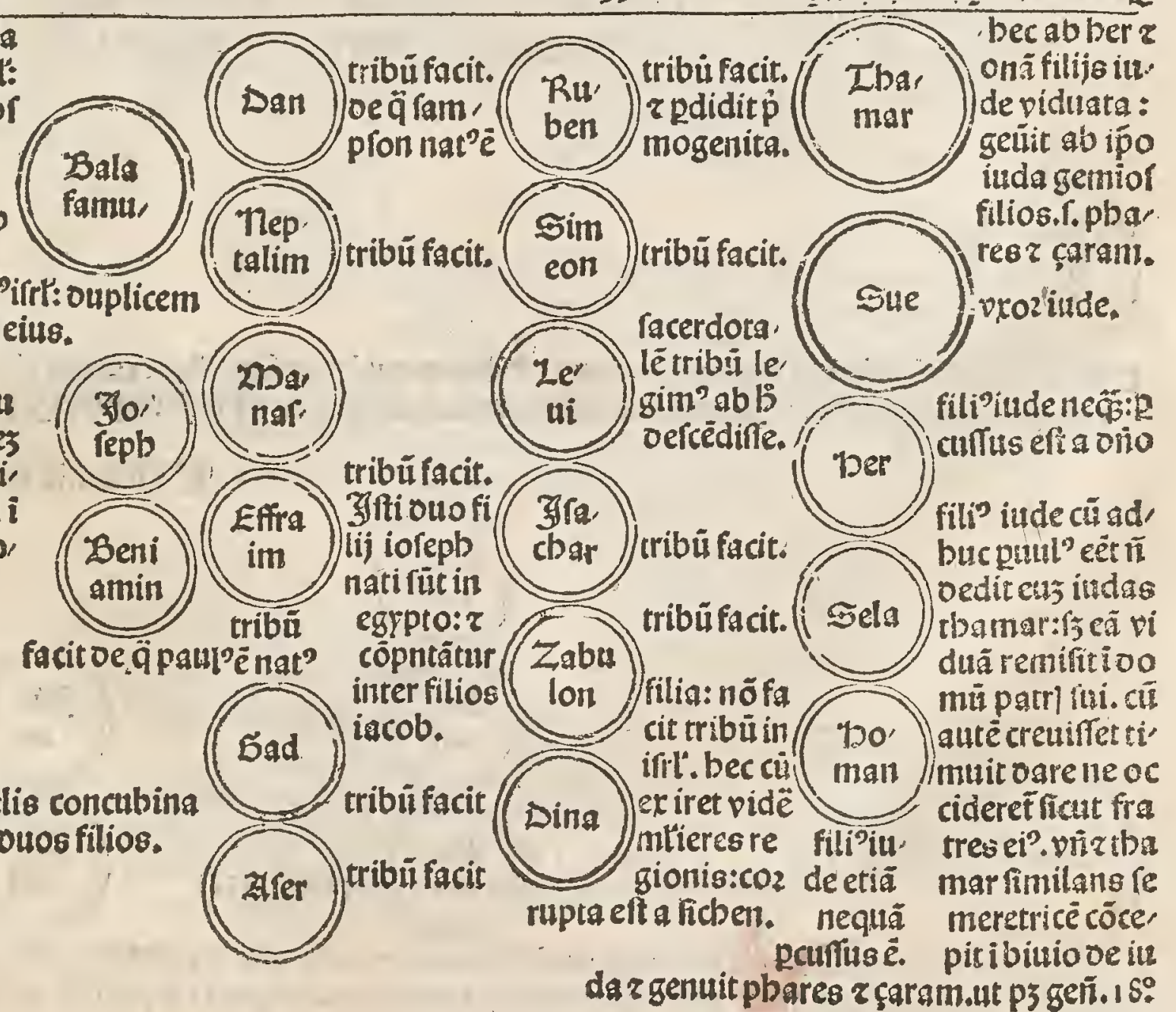

dazgenuit phares z caramit 3 gei. 1 s: $^{\circ}$ 


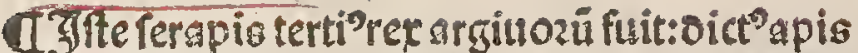
cu i egyptũ natigio veniffet z ibi moztutus fuifet fact'é a ceca gêre oiraz maxim'egyptiozoe". Ilic etiã mirabilis ínpltitio icepit oe boue oíccoloze: quéapé vocabât:eo 9 viuns colerét:z illo moz,

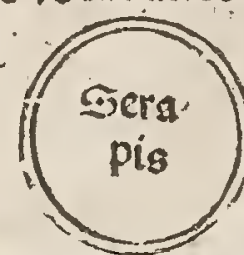
t1ö:nemones vitulü fimile sotdépcurabãt ad oecipien dum rudem populü. Zlinde venit $Q$ filii ifrael filtr oely. rabät.ut ps. Quidbacful titia miergbilins in bonine rationali"

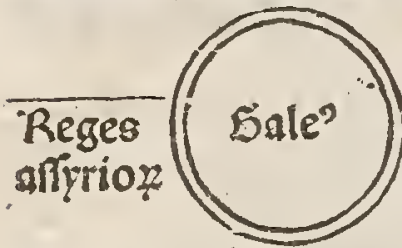

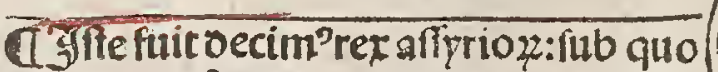
moztuts eft tigac: regnâte tuc apud fi chionios meflapo nono rege.

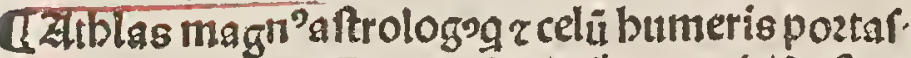

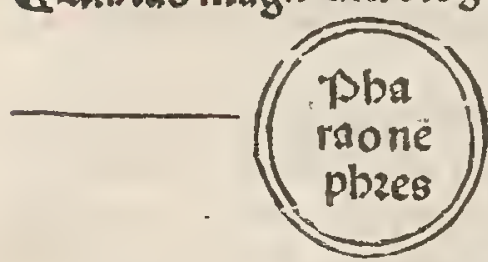
re oicif́ppter pitiã aftroz.

IJfte pbarno rexegpptifufeepitio repb:r exaltaut euppifomniozin terp̄tationē. vide pulcherrimä bifto. riam. Señ.41.

\section{T.} minibus.

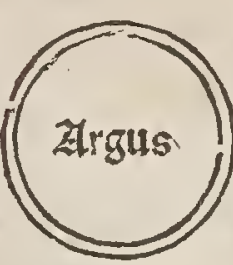

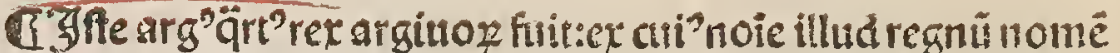
sccepit. Dic poft obitü: oe baberi cepittéplis r facrificiis bce nozatus. "boctpe grecia fegetes babere cepit:oelatis alitide fe TDmogiroms

I Átbentas cicrops côdidit: rer minerta nomen accepit. ad aratruboues beccititas nutrix liberalitis iuntit. artin: 2 multo 2 p boy fuit: th ludificätib? oemonib': fupfti CEozinth'codit. tiofa effecta é.vide iaug. 18. oeci.oei.mirabilë fabulä.

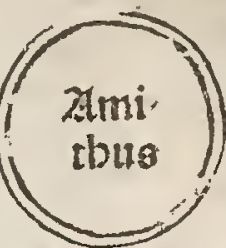

Q4a dilo oetobic"clar? babet: r pof mozté oeus babit'eft. 'bic etiả oicitur pbiton z arté illã magicã uenit: ă oí cit pbitonica: De qua fit mentio in fa, cra reriptura.

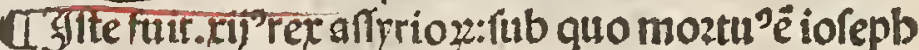
regnäte ficbionio ? plëmeo.xj.

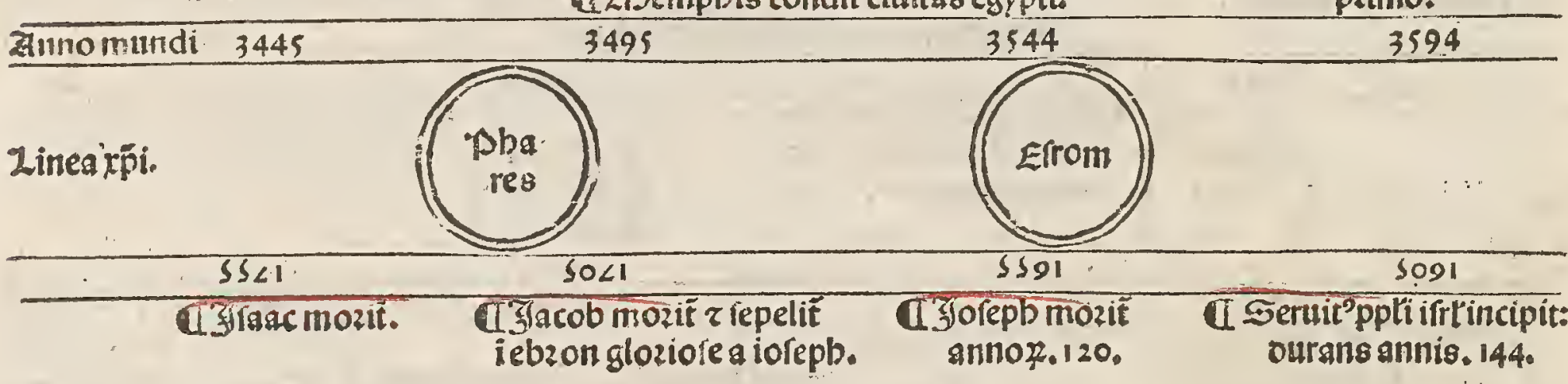

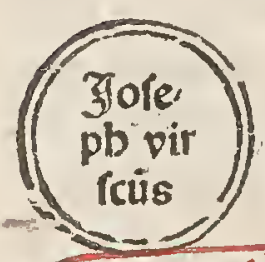

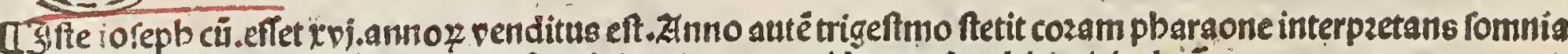
sis: qui z fublimauft eũ. Et quia caftus fuit r timozatus:ideo a oño vbiqg oirigebat.

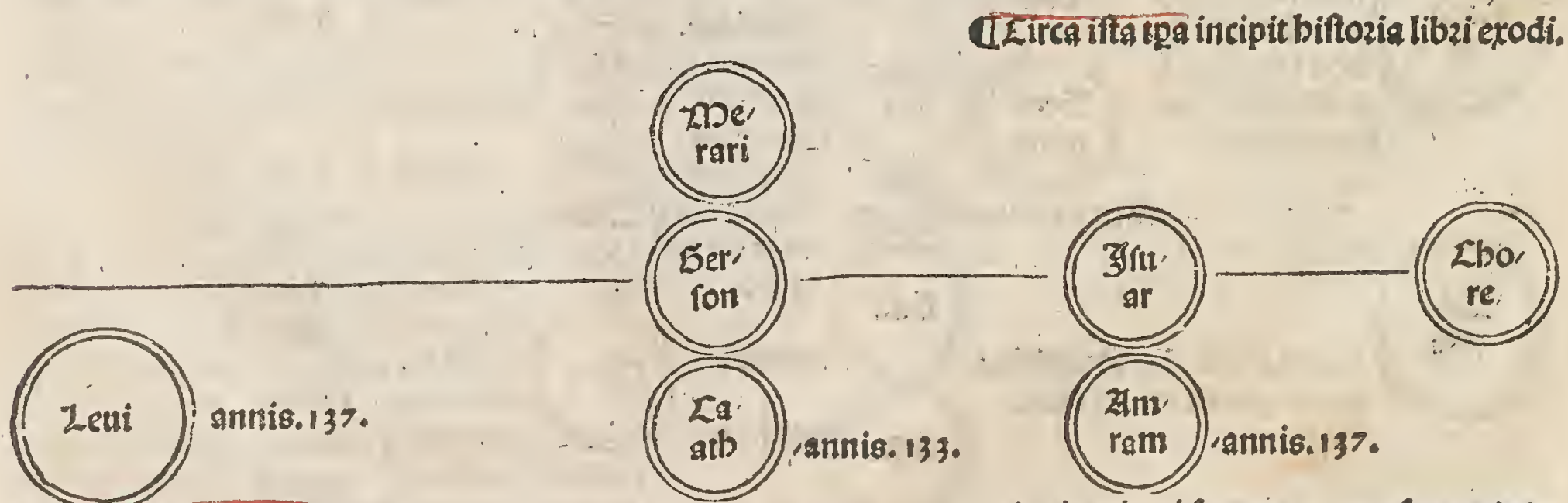

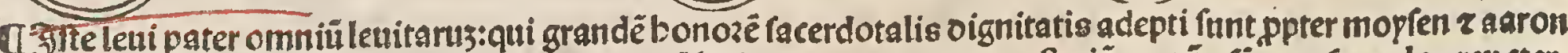

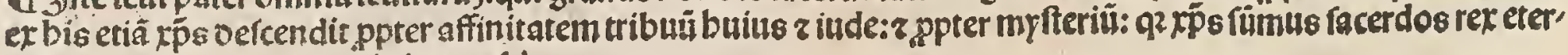
ntus:fic oebuit narci:z nobis innotefici. 
CEirca iftud tempus inceperŭt reges in italia regnare: z multotiēs noia variarüt:ex gb? romanoy fpago clarius oeducit.

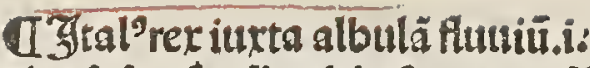

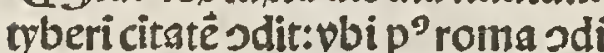
ta fuit:a å tota italia núcupata fui

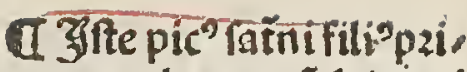
mus rex laurentü fuit:qui bellatoz egregi $r$ augar Reges
italie.

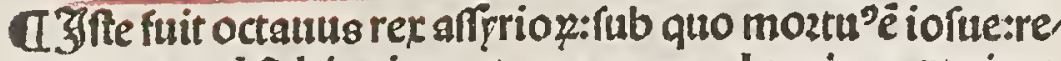
gnante apud ficbionios.16.cozace: apud arginos oecimo Danao:apud albenienres.4.erictbonio.

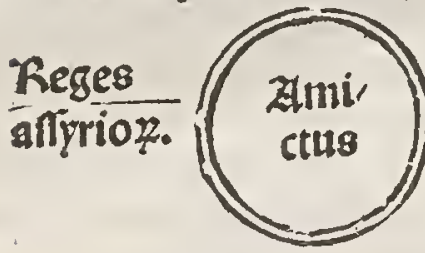

đErictbonius atbeniëriu p̉ ceps p̀migrecia q̈drigă iüxit đmercuri?:lyrä condidit.
QCadmils coodit tbebas:re gnäs ibi:z grecas lrãs ù unit Qร Senixpenititprüz fidonë $z$ regnanit ibi:z vfülräztra didit cis:z colozis fenicei $q$ ̊ capitalia facerent. argiluozí oefecit.

TSibyllagia femonoed cta apreppbetat oe rpo : z oe paupcula eius matre.

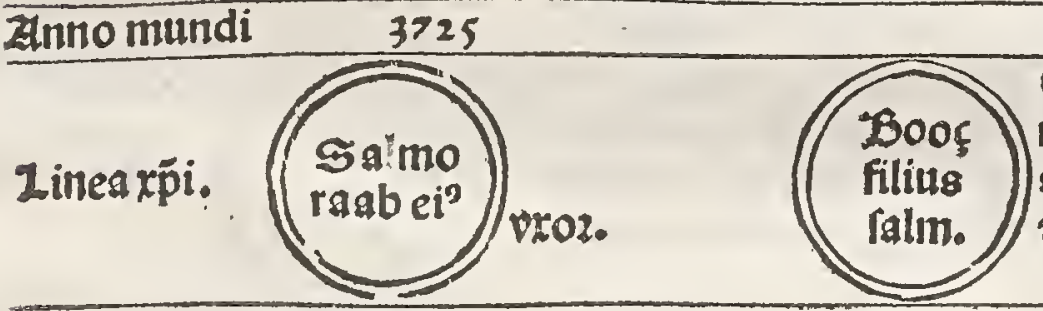

regnafle oicât. Et pzimus ftercis fuper agros p 20 Gerterinter (1) Zfte faturn' oe creta ifula dicié vẻifle i italia pi, zibi regnaffe: quëoeli, ri rolatre: que oelt teboiem fuife negât: cum tri eum cus ijcere oocuit:äre etiä ftercutue oiciťz: romani fter cozani poft oicti füt: z etiam faturniani. Et ifte pzi mus nümos aureos iftituit: $r$ ab indocta r ruftico multitudine oetus appellatus eft.

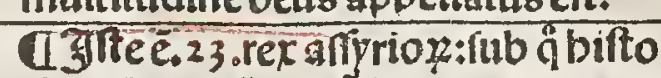
rigoelbozeãnorat Fm augl. 2 regnus

T fabule multe a grecis annotant.

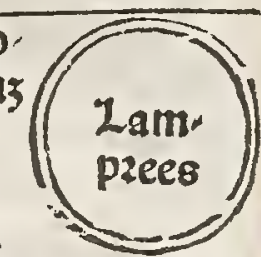
UI rois in Dardania regnat:z troiã condidit. USibylla eritbzes in babplone ozta:multapp be tat oe regno iudeozü: $\tau$ troia fubuertenda: 2 oe xp̣i incarnatione:z beata virgine maria.

775
I'Recbab oe qoefcēditftirps valde religiofa boc tpe fuifle creditur. ipfe aüt oe ietro cognato mopli oelcédit:
$z$ côtuer rus fuit ad indaifmü.

$\forall \angle \forall I$

เฉฺ

$(\underbrace{3825}_{t \angle 6}$

T2mogles mozit.

CHozdanio fiecat.

ITJ Jlericbo capit.

TEolicelo imobi lis ftat.

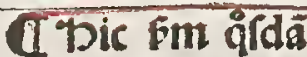
texit biftozia oe fructciöis benia min z gabão:ppé Ptupricrimen.

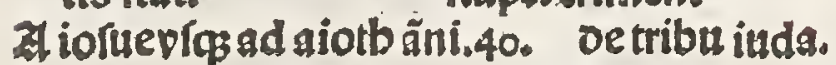
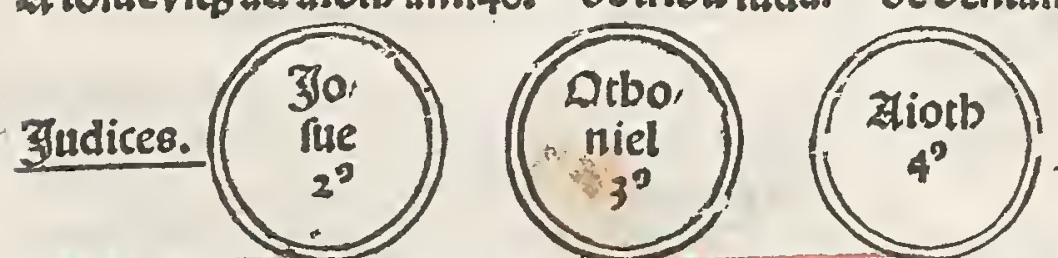

IIfte otboniel frat calepb itmiozis:liberauit ifrt oe op. p̈ftiōeregis mefopotbamie: quẽ geuffit. Ip pre accepit arã in siugë:que petiuit irrigaü stoperi?: z inferi? a píe fuo ca. lepb.ut ps iudicú pimo. pmo i velerto amalecb vicit.p" moztémopli a oco index oftitu. tus fuit fup írl: ut trà pplo oitui. deret.cui bella sopa z religiof mens:i libzo fuo oefcripta füt.

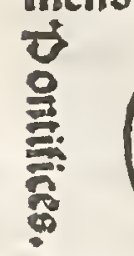<smiles>C1=CC=CC=CC=CC=CC=C1</smiles>
İbitozia libzi iudicu bic incipit. Tritorialibstiofue incipit. Cisteeleaçrus. $2^{3}$ pontifer: cú ioftue oiuifit ifraeli terram: ab eo oefcendunt pontifices ग exceptis.
CDiftoriaceidolo micbee fmerpolito res cöiter vicit acci diflepoft iorueillis 8.annis: $\{$ bebzeioi cunt ge tpe otboniel.
Cदुfte aiotb eculit eglon regēmoab:zli berauit ifrt, fuit,n. vir

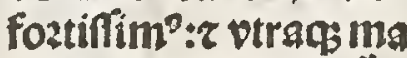
nup oxxtera vrebat. D\%bucfuit fangar: 9 percuffit oe pbilifiijm 600. viros vomere.itu dicü. $3^{\circ}$

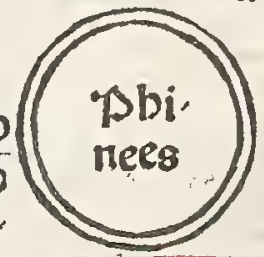

T'ste pbinees cu adbuc iunio çelanitp orio trantfiges luxuria z ita placatus é oritg. Thameri.2 
dY̧fte fecundus rex lattren cum fuit:qui etiã oeus fuit illoz:qui fic voluerunt tuel putauerunt. a Exboclatinozú regni oici cepit:? laturentu Defecit.

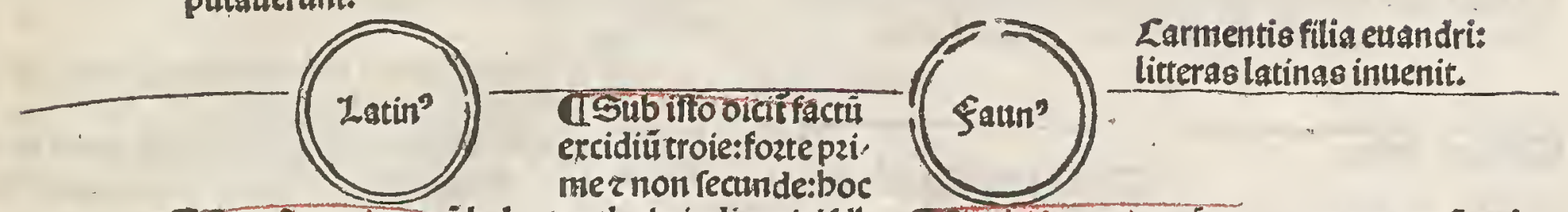

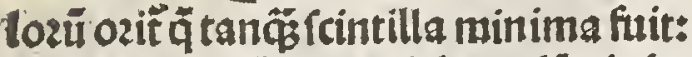
eo 9 laomedó in recepitberculë $z$ ialo né cübonoze oebito: $\tau$ ex tãtillo tot cre uerütmala. Caneat fibi gics ait comic? ASibyita oetipbieante troia na bella vaticinata é oebibi incarnati. one abfis maris coitu:z i bec vera füt: tpe tbola indicauitifrt"

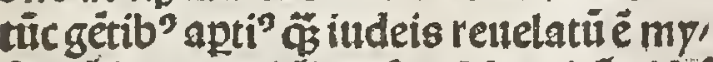
Aeriú incarnatiốis: $q^{8}$ valde mirü vide Fimiliter oicendü pidetoe iob.

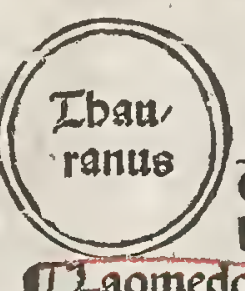
gnauit in italia.bec fictitia seceptozes rudiú po pulo sŏfinxerüt:qbus fua ftupza r adulteria palliarüt.

đSibylla pbrigia fert paticinata fuife ancbif: $z$ oe flagel latione potentî terre:z oe oefenfu oei oc olvmpo.

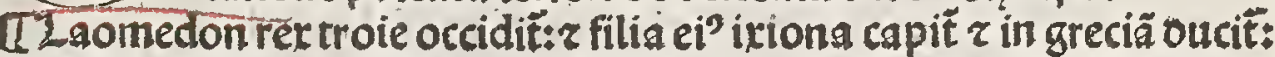
ppter que fecuta funt bella granifima z mala bozzendifima. vide bifto riam troianam.

Ubercules iliü vaftat:id è troiam cum iafone:que ftatim a paiamo re edificata fuit.idë bercules.xij.facta pegit.agoné olimpiacù conflituit.multa bella confecit : $z$ plurima mendaci

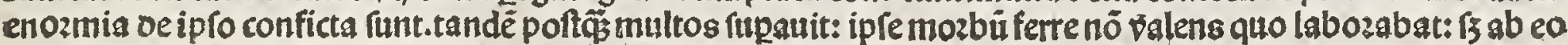
fupatus flämis fe iniecit:z moztuns inter ocos trantatus eft.

$\overline{(2000))}$

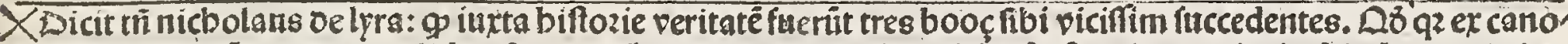
nica feriptura nó patet:pzo folido aftruere nó audemus. Doctri certiffimü eft: 9 inter pzincipiū iudicatus iofue:

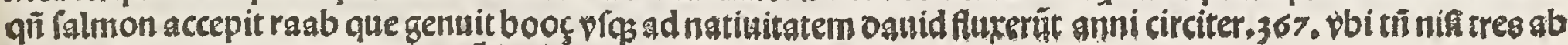
cuangeliftis generationes ponunt.

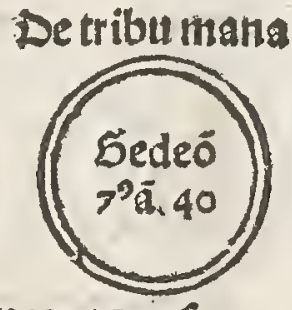

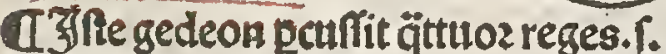
ozeb:çebee:çeb: r falmanã. $z$ büialiat" turalis gedeon nö tocat' a oito:

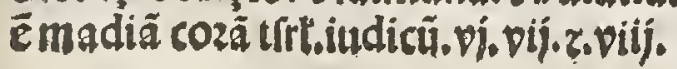

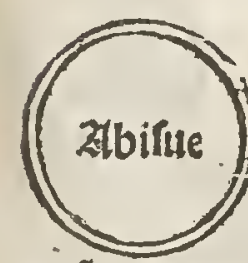
etiā mala mozte vitấ fininitit.iludi iponiiuffit.

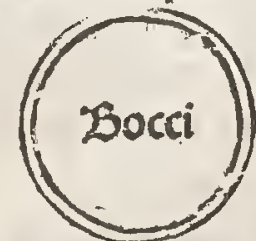

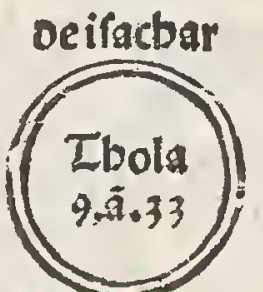

Tisfte tbola redijt ad pzi. Rinú modú. r.q̊indices $\mid \bar{p}$ erât 2 modú oirestiōis có fili, Inagis ä oominij.

asub bocthola: fuit bellit lapbi

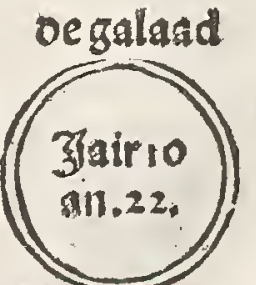

diffte igir babuit. 3c.filiof q̊s p̉nciper 30.ciuitatú oltituit z $q 2$ ipfa bong in fi lëtio rpace träreủ p5 $q$ in oieb'iftorti fit:z ió cüctopipere aduenerüt. otloy ift ono adbe

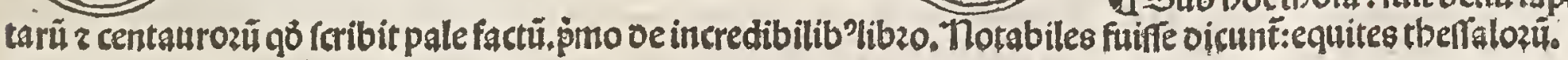


Thelena rapit a paride filio priami. Ipfa aüt regina fuit troz menelai regis.

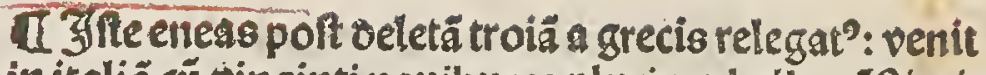
in italiã cũ vinginti nauibus: 2 plurima bella cöftituit bic fert in coniugè babuiffe filiã pziami : eleufinam $r$ vens factus fuit erroze vulgi.

Abector pmogenitus priami totus legalis:pzudens:fi delis r imcompabilis foztitudinis r ftrenuitatis.

IReges italie.

apsiamus rextroie filìlsomedōt poftâ cittitatë mirabilitex. truxerat:bellü in cboa uit $\bar{g}$ grecos in malus เมiี.

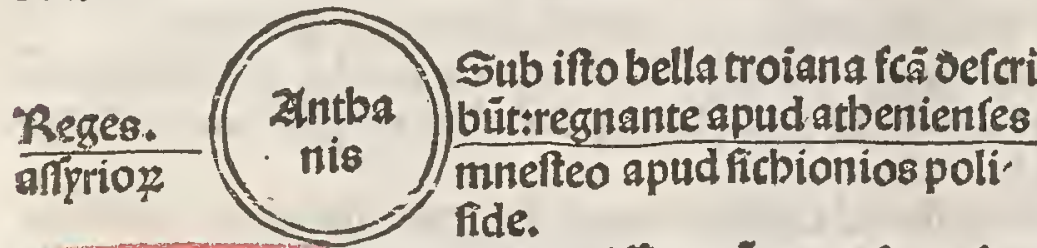

Ammaçones fut mulieres ferociffime: ă arma fumple' runt z bozzëdiffima mala p centũ annos ppetrarüt: tam in alia q̆ $_{3}$ in europa $\$ 2$ bes oelendo $z \vec{c}$.

CLartbago prims condita carcedone tyrio.

Żp fan fepe oeft tructã ferür z iterū reedificatâ.

Annomundi. 3975

Linea $\times$ p̆i.
QLroianu bellü oecēnale famofiffimum. UAgamenon rex frater mene lai regis:toti? exercitus greco rì oux:bellat côtra troiã $z$ tã dem capit traditozie z reanda lofiflime.

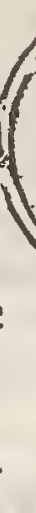

Eneas Debocoicunt oelcendiffe iulius cefar: annis trtbus octauianus anguftus. UUlixespir facundiffimpoft multa ma ris picula ad prozéfuã penelopé caftífí, mam puenit.

UÊtect pereunt miferabiliter poft captam troiä:tam in mari q̈: interra repatriando zpditozes affligüt. Znfe liciflimü pozzo fuit boc bellü: bi nemolaudẽ:onnes oammü repoztarüt.

(I Fabule ftultifime ve oiomede $r$ circe: bide augufti nú.rviij.oeci.oei. D qualiter oeceptus fuit bomo.

UL Troia paftatatrocit: traditaqantbenozér eneam vitiofifime fracta fide.

CEra grecozpaincipalis.'pzopter bãc victozia greci biftozias alia facta fcripferút:anno pimo uel fecundo zic. poft captã troiâ: ipfe eft tertius ann" abdon iudi' cis ifrael.

OF Fancio zttrctis troiani:fugiétes:ono

regna conftituút:Longe tr̃ poft rž.

CEpberds condita eft $a b$ andronico.

Linea xpi.

toiftozia rutb.

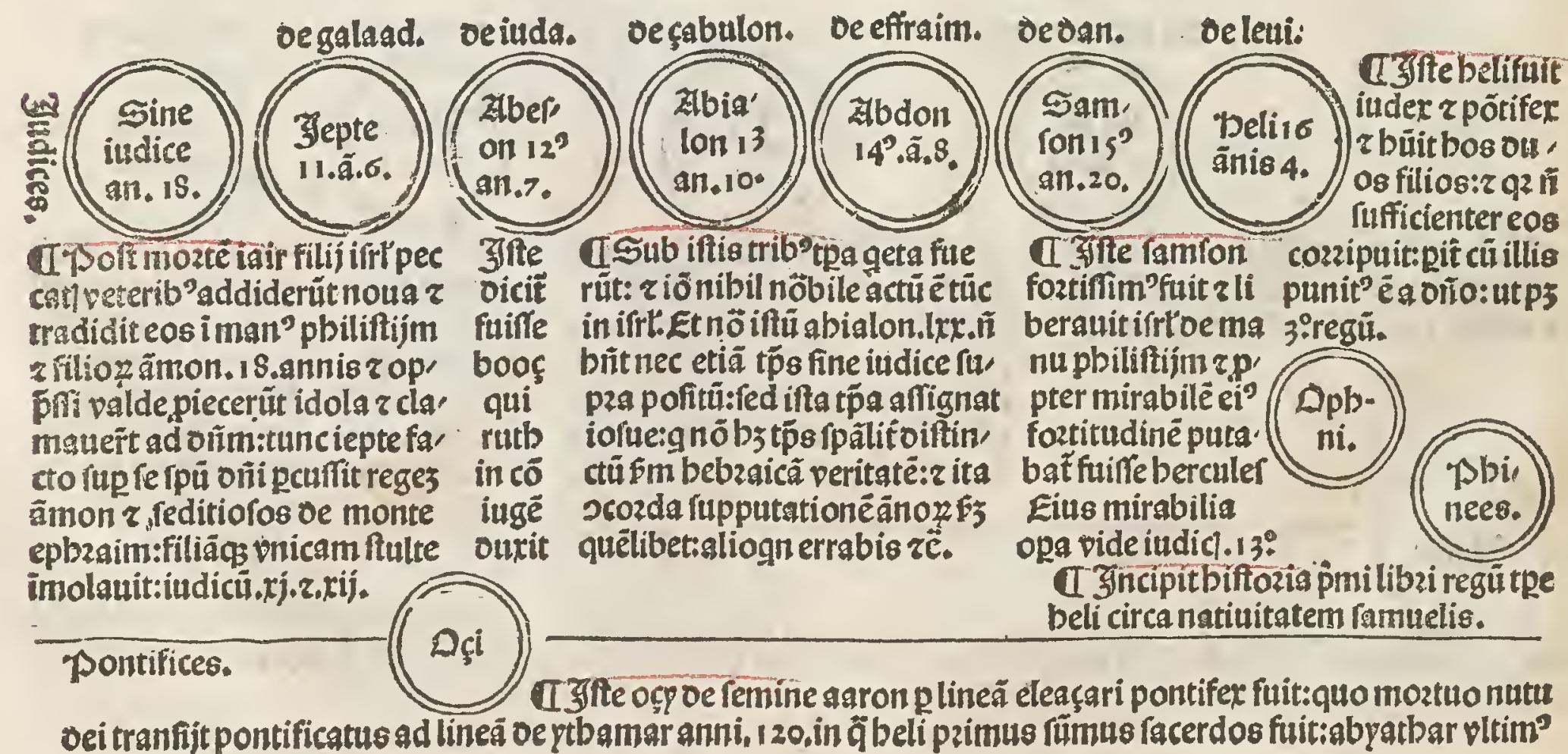


I. gfte af canius fili? enee oecretura albã cituitaté cổdidit zreğuit illic.

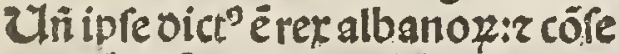
queni pofteri fui oicti fut albani.

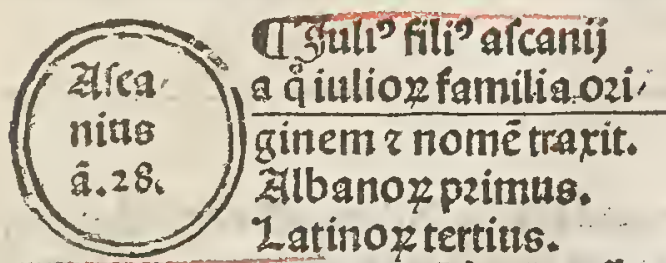

Tab 3 filuio enee oe lanina filia la tini reges feãntes oicti fût filuii : fuit enifilua nutrit ${ }^{2} r$ venatióe: bic nat? ép'moatē prisitui:vĩ poltbum?enee

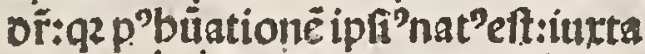

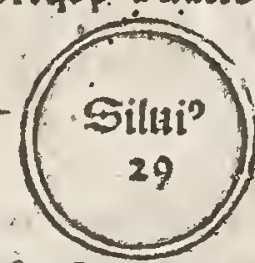

Ifyfte eneas filio dci filuif poftbuni regnauti ânis.31.5é, poze.f.faul.
ITftelatin filupregnatit änis.50.tern poze oalid.

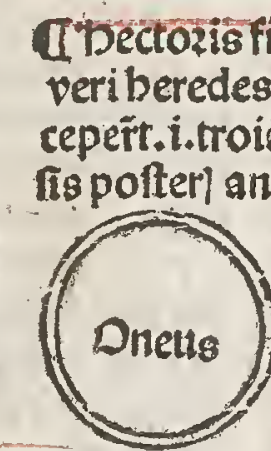

T'bectozis fillit

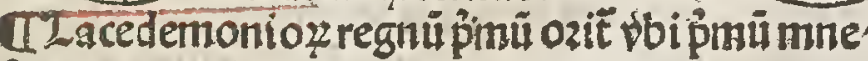
ftetis regnantit. TEozintbiozregni ozit: pbi p̉mü aletés regnat. IUtenetie z padua extruit a reliquijs troianop. IL Lodrus rex atbenienfiú:feiprĩ volütariemozti tradés: liberauit pplm funi. Dignũ exemplü paucl

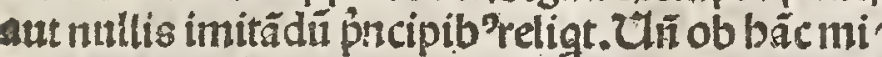
ram fidelitatēa fcis ooctozib'allegari folet:guafi quedã figutra xp̆i in co pzeceffiffet. a Anialecb oetert paul $r$ oefinit effe popultus ficut p̃dixit mopres exodi.17: dafte onte" 2 rex affyrio rub ạ ceffauit regnü ficbi.

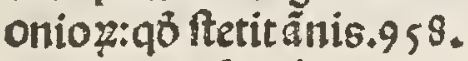
regnante atbenio melan, cbo.16.tpebely.

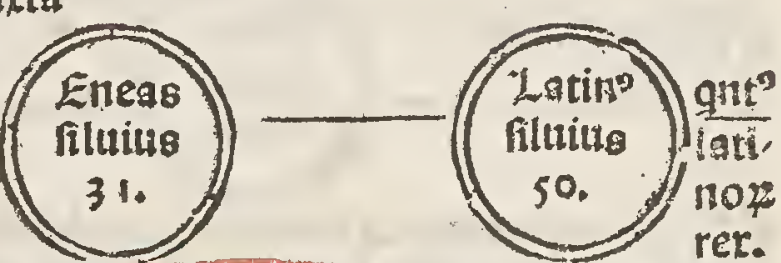

Uatbeniêles p'moté codrimagiftra G Lartbago itey adita oicita oidone reging:qz ia fozte oefnucts fizerat. abomer boctpe fuife putắ g mlta mẻdacia cố/cripfit: ficut fibylla eritbreg pplbetsuit. Zllî oicunt $q$ tpe acbac.

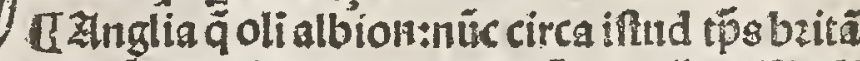
nia nücupari cepir: a batto röano ul"poti’itali co obtinet:ipe eni fugat"q fuis ad troia iuit col lecto crercitu oe religis troiano $\$ p^{\circ}$ ğndia bella filiã regl greco $z$ accepit טroze. Deindep maria vagädo locĭ aptū querëtes:cafis venerüt in an' gliã infulã optimã:ibi oeletis paucis gygantib" tpe beli racerdotis oeinceps tentterït vfq; ad tog fergij pape circa annos oniti.690.

4075

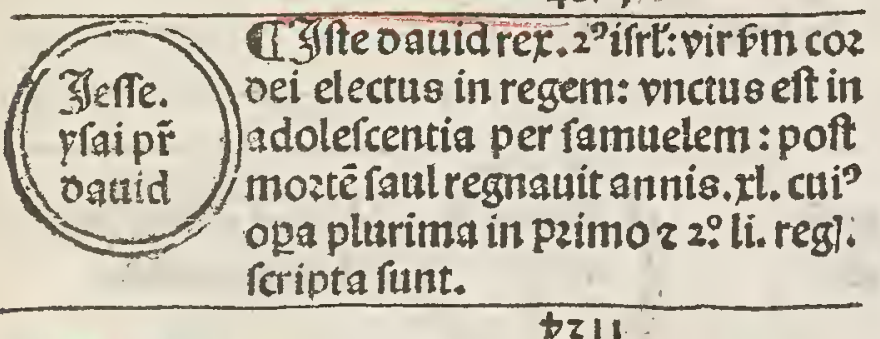

(1.3fteiefle fuirbi nomi": Q̨ etiä oict? fuit iraipat oguid: oe åmultotiens fit mentio ifacra feri.

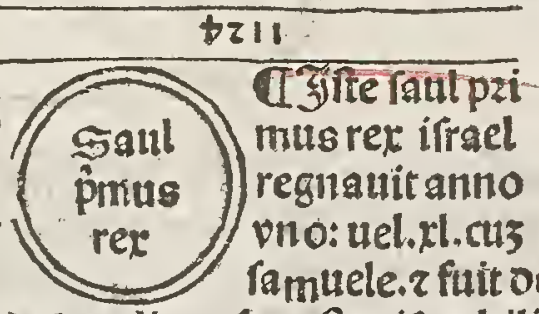

4125

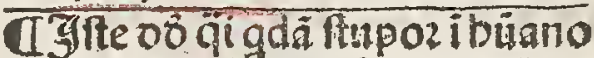

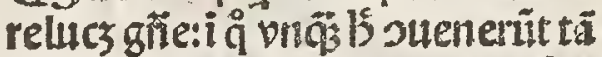
ta fublimitas z builitas:tăta ftre nuitas.tãta mititgs: tã grâdis ie culariũ cura tã pura z oenota rpi ritualiu stëplatio tot boies peri.

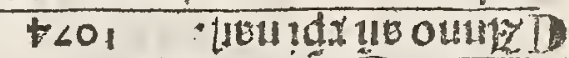
mere tot lacbarmas fidere. Ead Zfti tres ppliabat tpe od Thatbã żitenatbâ fuit filifiris Zlapb oauid radoptiu'ifai. ptura: 22 xp $s$ ab co defcendit. Fs poft miferabiliter oefecit. Eitus opera vide pzimo regü. 9 .

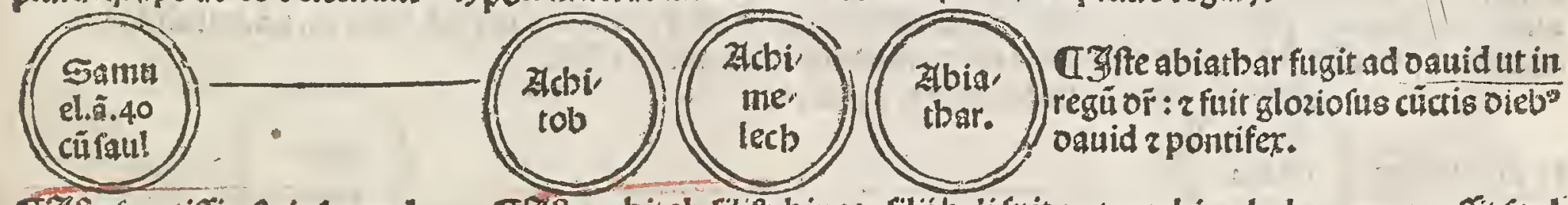

dyfte fanctifim? oefterilimrenat'miniftrauit

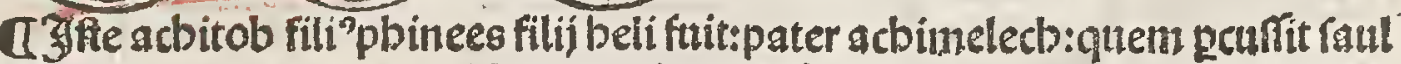
cü oi oomo fts ppter oauid.ut $p 5$ pzimo regit. $22^{\circ}$

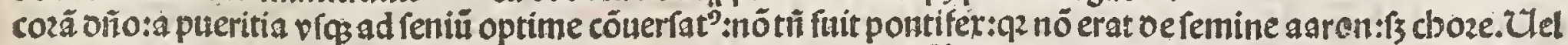

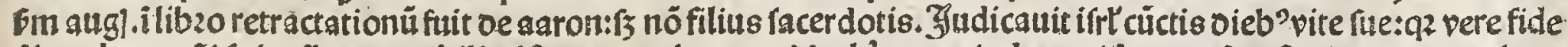

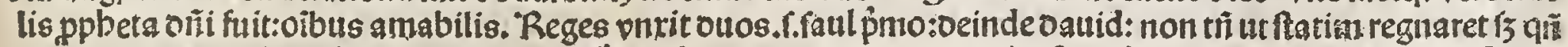
Diis oifponeret. "bic folus z mopres legunt́ ozaffe p inimicis i toto veteri tełtaméto: vĩ enägelicã pfectionē pzo,

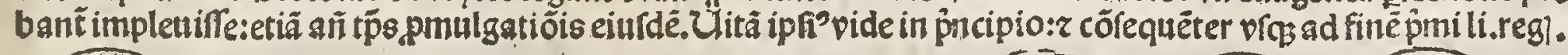

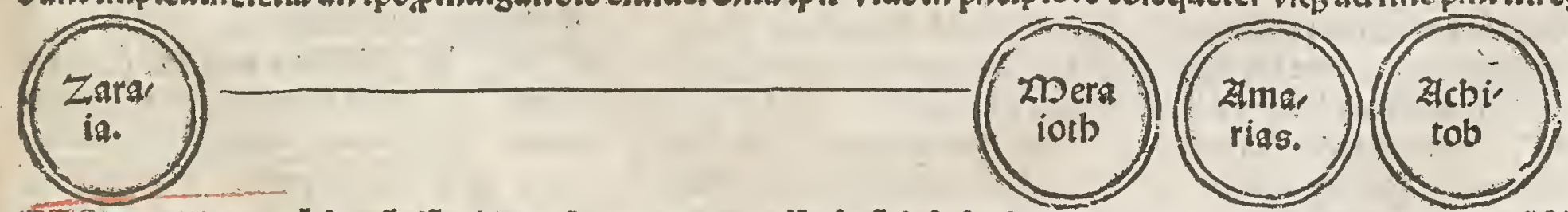

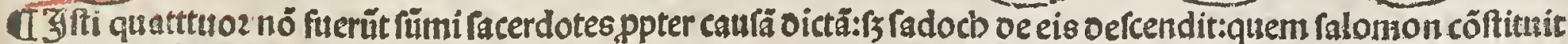
rumü pontificem fm verbü oñi in manu fumuelis:reiecto pzitts abiatbar oe facerdotio:qui fuitvitimus oe linea ibamar.ut pz. $3^{\circ}$ regú. $2^{\circ}$

ISecudus liber regú incipit a tpe onuid qui sepitregnare. 
TYItealbs fitui'fuit enee filuij filite ficut oičmgr̈. Et oicitaug?. bic edificauit albã ciuitatē a qua albani oicti rut:fozte pzipedificata: 2 bicinftaura

TRegesalbani
in italia.

d3̂t 24.tpe roboam: alibi repperi iprü regnafteänis.34. z fuit reptimus rex.

ISam?códita eft: 2 rmyrna invabis modũäpliata filuius

24
I'Regina faba andita fama fal omonis: venit videre enz. Et q2 fuit ppbetiffa fibylla oicebat: q3ppbetauit oe ligno fẽ crucis: $r$ or excidio in deozü. Suit eni cultrix vni' veri oei.

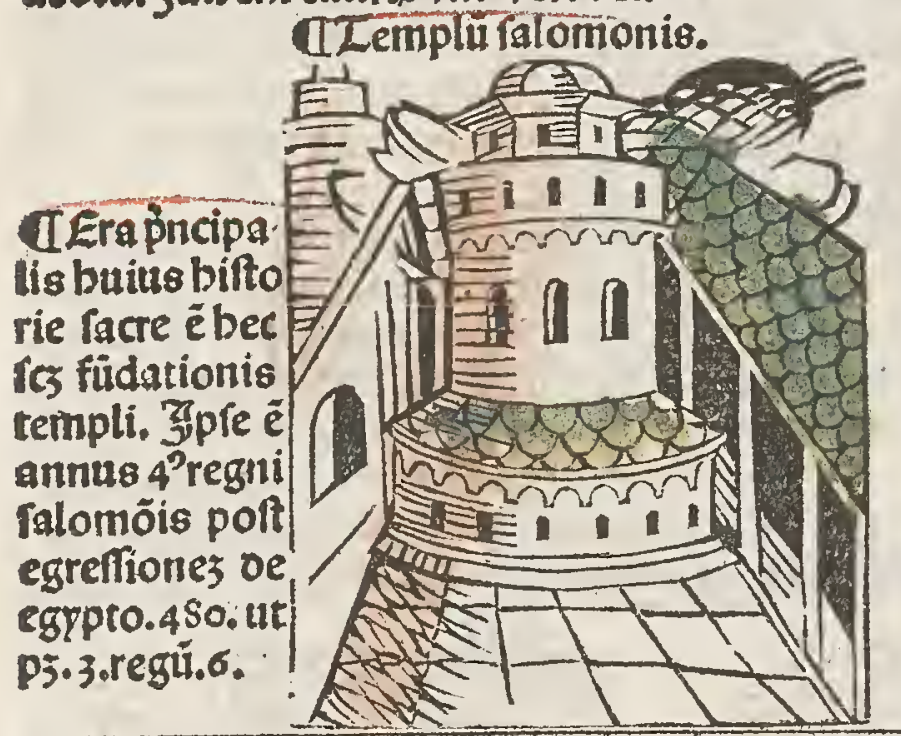

GDetepli oedicatióe:ac ceteris feftis indeozeft notädü 9 pi mobsbuerüt.7.fefta.f.fabbstū in q̈libet feptimana:neomeniā in pzincipio cuiuflibet mêfis:paics quartadecima luna apzilis

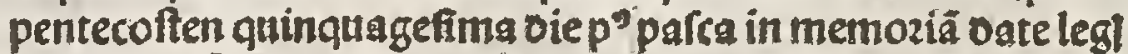
feftü tubarü pzime oie feptëbzis in memoziä liberatiōis ifrt: fe ftüppitiationis uel afflictionis oecims oie feptembzis: feftua Icenopbegie : qó fictionem tabernaculozú fonat quintadeima die feptembris. Poftea circa bec tpa fupuenit feftuz encenio boc eft oedicationis templi. Deinde tpe befter feftum furim.i. foztiü. Et becnotula valet ad intelligentiam feripturarü oiuev farumzic.

TIETag rex egypti profperat in multis:z gentee bello lupat:e contra roboam aicendit:poft in biertifalem.

I Reges inda incipiunt.

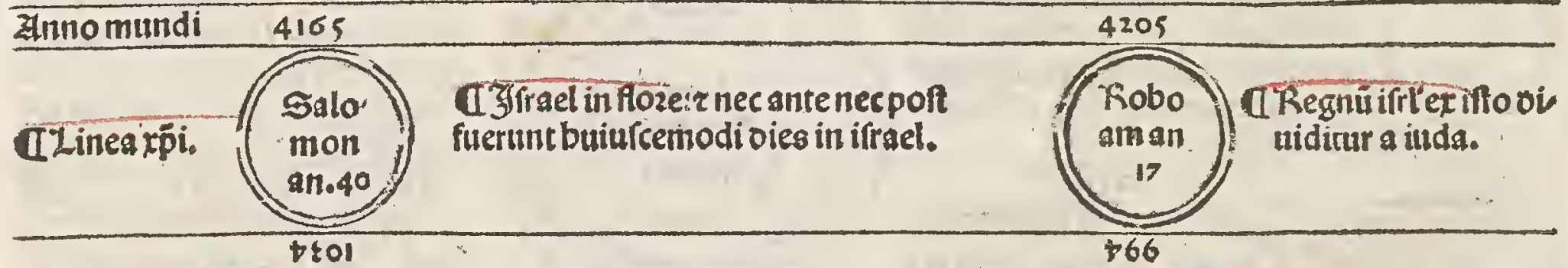

Q Salomon ifte rex pacis ex ono oei fingularẻ babutit excellentiam plo

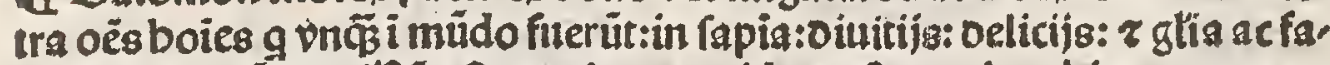
milisritate cü Deo. Thä zfi moyfes z oauid:petr'? paulus: bieronymus $r$

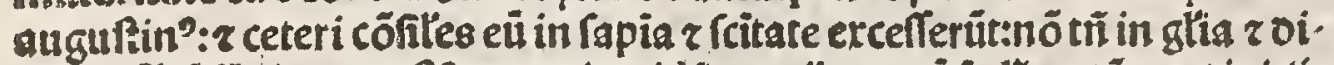

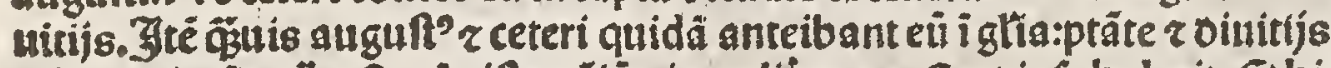
no trĭ in fapia rë. z fic oia ifta cöiüctim talit:nemo ficat ipre babuit. Etbic

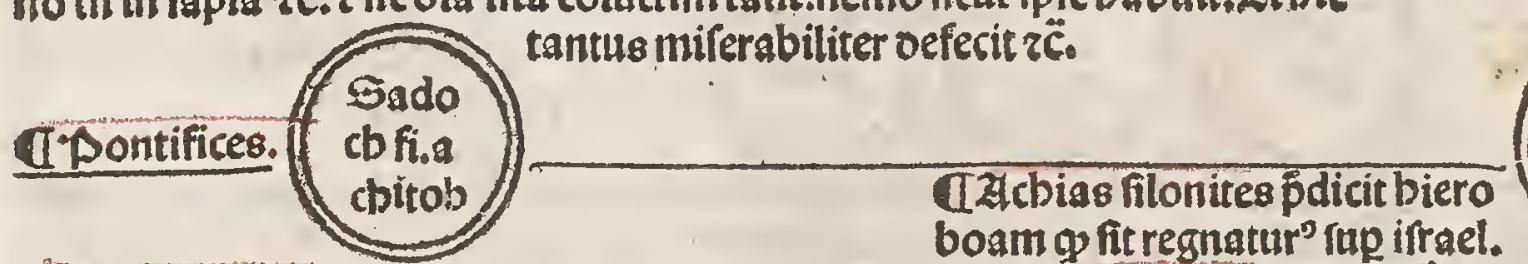

II 3 fte robog fuccefit falomóipatri fuo in regno: 15 in fapianó ita. Dece ptus nanq trib':eo g impzudéter nídít populo. utp5.3.regit. 12,2,2,parglipo, 10 .

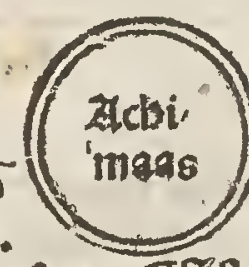

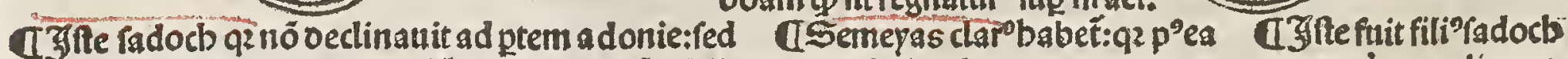
fuit cünatban pzo falomone:ió in pontificatü fubli compercuit roboam ne pugnaret ut pj p̀mo zalipo.6. matus fuit:reiecto abiatbar de facerdotio: $z$ fic pöti ficatts redijt ad filios eleaçari. Itra bieroboä:z feripfit gefts coy Iabdoppbetaclar'bsbet:g $p^{2} 5$ vitulos ppbetaut.

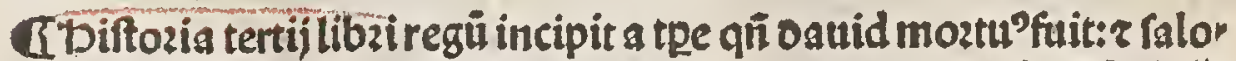
mon regnare cepit:pide ibi opa magna z multa ipfius vfag ad caplm

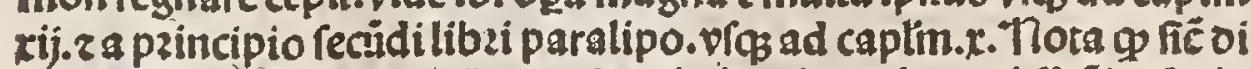
citaug? 17 .oe ci. Dei. Salomon bonis initijs malos exit'buit. Quip pe fecüde res ä plerüg fapientu aios fatigât: unagis buic obfuerüt ổ

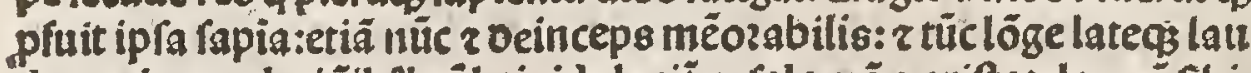

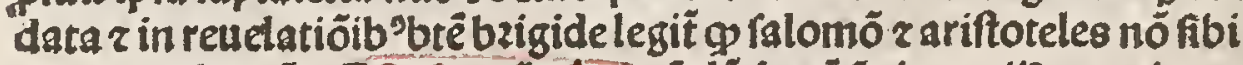

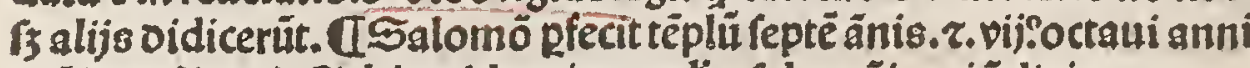

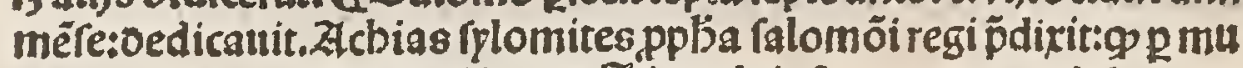
dieres:a mädatis oñi oeclinaret. 37deo ab ipfis caueat pnufgfø.
Theges írael incipiunt.

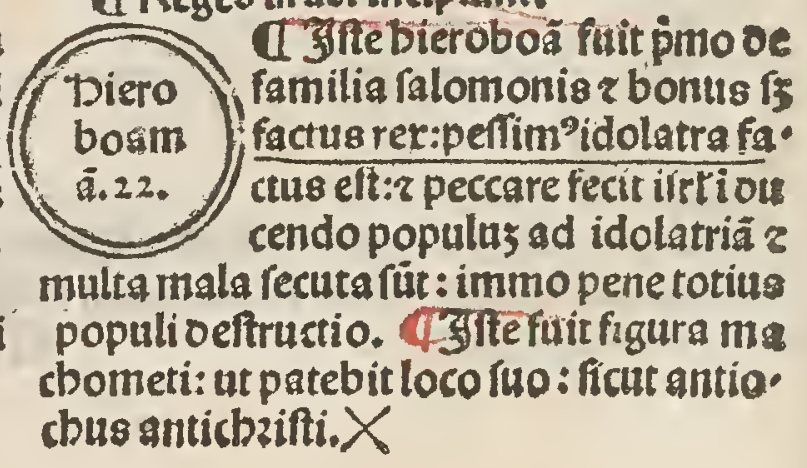




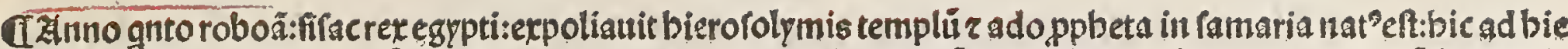

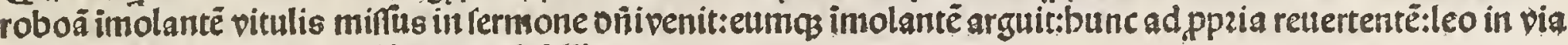
frangulauit eo 9 ppbeta alius eum fefellit.

TZmri rex ifrael:ennit monté ramarie a fomer:ouobus talentis argenti:z edificaut eñ. "bacbiel oe betbel:ieris cbo inftaurat.

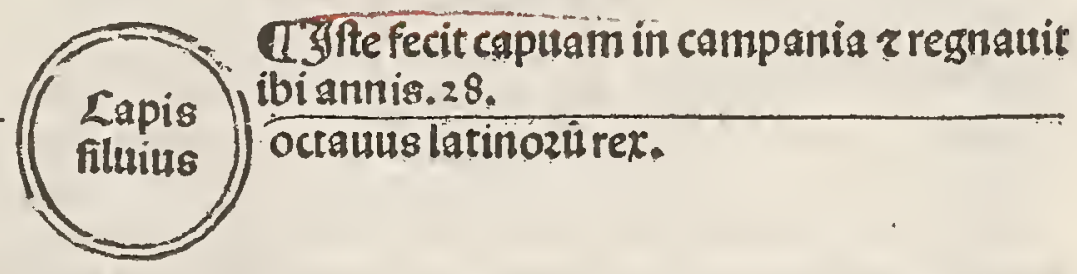

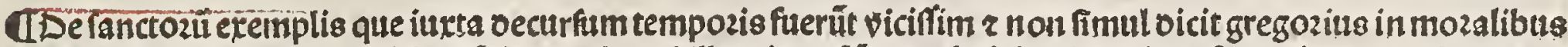
g. mira oif́penfatione oituinit? actü fit: $z$ quiqg ad illuminandü noctē pritis vite velut aftra in boc mundo radia. runt:oonec verts lucifer.i.redemptoz bumani generis furgeret. 'Tã ad oftendendã innocentiā venit abel:ad oo cendà actionis mundiciã venit enocb: ad infinuandü longanimitatis lpei r opis venic noe: ad manifeftandum obedientiã venit abzabã:ad oemonftrandú cöitugalis vite caftimoniã venit ífac: ad infinuandunz labozis tole rantiã benit iacob:ad rependendū p malo bona retributionis gratiã venit iofeplo:ad oftendendã manfutudiné venit morfes:ad infozmandü contra aduerfam fiduciä venit iofue:ad oftendendam inter flagella patientiä ve. nir iob. Et fic p 3 quô in pziftinis tempozibus admodú partus fuit numerus pfectozü \{́ circa bec cpa ppbetarum palde crenerü fanctitatis exempla:qui etiâ plures marţ̣riçati fuerüt p fide pritus oei. Ecce ö fulgentes ftellas în celo cernimus:ut in offenfo opis pede:iter noftre noctio ambulemus.

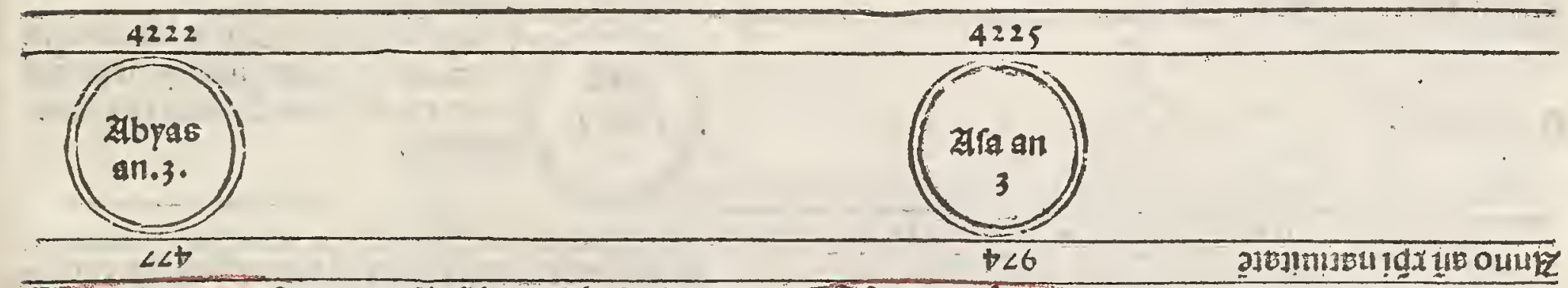

Tyite abias mixt? erar:q2 aliqũ bene fe babuit: ut $p_{3}$ in bello z fermone longo $\mathrm{otra}$ erercití ifrael i victozia oiuinit?oata:aliqui peffine:qz idolatrauit:z ob tã mı' gnã ingratitudinē pcuffus a oño parú regnauttut 13.3 . regl.9.7.2.palipo. 13. Sub boc fuit abrymelecb pötifer.

X Dpera bieroboã z ouritia mẻtis ei patët, 3,regü. 12. 2 frequenti caplo. Et nota $q$ iftud exéplü gniciofinhimü fuit pofteris z vfq bodie é: $z$ in futurü erit:qz plures $\bar{q}$. rentes occafioné oniandi retrabunt rub ditos a ing o fi dei:oiuerü $\tau$ alienú cultú inftituendo:ut $p 5 \mathrm{p} \overline{\text { pdictum }}$ macbometi r fequentes fuos.

đIsimilit greci volëtes recedere ab obediétia ecclefie f́ienter plapfi füt i varios errozes: nouú modū in oiai no aftumentes officio: $z$ ob bocmiferabiliter fepius ex, terminati funt.

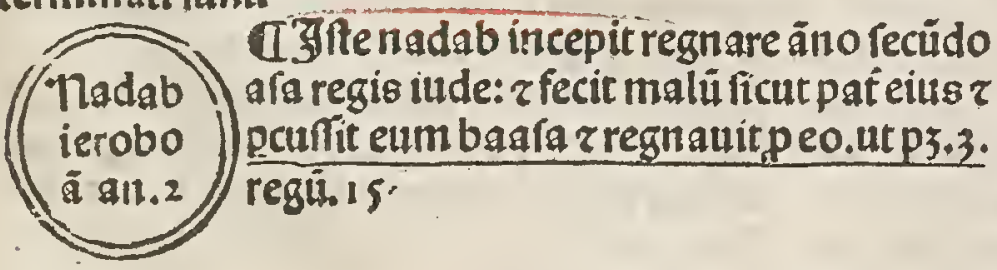

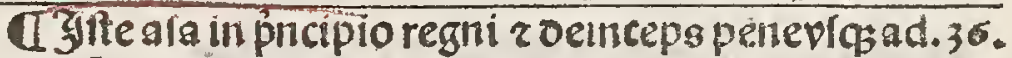
annü valde bene ambulanit:ficut osuid: $z$ pcufit etbio pes ś fe veniëtes r abftulit idola: 15 poft bec inijt fedus cum rege fyric benadab ppter baafa regé ifrl": $\mathrm{g}$ incepit afcendere 5 fe gó oifplicuit ono vĩ mific ad eúpplotes anaui:quéftati incarcerauit:z ió ooluit pedes: q2 poda gricus fact ${ }^{2}$ eft $\tau$ plagat? eadé pena qua pplsetä verautit.

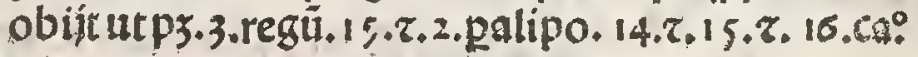

\section{CAçarias filius obed:ppbers clarus babet r oecapti titate pdixit.2.paralipo.15.

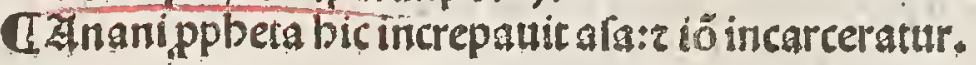

Tbieu fitionanip pleta mittif atra basa regen ifrl: martịrio cozonațab eo ppé voú oril ut p3.3 .regu. 16.ca.

oe ifacbar.

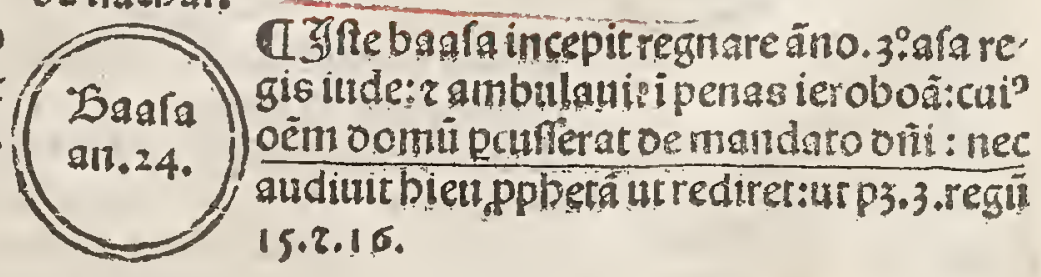


GJtecarpeftis nthius poft regem capis regnauit änis.13.in italia tpe iolapbat.

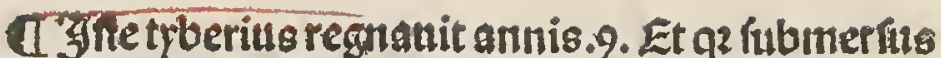
fut in tyberifutsio: $g$ anteg oictus fuit albula:ideo abreo nomen accepit.
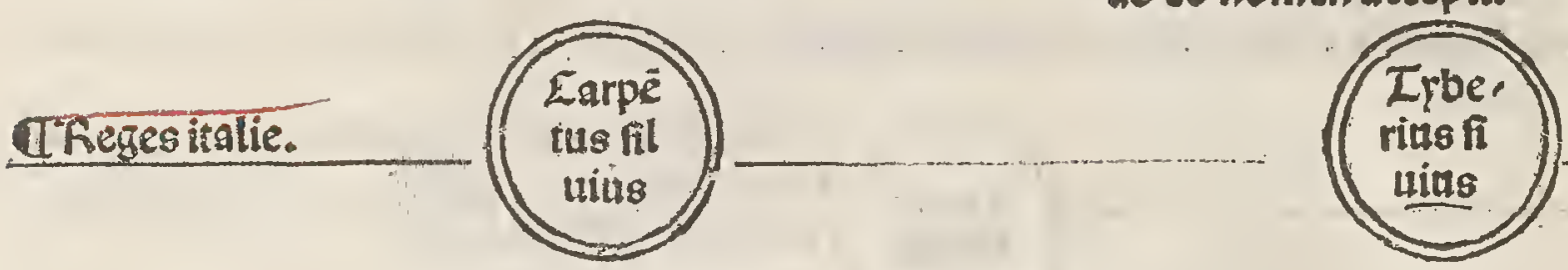

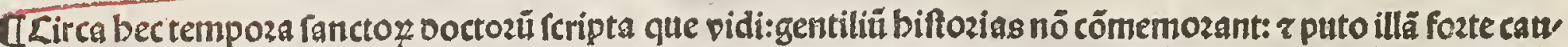

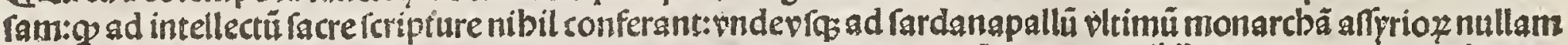

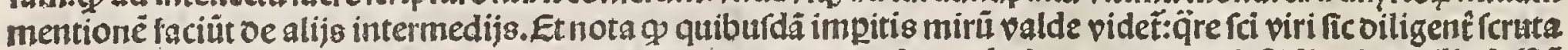

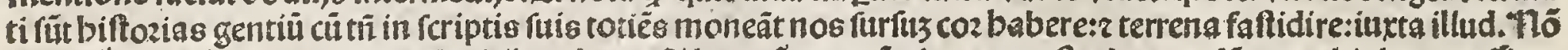

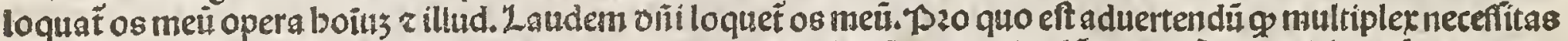
cos ad boc cogebat. Fuerît eni quidá beretici z gentiles:g facrâ fcripturã calüniabanṫ:quafi falla effet: eo g in'

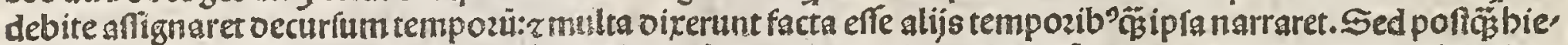

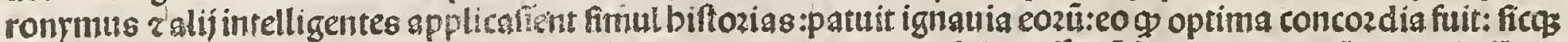

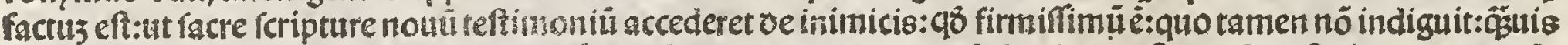
vtile fuerit pzopter impfectos, allia neceffitas idem expetijt:pzopter idolatriam oeftruendas. Quis enim tota fa, mul gentilitas falfos beos coluitreneceffe fuit indagare oziginem illius errozis:ut manifefte poffit imp?obari cul

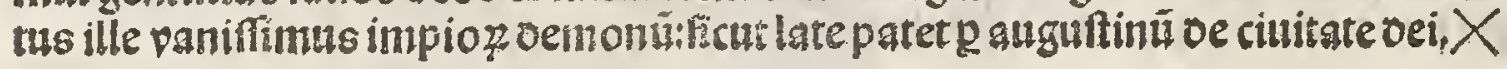

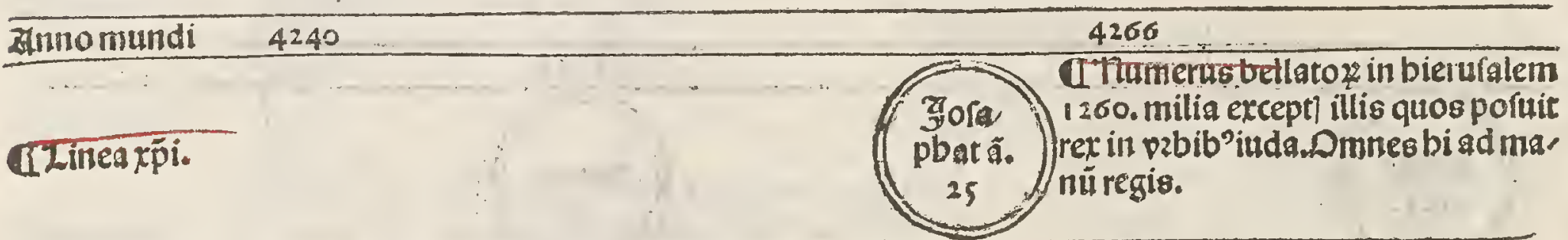

096

Cद्fte fuit fili?acbimags. pozzo pmo pa, tipo.6. vbi poniť catalog?pötificü ilte açarias genuit ioannă: 6 reg7. $4^{\circ}$ or : $:$ g ioiada ifti fuccef fit:fozte binomi? fiut:uel eft vitiü feriptozis.

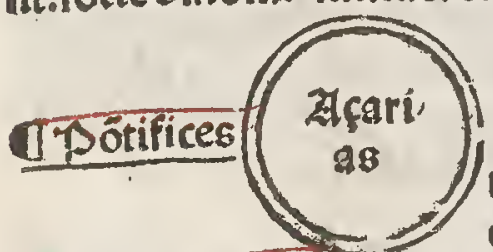
etiam requicuit fup elifeum.

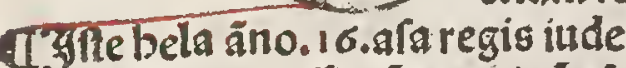
cepitreğre: $z$ pcuffit eü çamri cū oi dFamaria condit. somo prìs fui ut p5.3.regü. 16.
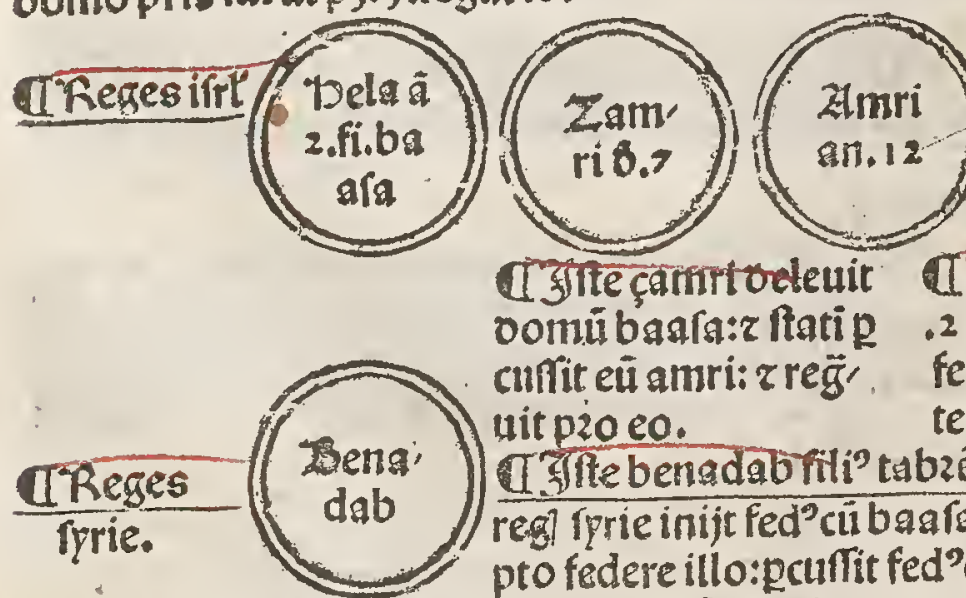

Uदोite çantortoleuit oomiu baafa:z ftatip cufitit eù amri: z reğ' uit proco.

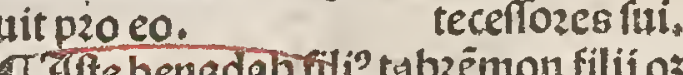
đ.gfte benadabriti? tabzëmon filij ojon

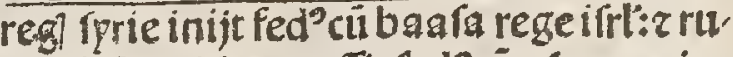
pto federe illo:pculfit fed'cil afa rege iu' da zextúcturbauerüt reges fyrie regnü ifrael ut p5.3.regii. 15.

\section{$£ \varepsilon 6$}

IIJfte io faplost fatis bon' fuit r gloziolos:oines zoetrot in via oni inec aligd mali oe ip fo legitin

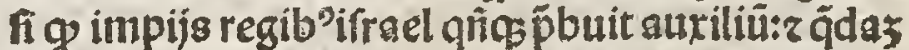
pua alia: 2 iō oñ fuit cü illo: $z$ pacé oedit $z$ pugna: uit peout p5.2. palip.17. cū trib? fequentib? caplis CElias tberbites oetra arabuz:oe tribu aaron pe pheta magn' claret feitate vite: zmiraculow gtia: 5 regü malle` fuit:g etiä i padifü curru igneo fub. ouplicé fprì babuiffe. f.ppbetie r miraculožz: qui (T) Iร̧ames mağin ifrliurta bubu clie.

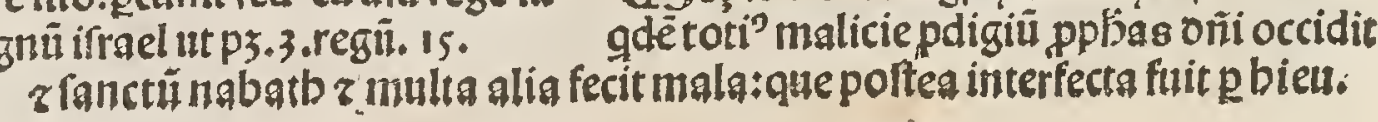

Cyfle paup bö rot'oeui' erat valde inita bilis:puerilití mitis: $r$ furioie ftênnt icepit reğre.3 S.âno afa r fug oés $\mathrm{g}$ a iniq̄ egit: fi babuiffet f́p bonã oirectionem multa mala nó feciffs: f̧ impia ieçabel $\mathrm{pl}^{\text {? }}$ regnabat ồंipre r ipulit iprü ut feq̆ret fe.

a 2Dicbeasppheta oe tribu epbeem:i mo rafti ott": quì peccãtéacbab lepi?arguebat z ipfï pdixit moziturù:fub iozaz filio eitus: pcipitio valde pozzecto iactat ${ }^{2}$ occubuit: utp5.3.regu. 22 .

đTyeçabel filia regl fidonio y: vroz acbab 
X ut etiä pbi ac ceteri ḃunofiozes vtriufá fexns boies: 208 verbis z feriptis redarguerent. Tertia caufa eque neceffa ria fuit: vacillatio infirmo 2 adbuc in fide tpe p̉mitiue ectie: $q$ feducti fepius fuerüt a paganis; oicentib ${ }^{\circ} \mathrm{g}$ meli?

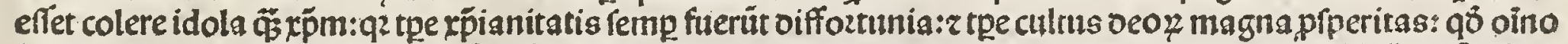

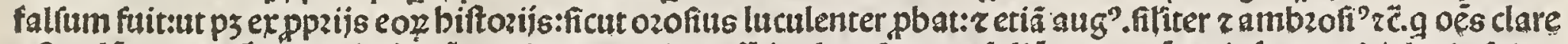

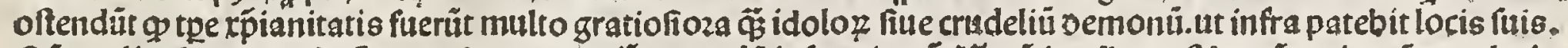

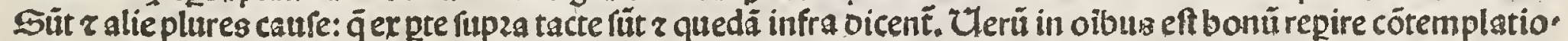

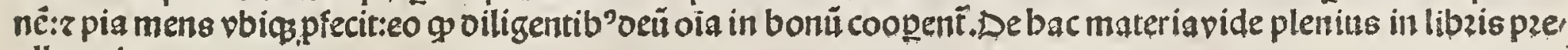
allegatis.

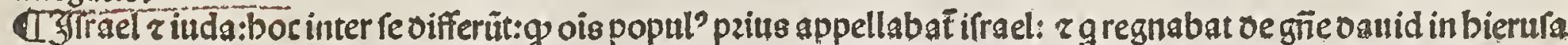
lem appellabat iuda. Et qin ab ifrael vituli aurei colebant in oan:z in betbel:ppterea ab affịrijs pzimu capta eft famaria nötñ aino oeleta. Et multo poft tpe:iudas a cbaldeis ouctus eft i babylonë:q2 minoza peccata babue'

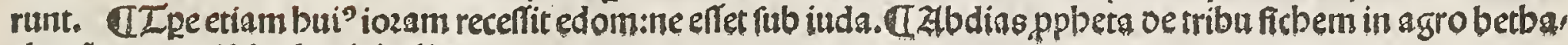
cbarã natus: díçipulus fuit elie.

GIfte iozam peflintns filins oe bono patre: occidit fratres fuos:z ambulauit in pijs reģi ifrael:z ideo miferabiliter plagatus in omnibus:infeliciter obijt.ut p5.2,parglipo.21.

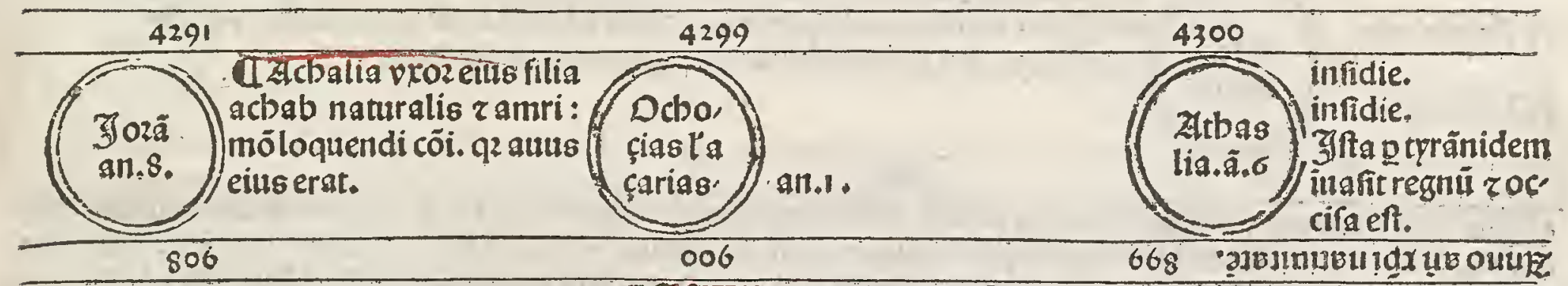

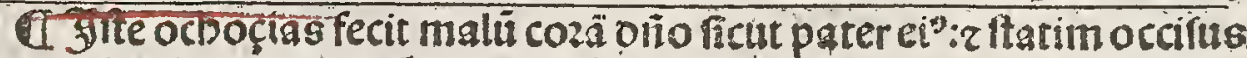

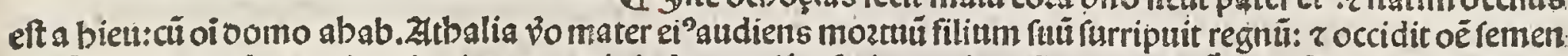

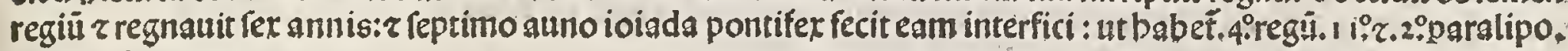
$22: 7.23^{\circ}$.

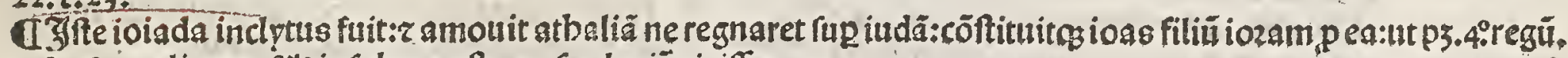

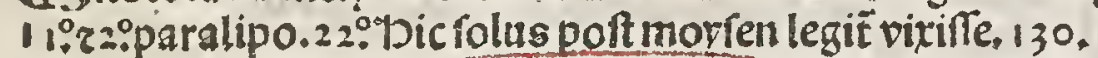

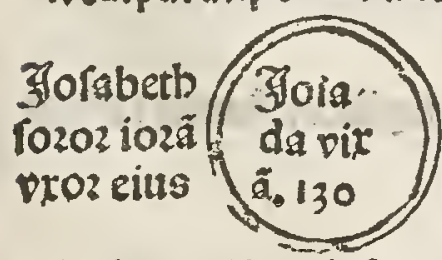
IJonadab filitis recbab clar'sacerdos babet:oe bis ftirps palde religiofa delcendit: 9

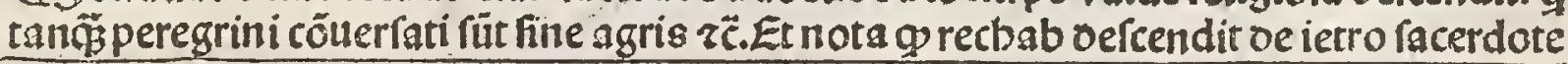
madian cognato mopri.

CElifeus pp beta fili"fapbat oe terra ruben gerat oe abel: furrexit loco elie:ouplici fpú

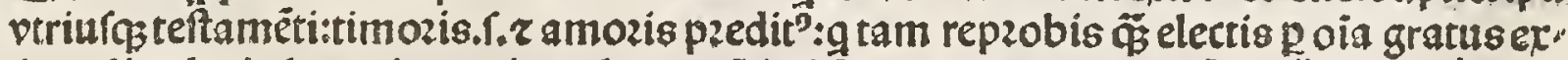

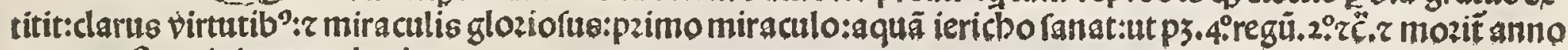
II 53.polt natiuitatem abzabe.

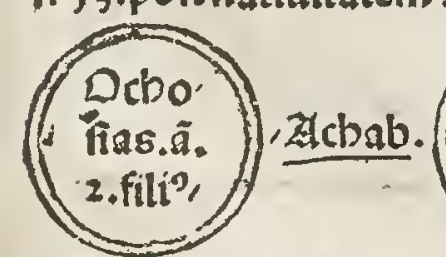

Tŷte ocboçigs mifit ad beelcebub veü acca ronifulëdǘn ponfýa. nari:ppter qo obijt iu xta boti elie:ut p3.4.re gi pimo. cepit autre $\overrightarrow{\mathfrak{g}}$. re.17. anno regiriude lorapbat.

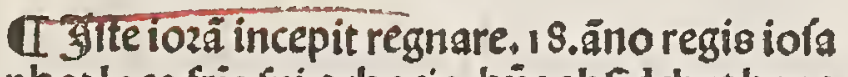
pbar loco fris fin ocboçie: buic obfidebat beng dab in famaria: $z$ oiuinit?meritis elifei fuit li

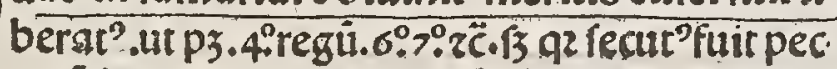
catũ ieroboã:interfectus éa bien cuz oi oomo patris fui utp5.9..z.10.ca: vbi fupza.

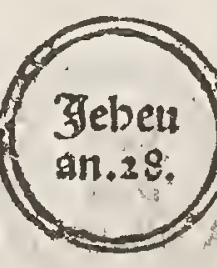

G3ftebien rex victus a puero elirei:pcuffitio, rã cú oí Domóa chab retiamo. chofià regê iuda 3 oeftruxit oomü baal zpphetas eius occidit: unde mertit pofteris fuis re,

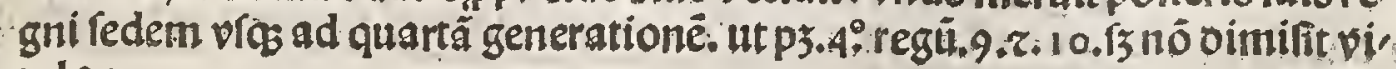
tulos.

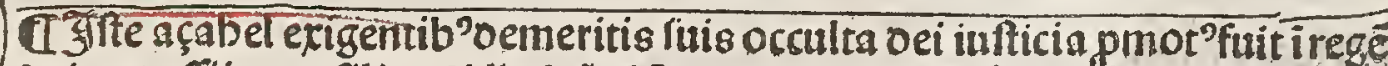
fyrie:ut affligeret filios ifrt' ? fuã plōgaret inigtaté. Zafflixit aut ifrt" vltra no.

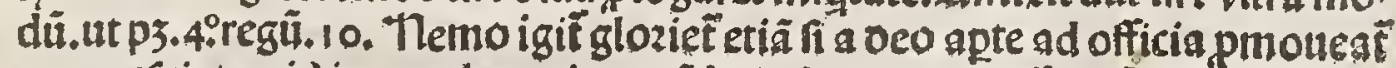
cum nerciat quid in occulto dei tremẽdo indicio oe fe diffinitü fit. 
OTitus lititus vocat ifur ro

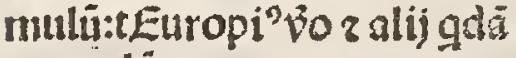
aremuli. Chegeritalie. $\left(\begin{array}{c}\text { aremu } \\ \text { lits fil } \\ \text { uit. } 12\end{array}\right)$

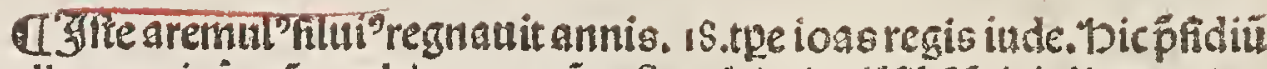

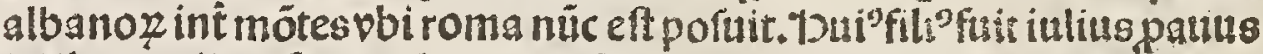
iulií pzoculi:g ci ronuto romá cömigräs:fundauit iuliä gentē.

Zlfte etiâ ob impietatê:fulmine ictus interijí.

CLigurgus fis tpibus flozuit: g liç gentilis fuerit:tii leges inftifimas näli iuri z oinino cölongs lacedemonis

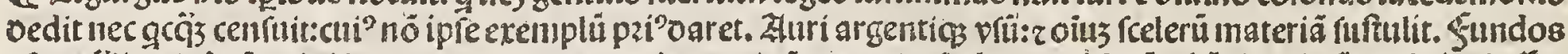

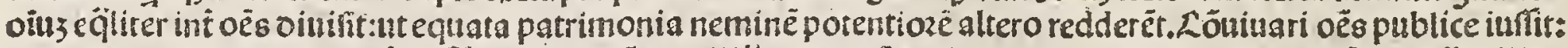

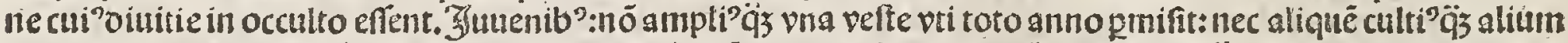
pgredi voluit nec opulëtíus epulari. Emi lingula nó pecunia:\{z compatiōe merciuz iuffit. Pueros puberes non

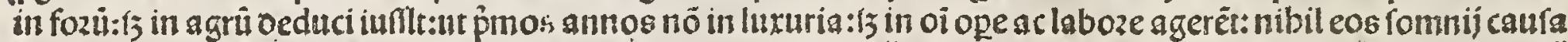

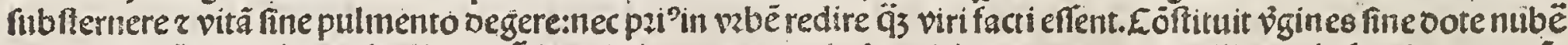
ut vrozes nó pecunie caufa eligerent: feueriufqg matrimonia fua viri coercerent:cuz nullis ootis frenis tenerent.

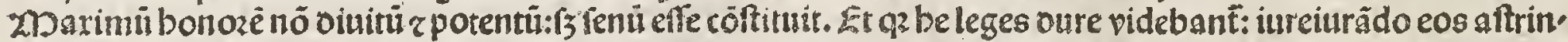
xit:ne gd oe tam oiuinis legib?mutarēt oonec rediret:z fic extra patriä pfectus:voluntariü gpetuo ouxit exilium

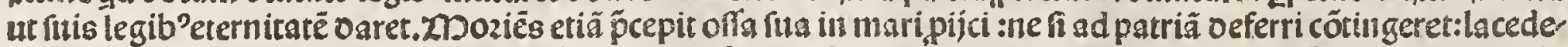

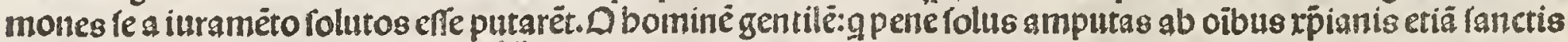

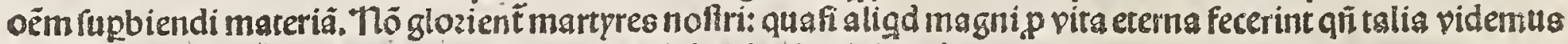
paganos feciffe rč. vide augl.pzimo.2.\%.3.oe ciui. oei.zfpecialuter in gnto.

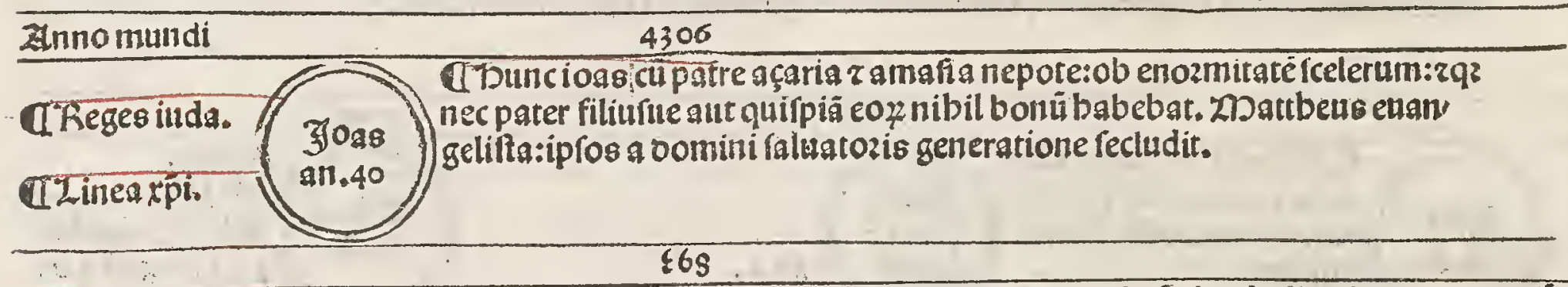

T. GRe iog o oum adbuc infans effer fubtractus fuit ab interfectione:que exercebat $a b$ atbalia. Eum suten eflet

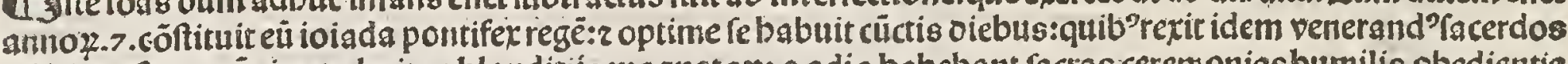
onit:f poft moté eitus oelunitus blanditifs magnat tor: 9 odio babebant facras ceremonias bumilis obedientie moraice legis:oepzanatü eft coz régis in interitü fuü rilloz:cunctis retro nationib? bozzendü relinquêtes erem

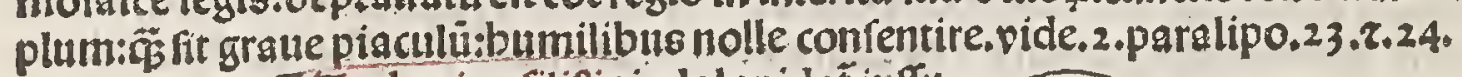

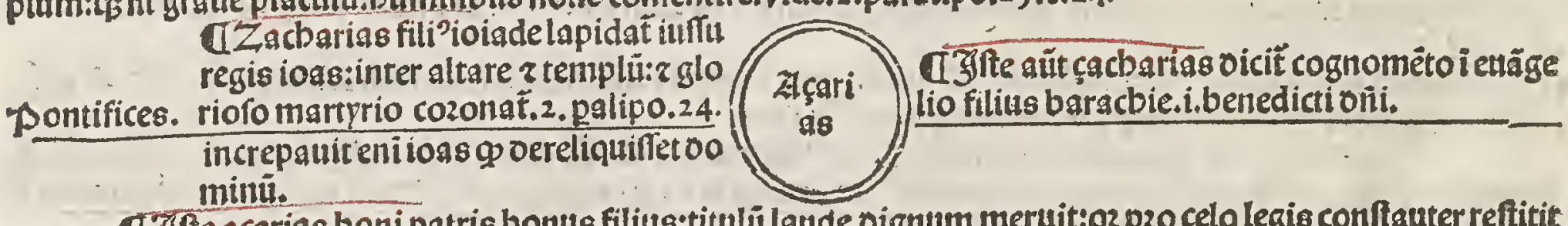

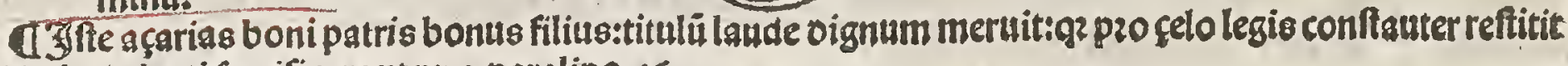
ofieregi inde:volenti facrificare ut $p 3,2$,paralipo, 16.

Regesifrael

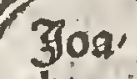

a11. 17

7ffte iogs valde attritus eft cum tota gente fua ab açabele rege f̧rie:r ideo oepzecabato onim:? pauxillum releuatus eft:ut p3.4.regü'1 3.2 cepit regnare.23.anno ioas regis iude. 


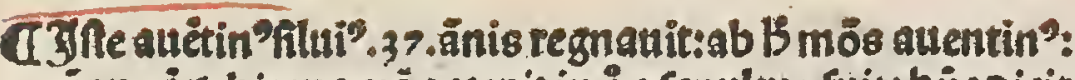

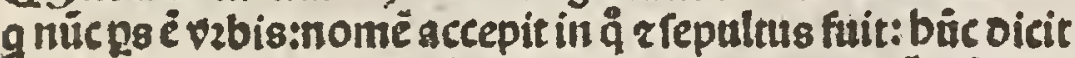

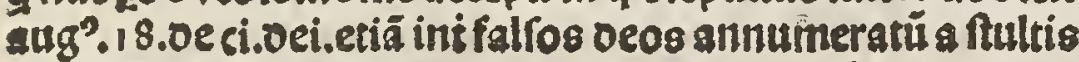

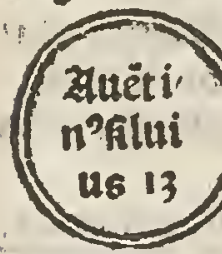
gentibus.
Tbic pzochas fili?auentini reğtit änis.33.tge to fie regis iude:vin virgili? audes et extollit iboc per fu. Dzoximus ille pebs::romene glozia gentis.

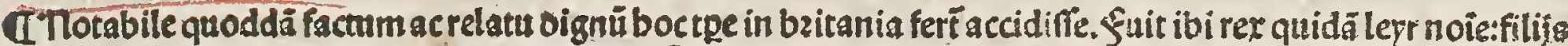
earens:\{⿰ tres pulclszas filliag babens:quib'regnū oiuidere cogitabat:ut tī fciret cui potiozé prë oaret:a fingulio

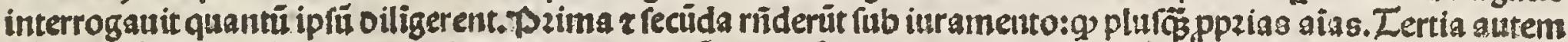

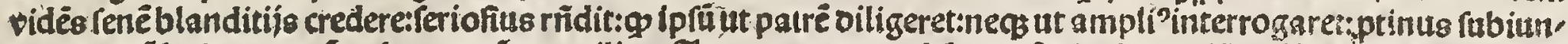
rit:quantü babes:tantū valeg:tantüqg te viligo. Zratus pater:ouab' regnü oinifit: tertiä auté exbereditautt:quã

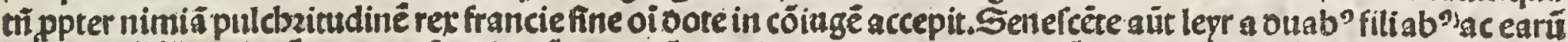

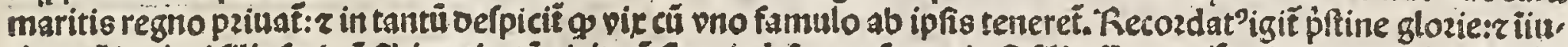

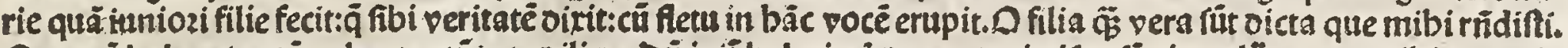

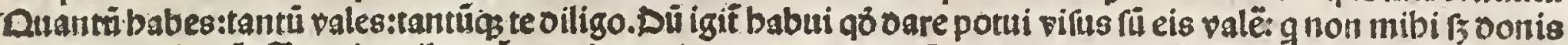

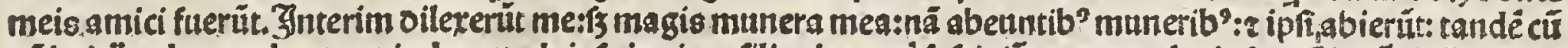

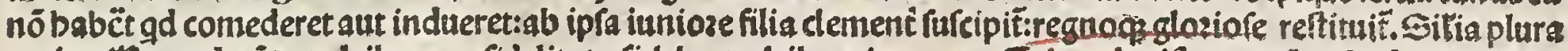

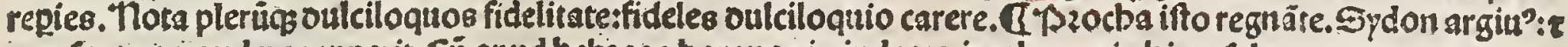
menfuras z pondera repperit. ᄃú apud bebzeos baranas in iudea: 2 ieroboam in bierufalem regnarent.

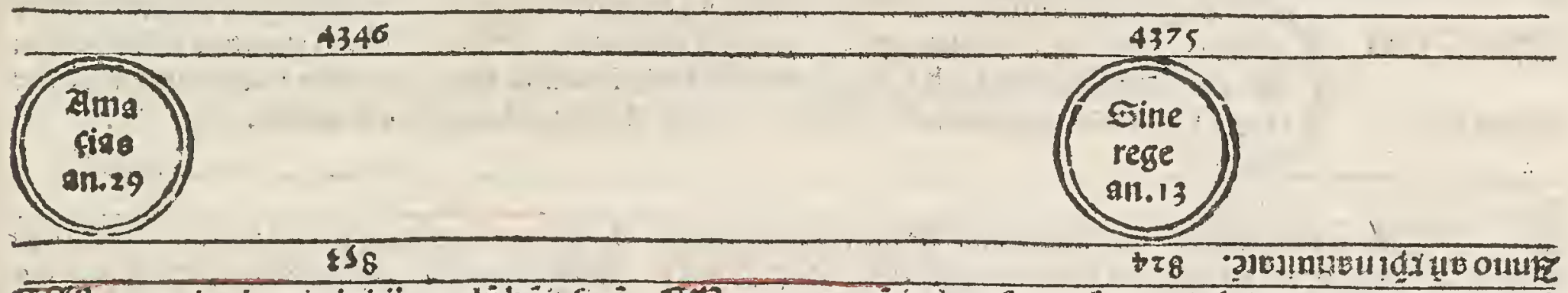

Tुłte amaçias bonis initijs malú buit fine

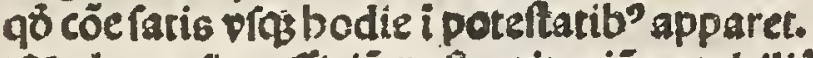

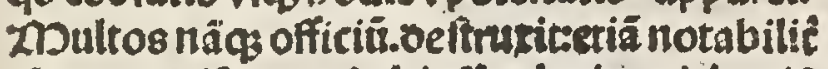
pbatos.cnipercmpla bic fút plarina:bic etiä De08 fepr adozauit sc̈.ut p3.2.paralipo,25.

IT Delleus mozit z ofra eiusppbetant: quiq moztu'furcitar eozü tactn: r tresvictozias ba

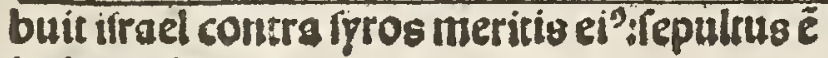
in ramaris

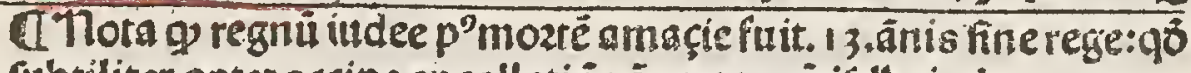

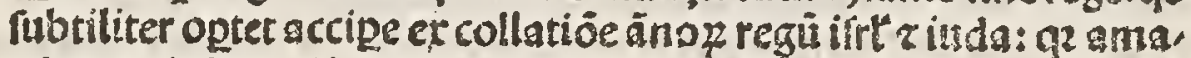

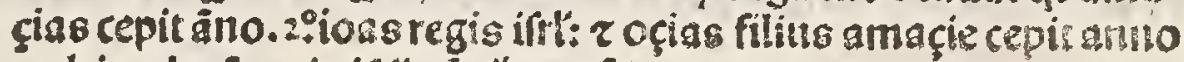

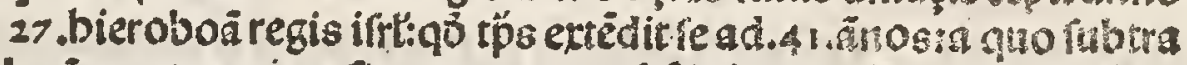
beänos amaçie: z fic manent. $13.9 b^{\circ}$ oçias putul erat:nec adbuc

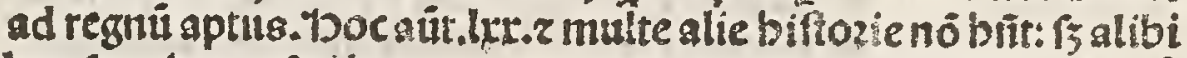

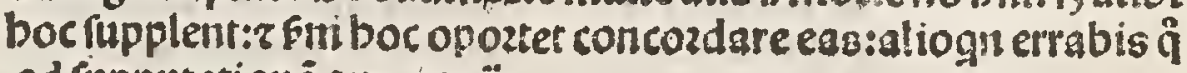
ad rapputationé annouz zë.

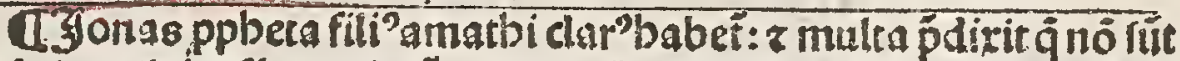
Teripta. Dicp'becmittit ad niniuë:ut ps in eius libzo. Dicitur aüt pipfun belias fufcitauit a mozte adbuc pueri.

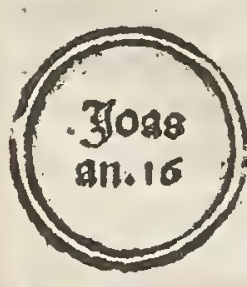

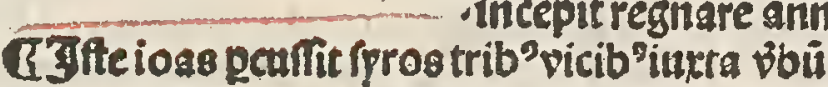
eliçei: 2 tulitwabes 8 mäu benadab filí açabet zreftituít regno fuv. IJp e etiã affixit amaciaz nôpolể: 4.regú. 13. Et cepitreğre 37.äno ioss regl iude

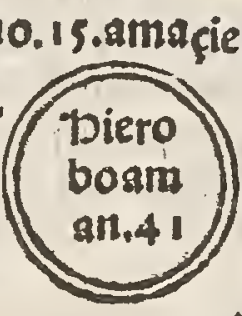

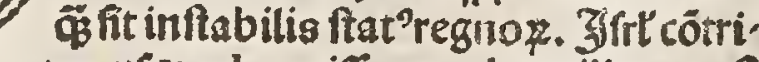
tus vfas ad uouifimum bumiliatus eft valde:fyri eleuati iam ab infirmis mira' biliter oepmunt:fic g fuit fupzafit infrs. $z$ eว̃ g fuir infra afcendit fupza:ut $p^{D} \mathrm{oe}^{-}$

Bena dab

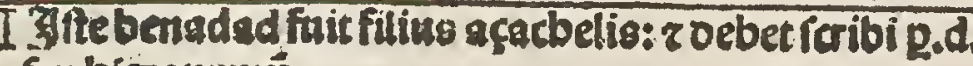
imbierongmü. bocaffumuntur a oño: 20 viri fenfati fcendat infra:bec é rotapolubilis buius tuis: $r$ iō non ef mirü 9 pauci electi ad

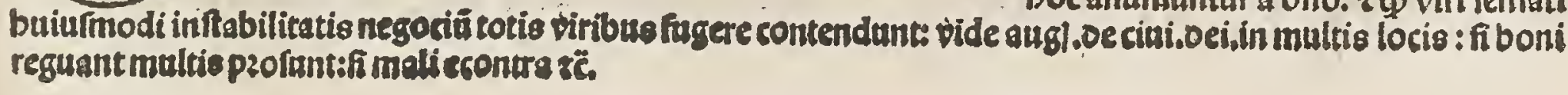
regis iude.

A Sffteierobosm fatis bellicolus z vi. ctozioftus fuit: $z$ contrituit regé fyrie $z$ re ftituit regni ifrasl ficut pziต:inritp z og. malcü itixta p̉busioneppbete. Antrende

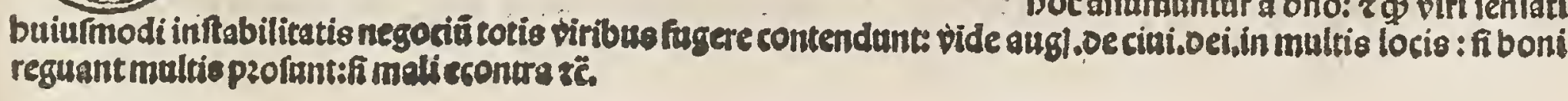


तiffe arbat ${ }^{2}$ icit farda napallü oñm fuú z móar

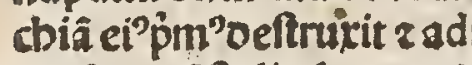
medos träftulit fpe magl

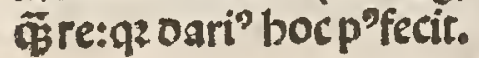

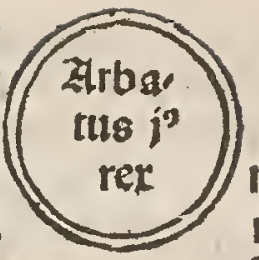
medore reğtuit. änis.28

Cheges italie. Uzmonarcbia affrioz illa mağ ceffat: itetit vltra.140.ānos z frargüt tha bozzen

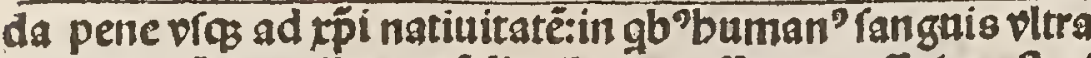

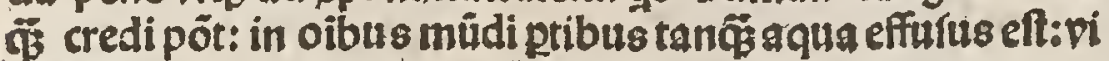
de cbronicã ozofii libzo fecudo z alio

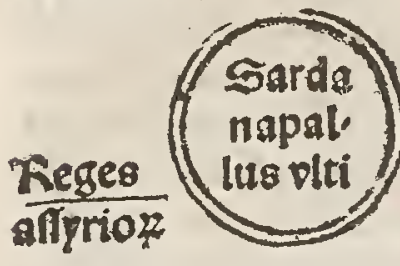

-mus monarcba afipriosú.

Tyfte lardanapallus tot ${ }^{3}$ itio fus fuit:pulainariacs Bm?'reppit

babitu mulieri ind ut ${ }^{2}$ :iter mulieres oelitijs vacauit.

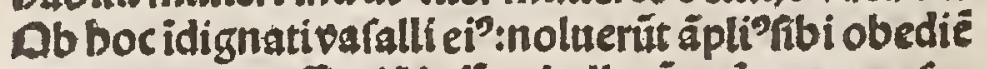
tiă fuare:aggrefi etiä ip fü oebellarüt:qơ cernens fe'

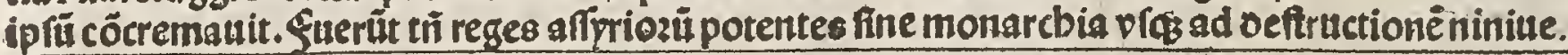

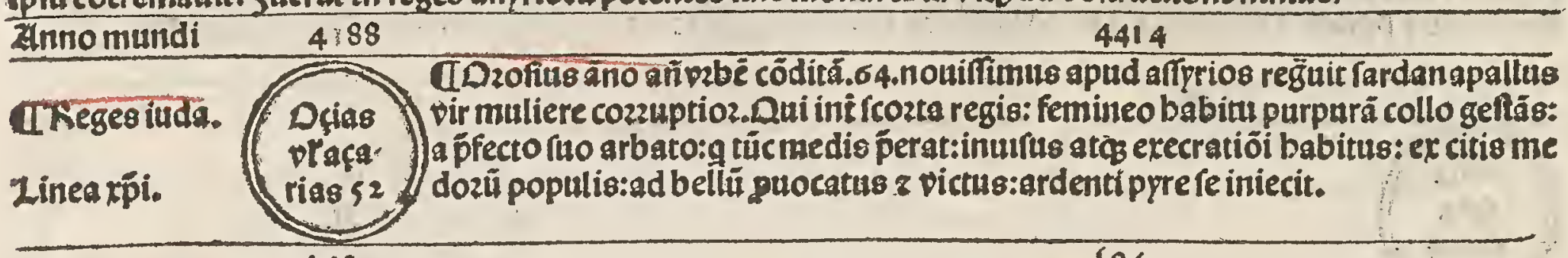

1 is

\$8L

T. Ifte ozias fecit ao boni erat cozä ono:nec aliquid ma li oceo feriptũ eft:nifi $\phi$ adolere voluit incenfü fup altare tbimia matis pbibête eî̧̧acerdote azaria ppter quả in obedientiả pcuffit CElaias nobilis pp广sa claret: $p 1^{\circ}$ oe ättuoz p̂ncipaliozib?: geuãgelifta magi

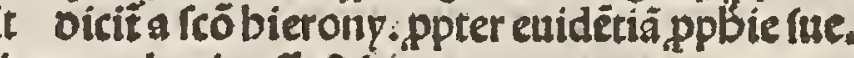
cü oñ lep2a.ur p5.2.palipo.26. Etiä tücterremor'factus fuit:z cineres altaris effufi funt.

IPontifices

UDTeespbeta pitin oc.xij.mittit contra.x.tribus

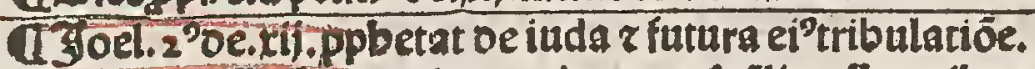

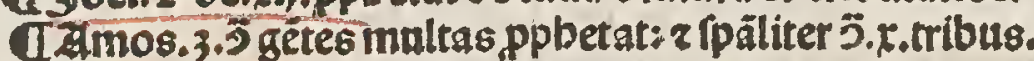
Cदzbdia8.4.0e.xil.pzopbetat contra edom.

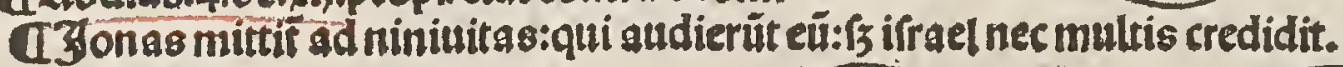

I'Reges ifrael.

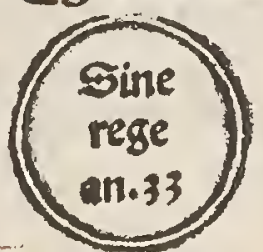

ITicregnitift fuit fine rege annis.33.quod p5 excollatióe reguminds.

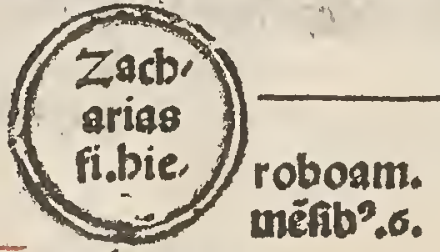

a'sffte çacbarias cepitregna reäno.38.ofie regis iude: $r$ fecit malü ficut pdeceffozes ful. Et bicef.4. p' bieu r parfit eú fellü:z regnauit pro eo: 9 ftati pcuflus a manabë:regno z vita ceruit at p5.4aregl. is

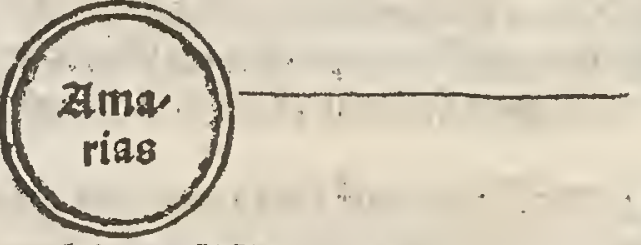

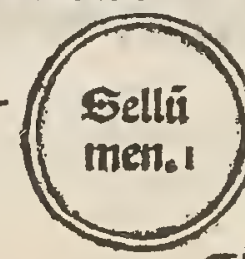

asfemanaben mans

ben an. 10 cepitreğre ăh0.39.0feregis iude fecites malú cozas oño z tradidit eĩ oris iman'regl affyrion: 9 indie rit ei taléta argenti mille: ut pz.4.

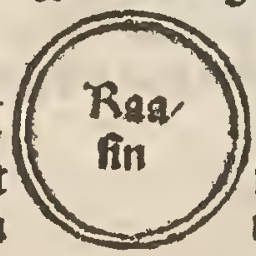
regũ.1 5.

Ireges fyrie. * Elaias ppbeta miflis e cu iafrab filio fuo i occartu achaç. ut oiceret eine time ret $z$ cos ei'ne formidaret a ougbus iftis caudis titionü fumigantiü:quos vocat

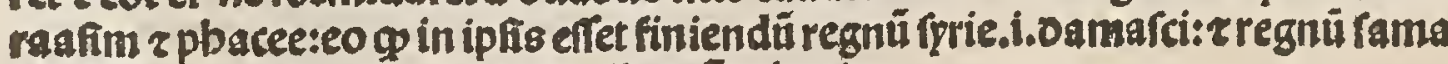
rie.l.t.tribuü:que alio noie appellabā̃ epbraim.

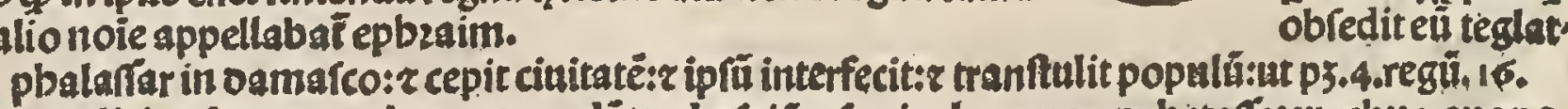
बigteragifitret firrievaftauit inda tpe acbafippter 9

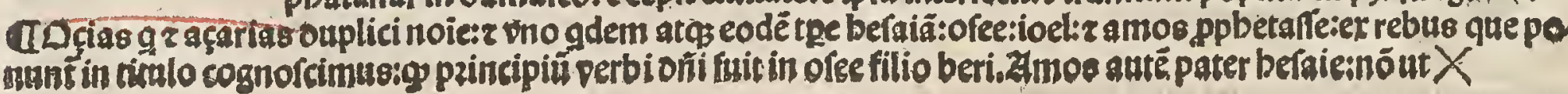




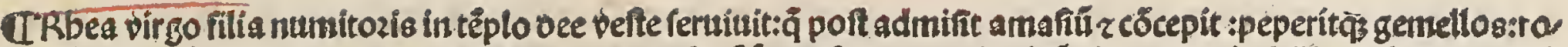
nulü z themú ob boc ipfa viug fepulta fuitppter iceftü:z infantes pzoiecti füt fozas:z mirabiliter a lup a natriti. - \$ozzo ob reuerentiä romano aut excufantes ut bonozantes.

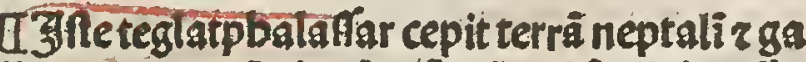
tilee: $r$ eos g träs iozdane erät trâftulit in affy rios $p^{2}$ etiâ ob rogatí acbaç obfedit oamafcí

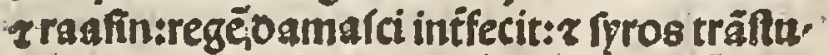

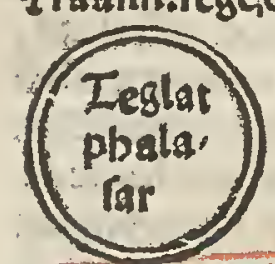
lit in cirenế:ut p3.4.regï.t 5.

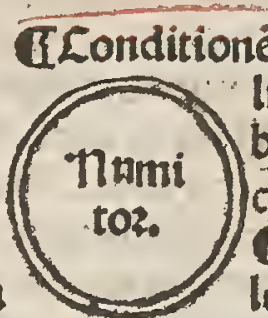

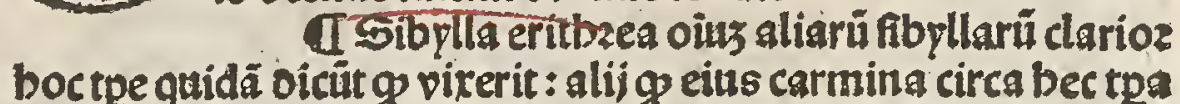
xp̄o zpulcbrevideang7. 1 s.oeciui.oei.

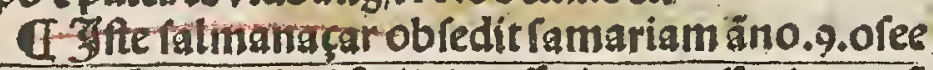
regis ifrael:cepit eă: $z$ regé mifit in carcerē: $r$ ifrael trâftalit in aflyrio $r$ ceflauit regnü

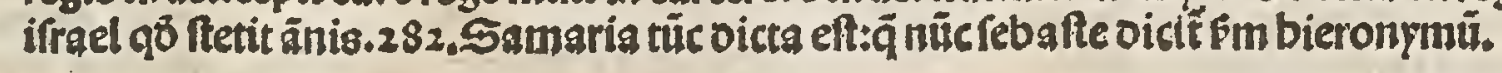

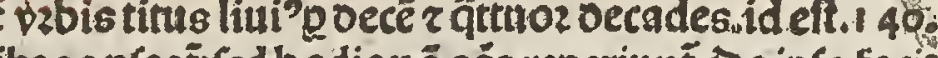
librosplegt:fed bodienỏ oés reperiunt. De ipfo facit btús bieron pn' mentioné in epla ad panlinü: $\tau$ lene ca in vltimi oeclamationul libzi prologo.

G3fte numito2 reftitut'in regnu:ftatim poft a romu lo occirus fuitutut ozofus teltat.

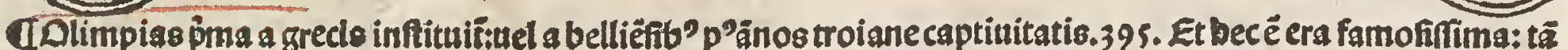

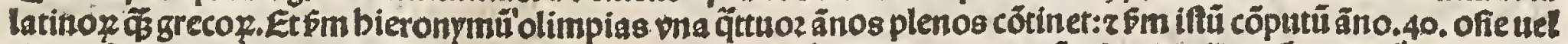

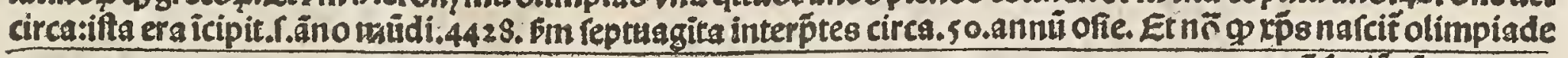

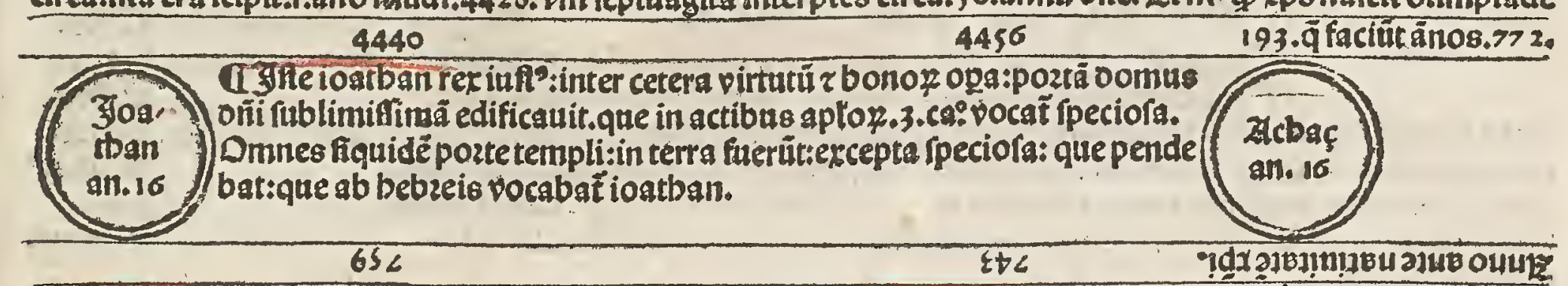

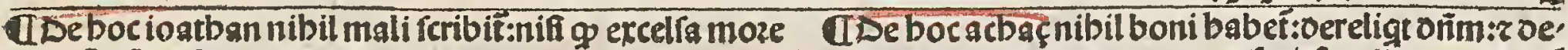
aliozünö abltulit ut pร.2.paralipo,27.

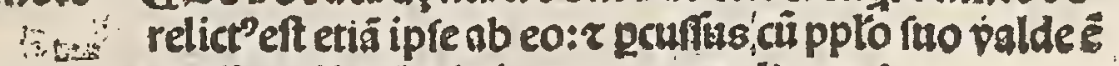
s regibus ifrael z fyrie ut p5,2.paralipo.28,

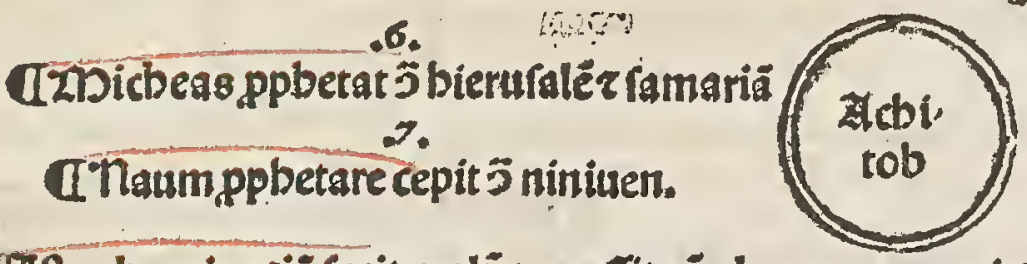

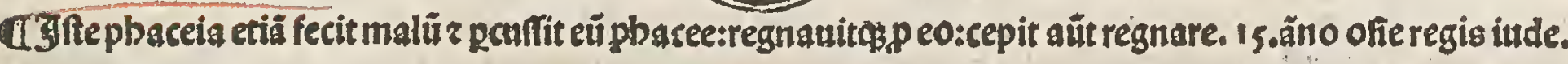

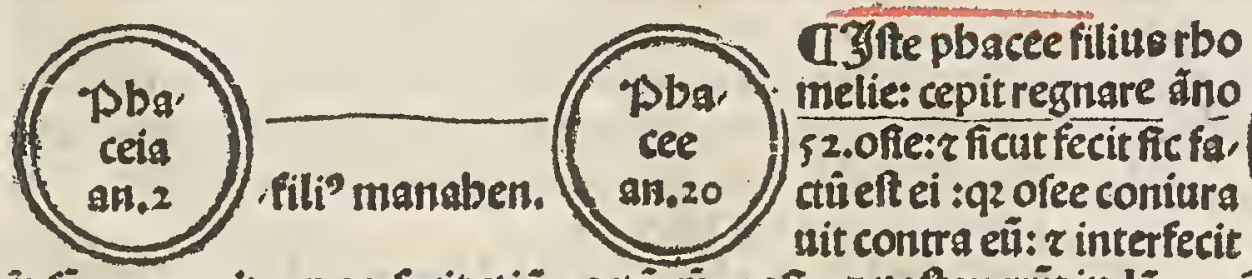

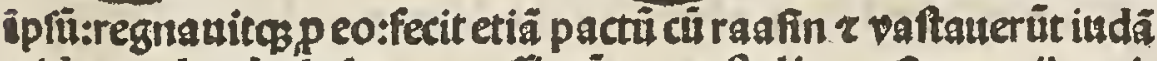
z ideo teglatpbalafar oppzeffit ein $r$ tranftulit quaf tres tribus in affyriog:ut p3.4.regü.15.

IDe ifto etiâ pbacee oicif $a$ btö bieronpmo:q etiã in famaria regnauit: $\tau$ pcuffit oc iuds

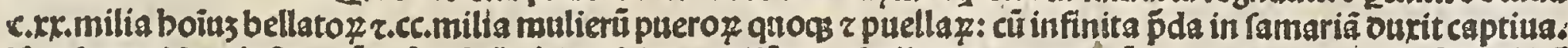

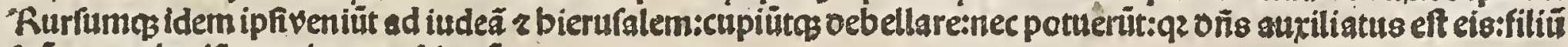
rui ppropbetiā nuncians nafciturü. *

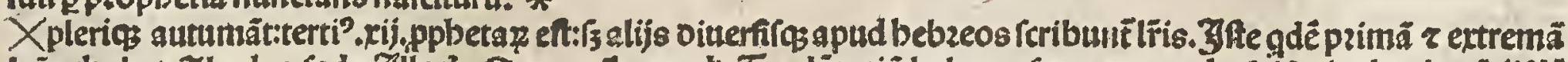

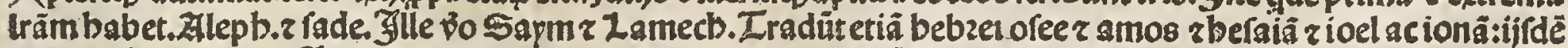

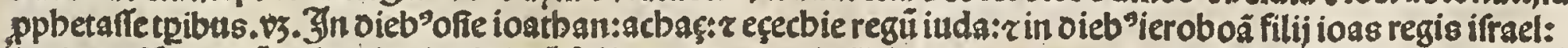

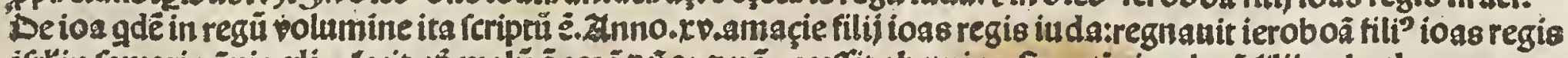

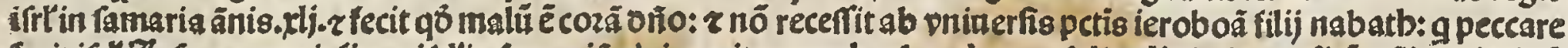

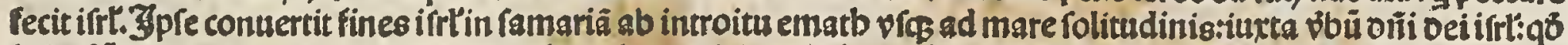

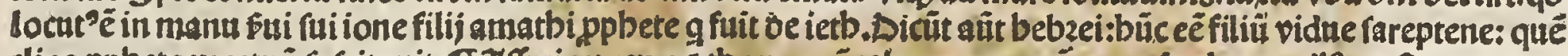

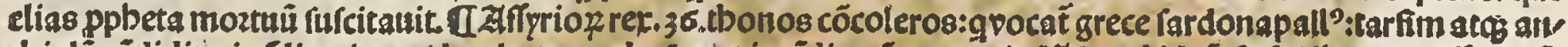

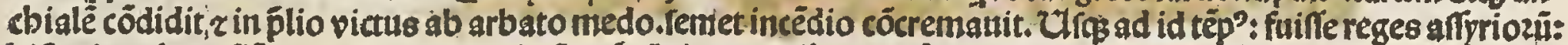

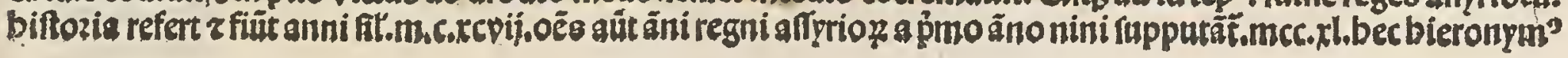




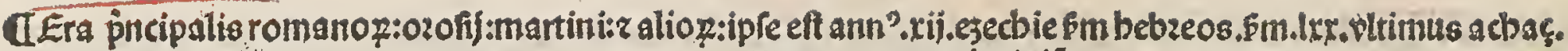
Keges romani incipiüt.

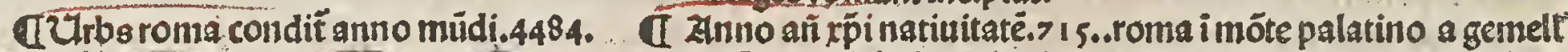

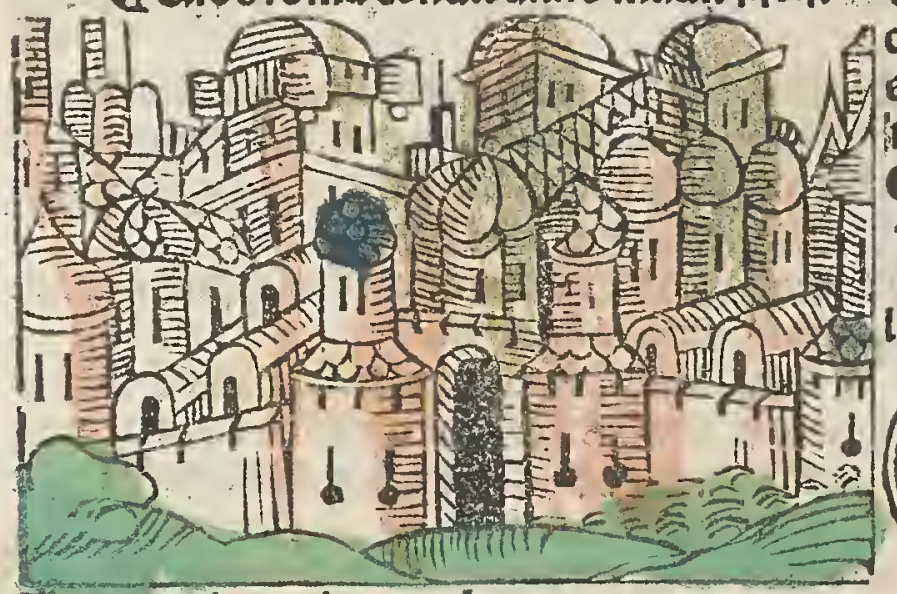

Inregere imperio popalos romane memento. De tibi fint artes:pacig imponere mozes. parcere fubiectis:z oebellare fuperbos.

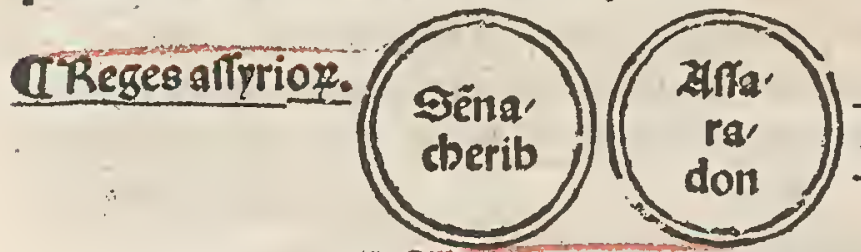

I Iffe rentnacberib afcen.

dit in iuda contra ezecbiä virum ferî: $z$ pcuffit

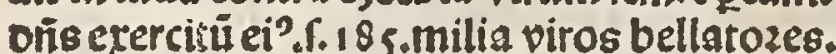
Zె̉ple aüt turpiter fugiés:puentit in niniue: $z$ af,

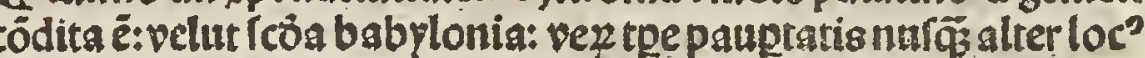
ea fäctioz:nec bonis exéplis ditioz fuit: $z$ quäto rerü nin ${ }^{2}$ babuit itãto min'cupiditat bébat.p'oiutic auaritiä z lururiã induxer̂t a Tlota $\$ 020 \hbar^{2}$ ób romulo multa mala feribit.f. fris fui $z$ aui

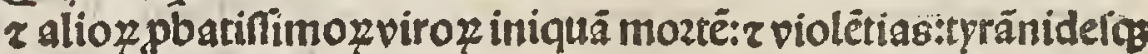

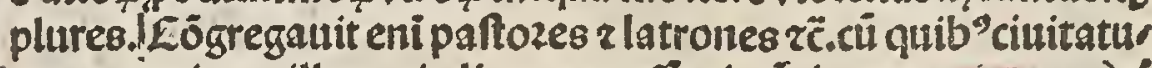
lam extruxit r p illam vi alios oppzefit circúcirca potertes. X Romu Rem? a labtemerodacts pin'rex lus an. afreor. 37.1 ?

äno.3.ff.

romanoz rex: cidit. oere.oi. I.vlti. a môarcbia: nec obediuit affaradon regi aifrriozú: fitr nec rex medox:z ob 15 nimis oefecitregnü affprt ozä: r reges babplonie ce. perüt effe potētes ilos ad lonie incipiunt.

\section{fili? rennacberib.}

\section{ULhales milefi'pn'oe.7. ́apiêtib"} clarus babet: 9 p'tbeologos.i.poe tas:'́opbi oicti funt.i.fapiétes. Zffte thales pimºtutit ṕdicere Defectū fo

lis zlune:ut oicitaug? 8 .oe ciui.ovi. baltbafar. vide magiftrú

mero dacb jo rexba,

byloniemifit müera ejecbie Iales. utp3.4.regl.20. Solon: Cbilon. useptéfapiêtes. Deriã. Aleobols Birs. Ditactue.

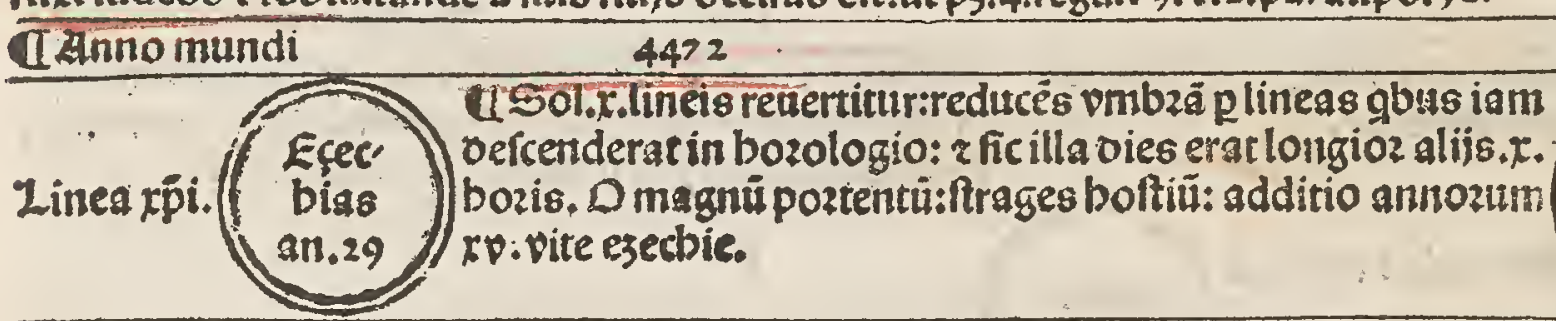

L2.6

(13)te esecbias optim? fili? o peffimo patre acbaç:äbulauit cozä ono cozde pfecto:excelfa abftulit:z oomü oei inftauraut:nec fimilis ei' fuit ante eü iu regibus inds:zergo oñs glozificauit eam utp3.4.1'egü.1 9.7.20.2.2.palipo.29.30.31.7.32.

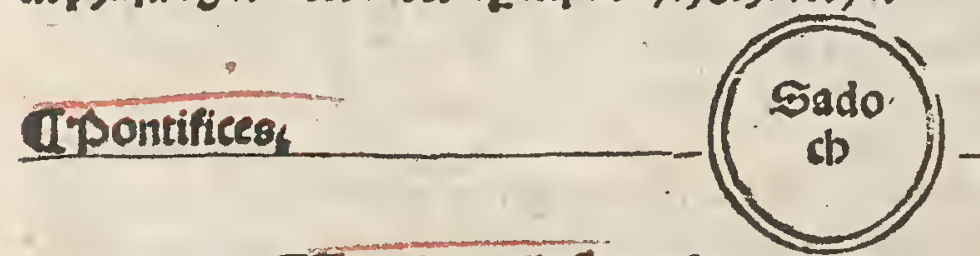
4.reqü. 21.2.2. paralipo.33.
4501

$\left(\begin{array}{l}2709 \\ 12 \pi \\ 211.55\end{array}\right)$

569

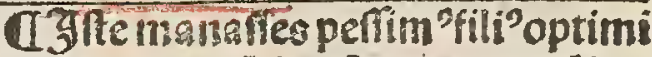
patris fecit malü fuper oeึs $g$ añ ipfiu fuerut: 2 fanguine ino centéfudit plurinū ppter gô rex afịrio pa vaftait iudam r ipfü manafien cepit:z i carceré mifít. p'ea ad coz rediens: zoîm oeṕcans: $z$ erandit'fuit $z$ in regnú fui reftitut'. Dia q̃ añ fecerat oeftruxit:z ivia oñi recte nmbuläs:nō finc grä di admiratiōe oius g eli añ nouerant titä beatã ouxit ut p5 QI obie biftozia oetlotifim 2 tota exēplaris bicteriť.

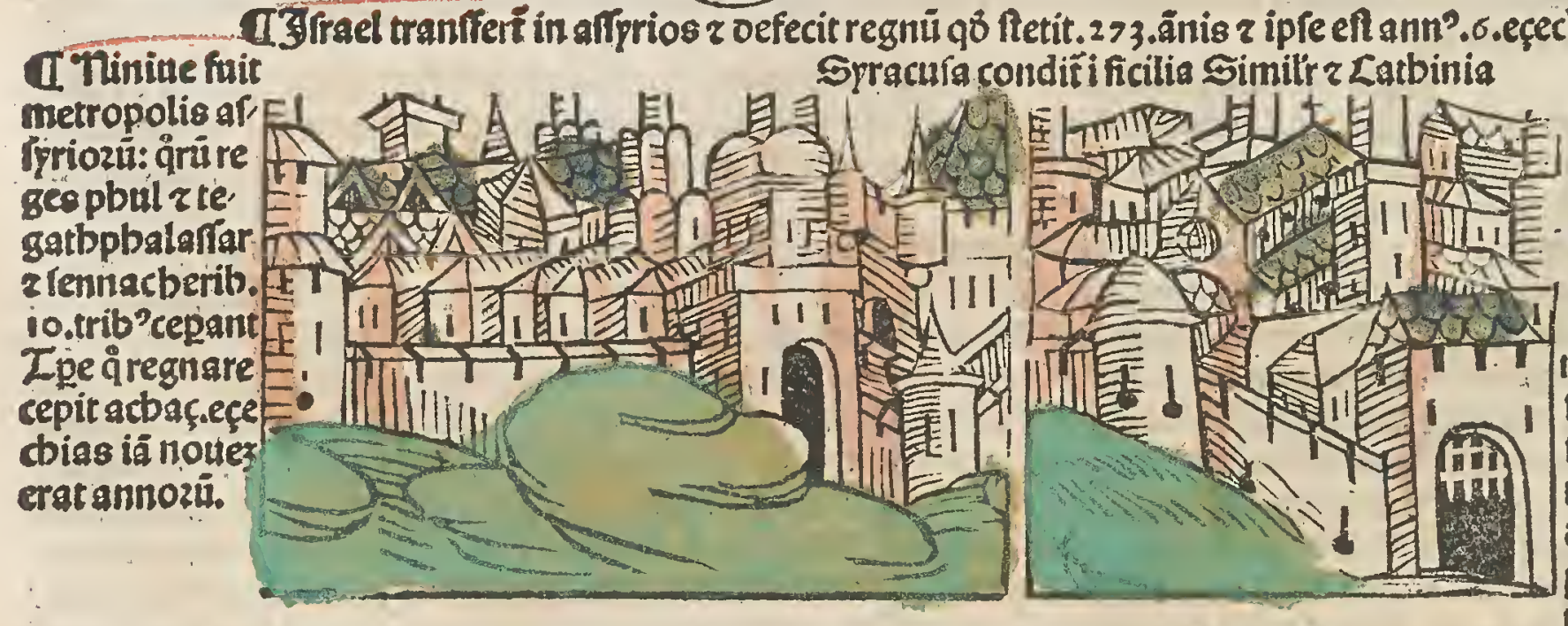
CEcecbias Q cuffit philiftîs vfos gaçã zoe populat'évíg ad termios cis a trecuftodus vfos ad vabes munitas वึ) fëracberib af fyri'pm?ince teras natiöes oeusftauerit pbilifteos. Ip ler captitum ourit ifrael. 


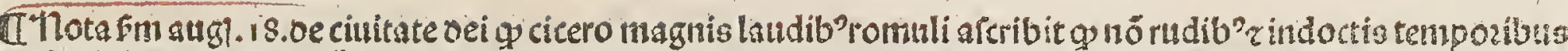

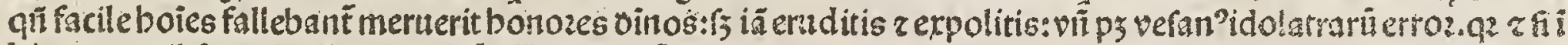

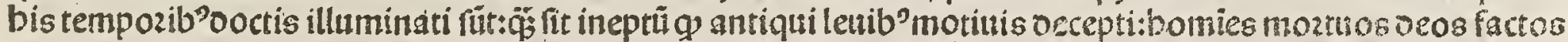

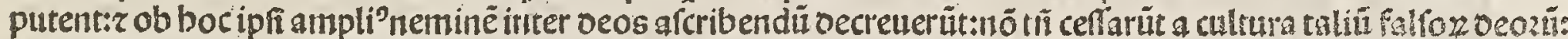

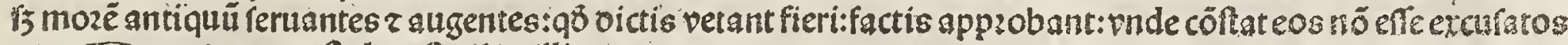

$\left(\begin{array}{l}\text { Nuuna } \\ \text { popil } \\ \text { an.41 }\end{array}\right)$ imo apoftolo tefte plits illis peccare.

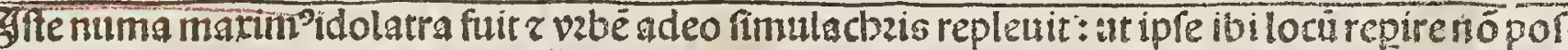

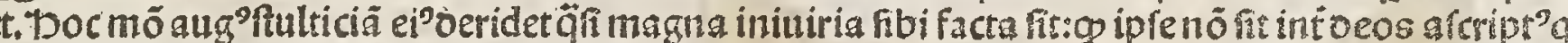

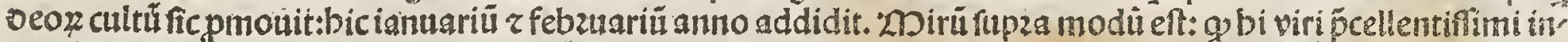

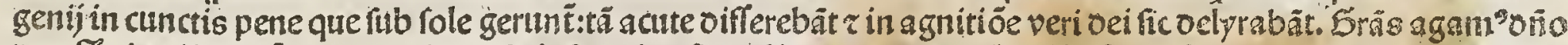

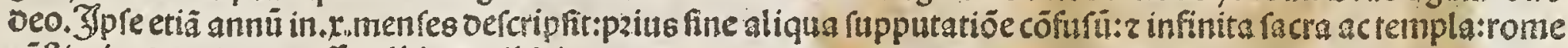
cöftituit.20 ozbo oeceffit.xlí.imperii rin anno.

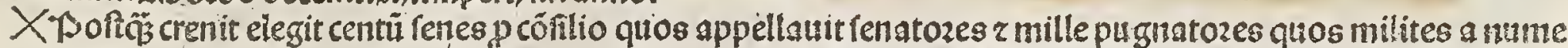
ro appellauit:ficat oicit eutropi ${ }^{9}$ :pfecitç i fublime:tandē ob oemerita fia inter oeos cörumerat? eft:eo os ecur

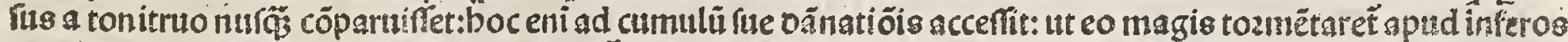

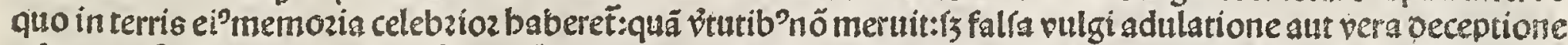
adeptus eft. $\emptyset$ zedicti fenes poft moztë romuli regnauerüt anno cü oimidio:erpectantes $f$ fozte rediffet zé.

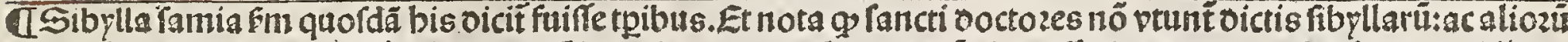
gentiliũ ad confirmationê tidei fancte xp̄iane:\{3 eas neçppbetico ipü clartifle:\{y arrepticias fuiffe oicunt. Ulinde

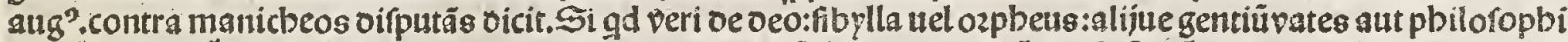

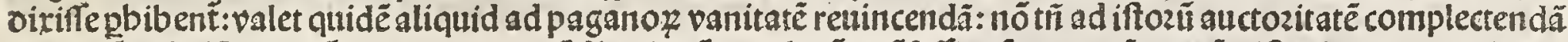

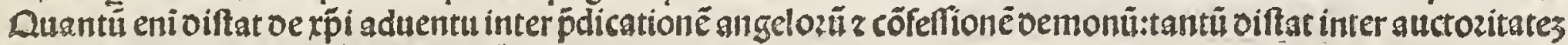
pzopbetarü zcuriofitatê facrilegozü.

\begin{tabular}{|c|c|c|}
\hline & 28 & \\
\hline 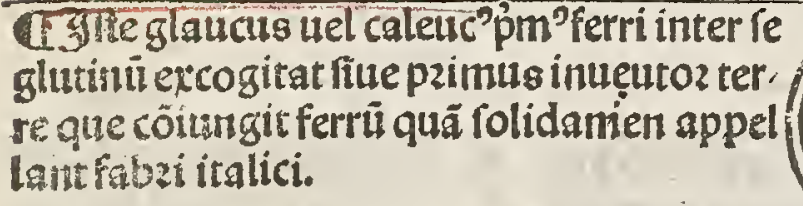 & 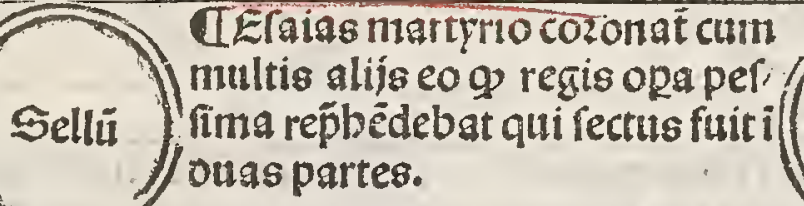 & Elcbi \\
\hline
\end{tabular}

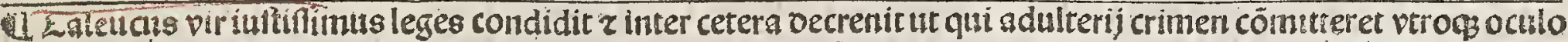

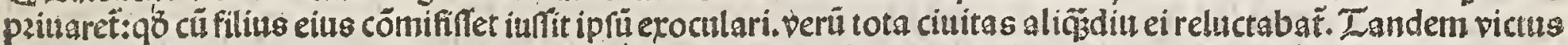

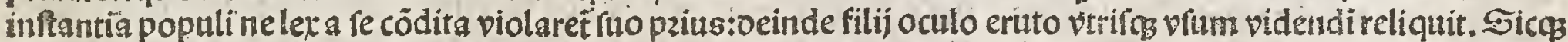

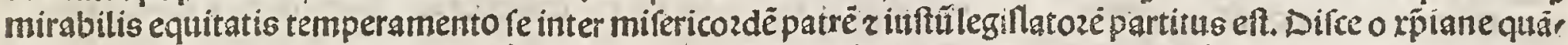

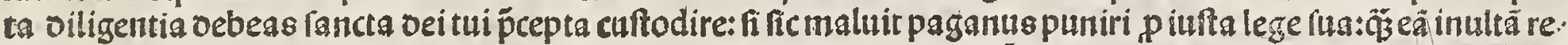
linquere. bec z multa fimilia opoztuit in populo carnali obferuare cus füma feueritate: quatenus timoze pene a pzanis cobiberent.

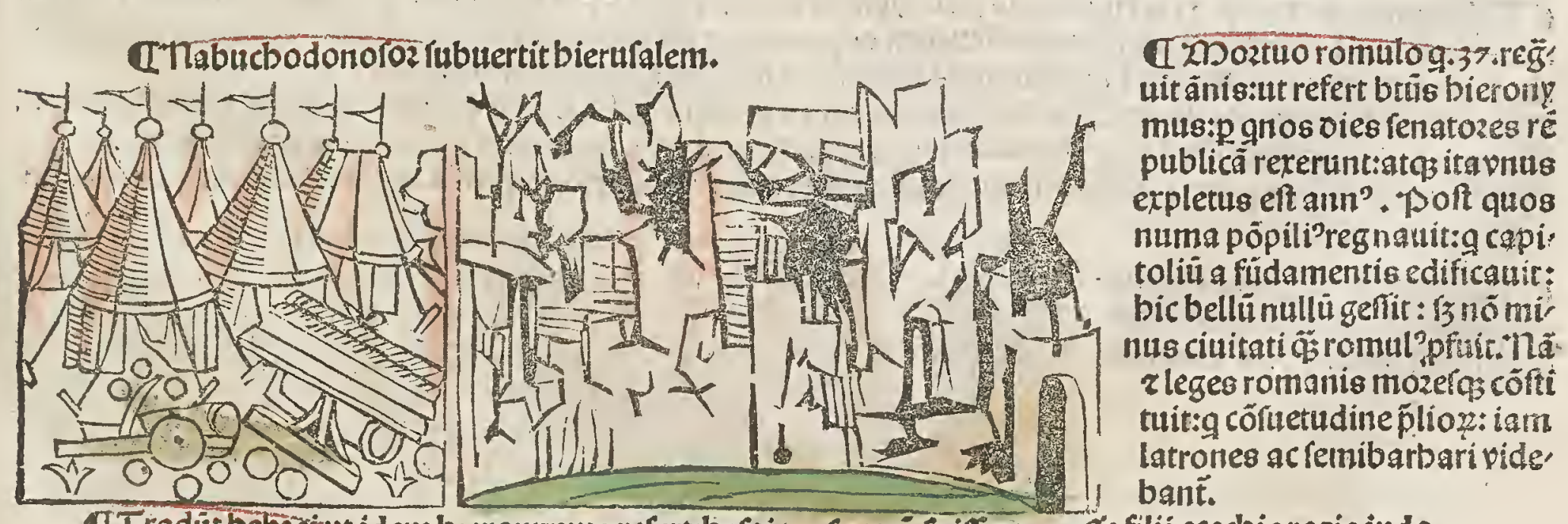

QI radút bebzetut idem bıeronynus refert:befaiam focerü fuiffe manafle filij eçecbie regis iuda. 


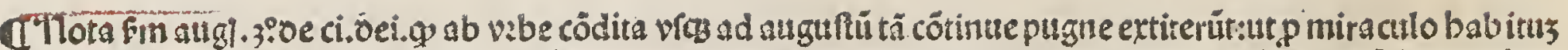

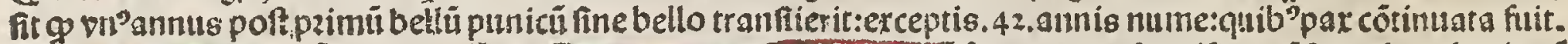

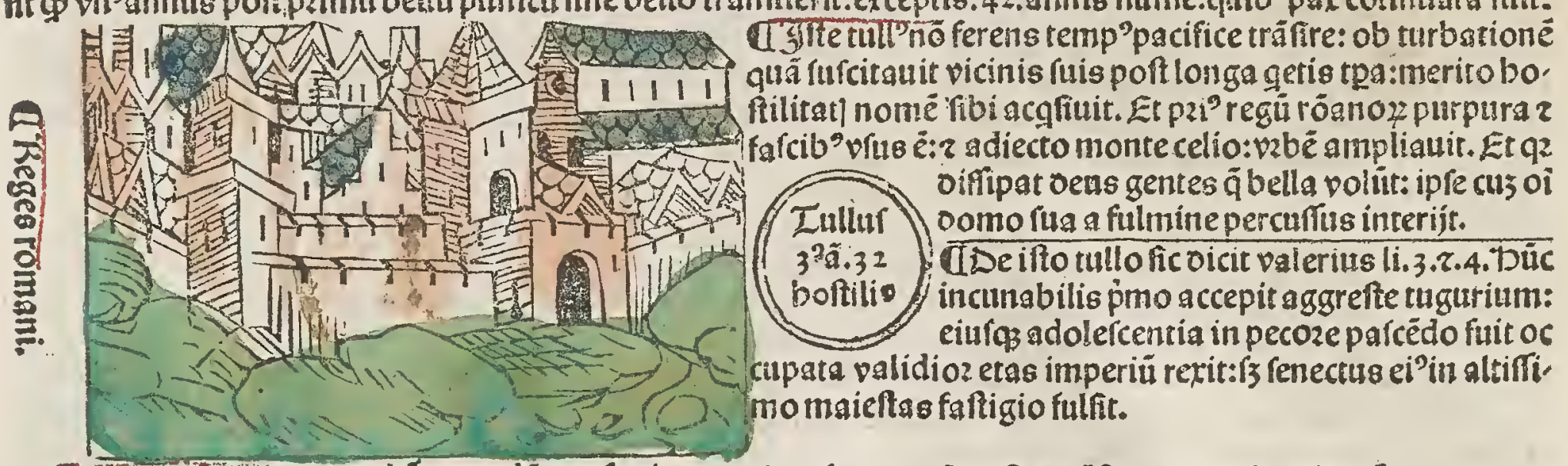

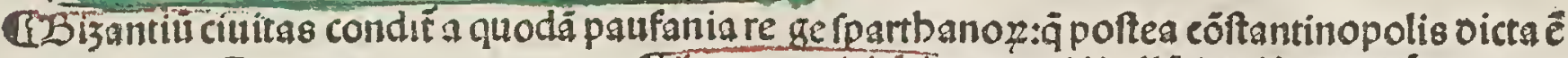

Kegesba
bylonic. $\left(\begin{array}{l}\text { Thabu } \\ \text { bodo } \\ \text { nojo?. }\end{array}\right)$

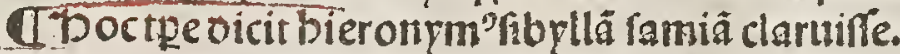

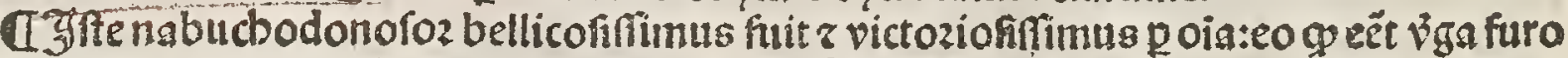
ris oñi ut puniret petã populoz nuiltozii. Dic p̉mo erat rex babplonie:z poftea obtinuit

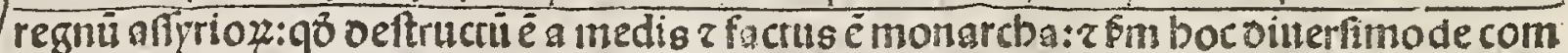

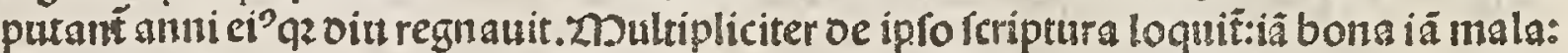

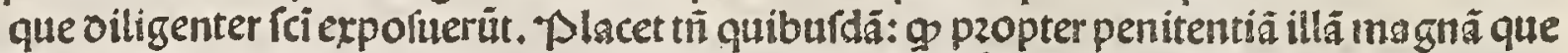

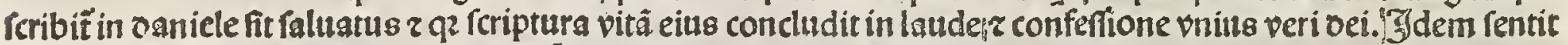

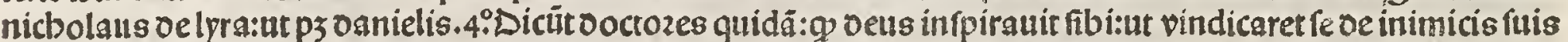

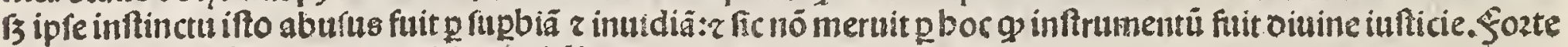
oe omnibus poft penituit:meritis oanielis.

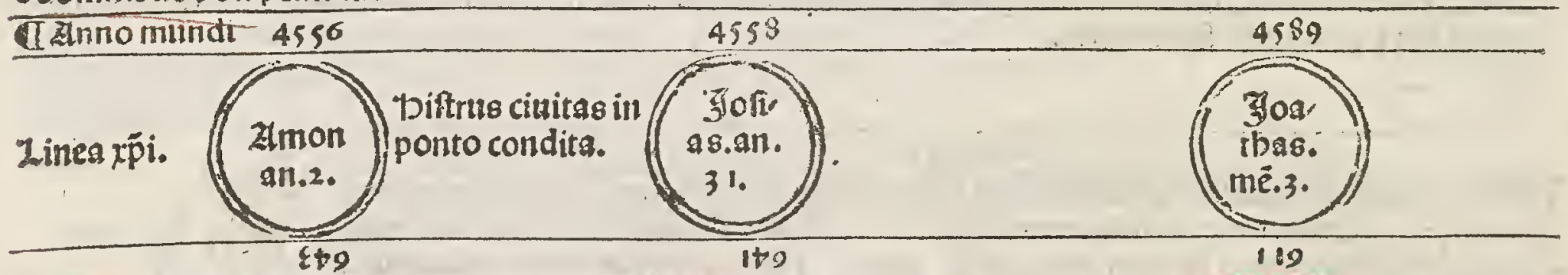

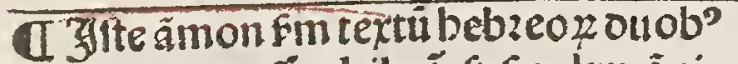

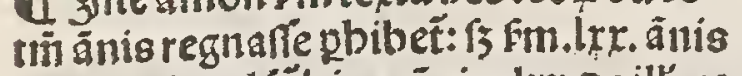
12.z ita fupplét bic.x.äni g.lxr.oe ill'. 13. o.fine rege. Et fm boc aptåde fút bifto rie alie ä cöiter fequüt.lxx. \bicidez rer fecitmalú cozas ono: 2 pcurfus a fer Tuis:finte penitentis obijt.

Ipontifices. $\left(\begin{array}{l}\text { Açari. } \\ \text { asfi.el } \\ \text { cbie. }\end{array}\right)$

G'Glte iofise optim? filins oe puerfo pie grä fin gulari p̈uentus adbuc in pueritia regfitut orim:z vfø̈ finë preuerauit lau

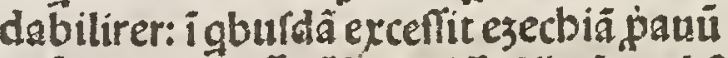

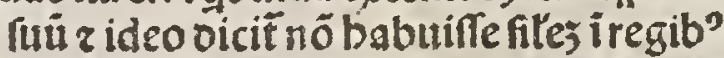
inda. Eius religióẫ vitã: 2 opa Yeã pluri ma:vide.4.regl.22.2.24.2.2.palipo.34. r.35.

CSopbonidspropbetat oeftructionë bientralë z reedificationem. Colda propbetiffa vroz fellum pzopbetat iofie regi $r \bar{c}$.

(13) moztép prio côftitut? fuit rex in biertm: $\{3$ qa nô fuit fecu ttrg exemplum piipatris fui iofie : ideo pbarao necbao cepit eli zourit eamin egy" ptum:t1t p3.4.regî.23.

s plen"opibus bonis z propbetie fpü clarus:pzopbetauit nãqs de veftru.

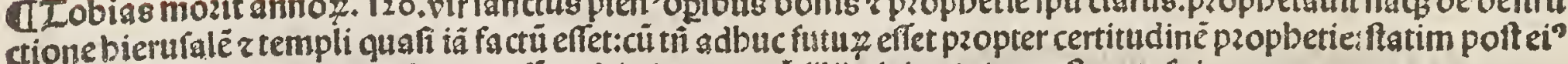
moztem $\forall$ roz eitus moztua eft: $z$ egreffo tobia iunioze cu filijs fuis ninitue oeftucta fuit.

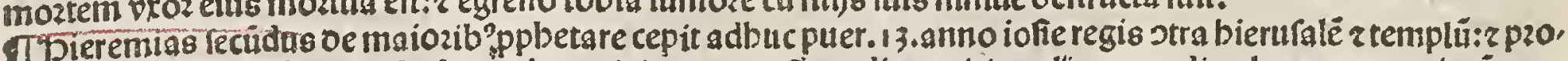
pbetauit annis.40. pter illıd qo pzopbetauit in egfpto. Brandis ouritia ppli: $r$ grandis plaga que punit eü.

वbieremtas futt to genere facerdotü qui babitabant contra feptentrioné in vico anatbotb: qui tertio miliario oiftatab bieruralem.

CTinitie oeftruit pregémedoz z regnu affyriozpenitusceflauit: ut putixerär naumpplisa z tobias.

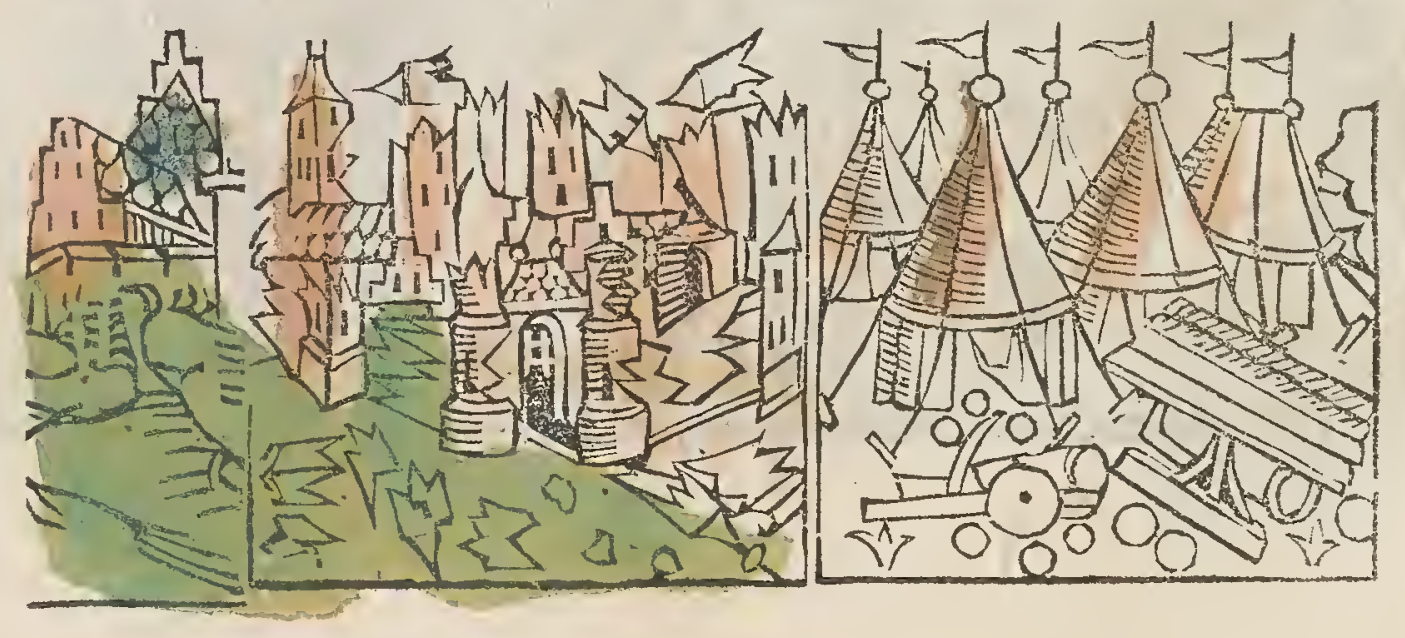




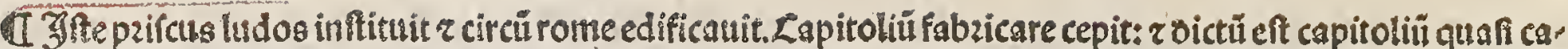
put folì:q2 in fundamento intentui fuit caput fine co:pe:quafi ppbetia futuri:qz ibi poftea fenatus refedir:quafi vnī caput rotills ozbis:z tftepsimus triüpbans:romam intrauit. Ip fo etiä regnante epiclaurtı condita eft:que poltea ouracbiú eft noiata.

Irieges romani.

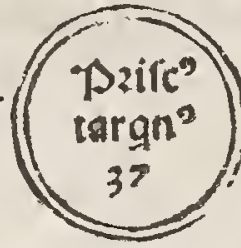

1. Âftyages rex medoxfonicã babuit filiã: quã cuidam militi piebeio tradidit: neer ea nobilf fili? nalcerétppt cảm quã magifter recitat:ne.r.pellerẽ̃ a regno a nepor te fuo:ficut p̃ direrăt fibi côiectozes:z qó verebat ei ac' cidit:nã ex ea nat'eft cyrus:g ipfú fupauit.

aร) fuit:bic bortum g furpenfilis oicit marimis expéfisvro, ri fue fabzicanit: $r$ multa magnalia pegit:ita ut berculë tranifendiffe actüi magnitudine r foztitudine memozeț: roe manubijs boftiütéplü belis magnifice oecozauit.

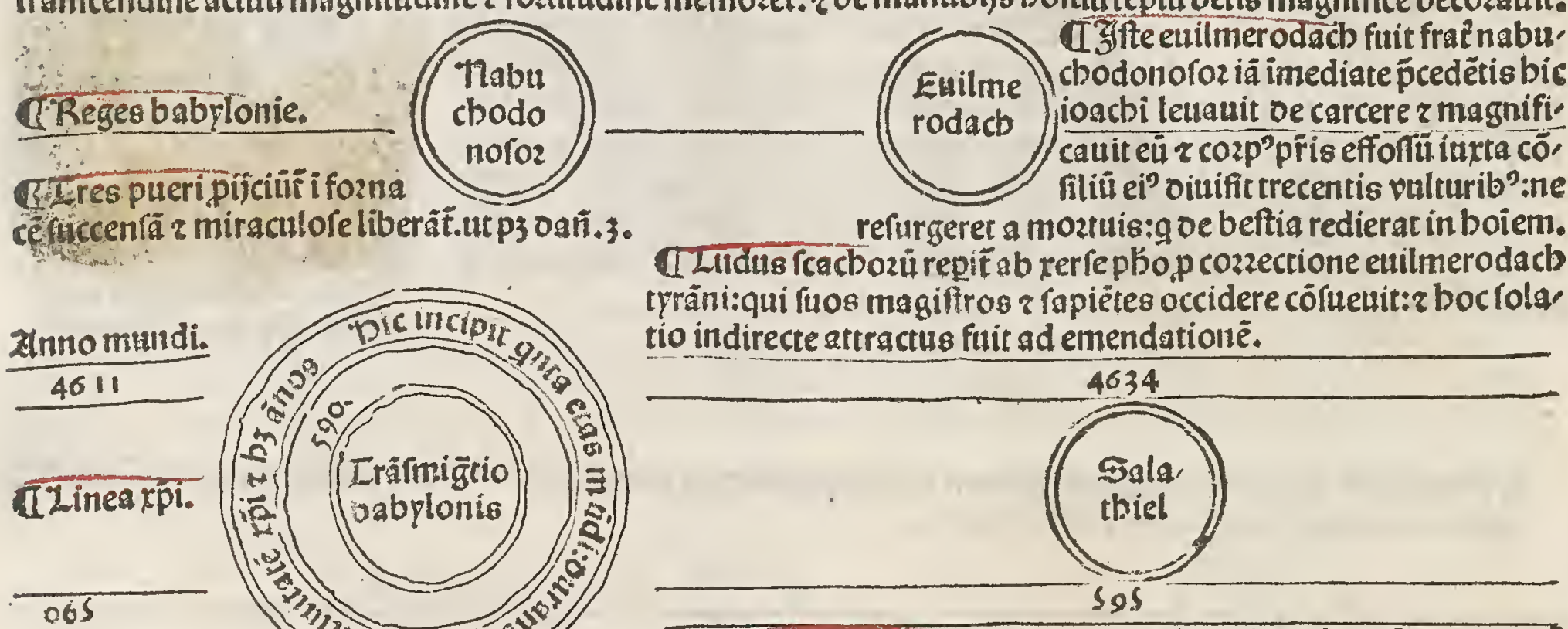

06

II द⿱乛龰te falatbicl erat filius ieconie regis inde qué genuit polt tranfmigrationē babrilonis ut euangelifta mattbe? oicit.

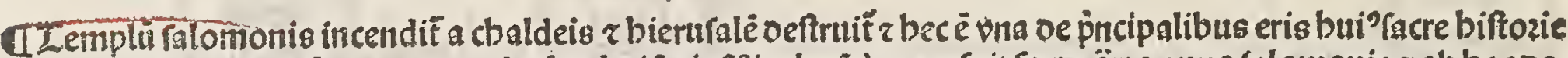

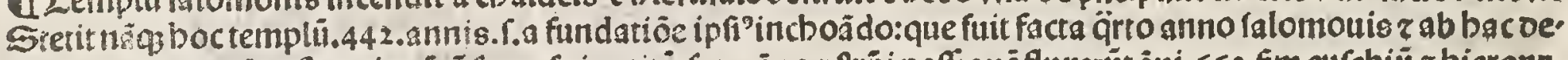

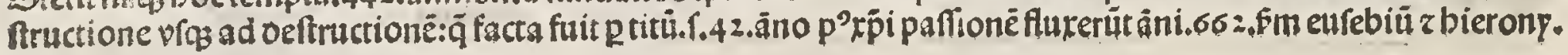

\section{apontifices.}

Cbieremias in egpptopp batatir z regib"egpti p̃dixit; coz idola fubuerterent cum virgo pareret: z exboc fa

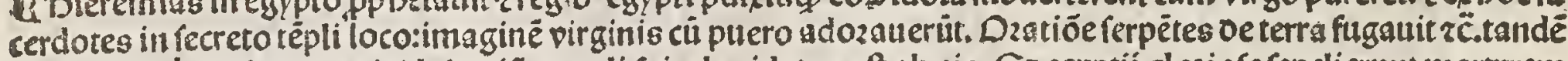
celans p populo increpauit idolatriä popali fui:s lapidatus eft ab eis. Sz eggptij gloziofe fepelierunt martyrem fanctīin fepulcbzis regü:ppter beneficia fua.

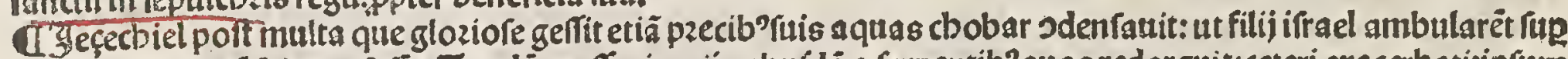
eas:cbaldei autếfubmerfi füt. Iandê pcuffis impijs gbufdà a ferpentib"quos redarguit:ceteri exacerbatisipfum

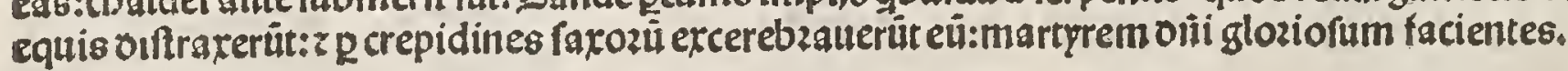

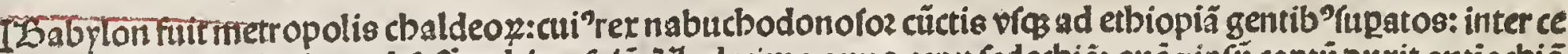

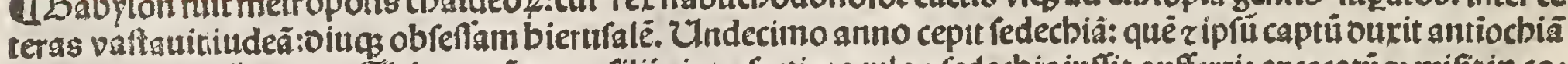

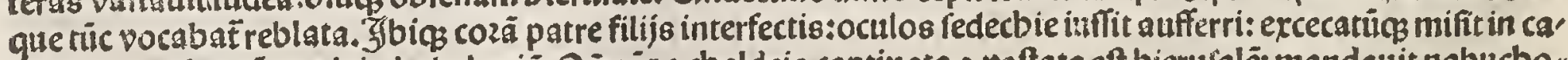

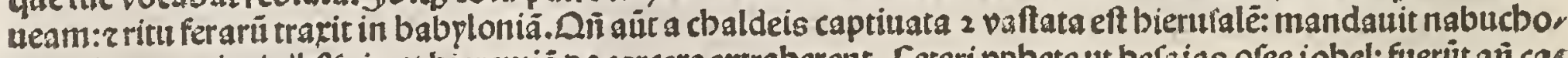
donofoz rex pzincipib'fuis ut bieremiä oe carcere extraberent. Leterippbete ut befaigs ofee iobel: fuerüt añ ca

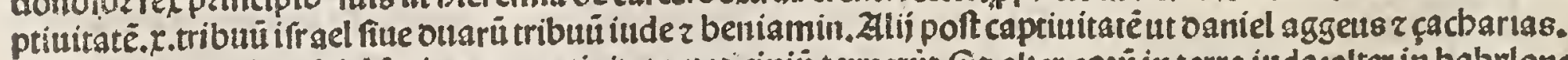

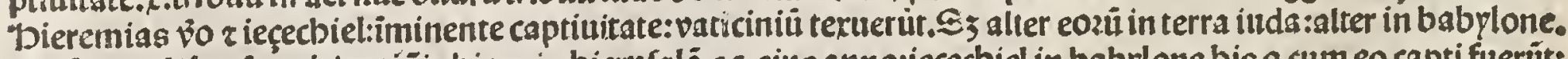

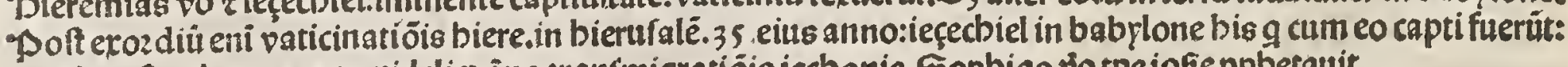
cro?fus eft ppbetare gnto videliç âno tranimigratiöis iecbonie. Sopbias bo tpe iofieppbetauit. 


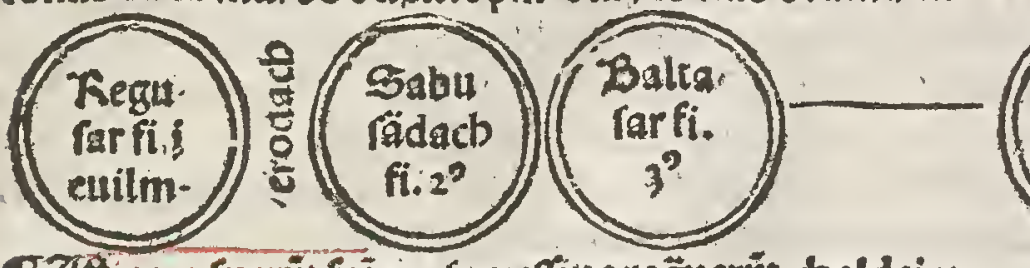

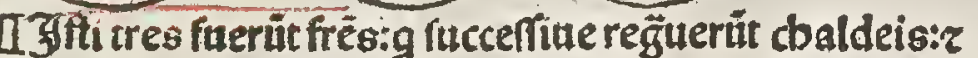

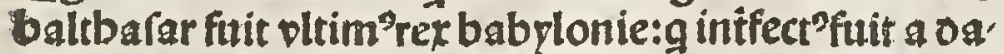
rio z çro:nö en i babebat filiú: z fozoz darij fuit mater ei"iō poscupanit regnū oari" củ adiutozio cyrinec'au, diut orì ipfú:92 vafa feã indigne tractauit.ut p5 0 añ. 5.

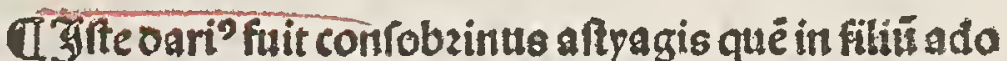
ptauit:qz non babuit nifi vnicâ filiä $r$ oedit ci regnú $q 2$ çrus otra el pugnauit:z tin äbo victi fút a çro: \{z tan nepotes eos tractauit benigne: q2 ano.f.aftyagi regnus bircoz cöceffit:z oario medozi.

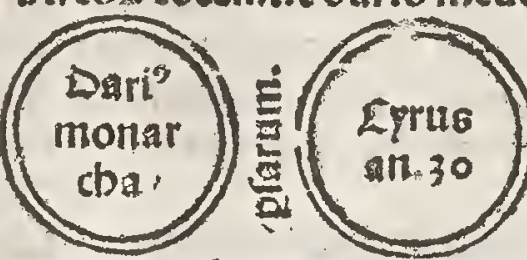

I3fectrus rexperfartum fuit pmo.z oepoft tranftu: it monarcbiã ad pras:bic ex pte patris plebe" ftit: $\sqrt{5}$ mater ei"erat filia regl afty agis.De ifto ppbetanic efaias:t babplonem vicit: balthafar iuterfecit: oaniclē magnificautit: $z$ ifrael remifist

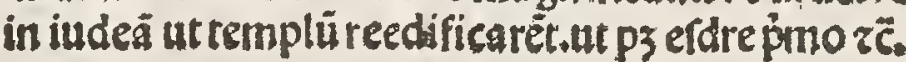

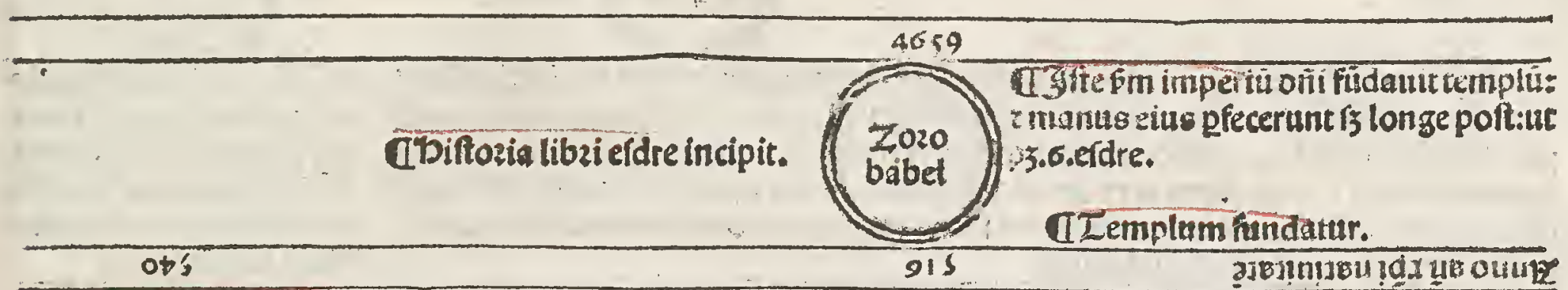

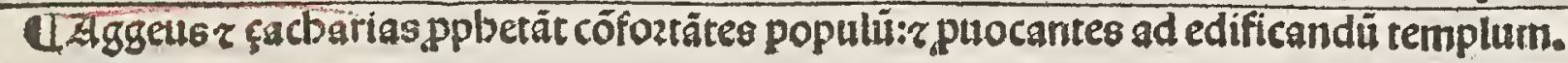

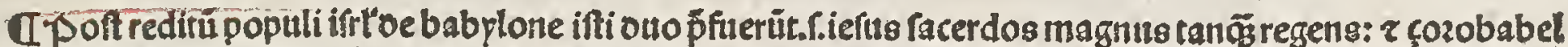

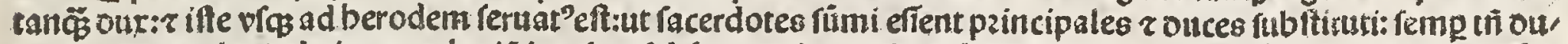
ces erant oe tribu iuda iuxta ppbetiä ia cob:z fub boc regimnne facerdotali optimo:nö legiét populıs oechnafre veritare fidei ficut ante: $q 2$ tpe udicã 2 regum repius gd idolatriam cozait. Et nota $q$ indei ifti qui bicredierü $z$ poftea oifperfi füt in omné terrã : iuxtappbetiã onuid:oifpge illos pral. 58 . fuerüt oés oe tribu iuda:beniamin: $z$ leni. 2 pauci oe oecem tribub": 9 sufugientes inr

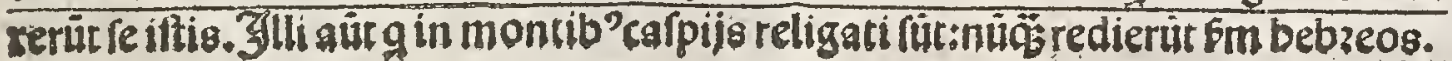

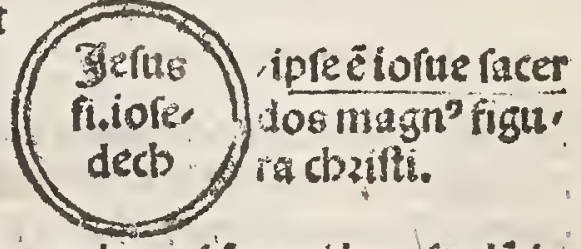

I Eldras facerdos oe firpe garon claret fitate vite z fopiētia ciu'grä di indufiria zlaboze:totus iudaic'ftat'in mutius refor, matus fuit.

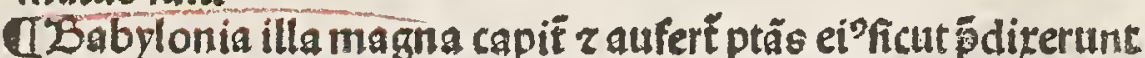
bet cai etiã opg oetis miraculis glicfis sppzo baut: $x$ iple rcripturã mp̣ftica i parietelegit $r$ in terpzetatus eft. ppbete fci. bec fuit pona $z$ maxima cinitas totiue ozbis oe qua incredibilia fcripta fut: $z$ bec tanta vna nocte oefe

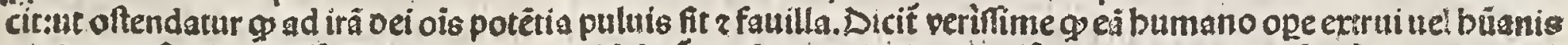
viribus oeftrui potuiffe pene incredibile videbat́: onde grande fpectaculü euidenfG exemplü müdus baberet fu infozmari portet feu etiam vellet.

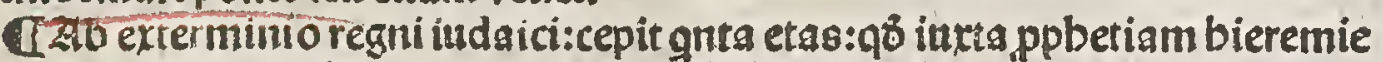

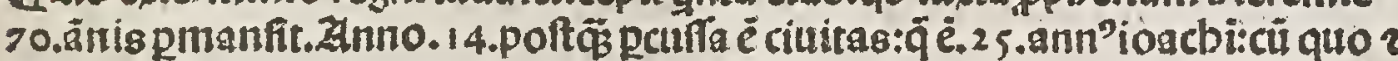

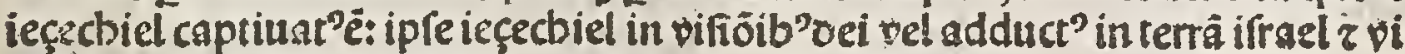
dit renouationc ciutratis ac templi:ceremoniarügs eits.

UL Confentit tofepb?in libzo antigtatü.x.gpaftata iudea a cbaldeis:nö ut af IYrij in famariā mifere colonos: 13 oefertant reliquere terrä:0onec poft ånos 70 .in ea redire iudei:in quo libzo fcribit templür bierufalè z oèm iudeam. Et nurfü enumerãdo reges babplonis:fi thi ille fic ieripfit:z non coder fallit men,

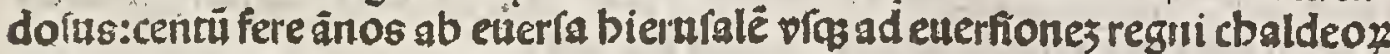
facit colligi: Scribés poft nabutb.g iuxta tefte f́criptura poft euerfü biernia. lem äno8.25. 2 poft frater ei regnauit an. 19.ragufar.40.fabufardacb men. - baltbarar. 17.quo tpe a crro z oario babplon capta eft. Eurebi'.30.an. oi

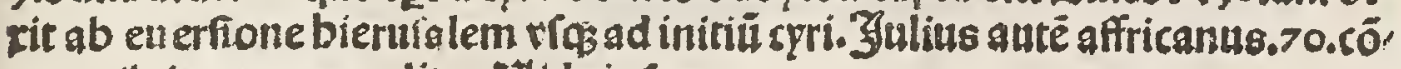
putat. Dieronyun a aliter.Z̈lide ipros.

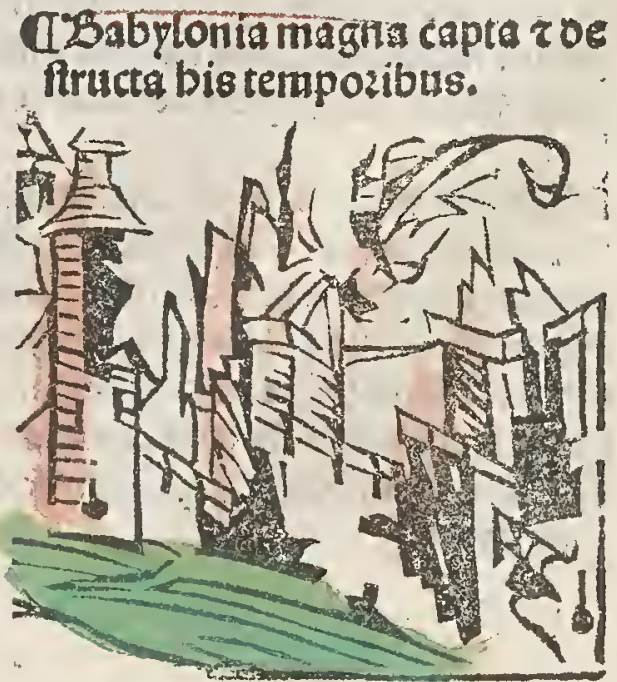




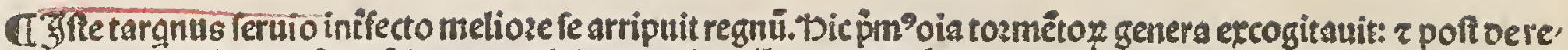

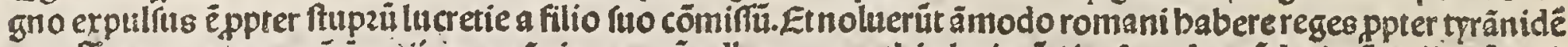

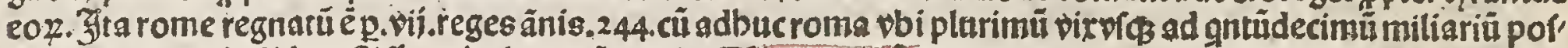

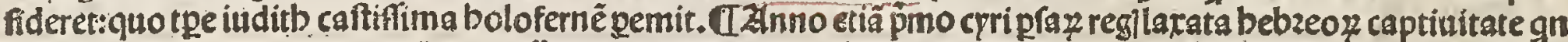

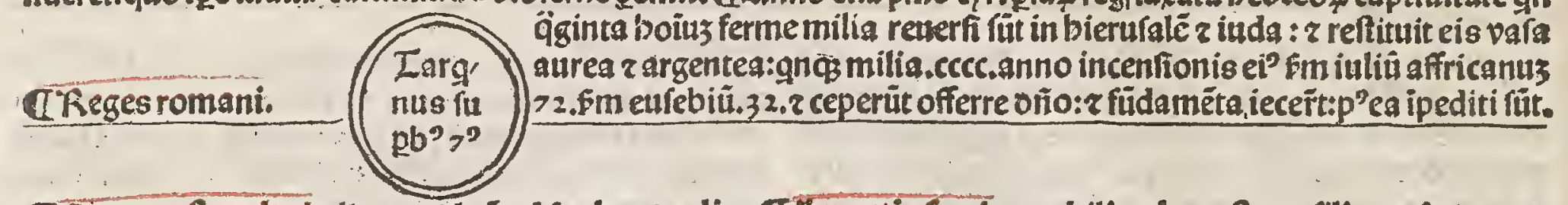
CEytıs poft multa bella tandé cü ad feytbas oecli naffet:a regina tbamiris capitz cui toto exercitu fino ad oncêtra mílía occiditi. Eaput ei précífú:in ptrem bumano fanguine plenü pzoiecir oicés. Satia te fä guine Quem fitifti.

TSibplla belleipontina be agrotroiano nata bis vicit fuifetpib?:zppbetauitíc oe xpo. Zlefms nafcetur oe cafta.

Reges perfari. iunioze violenter oppzefla:feipfam fulte gladio interemit Decin exêplì caftitatis allegari folk: \{z nó excriat ab bo. micidio:ut oicitaug? p.pmo oe ciutitateoei.

Q5abplonia noua in egppto condiťa cambife:qui tottm illud obtinuit regnü: z oeuicit eggptum.

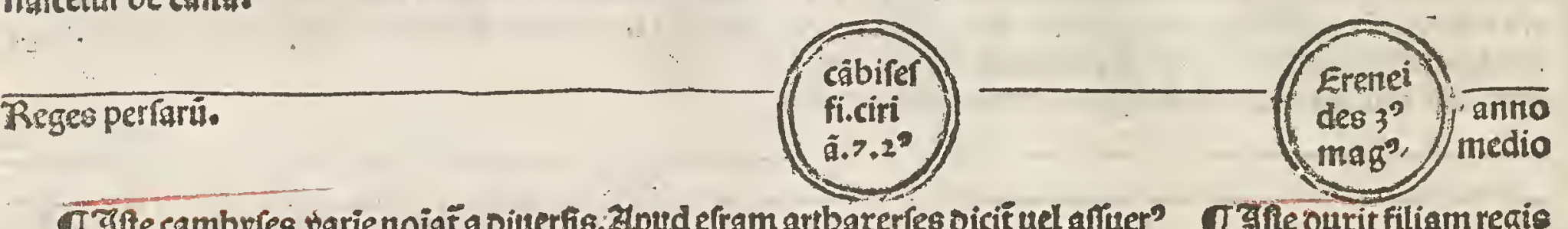

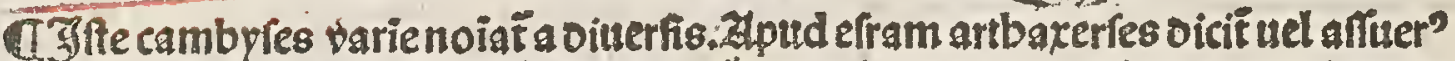
in biftozia inditb:que fub eo facta fuit vocat nabucbodonofoz. Dic potenter interdi, xit ne bierufalé gut templü reedificareñ É Et pater cius tantümodo peepit: ne ciuttas. extrueret: $z$ etiâ tunc p̉ncipes cpro ignozante:mpediuerút opus oómus oñi."bic quê, dam iniquũ iudicé viuu excoziari fecit:z filiū fup paternas cutem federe iufit:ut boc timoze fechs vitaretsz recte iudicaret.

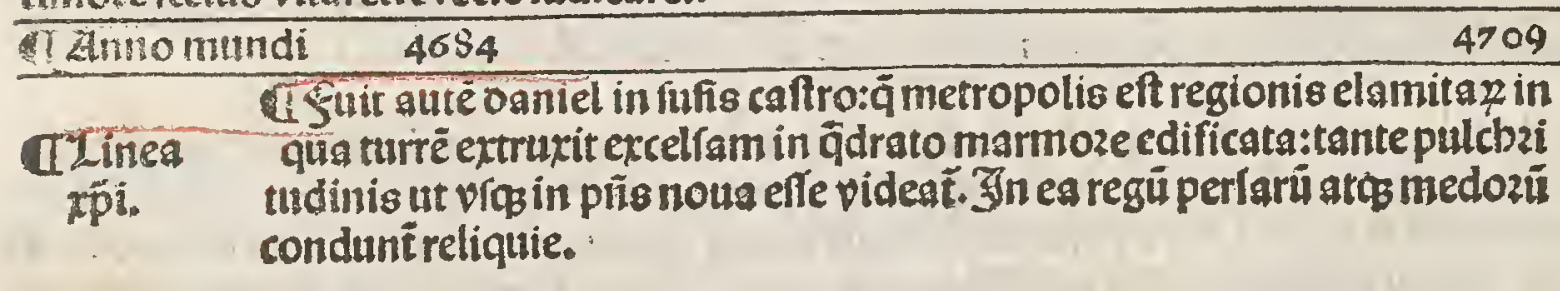
in vrozé: $z$ oiu poft mozi turop ätaptes filia cambi fis fuit bis ouob' fuccelfi ue in jillgem fociata $5 \mathrm{~m}$ biero.fun onin.li.3:
TArfarad poft motê çri p vim obtinuit regnủ medozũ:z edifica

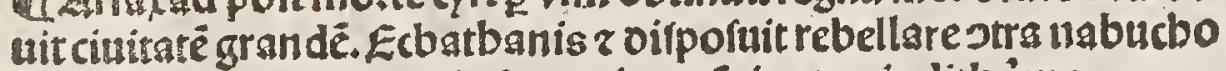
donofoz.i.cambyten: $r$ tĩ ab co victus fuit.ut $p 3$ iuditb p̉mo.
IDolofernes pzinceps militienabucb.cä bpfis : multas terras oño fuo fubiugant: 2 tädẻ venit ad betbuliä: zibi a iuditb mulie re interficiť:utp 3 iuditb, $2 . z_{1}, 3$.
Apontifices.

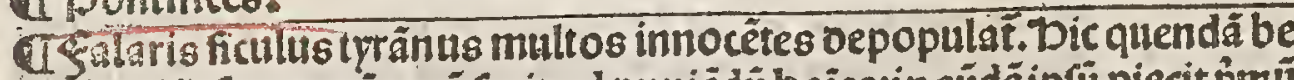

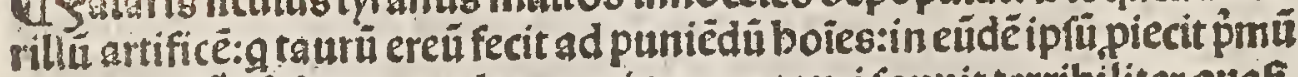
ut experiret qo fecerar: $z$ clamoz eitus 2 os tauri fonuit terribiliter quafi boatus beflie: $z$ fic tỵrãnus iniuftus: inuenit aliqñ quem iufte puniret.

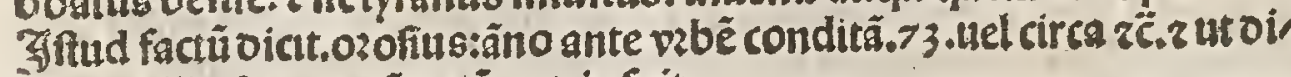
cittr:ficilia femptyrănozủ nutrix fuit.

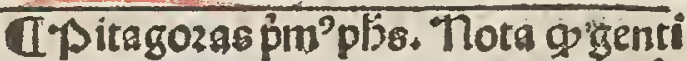
liī fapia qu totaliter oe creaturis fuit $\hat{p}$. mo incepit a oijs:qũ adbuctga grofla fuerüt: q2 tüc $q$ pauloplus ceteris f́cies bät:a populo ridioij putabant. poft bec creutit paudētia: z tunc tbeologi ve nerür. Ip fítút poete antigozes: qui oe

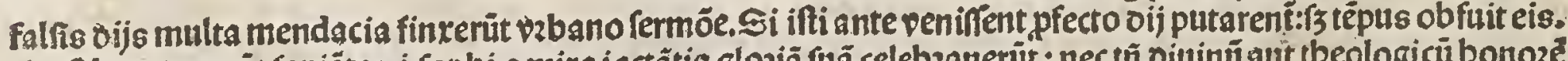

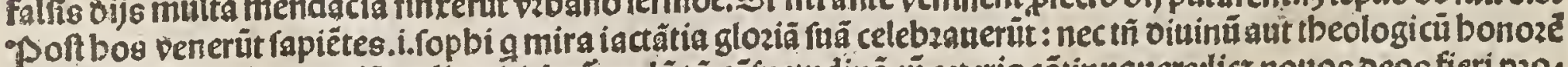

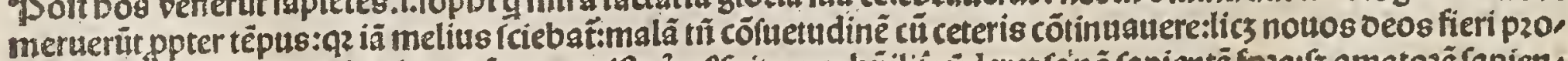

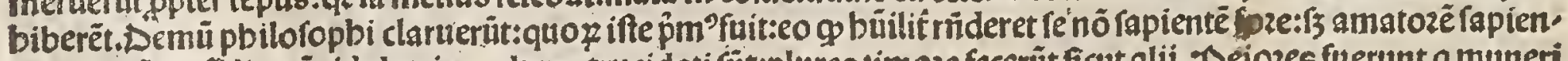

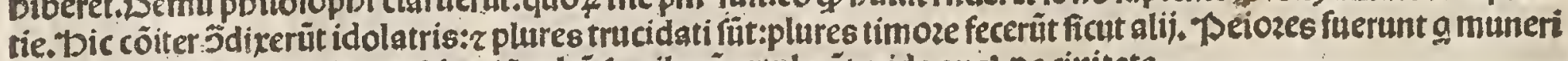

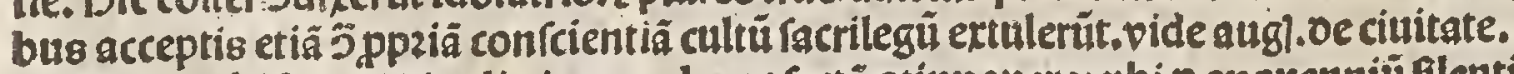

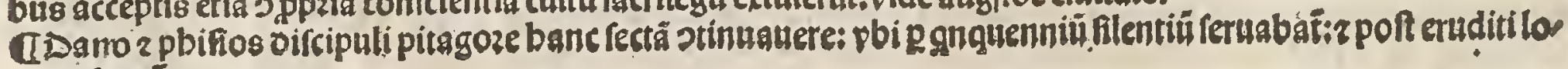
quebant. 


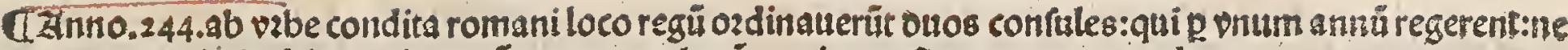
er moza tempozis in fupbiam erigerent: $z$ ut onus alterú cozzigeret fi erraret aut excederet.

a Zुfte oarius fuit on'oe.7.magis:z fubtilit regnũ acgfiuit. bicrecupauit regno pfapar. ryrios:z babplonia:afiâ:macedoniã pdomu it. Lüqs regis ferthaz filiä in vtozé oefidera ret:zei oare nollet:ob boc cü.700.milibus 5 Tepibas venit:non verit? p pni"bois libidine tot milia virozü moztis piculo exponere: $₫{ }^{6}$ vticg incautü $r$ crudeleziniuftiflimi fuit: turpit fugat’ .So.milia amifit: tandē cū refí duris a paucl atbeniếfib ${ }^{D}$ :puta ondecî milib? rupat? 200. milia ṕarú amifit:volens aü fe p'fugã vindicare:î́pro apparata cócidit. Et fm quordaz bona fpes eft oe ip fo: q2 babuit fidē vni ${ }^{9}$ veri oei:cui templü $\tau$ lacrificia fieri ṕcepit rč. vide lyram fun.6.ca:erdre.

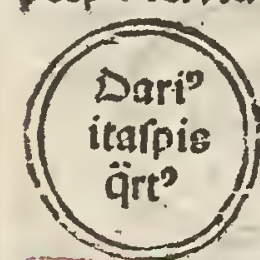

QTho 9 f 3 marm ifte oari? inftinctu çozobabel: iuffit re fumi op' oom' oci:pripiens p̉ncipib’fuis:nealiạ mōim pedirēt:你 ituarent: vide etiä édre. 5.7.6. De bac era ambiguni eft ppter oiuerfitatẻ ooctozum. Iemplī pficitan 110 $>0$ arit

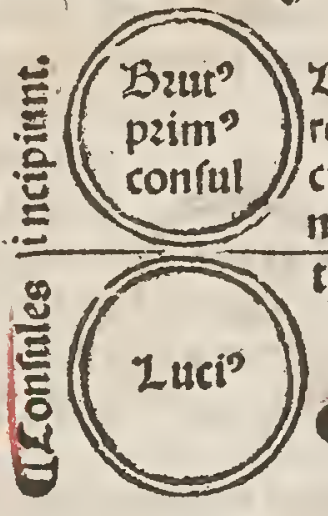

moutauit romapin cipatü:red non enafit tyranuide

Dicta' tozno,

\section{d Inte oictatoz creatus} fuit ut confules pzeiret potentia cötra inimicos

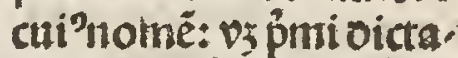
tozis fuit Largus. officij oigniozis.

It boc tempore facts eft rome oiffenfio plebis a renatu.

Tiglte reries milti.

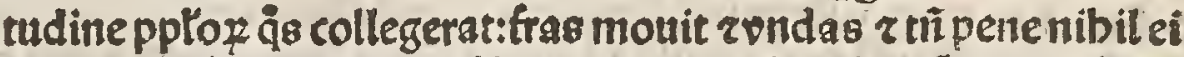
ṕpe fucceffit:amifít gppe ibzetri tpe oeciénonies cêtena milia vi

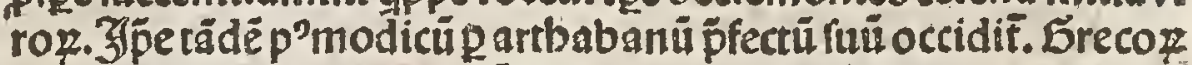
aut nuer"q victozes extiteruit:longe maioz erat occifo.$D$ tpa 00 lenda: vide ozofiu. CI Tarrat ent butus bieronym? in eplis fuis: 9 rerfes cū oé fublimi loco inumerabilë exercitu vidiffet: fleutife oicit: $\operatorname{co} 9 \mathrm{p}^{\mathrm{c}} \mathrm{centu}$ annos:

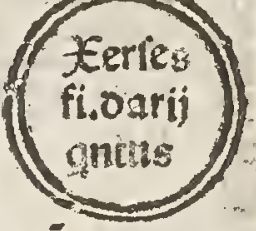
mullus eozü fuperfaturus effet.

Leonida rexpartanoz cí quattuoz milib'boiu5.700, milia praz pentẹtrucidanit:mirabile oictu:ait 'uif pzandete bic ta 1 ö apud inferos cenaturi: $r$ ita facti eft:qz ex fati. gatione ceciderüt fung moztuos; $z$ moztui funt cü illis pariter.

4734

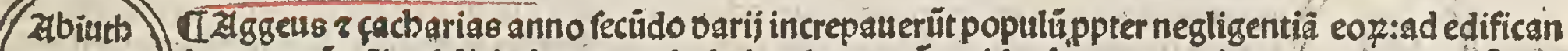
f:çozo. dum oomü onii: $z$ folicitabant çozobabel: ut loquerét regi fup boc:z annuit rex $z$ zccenfus eft coz babel. populi ut edificarent templü:ut p̧ efdre. $\sigma$.

Sob

196

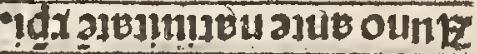

IDebocz lequentib?plag ad iofepb nibil babet in feripturis inifi $q$ a mattbeo nume rät:rideo nec tempus eop oebite fciri pö́

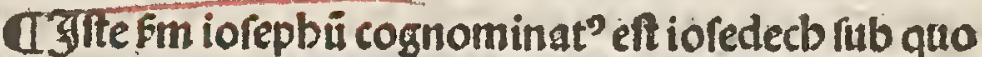
ciuitas bierufalé extructa eft: ut bicit etian Eufebius s bocidem psneemic.12.

$$
\text { उoa }
$$

cblm

fi.iefu

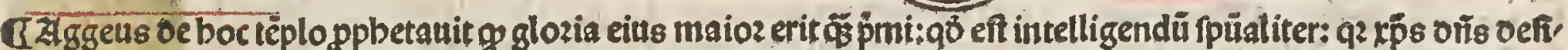

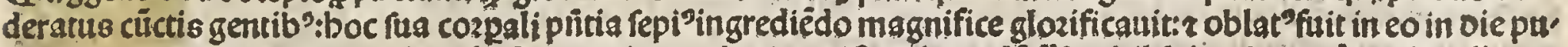
rificationis marie:aliogn nö poffet ftare veritas pp betie:q2 iftud fecundü äf nibil fuic refpectu pmi. Zlug? bic fu mit foztifimü argumenti 5 indeos og bec auctozitas neceflarijfime intelliga oe ecclefia : que eft oomus oei ex:

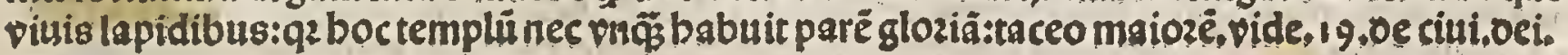

\begin{abstract}
ITis quog tpib"pptegozas pbis claruit:qui famo otiun dus:crotone oeguit. Houifi me metapontiu adijt:ibiqle pultuseft.
\end{abstract}

[isemochzitus phus leiphí exceanit:z de oiuite fe pauperē fecit ob amozē fapiētie. đzinaragozas:bic babuit fucceffozę:g oice bat arcbelaus:magifter focratis.

IDeraclitus cerebzolus.

UDeltilius tragediap foriptoz.

IISententias bo\% flozidas: vide in ipectulo

biftoriali vincentij. asindaruspoeta.

Tsopbocles poeta.

IEurpedes.

UDDerodatus biftozia zx fripto? clarueruit tpexerfis. USocratee plowenalci, 
CQuintius repertus in rure:ab aratro fumpt'eft: in oictatose

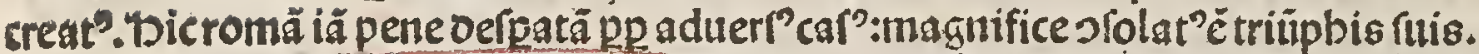

ITergini? filiã ppziä gladio tranffigit:ne feruituti traderet.zob. boctribuni infignia oeponere cogunt. vide titüliuiü oe cöditione vzbis li.3.

CIpeboy sfillifames

zgrauis peftilétia româ. A̧abiołgliofifí

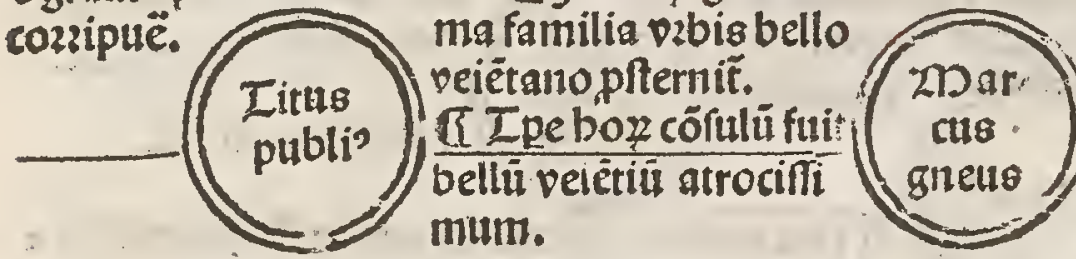
GLex.xil.tabulaz rōe inftituta e. Decéeni ta bule a grecis oelate rüt gboue addite füt a ro. måis:äno.300.ab vibe cōdita. Zplecéän'midi 4784 ?
CDsinferril tmedio vabis bozzibilit apparuir : oe cui" exbalatióe plures interfecti fuerüt: bbi cú fe marcus cur tius armat" pieciffet : cefla uitplaga ipiozú oemonú.

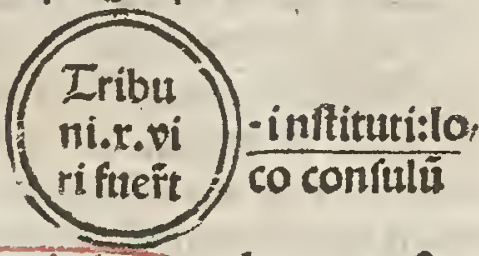

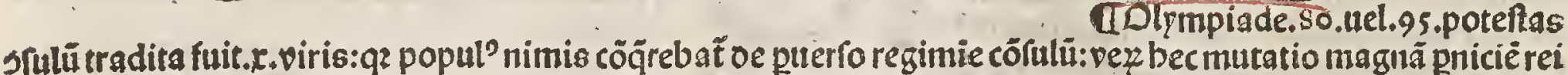

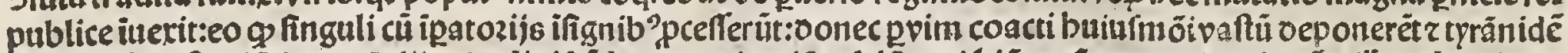

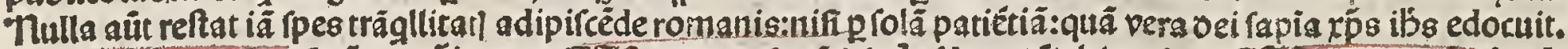

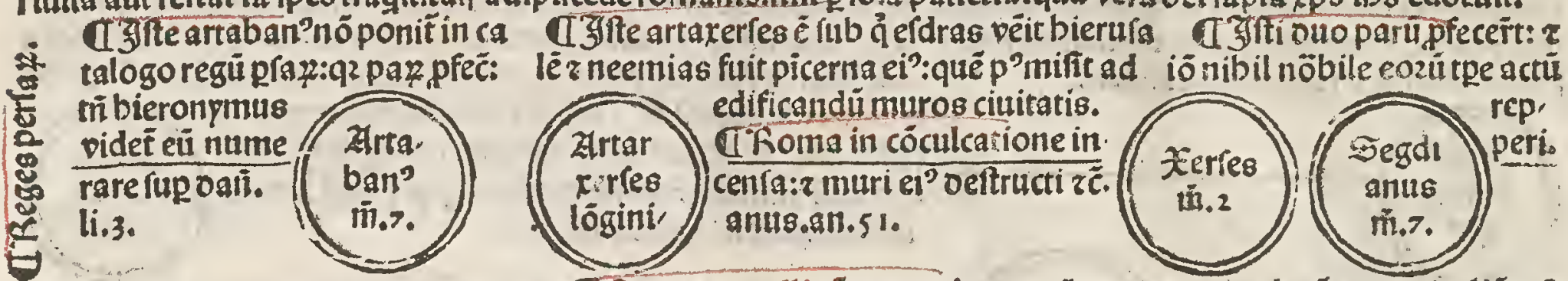

a SEnones galli cü romanis pugnät:z capta eir vzbs ṕter capitoliü:qż

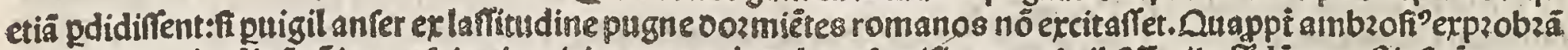

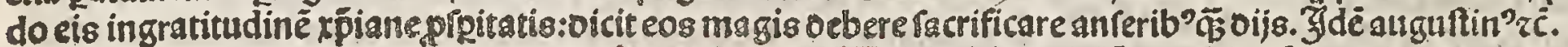

ATsebdomade on ielis bicincipiüt. De bis eft grandis altercatio inter

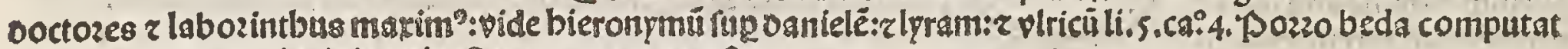
$\mathrm{p}$ annos ltuares: $r$ incipit a vigefimo anno artarerfis.

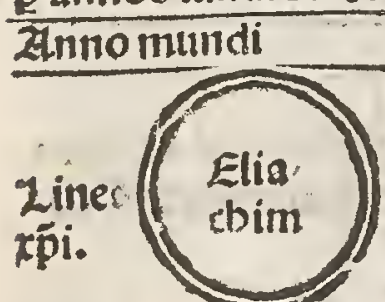
4759 4784

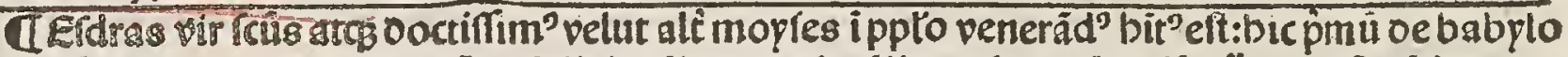

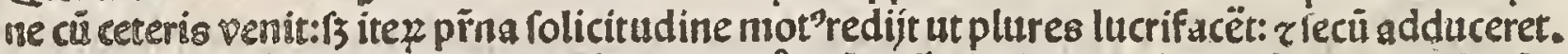

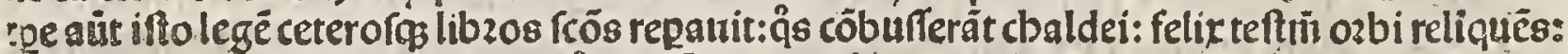

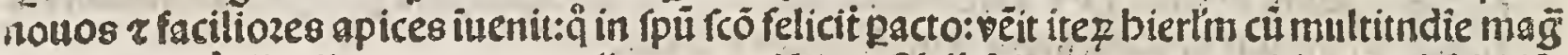

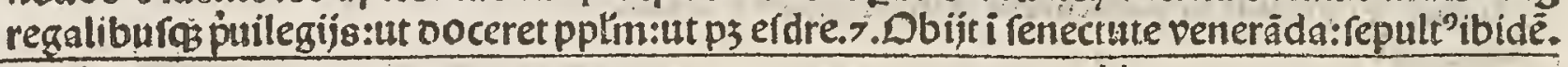
Sit ott

a Debocnibil babet in fcripturis:nifi mattbei pino. đThalacbias ppbeta claret:fic oict?.i.angel'ppi optimã vitả z oecozü arpectü. zlitutt: oze eodë quo ppbetauerat:angel'onii apparens eadem iterabat.

CEmpedocles.

IT Dermenides:phinotabiles maxime i mozalib":claruerüt. đSocrates pbs:bs bic magnas laudis p̈rogatiuss:quẽẽ brüs bieronrm'fibi in exemplä pponit $z$ alijb. fuit eni mire patiētie: $\tau$

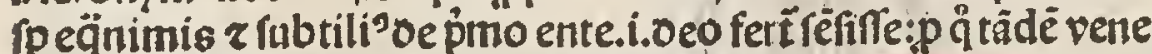
nü in carcere bibit. Dlato oifcipul'ei?. U. Sictagozas:çeno.z plures alii fuerüt tüe nóiati viri quo z ls bozes pmanferut. Qt'ppocras. QTheemias vir benignif fim? ac oetuotió pcipunsoe fufis caftro adueniés: fuit pincerng artarerfis regis plarú. bic vigefimo anno ei iuxts oei voluntaté

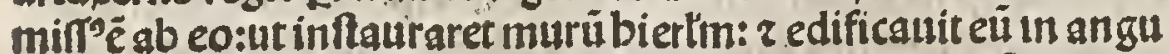
fta tpin:expleto aüt ope miraculofe igné rén repperertit:? muz

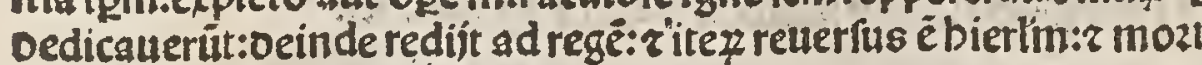
de ilibzo ei" 2 bic finit biftozia libzoz:g füt oe canone.

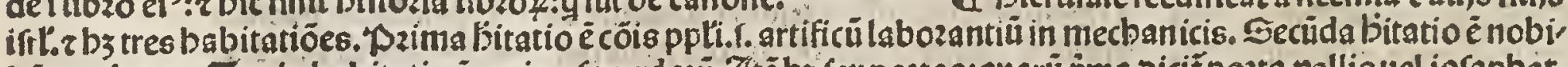

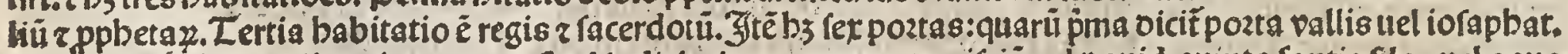
fecuda pozta fterglinij.tertia pozta vet’uel iudiciaria.quarta pozta píćiủ uel oauid.quinta fontis filos uel aqua rü.rexta gregis:uel pbatice pircine.

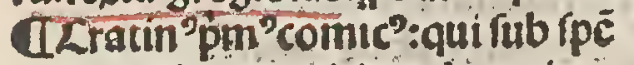
iocofitatis apte vitia redarguit.

Q Bella atbeniểiu famofiffimg quari fecuda troiana:circa bectrafuerüt: $z$ cófumpti funt miferabiliť: zin feruitutẽ redacti: quō perierunt qui oominabant populis:

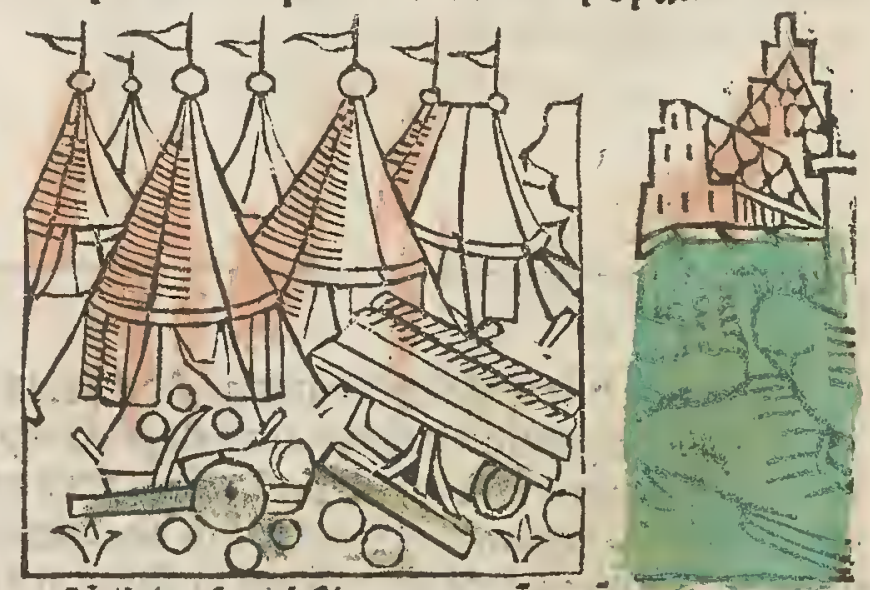

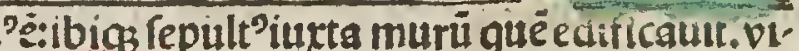
TEpicurus rozar.

Uarcbite taretin'ma d alcibiades focraticus.

IDiogenes aletâdro: gifter platonis clarer. GEudortis aftrologus. potêtioz $x$ oitioz fuit so gr quicgd oarepotuit contêpfit:quicgd auferre uel inferręnó expauit. 


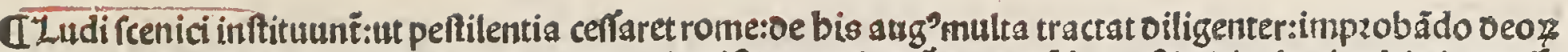
falfitaté qui talib) Iudis placari pofcebant:ita turpiter iftiexercebant:ut ne oü bonefti viri z femine bis intereffe nó vellent: \{s nec uel oe longe intueri. $D$ facrilegia oeoz: qb' nouella romano iz indoles ad tanta crimina pzauo trabebat exemplo:ita pzo oepelkenda tpali pefte cozpozü accerfitus eft ppetuus mozbus animarü.

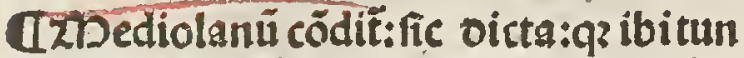
apparuit fus : ̄.pmedia pte portabat la' näp pilis bocmó omnia gloziór mundi apartis r pene vilib?oztübrit: zi idiprü tandem renertunt.

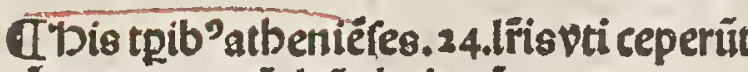
cũ antea. 16.trì. Lräs baberēt.

đZfte artateries cognominat'ë mine, nô oarij z parißatbidis fi.fic appellat? a 7.0.96 bebzeis aüt affuerus oictus.

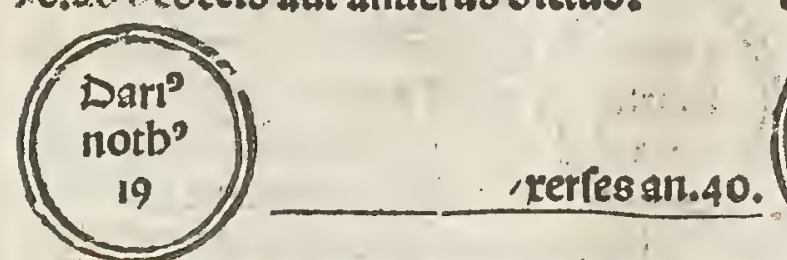

đIfftegraue manümifit วิatbenienfes. viì tandé cötriti füt g fup̆mi fuerüt:iuxta mozé mutabilitat büane: Sub eo egppt? receffit a perfis.bic babuit frēm nois cy' rü bellicofiflimü. vide ozofiüli.z.

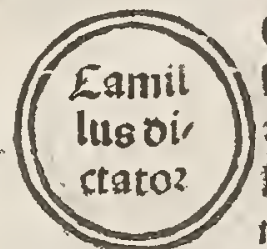

(1. Ffte campll' furi? o ict'extitit.g afflicte reipu.magni, fice fubuenit:expugnädo videls veniētes: $9 \mathrm{p} .10$. conti auos ãnos valderomanos attriuerät búctantüvirú po itea ingrata cituitas oănatuit. Dzofi? oicit bäcpictoziam magis vtilë ä nobilez fuiffe:q2 fine vllo oigno romane virtutis teitrimonio clädeftina obzeptiōe facta fuit. nec ob bäc ituiuriä oeftitic gn rediret iterü oe exilio: oenuo patriã oefendens. Et bic ma. gnü eft exemplü patientie xp̆ianis:Fm angl.

đIIte affiterns filius oarij: babuit fratrēnoie cyri: quëpoft moztem patris in bello fupatú occidit : qz nifi p letale bellü tibido oriandi neg' bat mitigari:cū tui tot terras poffideret $\$$ merito plur ä centū regibus fiffeciffent bominia e0\%. Dic p̉mo vafti reginä pulcberri

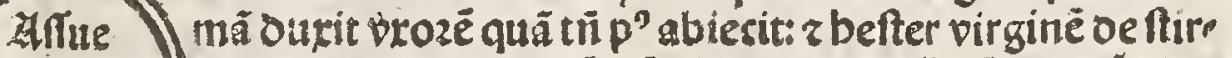
rus ol pebeniamin loco vafti fíp fit : 2 mardocbeú patruù eitus

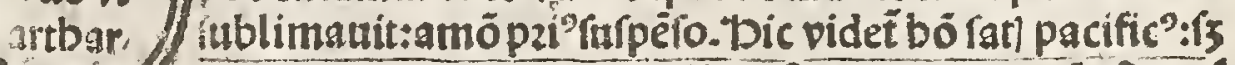
nimis luxuriofus: utpzin li. befterpzimo r. 2.ré. Sertur etia filios. 300.babuiffe:e quib' oarius quê in regé fublimauti: 2.40 .

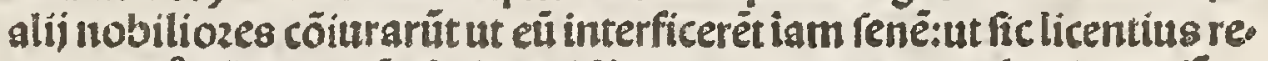
gnarent q̊ cöperto oẻs fecit occidi:qz q que go peccat q bec z punit.

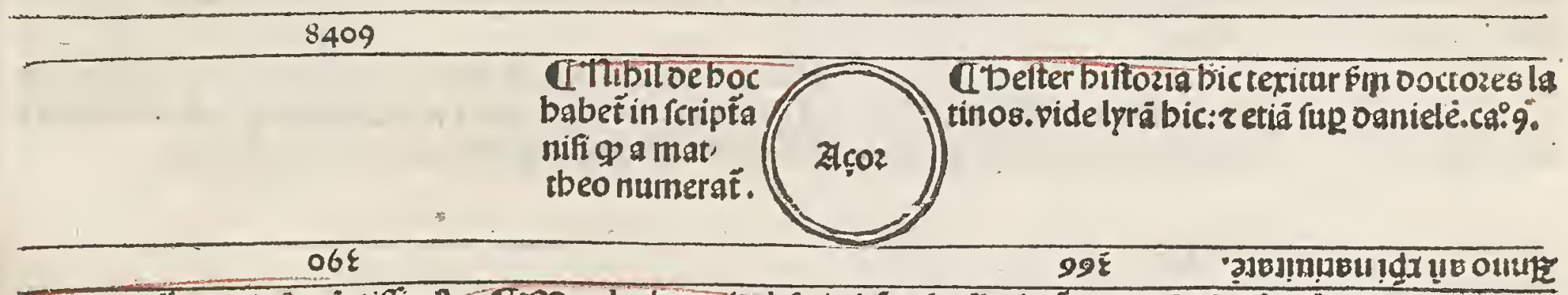

Toplato pbs diuin"noiatiflim? qué augl.extollit:q̆fi vltra oe oi uina feriptura aliquid fenferit. putationé latinoz:tpe eraltationis fue fuit annop̧.259. videlgram.

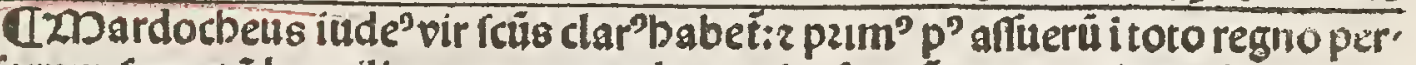

Zriftoteles vircipulus eius.

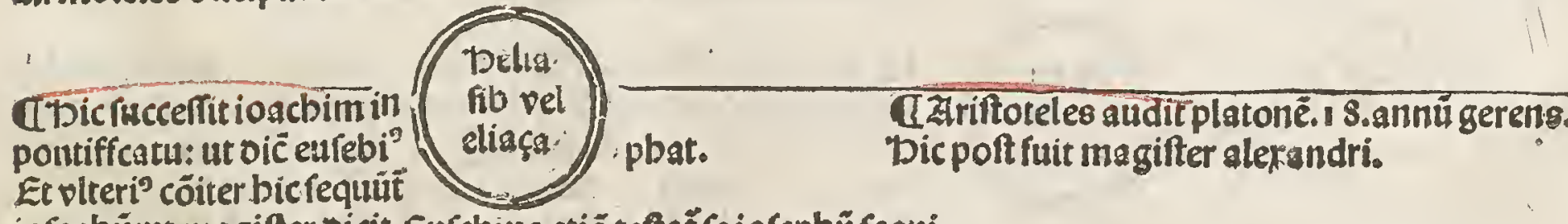
iofepbü:ut magifter oicit.Eurebius etiä teftat̃ feiorepbũ fequi.

CDtonghns ficutustyrannus peffimus oe ficilia expellitur. bicerat oifcipultus platonis:/5 nö imitator. Quodâ tpe vidua quedä paupcula p ipfo vijs imolabat oblecrans quaten'oiutius viueret:ipfo retro ftante fecre tius z admirante. Löplero aü facrificio accerfit interrogans air. Lur fiç me 02as: qui femp ti bi moleftus fui:

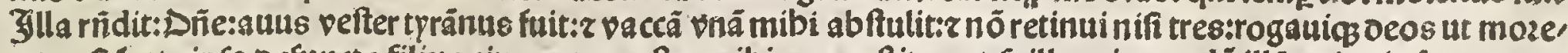
retur:f fozte ipfo o efunct o filius eius pater vefter mibi eam reftitueret:\{ 3 ille peioz:nedú illä retinuit: imo pnam

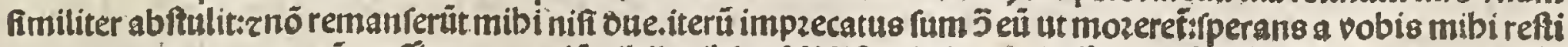

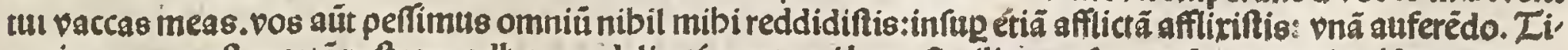
mui ergone poft moztẽ veftram adbuc crudelioz furgat:qui banc fimiliter auferat:z fame moziar, ideo veos ex02auip vita veftra:infeliciter experta: 9 pene cötinue res in oeterius vilabunt."bec füt verba vetera:z noua pza crica:cui experientiä nō oēs equaliter aduertunt. Qui qür bec patiunt a rifu fe cötinere noaserü. 
(100) all'to2quat'puguã incbo' auit attocillimia củ gallis:pculfo, QBgallo: $\mathrm{g}$ et ad fingulare certa,

Iรabrici'vir oigne méozie nulla potuit induftria pyrtbi regis a romana ciuitate oiuelli:pmiffa etiă ärta parte regni.tandé mépuocauit:tozquéaureä oe col pyrrbus ait. Dic eft ille fabzici":q oifficili"

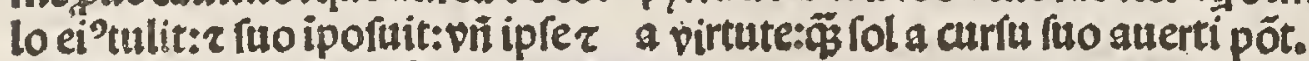
pofteri el’ oicti füt toząti.

\section{TRomani.}

I. Jfte quintitis oictato? cruétiffima congreffione

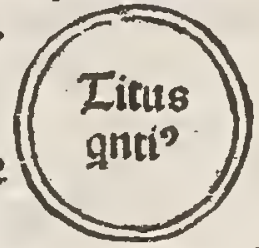

bellüa mälio incboatü precit: 2 victor fidel' fact?'in eadē pauptate pmanfit:fićaĩ.4.iugera fuis mani' bus colēe. bunc in exêplū adducit aug'. De ci.oei ja auaros $r$ fupbos rṕianos ấfdam. Iefte eutropio buic marco val.euenit victozia כ̃ gallü fiue gallos. ppî́ cozuú g infidës eibz acbio:eruit octos galli cü

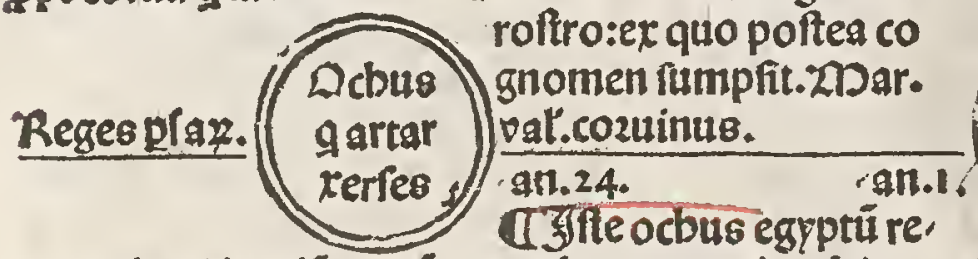
tocaut ad impiü pfaru: nectabano rege in etbio.

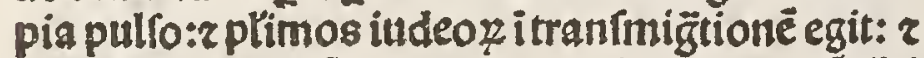
iuxta mare carpiū collocauit: g nimis creuerút ibi

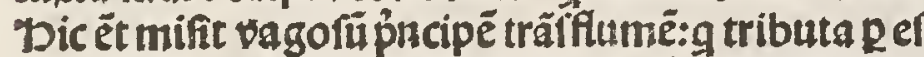
drä oimiffa repetijt. f. feptimi äni ppt fabbata terre 2Dirü eft quô bic ut putấ fili' befter ita fuit iudeis infenr". "hocét tpe ab alexädro alexādria códita ê. Znnomundi 4834

Samnites medij füt inter pi. Linea xp̄i. cenum campeniã r apuliã.

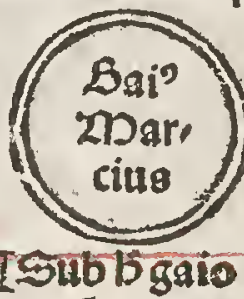

Tacto épugato tufcozü:quar octo milia ca' ptifuerunt.

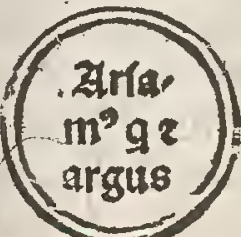

Ithicarfam? fucceffit ocbo: rparü reğtuit.
Imbinutio virgo veftalis pptec inceftù viua repulta eft. becr ritia allegari folent in exempluz tópia apud genriles puniebant.

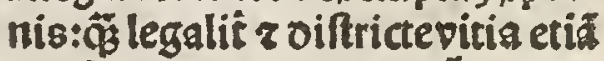

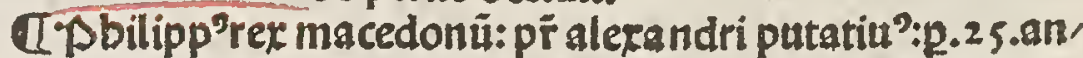
nos tyrannidé exercet fractio facramëtis: ita elat ${ }^{2}$ : ut licere

fibi oia ä cogitauiffet putaret.tandé oolołe occidit. Dzofius mar.

ctro pa

lerius 4. Iftemarecu. 6 : milib? romanis pia gnauit 5ु gallos:q̊日 in fuga vertit:z gra uiter trucidauit.

C. Alexäder nalcitur ex olympiade vroze pbilippi regl macedonü:adultata Q nectar banünigromäticü regé egppti:g $p$ incanta tiōes illudebat ei ẩî oe?amó scubuiflet cī ea bs colludio potêtii adulteria 2 ftupza folte bät excufari:aut etiā bonozari:\{z pauperú

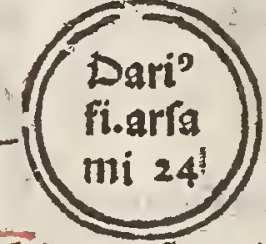
capitali pena feriebant.

Uदjite dart'potentiffim" au itus eft a grecis tributa expe' tere:c̆ fuic occafio oeftructio

bic trantata fuit ad grecos: iuxta ppbetias oanielis. Fert cs amiferit quinquies oecies centena milia bellatozü quos oés alexãder oe perfis occidit. nis toti’monarcbie pfarü: ä

I Lirca bec tha oicit oz ofius zetiaz entropins: 9 nox viq3 ad plurimã oiei parté tendi vifa eft:z farea grando id éveri lapides oe nubibus oefcendentes terram feriunt.
Tifte fuit rümus facerdos tpe mardo cbei: cui ides eplas mifit oe ob feruatióe oierü fu' rim:ut $p 3$ befter.9.

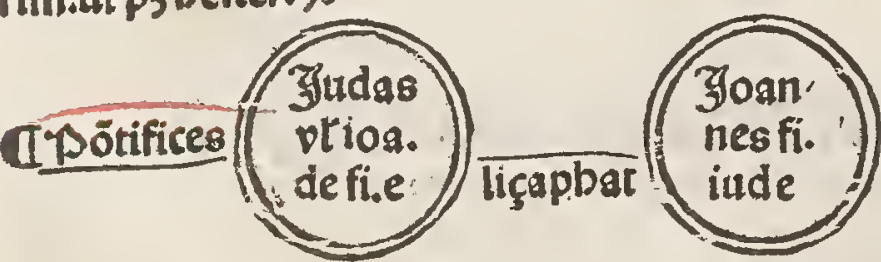

I. Zacedemones ipfi füt ipartani: expugnant $r i$ Ceruitutë redigunt:quozã impzoba oominädi cu pido infinits mala fúcitauit 5 m ozofiú. Tivemoftenes $02 a t 02$ fult.

व. Inbriliffimus claret:fectamøs perypateticozú conftituit.

IIpenfippus pbilofopbus poft platone: acba demicam tenuit. aZenocrates fuccefit:moztuo fpentippo.
TUlagofue pfectus ocbi templü fupbe untrat:z fpoliat: z tributa miniftris oei imponit:ppter oiffentioné pontificis cum fratre fuo iefu qué occidit.

I Jitte ioänes babuit fratrēg oicebatiefus : $\tau$ arpirabat ad pontificutū quappter familia ritatēvagofi po fecti trās flumen. fibi compautit. Cófifus aut fup boc altercari cum ioâne cepit in templo z adeo incitauit fratrë:ut eñ occideret.

ISidon oelet ab ocbo rege ṕarü. Erubejce fidon aitmare I ZApuleius r bermes o ircipuli platonis in temploz locis r

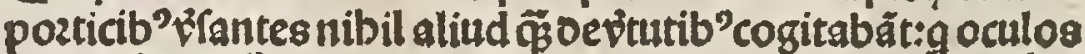

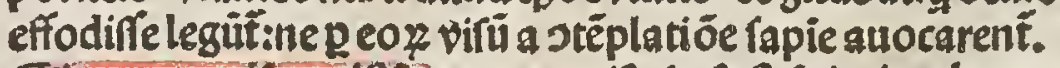

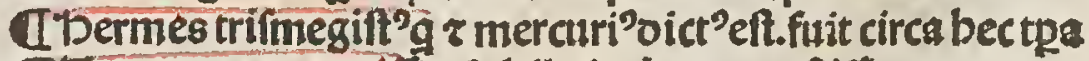

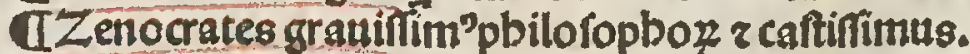

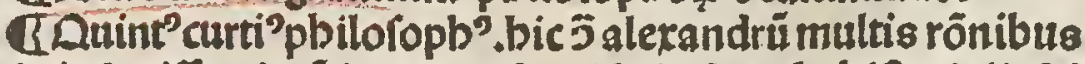
feriofe oifferuit eü increpando. vide in fpeculo biftoziali. Si oeus es inquit: brïficia largire nō anferss. î bomo: femp id cogita alijs poftpofitis,

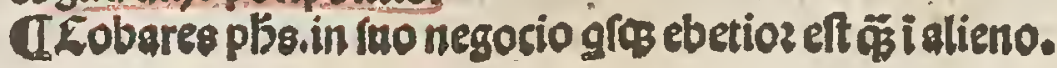


13) otro Julues cổtra latinos pugnătes:Decius occifus fuit $r$

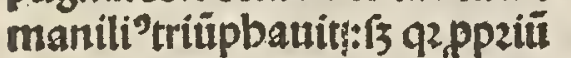
filiú occidit: folitas laudes nö

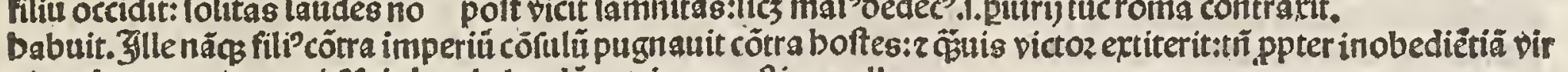
gis céus: $z$ capite punit?fuit.boc in laudē patris auguttinus allegat.

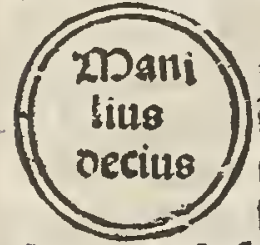

Q. दुfte papiri? cú adbuc puer eêt paudé cufim ${ }^{2}$ fuit: $z$ pulcbzü médaciu fincit ut

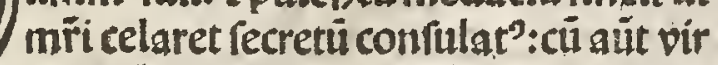
fact ${ }^{2} e \bar{t}$ :adeo bellicofiflim? fuit ut alexã

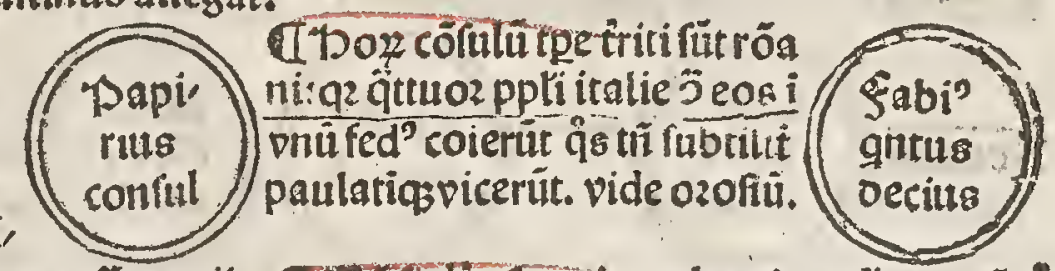

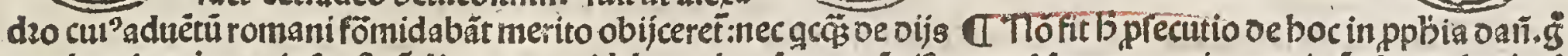

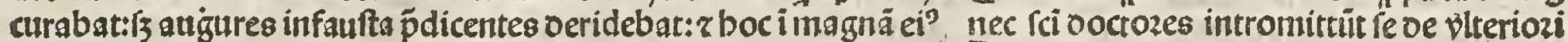

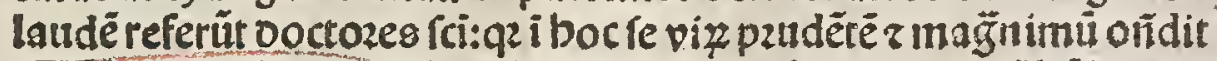

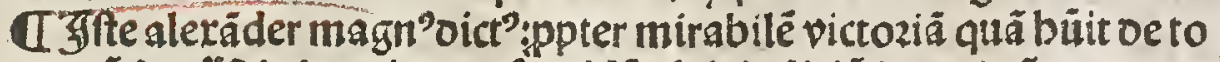

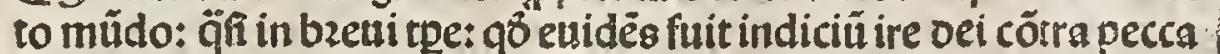

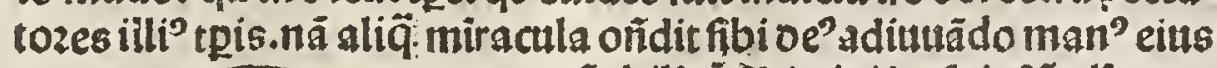
है az mare pãpbilicí fibi oinifuz fuit fić oli mare mbz iudeis:qñ pfequebat̃ onril etiã orone fu

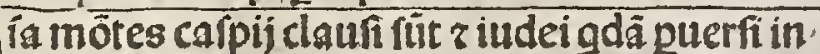
clufi:tandē in babylone baufto veneno mozit ãno etat) \{tue.33.âno monarcbie rex egypri 5.macedoni. 12,2 boc mó multe :

an. 40 . biftozie concozdari piit.

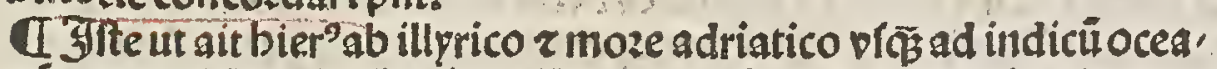

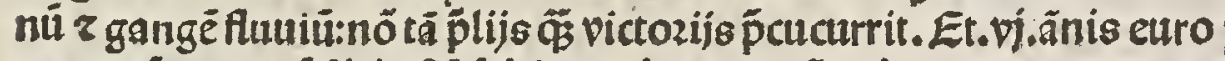
pe partê:z omnē ríbi afiâ fubiugauit:oono tĩ oei. donübic frater alexandri $6 \mathrm{~m}$ bieronymü.

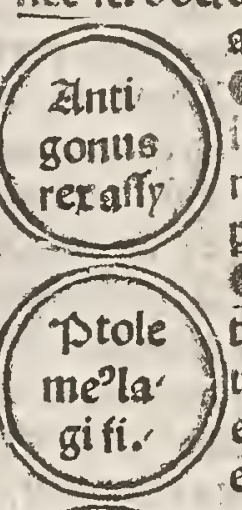

pbili pp $p^{D}$ rex mace. annotatione.

Trbic ait:nunตึ poftö pupurä indui verü sudiui $\int_{3}$ ä dâ nocte mutatata vefte: via ô feci mala peunctatus oidicí. TDebocregmoegytifit prect tio qzindeis quíqs ifelti quiq $\mathrm{fa}$ nozabilerfueftreges ip̄i?:qo ió euenit:qz regee fyrie pene fo cú egpptije pug̈bät: ifrít it i medio coy iugit a filigebat quociä re verrët:iã ab boc iã ab illo.zpzi mo ifte ptoleme? ğtuiter 208 af flixit:eofa capiés oolofevendi dit: $z a b$ bac occafióe oingfi fut 4894 in nationib':ut p3 acti.2. Zgpre aut ipunir' nó euafit: vide 020:

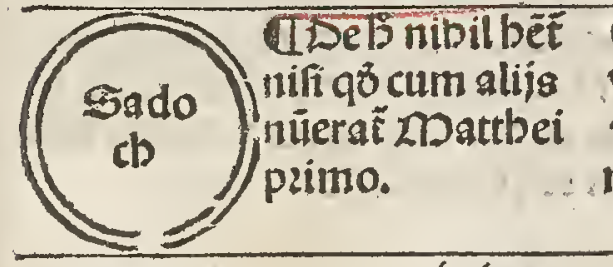

Sit ILpabozzedifima
vindiog vor fäguinis rclamor pugne.mi' ra beipatientia.
(1) Thota oefucto alexãdro cu. 12, illi gb regnu oiltifit in ter fe nô fonfêt cốcozdare infinita bella furgüt z multripls cata für mala fup terrã vltra modü: tandẽ contritis alijes ifti, 4.obtinuerür ptätē uxta ppbetiä oaĩ. vide ozofituni. Q Saraballa funpltitiofü téplūe edificar i móte garizi:vbi po cipit fífma iudeoł:qz multi adbéfertit ei:qui oës extüc oi cti für famarítani:q2 ppbani a iudeis uel excõicati. T'şfte iad'irato alexädro occurrit pótificalib?indut?: $r$ pla

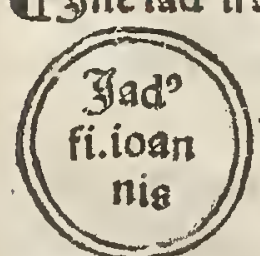

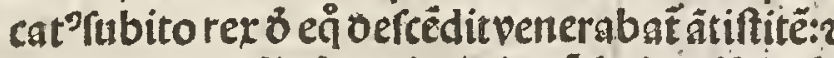
cü pace z gandio itrauit cituitatē fecitó fibi af gb" pactis gauifus é valde: qz oia q̆ p fomniū

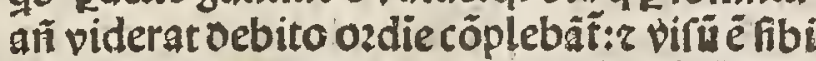
gipe eét ille oe å bec ppbetata fuerüt: $r$ maiozé ex bُ füpfit andaciä pugnandi 3 oariú: oblatoos facrificio iufit petere

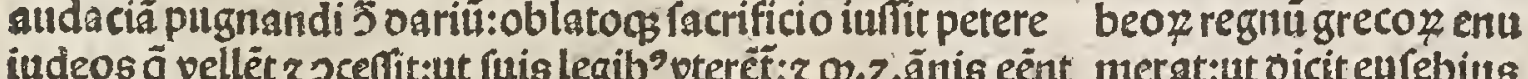
abfog tributo ppter fabbata terre: videmagiftri z CErercit'aletầdri ut oič o:on? fuitpeditū. 3 2.milia:eqtü. 4. milia naues. 1 So. bac tă pua mãu vnituerfï tra admirabili' fit q2 vicerit an q2 aggrediaufus fuerít icertü $\overline{\text { : }}$ Uisimn oceifo paruo:fuere quinquies oecies cēteng nilia.becidem.

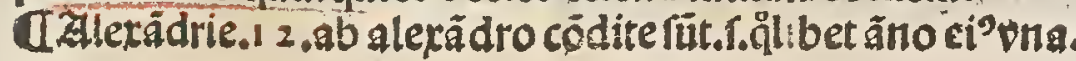




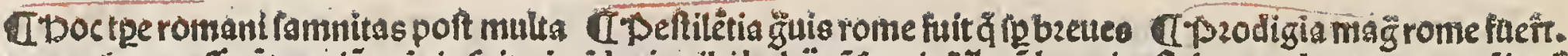

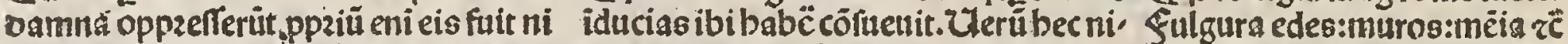

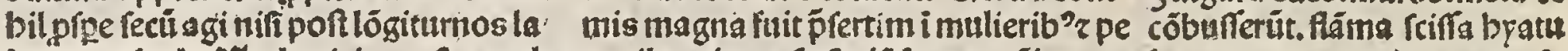

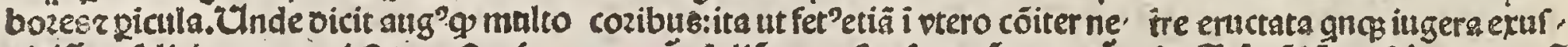

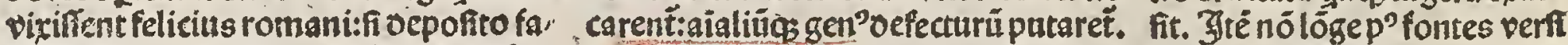

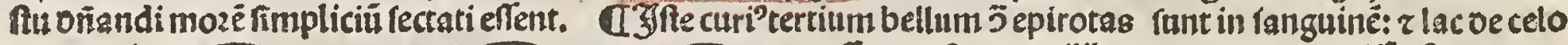

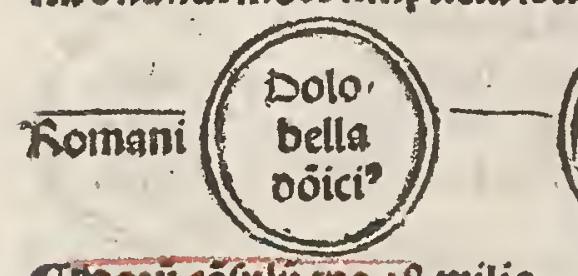

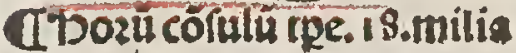
romanozum a gallis occifa runt:nec apparet:gn roma. ni iuftum bellum babuerüt.

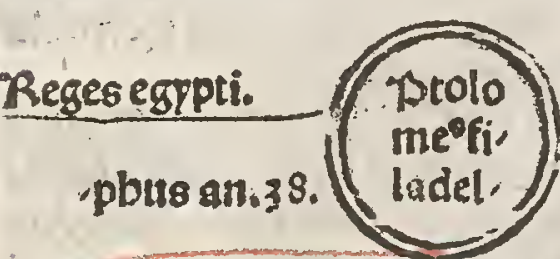

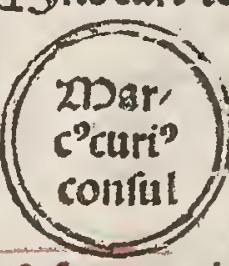

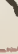

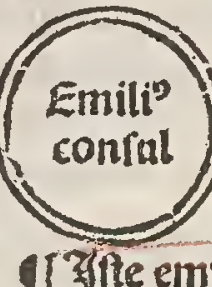

cótra tarêtinos iuftifímübellì e tarêtinis pyrrbo rege grecoz:bellatü êvltra.4.änor

Zandé victo pỵrrbo z i patriā redeüre miferabili.

tergs moziēte:tarétini cü cartbaginenfib' fed" ini'

erït: $z$ ex boc punica bella incboats fuerunt.

I bi roman z multi alij:ante bectpa z poft fuerunt viri $\mathrm{sm}$ feculi bone?tatem

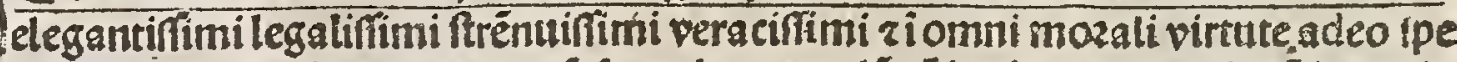

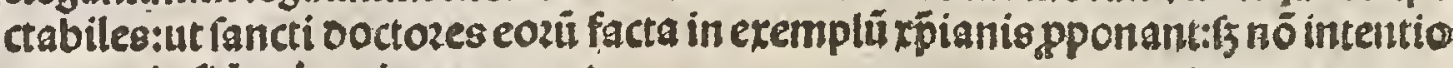
nem:quia fide pietatis caruermt.

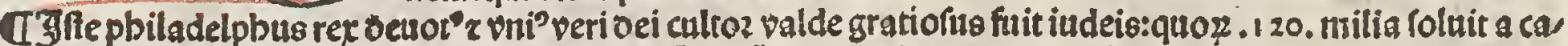

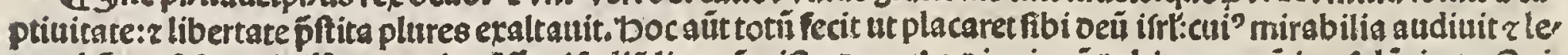

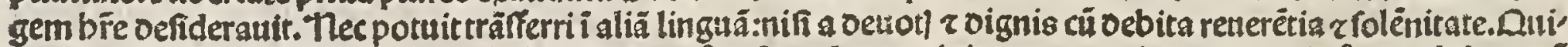

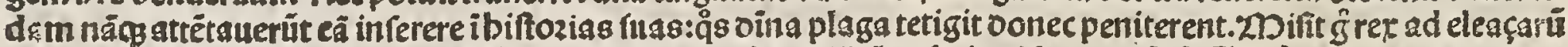

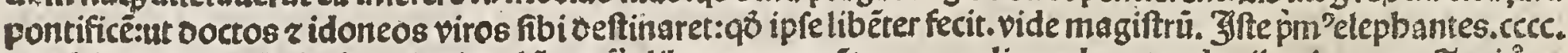

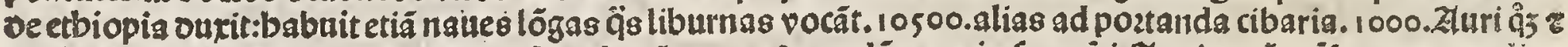

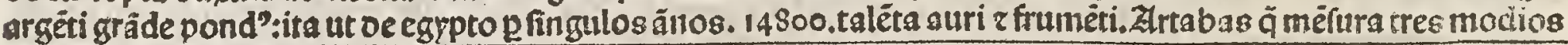
Annomundi $4909 \quad 4934 \quad$ ztertiâmodí ptê bz:gnquies z decres cétena milia.

Linea rp̄i. fili'sadocb $\begin{gathered}\text { utpzmat } \\ \text { tbeipmo. }\end{gathered}$
062 Septuaginta interṕtes legē tranflerüt oe beuzeo in grecá linguã cĭ gran

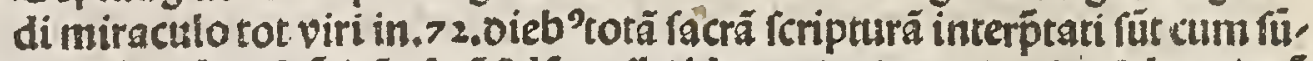

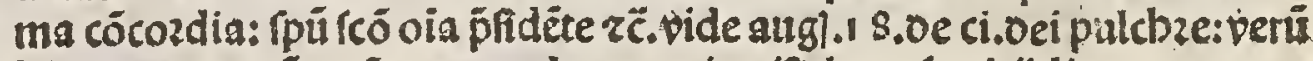

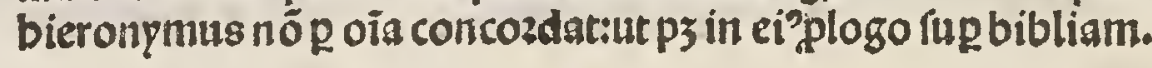

If fulgoz rónalis circa bectpa ceflauit fm iolepbü:qz appzopinquante fole oeficit auroza i. xpo g infallibi tem veritatể erat vocturus prime venturo figuralis côfultio terminata eft. vide magifturü fup exodü.

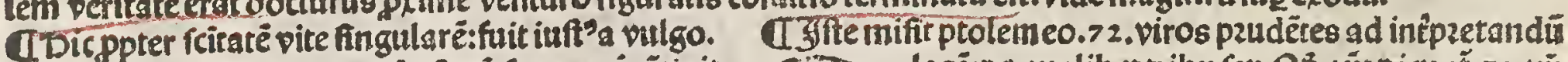

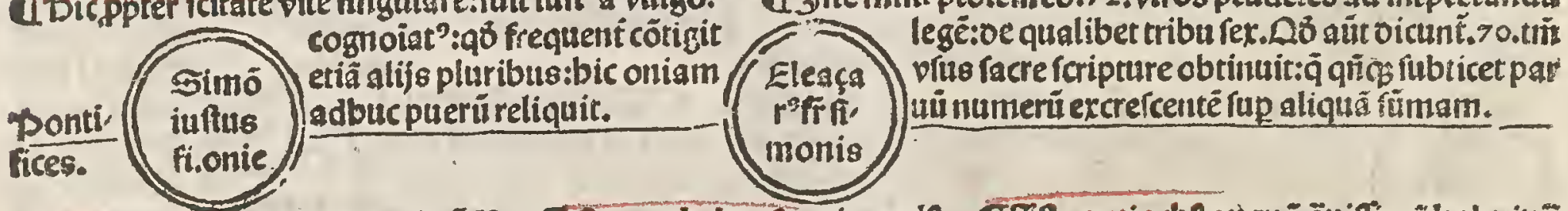

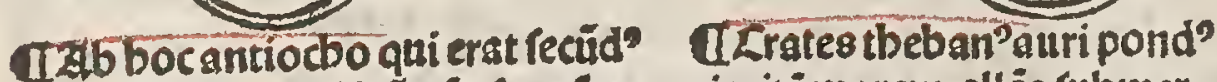
ret f́rie poft alexädrü oés fequétes reges fprie oicti funt antiocbi.

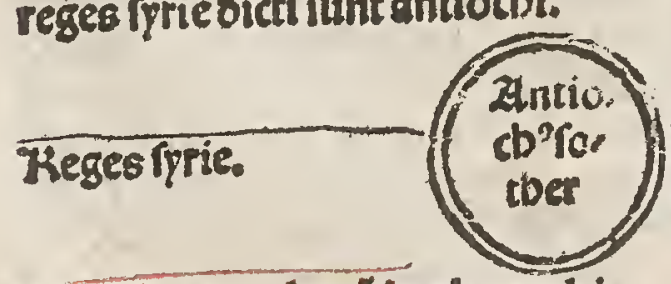

ISoftratus pbarü in alexandria confruxitin mari.

piecitimareimallés rubmer, gere oiuitias 舒 ipfe fubmergi abeis. IÉbatíppus plbus:bicoixit of ftultus nulla re fcit vti: $r$ g Anulla re opus eft $r \ddot{c}$.

Cärchetios pbilosopb'flozet.

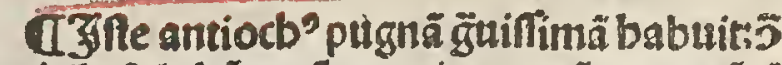
pbiladelpbũ regé egypti: 2 qa nô potuerüt : วcozdiã bellãdo puêrep gliú modú pacifi żntio filiä regis egypti i vrozé:iuxta cb’tbe ppbetiã oañ. pidebiero.ibide 08 a berafiftrat?medicus $z$ con ful clarus babetur.

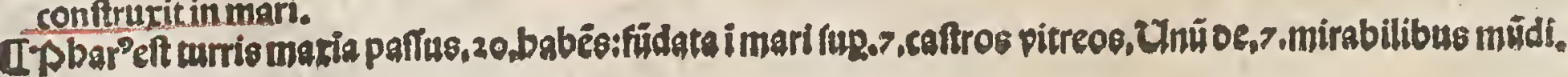


đIfte fempzoni? aduerfüpicentes bellatit zterra tremuit äfi fäguinē fundendä bozzeret accipere: $r$ pene ab vtraqs pte cozatuerunt paucis ror manis quafi victozibus erceptis.

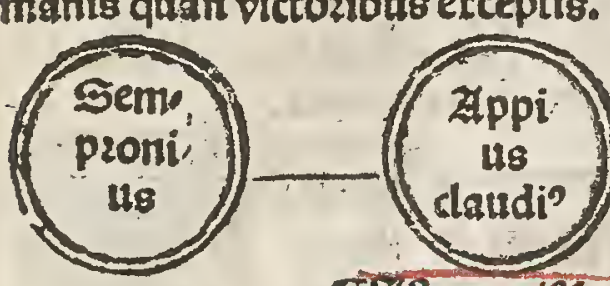

CIIfte appi?ipra,

curanos r penos fa cillime fupguit 2 imuletă impoluit:bic viā appiā ftra uit:z aquas claudias induxit.

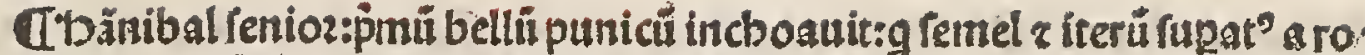
manis tandēab exercitu fuo lapidibus obzut?:moziț:infoztunat?

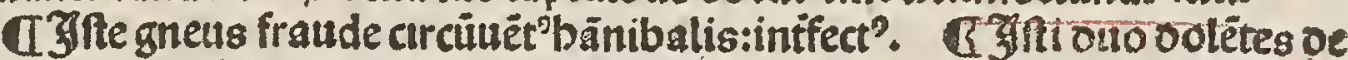

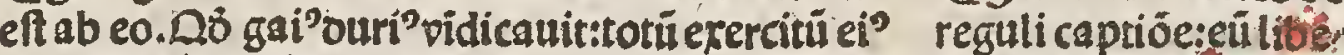
cōterens eúg in fugam cöuertit. rare venerür: 3 nibil pfecere.

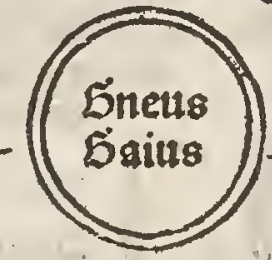

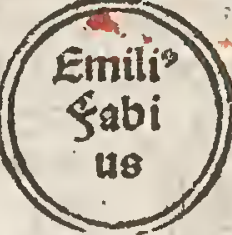

IIfte regulus pmü tot ${ }^{0}$ victoziolus: tres reges vicit:2.73.ciuitates rubegit:ferpentē mire magnitudis apud bu grada flutuin occidit. Luip coziü. 11 s.pedü longitudiné babuit: romä oelar

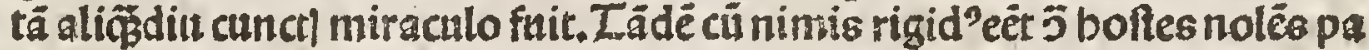

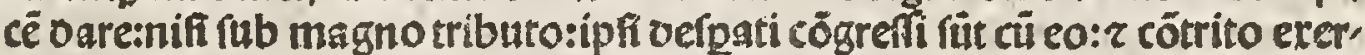

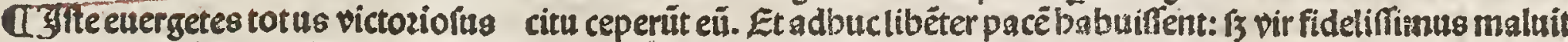
fuit.bic p'pafta tâ frriä z ficiliaz $z$ ptes afie inter inumera fpolia que cepit etiam

Dtolo
mepe'
uerge

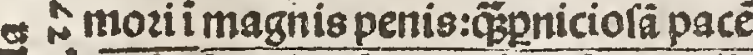
Eore. Eius laudes aug? valde ertollit . Ilarrat valeri?li.4.0 ab aratro accer

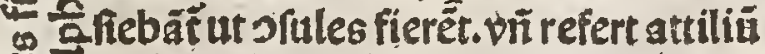

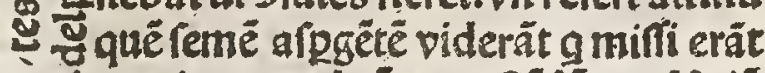

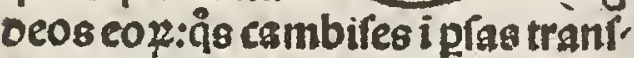
uexerat reuexit iö eucrgetes oicitur quod retiectioné fonat. populi furcipiendum: fy illo ruftico ope attrite man'falutê publicä Ita

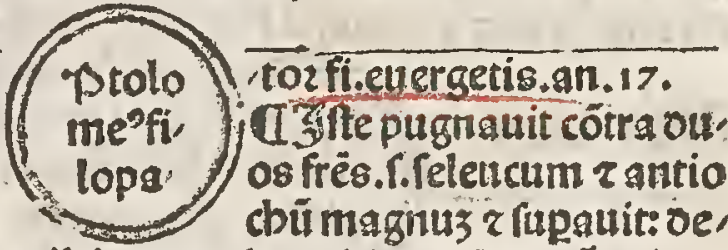
ijciens multa milia: $\tau$ trin non pualuit. Uide bierongmii fupoañ.

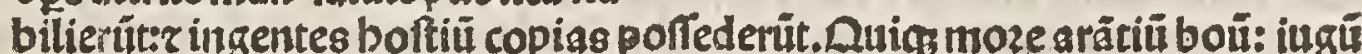

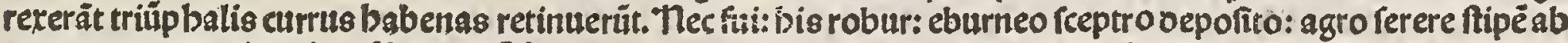

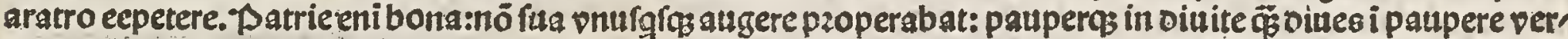

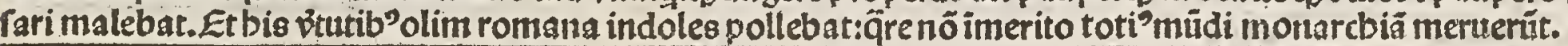

[Quintius ennius poeta tüc tarenti nafcitur:qui
poftrome oeguit.cótentus vi? ancille mifterio.
-4..

Tifte onias celo legis uel potiper auaritia tributa negauit euergeti:ppter qỏ tota iudeg pene fuifj pe riclitata:ut oicit iofepb'geú inbonozu fuifle teftat

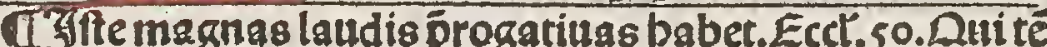
plum in melius refozmauit : $z$ ciuitaté pzeualut amplifi. care:c relígiofitu totaliter fuit.

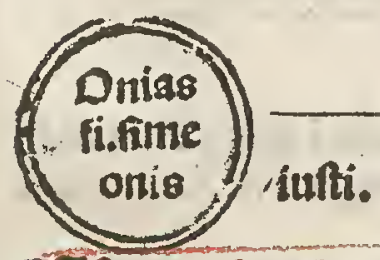

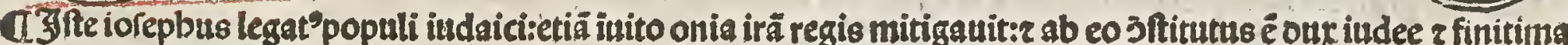

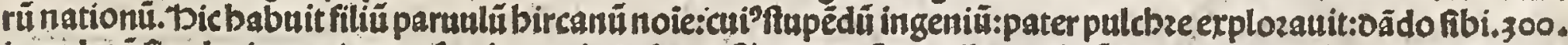
iug a boü fine lozis:ut araret z feminaret in oeferto. Zt puer nó puerile confiliu excogitaut: nä, 10, iuga occidit:

Zntio cbogal lericus carnes operarijs dedtt z oepellibus retinacula fecit.

QT ffte erat filius antiochi tbeos de pzima prozelaodiceque pirü fun veneno extinxit: z beronices

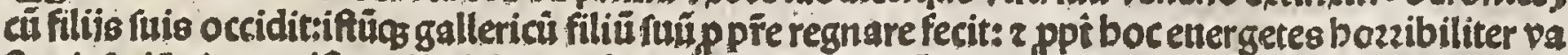

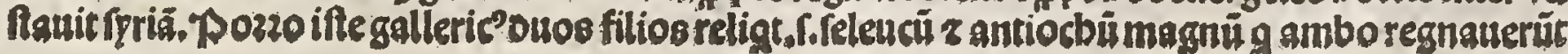




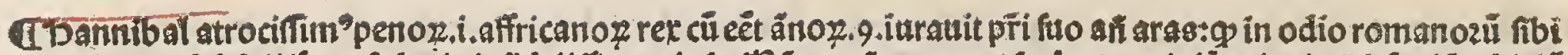

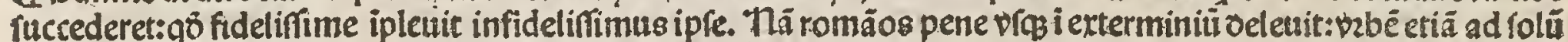

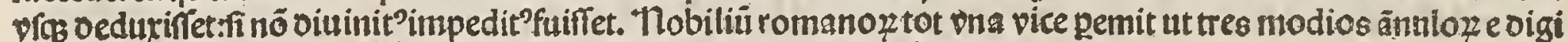

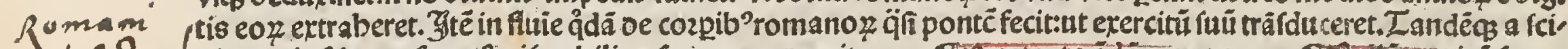

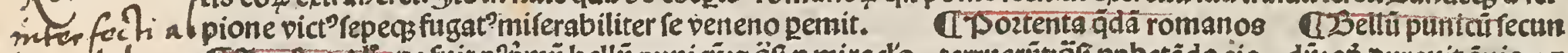

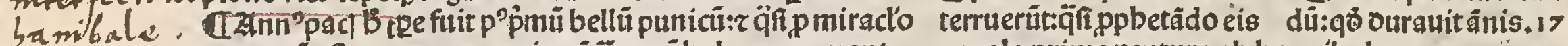
reputatü eft:qz in.440.annis nüq̈ pacē babuereromani. mala prime ventura ab banuibale.

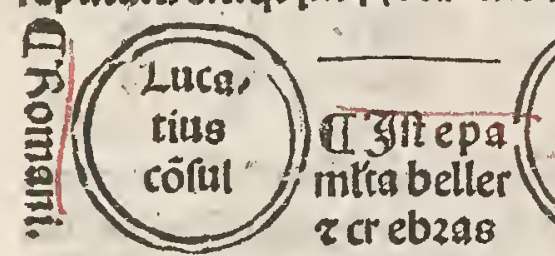
victozias adeo cötrituit car thaginểes ut pacé peterêt quâ etiā magnis pactís có

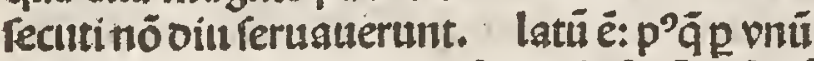

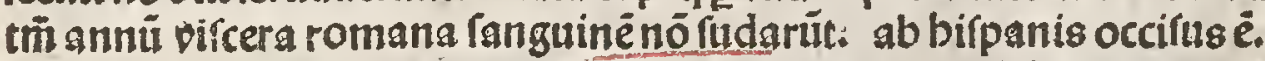

Reges egypti.

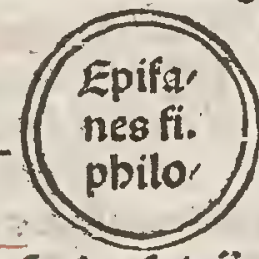
IEleopatra filia antiocbi magni: erat vroz ei'quá accepit oum effet annoz.13. patozis.

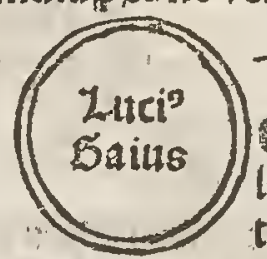

Tकi ju les robur toti'italie

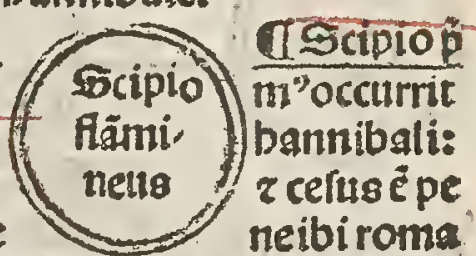

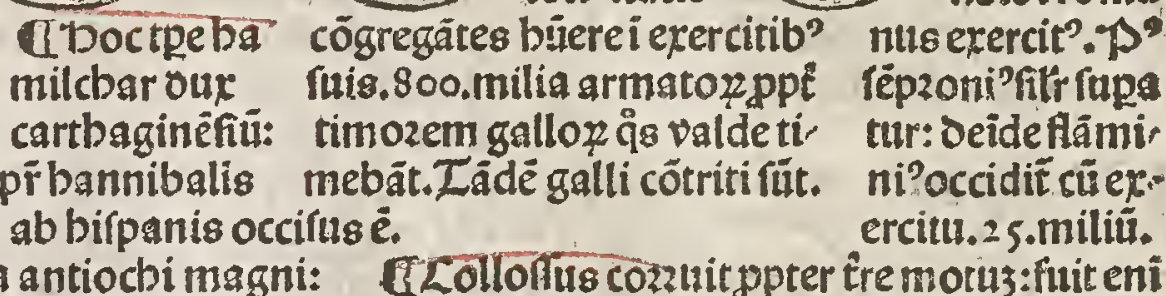

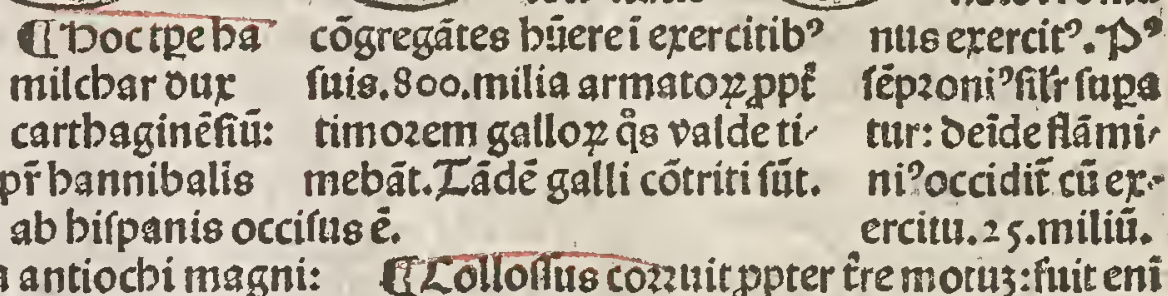

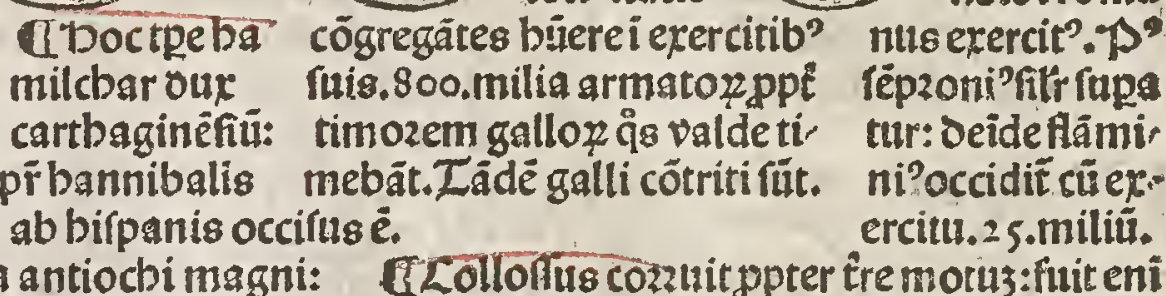

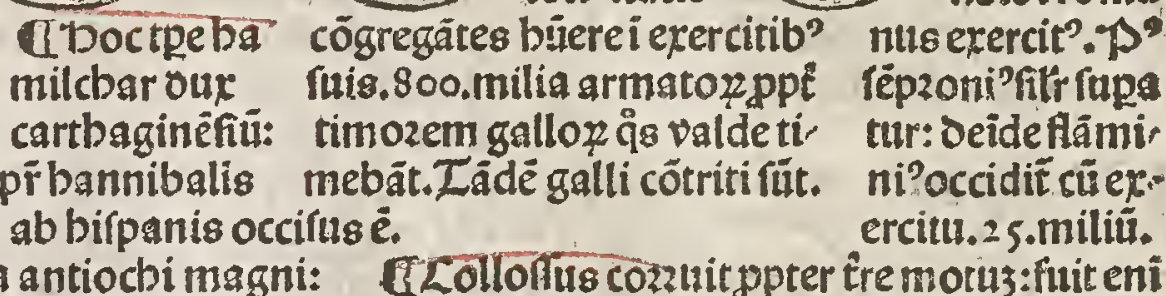
imago erea fufilis.1 26.pedu5. Papiss auté Dicit:qp fuit marmozea.

Ciplautus eloquens fuit.

QLitus liuitus tragedianú foriptoz:flozidifimus.

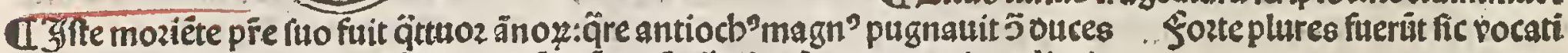

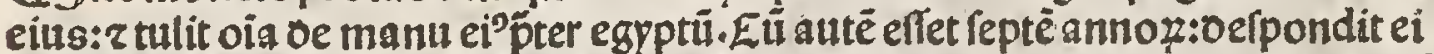
fuä filiä in oolo:cö́rentiëte eprpbane filio furo.i.antiocbo nobili.2Doztno autē

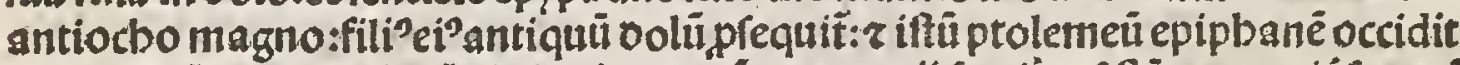

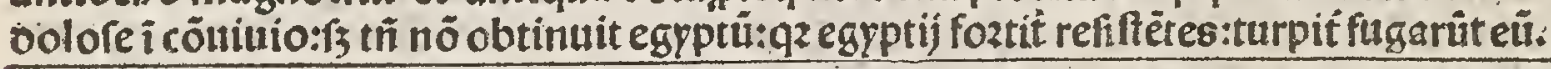

Zlnno mundi 4934 5009

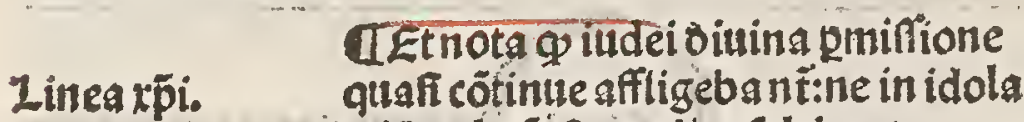
triä caderế ficint olim rolebant.
Cît Lemplü olit in egpto extruit ad inftar bierofoly mozü: qỏ pmanfit vføg ad velpafianü: z tüc fundit? oirutum fuit.

ITStolemeus p bilopatoz indeos vicit: occifis.60. milibus armato 2 .

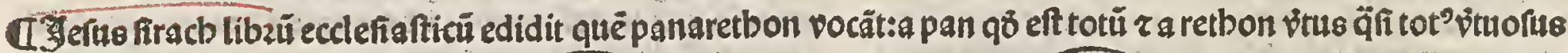

IDlaga grandis ex squa r igne vabem confumphit quafi. Ipontifices.

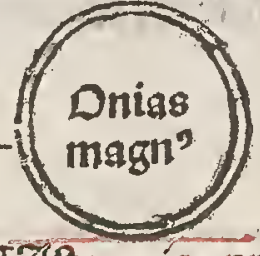

đ马ुtte onias ppter tyrannidë antiocbi:fugit cü multis iudeis i egyptü:fimuläs re velle implere ppbetiä befaie.1 9. pidelicet edificảdo templü: \{s in boc peccaut fupftitiofe agendo. Rex autem epipbanes gratiofe fufcepit eum:tradens ei terram beliopoleos ztemplü ibidem extruxit.

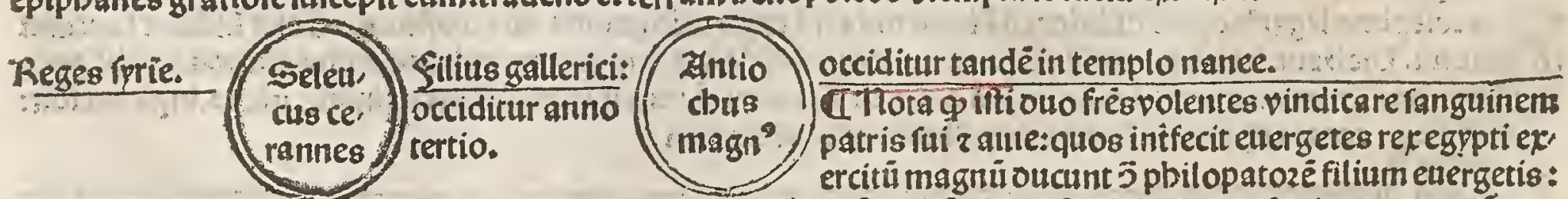

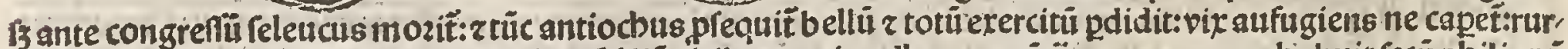

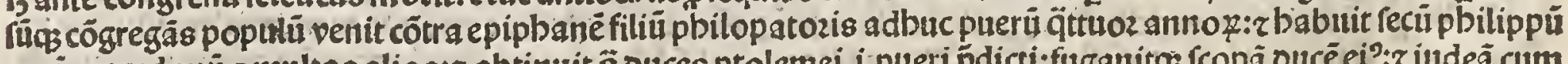

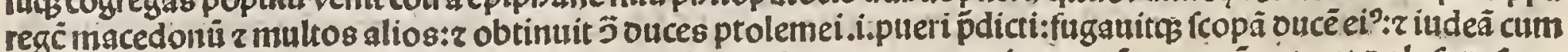

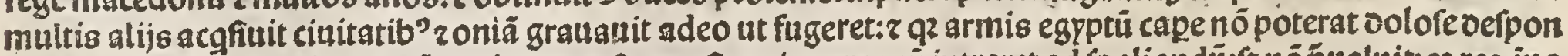

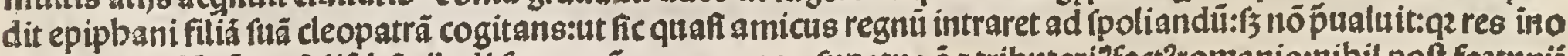
tuit eis: tandē cī pzefídiü bãnibali ferret côtra romanos:\{upatus é z tributari' fact'romanis:nibil poft foztunij

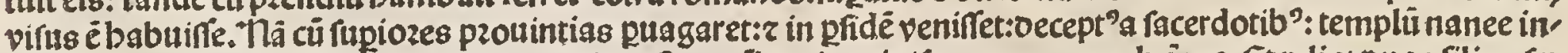
trauit cfi paucis:z ibidé miferabiliter occifus eft: $r$ mëbzatim oituifus:ut p3.2.macb. p̈mo. Et religt ouos filios fcs

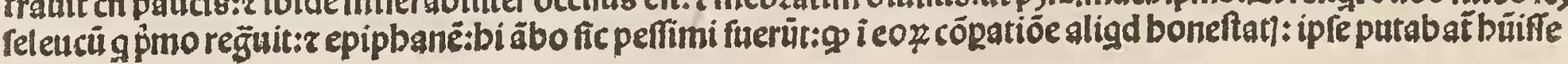


ORoma inmeroze:tot enifiterunt accifi:gr vem pene reliquifient.

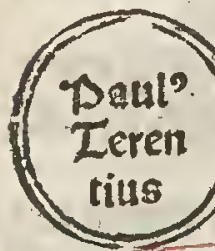

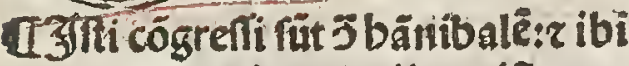
tota romào 2 fpes perijt occifis. 44 . milibus: $r$ poft cörinue fupant $\nabla$ lag

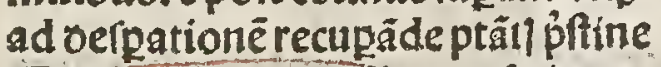

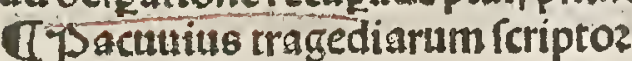
apud bandurum claruit.

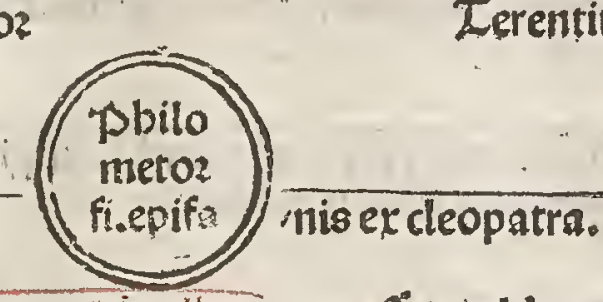

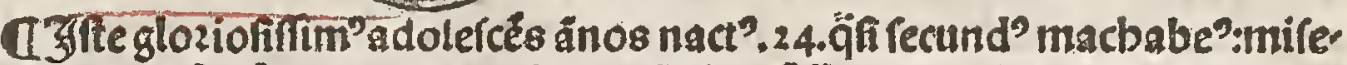

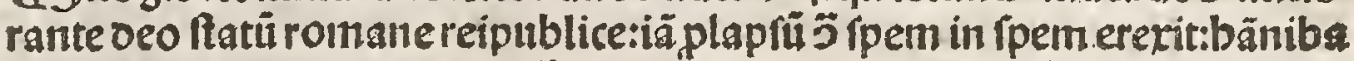
lêfinganit:Jupauit bifpaniâ:affricã oeicit:antiocbū magnū in fertüredegic afiã tributtariã côftituit. 'oic tant'ab ingrata patria exul mozitur.

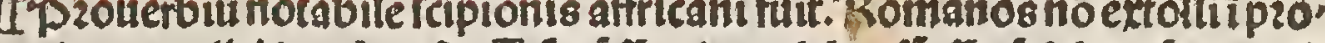

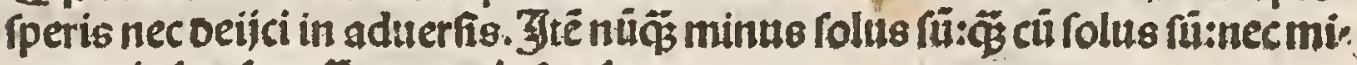
nus ociofus fun ös cun ociofitı fum.

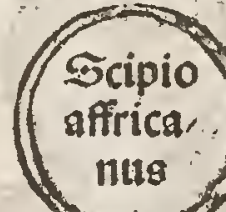

Dunc ou adbuc pher effet: valde oppzeffit antiocbus nobilis multis bolis z intî. difs:\{̧ romani miferüt legatos:g mandantes antiocbo:ne vltra in feftus effet amicis cozü : cãm belli terminarüt

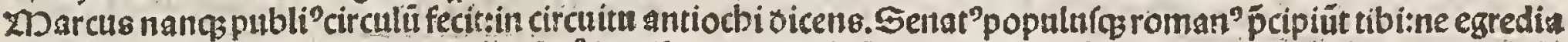

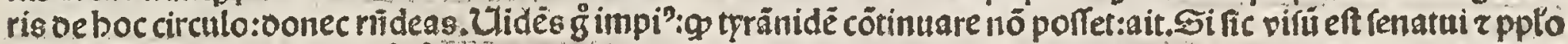

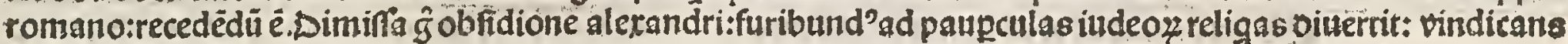
in eos:atod nö potuit in potentiozes re:ut p5 in libzo macba.pzimo r.2:

\begin{tabular}{|c|c|c|}
\hline & $\therefore 4$. & $50 \$ 4$ \\
\hline & abocnibilect:nifig & QZfles ignee videbant in \\
\hline & cui glijs numerst:ut patet & aere fun bierufalë oiebus \\
\hline & nrattb.pzimo. & 40. 2 requit plaga:ut patet \\
\hline & & $2 . \mathrm{macba.5}$ \\
\hline
\end{tabular}

S91

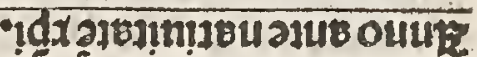

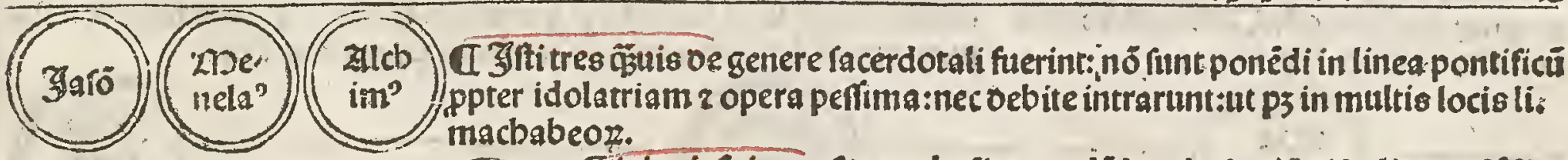

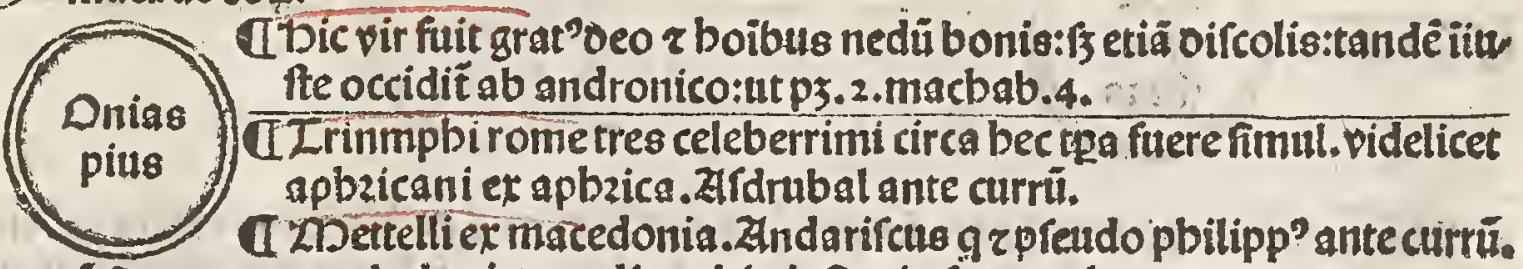

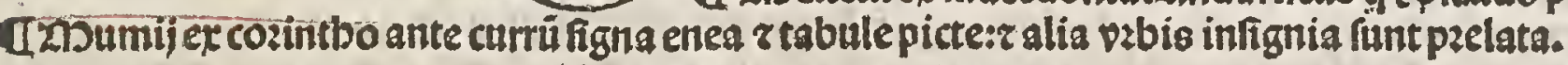

\footnotetext{
Seleu

cus in

ersfi. Jintiocbimagni.
}

CYIte paup bomo:groffis r vefpectus indignus bonoze regio:peflimus fuit ficut pater eitus parü regnatuit:az

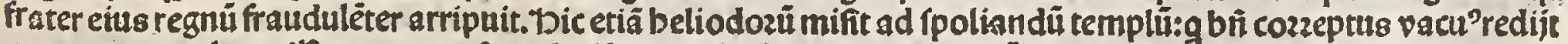

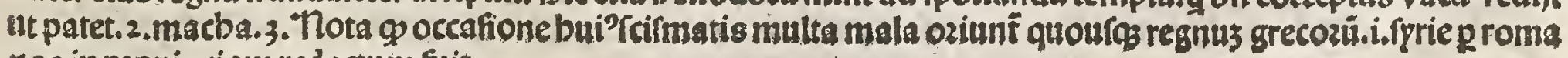
nos in pzouincians redactum fuit. 


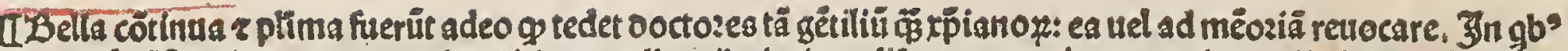

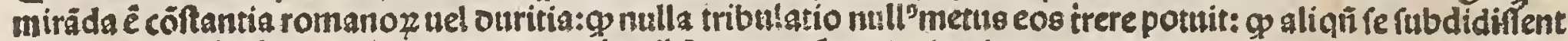

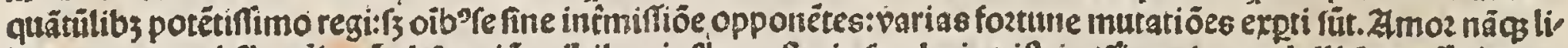
bertat] $r$ appetit'laudis:cū ob fuatiöe nibilomin 'bone/tatis fecularis oiftrictiflima:ita medullit’ tranffirit eos:

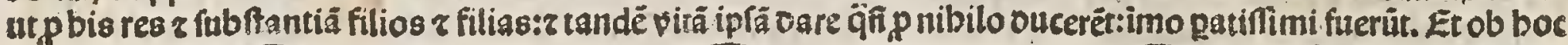

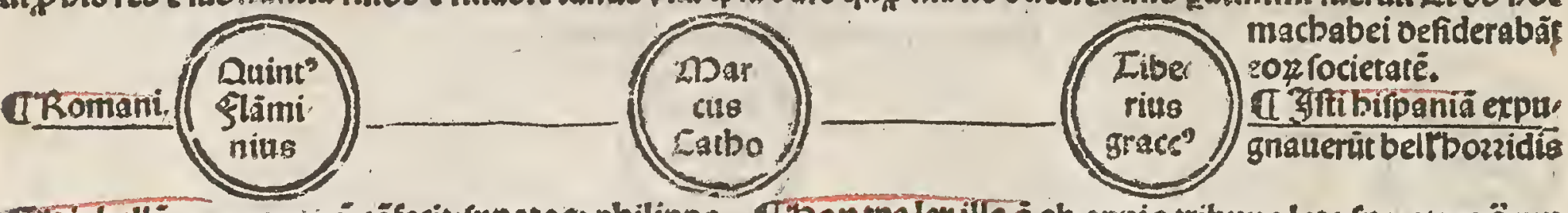

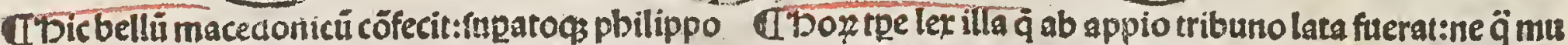
rege pacé oedit. Etbic ceffat regnum macedonum. lier aliā q̆ femiuntiā auribaberet z ne oiuerfi colozis vefti UTicit etiä lacedemöes 2 vẻditos romãos collegir. mento nec vebiculo $\mathrm{p}$ vrbem pteretur abolita eft.

GStatilts cecilius comediarü feriptoz.

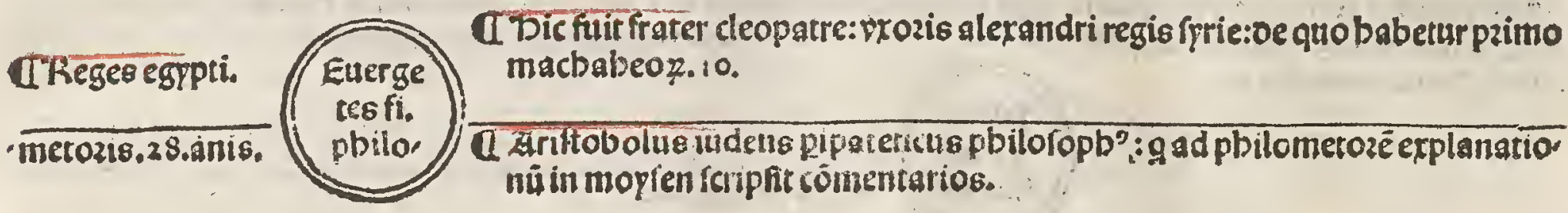

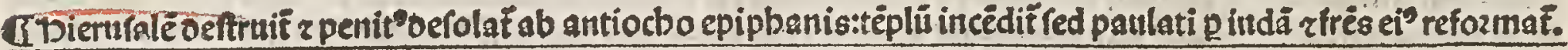
Annomundi

TLinea xpio martyriçanti. macbabeop.7.

dTemplu purgarur a iuda z fratrib"el'poltis tribus ânio propbsnatū erat: ut pz pzimo ma martrio cozonat. 2.macbabeoz.6. cbabeoz.4.3.2. macbabeo\%.10.

it?

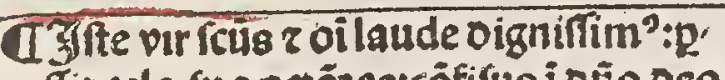
cuntit çela fto pctözes:cöfifus ioño oeo îrarl:ur p5 p̀mo macb. 2. Etbabuit fili. os gnq eitufdem çeli. Zlerü ipfenö erat pontifex:fed tres filij eitus.
Q Dic eft ille noiatifim?triupbatoz in írael:g nec flem babuic ante fe nec $p^{2}$. Eis opg gliofa rmagnifica.vide in libzis macbabeozü. "poft ur

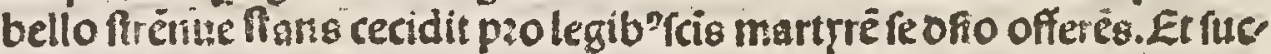
ceflit ei frater ru!s ionatbas: $\mathrm{g}$ creuit in glozia z feliciter fletit in tefta mento:tandé,oolofe occidit a tripbone cü ouobus filijs.

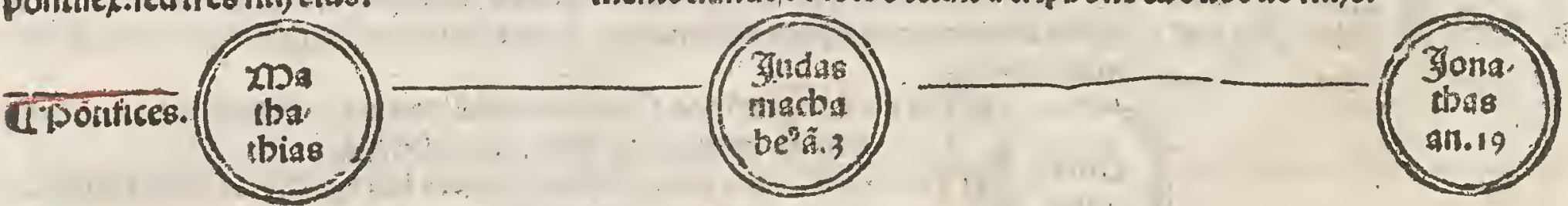

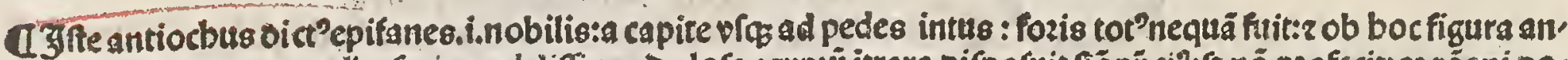

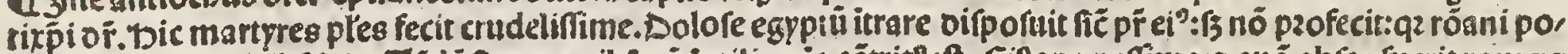

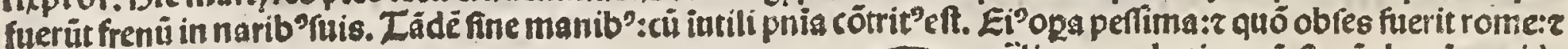

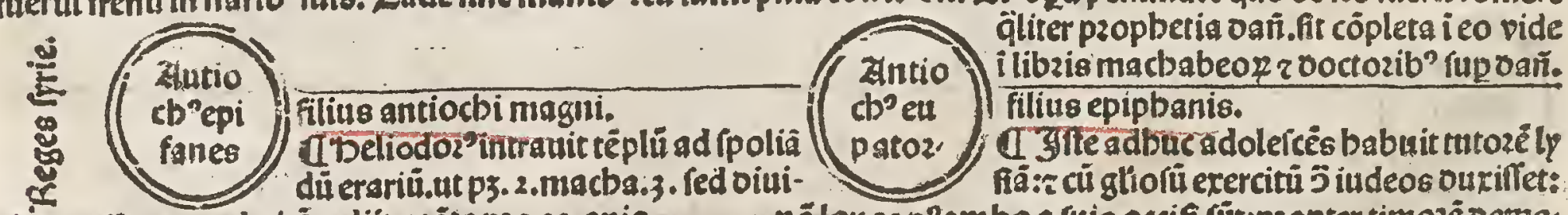
nit'pcuftus vix \&d vitāredijt ozäte proco onia. nölonge p'ambo a ruis occifi rüt:pzopter timozè oemé trij filij releuci ut ps pmo macbbeon.7:

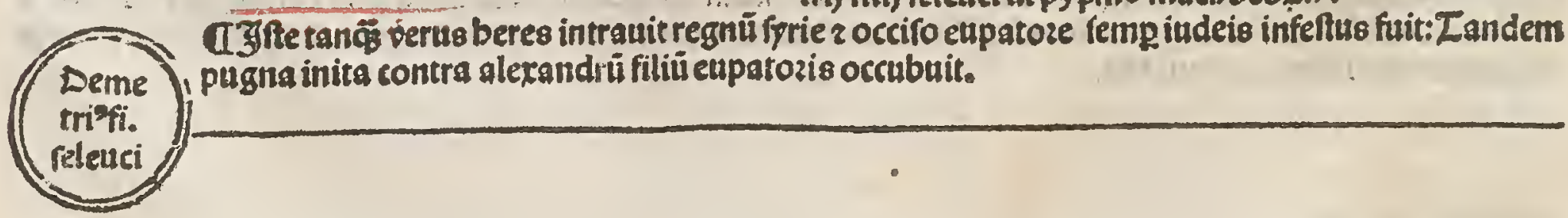




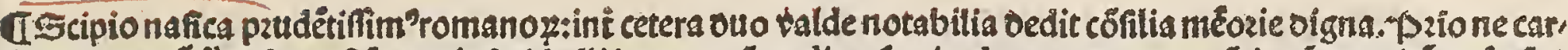

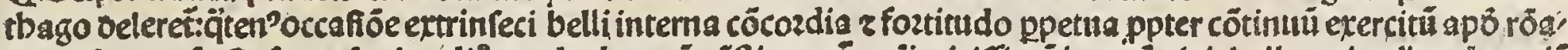

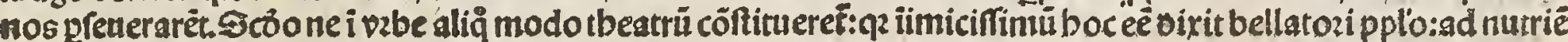

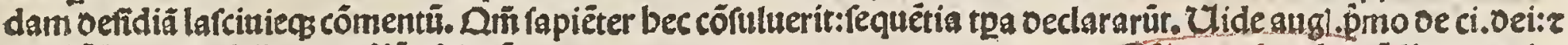
ozofiüli, z.mirabile remediü vitiozü.

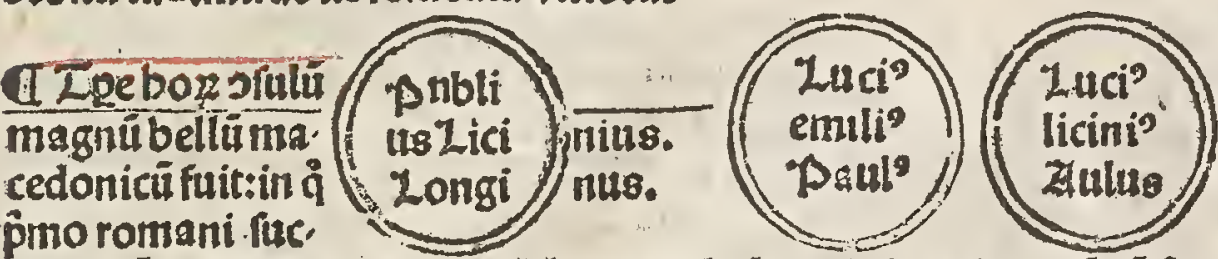

đZunno ab vabecōdita.602.in

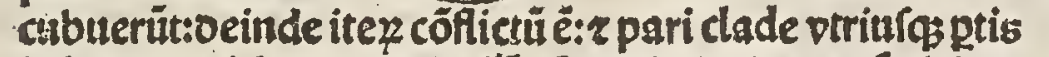
in biberno.i.byeme oifceffú eft.tertio lucius regé vicit: 9

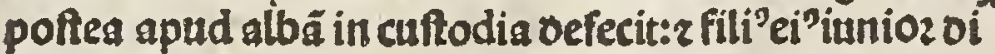
dicit opus manuale rome:ob tolerandam inopiam. aboctpeceltibe choatie éterriröanos terrue Iucis tii bellü pur

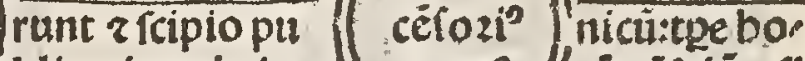
blius in apbzicas ( marco)/ rü cófulü z fi iuit: ibiqs multas initน̃ ầno.4. gêtiuftrages oedit. Sergi? auit galba a lufitanis vict" amifo exercitn viraufugit.

CEartbagoilta nobitifima me

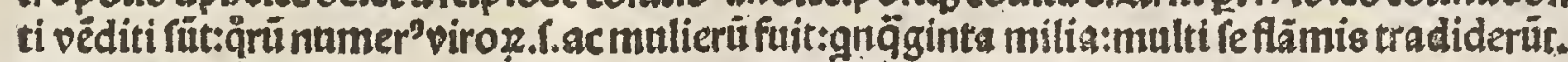

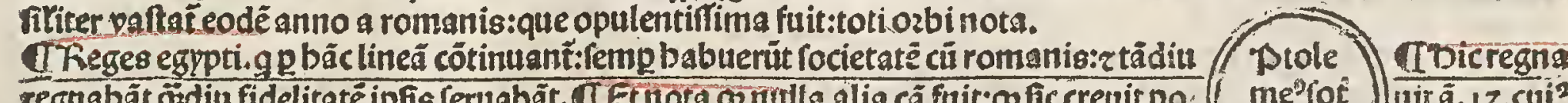

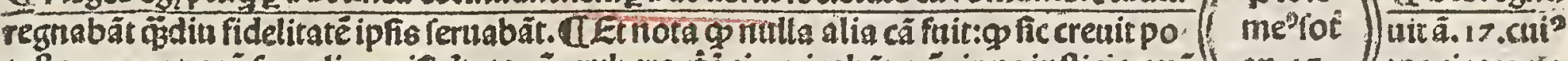

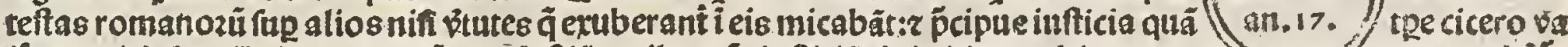

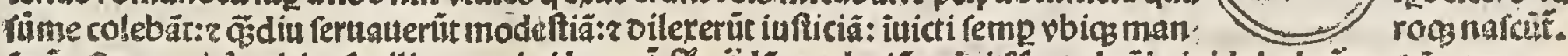

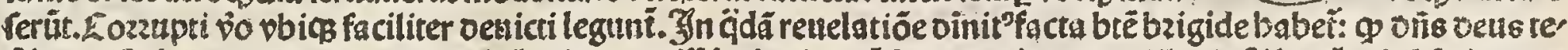

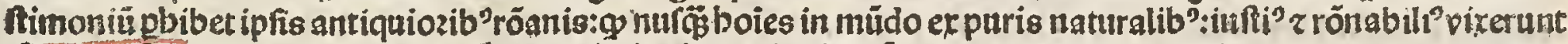
Analis aur tuminaria'er eis tpe xṕiane religionis refplenduerüt:in fequentibus patebit.

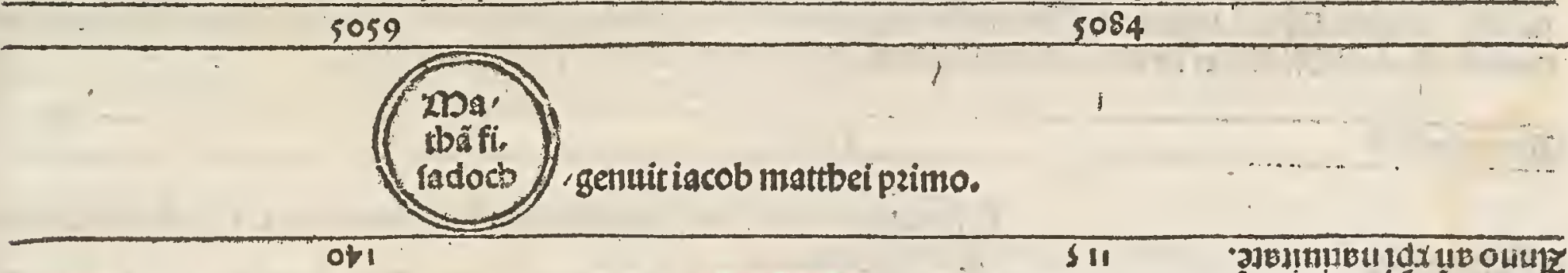

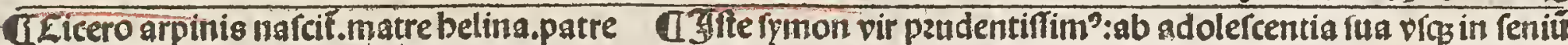
equeftris 02dinis:ex regio pulftozü genere. optime cöuerfatus:femp victozioftus:tandénequiter occidit a ge" nerefro:ut ps primo macbabeoz pltimo.

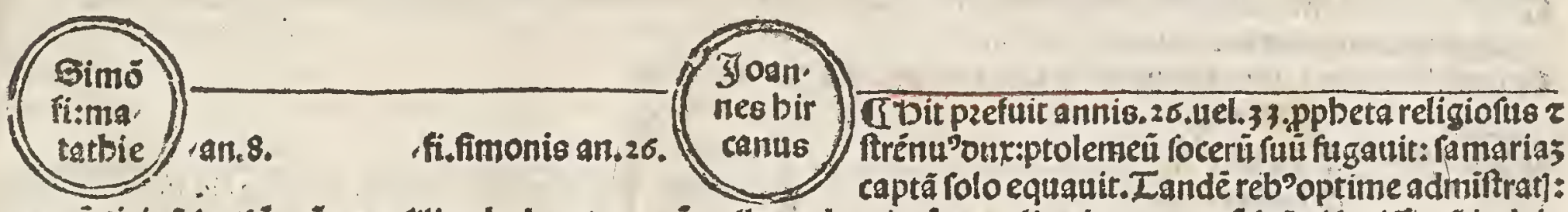

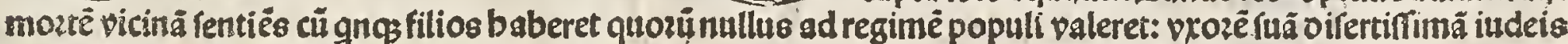
p:éécit z filije:perū nibil pietatis in filija fnit.

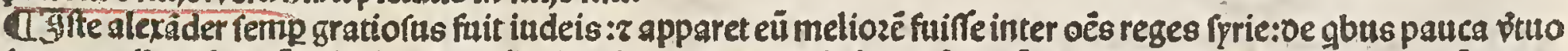
fa:aut uulla refertunt. Dic cleopatrā fil iã̃ regis egypti accepit i vrozé: verü rex egppti inf́que egit contra eú:ppter

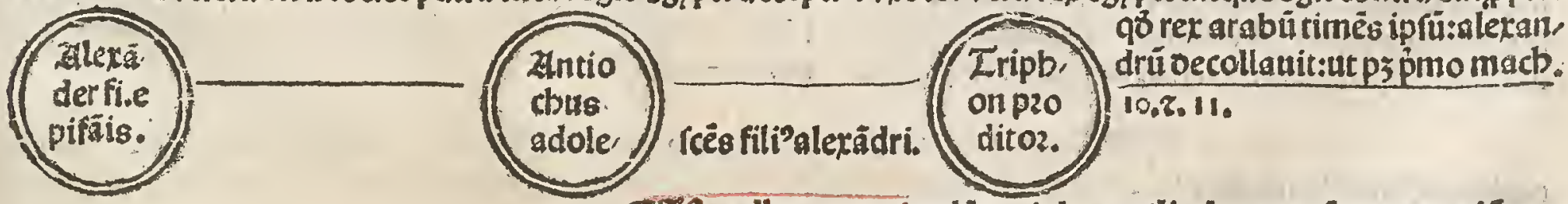

G'క̧fte adbuc puer:fuadēte triphone aligd motus ép rectipgtiōe re.

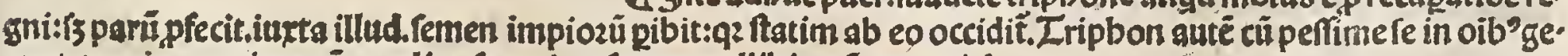
reret omnis exercittis eü oereligt:factufg g pugue:nullibi tutü repperit locum.

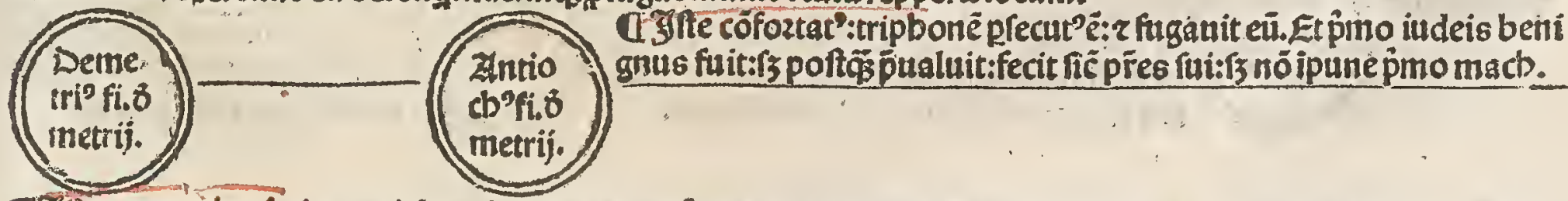

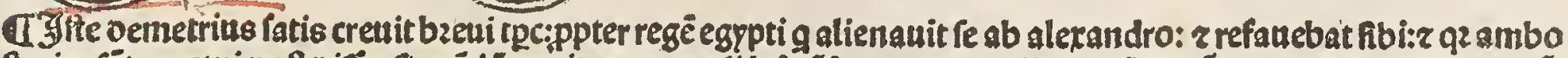

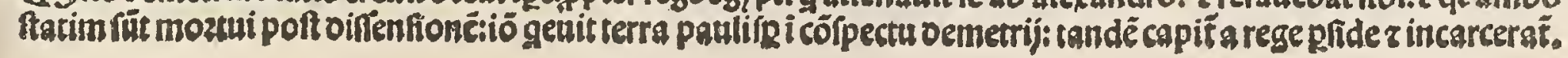




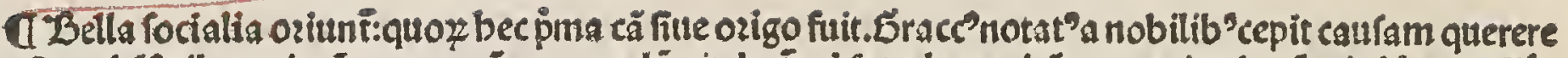

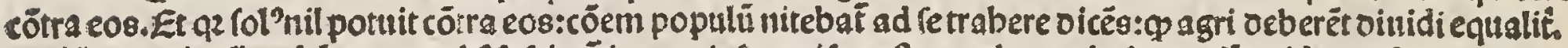

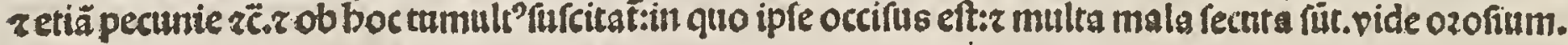

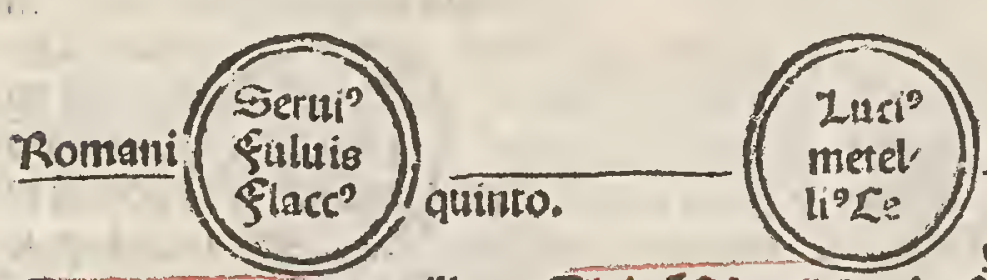

Qbox tpepuer ex ancilla nafcit: ädrupes:व̈driman? ocul.4. Etbna mons igne" flämas etromuit mirabilit r loca vicina vaftauit. $5 c i$ pionumantiā oeleuit.
C†is ṕfidentib?ulfa ef cartbago reftitui: roma. now famulis repleta $\dot{e}: 2 i$ vabe inteftinü bellú perti. tur atrocifitne.

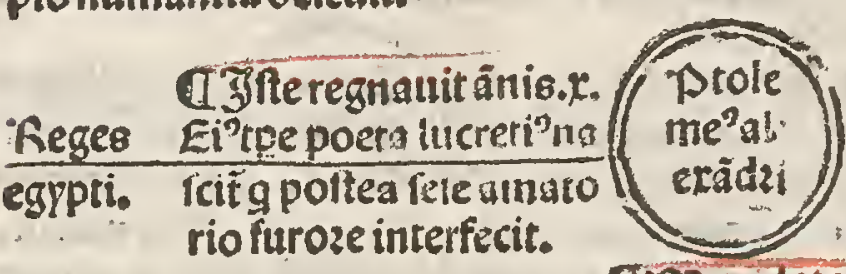

Tboptge rex numidanu:valde

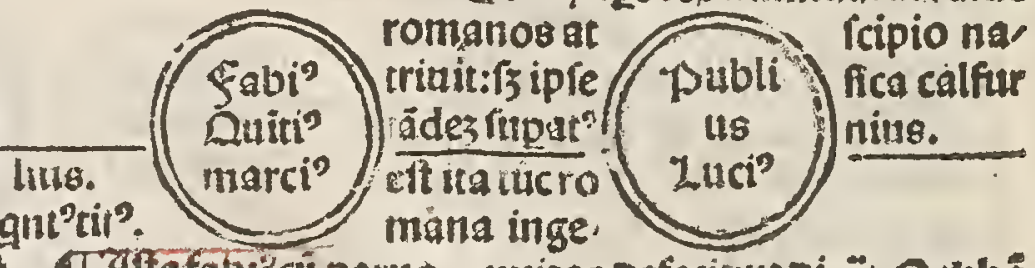

UIftefabi cu paruo nuitas oefecir:ut oicët.D to pplo regem arme, venalen z mature piruram: fi niefuperauit: rmerf emptozēitenerit:quafi oiceret funt. 1 So.milia arma, Sides in te perijt. tor i rodano. Quinti? oeleuit gallos: g fub radice alpiũ fiti fuerüt.

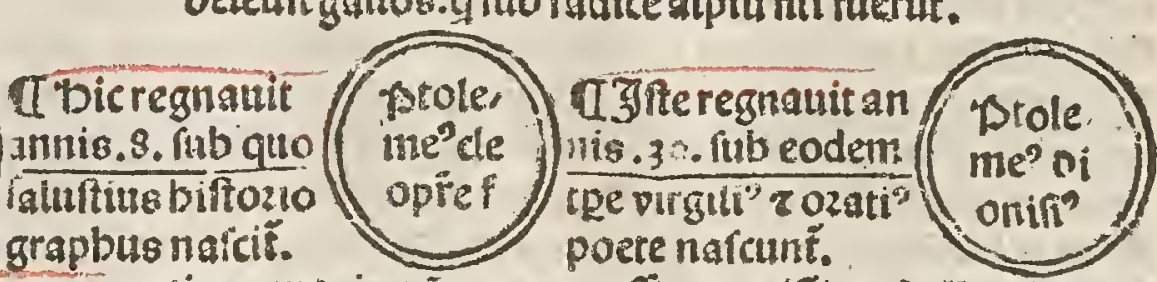
poete nafcunt. anifis"

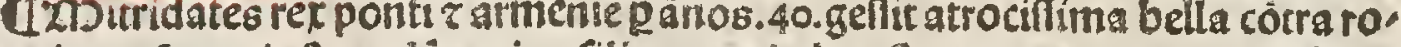
manos i modico fanguie furo:fepe victoz:fepe vict" tandęppzios filios gemit: baufto ve veneno: vrozes peliceo ac filias fecü extintit:fic miferabiliter perijt: $\mathrm{infinitos}$ penit. bic ut ozof" teftat:maximu nob is argumentmm

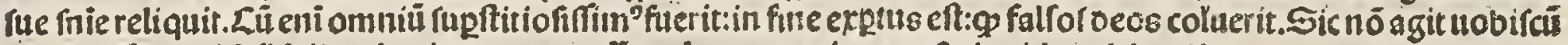

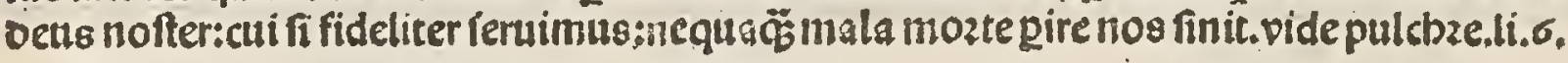

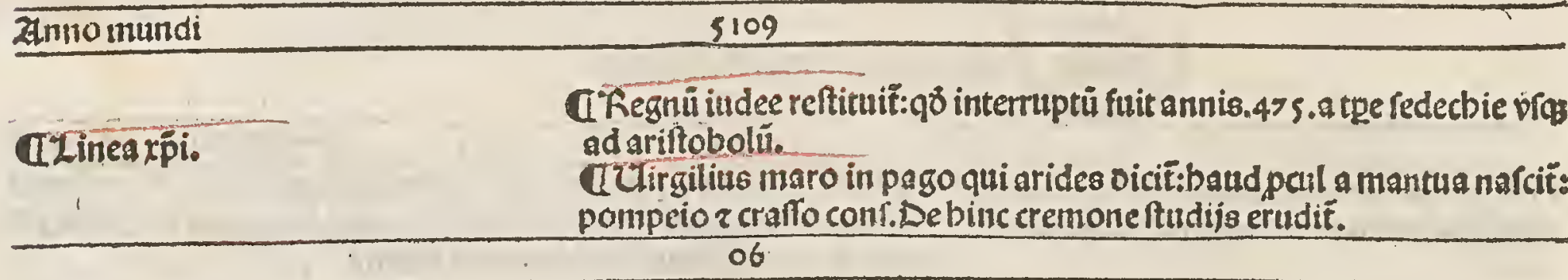

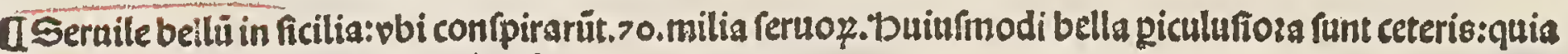
crudelioza:nec curant oe patrie falute.

CPeftilentia marima fuit in apbrica:perierunt vltra mille milia.

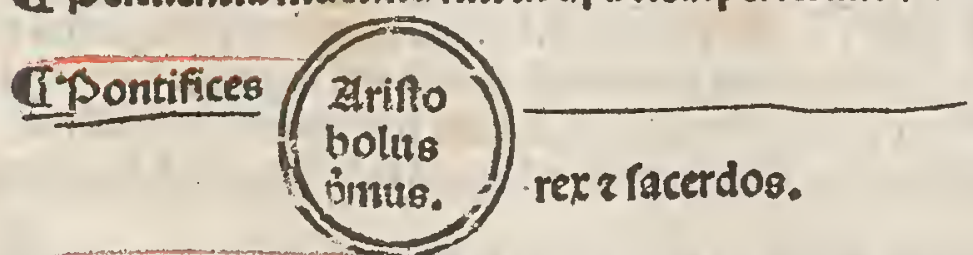

Q 3 fte vno tri anno pftit: $r$ biadema fib impofuit nec fuit cōtent? oe teltamēto patrl. iơ matrē cü filijs incarcerauir:ppter q⿳亠े miferabilit piir cü fratre fuo antigono:äui eü iuuitzč. videmggiftrüibifozijs.

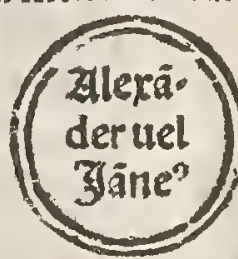

1 Dic p fuit annie.27.4tel. 38.2 cot"tyranmus fuit:[̈̈uis pzimū modeft'appareret.Dfficitis enifecitnotiu qualis intus fierit. Sratrem oc cidit. 2 in. 12 annis circit. 50 .milia fenio 2 interfecir: $\mathrm{g}$ facinoza eius oeteftabant. Zandez mozitur":0u08 filios religt f.bircanā z ariftobolú. verū vrozē regnare cōftituil:qz gra' tiampopulibabuit.

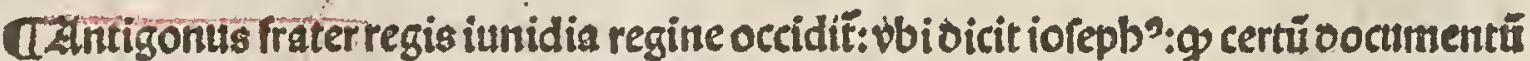

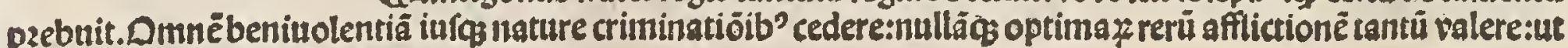
inuidie perpetuo poflit obfiftere.

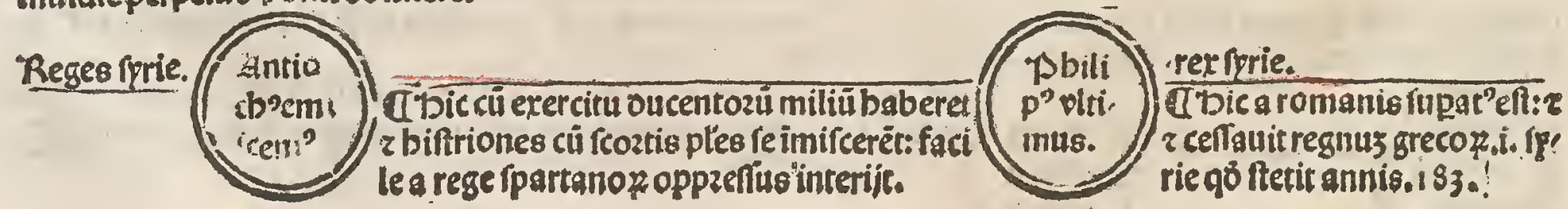


đ3ell intefting extraqg circa bectpà intantủ pualue rüt ut $\$$ magno miro babitú eft: $q$ ftat' róane reipu.pe nitus nö pierit. Uit $p ;$ g nibil potner it bellicus laboz ad pacépereandã: nifi a ǘmo veo magnü ifud oonú largiá nó a falfis oijs gb'tota roma pltra mille annis reruituit: vide ozofiu ad longü oe bis bellis.
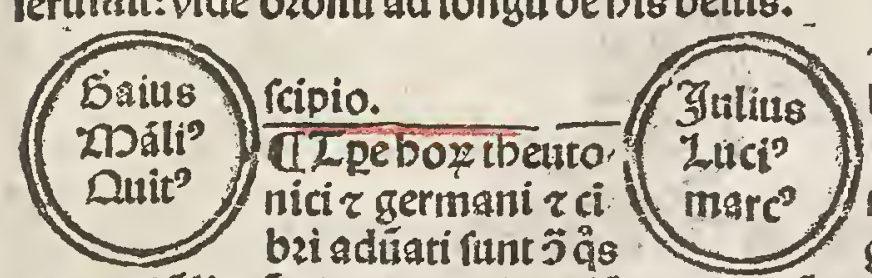

celar poft

factuseft. roctpe imulta pdi gia ifolits romani p̧liarüt:\{epeqs victi : tãdē eosfunguere fubtilit: $z$ oeleti fue. rü. 160.milia : $z$ intumerabiles fe iplos occiderút:z ftatip"itez inte ftiná bellá rome fuit: å mẩi cõ ful fedauit. terruerit romanos: 2 fati $p^{\circ}$ in oiuerfis $p$ uincís oelet'é roma nozu crercitus:ita ut ragai.iveftemerozis induerentur.

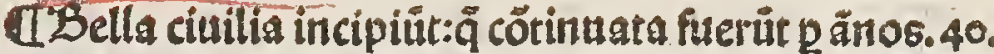
zadeo attrita fuic vabs ut neceflario regimen ipf? $\mathrm{mu}$ tat.ly ad mitos ânos optie rexiffent cófules. Zn felixpz"

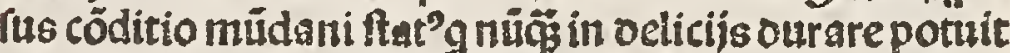

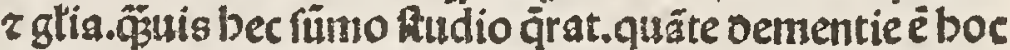
fp fudoze ac fanguie ärere.qơ cũ adeptú fuerit. nullo pa
CUarro marc? octiffin": g tã multa legit:tut aligd ei fer bere vacuiffe miremur.tam multa feripfit:qnanta vix ali quis legere poffit:ut oicit terentius. ULicero marcus tulius maximus rbetoz claret. IT Pompeitus femp victoziofus.22.reges frabegit (t)

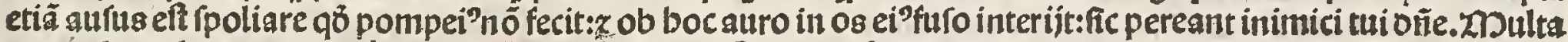
exempla oe bis intueniunt:g nö timent oiutha $z$ clerí oeboneftare:g iuxta pulgare oictĩ:mala mozte pire folent

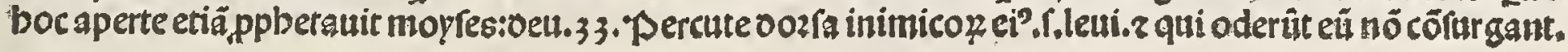

\section{4}

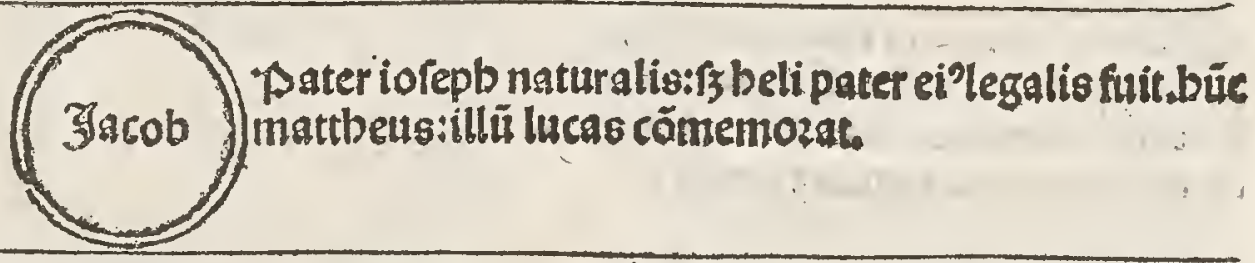

99

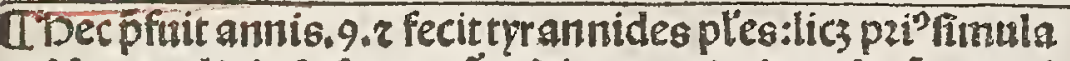
ta feitate:religiola famaret̃: $r$ bircanus in facerdoté pmouit zutp'fe regnaret inftituit. "Dec in linea pontificu ponițppt rupputationé annoż:nó go officiü pōtificale exerceret quod nölicuit.

ITberetis pbarifeo p circabectpa ozit. En nota tres erant fecte in iudea.f.pbarifei:faducei:z effei. Di oês a côi vitã reliquo» iudeoz oiftincti:mult? errozib'implicatippt arperitatévite fanctiozes fe alis oirerüt. Zidemagiftũ in biftozijs cirea ba. ptifmū ioannis. Żtẻ adbuc oue fecte:q quiburdaz afferunticarbonei:z genufte.

TI fimbzia iliu vaftar.i. troiä antiquã romanozü 5 fill fatim eam refaurauit.

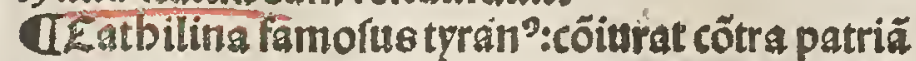
in vabe: in erruria to extinguit occifo ibi catbelina. Fome confcij coniurationis occifi funt.
T Zffte bircanus moztua mre in regno fucceflit:in quo modicum pfperitatis babuit pzopter partiali tates populi: nam fatim a matre fupat' eft:c poft iterü reltitut' auxilio arabū.tandem factus tributa rills romanis in pace aliquanto iem, Dirca, pozeregnauit:red non nomine regis: n'fi.s, inouifime miferabiliter obift:oecept ${ }^{2}$ lexãdri fraude partború quos antigopus cō. tra eum ouxit. vide plene magiftrum oebis.

I Ulirgilius excellentifim"poetarú clar'babet: UDDacius flaccus latpricus.

ISaluftus cripus biftozicus.

I'plotios pumo rome latinä rbetozicā oocuit.

apoflodonicus floicus.

IDecaton ftoic": g oixtt.oẻ boneftú in arduo eft.f vis ama ri ama. Dueris ad perfecerim.amicus mibi elle cepi.

ITRomenumerati füt.400.milia.64.milia bominû:oẻs in cole ciutatis.

ILibzaria.400.miliū libzoz cõburif in egpto:vnde patet quants frsit antiquitus oiligentia in libris colligendis. 
IIres roles apparuerüt in celo verfus ozientể:qui paulatim in vonü cozp\% folsre redacti rüt. Brande fpectactulus

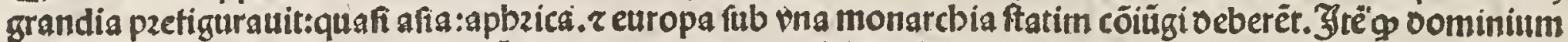
lueijantonij: z marci antonij in vnü rediret. Sz potius noticia vni? r truni dei:toti ozbi futura iminebat.

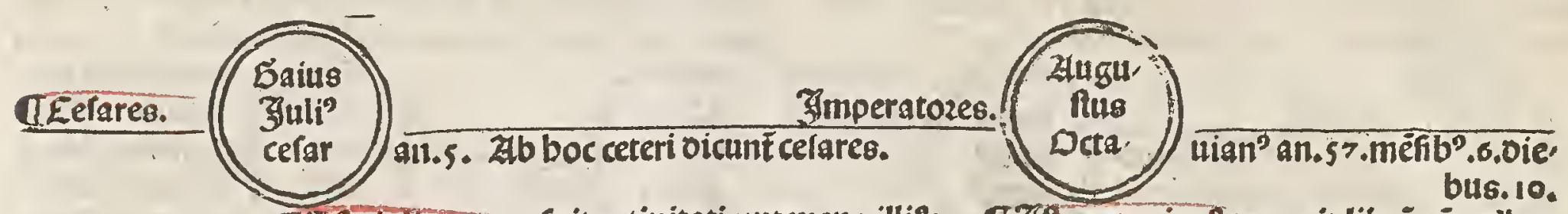

C'sfte iulius tante fuit actiuitatis:ut mens illi ${ }^{2} r$ man'ad impoffibilis ferme fuffecerit. 52 . vicib' pugnauit fol? $\mathrm{mar}$. cü marcellü fupgreffus:g ter centies nonies ferẗ pugnaffe. bic pom peio ac ceteris nobilifimis romanis occifis imperiü arripuit. Lan déanno. s.imperif́rui conf́piratióe bzuti: ac caffij oolo occidié ipłe

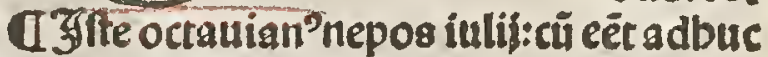

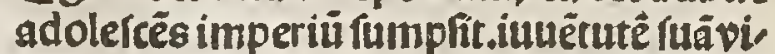
rilibus actibus oecozauit.gnğ milia bella geffit :z bzeuiter torü müdüpoft multa bel $\left(\begin{array}{c}\text { Eleo } \\ \text { patra } \\ \text { an.20 }\end{array}\right)$ oomitozozbie.

la in vnã tandê monarcbiam redegit. $X$

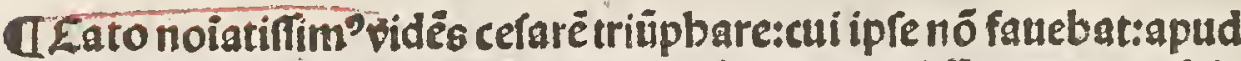
vticâ feipfuz occidit:iuxta illud.2nauult cato mozi ö oeroget vzbis bonozi:\{yppter boc fm augl nó excúat a peccato.

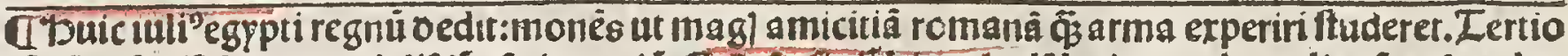

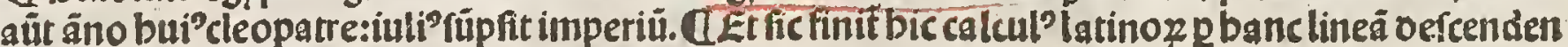
tium ad rp̉m:z fequit fuppuratio anno zplineam romanoz.

QBos loquit aranti. In bretui magis oe finent boies ä̧iumenta:nel ut quidamli bribabent frumenta.

USceptrú oe iuda aufert: $r$ our oe femo. re eits: gz in pzoximo fanctus fanctozì veriturus eft:iuptappbetiam iacob.

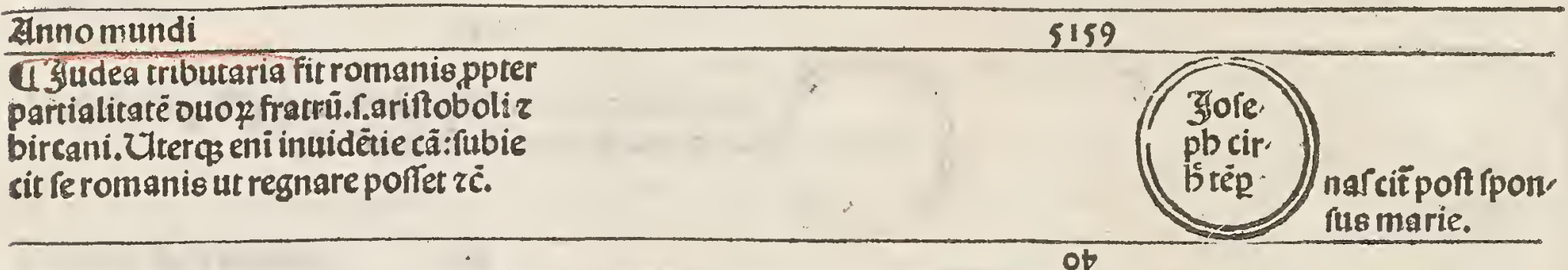

Q Jfte antigon ${ }^{3}$ fili? ariftoboli pbiqs infideliter egit:nec romanis obediuit:magnå plagã terris intulit:ut bircano expulfo regnare poflet. 'Kegi eni partboz p20" mifit talents mille: $\tau$ virgines gngenta 6 :ut fe iutaret: Lifania nepote fito id pcurante: 2 fic bircan ${ }^{\circ}$ ciectus eft: fa' felus occifus z ber odes fugatus. Ş cü berodes romā veniffer:r fenatui cūcta narraffet: auguftus eū regez iudee creauit:mittens cü co exercitui:qui bierufalem ceperüt: $\tau$ antigonü captü ourerüt ad antoniü:qui eü fecuri peuffit

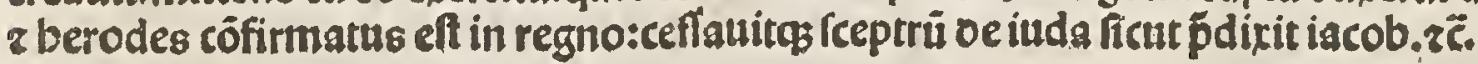

TScipio feipfum iugulauit.

d. Guba rex itigulari fe fecit.

Opetretus glado fe pfodit:? multi alij oe nobilifimis romanoz:q2 noluerü iulio fubdi:aut timuerüt ab co occidi:ficut plures iam occiderat.

IIítuslinius biftozicus.

Imparcus calliditue-0zatoz.

I Diodoztt8 fariptoz biftozie grece

CDúdius 119 To.

I. Bains falcidius.

iLoinelius biftoricus.

Tomarcus varus:bicait. 'thibilmagni" ficum oocebit:ga fenibil oidicit.
ILugdunu cödít a minatio plauto
ozatoze:qui fuit oifcipulus ciceröis.

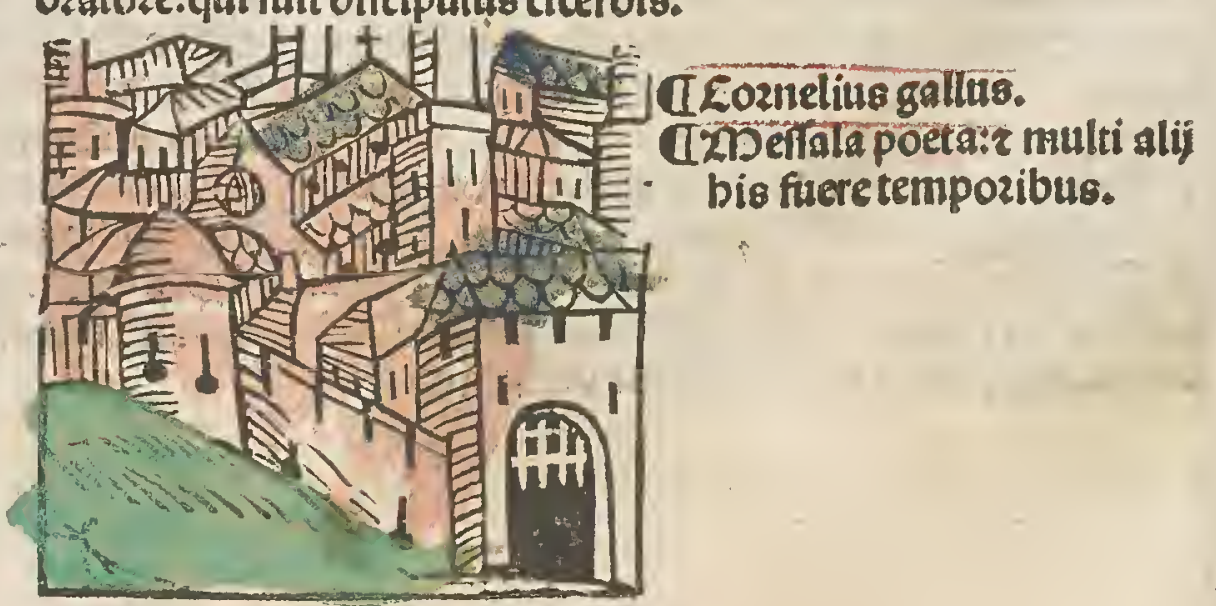


IRoma in floze; numerati funt ciucs eius z oeferipti nonagefies trecentena milia 2.80 .

Ciues fónas: : đUalerits maximus fuit boctpé vir magne fame.

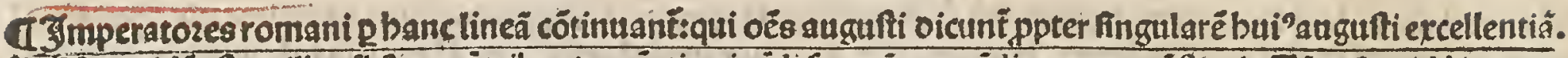

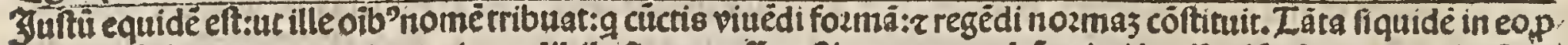

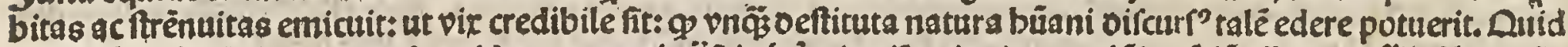

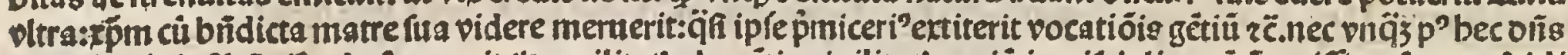

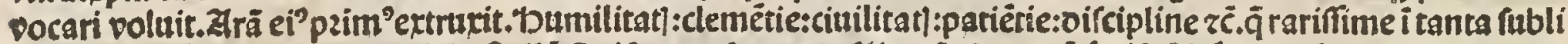

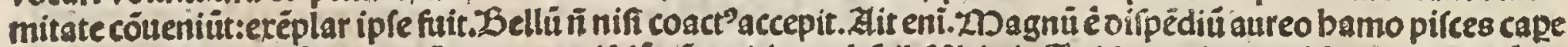

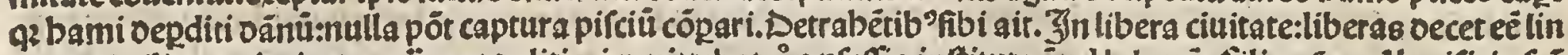

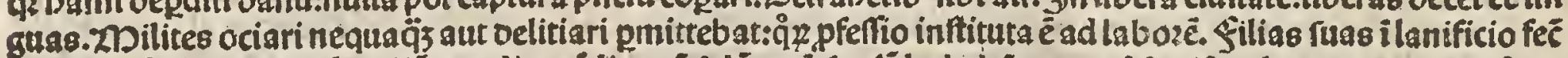

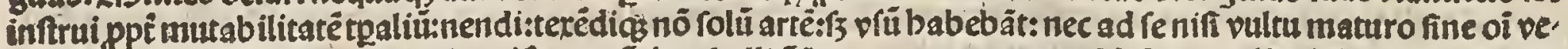
ftiú curiofitate accedere pmittebat. Regna ă iure belli äfierst pzeter pauca reddidit:aut alienis benigne tribuit. Ieftéfe i indicijs introgari:z repelli equanifino gio patiebaț. plures babut fibi marie familiares: $q$ cü meli"

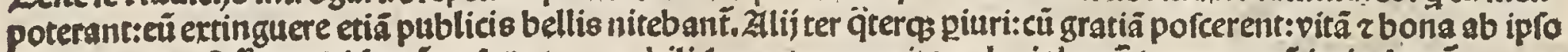

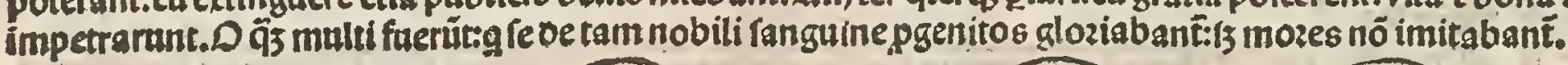

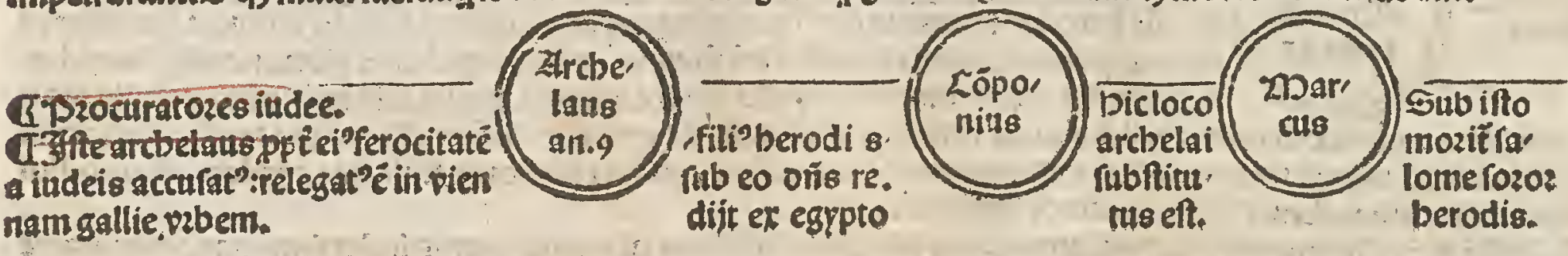

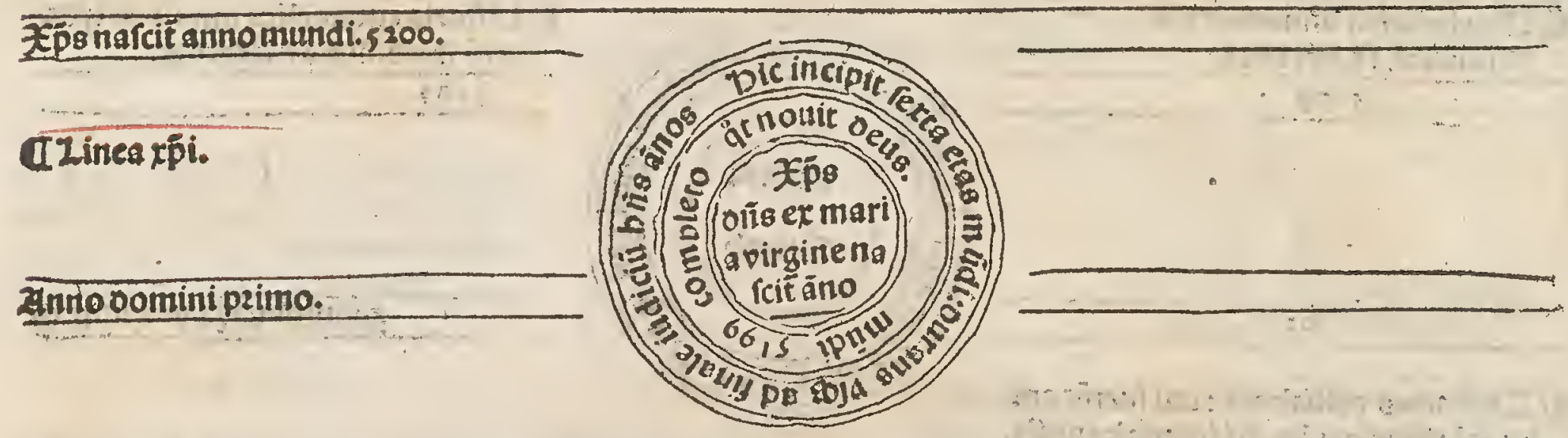

IThonulli reges in Donozêbuutce ciuitates cỏdebăt:quas cefareas appellarêt:ficut in mauritants r in paleftina:que nunc $v 2$ bes clarifí me funt. Et multi regesex regnis fuis vencrut:ut el obfequerent."

a that eft circa bectpa oriz nofter be virgine pura notio ozdine: $\mathrm{sm}$ ppbetica pmifla. Et becé plenitudo tpis oe â apl's oicit: quî̀ mift oe? filiú fuu i müdü. $Q b$ boc incipit bic ferta etas múdi: cuip finé fol? oe? nouit. Et oicit auguftin? $\phi$ bec etas o icit fenect? :q fepe extenditvltra

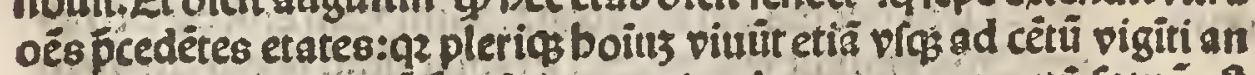
nos:aut vltra. Etrioti e 9 feragenarios feries vocamus: vi fatuú eft velle oeterminare quotitaté e $^{3}$. Plures eni boc attétarutt:g oés fuere oecepti:ficur pzobat ooctoz fanctus zé.

TErs rpiano p pncipalifima:omniti eraznotifima:celeberrimac: iple é.ann"octauiani. $42^{2}$ :olympiadis cétéfimenonagefimettie: $2 \mathrm{fm}$ bedã ân" múdi: 5 199. cóplet" onde perfus. Unú rolle oatũ:ad milia gnq; oucentis. Thácenti oito: beda oat a ptboplafto. Ttem: aî xp̆m

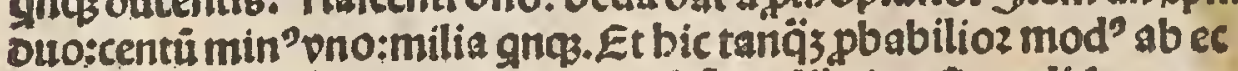
clefia feruat: $z$ eft magis pulgatus. Sut $z$ alij oitterfi modi fupputa tionū:quidä bzeuiozes ut bebzeozū: quidâ longiozes ut metbo dií $z$ alio z:0 quibus imenfus eft taboz tractare:vtilitaevo modica:vide fingulg tocis fuis $z i$.
UDe pripatti romano fic oicit cicero in li. oe officl. Lertü é fuifie aliqö tépus å fi. ne regibus viteb at. at poftọ̆s iure gentiü pofferfiones ceperü oiuidi: nö alia oe cã reges tût iniftituti:nifi iufticie fruëde. Thã cui initio. poneret multitudo ab bis g ma iozes opes babebant:ad vnü aliquẽ virü cöfugiebät virtute p̂ttantē:g pbiberet in. iuriaritenuiozes equitate cốtiturendo fü mos cü infimis pari iure ptingeret. Cüqs adbucregnantib? regibus oebiliozes nô

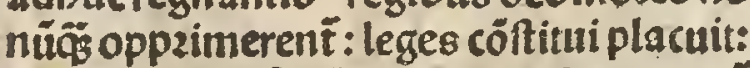
q̃ad iudicandü nó odio aut grã oucerent̆ is tales inopi äles potenti ṕftarent aures ấ fit ut leges nó folü populü $f_{5}$ regé quoğ obligare fciam', at fi regë cōtënere leges: rape bona fubdito: : violarevirgines: Itu pzare matronas: $z$ cetera illicita facercívi deamus:unquid illo fubmiffo: ali" fubli, mabit̃:g z bene gubernare: $r$ legibus no uit obtemperare. 


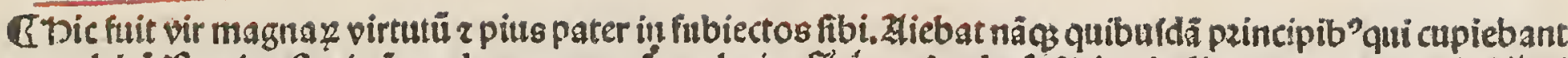

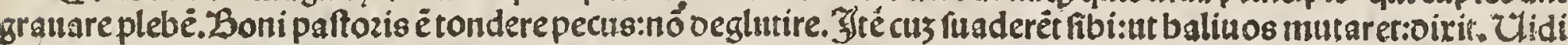
quendä:murcas egri vulnerib'infidentes fugare:qué eger inculpauit:oicens. Quoniam venture für ritibunde ut

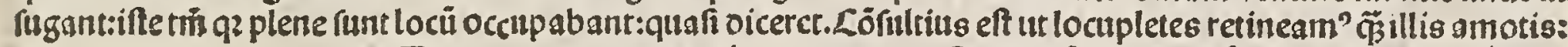

- octauiani ado ptione filius

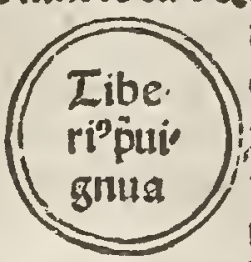
oenuo tenues oitare cogamur. D maanü patudentifimi viri confiliu. Taliter eni quidâ frandulenti folent infidiari p̣ncipib?: ut fes cōem populü cótra eos puocent:quo facto:lciut quoniã neceffarij funt eis: cogentes oeinceps eorde videlicet tam pincipes ö populü ficut volüt ac fuis aftutijs magis magifọs in uoluẻtes. Mnaxima pzudëtia pzincipü eft:ur fe taliter agant: ne plebib"exofi fiant:oéfó cōtrariü ruadētes:abijcereftatim oebent: ut famä fuã oilatent: $q$

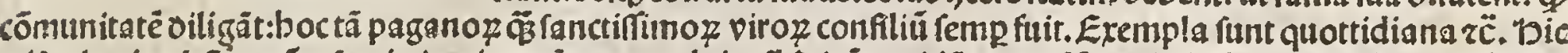

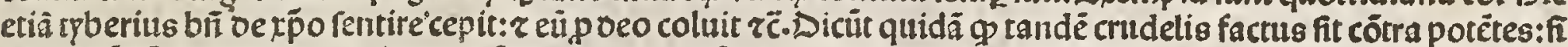

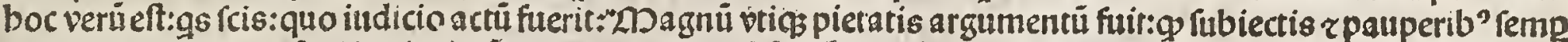
gratiofus extitit:pacẽ etiā babuit cüctis oiebns fuis. Dès xp̄i acxṕiano y cótradictozes:fine vlla miferatiōe oele

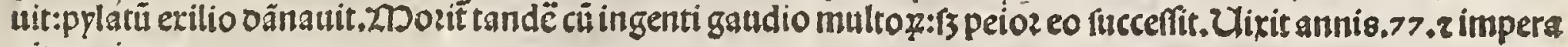
uit annis.23.

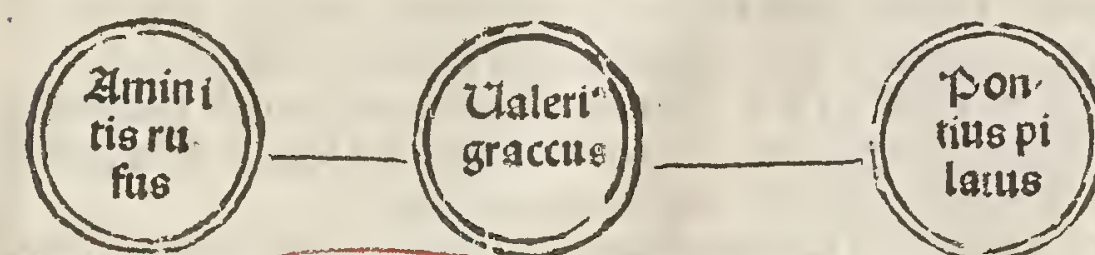

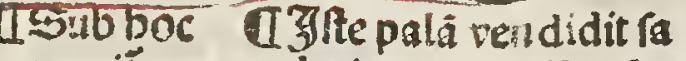
mozit au cerdotium. Duipl'oedit guitus. ille obtinuit: 2 fic plures in bzeai fuerunt. care zoñ $\mathrm{paftus}$ é:qué iple ob timozé céaris iiufte oãng uit ad mosté crucis: $t$ io p’ milerabiliter perijt feiplü occi dendo. De funere aut bui?mirabilianarrant.
¿Sup oía mabilem te mibireddit calix quë bibifti:ait Bernardus.

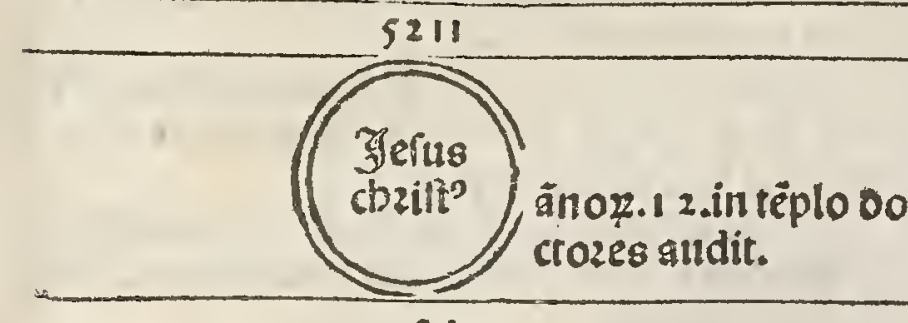

21 5229

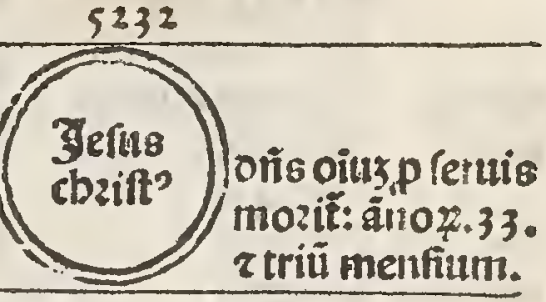

33

I'Tota 9 nibil repit oe ifantia faluatozis $z$ opib"

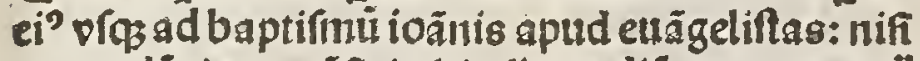
q) ouodēnis remãfit in biertm qudiés ooctozes rë

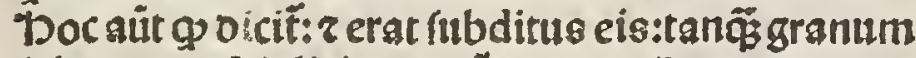
falutare multipliciter terit a oostozibus r oenotio pronis: vras bodic conantib" pruadere ä fuerit con

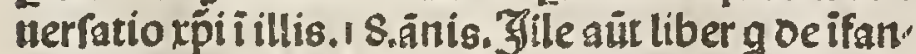
tia faluatozis ititulat: qz iam oitu inter apocripba oeputatus eft nil auctozitatis affert:nec verifile eft q talia biuina opa z gloziofa miracula pueriliter inter pueros fecerit:g vix tpe ob bito ad buimodi facienda portuit etiō a matre fua bindicta inclinari r filr aptis rê. oixit eni. Nōdum renit boza mea: $r$ nó fum mifus nifi ad ottes ifrael $z \vec{c}$. Zु) git omnib? credere: nulli credere:eque vitiofum eft.
30

TEircabectpa:grande pectaculü mudo inotu it a feculnō auditü:reue Intio apta btiffime trini tat|. Dr i voce:fili"i car ne:fpüfris irpé colübe z bicvngit nobis xṕsve rus faluatoz i lege pinif lus:gē via: beritas z pi ta: ₹ pter quẻ nõ eft fal? క̧ă annoz. ooctrine ipfi" $\mathrm{fa}$ lutifere: cum miraculis plurimis gloziofis ä lia nüäร vifa füt.

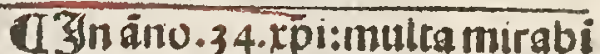
lia facta fuerúc. Thä ipro oie par. fionis eius: terra tremuit : petre rriffe rü:fol obrcurat? eft:ut p3 in euāgelio. Die parce oris refture, rit cu multis $r \ddot{c}$. Deide poft oies 40.gloziofe in celü arcendit cum pda magna $\tau$ č. Jn oie pentbeco ftes venit fpültcüs fup aplos rc̈. Et bec oiante falutis eterne funt: facramenta in gous oellotemen tes quottidianá iueniüt refectio. rie. Destus q verfát in bis: quor niā fructũ pcipiet fempiternü.

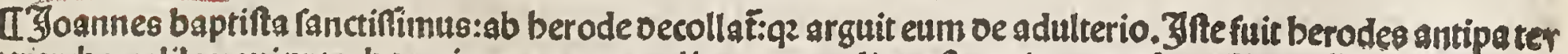
torarcba galilee:quippter boc crimen z temporaliter z eternaliter eft punitus cum berodiadezö. 

effe poterít:quā glozificauit tota fimul btã trinitas:quā oefendit oina maieftas:quã illuftrat oin claritas:quẩ regit oina bonitas:cui'caput xṕs iefus:ver' oeus r bõ :cui? ciues oés electi fït:cui? niftri angelisilli briffimi f́pús crcubantes fupza muros ei’oie acnocte. 'Dec eft quā edificauit vni. genitus oei fupza firmä peträ:nec pozte inferi pualebüt aduerfus eã. 'bec eft fyon illa oilecta:cui’ poztas oiligit ooninus fup tabernacula iacob. beceft f̣onfa illa imaculata: nõ babens maculã neqg rugam : quã nö vili clenodio: fed ṕciofo fanguine fubarraut oominus. bec eft mater pulcbze oilectionis z agnitionis fancte [pei : que filios generat in eternum regnaniros. Tanc pzenunciauerüt patriarcbe. $X$

Eredo in oeĩ pa.

'petrus tréoipotenté crea' tozē celi z terre. Et in iefin xṕm filiü

Zundre eius bnicam orim

ab. noftrum. Dui conceptus eit

Foan, oefpúfanctonat?

nes. exmaria virgie. Daffus fub pootio

Jacob" pilato: crucifitus: moztt'r repult? Defeendit ad infe,

Ibo, ros:ctis oierefur-

mas. retir a moztuis.

arcendit ad celos

3lacob" fedet ad oetterain Zimos Dei pris oipotent?. 11 .

Znde venturus eft

'pbilip' indicare viuos 2

pus. moztuos.

Eredo in

Dartbo fpiritum

lomeus fanctum

Sanctam

200t' ecclefiam

theus. catbolicam. जิcö́t cốmuoione

Symon remiffionem peccatozun. Carnis

Zutuas. refurre

c

Etvitam

Ima. eternam.

tbias. ZAmen.

lacbi 35. $?$. अeçe

biel. 3
'Dierëi "Patrem vocabis TExodi.20. Thöbẻbis oeos alienos cozä me. Defaie 45 a8.2. me:rp'meingre di nö cerfabis.

Zuba Ego autẻ in oño

cac bl gaudebo: rexul

timo. tabo in oeo iefu meo.

Ego orìs z tî é alter creãs tenebzas:z fozmās lucê. ồ fal.

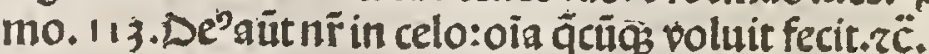

["ptalmo.2. Dns oitrit ad me fillus me es tu:ego bodie

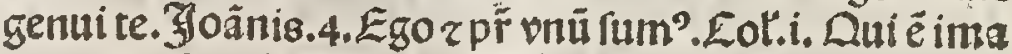

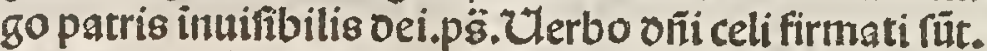

Qbieremie.31.20utier circuidabit virum. Balatbas.4.

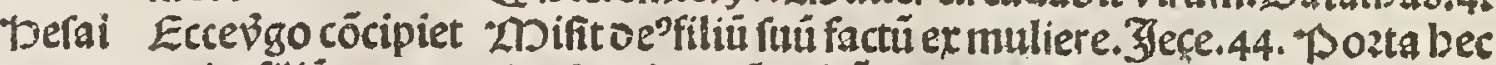

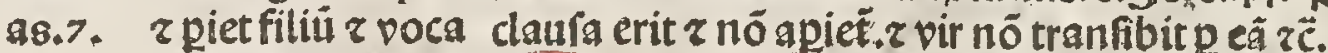

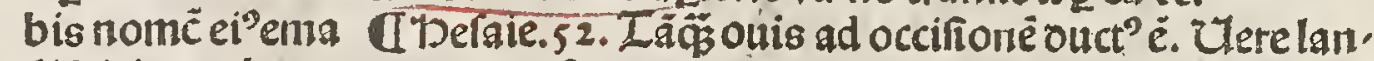

Zaca Zfipicientad me guozes noftros ipfe poztauit. prima petri. 3 . Xps femel

rias.2. quem côfixerút: $\tau$ paflis eft p nobis:iultusp iniuftis.

plangent eum. QPB 15. Tlecoabis fanctü tuä vidë cozsuptionë.Epbe.4

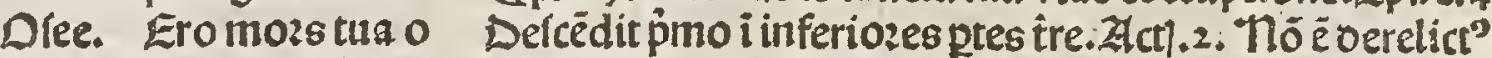

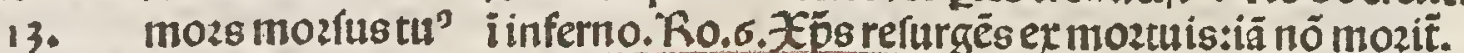
ero inferne.in oie Ip3.67. Iter facite ei gafcédit fup occafum. Et ibidem. tertia fufcita no8. Żicendit in altū:captiltã ourit captiut tatem.27Dicb.2. Edificat in celo zarcendit iter pandens ante eos.

ma afcēfionéfuã oris

nomenilli.

a8.3. Zarcendazad vos

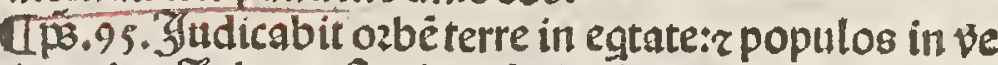
ritare fina. Job. 19. Sugite a faciegladij: qin vltoz inigta

Zoet in indicio: zero

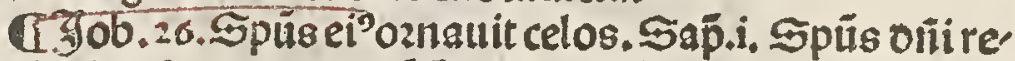

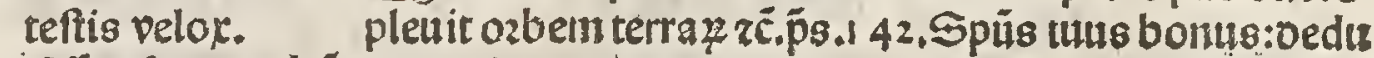
$2^{\circ} \quad$ Effundam oe ipü cet me in terram rectam.

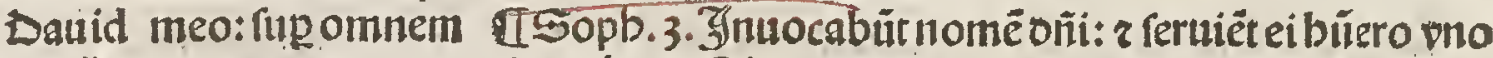
in p̈̈. carnem. 2Dattb.13. Si peccauter it i te frater tu?:oic ecclie: 9 fi ec

Eöfitebor tibi in

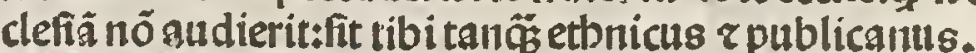

20Di ecclefiamagna, Tp3.118. Particeps fú oiuz timentiü te: $z$ cuftodientius cheas. Depöet oés iniq' mandata tua. Эeçe. 18. Ulillo ego oicit oñs:nolo moztes tates nĩas $\tau$ proí peccatozis: [3 ut cóuertat $z$ viuat.

ciet ipfüdü mar]. I\$ob:19. In nouifimo oie oe terra furrectur? fum: $x$ in

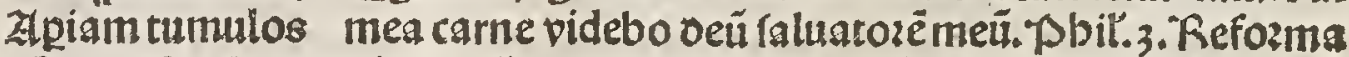
pros z educā pos bit cosp'bumilitatis noftre: nó figuratū cozpi zč.

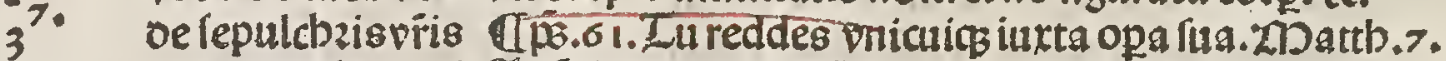
20ulti oe bis qui בुbút bi in fuppliciü eternù iufti autê in vitā eternam. Dani, oozmiüt ipuluere 2. Eozintb. S.Domi babem?nö manufactā in celis el.1 2. terre euigilabunt:

alij in vitam alifí in oppzobziū ut videant femp.

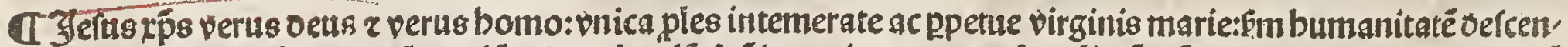

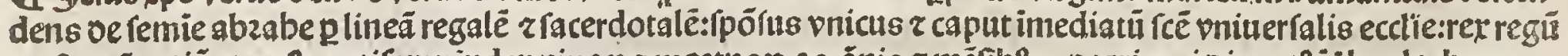

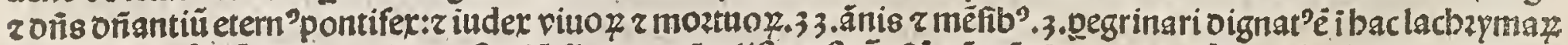

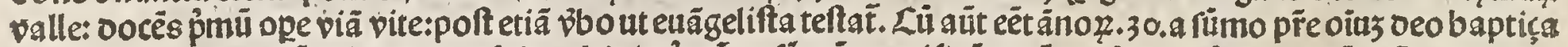

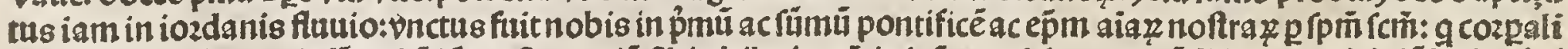

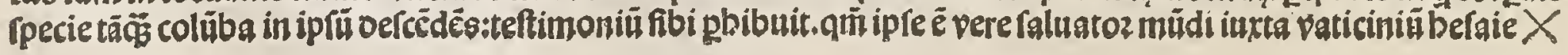




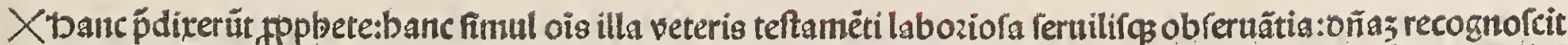

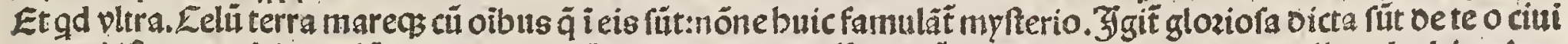

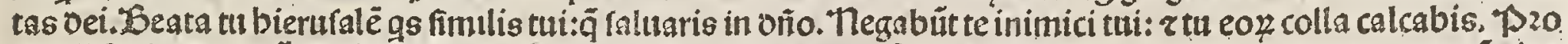
patrib?tuis nafcent tibi filiînec oeficies in fempiterna fecula. Benedic oĩe fortitudini eitls: $r$ opa manuñ eills

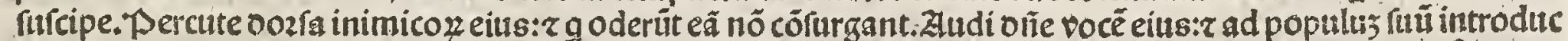

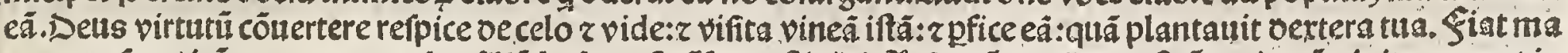
nus tua lup virü oertere tue: $z$ fup filiū bois quẽ côfir pnitate ípü fancti oeus in omnia fecalla benedictus. Zmmen.

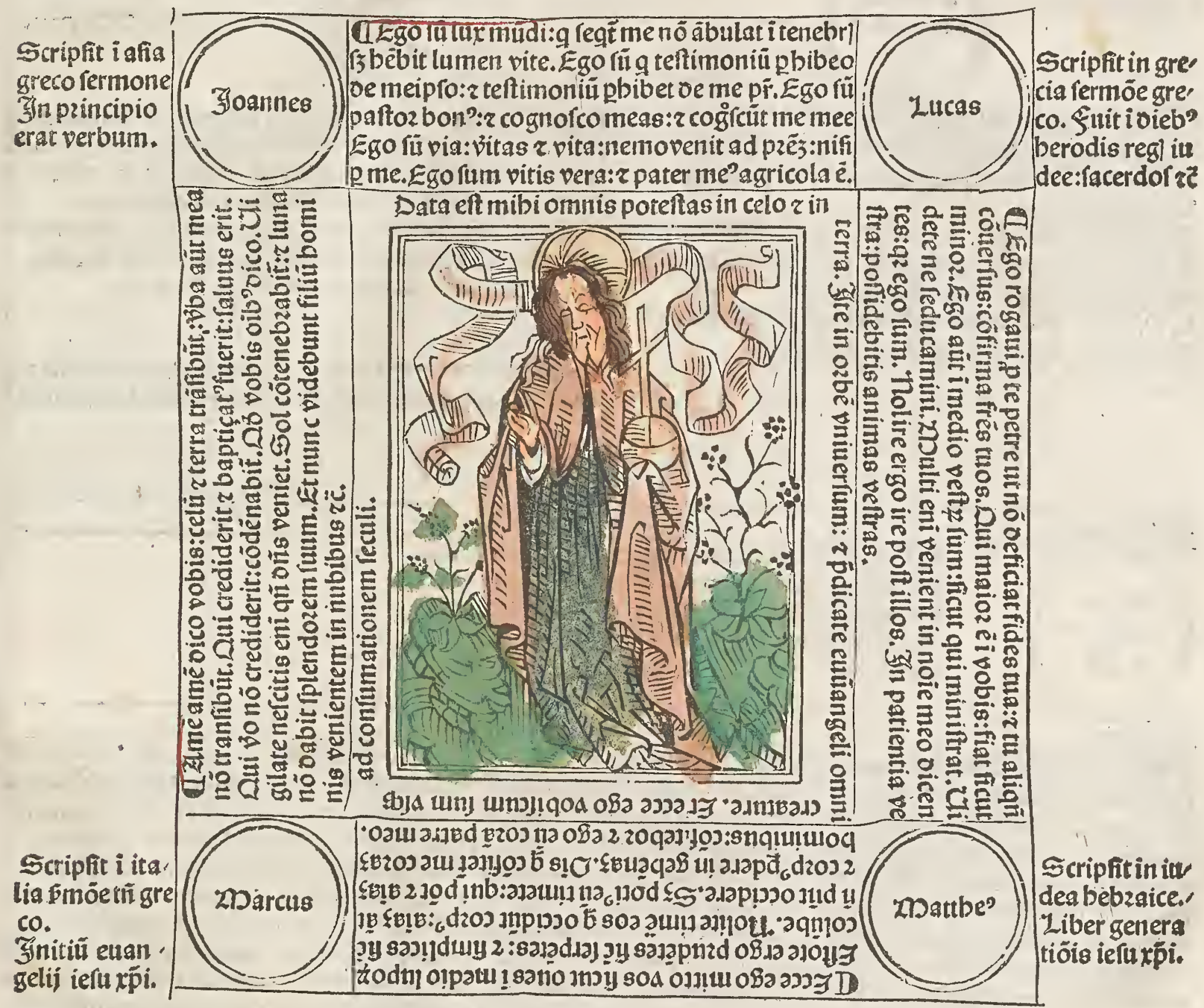

Xppbete fancti.bic elegit oilcipulos.72.quos mifit ante faciē fuã:z.1 2 .apoftolos quos mifit in oz bè vniueriu ad pdicandü euãgeliü:nec ampli’

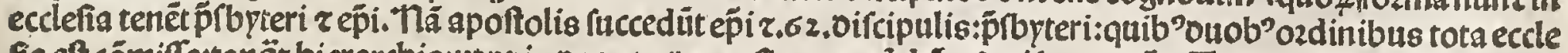

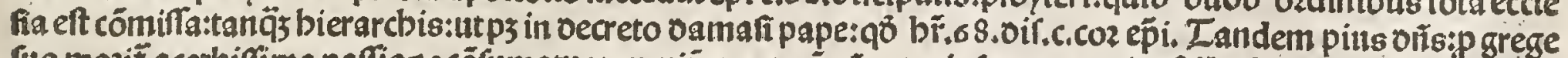

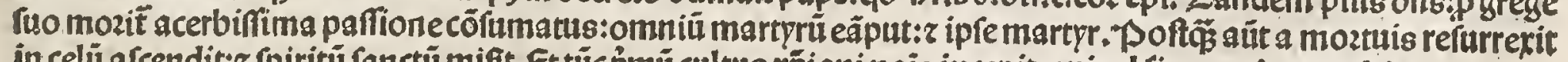

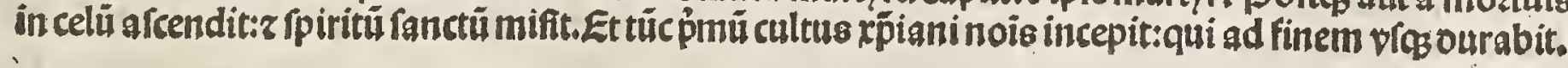




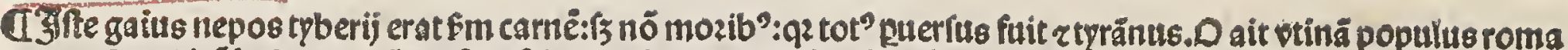

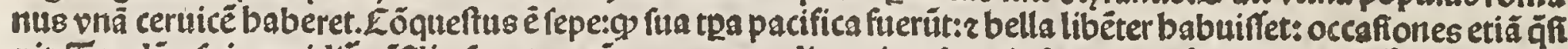

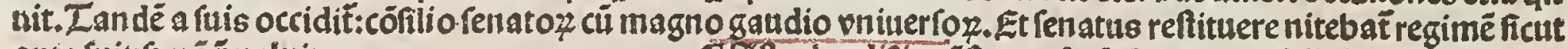
ante fuit:\{3 nô pualuit.

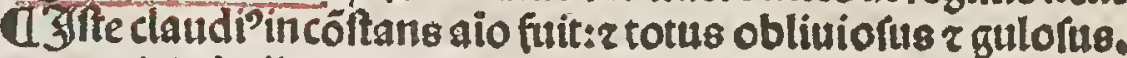

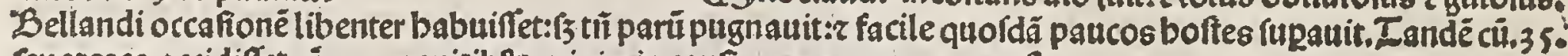
renarozes occidiffet cú. $300 . e q u i t i b$ 'p minimis caufis.penento moztuls eft.

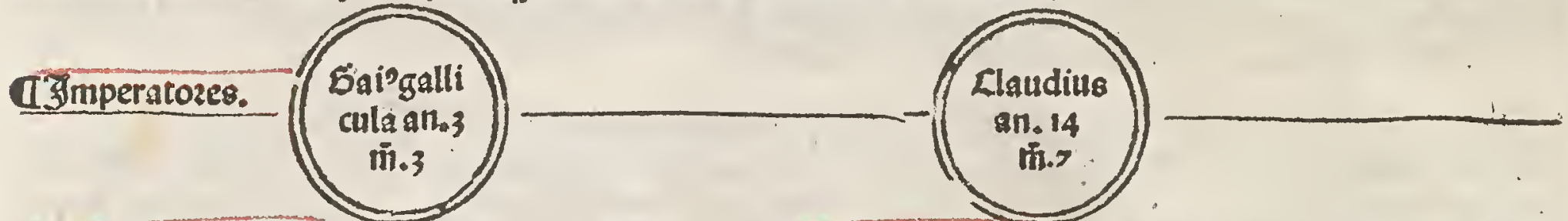

T'biftozia actui apto zbictexit.

Spüs faús venit fup spftolos in linguis igneis.

UEtbic osit cultus xpiani nois.f. in oie pentecoftes.

fmanguftinü.

CStephan'lapidatz ptbomartpr inclyt'oño cöfecrat. đIsaulus piternit:z paulus egregi’pzedicat oz erigit qui babundancipoibus labozauit.

IT Thilooilertifintus:cui? libzi inter ecclefiafticos computanẗ:clarus babet̃:nationeindeus.
I3 I cob'maioz apl's:martprio cozonat ab berode agri pa:z petr'incarcerat:ut p3 actuil. 12. Eozp' aüt bri iacobi miraculore tranffert in galiciam bifpanie: $r$ ibi eft fedeo patriarcbalis $p^{p}$ facta:äfi a finiftris répectu rome.

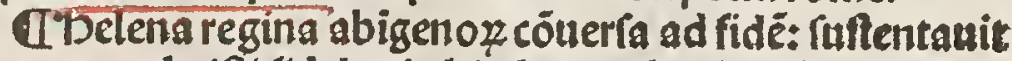
paupes cbrifti fideles in biertm tpe famis fub claudio. IPperronella filia fancti petri:

đIAffumptio marie virginis gloziofe matris oeisfacta e 12,ãnis elapfis poft afcentionẻ oni xp̃i:Ğ bieronr̨mū.

\begin{tabular}{|c|c|}
\hline Znno mandi & 5233 \\
\hline $\begin{array}{c}\text { iude? put? } \\
\text { papa }\end{array}$ & 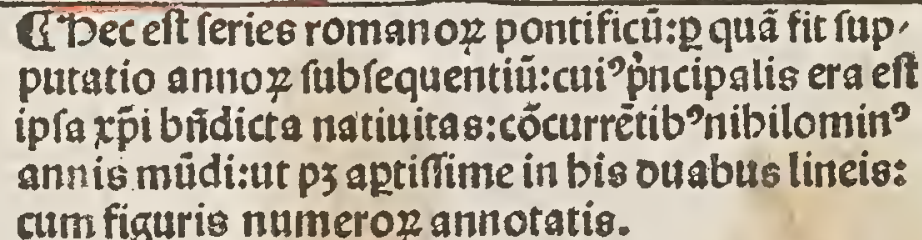 \\
\hline
\end{tabular}

Anno rṕi.

34

44

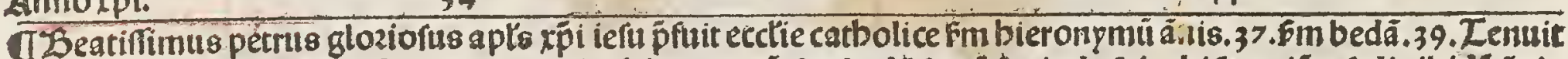

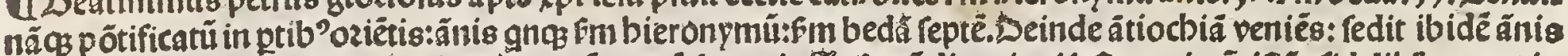

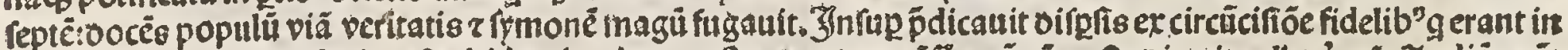

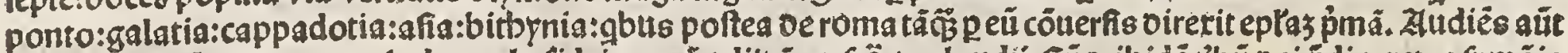

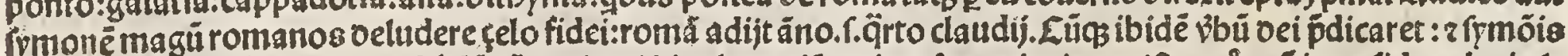

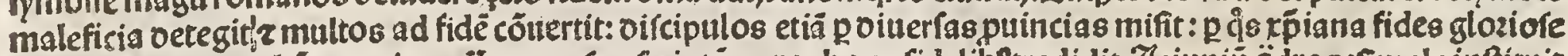

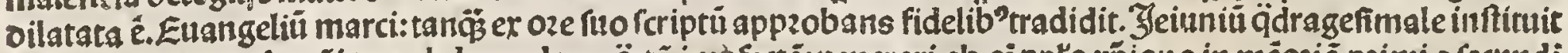
añ parca zañ natale oñi tres ebdomadas z ärtã imṕfectä: venerari ab oipplo xp̣iano in mēoziā pzimi z fecundi

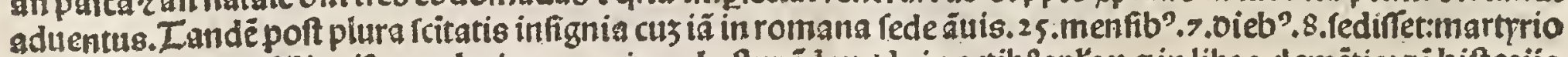

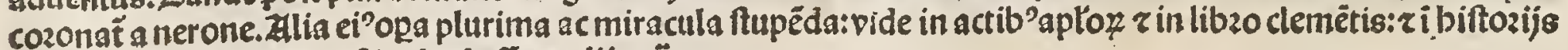

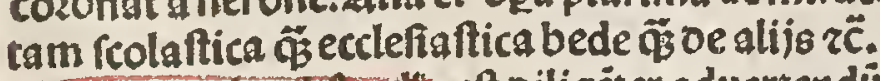

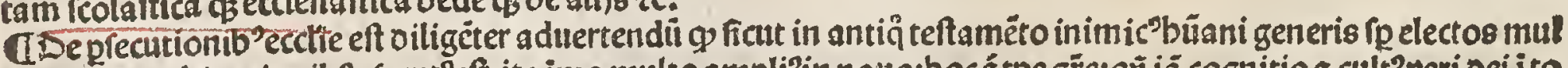

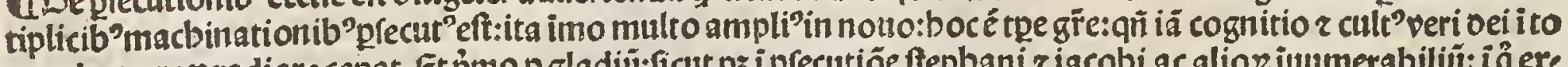
to ozbe terraz radiare cepat. Et p̉mo p gladiü:ficut ps i precutiôe ftephani r iacobi ac aliox iuumerabiliú: $i$ ả ex.

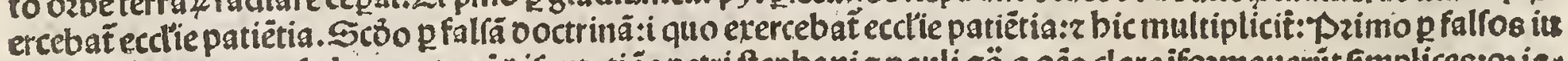

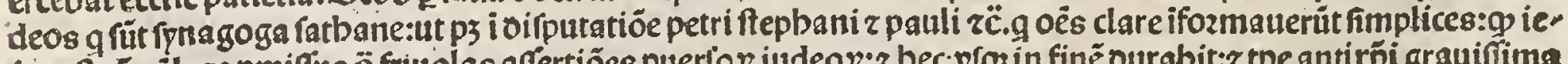

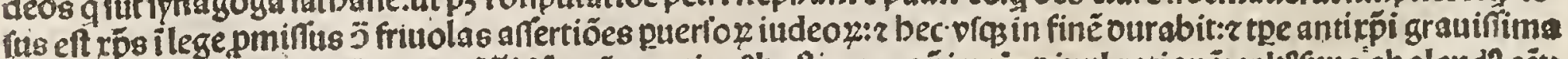

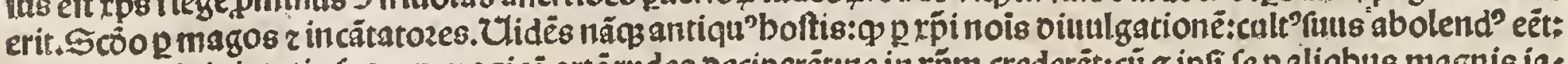

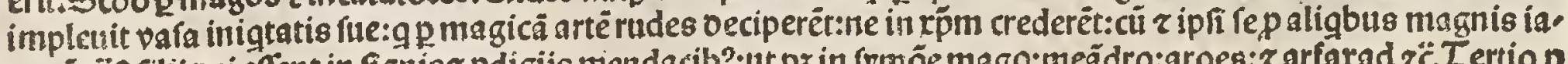

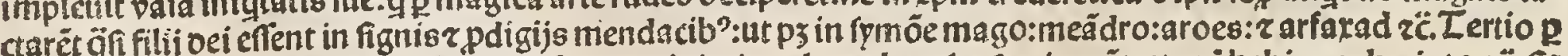

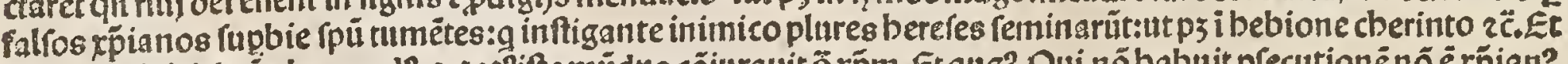

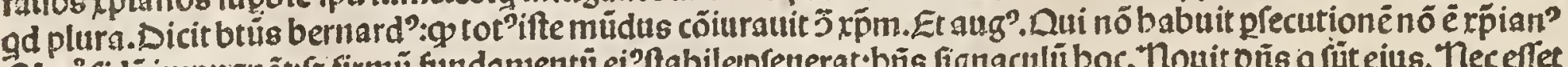

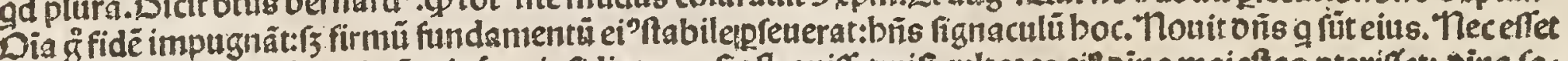

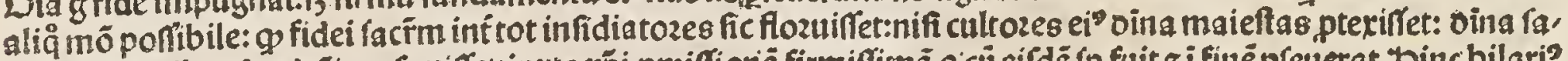

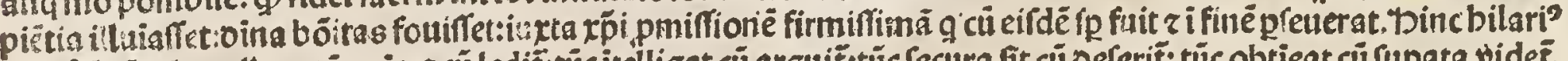

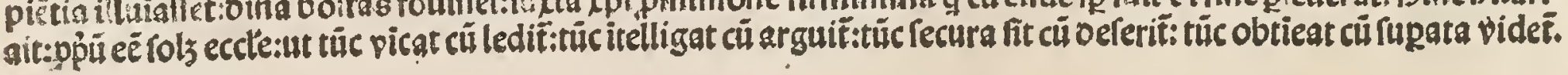


ISeneca ftoicus clarus babet:magitter neronis a quo poft cosct?é feipfiu occidere.

TPperfitus latpricus

a.suenalisatyricus.

¿Lucanis poeta:patru?

renece.

TDuidins poeta.
I'Refert feneca oenerone: $q$ erat nataraliêab in fâtía f́p clemêtiffim? 2 ita gratiorus: qr nemo vnộ populo romano gratioz fuir:ita $q$ in oblinionem venerüt ceteri p̉ncipes:ppter fauozis magnitudine Ulez ptãs multos pzobiflimos fecit atrociffimos.

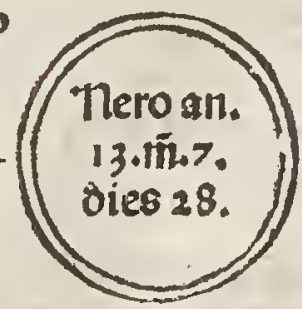

Tparilla rnitueratis totins oq, bis quâ romani babuerit p an. nos ferme.70.ppaucis bellis ex' ceptis ac paruis circa bectpa pzo pter fentitia neronis turbota eft $\tau$ pzouincie quedam recefferuntab obedientia romanozú quia fidez cbziftianã perfequi ceperant. die pzo aliquo peffimo poni folest: $z$ qz contra optimam rṕi legem paimä rurcitauit pfecutionem:merito antixp̄i figuraz tentuife oefcribit: Tanden a fenatu boftis pzonüciatus cū turpifime fugeret:feipfum occidit anno etatis fue. 3 1. 2 letata ë roma quafi pictoziam obtinuifer: contra al iqué peffimü inimicü cultiozibufos veftibus fe induentes epulati funt.

U'J acobus minoz aplus ac bierorolymozü ep̣u:a iudeis occidif anno fexto neronis.

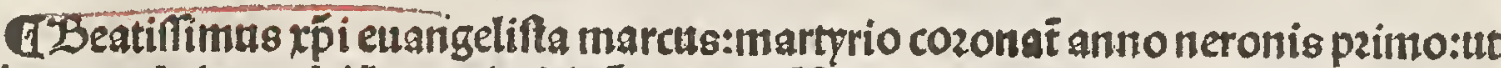
oicit pbilo cötempozaneus cius:apud alexandziã egypti:vbi epus erat cöltittus a beato petro:fepultus ibidem miraculis claruit: $\tau$ fucceffit ei anianus vir fanctus.

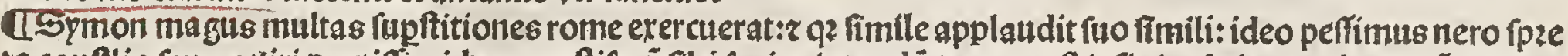
to conflio fenece viri ooctiflimi bunc peftiferü fibi fociauititandē ptercs poft infinita icelera:in baratrũ oamuna tionis eterne turpifima mozte oefcendit.

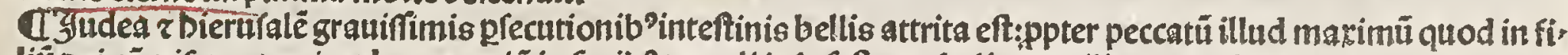
liü oei cómiferunt: $z$ circa bec tpe etiã in fozib ${ }^{9}$ templi ip fo fefto parcali. 30 . milia necati fiunt : $\tau$ continue ourauit oiffentto:Donec penitus deleti funt. Barrabam enipetierüt:z nô iefum mitem z bumilem.

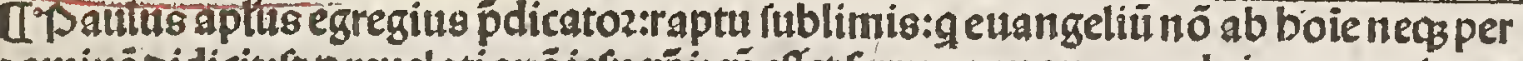

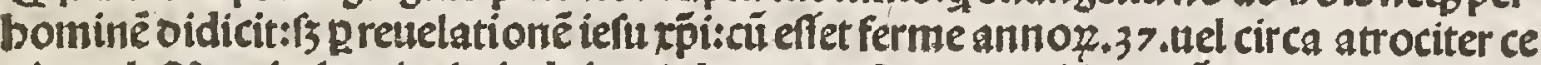

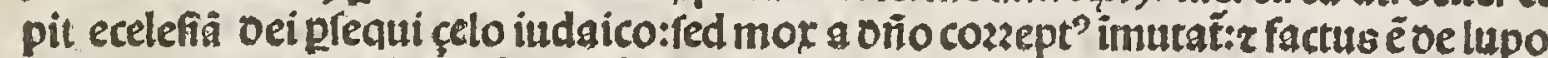
agnus:oe píecutoze fidéliffimus pódicatoz. Znno autẽ. 14. cöuerfionis fue:apoßtolatü

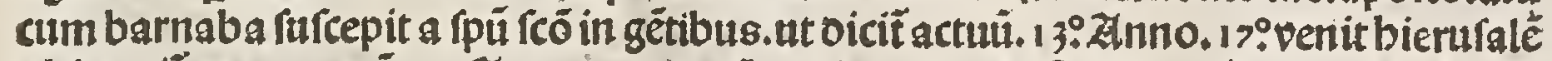

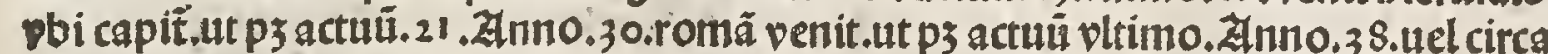
cü beato petro:a nerone martyriü pafius eft:bic inter fanctos tam ialtitudine côtem

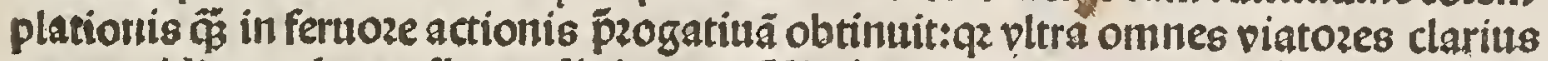

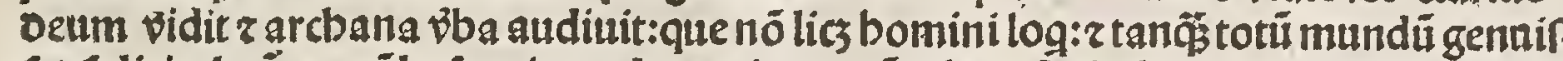

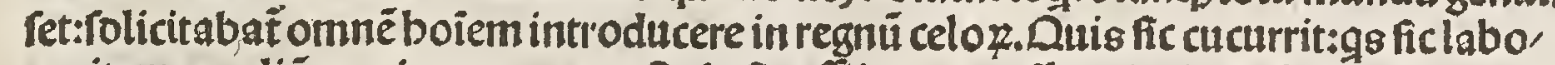
rauit:euangeliü grecis erponens:'Quis fic afflictus:pcuftus piculis infinitis excoctus Quis fic gloziari poterit:ut oicat: $p$ lus omnibns labozaui: $z$ in fapientia mundana: z confilijs buius feculi falus omni iufticia z fide: gs fic emicuit:ut etiã amplifimo fe' natui miranda contulerit:eius laudes iognnes chaifoftomus oeferibit.
The udentiana virgo.

1'praredis virgo. befuerüt forozes timor tbei rnouati.

CLonftentia martyr.

QCitalis martyr.

Tlacarims marty.

CLelíus martr.

Opzoceflus mart\%.

Uzmartinian'martyr.

Iprotalius marty:

UEeruafius martyr.

a Lorpesmartyr.

Gelix martyr. 


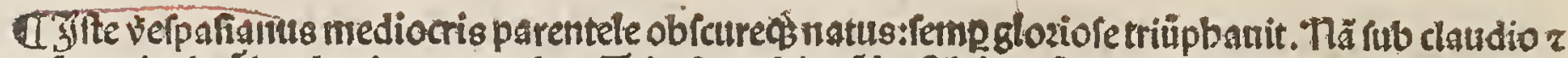

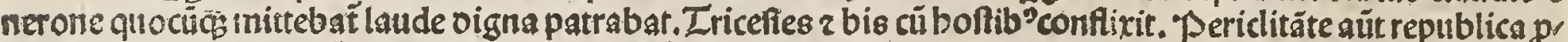

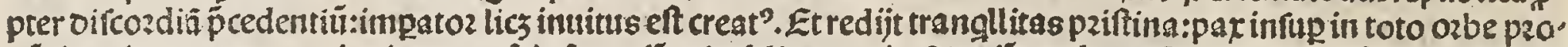

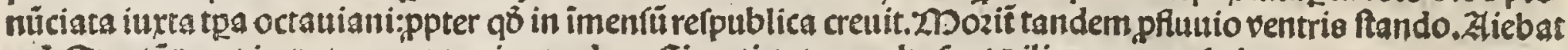
eni. Stantê oecet impatozem a terris recedere. Eius virtutes multe funt oiligenter conicripte.

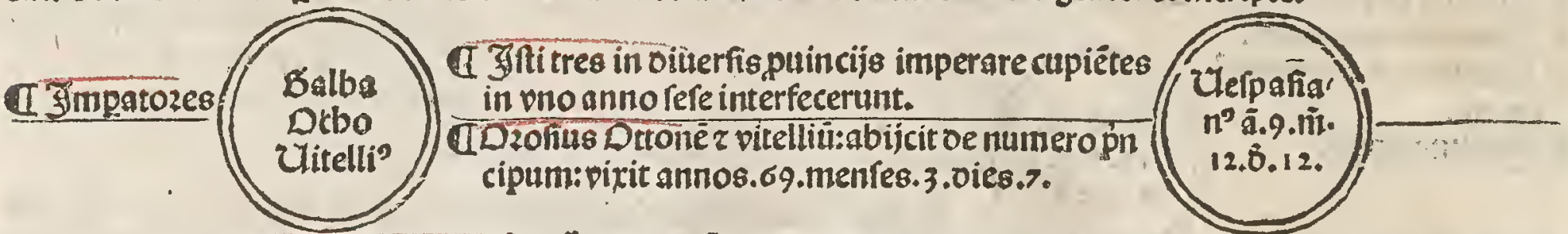

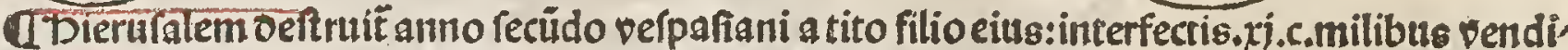

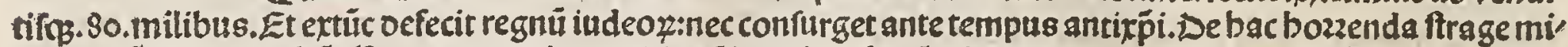
ra legunt: vide iofepbü. Thota $\$$ ppter banc vltionēlegittime factä:oicunt doctoses $q$ in toto múdo xṕus pacem tribuit ficut in natiuitate fecit.

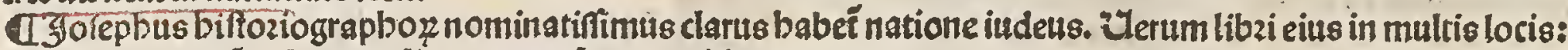
vitio f́riptozü ac longitudine tempozú cozzupti funt.

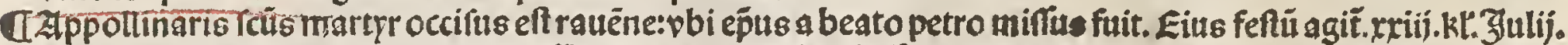

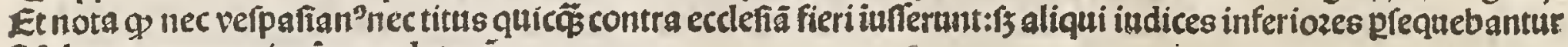
fideles pzetertu pziozi mandatozu.

I'perfecutio pzima fit rome itufu neronis in qua beatifimi pzincipes cbziftiani populi.f. petrus r paulus mar tyrio cozonati funt ci alijo pluribus.

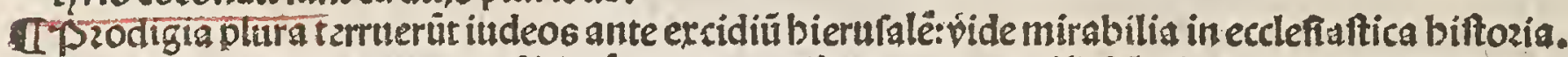

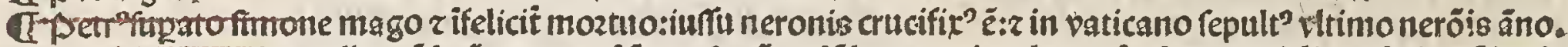

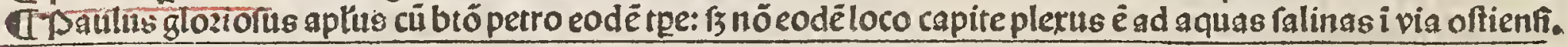
zanno mundi 5273

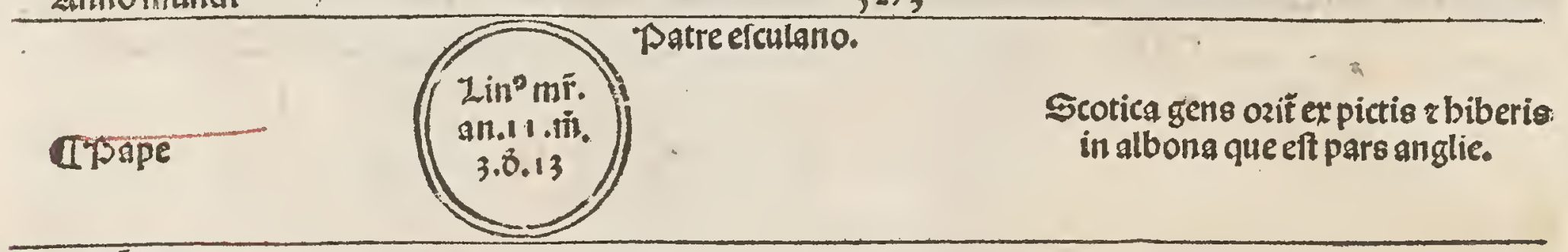

Zñno xṕi. 74

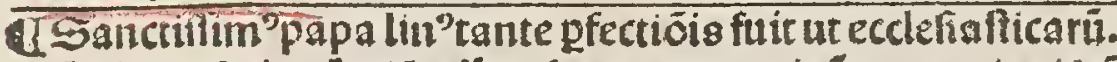
rerü oifpenfationê etiä adbuc beato petrovituëte:mertic oípé, fatoz ab eodé conftitui. bic ftatuir:ut mulier velato capite ee, clefiä intraret. Iandē martyrio cozonatus: \{epultus eft i pati, cano iuxta magiftrü fuú ac patrē beatú petrú.

Izosarialisepelemoniceit.

Isatuinianuseps zencri.

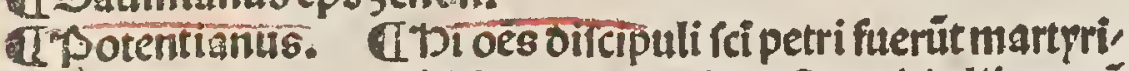

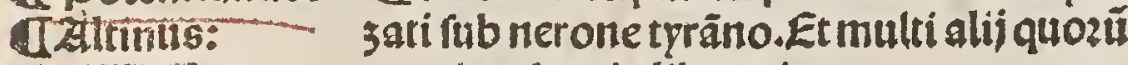
CEodalduts. nomina funt in libzo vite.

aserorinus.

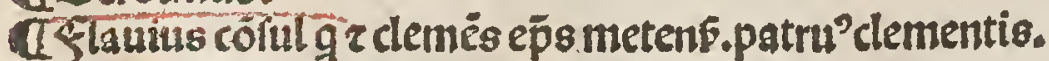

0xsentile epscatalaunen.

ILicharius epustreuterenfis.

Tsimituseps fueflerent.

CDomitian' fub dracon": a btö menio a mozte furcitatus.

I Iecla fancta virgo:pauli oícipula.

CLropbinus eṕs arelateñ.

CIture eps cretentiú.

CDinefinuts efis ephefioz.

arreicens eps galacenent.

IEpaforas ep̃s cololeneri.

aIbomas g partbos in fortem accepit:marty riçẫ in indíg oinz ozientaliu apoftolus.

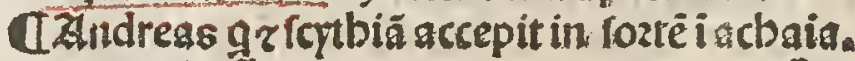
martrricat. ‘martyriçat:

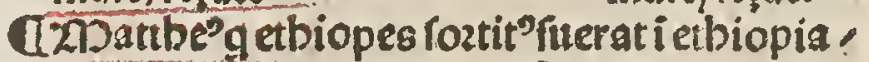
đSimo r iudas martyrizati füt i regiōib'p pidis U Bartbolome gindiã accepit in foztes: poftö: ficautit licaonie antiquiozib' in albano vabe maiozis armenie martyrizatus eft.

C'pbilipp'p 'cptbiā.20.änis ṕdicans ierapoli geuiti onio: $f_{3}$ i paffionali oicit 9 fuit crucifixue Solus ipfe rioânce enägelttta nô fütmarţุri 3ati. Ceteri apofttoli oés occifi fuerüt $z \ddot{c}$.

C20atbias itudea uel egppto cozonat. De tpe zloco z modomartyrijei? oituerfe füt frie.

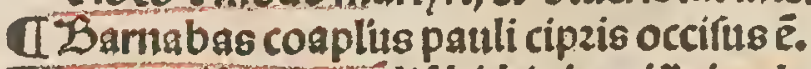
ILLCas dícipls pauli i bitbinia miğuit ad oñ ¿Lit? opacon' pauli oícipl's apó papbü geuit.

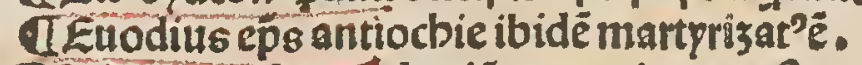
dEileas apud macedoniä martrrizatus eft. 
Itoictitus fait mire behignitatis CIfte oomitian'fili? velpafiani z frat

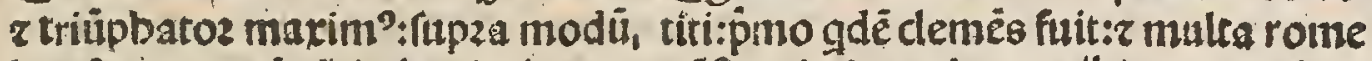

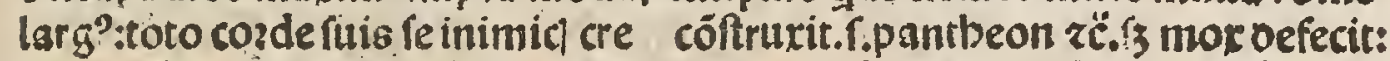

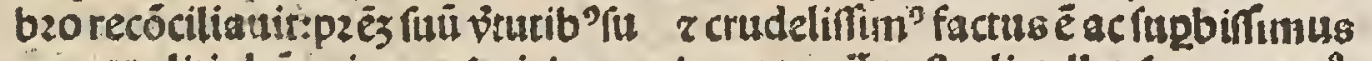
pans:betitie büani generl oici me ita ut tanö: oe coli vellet:fenarozes ås ruit.mirs oifpéta

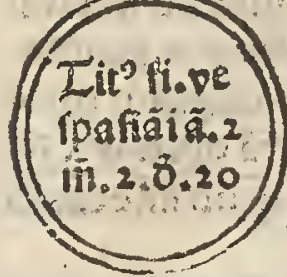
tiōe fupni rectozl: nūc optim?ninc per fims nueparc ntic pdig?:mutefienunc glit inftitur? 9 d re. gni gubernacula puebiť́:gsabpriú tãtoz iudicio ₹ frutaripualet:mo rí titusiano. 3. $z$ tant'luct? in vzbe dä intrecitsi rōianos lecú Domitia datn precutioné furcitauit nus fr titi randê olbus odiofus ips: an. 15. Iatio a fuis occifus é z cuz nedecoze fepultus. opaxpinturfalis torius 0.bis itest turbata ê:ppter feuitiā oomi

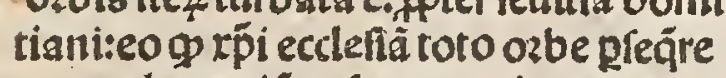
tur:multe natióes fe romanis oppofue

Comareagripps ptect? vibisper. fas oeuicit: $r$ ob boc pantbeon etr. tructú ê.i.templum oius deoz iufra fibylle:ipte etiam agrippinas iupzs rbenú compleuir:que antea fuit ab

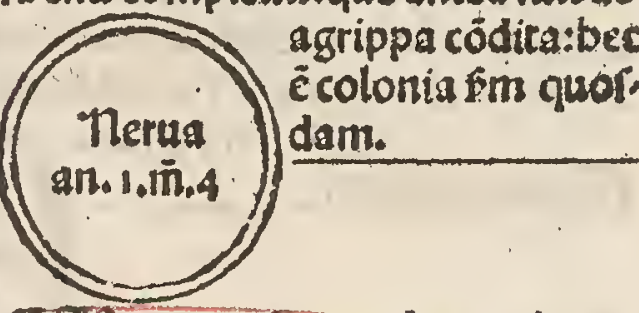
CIftenerua lenetadoptauit tra ianum in filius primogs edicto oia foze facta oomitiani retractauit. fuitur

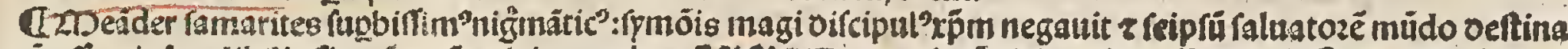

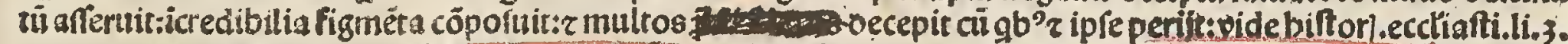
Iperlecutio fecuda ecclefie fit rome iufu oomi.

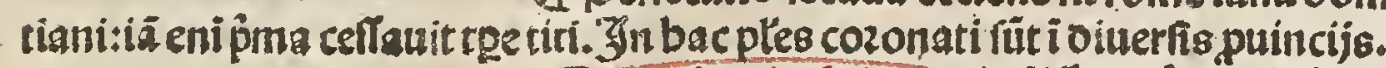

¿Derefis nicolaitaz $g$ indifferent vrosib'vtune oicentes oia oebere êre cóia inter rṕianos. UL berintus bereliarcha furrext: crapulorms ac libidinofts tot?: a quo oicta eft berefis cberintiana:bic oicit legalia fertäda. Utbebion berefiarcba a quo bebiones beretici

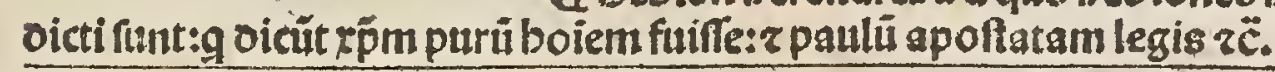

U3oãnes euãgetifta adductus iufu oomitiani ab epbefo ro. mã cĩ facrificare nollet idoĺ po niť i ooliü feruçtis olei : $\tilde{y}_{3}$ cü nil lefiôis fentifiet:relegat'éi patb. mos infulaz:ibiqs apocalppfim rcripfit:rediens aút epbefus:tpe traiani in pace quienit.

Romanus ex patre empliano.

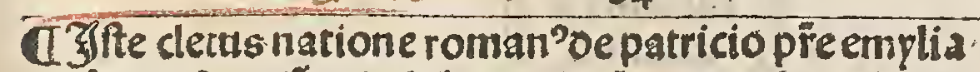
no p̉nus itsenit̂́ fcripfiffe in fuis lî́is: faluté z aplicam bridiccionë:ozdinanit p̈ibytos.21.in rönavz be menfe vecébzi:pegrinatióes ad icós appbautit. oicés q vali, dioz $\bar{c}$ ad relute fci petri vifitatio ô ouo annoy ieith niü:ercöicaut iflug $g b^{\text {'mó }}$ vifitatiöes impediut sut oifiuadêt. Landé nartrtrio cozonat́ fub oomitiano.6 klt.maij.fepultus in vaticano.

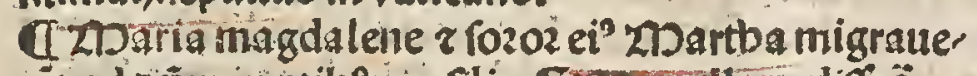

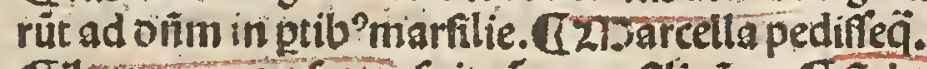
QLaçarus cap frater fuit eps marfilieñ. đEtbtús maximin'eṕs aqueŕ, bic viaticü oedit magdalene. Q Jullian'gr frmonlepz ofus ep s cenomanneñ. I İnlianus alius g verüqg parentẻnefcius occidit. d. Ariftarcus r pilifus martyres.

I'patus eps marbonentis.

đSatuminusepostbolóanus.

(1mortialis eps çancbdoñ.

Cantregintus eps lutburien.

QLantianus epus turoneñ.

Q Beozglus eps bellaceit.

I'Dprenens cpsligdun.

Q Serruntius eps befunctioneñ.

TEutropius eps arifitaneri.

IIEtropius eps a guitanien.

a frontu eṕs pesrggoniceni.

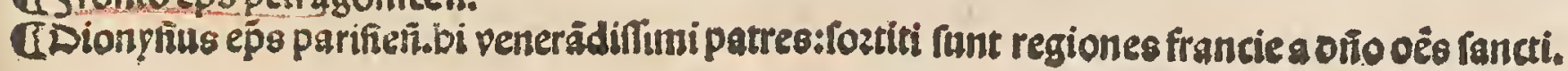

ISanct elemés pmu a brō petro ut of ozdinat fuit fibi

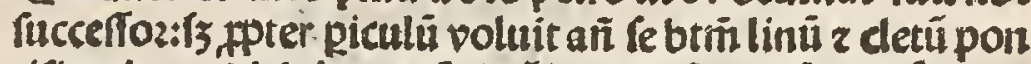
tificari:ne videly bocexêplo p̈lati fub ftituerët fibi âs vel. lent.bic fecit gefta martyrüp regiöes cốccribi:fititer z ī̄e multos libzos edidit. Statuit etias ut catbedra eṕalis in eminétiozi loco poneret̃: $r g$ baptiçat ${ }^{2}$ put cutius poterit cöfirmet. Fandè martyriçat lub traiano fubmerfü i ma ri a be eifunere mira fcripta fuit. Lospus eils roe nicbo ? lai pzimi reptü fuit $z$ rome tranflatü.

UDionyfi? âno 90 ariopag:ts penerabilis pater:lume ozbis:martprio cozonat in gallia cú eleutberio z ruftico vbi miffi fuerit a beato clemente.

TEutropius eps çancteri.mar.

ISanctin"eps meldevi.cum antonio a mozterurcitato: Difcipulins oionpliij.

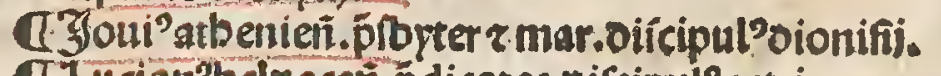

allician'belnacen pdicatoz vif́cipul'petri:

đL̃arānus mar.carnotenfí ṕ dicato?.

C'Regul'eṕs arelatert.

UEugeni'toletaî,mar.

Q27saron martyr.

deutbices martpr.

IUlictozinue martyr.

ISymon cleope fili": frater iudes ep̃s bierofolymozum 120. annoz crucifixus eft:martyr glozións. 
TPlutarcas nobilifimis plozà claret:magifter traiani:cui epiftolă

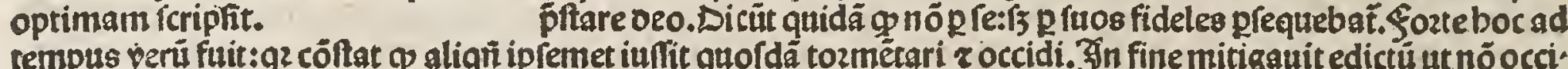

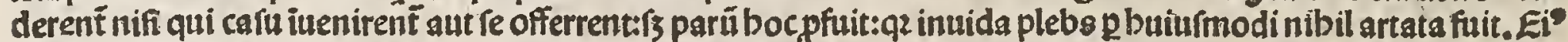
laudesp nibilo oucerénifi beatus gregozius cius pietate cömotus: lacbzpings fudiffet $z$ eum ab inferno liberaf.

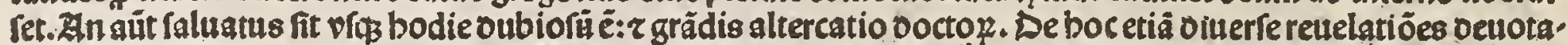
Timperatozes. Dínus.

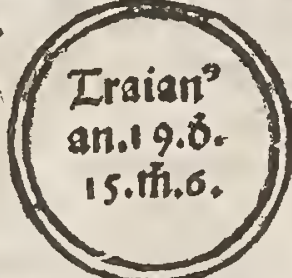
rü plonarü repiunť que oés qugs ego vídi bocintendunt qu nö velit oîs aliud nifi ut cam timoze falutem nofträ opemur z oe buiusmodi curiofis queltionib?quieti fim":eo qu nó fine caufs bec z fimilia ecclefä fuã vult latere.

đ'צfte idem tralanus apud agrippinā gallie:infignia imperi? initus füpht:germaniā reftituit:oziêtales puincias:babrloniä

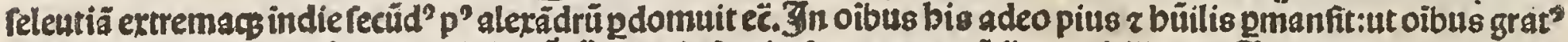

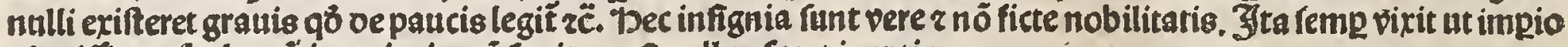
oigniffimus baberet:ita pzincipatü fugit quafi nullus foret ineptioz.

Q perfecutio tertia ecctie a traiq no erercetur in qua perempti fue runt infiniti.

GLandē cobibita fuit interuen' tu plinii fecüdi / 3 nö totaliter. II imorbeus epsepbefioz oircipul? pauli marţriçat ibidem.
đYygnatius oocto2 gloziolus epos antiocbie:oifcipulus ioannis martprio cozonat nobilifimo. 'buins co2 feifum:in fe aureis lit" teris boc oulcenomen iefus inuentum eft babuiffe oefcriptum.

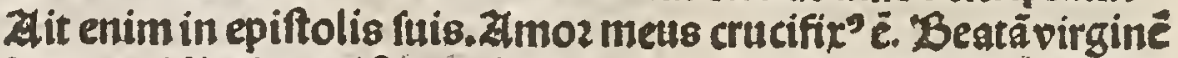
i carne vidit eigs epiftolas leripfit:in quibus fic babetur. Xpifere

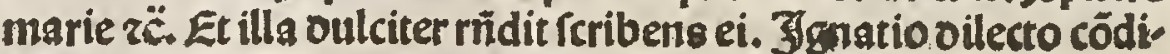

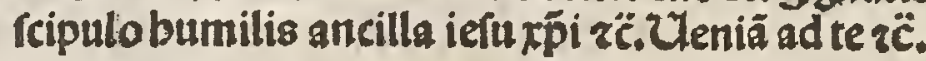

ILarinus epilcop'ebozaceñ.zgangericus.

eius frater ep̧ 8 cameraceĩ.oifcipuli oionprij.

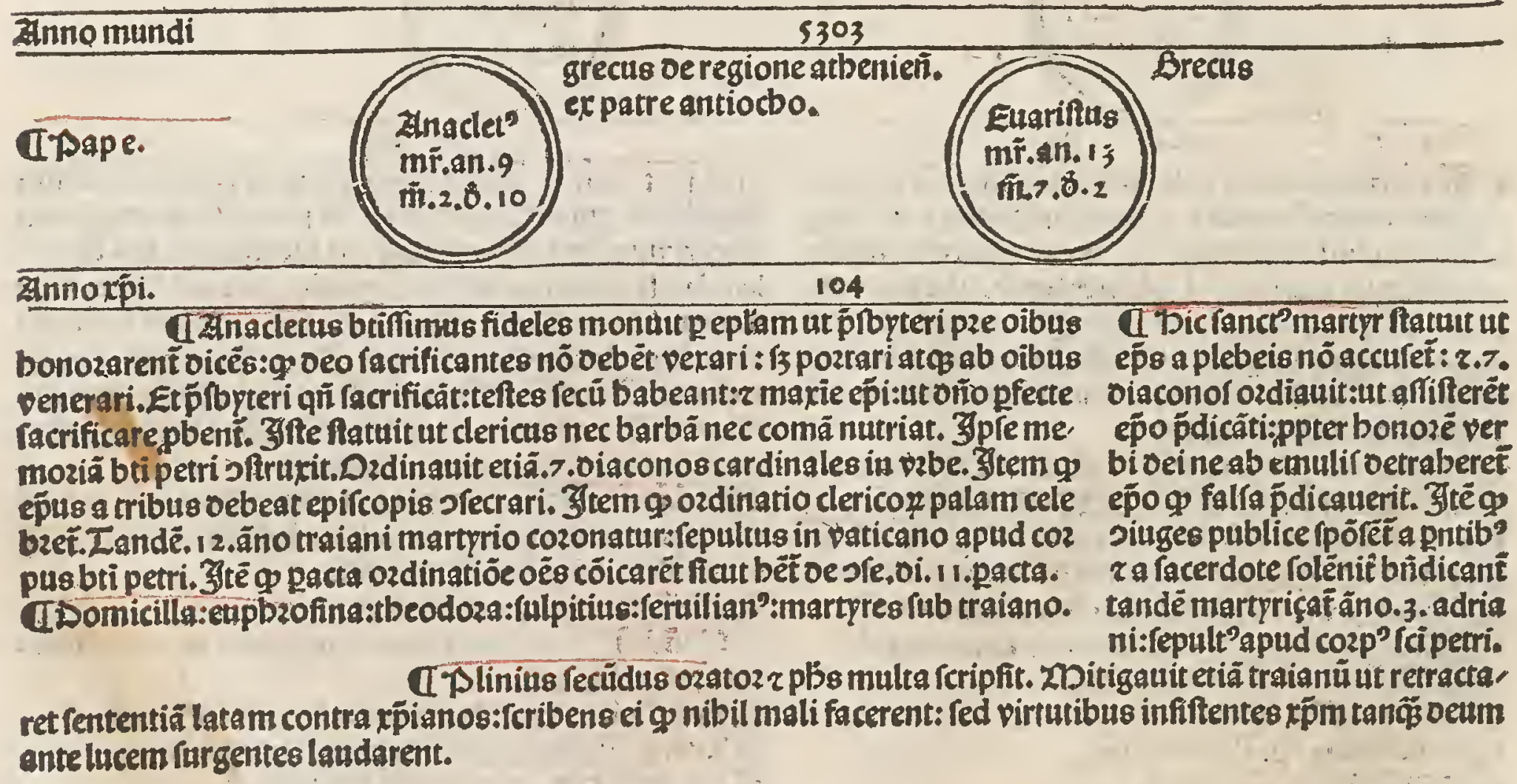




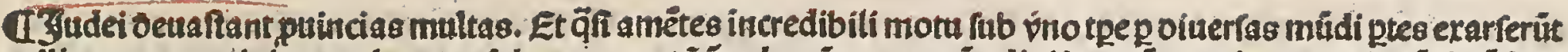

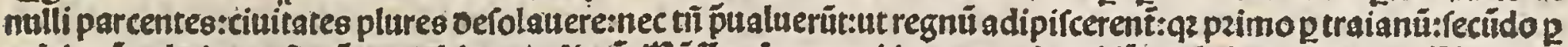

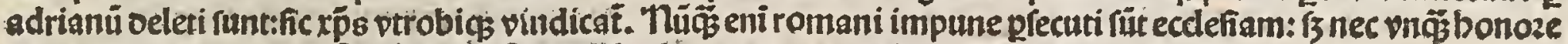
aut emolimeuto caruerút quotienf́cúg fideles bonozar re. De boc plenius vide ozofinm.

ISecidits pbs in filentio oeget:r ad interrogata

adriani feripto répondit.

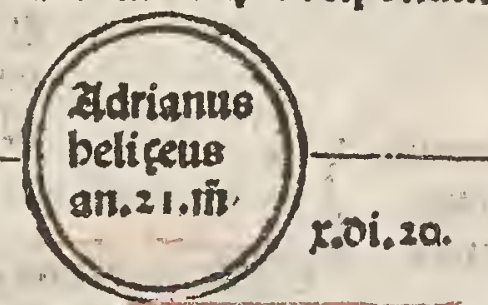

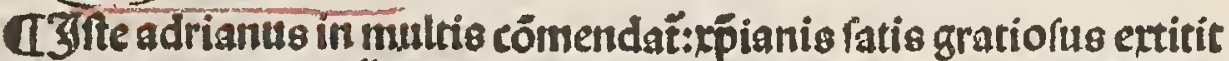

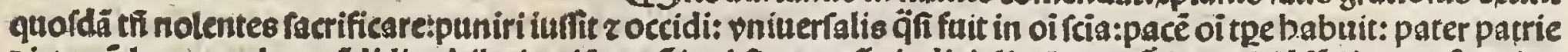

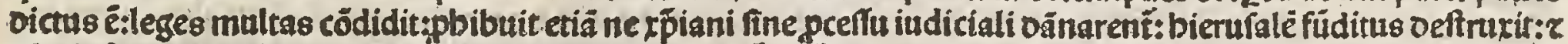

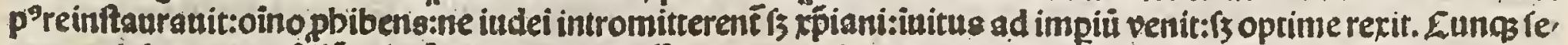
natus obfecraret:ut filiü cefarẻ appellaret. Sufficere ingt oebet:ut ego inuitus regnauerim: cî́ no mer ear:pzinci

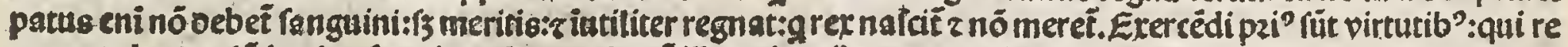
gnare oebent $r$ z̆ in eis pfecerin tadeo ut pbent illos virtutibus antecedere:quos oebent bonozibus anteire: in uitatiafcendant:r fe ciuiư fư potis nô fubtrabant.

I Euftacbius alio noie placidas:r theofopita eius vroz: r ouo filij eitus agapytus z thefpires: quozü miri actus legunt̃ circs bec tpa fuerút:qui oés iuffu adriani gloziofo martyrio cozonati funt.

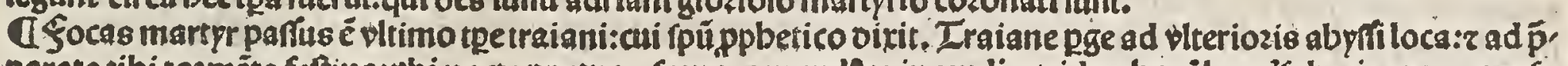

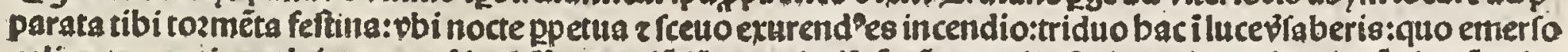

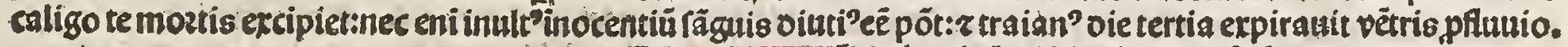
GLuadratus eps atbenieni.oifcipulus apoftoloy.

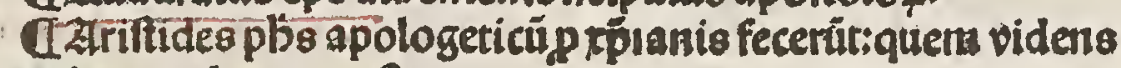
traianus:placatus eft.

UDermes piefectus vabis martyr.

5313

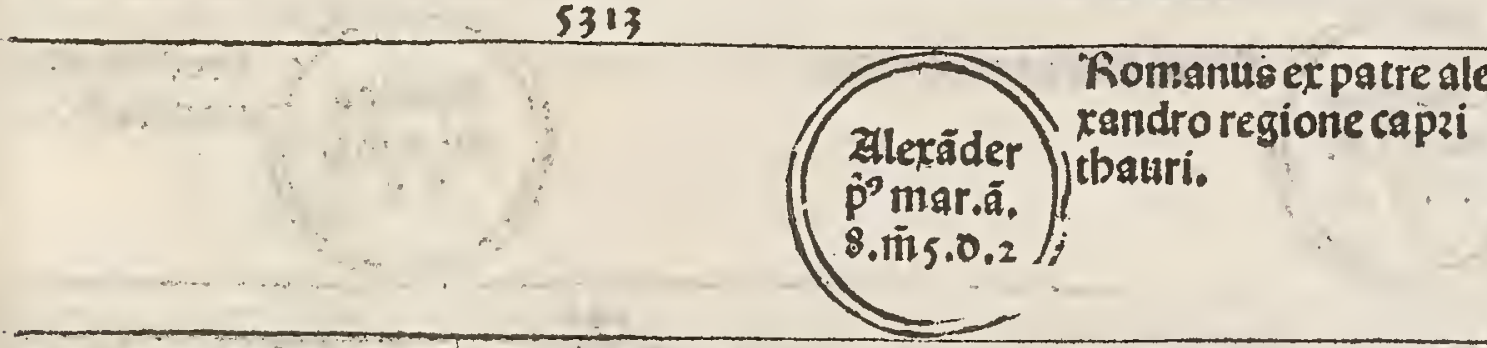

114

ब3ite alexander maiozé parté fenatozì or bis cötuertit ad orim bic ftatuit aquä bridictả cú fale arpgi in o omibus fidelium

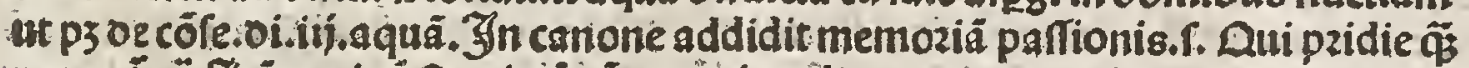

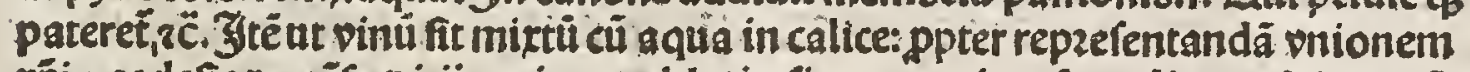

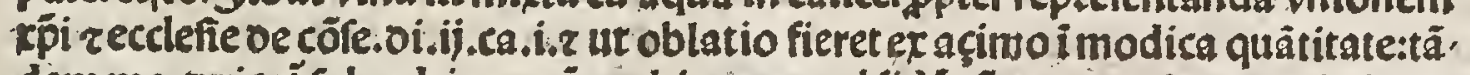
dem marturiçấ fub adriano cü multis quos ad fidé cöuerterat:fepultus i via nu. mentans. Pofteg tranflatus futitad ecclefiam fancte fabine.

TDuirinus mar.tribuntus.

UL beodolusmar zoiaconus.

UEtiéntilis martyr zpzerbpter.

5323

$\left(\begin{array}{l}\text { Fomanus } \\ \text { mar.â.10 } \\ \text { expatrepa } \\ \text { ftozeoeregio } \\ \text { nevialata. }\end{array}\right.$

124

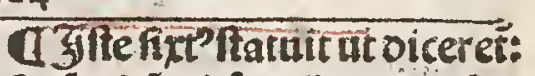

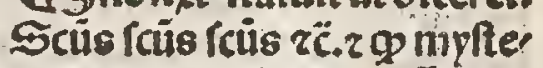
rị facrata nó tãgerențî̉ a miniftris oe cốfe. oi.i.in lcā. Ztč ut cozpalenó fieret ex f́e

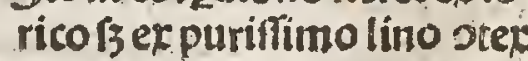
to r nô tincto: z ut mulier fa cra thafa altaris z pallas non tãgeret. It tẻ ut gciqg epus ro catus ad redéäplicam:rediés

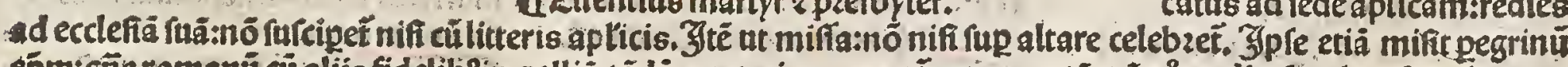

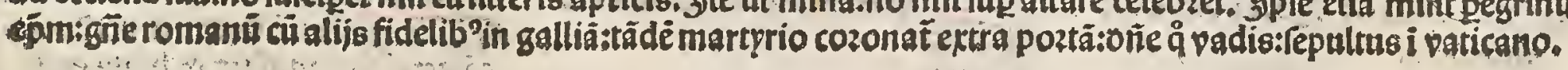


OTientalé refteurat̃o adrianū $\tau$ noie citts belia vocara fuic. Er am plificata fuit:itaut loc? peffiócis er fet itra muros $g$ pus extra fuit. Eté bec trtia reftauratio: q2ter oeftru cta fuit.f.a chaldeis:tpe fedecbie. Zib antiocbo:tpe macbabeoz. Et a tito tpe verpafiani.

IIImperatoze.
USalienus medias pgame oziüdus: interpzes bypocrat romedaret.

C'pompeitus troguc:natiỏe bifpantuebiftozias totils 02 bis a nino víc ad octauianí oeduxit.

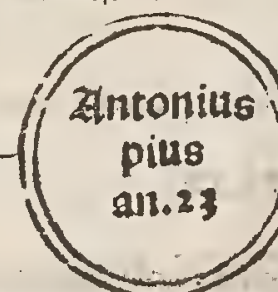

I proteme? rex mirabilis:in matbematie oüz afronomoz p̌cipu'pplur addidit ổ añ feintuentü repperit:z plura feripfit

A I baur? hobiltfim? plio atbents claruit. bic ait. In prbitico mos populi: in pzituato natture ius gentiüqs feruet.

(1Ualentin 'beretic":oirit xp'm celefte coz' pus attuliffe rë.

(CEerdoberetic"bic fuitmgri mardonio.

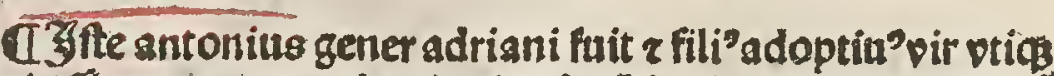
pitiffimus z natura benign": å̉ nō facile in pno boie repit

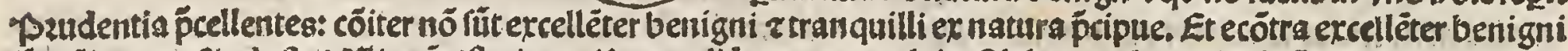

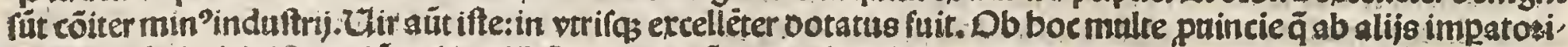
bus receflerât:\{ub ifto volútarie redibãt:q? verepĩ patrie fuit. Dibus cbar?:nullis acerb": fídelib" clementiffim"

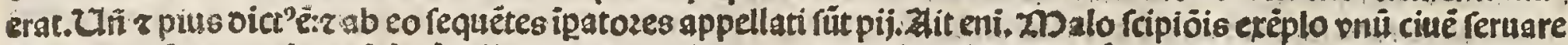

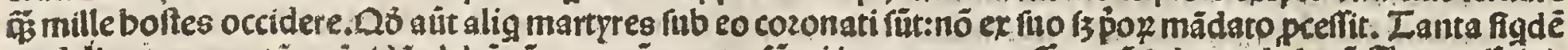

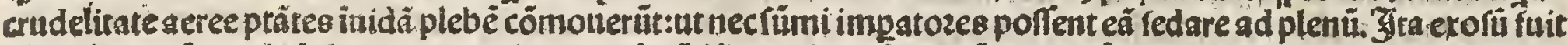

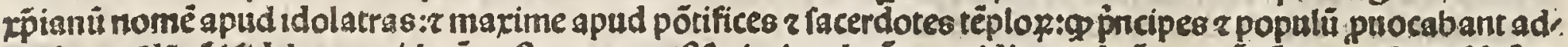

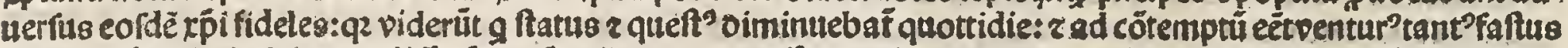

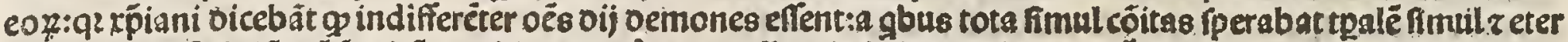

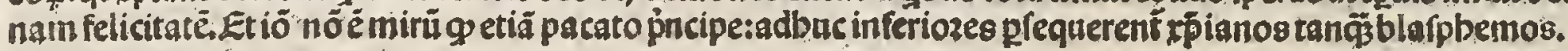

A Decé milia martył crucifixi füt i armen ia i möte maxio aratb:åz feftù celebze coli

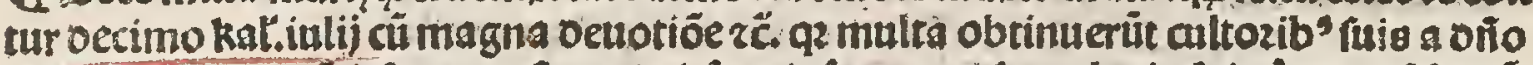

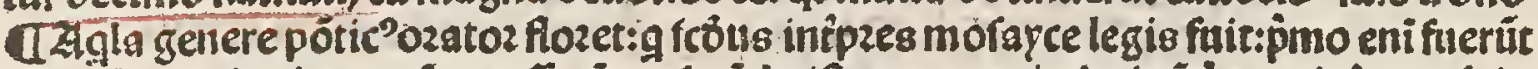
70.0 e bebzaico in grecütranfferêtes:fecuido iffe oe greco in latinü p̈mns intpzes fuit.

Umartion beretic que Dolicarpus oixit eflepzi mogenitum viaboli.

Annomundi 5333

Anno tṕi. 134

144

Olyte tbelépbo:ns ftatuit cantari bymni angelicu rcils:glozia in etcelfis: $z$ euăgeliū ante facrificiü: z i natali oni cantari tres

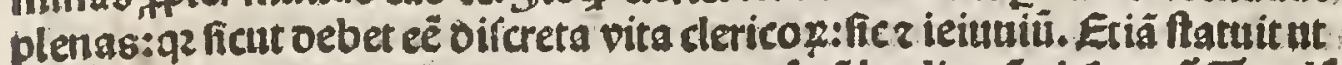

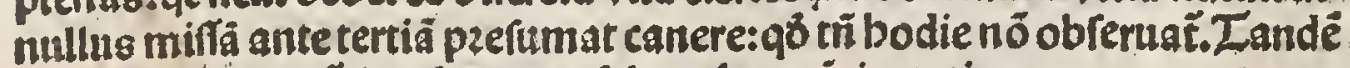
martyrio cozonat: fepultus apud fanctir petrü in vaticano.

I'peregrin ${ }^{2}$ eps antiffodozeñ.mar.

ISerapbia mar.r virgo.

IStibinamar.z nobilis vidus.

IT zobira martyr.

ULalocerius martyr.

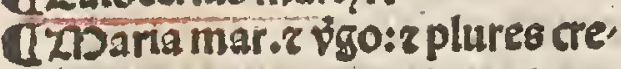
diderant.
đIJftin'pbs oificipul ${ }^{9}$ pompei li b208 ei abbretianit: bic etiâ libzá oe xṕia ta religiōe edidit qué anto. nio tradidit z benignú rōianis fecit đSopbia nobilis matrona cübis trib'filiab'martyrio cozonata el. Afides.

IIsper. TLbaritas.

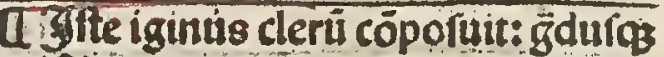
oiftinx it:r ut patrin? 2 patrina:ifan. tem furtipet in baptifmo confirma tione z catbecifmo. Scripft etiā vnã epiftolä generalem oibus fidelibus: be pno z trino oeo. ZJtem g nullus eps metropolitan": excepto romào pótifice:audeat fuffraganeú fuú cō dênareinifi cã in cócilio pzouincialí ruoz epo z fuerit ventilata. Iandes martyrio cozonat:repultus in eccle' fia fancti petri.

A SIIte igin? etiă ftatuit gu ecclia nó cốfecrat fine milfa: $r$ g ligna eccle fiarü oeftructarü:zbaiufimodi:non

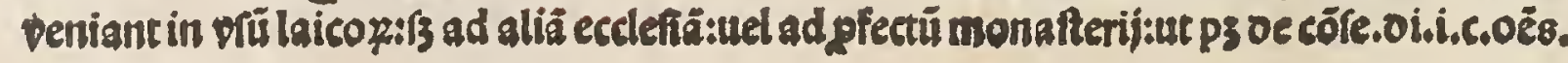


[37)

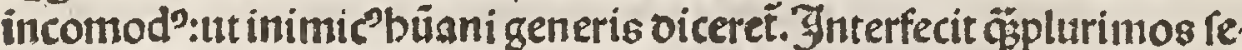
natozes:z maxime quos aigduertit nobilitate induftriaq ercellere.

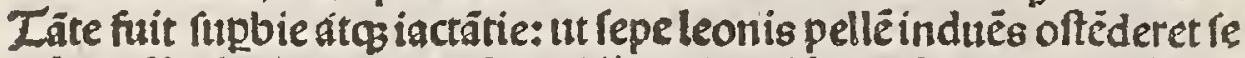
efferegë boiuz ficutleo beftiaz. Ulez vbi f́plédet oftätia martyrütedet amplius oe carnalitate bomiuü mundano termoné tèrere.

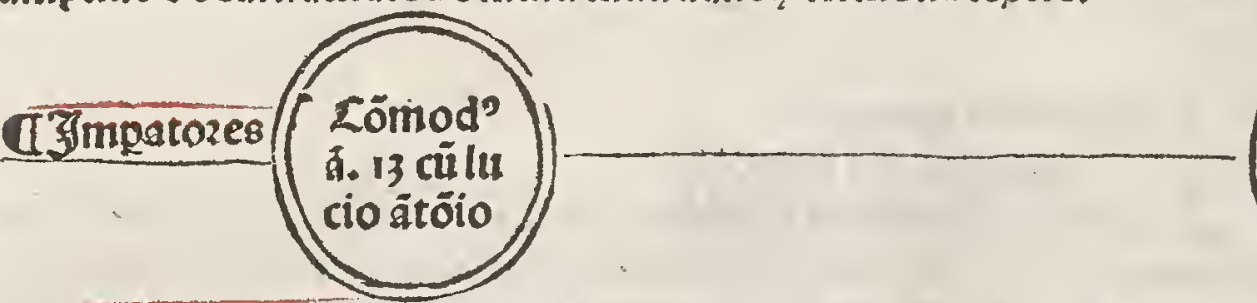

TQuinta precutioectefic fit infu Peneri quả ilico oining vltio fubrecuta ē ppí ci, uilia bella i gb' romãi nimis attriti fuer̃t I Jifte beli? vir grandetus inuitus acce.

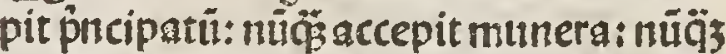
ad vlcifcēdü reduct'é. Serto mëre inter. ad blciredn reduct exto méte inter

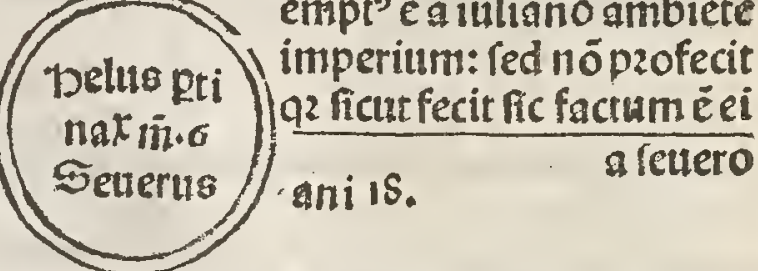

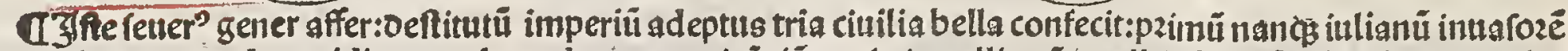
imperii expugnando occidit rome:fecundo contra picèniü:tertio in gallia cõtra albinü fociü iuliani: cum multo vtriulas patris fanguie bellauit $z$ vicit. Đicnä feuแs:multis femp bellis laceflitus foztiflime quidē rempublicas I5 laboziofe rexit. $p$ artbos $z$ arabes adiebinos ittdeos $z$ famaritas fupauit $z$ multa toto o: be rontano imperio

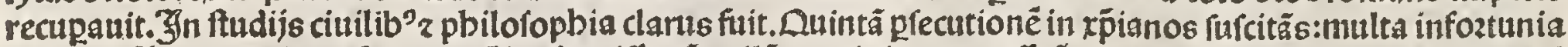

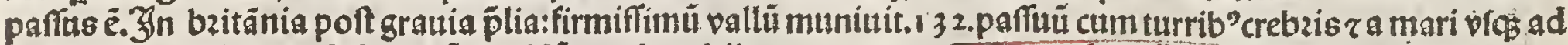
mare gduxit:ibiq apud ebozacũ oppidũ mozbo obijt.

I Spmacbus ğrtus diuinelegis interpzes.

TLbeoplitusepsantiocbie.

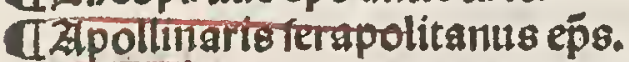

ITharcif patria rcba bierofolymo TDtonfinsepés cozintbiox.

îtuitippts epstrecentis. Thutippts epstrecentis.

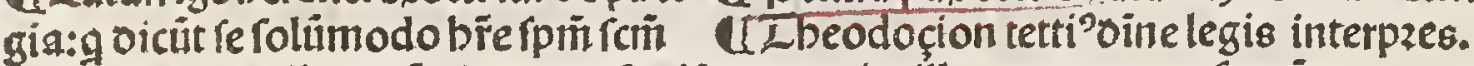
nec aplis nec alís oatü. 20Dontan'pzifea z maximilla autozes eo z fuerüt.

\section{filia engenia r eunucbi eitus.}

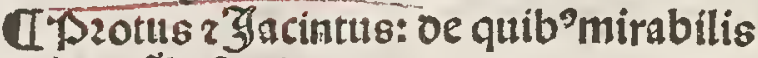
babeẗbiftozig mart?

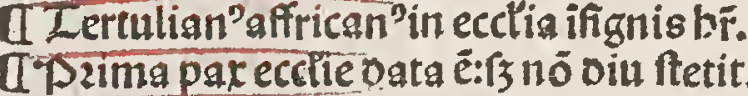

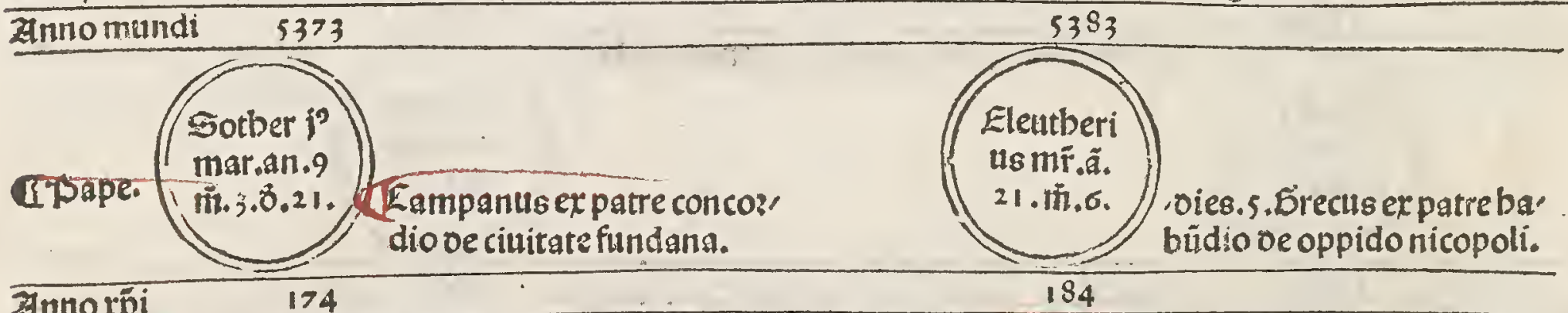

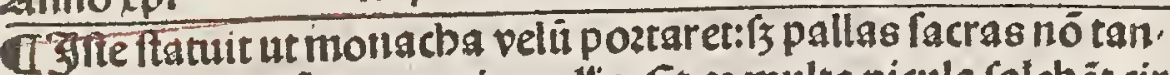
geret:necincenfï foneret in ecclia. Et qa multa picula rolebär cir ca matrimoniü cốtingere:ideo côft tut 9 legittima non babeat vroz nifi $\mathrm{p}$ fecerdoté fuerit brìdicta: $z$ a parentib? foléniter tradi. ta:za paranimpbis cuftodita. Iandem poft feãm vitä:\{anctioze mozte migrauit ad orim cozonatus martprio: $z$ fepeliertunt eüfi, deles in vaticano i ecclefia fancti petri: $\tau$ ceflanit epatus oieb?. 22 .

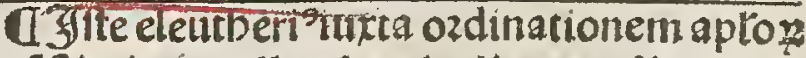
côft tutuit ut nulla efé vfualis repudiaretur a tōianis:ă rōnabilis effet z büana. ZTĕ qu nul

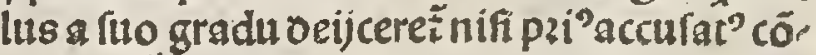
uinceret:eremplo oñi:g iudã accufarü nó fu. Ptinuit:zgegd interim inter aplos egit pzo oi gnitate minifterí ratü gmà fit. Gtê ut abrente eo cuims caufaventilat:Fententia nullatenus p2oferát. 2njifit etiä legatos lucioregi baito

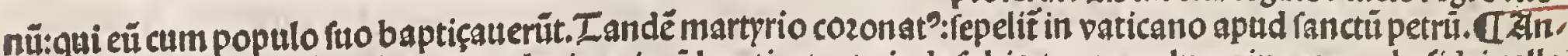
glia ad fidem cöuertit: folêniter rege lucio pzimü baptiçato: oeinde fubiectus populug; eius exemplo fídei colla fubmifit pacifice. Suganus r oamian?quos eleutberius papa mifit pzimo:illuc pdicauerunt.

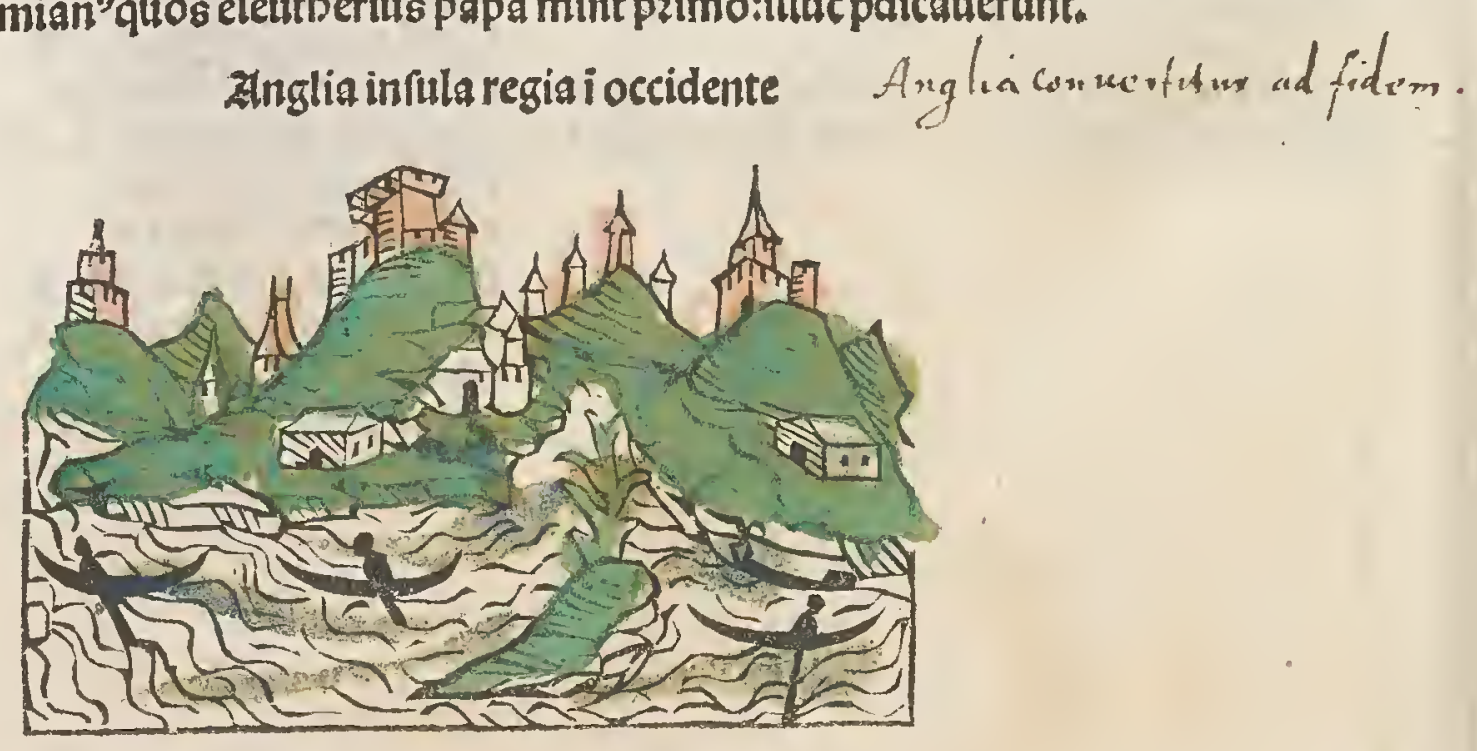




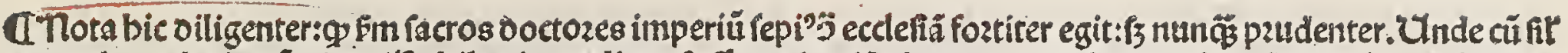

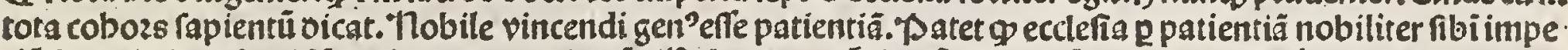

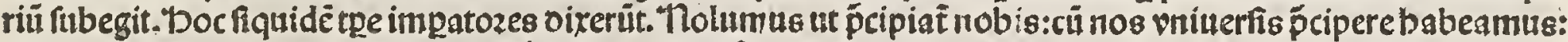
o octiozes oibus boibus foli romani pdicamur. poftea fine gladio aut fufte cus longanimiter fuftineret ecclefía ad boc oetuentú eft:ut maieftas romanti imperij folëniter ac bumiliter pfiterét: qu impiales leges nó oedignarent facris canonib"obedire. "Deceft mutatio oextere excelfi. Zुgit vincere fi vis:oifce pati:figntum pfecte pzudêtic eft:

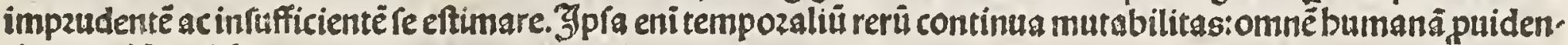
tiamoeriderefolet.

TLacius rex bitänie que poft oicta ëanglia: ad fidē cü populo fuo cốtertiť: 2 baptiçati funt a ouobus viris religiofis quos ei mifit eleutbe rius papa:g oicebani fuganus : oanianus.

Teonides peter ozigenis:pro xp̃o yecollať martyr efficit̄. El ozigenes tüc. 17.ănoz fe cum patre martyrio obtulit: 5 pia matris fratude im pedit'totü primoniú pdidit:eo $q$ rṕianus effet zë. Ip fe aût oocẹd o fcolares grämaticä:matrē repteni fratres:fecum oepzerio parcebst.
A'Dyrene'lugduin. eṕs:cümagna mul titudine cleri z por puli martyrio cozo natur.

IIIIdecitus lubdia contus: oifcipulus policarpi martyri çatur.

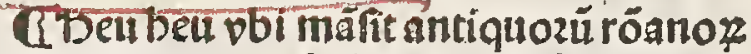
tanta probitas:Itrénuitas:legalitas:ací cógabilis pzudētia:z boneftas. Siquidé boctpe ipii ad man'ftulto zoenenit.

ATlote 9 ftultus fi fe ftulti putat:adbuc aligd oe lumie naturalis intelligentie bs Sz fi fe fapientěexiftinat:tuns completa eft ftultitia ei":necerudiri poteft: $\bar{\zeta}_{3}$ fapiē tes prequit:fímilefa; fibi fociar.

A. Artbemonius bereticus oicit xpom effe purüboiem: $q$ abfa co plures babuit $r \ddot{c}$. gbancberefim tenuerut.

\begin{tabular}{|c|c|}
\hline 5393 & 5403 \\
\hline 194 & 204 \\
\hline 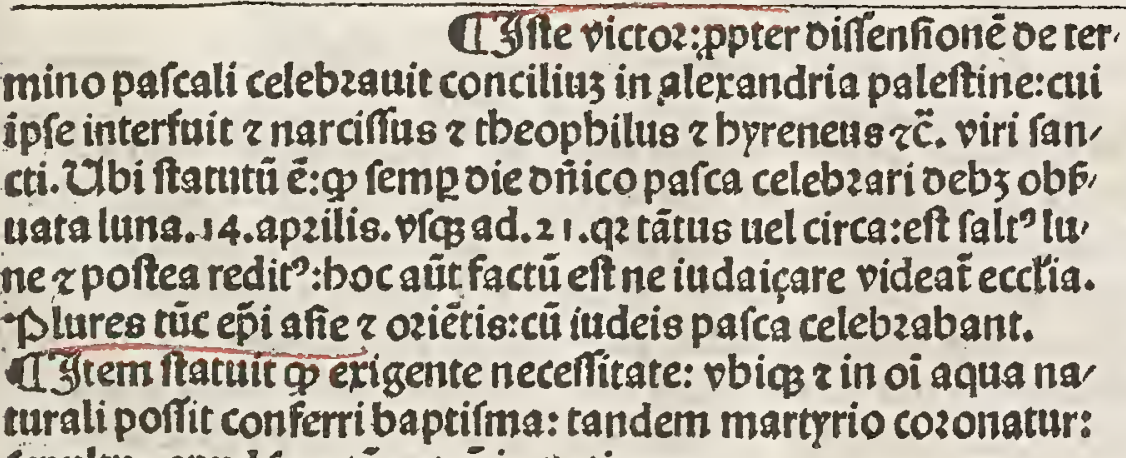 & 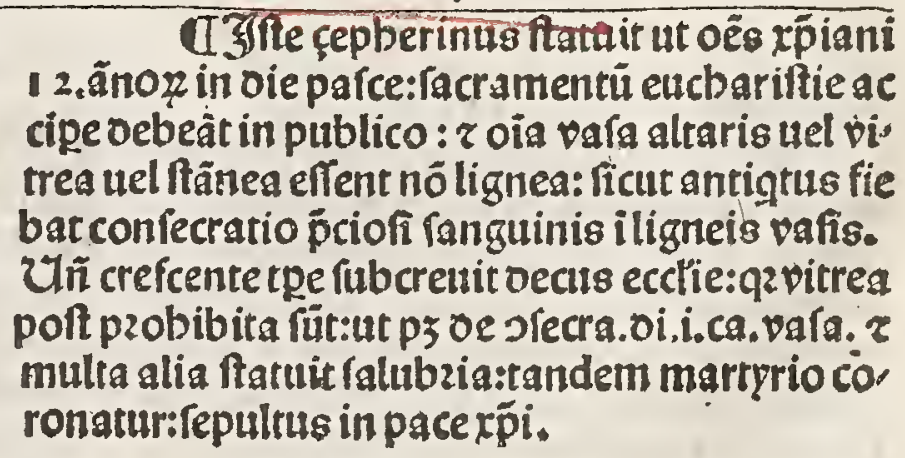 \\
\hline
\end{tabular}
Sepultus apud fanctū petrü in vaticano. 
T. tiffinus fuit ita ut nouercä fuam ouceret i vrozé: papinianũ ituris cöfultũ z oocrielegalis tbełauz occidit. Et fié fecit factü é ei qz ab boftib" circütuêt?

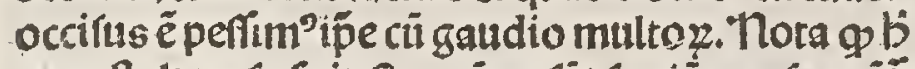
mos ftultow fp fuit:fi porētes füt fapiêtres prequiti: gb'fubla: neceffe é ut ipfi çs peât. Sol'enî intelli gens gubernacula poffidebit ut oicit puerbio z.i.

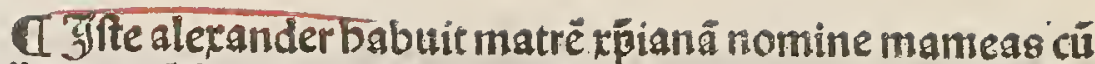
q̈ ozigené ṕp byterü audire curauit. "bic fuit iutuêis ḃtuofiffim? z rempublicä falubsiter gubernauit conftio plpianivfus qui fuit legalis fcie p̉nceps. Xerfen regë prarü maximo bello op' pzefit r cozpus fci tbome apli iuffit tranfferri oz indiagd fy' riã: z fic ventit ad ediflam ciuitatê abagari in ä littera ícripta babebat oe manu faluatozis. Iandes etiä ifte alexander tu multu militari occidit apud maguntiacũ.
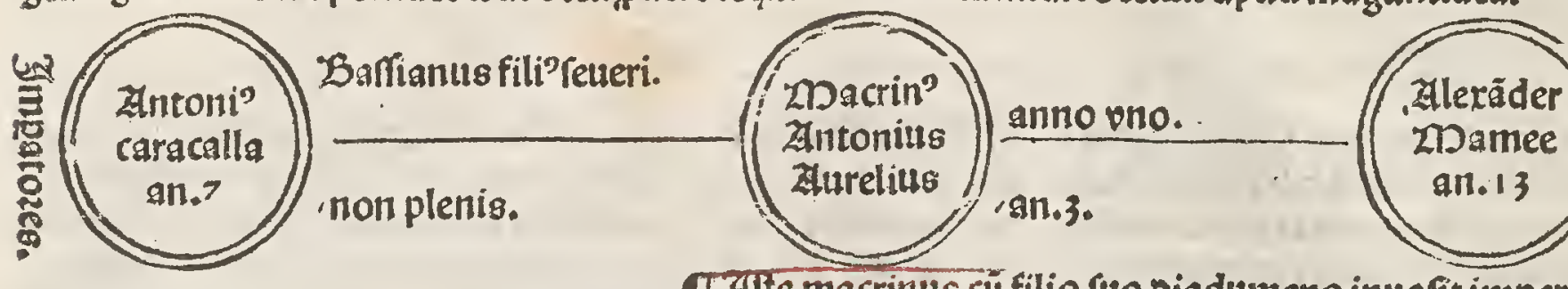

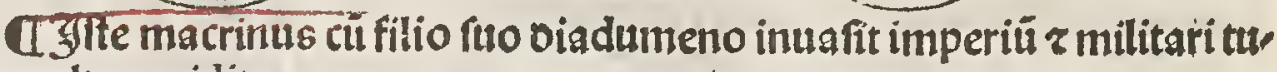
multu occiditur.

Q İtte antoni? obiceniffime vixit:z ideo cai matre occifus fuit tumultu militü ficut macrinus: $r$ fuit facerdos beliogabali templi.

QDzigenes ooctoz egregius:

ac fcitate vite incöpabilis clariftim babet in ecclia oei. De boc pene fper trema repimus fcripta:quidã oicüt eü optimü:gdaz peffimü fuiffe Supza modĩ mirü $\vec{c}: g$ viri grauiffimi auctozitatis ac ŕcifime vite ita cötradicto rie oe ipfo reriprerut. vide in biftozia eccliaftica libzo.c. 2 alibi $z$ cetera.

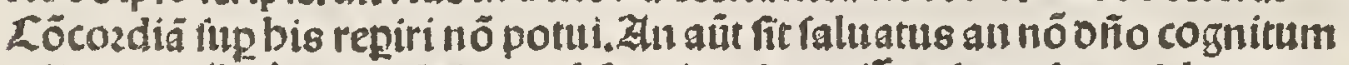
religmus $z \ddot{c}$. Brandis la bozin b? a oiuerfis terit oe fomprone: falomone traiano $r$ ifto ozigene an videls faluati fint an nô:ā q? fine piculo néciüt: nec etiẫ ecclefia cerrificata eft o e bis:oño toraliter cómittëda funt.

QClpianus iuriftegalis cốfultus ma 1 Quntuta editio repta elt boc rimus ut ps in cozpe iuris ciuilis p totĩ. tpe in iericbo cui'auctoz igno

Afelix martyr. Thucian'mar. a Calopedimar. Couiric mar. difftozius mar. Ifutita mar.

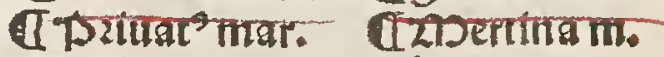

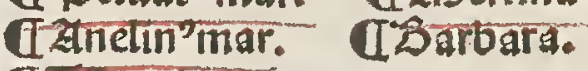
CItburtilismar.

GUalerianmar. TLeciliamar. Tzoxam?mar. IT 'palmatip mĩ cĩ prozer familia. rat̃̃ iõ oicit côiter vulgata.

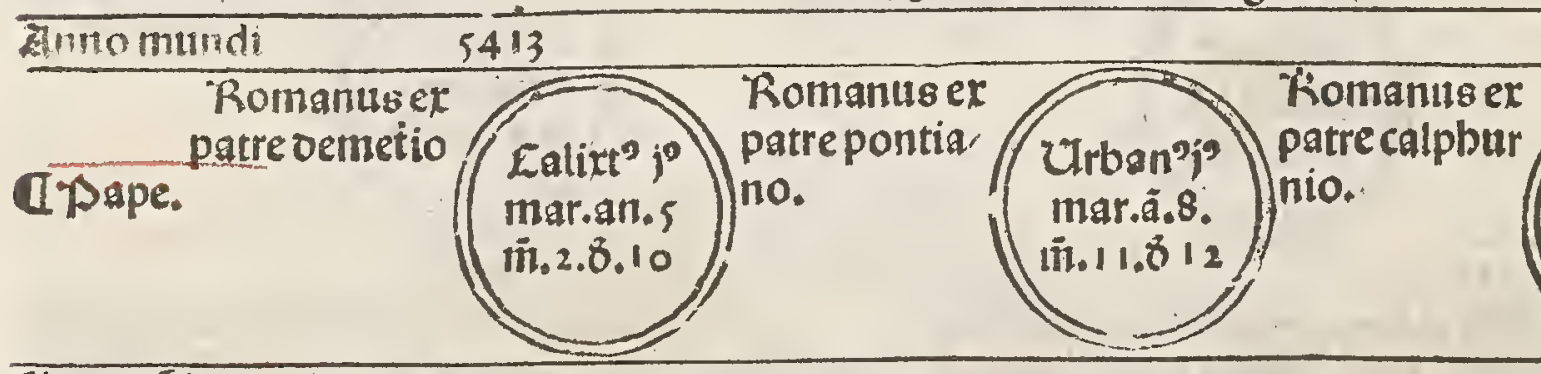

$\frac{\text { Anno rp̄i. } \quad 214}{\text { OJjte calixtus inter cetera que fecit }}$ bona cimiteriuz in via appia extruxit:pbi multa martyz milia fepulta füt. "boc tâ oi citur cimiteriü beatı calizti. Złtë ftatuit ie, iunia quattuoz tempoz obferuari. ZJtë fe cit ecclefia beate marieträs truberim. Zुtê celibattis vniuerfis facerdotibus indixit. Zandë martyrio cozonaț: fepult? in cimi. terio fuo. Cel.batin primus facus sto

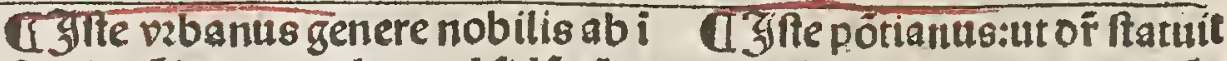 fantia rp̄ianus:multos ad fidẽ côtuer ut pralmi oie noctuqs p omẻs tit. Dia facrata mppteria fecit argen ecclefias cantarent: $z$ ut an ce tea uel aurea uel fitãnea :tändê marty lebzationê mif́e facerdos có

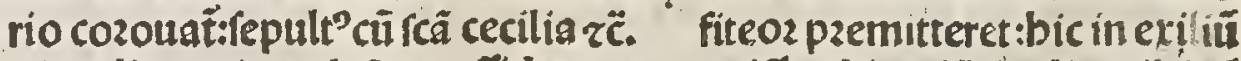 Dzedia cepit ecclefia poifidere tpe bui'oe gb' dericl a notarije fiapt? oe putabat:g gefta martył cöfcriprerüt Żntea víuebãt moze aplico:g iacti bus apoftolozü fcribit. miffus $i$ infulä fardinie ibide martyrio cozousat. Sarict? fa bianus:cozpus ei'seduritron mã:z fepeliuit in cimilerio car lixti.

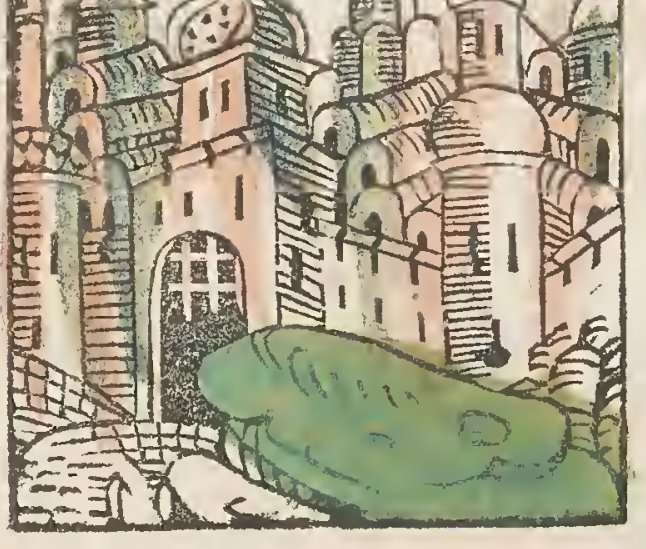

Cinitas edifia: in quababeź littera feripta maum faluatozis oni noftri iefu rp̄i:fub abagaro ipfi'ciuitatio rege. 

ab exercitu: deuictis germanis $z$ ptbis:3. anno occiditur.

AZfte gordiantus adbuc puer: oenictis partbis:a fuis frande interfectus eft.
TSeptina precutio ecclefie iuflu oeci) acerbanimis \{s non oiuturna: q? ficut cötigit pziozib’ficr ifti qz ftatim occifus fuit.

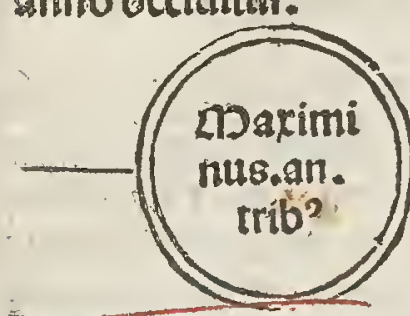

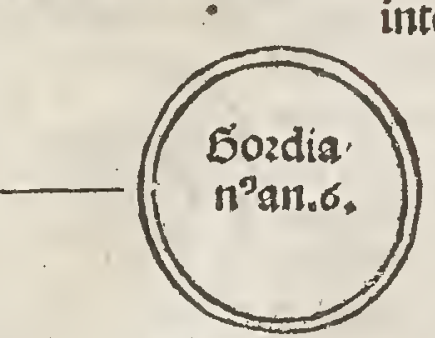
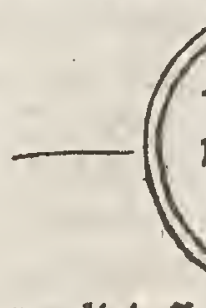

प'3fte oecius tot?tyrănus in uafit imperiü. interfectis ouobus philippis oñis fuis z ficut fecit far
Irbiru rpectactulü circa bec tpa fuit: videre oe ouplici gî̀e martyz. f. xṕ z oemonü. martyres xpi fuerüt fcipape z alii pzelati cü fidelib? fuis fubditis: $q$ xṕana republica.i.fide

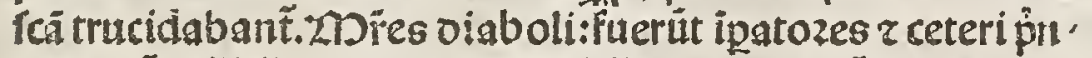
cipes cü militibus fuis:g p republica z oemonü cultura fe Juos interficiebar:ut regnare poffent. "Darpena: fed Difpar

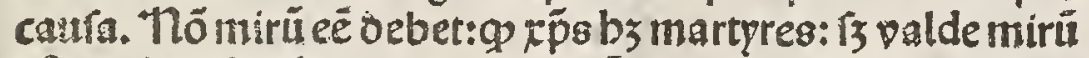
eft og oiaboltus b3 martyres: verü martyres diaboli z müdi quottidie inuenimi r in magno nüero:kp̉ iaüt nó fic. Quot bodięp midi pompa:cami solitiís:terrenis oilutijs libe ter agoniçâ: $z$ tandé nemune cogente volütarie fuccubunt: Ted rp̄s nenini ṕcipit ut fideles occideret:ly ad bzeue têp"

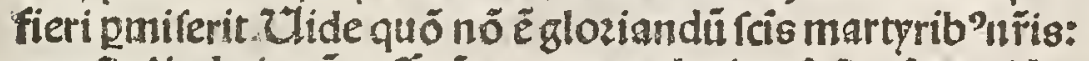
quafialigd oignī geflerütp eterna glozia qui fic oi tpevide' mus decertaffe vanos p infania falra : ut pz $p$ auguftinu de riui.oei.li.5. CUidepulchza illic, $r \ddot{c}$. dद्lte pbilippus.14.ab augufto impatoz creat' $\vec{e}$

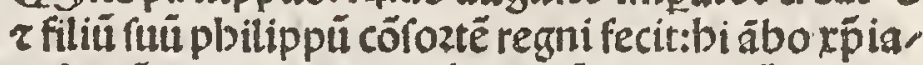
ni fuerüt:r pzim? oius róianozü impatozū : bic ca put eft:z poft tertiū annú imperij fui ad gloziã cele bzauit cu 3 ingentibus ludis millefimmi annū vzbis condite:tandem frande oecij occidit.
UAllexander eṕpbierofolymoz
martyr.
đ20opres p̧ boyter z martyp.
C2maximus pzerbyter $z$ martyr.
Ciproximus prbyter z martyr.
đThicoftratus diacon 1 s niartyr.
Istppolonia b̉go r martyr.
đSserapion martyr.

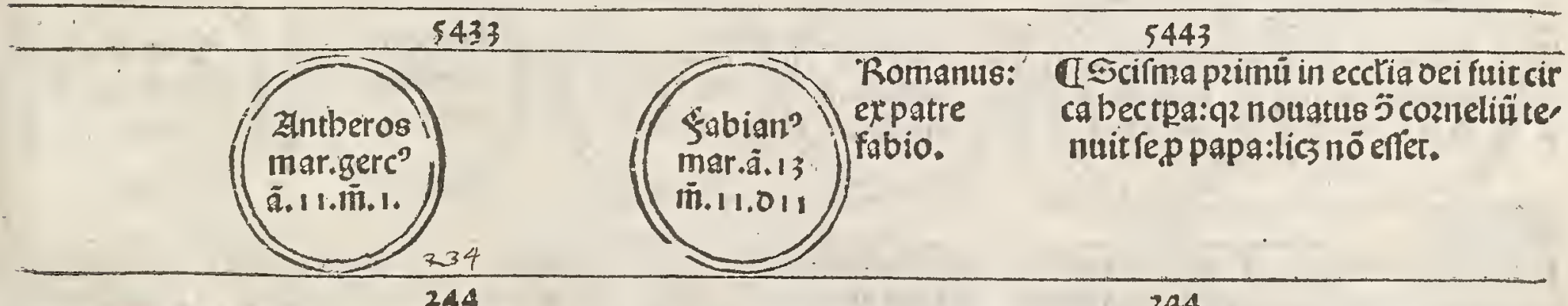

Uj̧fte ant theros cöftituit $q$ eppi oe rede in redem poffint tranfierri:z ut geita martyrĩ

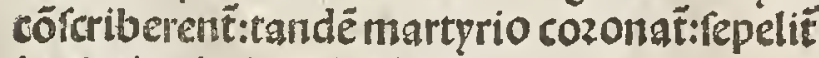
in cimiterio rancti calixti.

Thota go in qburdä biftazijs babet: cus fucceffit pontiano imediate z papati oi mifit:ut cü virginib'martyrio cozonaret: $15 \mathrm{ra}$ tio tpis boc nô pmittit:utpz in legendavnde' cim miliü virginu.

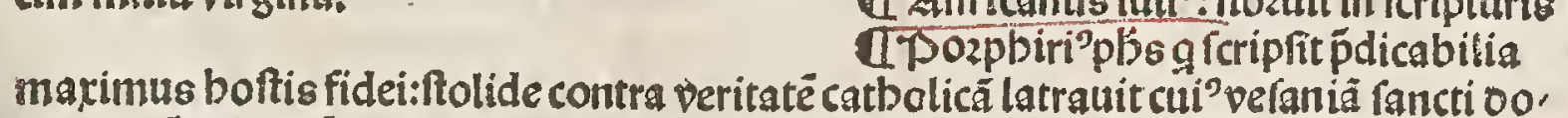
stozes cöpécuerüt:nec vltra pfecit:nec intellexit Dequibus affirmaut.

TDionprius alexandrino 2 ep̃s oifci pulus ozigenis:multa fcripta religt.

Tzppianus gloziofus ooctoz zeps cartba ginenfis:clau'us babet̃: $r$ poft martyrio cozonat.

CTlouatus pibyter ectlie romane am.

[bic feiflimus fabianus:ci oefücto papa cú ceter) fidelib"erpe' ctaret futuri pspe electioné: fubito colüba candida fup caput eius oefcendit oicés. Rome ep̃s ozdinaberis. Db boc ftatim elect' fuit bic ftatuit ut cbzifina fingulis annis in cens oñi cölecreț. tit pater

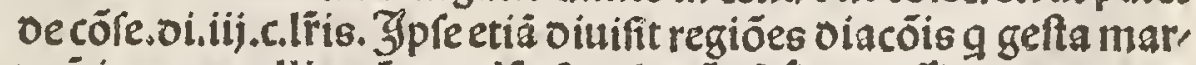
tyrü integre colligerêt:tandē p'multa â rciffime geffir:martyrio co

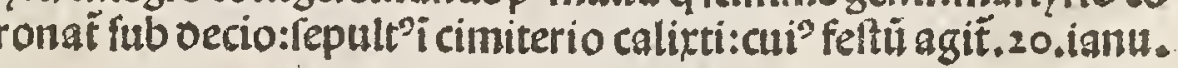

I Effricanus iuli?: flozuit in fcripturis eccliafticis noiatifimus. UAgatba vigo zmar. ISepté bormiêtes.

IL Lifon pter g oemones eijciebat inicena paffils eft. Uदz don z Tennen mires. U सnatholí bigo r mar. dCictoziaibo r mar. Et alij plures parfi funt?

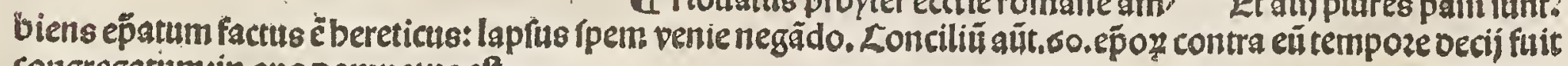
congregatum:in quo oamnatus eft. 


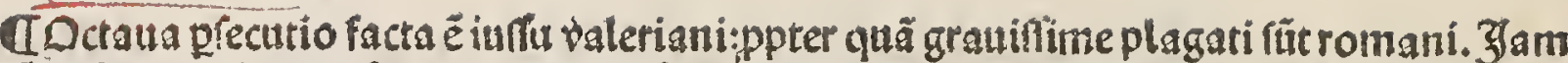

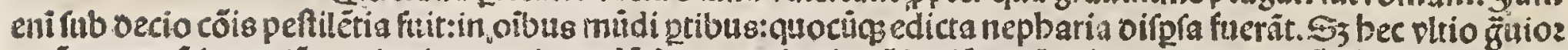

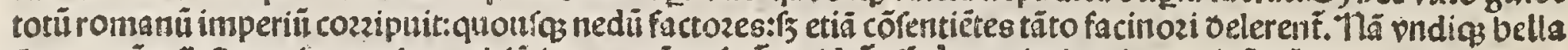
furrexerüt zë.Et oacia tran

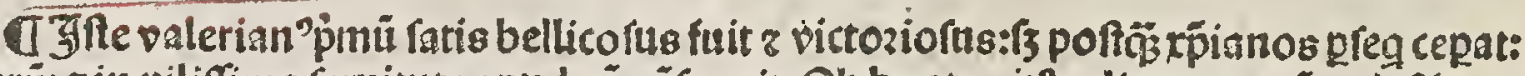

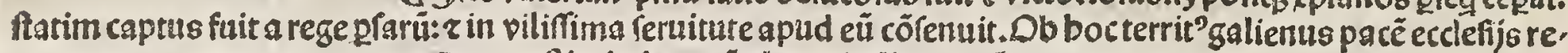

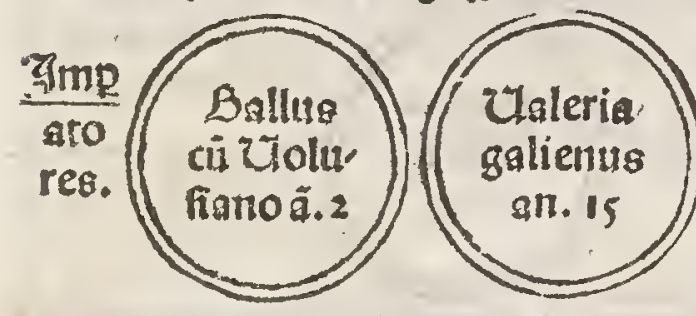

Rituit:\{5 q2 nö plenevindicaut xṕp. anou fanguine:plib' bellis attritus fut romano zexercit?. Tandë pius oñ̄ nö oimifît rếpublicã:iam pcne oéperatã oino píclitari qz multi tý, rãni illico fuerüt interfecti zppigitas redije infperata.vide oz ofiü.

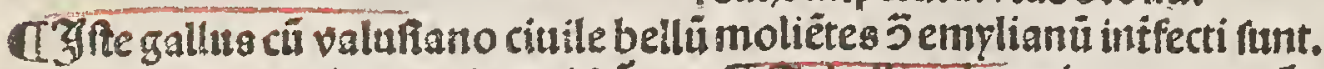
Et emprlianus tertio menfe occidit. UPilicus martyr. T2Dalchus mar. Comarinus mar. TPatricitismar. Isructuolus mar. apzorits mar. U. UEngenuanar. CLlaudianar. USabellitisereticus negat xpm filium dei efre.

Taurenti"glozionfinim?mar.

aselicilimus mar.

đสี้gapytus mar.

Uhomanus mar.

Utsppotitus mar.

CLoncozdiamar.

Copreneusmar. $\left(\begin{array}{l}\text { Clandius } \\ \text { Anintili? } \\ \text { an.2.8.7. }\end{array}\right.$

Q Iffe claudi gotbos nobilifinie triumpba uit:giã p.15.ãnof illy, rici macedontã $\mathfrak{B}$ va ftarüt : $z$ ideo ftatuam suream mernit z mozbo interijt. (I2) Danicbeoze berefis impijpima: z groflifima erozitur: : quodā ma nes pfo: barbaro mozib?žc.bicpo. nit ouo p̉ms paincipia.

đQuirinus martyr.

(1262. martyres rome.

1द्abacuk martyr.

CLearius oiaconius mar.

a Teontius cortataris mar.

d 3ulismus mar.

afelirmarter.

CEutebilta monacbus mar.

U46.marrzres.121.martyres. UIropbonia vxoz Decij žc.

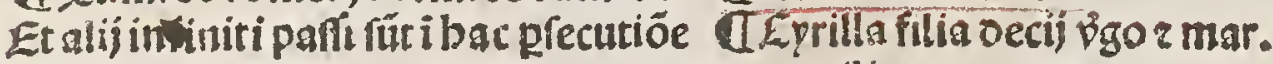

$x$ \%.46.milites.

ânomamdi

सmmoxpi.

Tzylte conneit? cele

baenoméritall bz

z fupmozbü cadn

cum fingulariter ac

cepirporeftatéa oo

mino.toic cozpora

rcöspetri z panli le

uatiit r bonozificé,

titus repoínit i locis

becentibus cuz btä

lucingrë. Tâdez cü

multis alijs marty

rio cozongtur. Jpe

ranciuiturfacerdo.

tes peerta cä iura repoflent fi vellêt. 8.46.mitites.

5453 Romanus. Brects

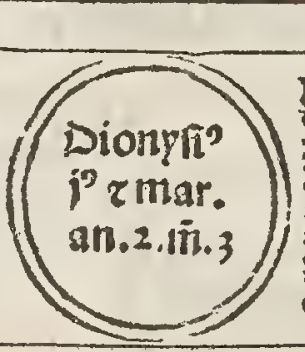

254

Ijttelucits ita ruir ut ono pibyti zrres olaconti: cü ep̃ofintr reänt eit in oilocopprer teftimonitis poita tig: liç cöfciefecu ritas fufficers fibi plua falute:sin tpe maliuolos o; ep̃ babëboni tomé apud eos $g$ foris für.ur 5 oe cõ.oi. i. Jubem?. Iådeร martprio co:ondt fub paleriano.
Gylte ftephan? ftatuit neveftib? racris p̃terộsad cultũ oei gs vtat utpzoecốre.oir. i.veltimẽta.tan, dẽ martyrio co. rount in celeb:a tione miffe:quia templuz martis ozationefibuer tit.

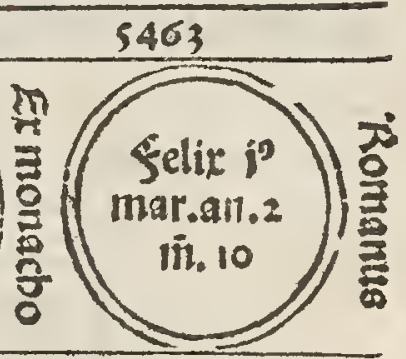

264

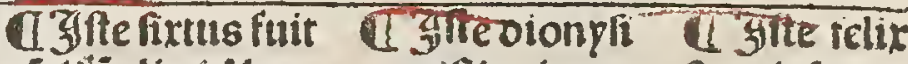
própualisfcilau usoiftinxitpa ftatuit fupza rentij: $z$ ftatuit 9 rochiasmãdãs méozias mã mifia rupaliäe fi g paltozes con trrujmiffas eret qỗãtea nifie tenti effe oebét celebzari.itë bat:tandē marty terminis fuis. riocozonat cum Limiteriaconalijo plib?fubga fruritivzbep' lieno:quialiono pter pniasz ba

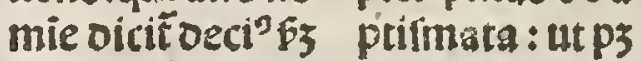
vincentiu zalios 13.q.i.ecclias. z becê verioz po. Iandes marty fitō:utpsil legéda rio cozonıtur: fcilautrenti.bui repultms ipace etian tpe berefis xp̆pi. Therefis fabellii: orra fuit pauli faramoli apóptolemaidá. tañ. ozit̄. feftú oedica tồis ecclée fin gutannis fta. tuit agi:tàde mrio cozőa repult? in ec clefía ina zé. Doc tpe Oziť berefírmani cbeoza âdă ocỏmaneró pfide.oe äre cta peftifera babes, 24,0.c. vltima. - ХDtigenes.lxt.anno etatis fite:nõdum integre impleto:Defunctus eft r fepultus in, vibetyro. 
BDecima plecutio edclie fit iufiu oiocletinn z maximiani:que oib"p̌cedĕtib'grauioz fuit:z decẻ annis ourauit. Zn tantü fertuebat.ut in. 30 . Diebus viginti milia cozonarent:ecelefije z facris libzis cöbuftis.

a. 3 anglia pene tota fides exterminata eft boctempoze a maximiano.

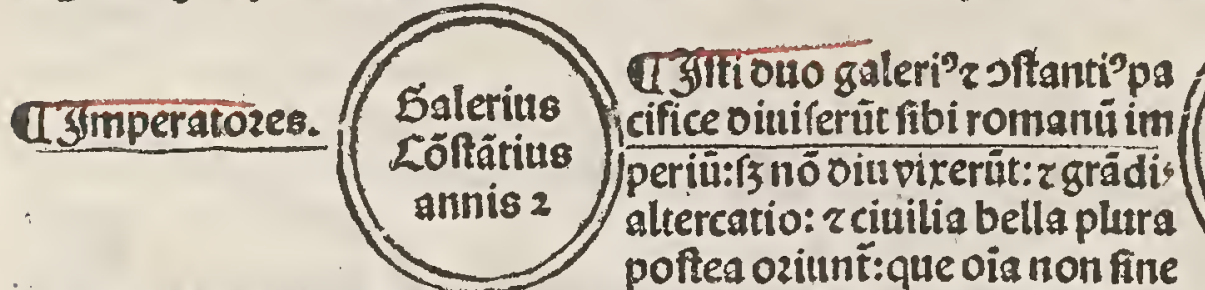

grandi laboze cũctis tyrănis extinctis:ftb cöftantino magno quie uerüt. Zlliq etiä celares tūc creati fuerunt: 9 xp̄ianos marime preä' bantur:quoz maxentius pnus fuit:pide ozofumr

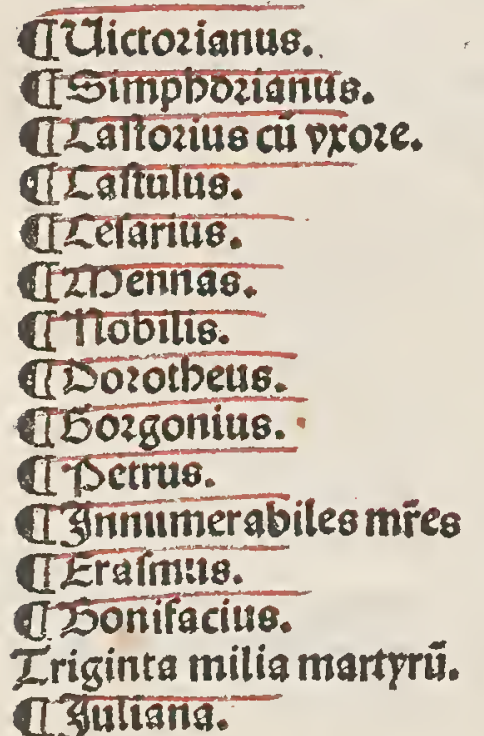

İgapes. TEbionia. Cibirenea. CLbeodora. d277.martyres. CIFlozianus. ITsim? relicianus. dUítus r modeftus. CErercentia. CZalbint18. IRogatianus. UDonatianus. CPancratius. Ekatbering. dipargareta.
(1) 3fte confătin' impstor glo riofflim? celebzenomen relige In bellis victozior": i gubernã da republica paudens: in nego ciis fidei incôpabiliter oetrot? Eippietasr fanctitas ex multis fcôz oocto

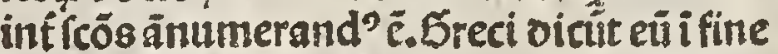
viterue monadbú effectü: agètes feftú eius 21.martij. Eteulebi'z 0zofi ${ }^{2} \tau$ alij oiligëter cius facta oeferipfertunt. I Lucia vigo r Anbeas rer. II rigitalepte milia martpres Cistmplic ". Tatutin" beatrix. ITantbaleon.5eozgilts. स3titis. Leocadia.

IL relterís pene tota martpri. cata eft prictiouarú.

LLDziftoferus. Qf felir $r$ gdauctus. I. U2tntonia: $\tau$ alij infinitinume ro paffífunt in bac perfectutióe: quoum nois oeus feripfit in li. bzo vite.

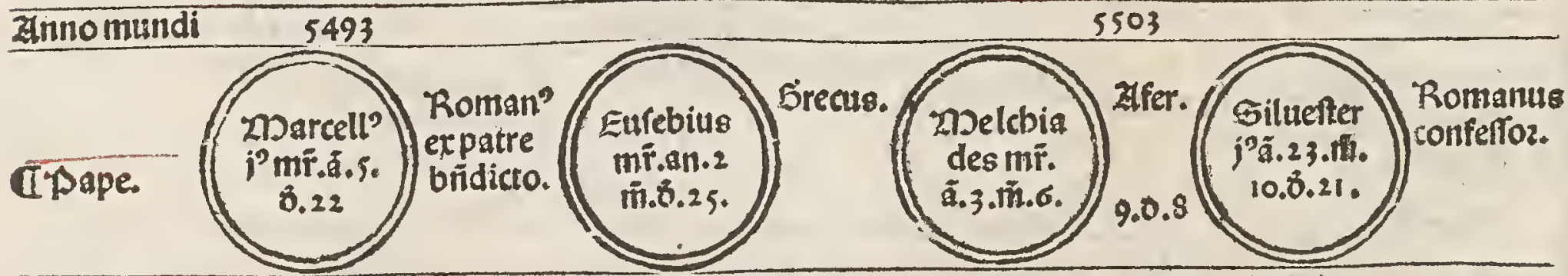

Anno ז̄̄i.

UIfte marcellus magnạ babuit cü maxentio altercationē:oicēs. Soni p̉nci. pis é ecclias cötritas reparare: $z$ oci facerdor

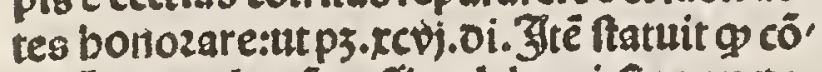
ciliü generale nô poffit celebzari:fine aucto

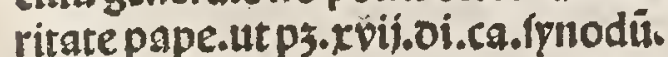

d. Jre elegit.Ts.cardinales in vzbe:ppter fe pulturas r baptínüü rë. Iandē poftlongam cuftodia iumento z: i cuftodia publica reclu fus:moziftyrannide marimiani:fepultus in cimiterio pzircille via falaria. Eius feftü agi tur. is. ZJanuarit.

ISelix. QUlicto cup arentib?. IFabints.

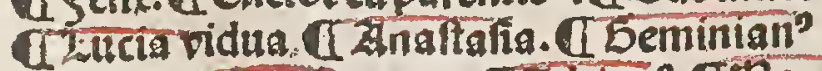
cum.79. TLb2plogonus. Cadrian". Tht talia. TLugenta.

Ti Dulus eufebij tee fin aliạs antiçs cbzor nicas inuèta eft crux oni nof tri iefu xṕi.5.no nicas inueta eft crix oninofriefuxpi.s. no

QIffte eurebi? ex laico ipapa affupt" eft: fuit eni medic: q8 repe factú sitat tpib"anteriozi bur bic ftatuit ut laicus fuum ep̃m accurare nō poffit:nifia fide etorbita. ret:ut.ij.q. vii. ca.laicos zc̈.

Zandë marty' rio cozôat fub marentio rë.
T3ftemelcbiades ftatuic op 4 Gne filueiter ote onitico r feria gnta nullo' gitolus cófefto? modo oeberet iciuniú obfer xṕi multipliciter uari ppter reuerentiâ oñi: ul" eccham oecoza. q2 illoroies pagani âfi facrú uit tä ifcripturis ieiuniū celebrabãt:oe ore.oi ö̈ imiracut:ad iij.c.ieiuniú. tandë martyrio mirabil' fuit. oe cozonat ficut oés predeceffo creta multa con res fui. Et nota $q$ bic eft viti fituit berefer mus marty 4 a fó petro. $33^{\circ}$ matuit: cardiales in ozdine pontificü romano ozdiauit:primo rü: $g$ oẻs fauguinê fuderüt p niü btipetri.f.re teftamento fóo. Ettüclanda gnú italie cüto. bile fuit fm Sregoziū epifco ta pzbea cöftan pattm appetere. tino fufcepit: $\tau$

Tracudentes puntifen ores ad cultumectie

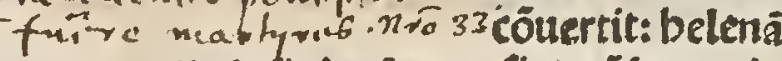
cû́ iudeis baptiçauit: $\tau$ alia iufinita fancto fine cófumauit. zmartprio cozonatus eft cü alijø. 


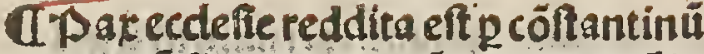
z incantu firmata:ut gaúq lederet xp̆ia nü puniré. becreuera émirabilis mu tatio oextere excelfi:iuxta illtud $\mathbf{p}$. Filia babplonis milera: btüs gretribuet tibi retributioné tuã quã retribuiftinobis.

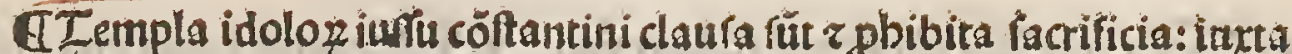
illud Efaie ppbete. 'Di qui nö fecerüt celü z terrä:peant oe terra. Incre

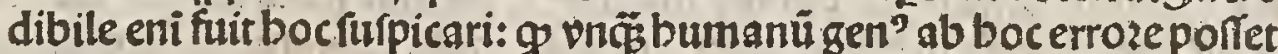
abfolui in quo a oieb" nini regis alfyrioz vlas ad bectpa: pannos ouo milia trecentos:erat miferabiliter multiplicatü. verü oigitus dei eft boc z magna mifericozdia eitus:nö bominis meritū.

\section{TEurebius cerareepa} leftine epus in oituinis fcripturis ftudiofifi, mus fuit.

C2Antoni? $9 b b a s$ cis fimus potens in ope: 2 fermone clarifim? in prituerfo ozbe bët. ITsafnucits oilcipu lus fci antonij. CEtmultiberemite? monacbi in oefertis lo cis boc tpe claruerut.
Abelen regina mater conftan,

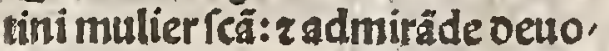
tionis z actiuitatis.crucē zp̃ i rep : perit:feptuagintaduo collegia fú daut totúqs ftatü ecclie incốp bili fertioze glozificautit. alticolaus eṕs mirree ciutratio fcús $\mathrm{p}$ oia $z$ venergbilis.

C.Atthanafitus eps alexandrinue ooctoz gloziofus r côltantiflim" cōfeff́oz edidit fýmb olü.quicūqs Dult faluus efle $\tau \ddot{c}$.

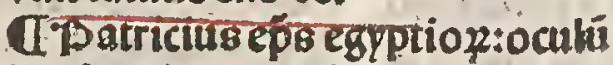
in pecutione amifit.
Q Alexander ep̣s alexandrin'no: tabilifimtis in concilio niceno. C. Arritls bereric peflimus totus bypocrita:affer it trinitaté p fona fspnitaté effentie negat:fupza mo dũ ifta berefis afflixit ecclefiã.

đEonftantinus fecit crucé aureà puriffimaz ponderanté libzas.cl. quä Donauit ecclefie fci petri. Thtê aliã eiufdê pōderis : quâ oonauit ecclie rci pauli. plurimg etiaz alia ornaméta ex suro $z$ argento fecit: acetiä plures bafilicas cus ootib" rais oznauit.

1Zofimss abbas:qui mariam egpptiacam repperit:tamen quidă libzi oicǘt: 9 ambo fuerüt tpe valentiniani.

ULe poffeffionibus ecclefie quas p̈lati circa bectpa babere inceperüt: grä dis altercatio fepe inter doctozes fuit:

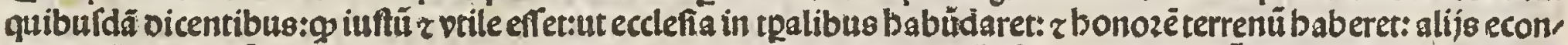
tra g nô:nec mirū. Quicquid eni ecclefia facitusel oicit aut babet:fignü eft cui contradicí. Elegit oiu in pauptate z penuria vittere:fignú elt cui contradicit. Sufcepit oèinde gratis oblata tpalia:fignú efl cui contradicié zê. Sed

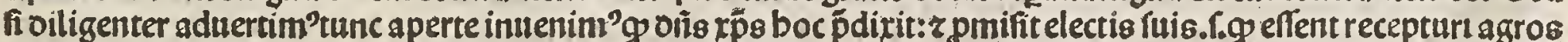
cum piecutionibus:ut patet marci.x. Et oicente beato petro. Ecce ouo gladí bic.onis rindit. Stufficit. Ul bi beatue

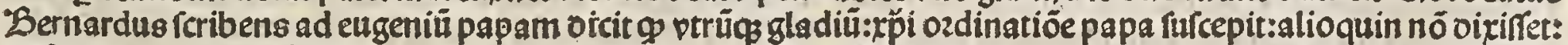

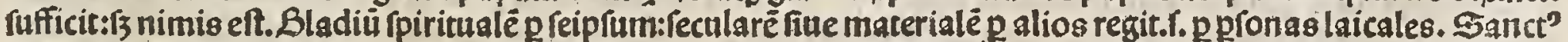
autem tbomas talem format rationé ex oictamine iuris naturalis z oiutini. Ex quo tota xp̃anavita ozdinat pzin

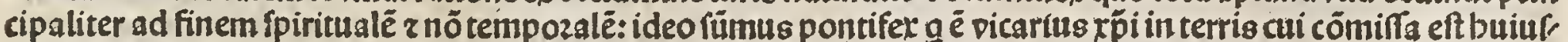

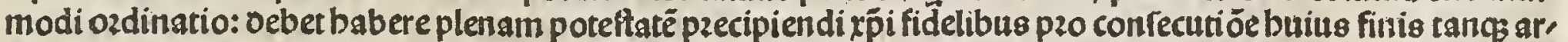
chitectoz:qzei ad quem ptinet vltimi curg finis:fubdi oebent illi ad quos ptinet curg antecedentiü finium $r$ eius imperio oirigi.qui oebet enim vti armis imperat fabzo qualis oebeat facere armu.z q2 finis ifte eft oignifimus

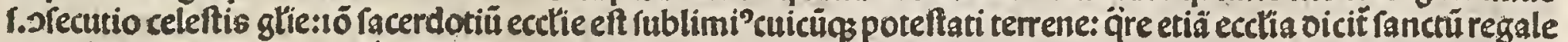

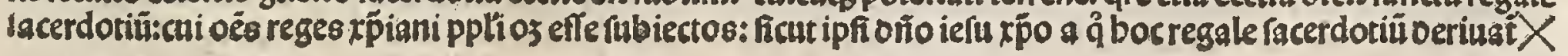


CLonftantis filta côttantini magnivgo f́ä củ multis alís in f côppofito oño rer. uitit beclepzofa fuit ficut pster einf:fed

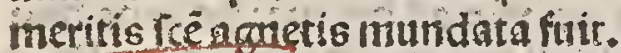

đCometa apparint ante moztésftãtini pĩ oicit maro: $q$ mozs côftätini oenticia ca eft p ftellă crinitä inufitate magnitudi. nissquä areci cometā pocant. I Sequü mals if́nita älongo tpe ou

IIMperatozes. rabant.

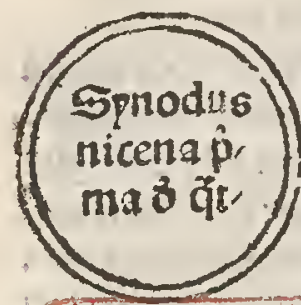

tu02. Eaz auctozitas eft fícut ầtนo eusngelioz.

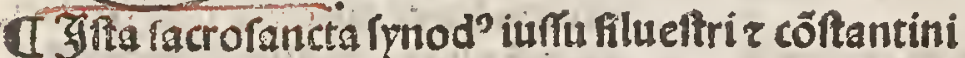
cögregara fuir in niced ciuitate bitbmie. \&t fuerüt in ea.3 I S. ep̣icatbolici viri fciflimi: miraculis gliofi: 9

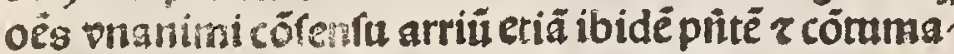
cen oäna rür: 2 lịmbolü ediderüt: 2 fidé exponentes plu rima ftatuerü:ut p3. 16.0i.c. ferta fynodus.

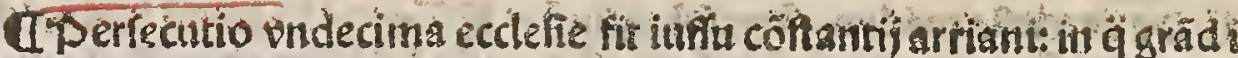
turbine fides fubuer a fuit: multiviartyrio cozonati : multi exilio oã

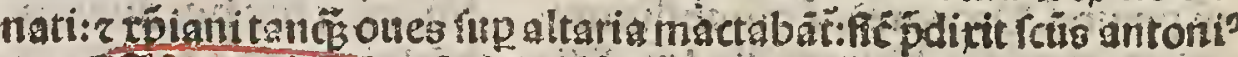

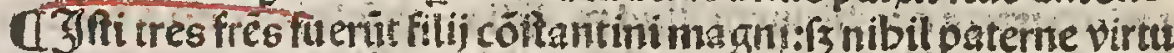

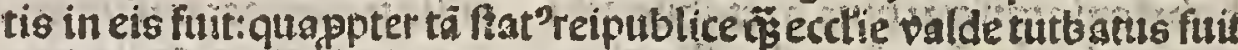

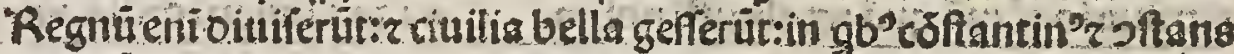

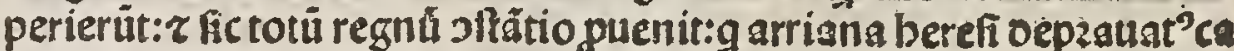
tbolicos pregt:r multa bella furgut:ita nt nultä oeinceps

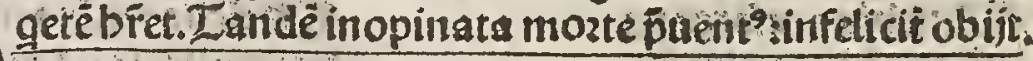

ISymeon arcbiepos feleucie:martyriçat in ofide.

IIsedecim milia martyru z alij infiniti paffi funt. Cisucenti z ghquaginta derici:cü alijs monacbie z fa cratis virginibus ab arrianis interfecti runt. UAmos pater triü miliü monacb oz: zalitis amon? I. \$acbomi" vir feifim":pater inumerabiliu monsacho nü z monialiü: $\mathrm{g}$ indifferenter oés recépir iutsta regulä ab angelo fibi oatẩin eggpto fuit.

UDonatifte beretici ozinnt in affrica:fic oicti a quodam oonato. Dicùt ecclefta tninmodo in affrica mànfife apud re z rebapticabant catbolicos. Din oiranit.

U'bilarius pictauieñ.epo claret ooctrina zvite lanctitar tein gallia.

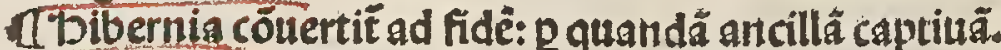
đxDariminus eṕs treuereri. maguus confertioz.

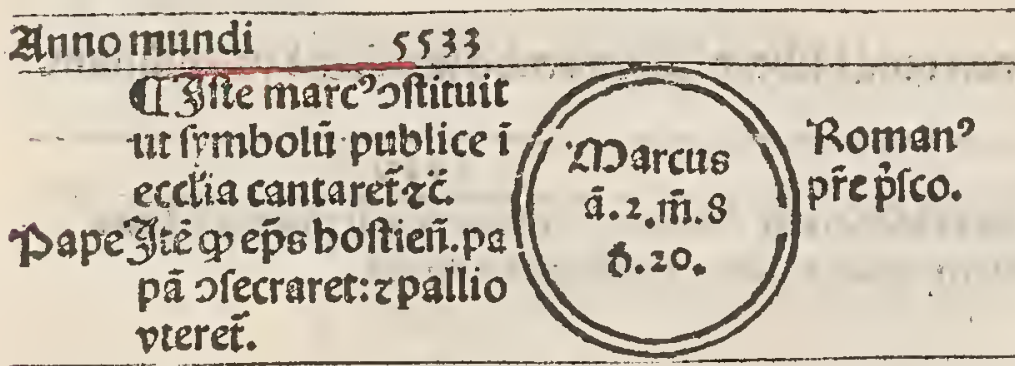

Anno xpi.

\section{3}

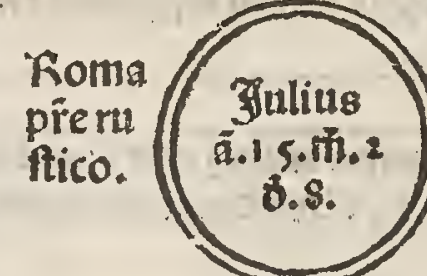

Uदुfte utli'multas plectitióes fu finuit a oftảtio arriano:z p.x.an 308 fuftinuit exiliü tädē moztuo sôftätio:ad redê fuã rèdít zouas bafilicas extruxit. Dic mlta côfti. tuit:tảdẻ btă mozte potit ${ }^{n}$ : fépelit 344 i cimiterio calipodij.Ei'feltū agiť.2.id"apzil

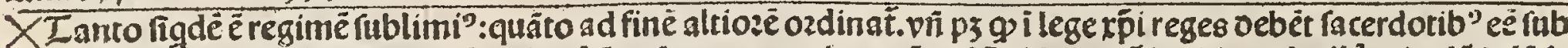

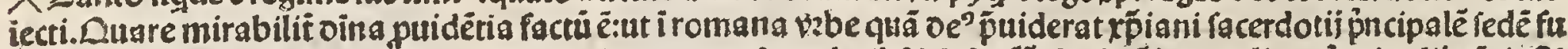

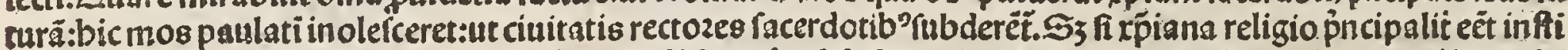

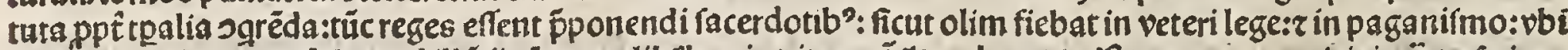

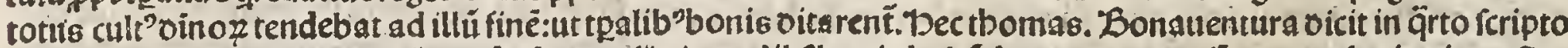

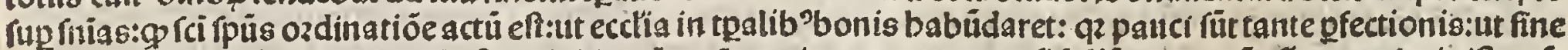

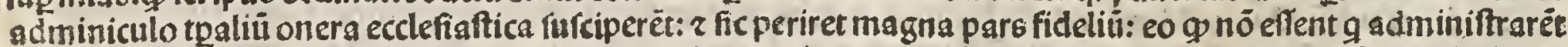
fphatia. Sancta bzigida lib20.4:ca.76. fcribit: $\$$ beata virgo maria bec verba fibi oixerit in quadā reuelatione. Ecclefia oe phrtis tpibu s paup erat in tpalibus volütarie :pceflu vo to to ut amici oei feruentioses z expeditiozes

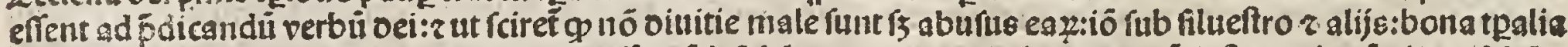

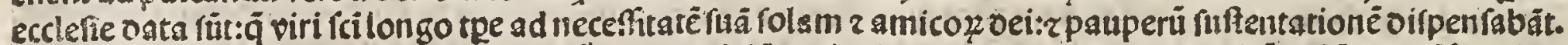
Ergo tales fcito amicos dei:g contentant oe oifpofitiöe oei: $z$ ipfe videt 208 . bec illa. Dicür gdä:qu nedu tpalem

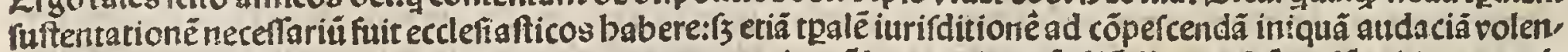
tiü bong ecclefiaftira fuis vfibus appzopziare:nec dectuit ut p̈latus ptäte fpüali p̃ditus ptätëtpalé cui imperet ab

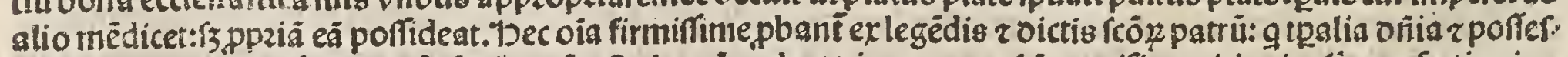
frones terrenas latifimas iufte babuerut. Quis eni audeat oicere. $q$ tot fci pontifices viri vtiqu fime pfectionis literature:miraculis gliofi: g oia tpalia arbitrabãt ut ftercoza:quozü ooctrina fulget ecclia:ficut fol zluia:quo.

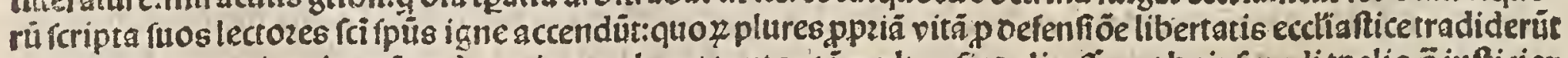
marryrio cozonati:gs inqna andeat oicere tales at tantos tă multos fic oelirafie: ut buiurmodi tpalia 5 iufticias

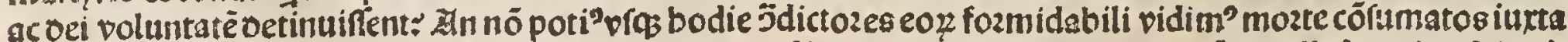

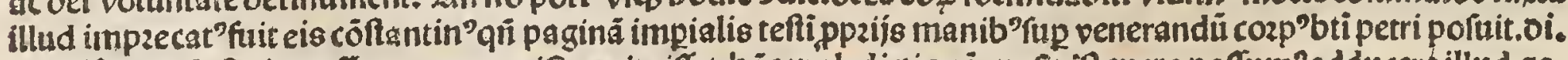

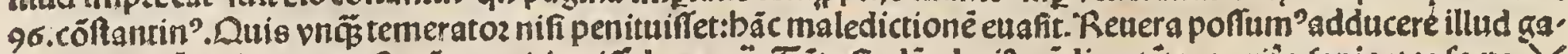

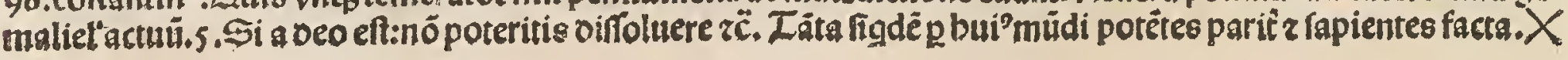


A Derfecutio, xii.ecclie: fit iuffu iuliani

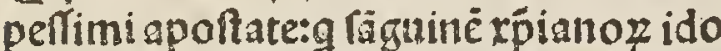

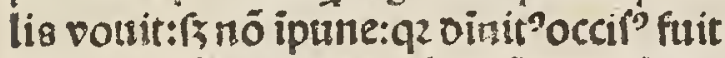

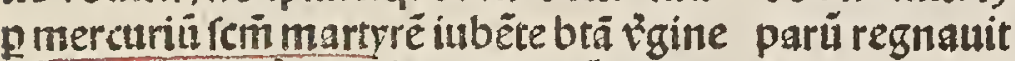
đİfte iulian'p̉mo rṕian':Demü monacb? tùc mağ:oenuo apoftata:tãdē celar zoolo auguft' fuit: totaliê fidē nite. batur oeftruere.

dEunomi"reretic:cozpe r aia leprofus:a qunomiana berefis oicit filiünōnatura: Bjgratia filem patri. C20Dacedonius beretic'ne gat rppri ranerũ eälë pr̃i z fi. lio:berefis magna. I'Paul'implex oircipul? antonii: g merito obediētie cito ad pfectionē ven it. C'Dilario. I Sonat'mar.

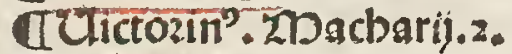
GDonat grömaticus ma. gifter bieronymi.

Ifpautin"epstreuereri. (1) cboz or pfallêtiūi ouns ptes oiuiferüt:zvigilias ad repulcbza martyrä inftituerüt.

(120atilius magn'confeffoz $\tau$ éps céarieñ.claruit.

(Tbregozi"emifen"epus z fra ter bafilij z petrus.

C.Tloantites paul'martyres. đQutriacus eps z martpr.

Eballican'mar.

Ijulianemar.

UTheodozic'martyr.

द 5 ozdianus mar.

UEpimacb’ mar.z alij multi

CIfte valentinian oeuot' totalit fuit: in fide fabi. lis oiung ozdinatiōe ad imperiū puentit: qzenim fub

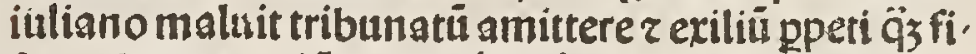
dem abnegare: iō retribuére xṕo: meruit ad imperiuz fublimari femp victoziofus fuit:farones z burgudio nes vicit.

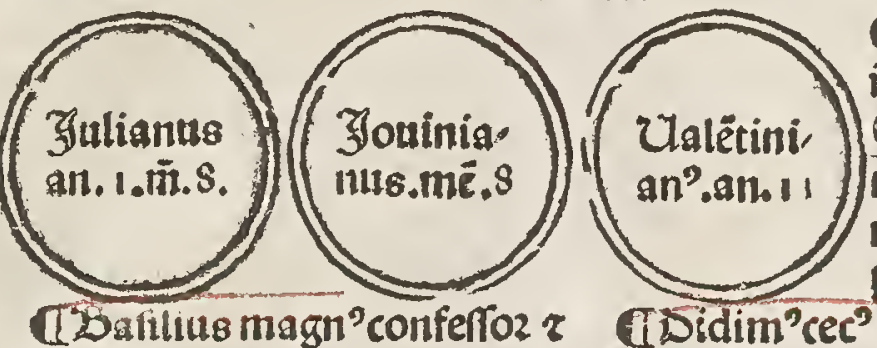
Trrando marima iumenta a pud conftantinopolim.

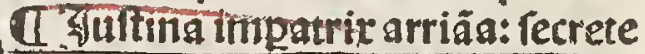
cpe viri fui:\{3 p? rë.impiavror piffi mi valēriniani impatozis:p?multü pregĭ catbolicos z ṕcipue äbzofiit.

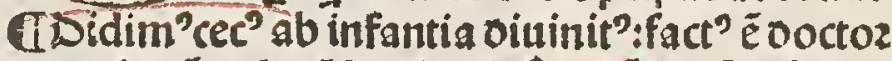

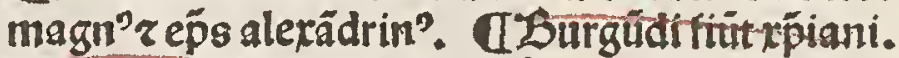

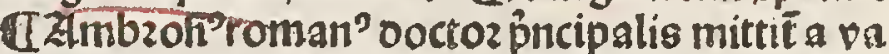
lentiniano ad mediolanü: $r$ ftati in eṕm oinit? eli git:ut ipfe tefata itibzo ve officiís. Rapimur oe tri bunalib? ad inftulas: cogimur fitoifcere zoocere.

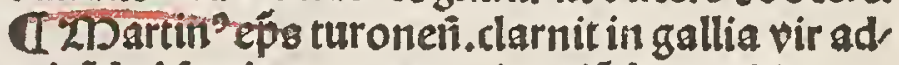
mirñde f́itatis:oe pannonia oziüdus extitit.

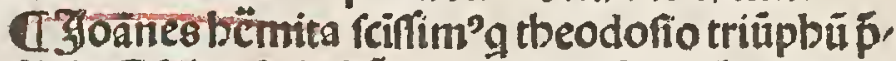

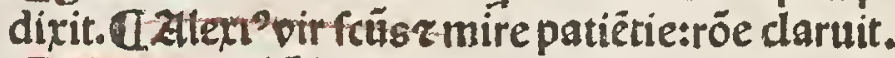

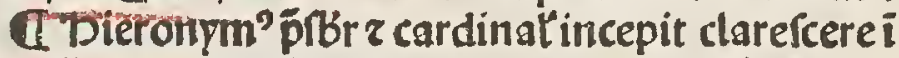
ecclia oei oe oalmatia oziund?: Femp ficifime vire

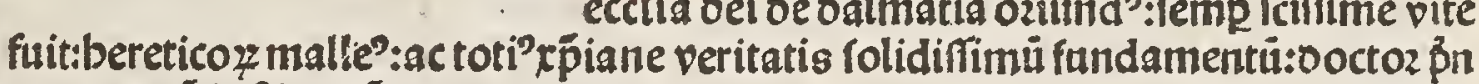
5553

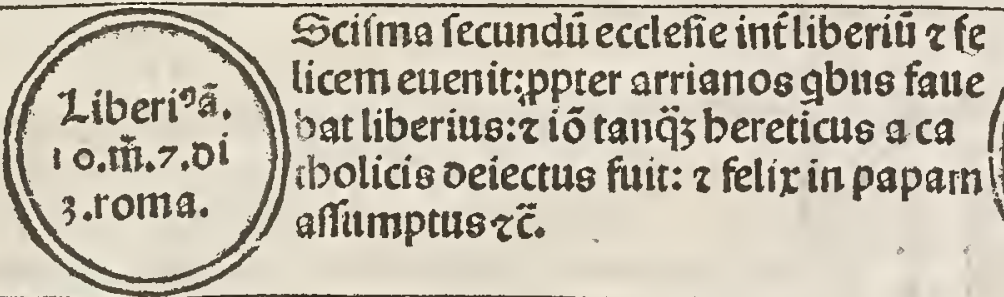

barelicuh 353

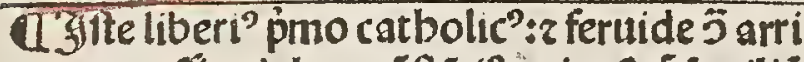

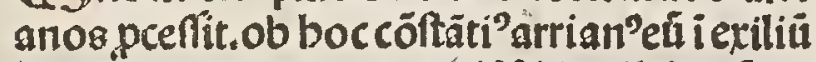

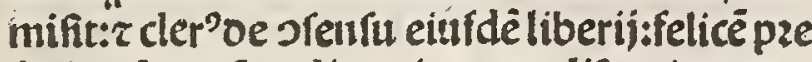
fbytep̌ i papã ozdinauit:g ampli?arrianos ex

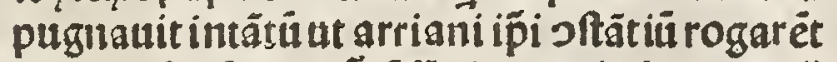

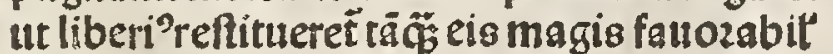

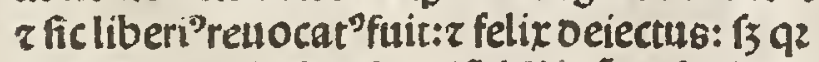
liberi?arrianis fanebat:iô felix cî catbolicis

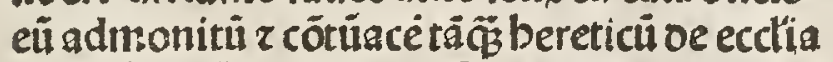

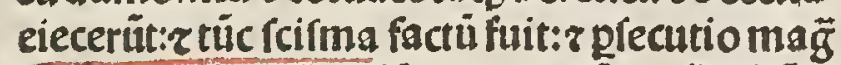

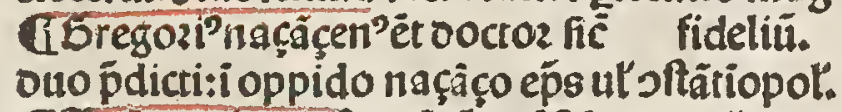

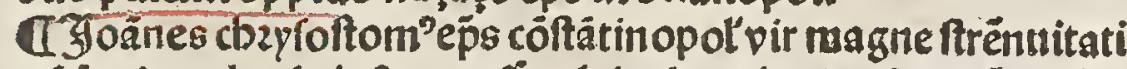
z fcitat\}:multa fcripfit:? paffus fuit ab arrianis plecutiōes ples C2Doples abbas. Fynclete. Lopzes. Effrem. Pamb? Sera

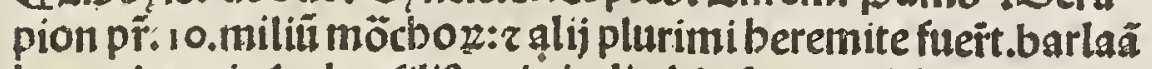

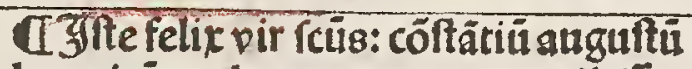
bereticü oeclarans:oe papetu eifiti:?

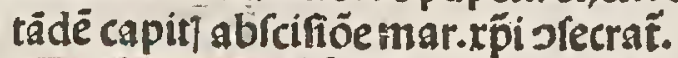
UEtbic nota 9 p̉mü romana ecclia circa bectpa ifamépapā büit: q2 Oēs añceflozes builliberif́fuerüt fai zerë, plares:ut fupza p3 $\mathrm{g}$ annos.350. 20 . (T)änes oamafcen?o octoz egregi? multa feripta religt. a Rufin? pitope multa feripfit:z biftoziajecclefiaftica tranftulit.

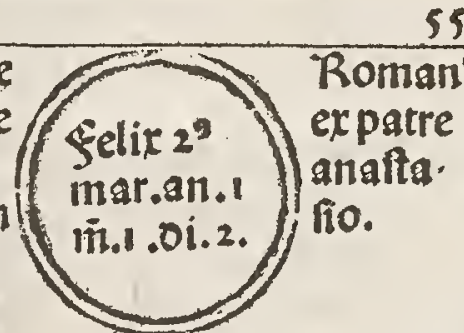
5563

$\left(\begin{array}{c}\text { Damalit8 } \\ \text { ofer.a.18. } \\ \text { patre } \\ \text { pantonio }\end{array}\right.$
363

CIfte oamafus gtiofus cöfefloz: multa laude oi gna patrauit:adiutue flo. ridiffimoz virozá fttudijo quozü grandis numerus the fuoclaruit.cbozos ca tantiü ozdinauit:in eccle fia glozia patri zć.poft fín gulos pralmos dicere iur fir:rogatn beati bier ony' mi in verfib? oictandis ex cellentiflimus fuit: plurimag feripta reliquit $z$ г ṕcipuebiftoziä papari z martprum. Eonciliú etiâ recundî pniuerrale.i.cóftantinopolitanum contra macedoniü celebzare fecit. Eius feftum agitur. I 1.oecembzis. beremita: $z$ iolapbat fili'regis indie:bis fuere tpib?

X leģimus côtra patrimoniü eccle lie pene in oibus finibus totius xp̉ianitatis

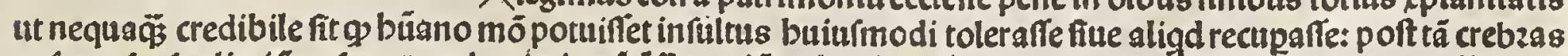

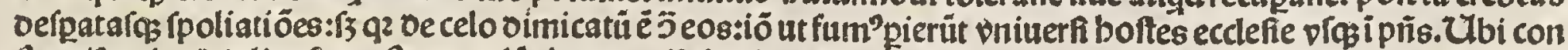

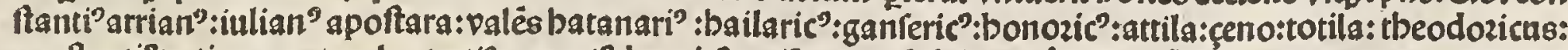

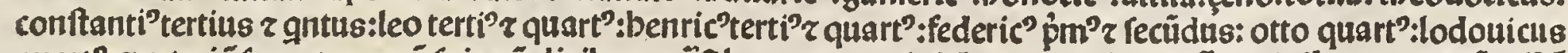

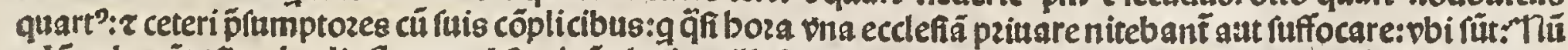

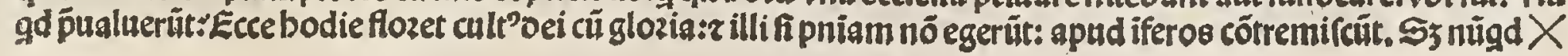




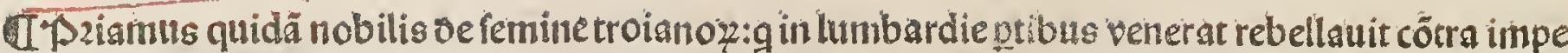

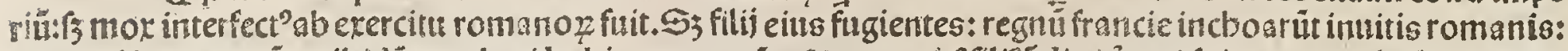

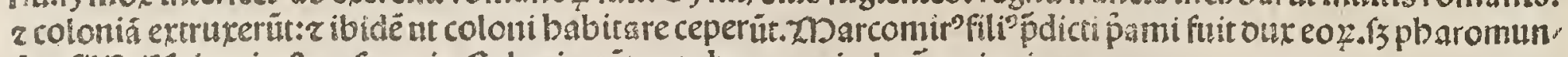
dus fili' ei' frut pzim'rex francic. Solonia aü ante bectpa oicebat agrippina.

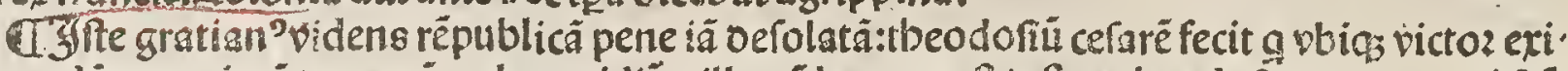

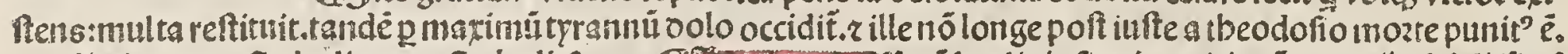

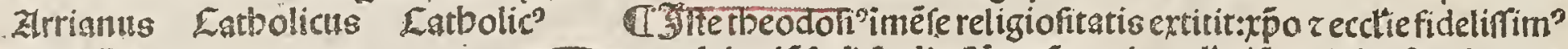

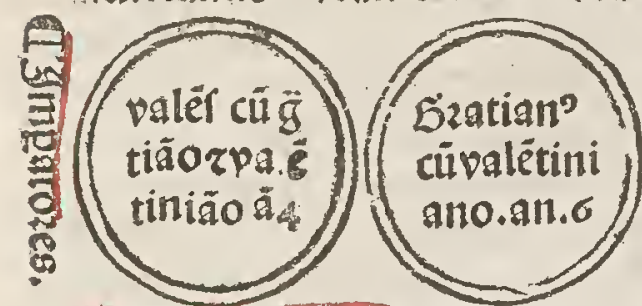

Tद्वाte valés frater fuit va Lentiniani: $z$ că eo oiu regna, uit $\mathfrak{I}_{3}$ timoze ei $^{9}$ conceptầ tra

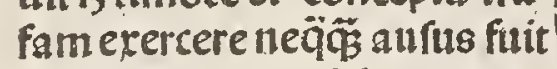
is eo moztluo cuj folus regna ret: catbolicos plegte rmona' cbos ad militandü reuocaut Landē poft multa ifoztunia: impia mozte perijt:tĩ cia ali. qualipenitentia. C20sartpres multi facti funt niü bereticī. in egppto $p$ valentë iftum:q2 arrianus fuit.

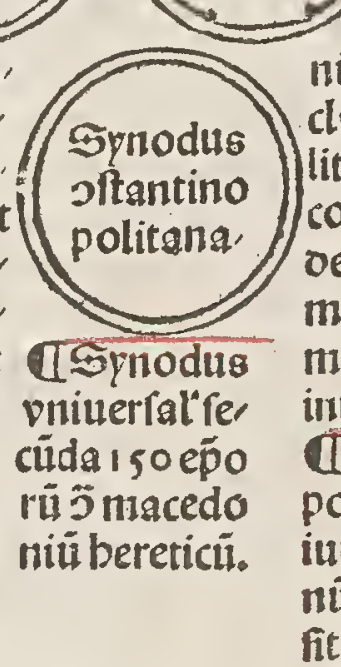

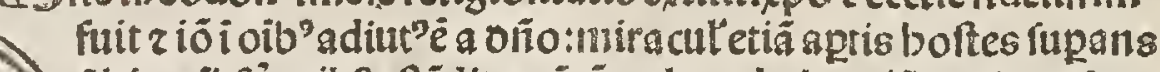

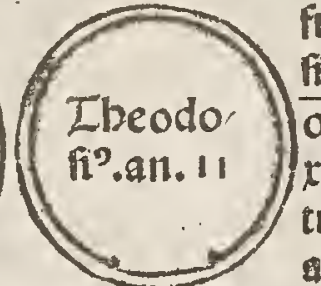
fibi z oib'p̉ncib'oftêdit quátü val et ad victoziã obtinendam ozatio deuota cülacbzymis. Ab inumeris barbar circüdat?

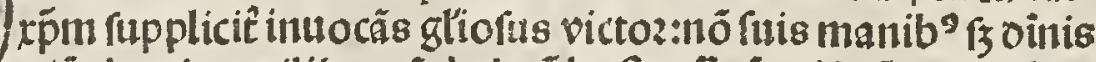

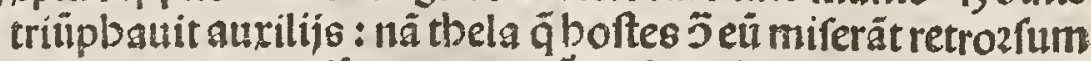
acta: i ip $f_{0} s$ atrocî́ renertebant. Dó vidêtes barbari pamoze nimio pftrati stinuo fefe kṕianifimo pncipi fubdidë.vin z poeta claudian's pagan'b idē teftat̃ oicē8. D nimiü oilecte oco tibi mi, litat etber. Et cồiurati veniüt ad claffica venti. Q̋̈ büiliter fe büit in cozzeptiōe ambzofij:pz in legēda eiufdē. ZTide auguftinú libzovlti oe ciul.oei. Et quó idola fubuerti cü tēplis iuffit:z quố ioãnē bere

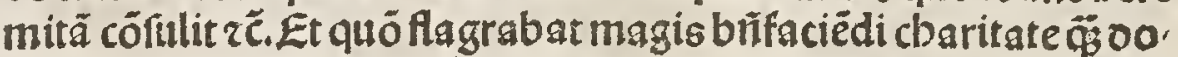
minãdi cupiditate: mozit̃ trĩ bii oifpofita republica quã oefolatas inuenit:pmo ftabulari? fuit:\{3,pter virtutes pmotus eft.

đI Aluguftin? cartbagineti.oe affrica rbetoz maxim":rioi pbia ac

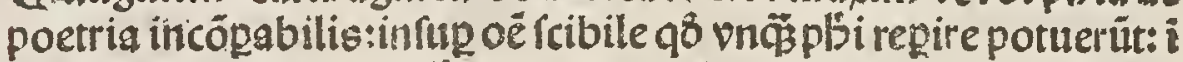
iunëtute fine magna oifficultate a dept?:circa bectpa ad mediola.

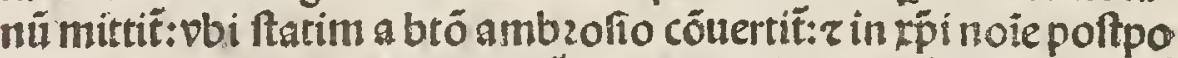

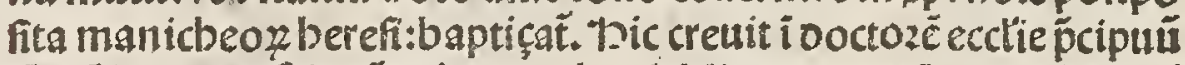

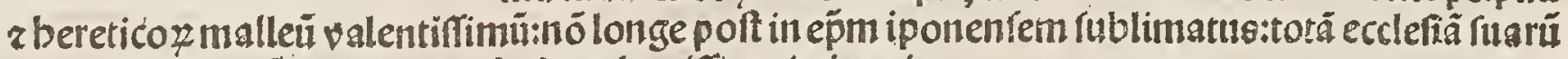
fonte Doctrinarü pannos.53.babundantiflime irrigauit.

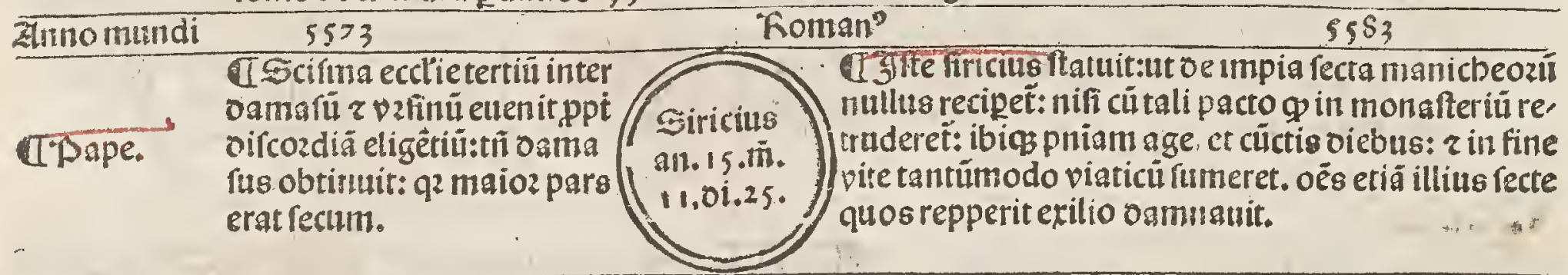
Anno rpi. $\quad 374$

CLeiti ${ }^{5}$ oamafi pape vaftas illas egyptias folitudines:bactenurg oifu fas quasppt fitim $r$ fterilitaté piculo

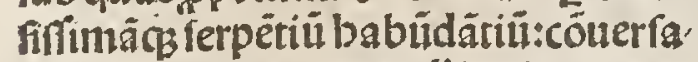
tio búana nó nouerat: bitatio mona, cboz cöpleuit.f.arfifius:picbi’:penne' nes:paftoz:çofimas:marina: eufrofi na:iofeob:fyrtis:agatbon:acbillis:lit frion:ioanes bzeuis beffarieñ.çacba rias:fyroi:mocbois:gebalon:egladi? gelafins:arfenius: luci?:z alij inume' rabiles:quozeft oigna meinozia.

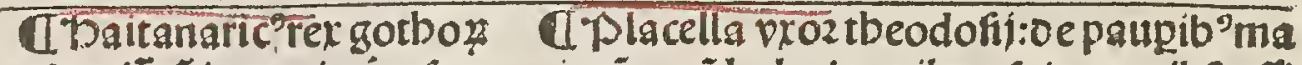
prequit xp̃ ianos in tra fua ximä curä babuit:quibus fuis manib? offi vbi inultimartyrio cozona ti fuat.

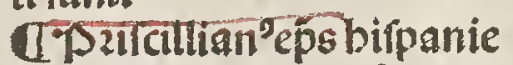
cadit in berefim peffimam inde berefis pzircilliana. Cisimin'epsambianeri. UTonozat $r$ Sabin? ibi dem:oés rci cö́feffores.

ITsala vidus ifitima: $z$ fília eius eufto cbiü virgo claruerüt:quarü btüs bieronym? 'repi? mes minit vitą̈s paule oignis laudib’confreripfit.

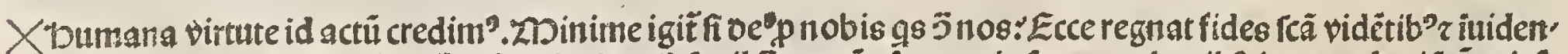

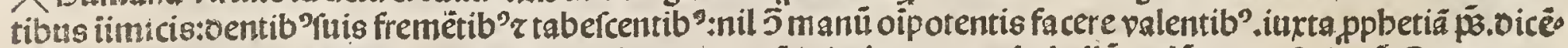
tis. Dixit oñe orio meo fede a oextris meis. Donec ponä inimicos tuos:fcabellü pedü thoz. Et iterü. Sepe expu'

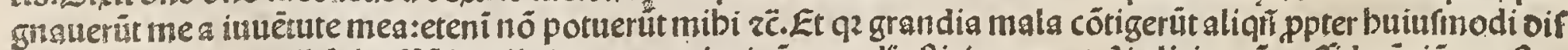

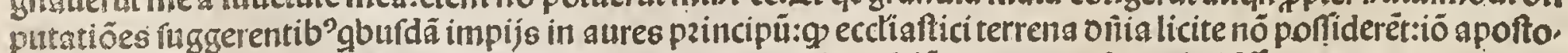
lica redes inbibuitne amodo fiăt:neq vlli liceat oeinceps in oubiü reuocare: go tantis fcifimo 2 viroz octrinio

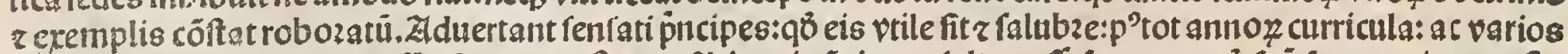

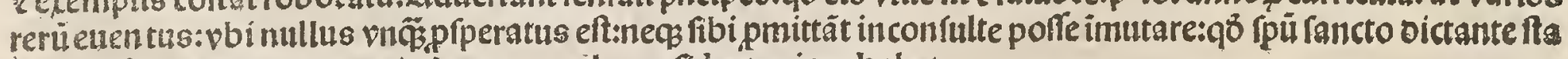
tutum eft:ac tot patronos 2 infipectozes celo prefidertes iam babet.
}

TLizonica fá bieronyni finit circa annos onii.380. 


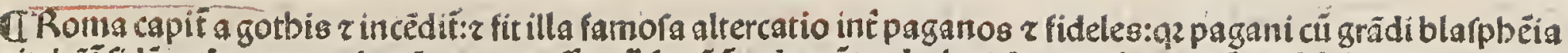

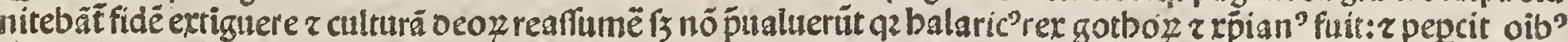

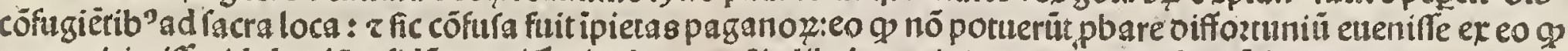
roma abieciflet idolatriä $z$ fidé recepiffet. Deboc $a u g^{3}$ in libzis oe cilti.oei: $z$ ozofius babüdanter tractant.

1 Zुte arcbadi'puer adbucfuit:qri pï eius oefunctus fuerat:z quidē fatis bon? fuit:仿 ples aduerfitates clim fré furo bonozio ppeffus ë:qz multa picula z tyranni oe

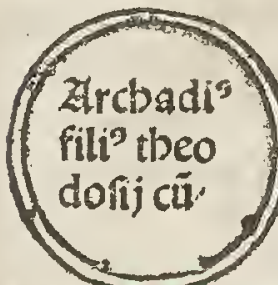
gentib' barbaric1:\{cytbis:gotbis:L)ã dalis: $\tau$ bünis:furrexerüt q mitras, pui cias oepopulati fĭt : 2 nifí xp̉ grä fin gulariêxp̄i fidelib’pncipib: bonozio fuccurriffet:totalit pijffent an. 13.

imbafceçel comes arcbadij:meritis fcōz quos recũ ouxir: exêplo tbeodofí cî. s..milib' pêruitboftiiu.70. milia: fcō etiã ambzofio fibi in vifiốe apparēte zc. 仿 p"elat": fcös viros cepit pfeg z ecclias temerare aur" eft: $z$ ftati occid it. pbauitos i fe vno: ad vtrüg fo oinu

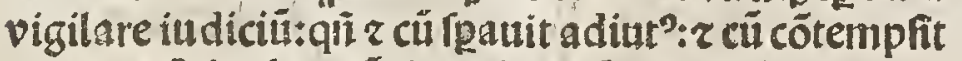
occifus eft De boc (út infinita exēpla:etiä bodie.

CLlaudianus poeta rome.

QTprtdentitts poets cbaiftianus.

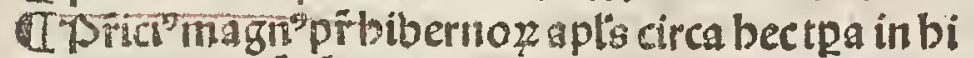
bernia venerat cú fuig: fozozib": angeli repecollogo' TSunctisberactides: Tozofius. fruit. feripfit vitas patria ad lautum ep̆m.

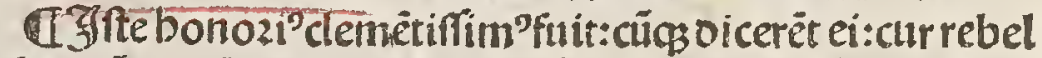
les nó occideret:ait. ZTinä eflet mibi poffibile ad vitam moztuos reuocare:z ob piä fidè quã ixpo büit:Inltos ty
ULonitatitls comes bonozij mirabili felicitate in bzeni multos tqrãnos $z$ barbaros pitrauit:xṕi adiutozio fufful tus. Er nota ge ficut oicit btüs biero": romani in p̉ncipio erant foztiflimi: fic in fine o ebiliffimi: nä ad ppulfandus boftes neceffe eff quottidie barbaros cốuo care.

CLiconius afer multa feripta reliquit.

UDonatuseps.

CEpifanius ē̄s.

ITulpititus feuerus.

IDolomgcius martyr.

GSprinnius.200artirius, Zlexander:ifti funt in italia

Tomelania.

IDiocher.

AZncilla.

CTatbanael.

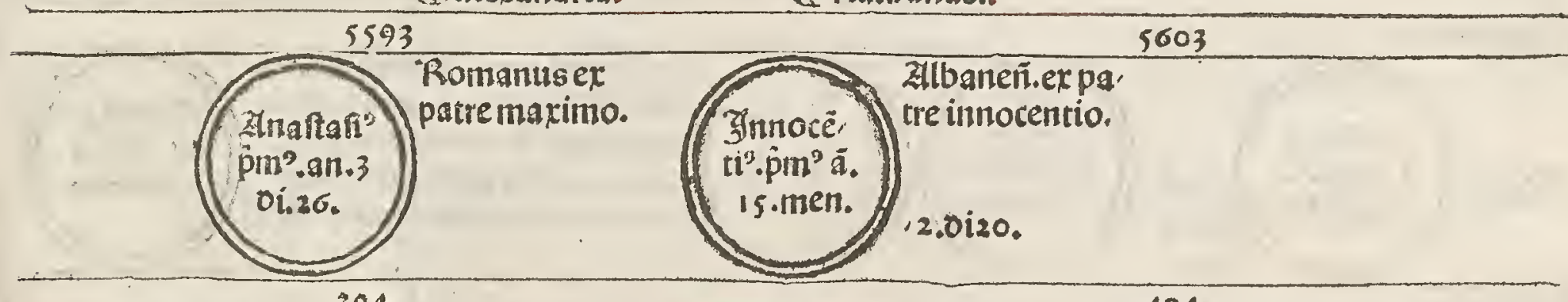

404

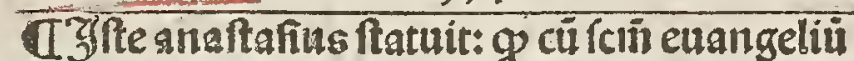
legeret:oés ftare oeberêt: $z \mathrm{~g}$ caret aliquo mé bzo:non oeberet fieri deric? bic fecit fieri फnã bafilicã prope fcolam mamertini.

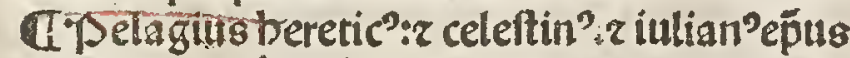
a quibus pefima berefis pelagiana: oicit bo. miné fine grä poffe mereri:z baptifmü z ozatio

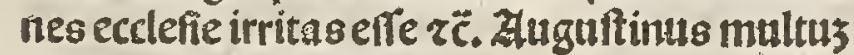

contrg earn labozauit.

CI balmud indeozum: $q \delta$ fonat apud eos oo ctrina:cóponit circa bectpa äno. 400.4 ouob" nopolim ab arcbadio.

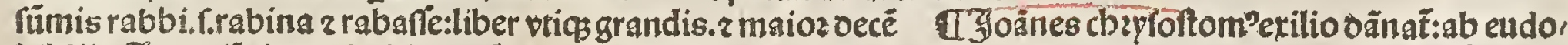

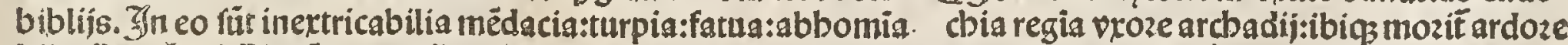

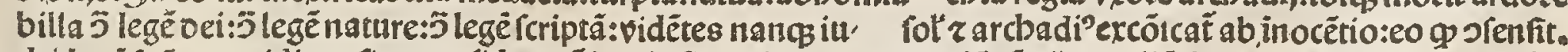
dei legē fuã quotridie oeficere: 7 fidem xp̉ianã pficere in toto ozbe:etiã cü glia tpaliü: bos ouos oeceptozes infti,

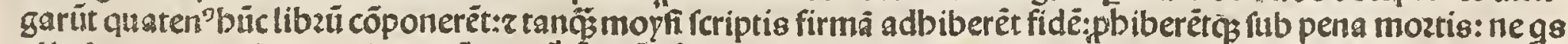

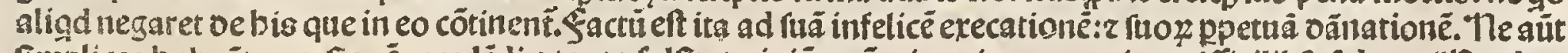

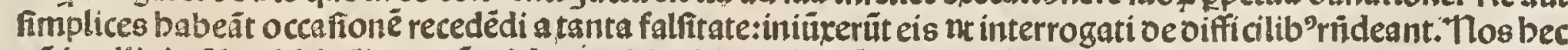

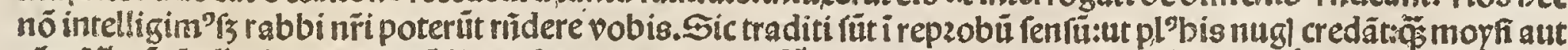

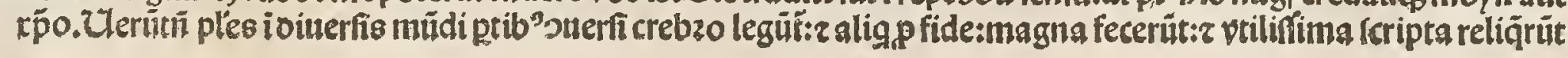




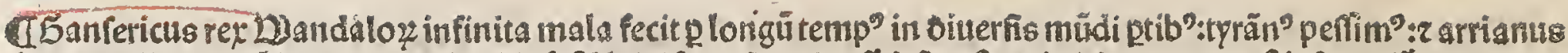

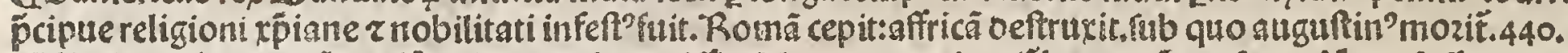

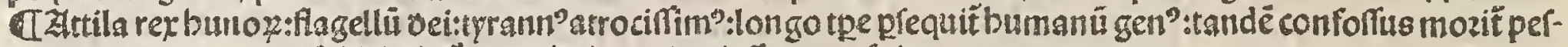
fime moze tyranno p. Allibi oicit op pprio fanguine fuffocattis fuit.

T'bic tbeodofi? rotus catbolicus fuit zoenonts princeps:nectii

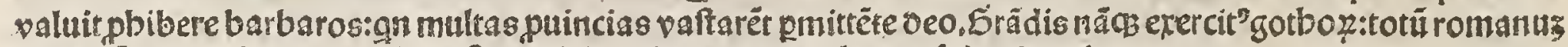
imperiü in partib'occidentis vaftauit:\{ 3 in oziente tranquilla pax fut $z$ fanctitas.

\section{Timperato:es.}

CJoannes caflian? beremita eiectus a chzifofto mo oe côftantinopoli:penit marfiliâ:collationes fcripfit $z$ glia. Et fuerüt infiniti fancti beremite r monacbiz $\ddot{x}$.

đIimotbe beretic:sicit xp̆m verũ oeũ:z boiem quidé effe: red addidit falrú:oicédo oiuinā naturā conterfram effe in bumanã. fuis meritis ab bünis.

TLóciliú cartbaginë fu fuit oucento z: r. 1 8.patrü 5 pelagiübereticum:in â fanct?auguftin'?olennis triüpbatoz ş bereticos apparuit:cunctos vincēdo T'Pzedeftinatoz Terpit berefis:que oicit nil pder read vitam $q$ fancti virtuofe agunt.

Cosalladius eps mittit ad rotos.

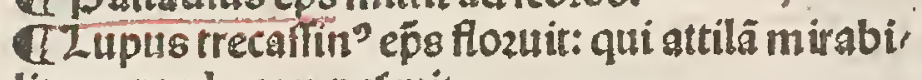
liter a pzeda compercuit.
İŻmanus ep̣us gureliaceri.cinitaté fuã liberatuit

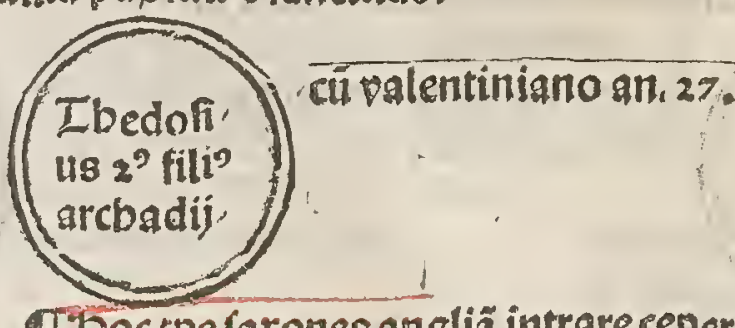

Cboctpe faxones anglia intrareceperüt:z pathlatim creicentes tandē totf́ regnü: $\tau$ oiedena obtinuerüt CLyrillus alexandrin' epss fuit in concilio epbefino. a'Tertozi eps cóftantino politan?oicit $x p_{5}$ puzzoie? nó veü berefis magna.

C'bieronymus obiit: mira

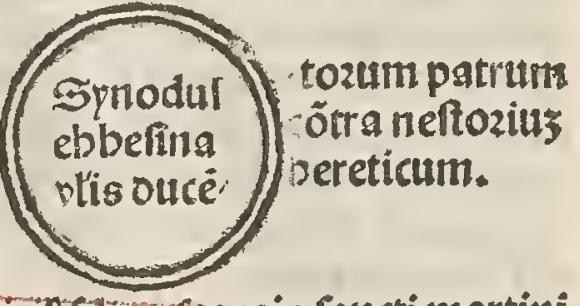

cat inandity clar" CPatrici" filius fozozis encti martini IEvfebi? oif́ci mittit in biberniä a celefino papa:pir mi pulus bierony' rabiliti operù. Ülixit annis centü viginti. mi claret $p^{5} e \tilde{\text {. }}$.

USerman'eps antifiodozeñ.tres moztuos furcitauit: zetiä

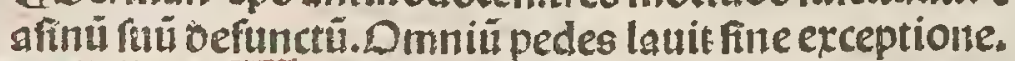
a"Saulin" eps nolan'vir fcus:oe å oic greg? in oialogo fuo.

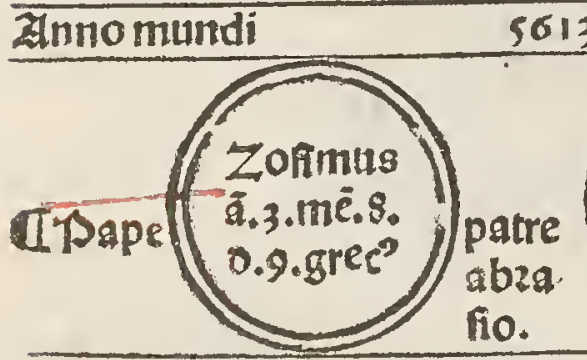

\begin{tabular}{|c|c|}
\hline \multicolumn{2}{|l|}{ Annoxp̃i. } \\
\hline G Zुfte Zofim?ftemit: ne & Uyfte bonifaciptar. \\
\hline clerici tabernas teneät:aut & tuit ne mulier tãgeret pal \\
\hline $\begin{array}{l}\text { ving vendât: z ut cere } \text { be }^{\prime} \\
\text { gedicgur in fabbato fâcto }\end{array}$ & [ã altar|:aut lauaret. Zpe \\
\hline medicatur in fabbato fäcto & babuit fcíma cus eulalio \\
\hline 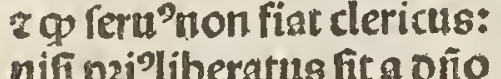 & ṕfbyito: q fecü electus fuit \\
\hline nifi pai?liberatus fit a oío & r pualuit:q2 maioz $z$ fani \\
\hline $\begin{array}{l}\text { Tho ipre mifit legatos ad có } \\
\text { ciliu cartbáginenfe pzo ro, }\end{array}$ & o2 pars fecü erat z impera \\
\hline $\begin{array}{l}\text { ciliu cartbaginenfepzo ro, } \\
\text { bozationeciufdem. }\end{array}$ & toz etiam cü vrozefua fibi \\
\hline bozatione ciurdem. & magis fauebat. \\
\hline
\end{tabular}
5633

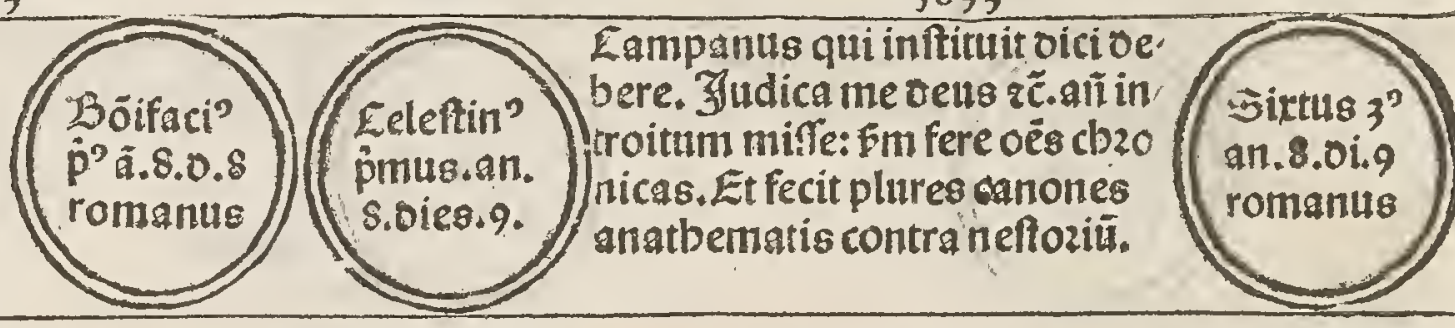

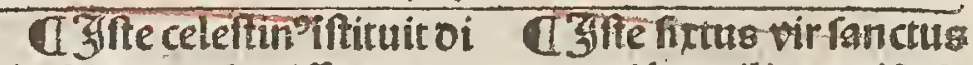
ci pralmos añ miffas:z ex erat tot' bumilis z miferio boc exozdiürüpfit vfus qué co2s. Ecclefiam ícē marie p"ecclia feruauit oe introi maion edificauit. Dabuir tu z graduali z tractu. Ipe quenda emulü noie baffús ei celebzata eft fcâ fynod" qui eus oiffamauit oe quo epbefina: J̈berefím neflo cúfe i cócilio purgaffet fta rijep̄i cốtentinopolitani timpoft:baffus mozit̃:qué gregabat btâmmariâ ve tr̃̃ pkzijs manib'Tepeliuit.

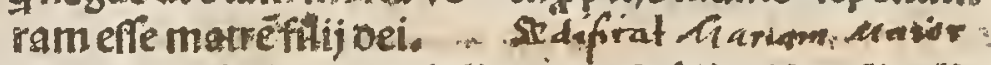
CEcima quartil quod fuit inter bonifacium zeulalium:caufa frit oifcosdig els. gentium: z obtinuit bonifacius:guia maioz z fanioz pqrs zrat fecum. 
A Arctur"rex bzitanienoiatifin"i victozijg:quadringẻtoflexaginta viros gladio fuo interfecit. Ecclie oei fubuenit:z fidë valde ampliauit: oëfq; tras

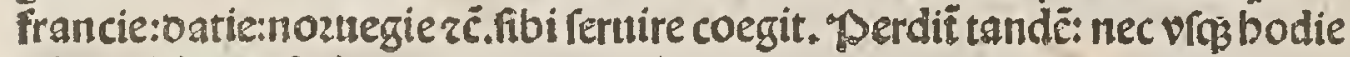
fcitur vbi manferit.

UDubzicits pmas anglie:vir fanct?:miraculis clarus:p'beremita:cozona uit arcturú.

\section{TImparozes.}

TTelifei ppbete offa tranfferunt oe famaria ialexandriä.

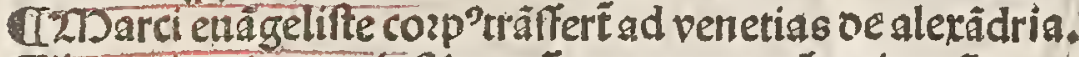
CLetanie ninozes inftitunnt a mamerto é̉o vieneñ.

TRernig 'Temés eps: 9 poft clodoneüregẽ fräcie cổtertit. T'Derpetu? eps turoneñ.

IT Dzofper eps vir clarus fciaz fcitate vite: De agtanie terra. ULbeodoz"eps firrte fcripfít cbzonicã: $\tau$ plura alia.

UEppzian?amfilieñ.epus:vir fupza modũ mifericozs totũ q8 babuit fratrib'in neceflitate oedit.

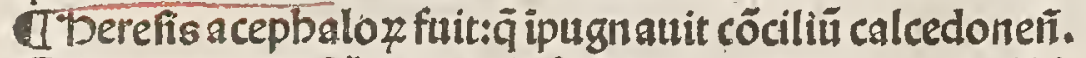
Uameretrix quedã peperit infante6.7. pno partuir in pífi. näpiecit:z vnus factus eft rex longobardoł. qu os impegerǘt:ceciderüt. Et fíquidẻ miferabilis victozia:qü victoz paucos autnullos milites retinet. Unde an dacia plurimuinocet:g̨i pzouidentia nö gubernat̃.fic arcturo contigit.

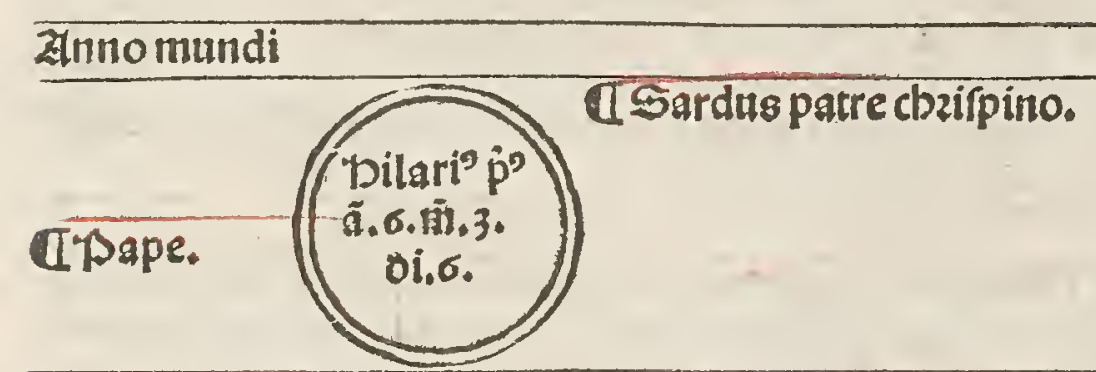

âno rṕi.

A Zfte bilarius oedicanit eccliam bti ftephani iuxta bafilicâ bti laurëtij:bic cöftituit ut nnilus pontifer fibi fucceffozé côftituat : ut babét.3.q.i.

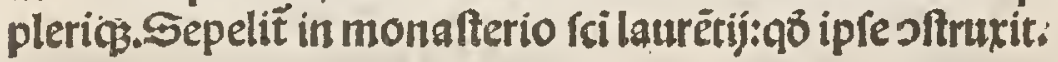

GZुfe Zeno fuit surian?: z totaliter crudelis ว̃ catbolicos. Sed' inijt cus gotbis: z filiü leonis interficere vo' oü volút foztiter j̄ foztes agere: parit cū foztibus i

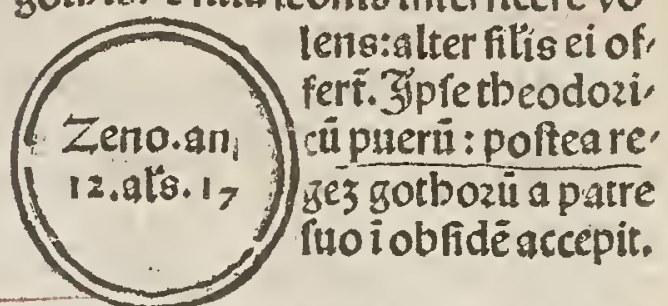

UEtbicipenato in burgandia tpe famis.4. milia pauperü fuftētauit:z celeftł pmiffióóisvocé audiuit

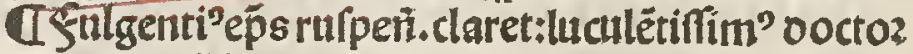
reientia r fideplenus afer.

CIAnglia in flozetpe arcturi:cui ter oena regna ler tierüt:\{ the paruo. Et nota fignū infallibile:qui vi delicet militaris celfitudo bellí oelectabilit appe. tit:z occalionë querit:tü requit finis cöiter mirera

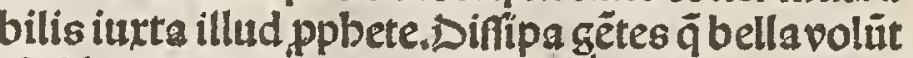
Driboc tpe bzitones gnic oicitît anglici:pzudétia vera gub ernaffent, totius europe onii fuiffent. Sed
बÜenetiarũ cituitas incly ta côdit:aut poti'ampliat circa bec tpa:âno.450.11 on a paftosib? fictut roma: fed a potentiozib'z oitiozibus puinciquaduenis:illippé plecutionéattile sfugiêtib? 2Dirî é z fümo extollendü laudis preconio:potuiffe'a tot tãqg oiluerfis vabiü z op pidozpplís oditã ciuitatẽ: pannos mille cú tali incre. mëro ac glie rplëdoze: vna nimiog fagacitate Jieruare

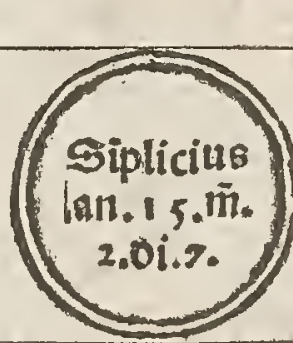

5663

Ipburtinus patrecaftino.

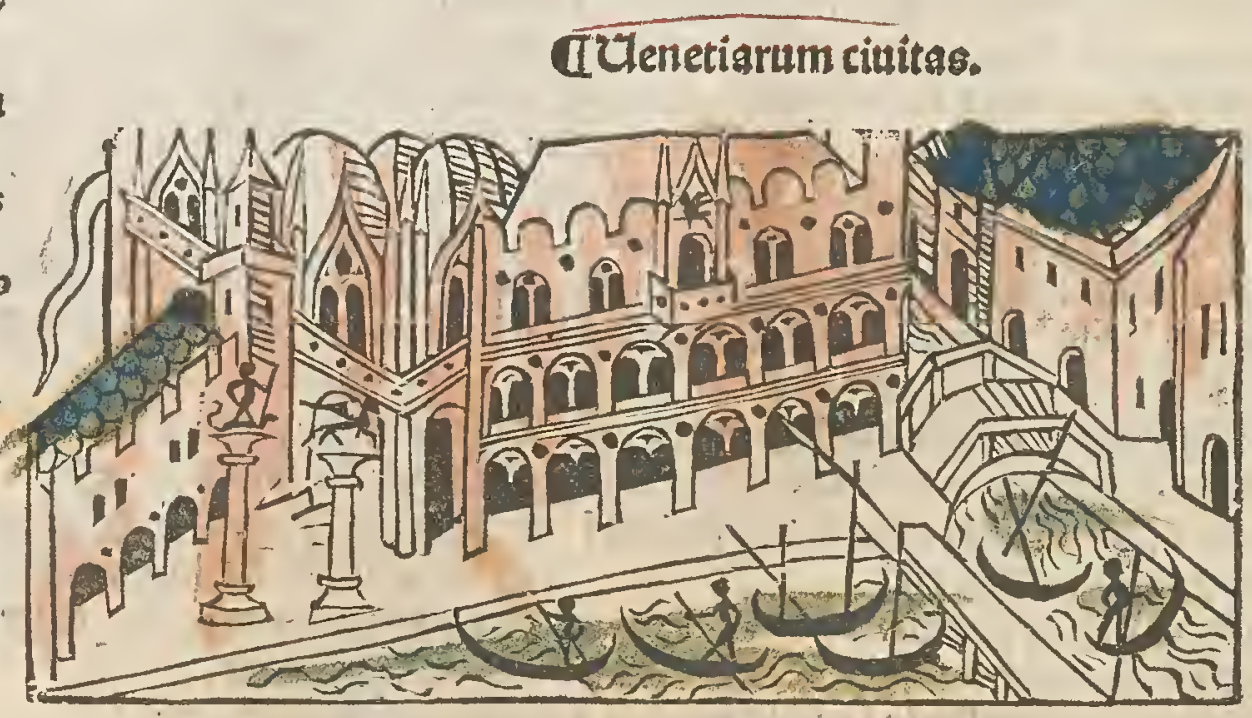

Ifte fimptict oiuifit vzbé in gno regiones: 2 plures ecclefias dedicautit. bic côftitunit ut clericus inueft turã nö recipiat a laico qb fuit $p^{2}$ palios magl robozatü:ut py.16.q.6.p totü. Sepelît in vaticano. 


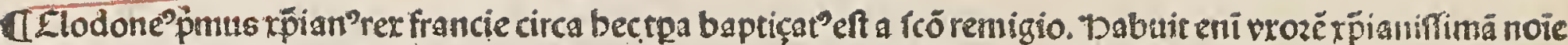

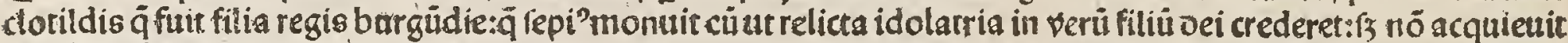

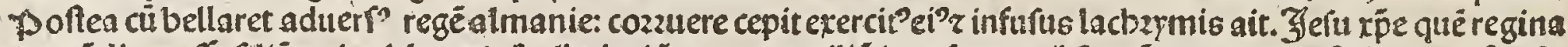

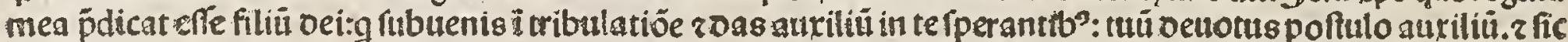

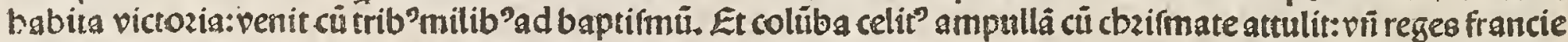

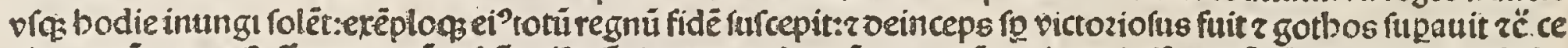

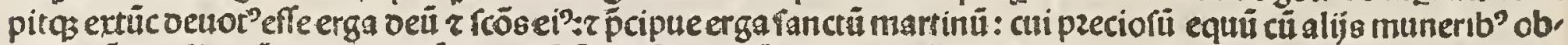

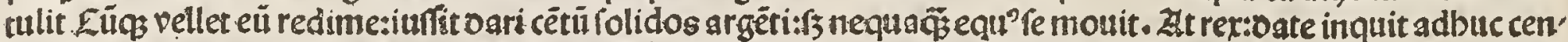

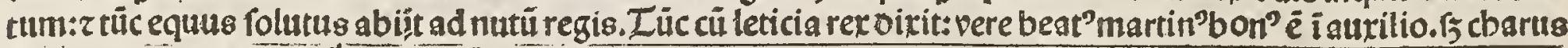
in negocio. Et bic pidet quafi fecudus oftantin?: z lecunda belena rememozari.

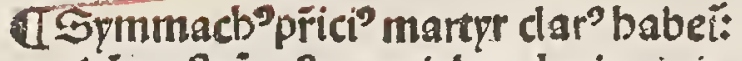
vir fás z ftrènu": $q$ regi tbeodozico iniu ftofepe obftitit:ob qơ tandéab eo mar. tyriçatus é cum ioanne papa.

USoetitus vir Jutaris:incōpabilis reie

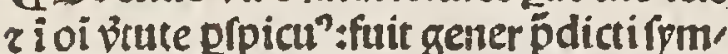
macbi:z p'nutta ã gloziơ geflit:tandē exul ingulat pro iufticia a theodozico:fe pult?papie. Dicūt gdã eü canoniçaiū fub noie feueri. Quãta aut feripfit: tota xṕia uitas teftis eft. babuit vrozé pzudétiffi. mä noie elphe: ä fecit bymnú. Oliue bi ne ré.oe petror paulo.

aDigniffimus r gordianus r alij multi martpriçati funtr alaurentio feímatico.
Ubenebald?p̀m?épuslaudu. vir fürs babuit pmo vrozê:quam oi. mittës z iterato admittës: zenut ex ea fain virí latroné: $q$ ei i eṕa. tu fucceffit. 2DDirabilé fecit priay. a Iibrian"ícot cil fuis fratribus $z$ fozozib'claret fanctitate. TUedaftus atrabateñ.

A Leonard'Lutiocen.r Lipbar dus oifcipuli remigij.

đSetueri? abbas agauneñ.clo,

doneum fanauit.

CEantiantis rotboneri. U2maxent? abbas pictauieñ.

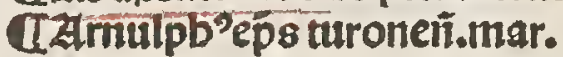

AzDelanius cófiliari'regis.

đälbinus vir fancteaialiji.

đUicto2 cus plurib' illuftrib": 9

tuncfloztuerut in gallia.

IzDarius.

CLantoritis.

व 2 Aut $^{0} \mathrm{abbas}$ aurelianeri.g02a bat oimp filips clodonei re.

aronciliuz aurelianeñ. celébzat iufu clodonei: qô reüs melanius congregafte or. Et nota q multo fucrut concilit aurelianeri.

QEumodius titiueni.ep̄s.

UEarileptsus vir.valde faüs:qui nun nec a regina oenota francie.

Lipape.

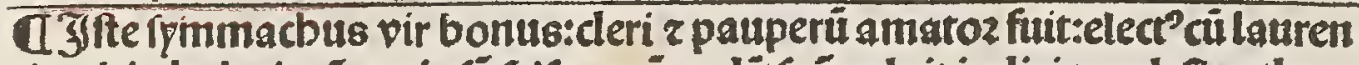

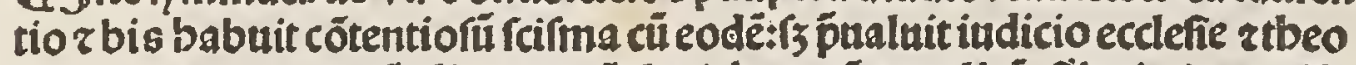

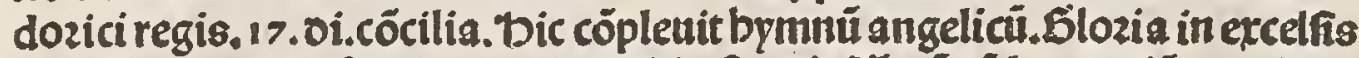
veo zč. $z$ cătari inftituit: $z$ multa vtilia ftatuit. Uerü cü laurentiú ex miferi

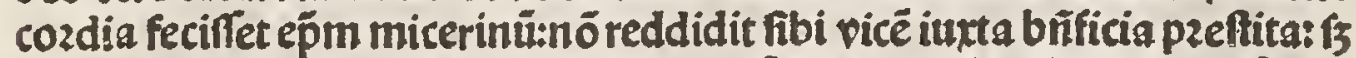

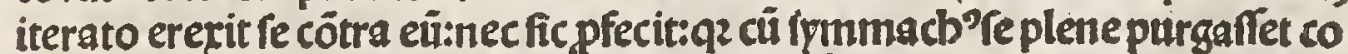

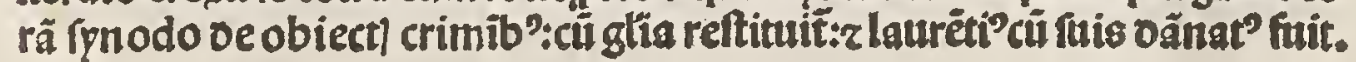

đIftebozmifda vir mifericozdia rî fuit:ecclefís multa ozıamëta có tulit pauperü elemolipnis intentus frit. Zple clerü compofuit: $₹$ grecos recốcilianit: g fuerant excóicati pzo pterberefim neftozianã. Sepultus eft apud fanctüpetrú.

IScirma quintu qo fuit inter fymmacbú z laurentiü:cä fuit oifcozdia eligentiü:Fร fymmacbus obtinuit iudicio concilij:in quo tbeodozicus rex, pronaliter fuit:q2 maioz pars erat fecú: Fs poft annos quartuoz furgit iterü alter

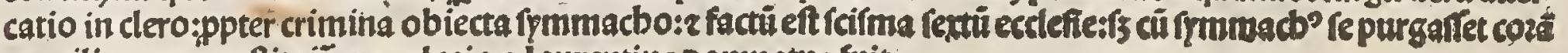
concilio z rege:reftituit cum glozia:z laurentius oamnatus fuit. 


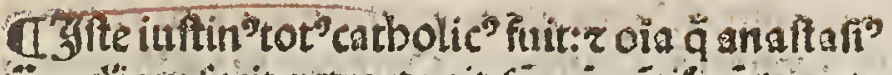
כ̈ eccliam fecit:retractau it:fümü pótificé oevote régfiutit. venerabilé papã boznírdã: z re libēter eide obed ire velle:intimanit. $q \delta$ r factú eft: $q 2$ cü

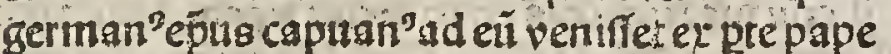
ut ep 0 o oe exilio renocaret:ftati fecit: ci niagna

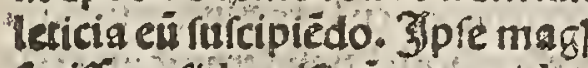
feciffet p fide: vifi en tyranuides tbeodozici impediuiffet.

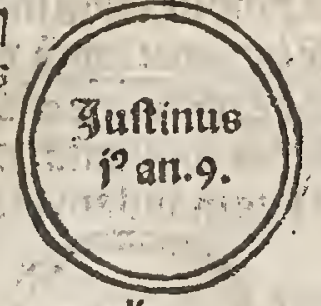

al.i!.

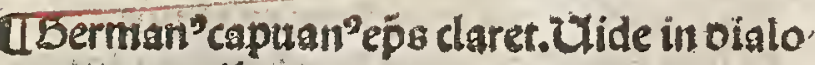
go gregozij.

ICtigoz boiaceñ.ep̆s g moztuü fifcitauit.

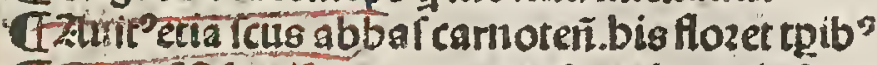
I solin'fidoni? octor magn": multa feripfit.

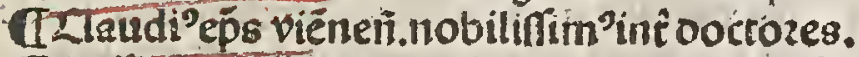
ICsmodo?'gliorus vir zooctoz luculentus fuit primo fertatoz: cancellariufaz regis theodozici: oeinde moniacbus pliara feripfit.

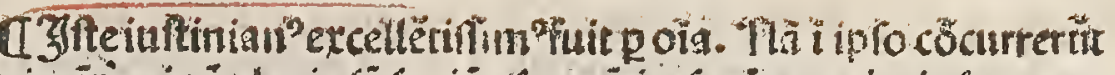

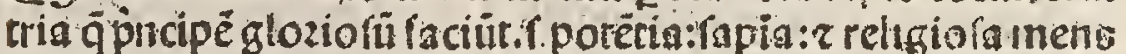
ad oiniñ cultu. "Der pmiboftes fupatrit. per fecudü iufis le

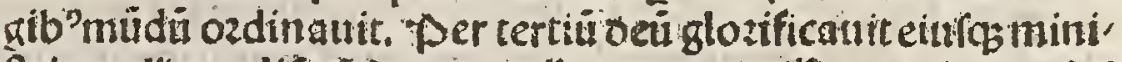
ftris ecclias edificã do:opes ples oonatut. Nota os leges cimi

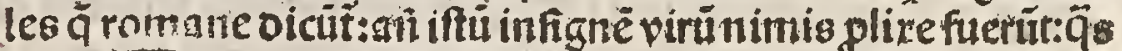
ipie admirabili bzentrate cozzexit:z ad.12.li.

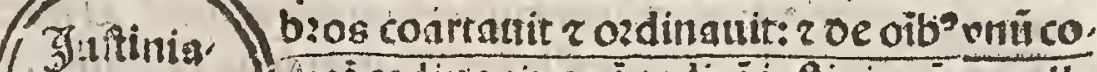

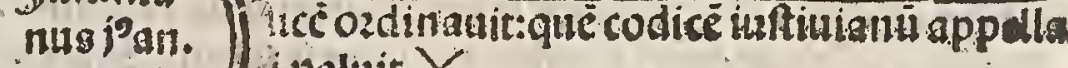
$3 \mathrm{~s}$ ivoluit. $X$

Caratoz poeteflozet.

Cosifianus grămaticus. Ctonta rex gobboz:multas exercer trunanidza: pene to ta italia vefruit.

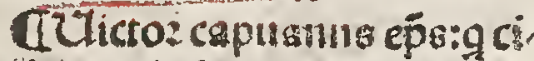
clos parcales rctipfit.

Corego:ie ps lingonevi.oe renatozib'pzi'babutit prozẽ. itticecus treuereit.

CDomitian?tungren.

Chatodoaldus fili'segis francie p̈oyter fǘs monafteriü côdidit.
(TS Sellifarits parricits cor mes iuftiniani mirabiliê oe perfistriüpbattit.deiñ mifn" ad affricâ: Dandalo z gente oeleuit. De binc romä libe. ratit a gotbis qu ptotú annü fuit obreffa:regéctia gotbo. rü cepit:z ad impatozé ouxit z roma fepi ${ }^{9}$ capit a gotbio guaf in nibilú redigit.

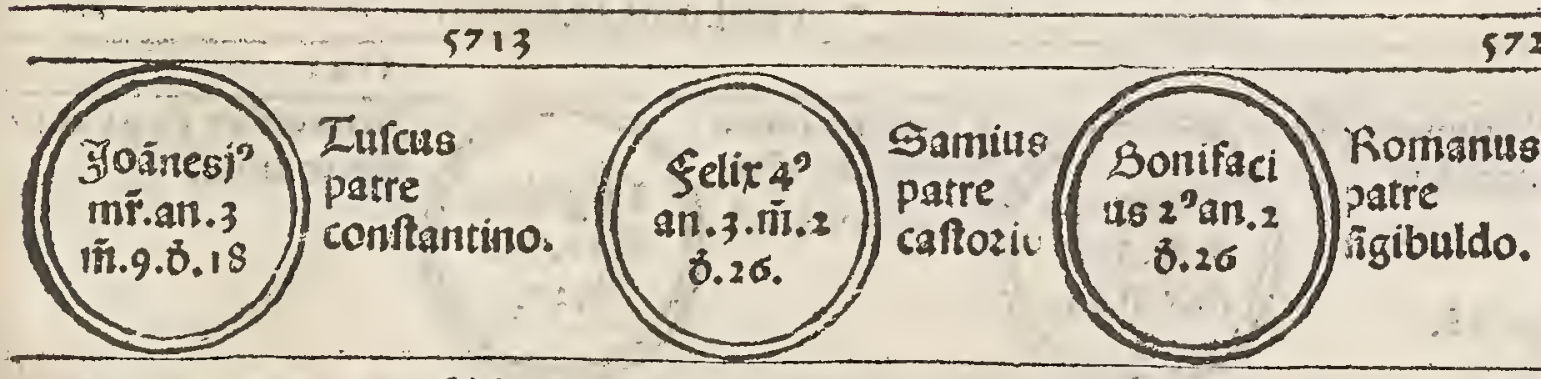

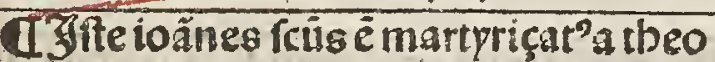
dozico arriano cü fymacbo z alijs eque catbolicis viris cui fefti a giť. 27.maij.

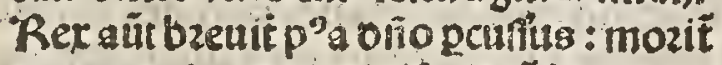
$z$ in 0 s pulcani ab eifdépijcit.bic in ca, ftodia afflictus morit.

(ISanct benedict pi maximus daret totipecdefie fulcimentum: 2 nozma reli gionig:bic vir venerãdus inclytiffinos babuit oícipulosz plures nüero:z ob, tintuit ozbem terraz z $\overrightarrow{\mathcal{C}}$. Eitus vitam feri prit beatus Éregoaius in fecundo oialo Bortim:
(I) fte felix iufit infir mos itungi añ trã̃ tũ vĩ pats guni fepe fta tuit:qz nó fofit execu. tio: aut ġneceffe eft fe pius replicari:aut fow re ioleuit qỏ $\rho \mathrm{i}^{0}$ ftatu cữ fuit:veruj prcipalit pxpm inftirutu eft: $q 2$ oia racraméra p rón trgdita funt ecclefie.

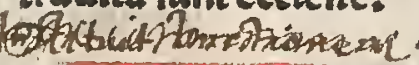
a perfecutioiterti in affrica fit carbolicis a D) ädalis arriâis:epis gburdá ligue abraide' bät: $r$ tin recte loăbãt.
T'yrtebonifaci? ftatuit : ut clerici fint oinifi a laicis icelebzatióe mir. fe: bunc gdä libzi oicitr electí in oi. rcordia cú diorco ro z fuit fcirma 38.oieb?: fs moz? tuo tivic diofCozo bonifacius obtir ntuit.Allijoicür $\Phi$ bocfitfactutem. pozefyfinnij:atifra patebit.
Joannes: Romanus jatre in.4.0.20 proiecto.

(1) Intonif abbatis cospus inuenitur: in alexandriam tranffertur. 


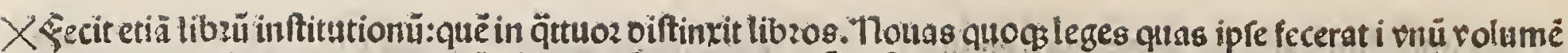

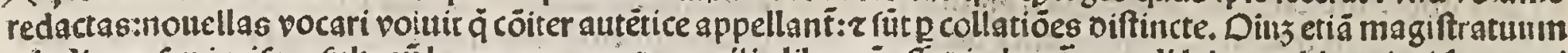
ziudicum feu iurifconfultozú leges:quarum ouo milla libzozú effe oicebant:grandi laboze abbzeuiari fect $z$ ad numerü libzozü. 50.redegit:z ipfú libzü oigeftozü fen pandectarü appellaremandauit. Er oebet Icribi p.0.g.15 qz

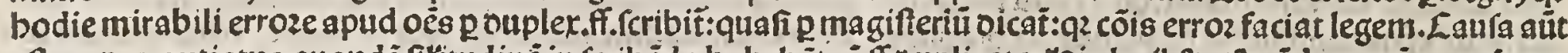

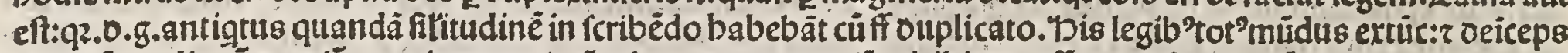

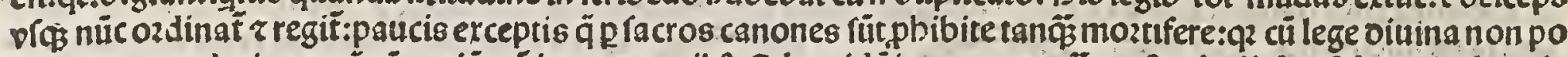

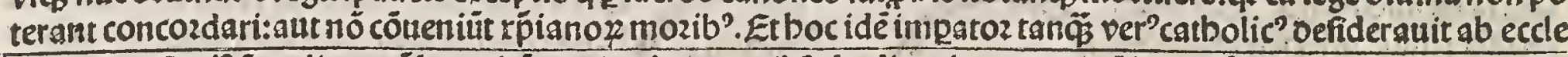

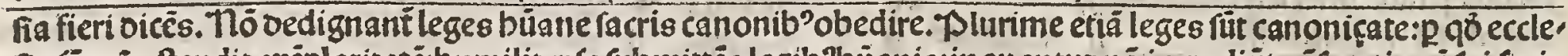

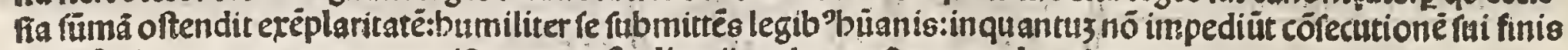
qui eft vita eterna:quam promifit deus cuftodientibus legem fíue mandata fua.

ILafius narnielì.eṕs.

Ümedardus notion.

ARomantis filiter rč.

İbitgard"epss rotbomageñ. frater fancti medardi.

đÉerman'parifien.

UEleutberius Ioznacefi.in gallia claruerunt.

CLbeopbilus gomagiú oia bolo fecit:\{ 5 p beatã virgine mariä reconciliat?eft.

G'Senedict'iunioz:quiato tila multa pantus eft.
U2matr"oilcipul'si bridicti.
ISigna bozzibilia spparterüt quedâ ftella côtra lunas veniens intraut: vue oe fäbuco nafcunt. Dyems grasis fuit: ut aurs ma nu cap erent. §ames validifima ut matres puerosppzios mådu' carent $x \vec{c}$. Eelum ardere vifú eft igallijs: rfanguis ftillauit a nu. bibus.

IIbeodebert' rex francie fuit q beato mauro túc abbati ande: gauéfi pl't oedit. Siltit z clotari' filius ei? . nsagnis eni miracul clarnit btǘs maur": poia fic bi diet'magifter ei ${ }^{9}$ venerabilis.

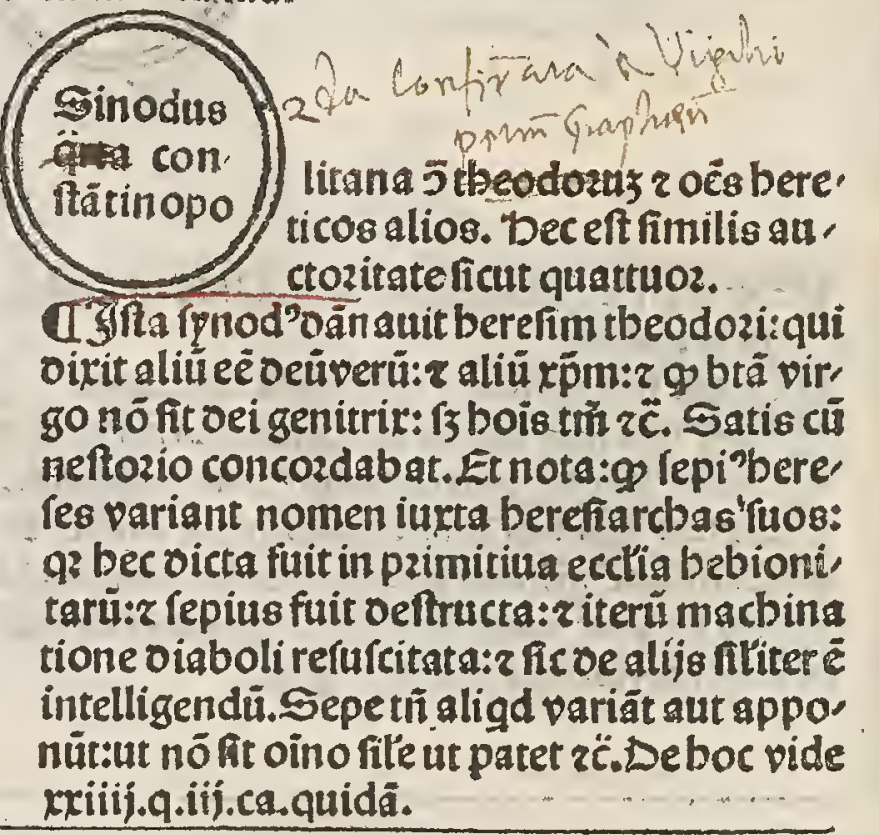

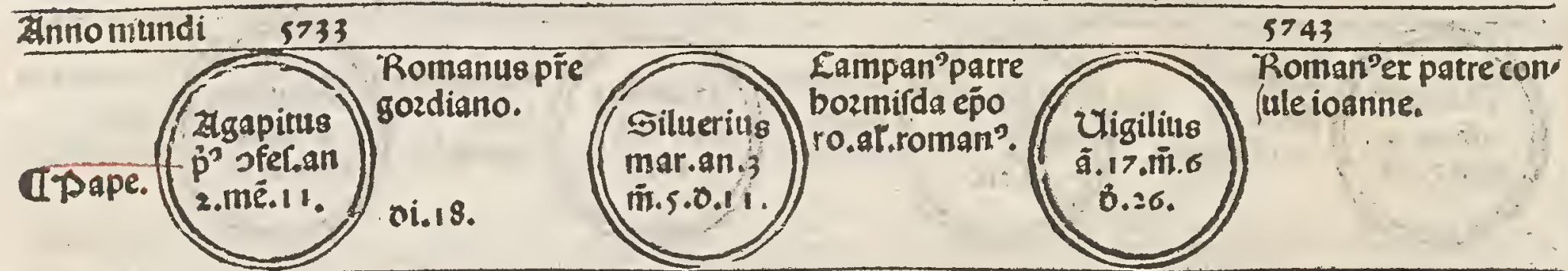

Zinno tpi. 534

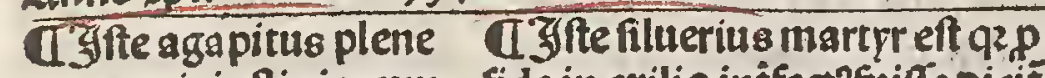
reuocauit iuftinianum fide in exilio intfect?fuiffe oicit ab erroze euticetis.bic pcuratione tbeodoze impatricl cöftituitpcefliōes fieri $q 2$ anthemiü éps oeftiutü 2 dē oiebus oniicis.2mozit natüppíberefim:reftituere no. sftantinopoli r relat'é luit. Dic factus eft papa $\mathrm{g}$ vin

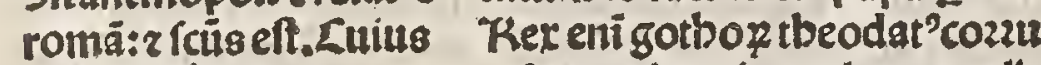
feftü agiť.xrij.apailis. pt?pecunia:minas clero zpplo intulit:nifi in eius electioné có uenirêt. Ei’ fẹtü agit. 20.iunij.

a Seftū purificationis inftituit apud côftantinopolim: ad redandü pefté graú. Et nota 9 iepi legunteadé fefta inftituta s oiuerfis: nó fine caufa: $q 2$ aut nó funt recepta:

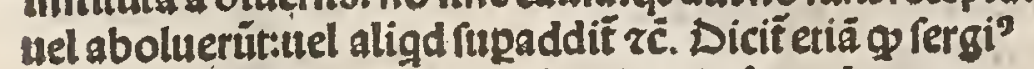
inftituit uel forte rupgddidit lumilaria ferenda.
(13) zprécutioné fuftinuit ficut filtuerius. gotbos fupaatit glíofe:tandē in exilío mozit p' graues paftióes in con ftantinopoli ppenlas a tbeodoza:z creditur martyr:fe

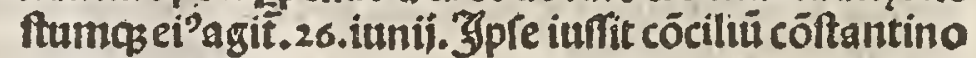
poli celebzari.z fuit pzimo arcbidiacon ${ }^{\circ}$ filuerij:z cue pidus ad papatū. oedit modú impatrici qualif filue rium amoueret:que eú poftea peius tractauit: 2 fune in collo eius miffo:p totam ciuitatez trabitur a mane

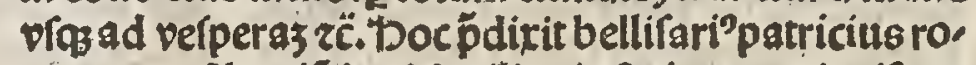
manus:g filueriü inut? exiliauit:fic ingens. 'bui? $\mathrm{ma}$ chinatoz Íceleris:nö effugiet irä iudicis cücta cernètis Sed oe oïbus poltea plene penitēs:z foztiter pzo fide agonicans feliciter vitam finiuit.

IT berculian'epso pufinus a totile fecto capite marty riçatur. 


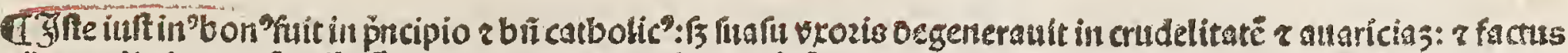

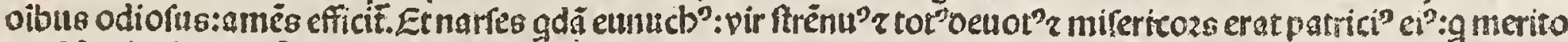

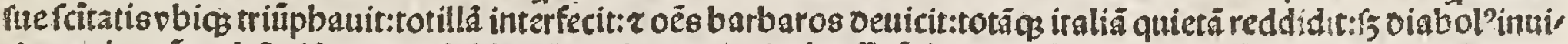

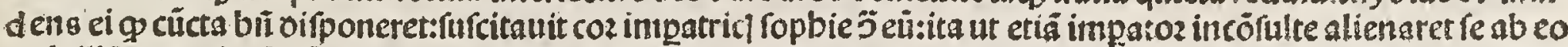

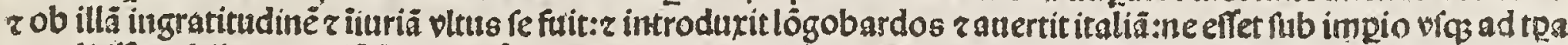

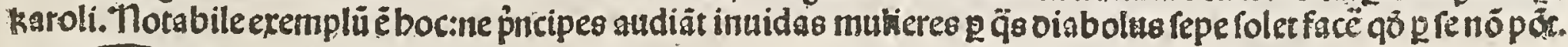

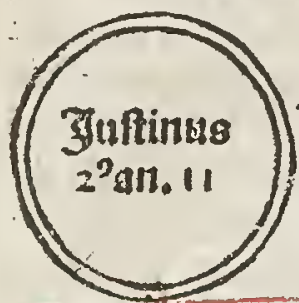

ULemplú lcé ropbie maximú in conitanti nopoli extruí piuftinianú. putaẗ $\$$ s con ditiôe müdi nốfit tale opus it o complete fa crí.ibi eft impator fepultus in pace tópi.

(T Lempoza ratis turbulenta r moztalitas magna in ita: lia : ổंdiu fuit imperiü bipartitü : fuerüt turbationes con tinue. Et beatus gregozius repius facit mentioné oc bis.

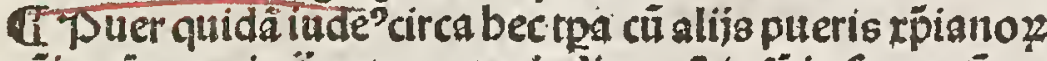
cổionēaccepit:äppter pater indignat?:iṕü in foznace piecit : fz illefus eritut:oicēs.mulier illa qu in ecclia eft oe picta:puerü in bzacbijs tenēs:pallio fuo igné excuffit.
TSampron eṕs oleri. CEtbbinutu britănicus. Colmitianusabbas.

QBatolis abbas.

Isindulph"pzerbyter.

adsingalot?pzefbrer z alii fciflozuerunt.

ID afimuida regina fräcie vroz bilpici regis:qui in no cte iนgulatit eâ:fcả mulier mi

cttre $r$ ranguis exiuit

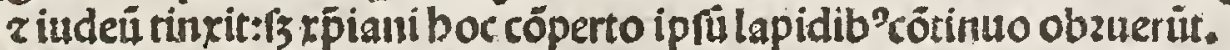
T Stepbani ic ptbonar. offa oelata lüt romä: $r$ invna tüba cú fcô laurểtio locata

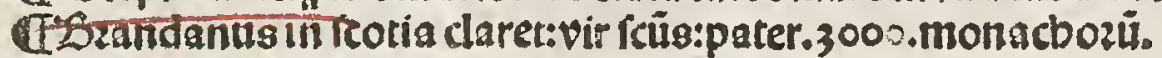
f2TDacbutes otrcipulus fcibzandani mirabilia fecit. fili'gozdiani fenatozis:clar'babei: 9 rex monafteria i ficilia furn, datuit $z$ mun in vzbe:fit monach"expzetoze: z polt dutuir"papa eligit.
Apqul'.eṕs leoneit. 15regozituroneri. eps expolitiones fa cre ecripture fecit Tomegtort'epsoolen. fí fampronisfus: ceflor.

Q Zminandus vir tcĭs: poft eṕs trsiecteri. raculis claret.

fiformatrspoe ta ialiculs: 2 eṕe pi ctatieli.multa teri' plit.

TLeander gotbos couturtit:p'eṕsbi ipaleñ.cui greg? mifir libzos inb. 5763

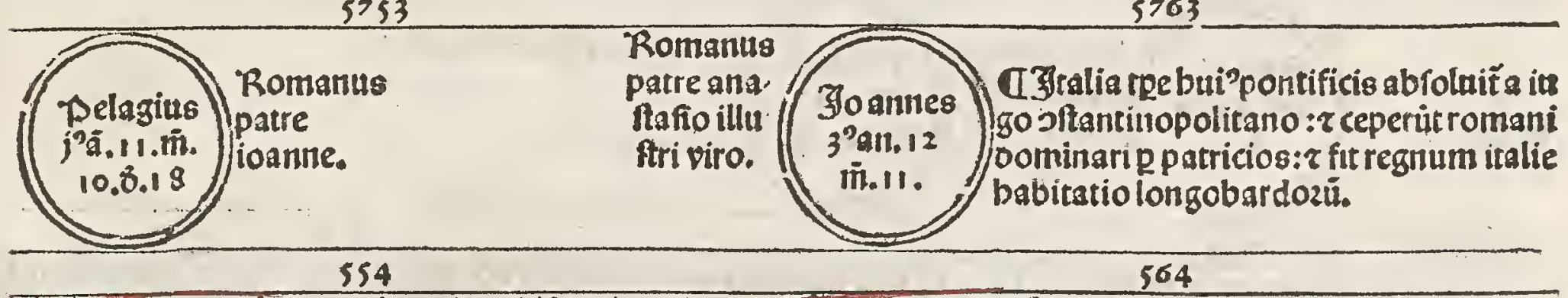

Tozite pelagius fatuit:q ber etici r filmatici oebe ant p recularē prätēarceri.xpiii.q.v. relegēces. $z$ plu, ra alia:bic oiffamat' $z$ culpat'fuit oe moztevigilij: 3 co2ä omn populo tangendo crucē $r$ euangelium fa cramento le purgauit.

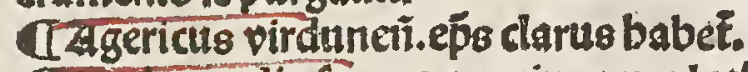

CTadegandis francoy regina proz lotbarij:claret reitate:que poft monafteriũ intrauit.

Cl Leonardus beremita fcüs cenomanentis fuit.

CLoluban'patervenerabilis clar'babē i bibernia z $p^{\top}$ venit in burgundiă sfltiruës ibi monafterium Iurouienfe:r factus eft in gentë magnà.

UxDons magn?,igallijs mugitũ oedit:oifcuffus ab alio monte: $z$ cüboib? recctis irodanū pcipitat. c. 3fte ioannes reftaurauti cimiceria martyrü: z eccliam beato aploz pbilippi ziacobi. Gn oieb'itis mita figna zpdigia appartuerüt infolita:fignificantia cladé furturam qualis nüqü fuiffe putat̃:tandē por multa bonta ope nto ritur:fepultug apud fanctii petri.

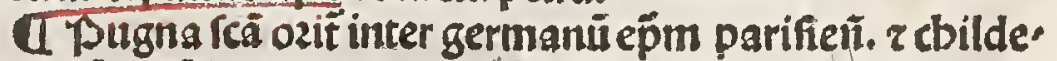
bertü regē francie:quozu qülibet certabat ad rubuenien dü oebilibus z pauperib". Er qz vnus aliü p̈uenit: nō modica cócertatio erat inter 208.0 pbi manferü bec.

CIAcies ignee viterunt in celo oe quib" $\mathrm{gregoz}^{2}$ in omer lía. Et oe veftib? quozùdã verus effluxit fanguis: oomus etiã cuiufdã afperfa fanguine apparuit: z figna in vafts cำ nö potueruutablai. 


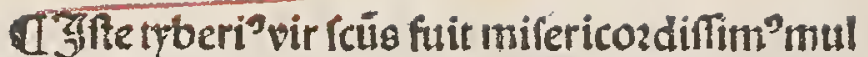
tas ecchigs reftaurauit:eratq tã pfufus in munerib" largiëdie:ut vroz cius fibi oiceret: $q$ oilapidatoz eêt bonoz iperij: Lui ilie. Eôfido in oño qu fíco nro nō oeerit pecuì:ti oe bis q̆ons nobis cötulerit elemt of nas faciëdo:tbefauros cōgram? in çelo. Et ftati $p^{5}$ cî̀ Imperatozes $\left(\begin{array}{c}\text { Ziberius } \\ 2^{2} \text { an.7 }\end{array}\right)$ vidiffet crucéfatlprä in pauimēto:ait. Lellate tabulä:qz indignü è:ut cruxpedib" côculcet:ä oebet cü renterētia îpe.

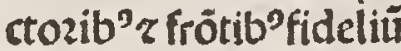
poni:ibig'maximü repperit tbefaus:iple plas vicit.

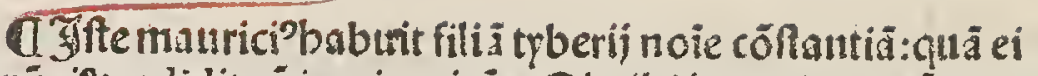

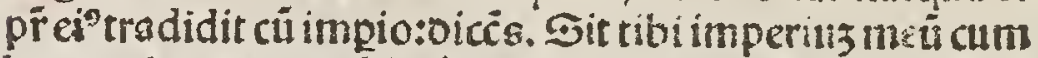
bacpuella vtere ea felicit: $z$ babe inëte egtatë z infticiam ṕipua cé infignia optint impartosis: gb? oiçis pijfimus trberi'expiraut.2Daırici? güt ftipto impio: multũ vtilis fuit reipublice. Iandé cu; btö gregozio nimis oetraberet

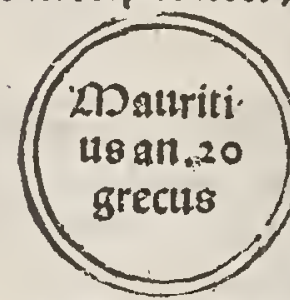
z mozté cöminarễ: ว̈ fe oiuinä puocauit irä:mertt tii bti pontificis bic punit? ${ }^{2}$ fuit eo 9 quortidie p eo ozaffet. fuit eni expul ins oe regno:fugat ${ }^{0}$ d dinfulă quảdä zibi cū vroze r oubb'filijs p focã interêpt'eft Sibui fernaffet ooctrinä foceri fuillü añ pedes fuo s babuifet pftratü : quē nüe fup fe fenfit leuatü. Iamé oe cius raluatiōe bona fipes eft: ppter caurâ oictã.

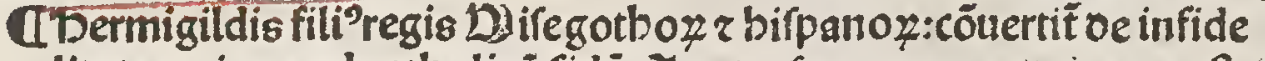
litate arriana ad catbolicä fidē. Al patre fuo rege martyriçatus eft. Ityorpitus r gdâ Dinnatus bzito:clarent in gallia fanctitate.

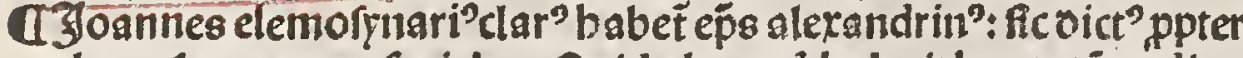
elemorynas quas faciebat. Duid vitrs:qo babuit boctotii oed it.

U'Retbaredus rex gotboz:qué biftozie tradüt virü fuiffe virtuofü:cü

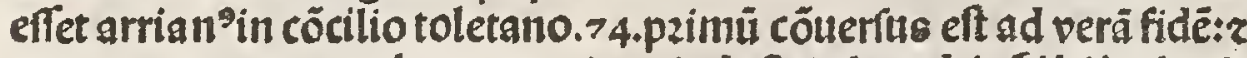
cum co tota gens gotboz: monitu z induftria leandri eṕi bifpalenf. 27Dagna gratia in populo barbaro: qui buculq malā babucre famã z nunc fanctos babere incipiunt.
U.Antiocbia fubuertitpangeli oeig in vefte alba apparuit: $z$ tin $n^{2}$ vir elemo, Y̧nis vacans liberat'fuit. Quidā oicūt $\mathfrak{g}$ medietas cinitatis fubzuta fuit : zaliam vir ille precibus fuis faluanit.

QLanica ovii inconfutilis:reperta eft in fapbat:z in bierufalépofita.

If Inundatio pluuiarĩ maxima fuit:ita ut fecundú oiluuiü crederet iterü ventu. rũ: $r$ Tequiť moztalitas maxima in italia que oicitur inguinaria.

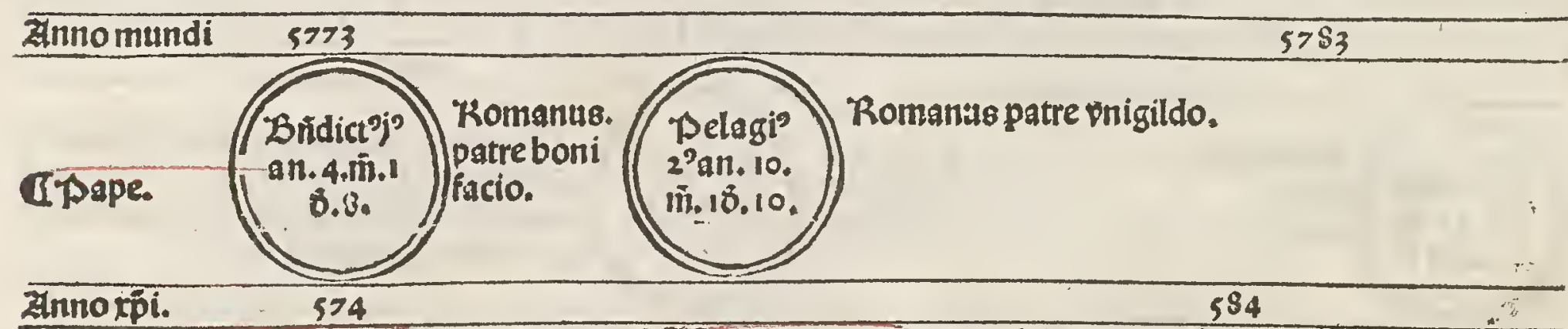

U马fte benedictus multas fu, finuit perfecutiöes:r vidit mala gêtis fúe ppter famé:peftilentiä: $z$ boftes: $q 2$ longo barditotã italiã inuaferunt:in gb\% labozi. bus mortuus eft:lepultus apudirem petrü
I Zffte pelagius ozdinatus fuit $a b f_{\mathfrak{B}}$ itufionepzincipis:z lōgobardi obfederút romã: $₹$ vaftatio magna fuit: $₹$ qo male inchoati fuit fub co:in pei'p piciebat:ppter tyrãnidē barbarozü z peftē. Ipptemifit gre goziü ranctü virñ ad oiuerf́a loca:in negocijs ecclefie exptiffimum. Landé in pefte inguinaria moziț:fepultus apud feñ petrü.

\section{Eiuitas Zantiocbie fabuerfa pangelü:ut rupza oicit.}

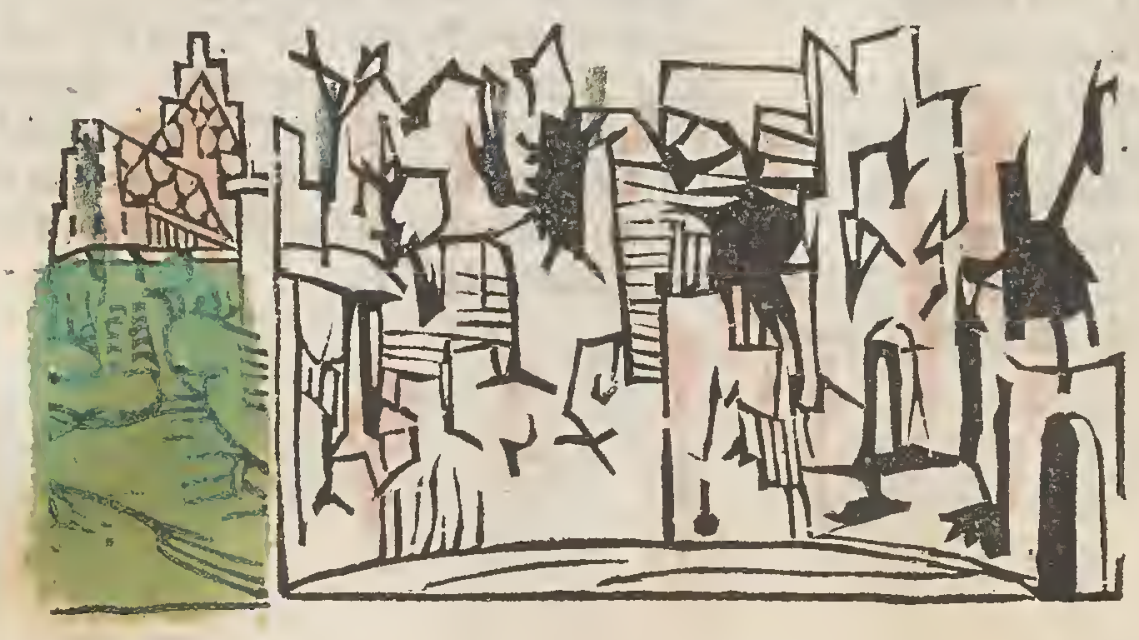




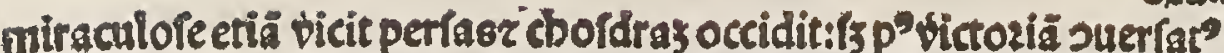
etaltatióe ícé crucia:quo

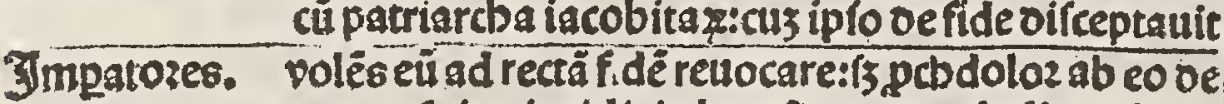
ceptus fuit:r incidit in berefim monacbelitaz:i qua

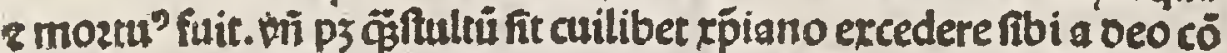
Atiutã regnlä. Qñ enilaici intromittere fe volut oe illis z filib" peri. culofis queftionib"fidei:z qui slerici bellis fevltro ingerüt:z raro sut

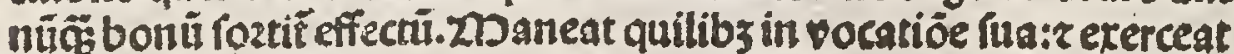

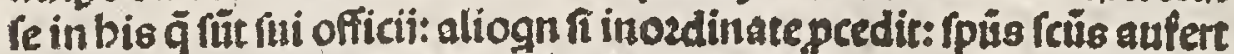
re fine quo nemo gcäboni pöt pficere. Simile de oçia rege iu da:ut p3.2.palipo.xFvj.z funt exempla plurima quottidie. Cletü ifta male dictio penit fup eracliam propter fupbiä fuã : q2 pof ill victoziam paupes fibi fubiectos nimis inbuanitz oppzefftr: qó oeo femp oifpli.

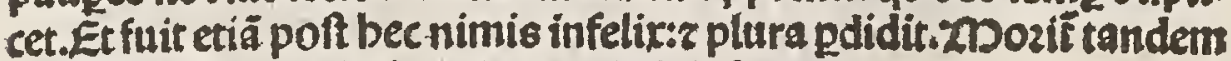
infeliciter:bidropfir r berefi maculofe infectus.
Eraclius
a. 11 , bic
leones re.
pe interfecit in arens.

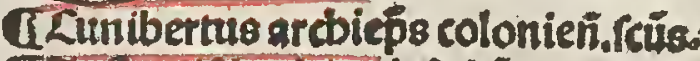 Uzuftregifilus biturieti.füs.
đStlpitiu biturieñ.fcü.
UGoannes tungreni.fcü.
a salaberga abbatiffa mulier fancta:
ouomonafteria conftituit.
đEzaulio celar auguftanus epo zoo
ctoz clarris babet.
ASeftú oinz ré̃e inftituit a bonifacio.4:

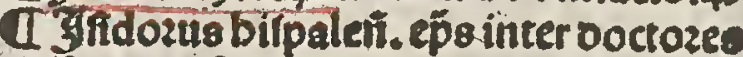

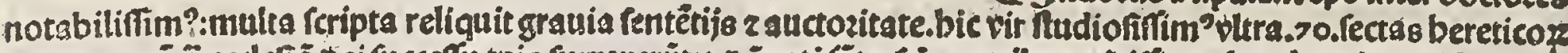

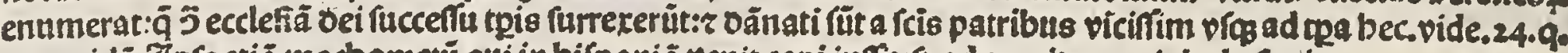

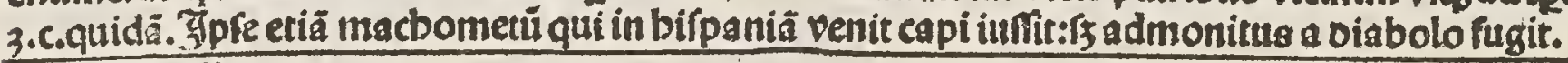

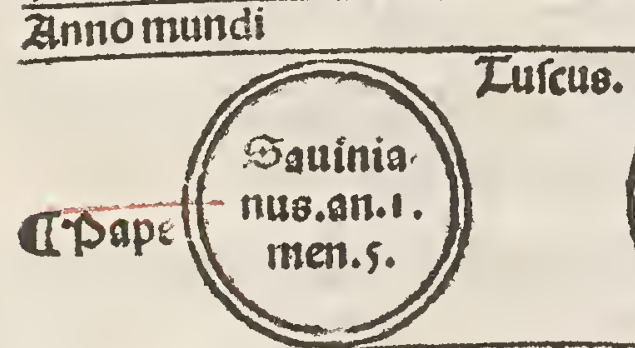

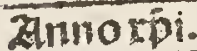

IJfe fauinianus

ftatuit pulrủ cäpanaz ad bozas viei. Et quatemax fuit:r fancto gregozio vetrabere nö timebal a. Jeo pcufflts interijt: $r$ bic ë ter tius oe toto catbalogo pontificu a formidabili mozter culpabili

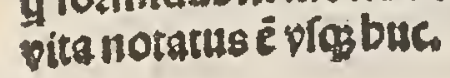

5813

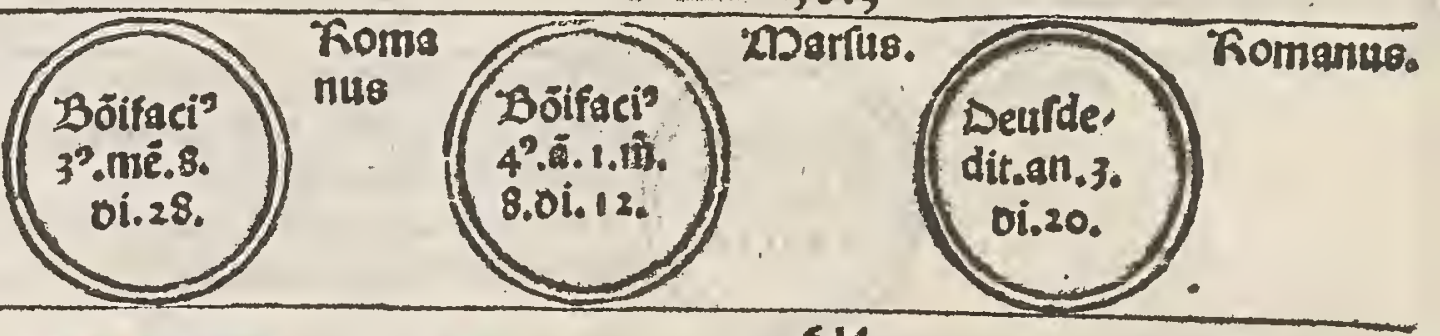

614

पदgfebo. nifaci?ha. tuit ut niti, dus pants" Tup altare. poneret.
I3ftebonifaci?fecrauit patbeon Demplu olus deox vbi xpiani piclitabät a fuit vir fanctiflim?

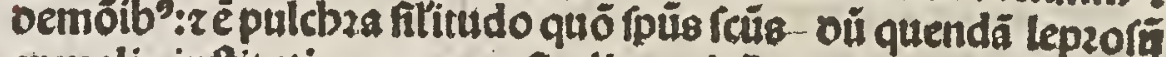
ex malis inftitutis pagano fit eligere $\mathrm{cth}^{\mathrm{k}}$ exercitiū oeuotiōis : quaf medicina fiat ex veneno:vbi impij colebăt oés vemóes:ibi rp̆iani colüt oês f́cös:fic are oeludif arte. of́cularetur: ftatim müdat?é:mults bo na fatuit.

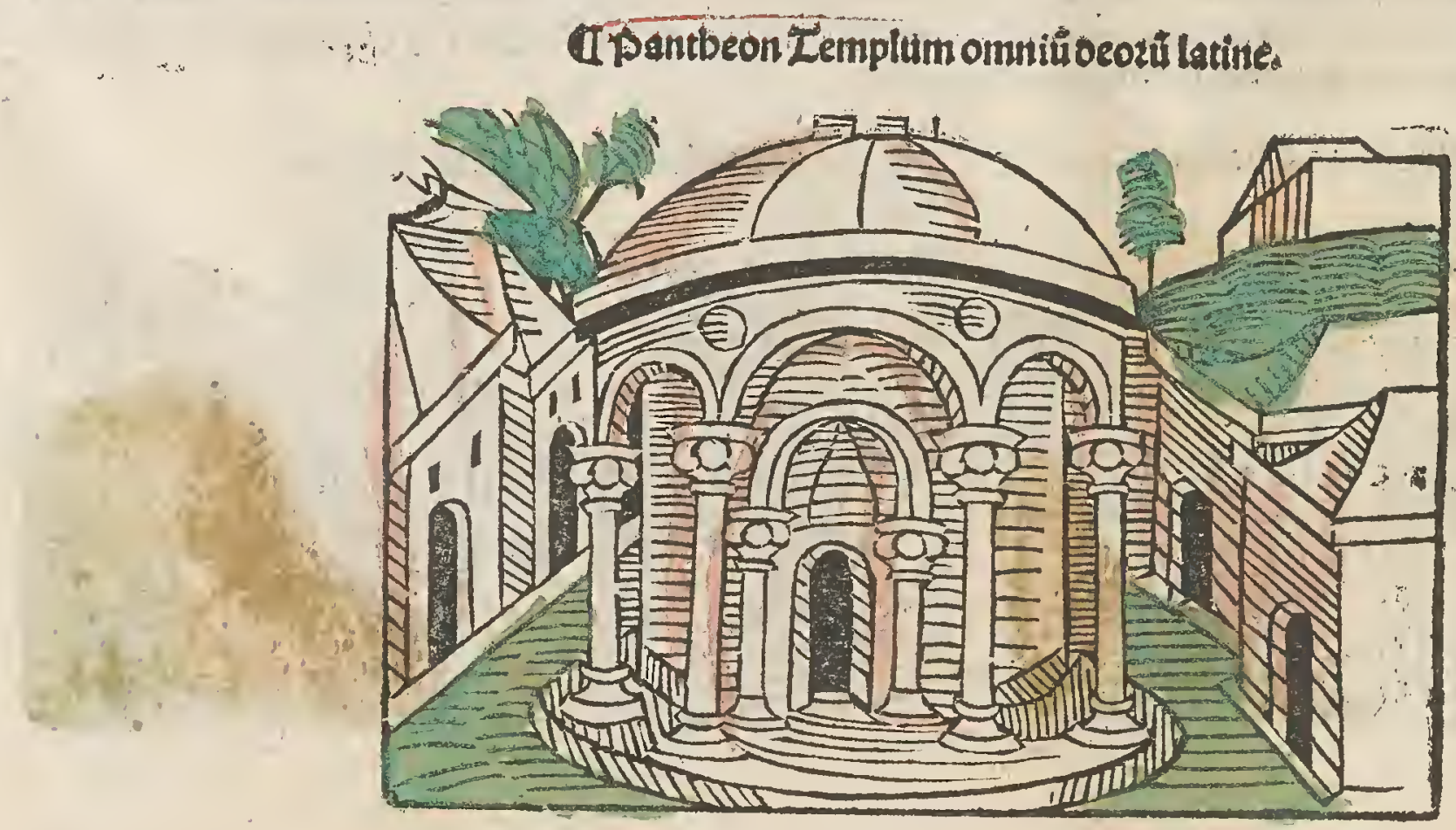




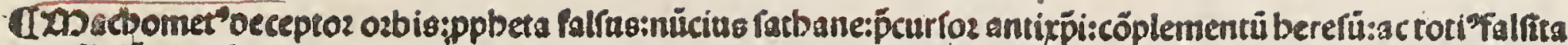
tiopdigiü: circa bectog vefaniä fus oftentare incepit. fuit eni magus z mercaroz viliftim":z factus pnceps latro. num rabtilie, arabes fibi attraxit:g tü valde ab evaclio grauabant.plas vicit:z gentes alias miultag: gbus oedit

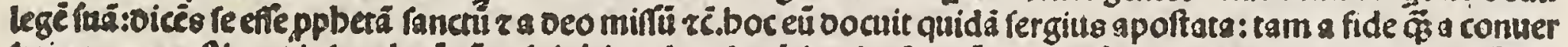

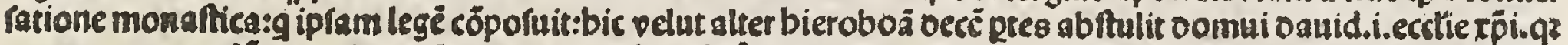

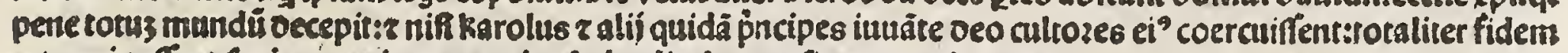
exterminaflent. fepites creuit 20 ecreuit vfos bodie. f. 1460 . finem nouit oeus.

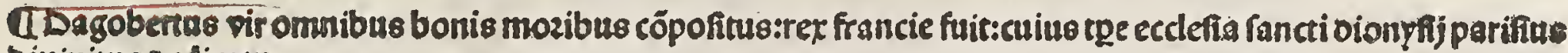
biuinitus oedicatur.

USigibertus filius regis oagoberti:cum baptifarē a fancto amando traiecteñ.epo:refpondit amen clara poct infans adbuc quadragints oierum.

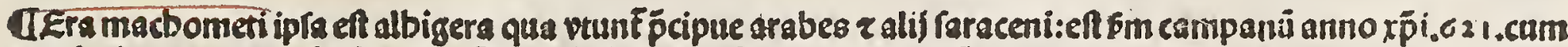

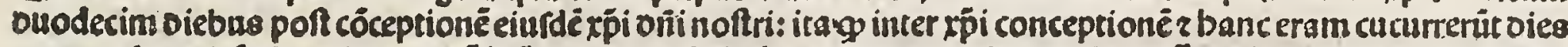

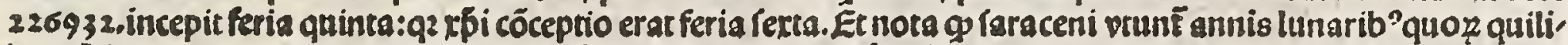
bet cốtinet. I 2.Itnationes equales:boc eft. 354.0 ies. faluo biffertili. nä in. 30 annis babent bifferriles: quosum quilibetgabet.ess.oies.z tunc redit ficut a pzincipio.

UTota lanatio ṕcifa. 30. annos babens lunares:reducit medias lunationes ad cófmile tpis initium. U2nognobodus andegaueñ.ep̄s vir fanctus claruit.

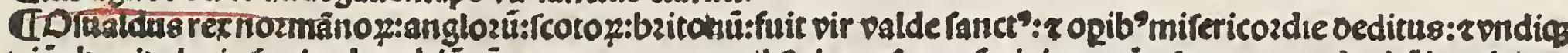
triüpbani gloziofe:cius bzacbiú cü oextera manu:quib’ elemofynas fecit integni greuerat apud vzbē bembam.

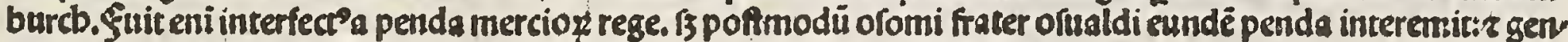
tem mercioz ad fidem rōi cōuerti fecit: $x$ pictos regno fro.i.angliefubdidit.

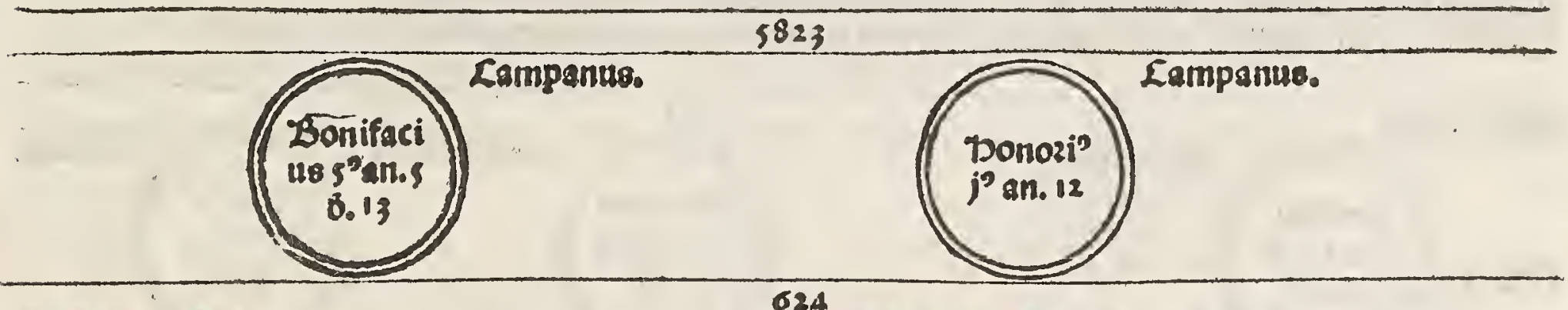

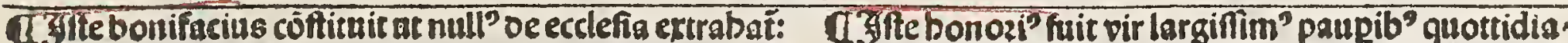
zatacolit? nỏ audeat religas leare. onde p 3 quanta fuic olim oetrotio in rṕianitate:boc unc cleriépbibsbat: qơ nüc mulieres etiä indifferent̂ faciür z seteri quicungszč. nas elemolynas oedir multas: ecclefigis in argento $\tau$ auro oznauic. J bic flaruit apud fanctü petrü fieri leta. niฉe: 2 clerü erudiuit:z ipplü boneftifime ozdinauic.

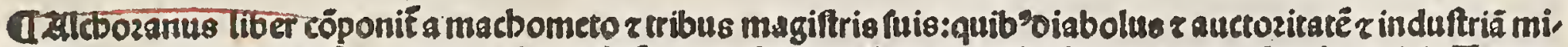

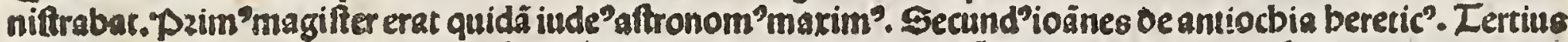
rergi"arrian":bi lege abbominabilé cöfnxerär:refecantes gcgd ardun erat in crededo: 2 oifficile in opando:con

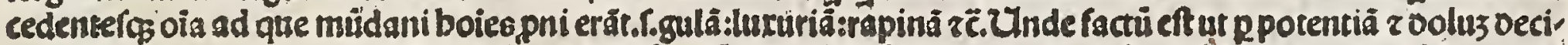

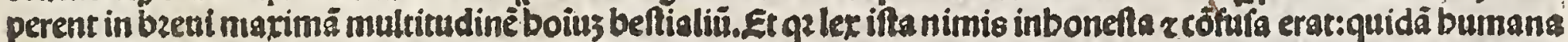
verecüdia pmoti plara retractanüt:ac velut expoftozes: rōnabilitinter p̄tabant aliānimis mẹdofa. vnde quidas xp̉iani etiä litterati boc colludio oecepti fuerüt:g biflozias tranfmarinas nò viderür. Auare aüt tam infamis bö

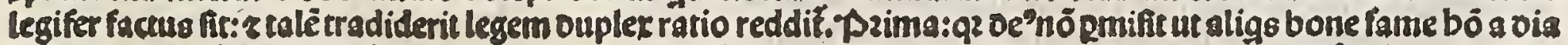

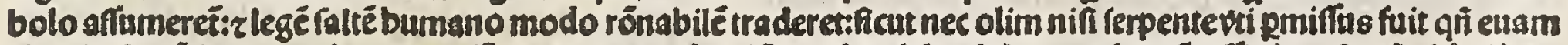

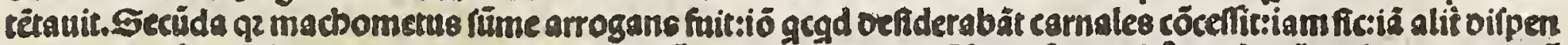
fando. Et ex bac collifione ooctrinaz variay 8 cötrariax:tot?

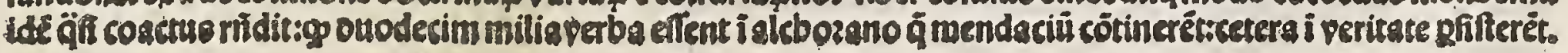




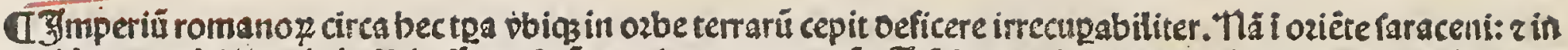
occidente gotbi: oominis fibi affumpferür $z$ oeinceps tenuerüt. Z3 té farnceni oe etercitu impatozis interfecerunt

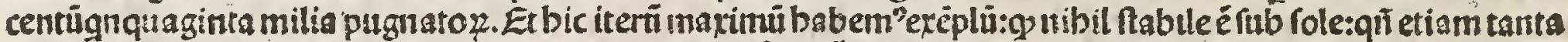

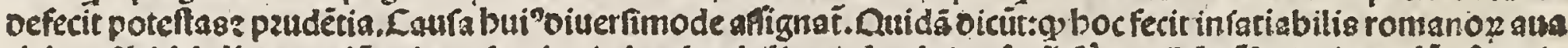

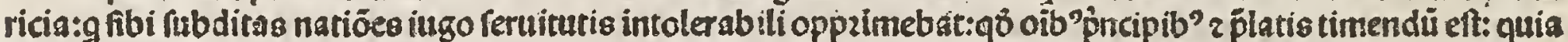

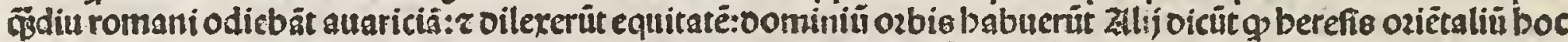

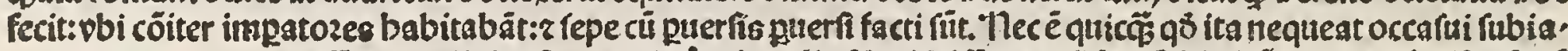

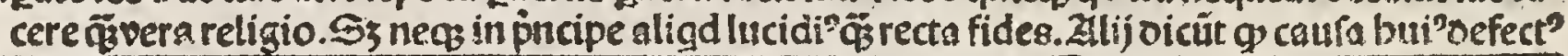

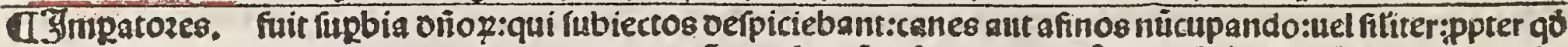
pudoze zooloze incitati:erererüt fe $\tau$ fecerüt qơ cernimus. Sozte oéo be fimul funt mia caufa:

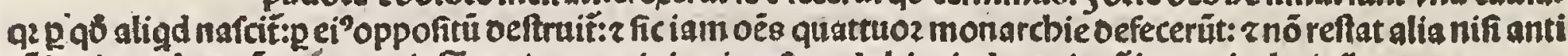
xp̣i cuius aduentú oeŭs nouit. Interim oominis oituerfimode bincinde variant̃ in particulari zč.

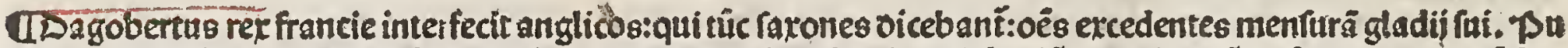

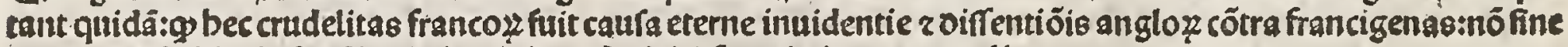
oammo vtriufos vfís bodie.zóittat pius onis f́piritu pacis inter eos z alios.

alidanus eps daret in anglia:fanctitate:oircipulus fancti colïbani.

đEligius aurifer fanctus vir:pater fuit fpüatis ifto zqui multa monafteria fundarüt in francia:oěs fci. Tepuit fides in oziente: ferter bic in occidente.

Q72do. TKado. CDado. IRemaclus.

Q 2 f.

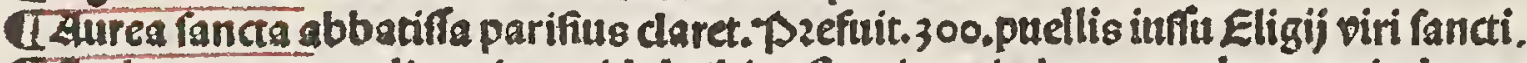

đErubertus rex anglie:pzimus idola ibi Deftruxit. 2 gireborus gotbo zq rex indeos ad fidē cöuertit.

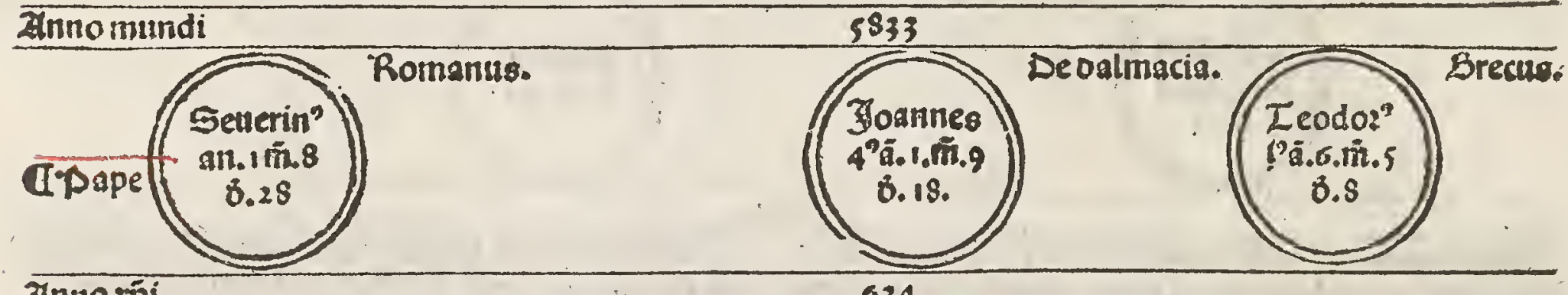

zinno rṕi.

634

OZfte feuerin'fuit vir benign' 2 fcüs:amatoz cleri:erga paty peres larg'serga regimé ecctie oiligés:quã in p̆ tis mirabilit ampliauit. Sto tpe quidâ mauricius cú fuis fa' tellitib'ecclie thefauros oiripuit: infclix facrilega nó veritus:

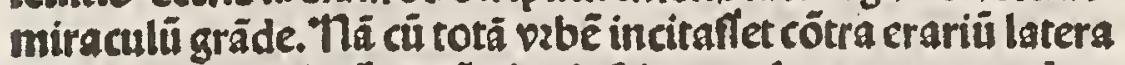
nenfe null'p potuit epm nô oico infringere:\{ 3 nec intrare gdem Qsóvidés pace fímulata:tandé gfecit qơ intendebat:accipien

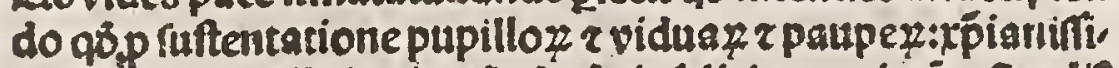
mi impat ozes illic pofuerât:f5 oia infeliciter perieruit. Eracli? fuit priceps facrilegij bui" fact": cui mifit ptè oe pecunijs els' tis, 550 ö multipliciterp buiturmodi oânificati fuerunt.

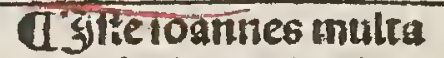
milia boints oefertitu teredemiteclefietbe. rauris:pia mot' inten tionepbifriam zoal. matiâ: bic fecit adduci reliquise f́cōpvincentii zanaftafij:z alioz mar ţrïzrome collocauit miraculum. a Sub ionnne fuit gdä noie Kbotari:rex longo.

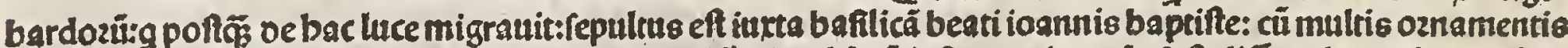
Que oum quidä cupiditate babendi:nocte aperuif́tet repulcbrü ipfins regis:r oia fuftuliffet:a beato ioanne ba ptifta:p vifionem bozzibilē territus eft:zphibitus eft ab ingreffu cius ecclefie. Sicgs femp repulfus eft ab ea: nec

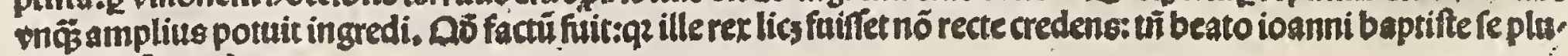
rimum cómendaucrat. 


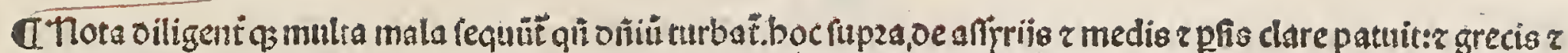

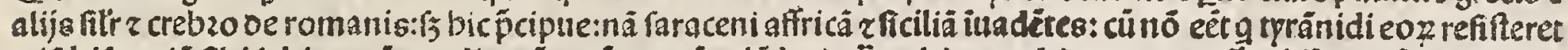
etiã bifpaniã fibi fubiugarit: vndiç xp̆

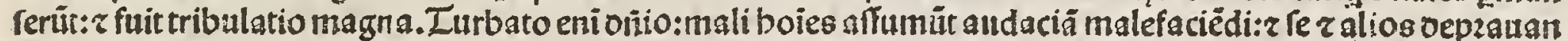
di in vita r ooctrina:z ad pplos $\tau$ ad p̉ncipes cozzüpendas: $\tau$ ë retsera bozzendü fectaculü äliter miferabilis ifte

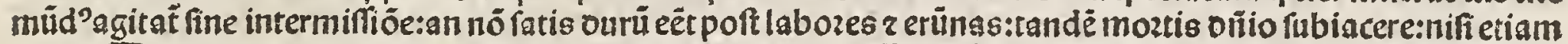

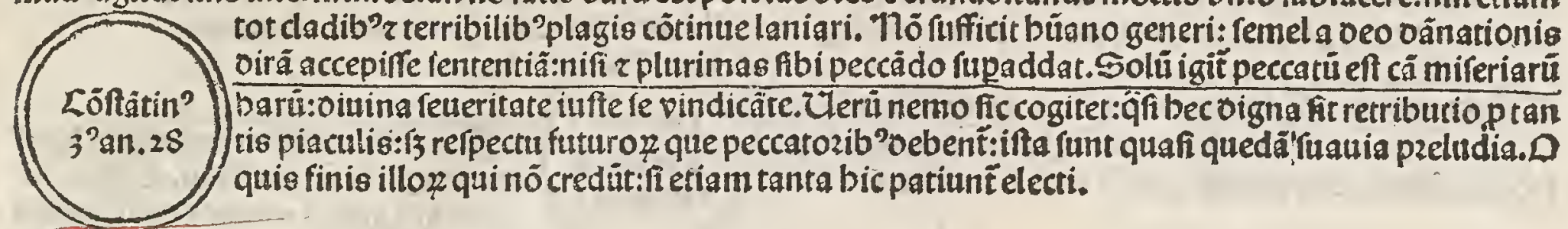

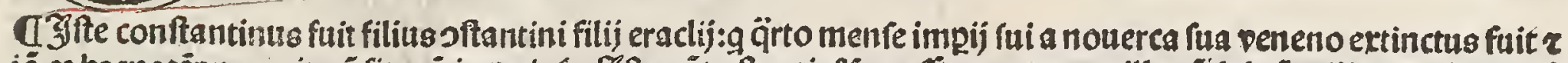

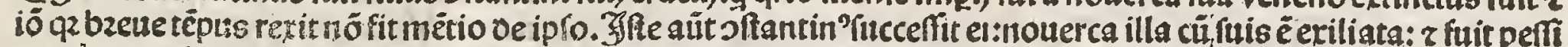

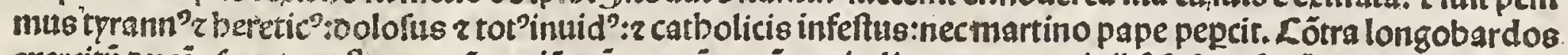

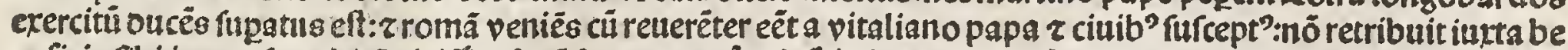
neficia fibi impenfa oebitã vicifitudiné ficuti oecet p̉ncipẻ:infup z tyränidè magnä r facrilega ppetrauit oia pul

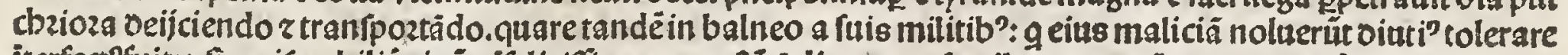
iterfect? fuit:z fic miferabilit viuês:ifeliciffime moztu?

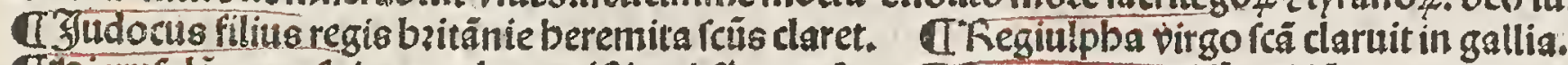

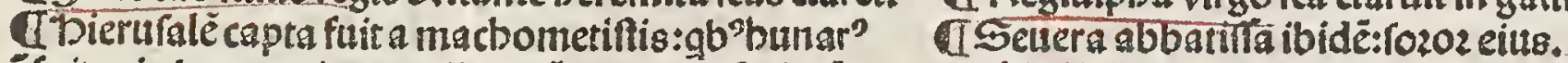
pfuit:gin loco antigtempli noun ererit fupftitiofï propbanü:ablatapzills cruce.

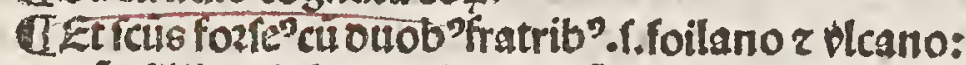
TLondoaldus vir fás claret: $q$ beatü lambertĩ oocuit. oés filij regis bibernie venerüt in galliǰs fancti.

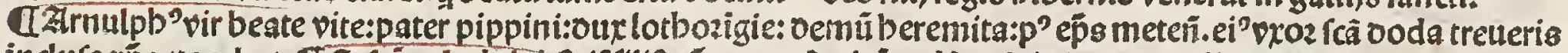

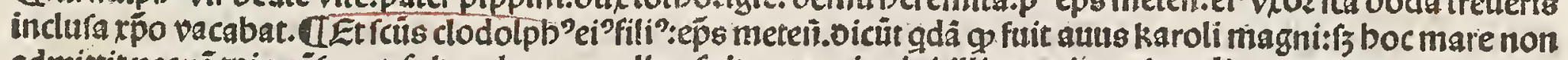
admittit nec rôtpis côfonat:信karolus marcellus fuit pater pippini:illius qui eratkaroli magni pater.

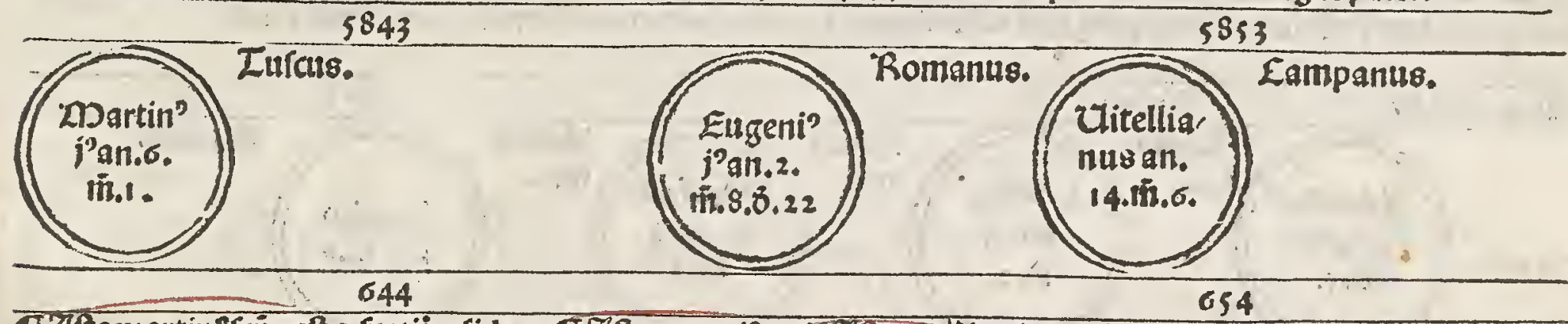

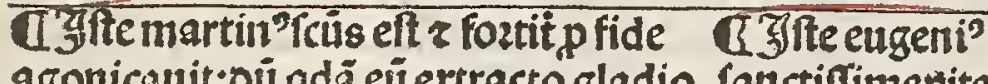
agoniçauit:oú gdä eli extracto gladio fanctifimevite interficerevellet:adbuc ari altare ofti futit: oib? ama.

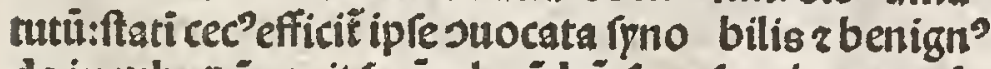
do in vibe oanatuit fyrü:alexädrü:Ter, fepultus apud giü:pirrü: z paulübereticos: ̈̈re əftä fanctü petrü. tiuns eũ in exiliú mifit.eins feltü agié pij.nouembzis.

đRodoaldus ē̄otrenereñ. TSozfeus latiniacúcenobii río cozonatus quiécit. IS Sigibertus rex francozü onodecim monafteria fundauit. Et fit tmagn' fructus in francia zanglia p fcōs viros UThauta quidă negando pauperi panē:bac pena percutiťtut omnes eius panes in lapides cönerterent: ficut idé pauper ei impzecabatur.

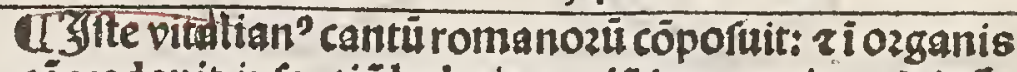
cócozdauit. ipfe etiā babuit gratiä impatozis: g fusis p̄ deceffozib'offenfiuus fuit: tĩ poftea nö fic pmanft. nec vfq buc potui iuenire: 9 vnögseclefia romana babuitplene p'mozté côftantini magni oñius vzbis z aliozĩ q̄

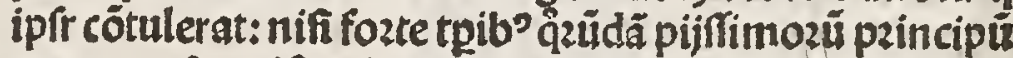
panco imperatoz ifte peffinus pziuilegia ecclefte confirmaret rtamen poft infregit. 


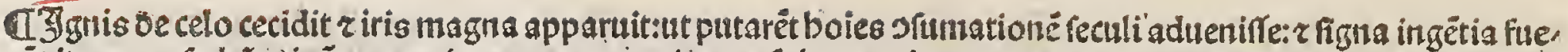

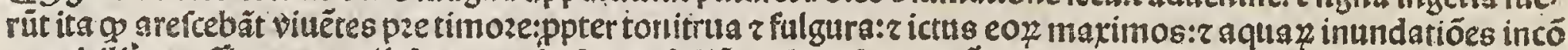

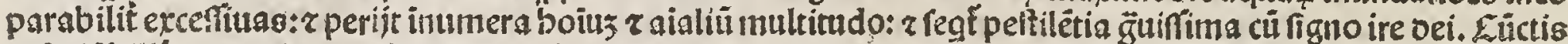

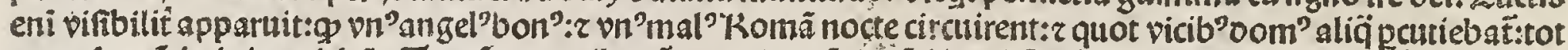

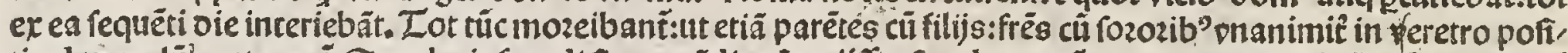

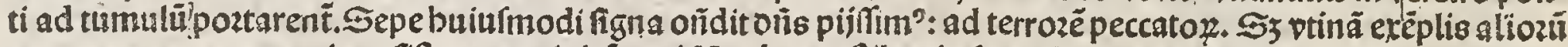
terreremur:ut a peccatis oefifteremus. Dicuit quidä $q$ becpcftilentia facta fit the benedicti fecundi.

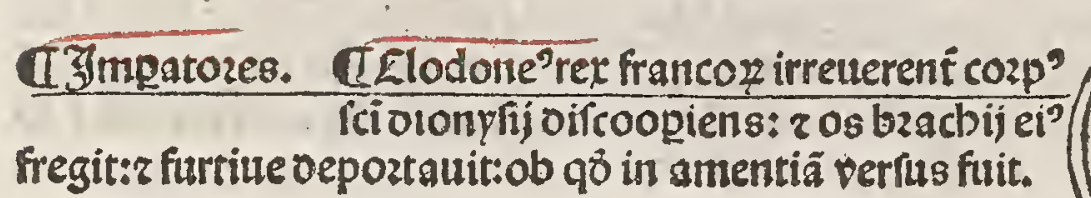

Q3fte coltantin? fuit catbolic $r$ bon? tini an.17

çelorus q oì כ̄ bereticos. Ecclias re. parauit: $z$ greciä romane ecclie recōci liauit. Gnnoduz rextà cögregauit:in ä

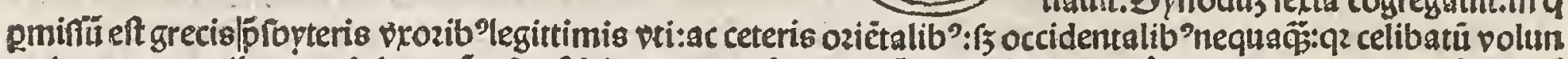
tarie tpe gregozij r ante fufceperüt. Et eft bic mature aduertendü quantü bonitas pincipis valeat ad bonü r getī

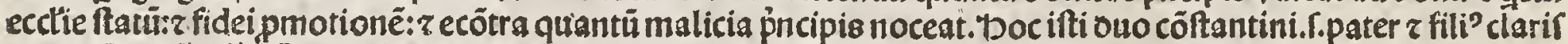

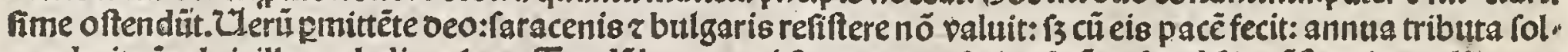
uendo: ita iualuit illa maledicta fecta. Iandē bona potit?mozte tranfiuit ad xp̄m:fepulte in côftantinopoli:

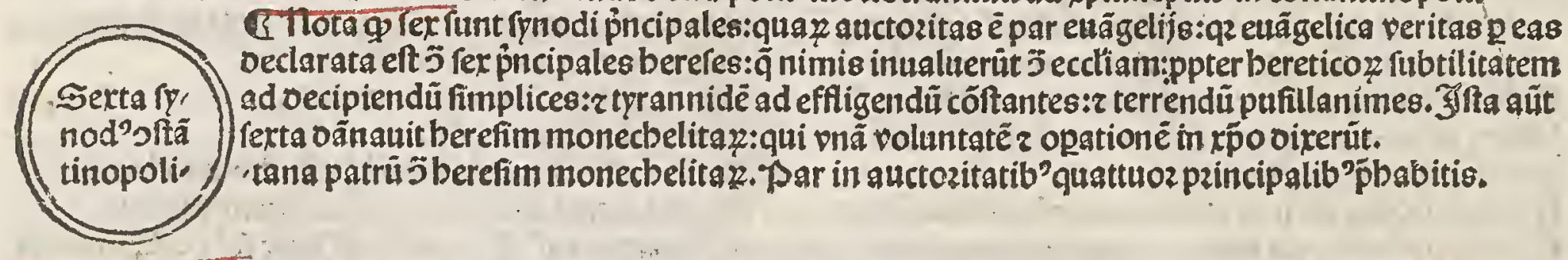

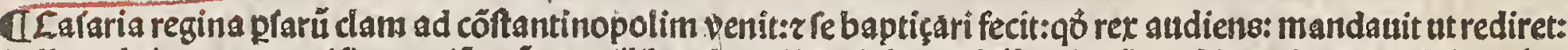
13 illa noluit:o onec pacifice veniēs:cū.40. milibus baptifma fuf́ciperel. Noutit oñs qui funt eius. 2mpaluit mulier

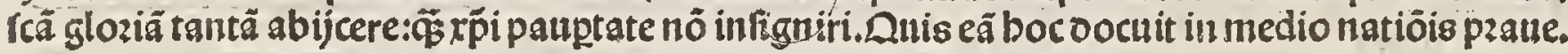

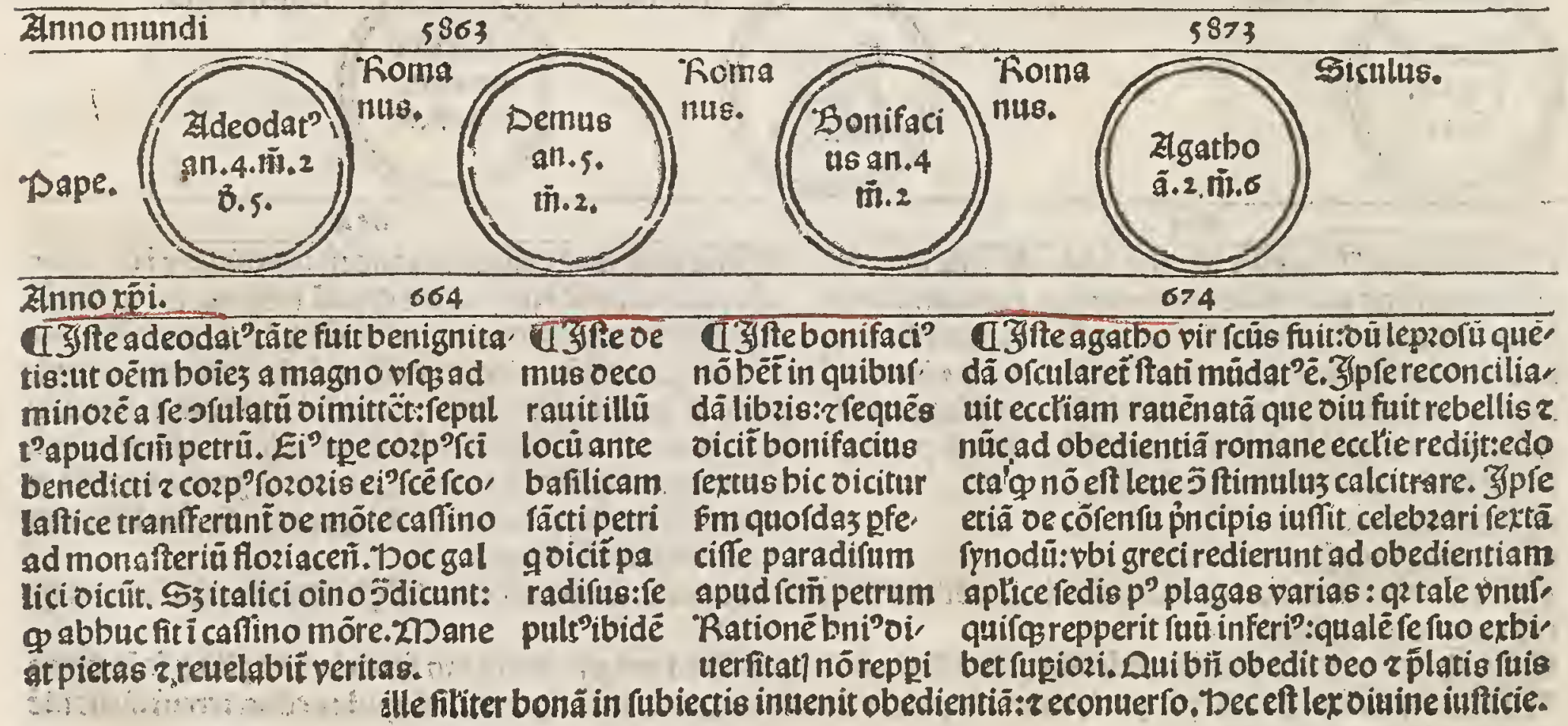




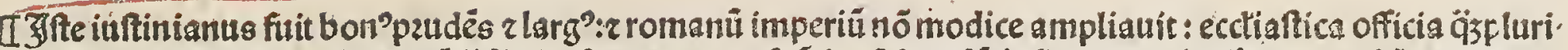

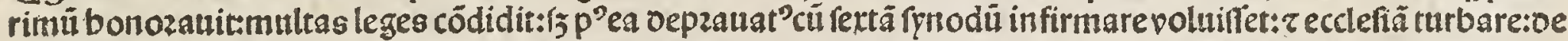
cino âno fui impij a leone patritio z tyberio z gallinito patriarcba capt' fuit:pziuatufag nafo z lingua:regno es.

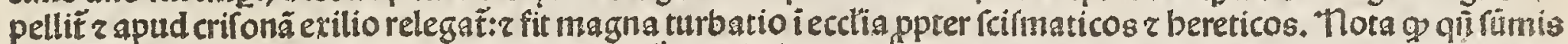
o ominijs fiüt violêtie:túc errozes multiplicant:qz nö eft gerrätes cozzigat $z$ a malo cobibeat:boc valde fepe ex.

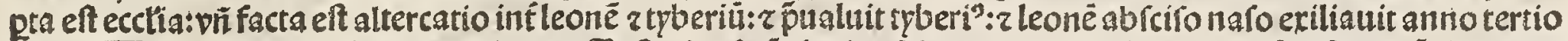

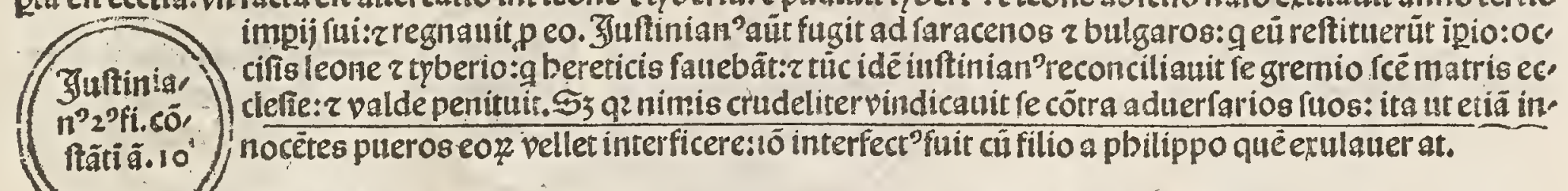
Tंßuโgaro

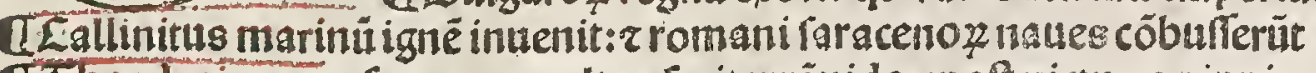

II beodozicils rex francoz multas fecit tyränides:pof victus a pippino.

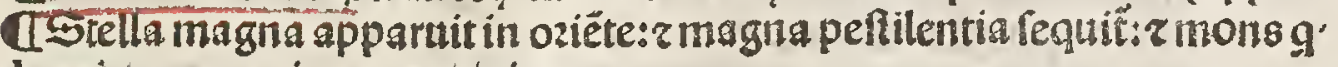
dam in campania eructatut ignem.

ISancta berta martyr $z$ abbatiffa claret in gallia.

15atbildis reging francie poftea monacba.

Trenefíts lugduneni.

IDzoiectus z marinus martyres cin fertio ftuo.

T20 arelédis vigo r mar.p b̈ginitate miraculis claruit.

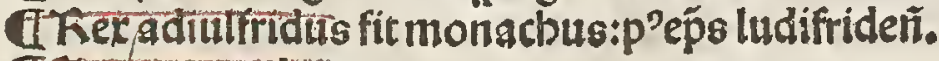

TAmartus exulatur.

ILbeodozus arcbiéps anglozü.

QLeodegarius auguitudineñ.

ULbilianus és fanctus.

Thirpenicirca bectpa magnifice ö faracenosbellareic

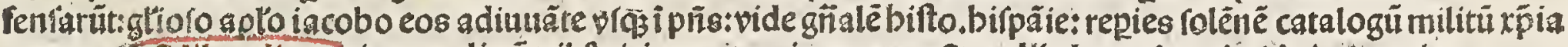
noz. IEdiltrudis:regina anglic q trib' viris nupta:virgo pmanfit: $z$ alij plures fancti. vide in fpeculo.

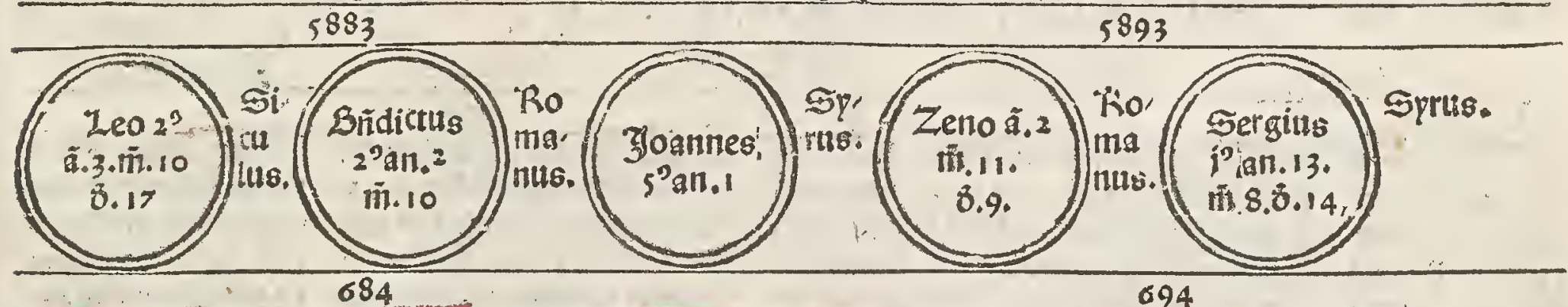

Ij)teleo virfins fuit greca z latina lingua fufficienter eradit? : eloquétie q̊z fingularis.ergg paupes î roli mé. tis pietatef $f_{3}$ tiam ftudiilaboze folici tus: bic oftituit $\mathrm{pa}$ cé oari p'agn' oei z utp pitu pallijar. chiep̃us nibil prol uere teneat. Eip $\mathrm{Fe}$ ftúagí. 28 .iunij $r e$ pulttis i ecclefia fci petri.
IIJ1te benedict: fuitpoia vituofis $z$ vita eills cócos' dat cĩ noie. Eius tpe fuit maxia pe. ftilentia.bic abi, peratoze pijfimo factus eft papa: re pe eni iftebonoz factus é impatozi bus ab ecclefia:p. pter caufarparias ptempoze occur. rentes. djofteion. nes fuit vir Atrênu':mo, deratiffimus z f́ia redimi cus deantio cbía.

Ozfle çelio fuit vir valde fcüs: nec unö actibufos fecula rib’inifcuerat. erat eniafpectu sngelic":anicie venerãd?: mozi, bus get'seligiofevite:fermone veridic":aio fimplex."bic elect" fuit scordit: etiâ laicis sientien tibus.magna eni oiffenfio erat: qz cler' intêdebat i petrü arcbi. piban:zexercit ${ }^{\circ}$ itbeodozp pze.

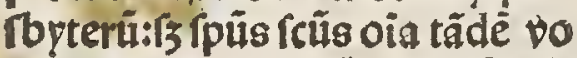
ta ว cordauit in iftü oigniflimü. dy fite fergi magne firatiz conted bilis vite fuit: $r$ ielectióe ei mag̈ oif fenfio fuit.nã vna pes cleri elegit tbeo dozì arcbiópibzm:alteraparcalé:ied volête oino tandé in bücvenerabilez virü cönenerüt:bic cosp' 'ci leonis p̉ mi trã ftulit Dlirfenburch reueläte fí bi oeo. Zpre etiå inuenit magna ptê fcé crucis i loco obfcuro:z regem an glie g r fatonuz:baptiçanit. Zlgnus dei ter cantari iuflit ad mifä. Et idẽ reduxit ad pnitatếfynodü aglegieñ. qnoluit recipere fertã fynodü oftan tinopolitanä:z fuit grande fcifma in ecclefir oei : az ono vlis cócilia כ̌te oiffentiebãt. fepult? apud lemi petrû. 
T scus lamptus filits âpri comitis poft multa oga feitatis martyrio sumatus eft a Dodone ouce aranie: $\mathrm{q} z$ oixit $q$ fozoz $\mathrm{ei}^{9}$ al paida nó eflet legittima vroz pippini: ouxit stra fas: viuēte adbuc plectrude. "Dic elt çelus belie r ioannis.

U.mperatozes.

UBeda venerabilis p̃or̂ $\tau$ pr ğuifime au ctozitat] claret i anglia.2multa icripfit $z$ bi ftoziã talde fannofâ religt. §idelio laboza toz in ecclefia $\forall$ Íç in rentectã zc̆.

TSanct oda oucifía agtanic claret.

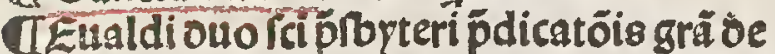
anglia venerúti D)eftpbaliå: $z$ in villa ödă laer oicta fuis pócib' fontē oe rupetrarerüt:

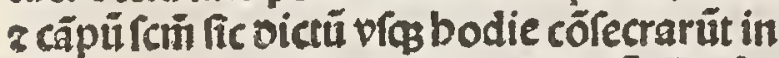
vfus paupez vbi mentü feóz volentib' facere:z bozzibiliter plagati füt. Etvocante ibi vulgariter onti no fri de fancto campo uel pzato.
TD eftpbalia incipit contterti ad fidem circa beetpa: tbi pzimum p̈dicti ono eualddi.f.albus r niger ṕdicauerunt:qui poft martpriçః ti fuerüt in comitatu oe boia:pzope bzemenfem ciuitatem. Eozpo ra eozú tranilata fuerunt colonic.

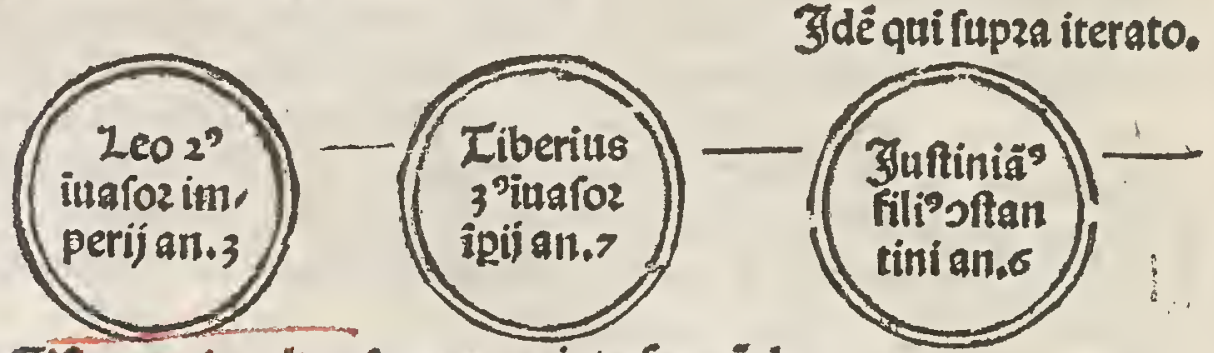

Thomani maltos faracentos interfecerüt boctpe.

IRex anglie:g r faxonti:q2 faxones angliä obtinueruit:r iōnome infule mutatu fuit:bic venit romä: 2 a fergio baptiçatus ftatin mo ritur enolando ad $x \bar{p} m$.

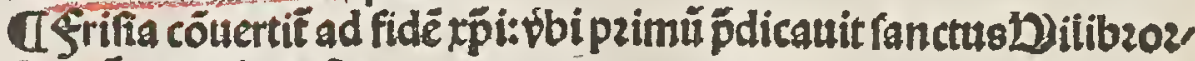
dus eṕtus traiectent.

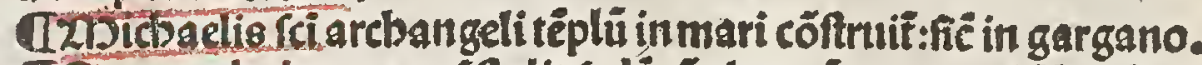
İ Sanctus bubertus: trắfulit fedé ệalem cū cozpoze fé lamber' ti ad leodium.

IScilma Teprimueclefie fuit inter Yyfinniü $\tau$ oilcotiü: $q 8$ fuit con tinuatü p fucceffozes eo in imperio कึ̈ in papatu fuit altercatio fcandalofa.

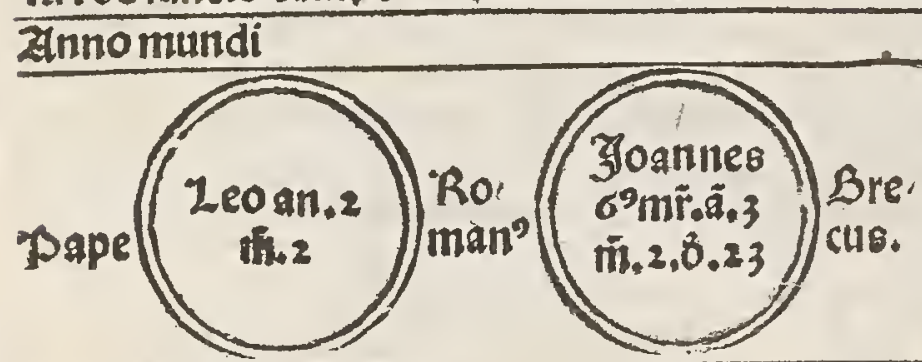

มnnoxpi.

ajfteleo:fact? fuit papa ppĩo. ciniü romanoz z noo porrit in ca tbalogo pontifi ciu: forte pémal lü introitu: z fee quës oicitur leo tertius: nibil tĩ male egiffe feri. bitinecpapa fu. iffe.

paptana ad catbacambas.

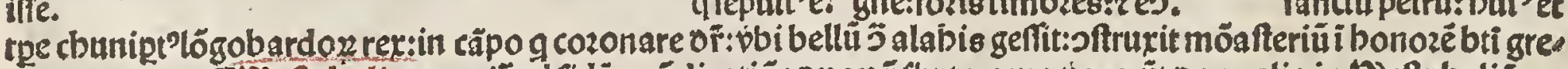

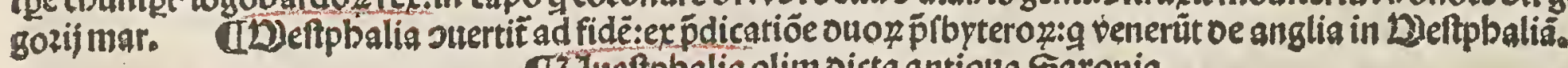
đUueftphalia olim oicta antiqus Saronia.

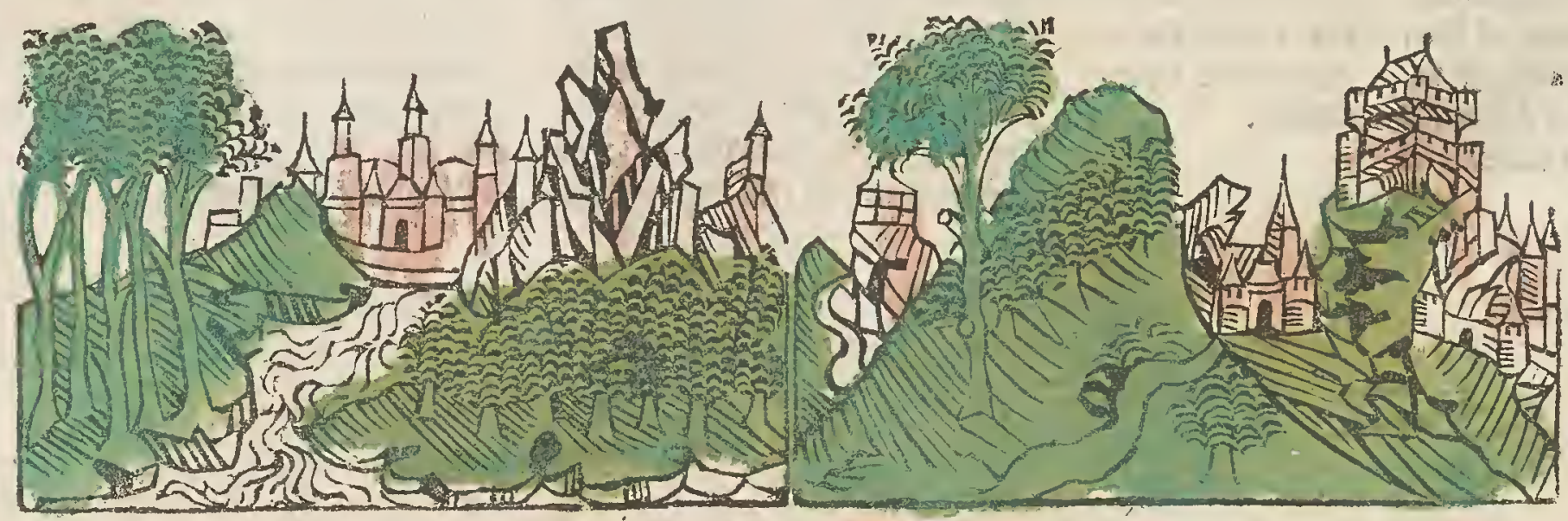




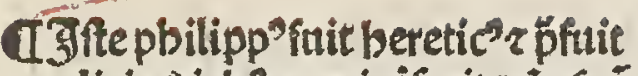
modicis oieb" 2 q 2 intfecit on 5 fuú ipfe etiã male periit: fictut fecit far ctumeft ei.

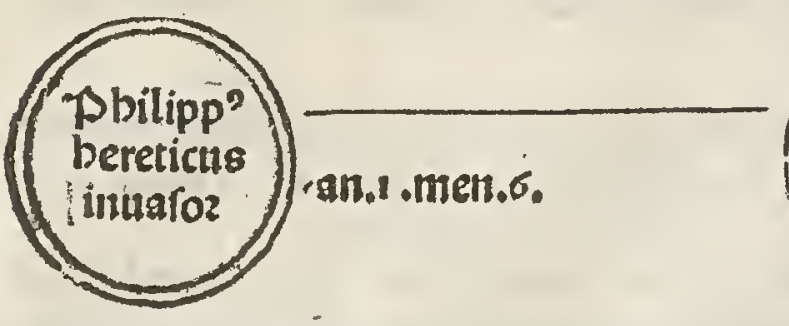

IIffe anaitaf' fuit vir bene fidel z catbolic'? q2 pbilippus ercecauit

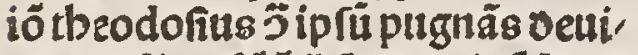

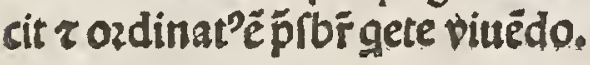

T. ffte theodof $^{9}$ totus catbolic' r bu milis fuit $r$ p cife ficut fecit factum Ẽ ei q2teo eum oepofuit: $z$ in pzefbpterum elt ozdinatus.

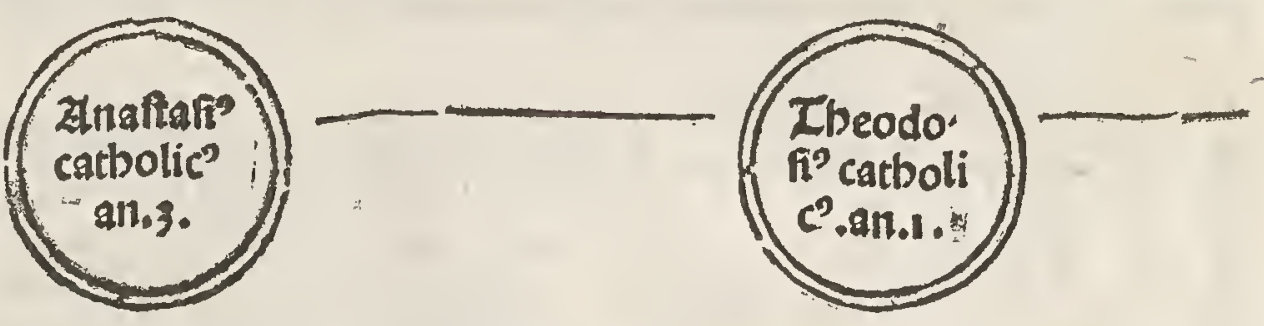

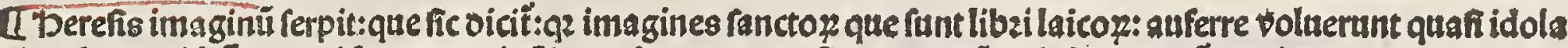

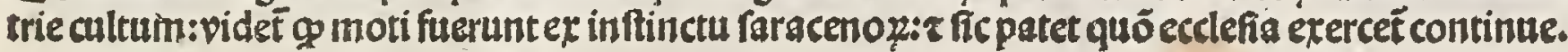

Iharolus marcellus filius pippini: imenfas victozias babuic contra infideles oiuinitus adiutus fuit victoz glo riofus pomnia:f5 q2 bons ecclefiaftica fib i vrurpautitspter neceffitatem bellozú: iổ in penis infernalibus anims cius vifa eft cruciari ab eucberio viro fancto. $\mathcal{O}$ quid?

Cisuo reges anglie veniüt romã f fitit monacbi:imostali oño oeinceps militantes.

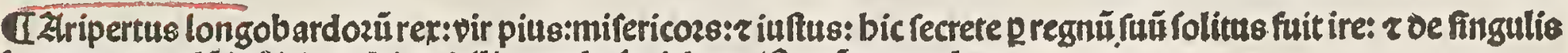
ingrere: z qualé iufticiam rui vafalli populo faciebant. Bonú exemplum.

5913

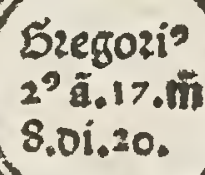

Romanuser

patre marcello.

714

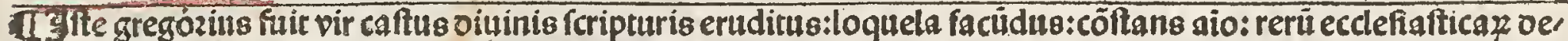
Fenfor follicitus:z boftiü ecclefie impugnatoz fortiffimus. Et nota 9 circa bec tha: inceperüt oñi pape plus folito etiã in toalibus fe opponer eimpatozib"ppter gfidiã eoz: $\tau$ etiã tranfferre imperiü oe gente in gentē: put tempus

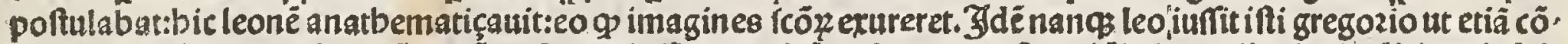

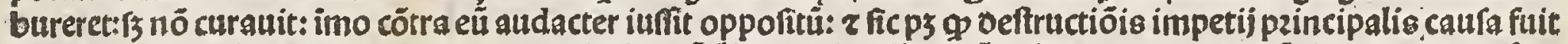
berefis:nam ob boc fideles populi: vnanimiter cu platis fuis adbeferüt orio pape: 2 coegerüt impatozes ceflare a tyrannide beretica.

(13) ozientalibus regionib" circa bectpa valde oefecit vera fides ppter impiã pfidi macbometi legë: $z$ p confe

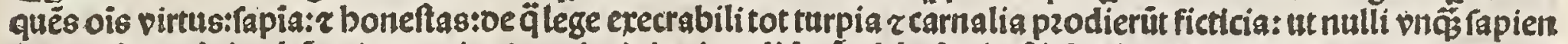
tes in rebus oinis z buan is exercitati a pzincipio ei crediderüt:\{ 5 boies beftiales in oefertis mozantes:ois o octri me pzozfus ignari.q quoz multitudiné aliquos armo z violentia i, fuä legē peftifer ipfe coegit:ut oicit zoctoz fan ctus thomas in fuma côtra gentiles libzo p̉mo.c. Di.nulla etiä oiuina ozacula ṕcedentiú ppbetaz ei teftimonium pbibêt:neq oocumēta veritatis attulit:nifi que oe facili naturali ingenio cognofci poffint. Thec figna fupnaturali ter facta adbibuit: gn potius vera que oocuit fabulis a falffilmis ooctrinis imifcuit : carnales voluptates pmit tendo: $z$ eifdem cófozmia peepta tradendo:z q2 voluptati carnali babenas relarauit:idcirco mobile vulgus faci

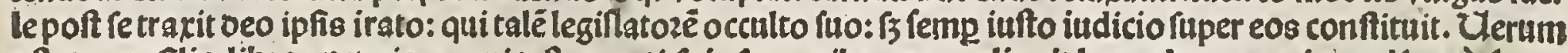
aftuto confilio:libzos peteris znouiteftamenti:Iuis fequacibus non reliquit legendosmec etiam oifpu $X$ * 


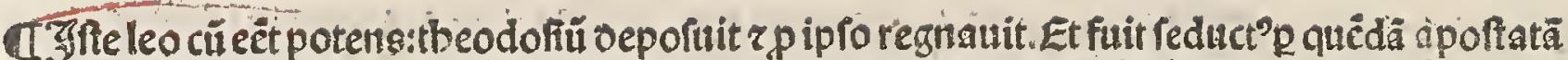

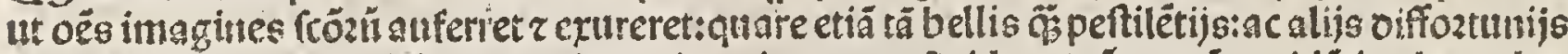

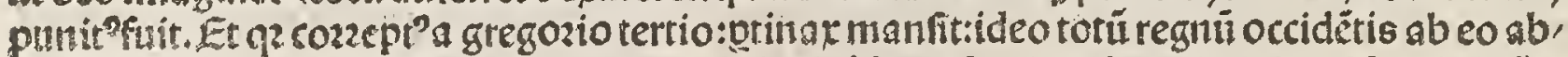
ftult:mandäs ne fibi obediret aligs:vectigălia intdicendo. Et q2 beretice vixit:fci viri ei côtra dizerüt.Et martyriç̧ati z exulati füt ab eo plures. Iandē in pfidia miferabiliter oefunct’eft.

Tiselagi rex

bifpanie grădi miraculo re gunu illud cepit recupare.

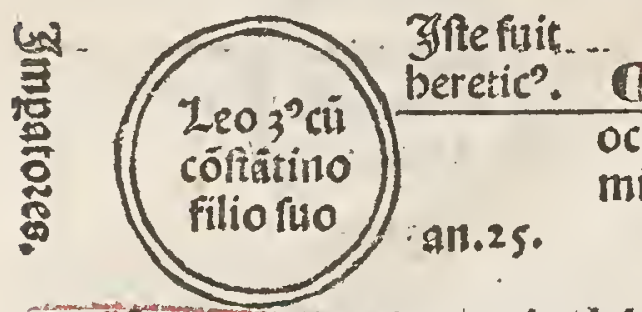

TEốtâtinopolts a faracenis obrefls

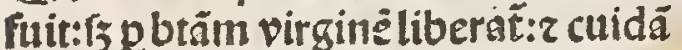
beremitevifio mirabilis oftéfa é oe io fepb qoiñ fepeliuir:z/p’paucos änos 300.milia boius in peftilétia obierũt ibidem $2 \vec{c}$.

Ucyrtus âtâtinopolitan'eṕs:extulat profide.

ILelariaretateri.oocer monacbos. I atbititus éps andegaueñ.

IEucberius eps gurelianeñ.

đ2D agnus arcbiep̄emaguntie.

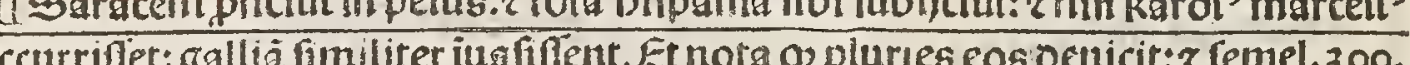
milia z vltra no ipfis occidit:oe fuis.1 500 , tantumodo pftratis.
Trantatio reiguguftini oe fardinia in papiä fole
CEerman'exulat niffime facta ë p lüpardū regê lögobardo z oetuoti. CEgidi?abbas ranctiflim" clarus babet.er grecia venit in galliam.

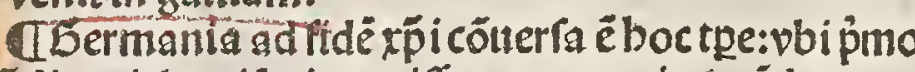
pdicauit bonifacins mifus a gregozio lecudo.

(1200onafteriti cibenedicti:reformat́ in möte caf fino a quodä cine bririano. Et filtiter quedã mona fteria oitifing füdant in almania. . vuldeĩ. zż. CEgberch Tus:Debibernia venit in galliam. U.Derminus epus lobient.

TTsertusepsos,

maicentis.

¿ Petr? ${ }^{2}$ manie? martures.

QLebuin?popter reisanglic ṕdicat

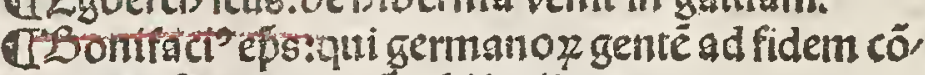
uertit:poft martyriçat a frifonibus. (1D)olfranus epue çenoit. i velua: $p^{\text {Pin faro }}$ nia antiō.i. D)ef?. pbalia. Ei $i^{9}$ cozp? $^{\text {in }}$ oauc̈tria colit glo Qbuericus epseçenoneri. riore.

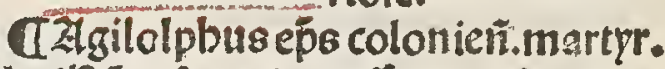

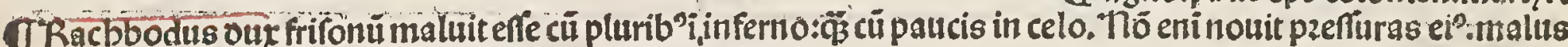
iocus. Ss filits:mozte eins fubita territus:côtuerfus fuit.

Innomundi 5923
Zln110 xpi. 724 734

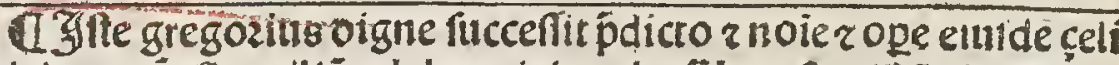

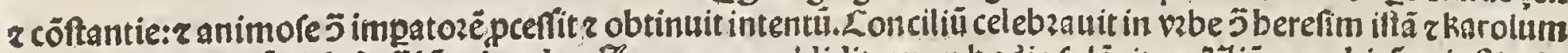

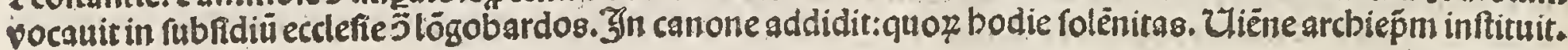

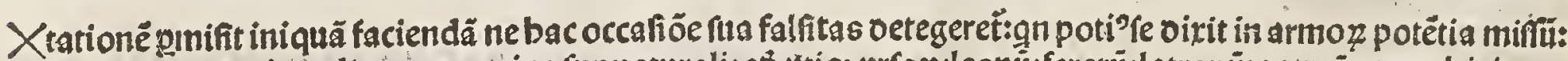

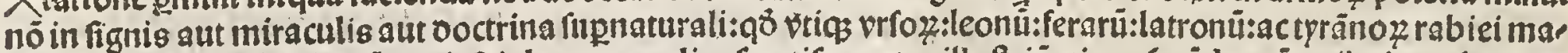

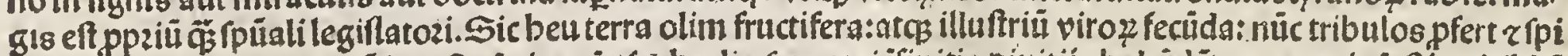

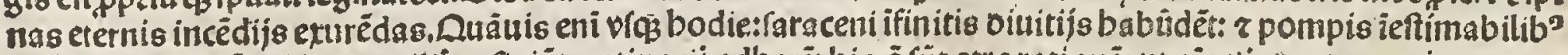

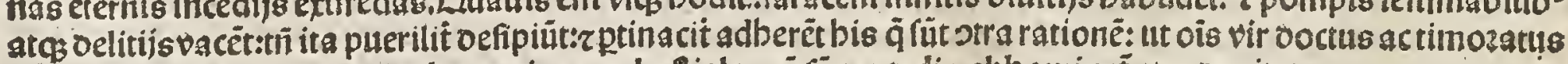
coł confoztiü fugiat: $r$ eos velut caninos ac beftiales cü ü̈mo tedio abbominet atç oetnitet.

Eermania Ciutas Zluinionis capta a karolo rege franco z: oetuictis zpftratis faracenis.
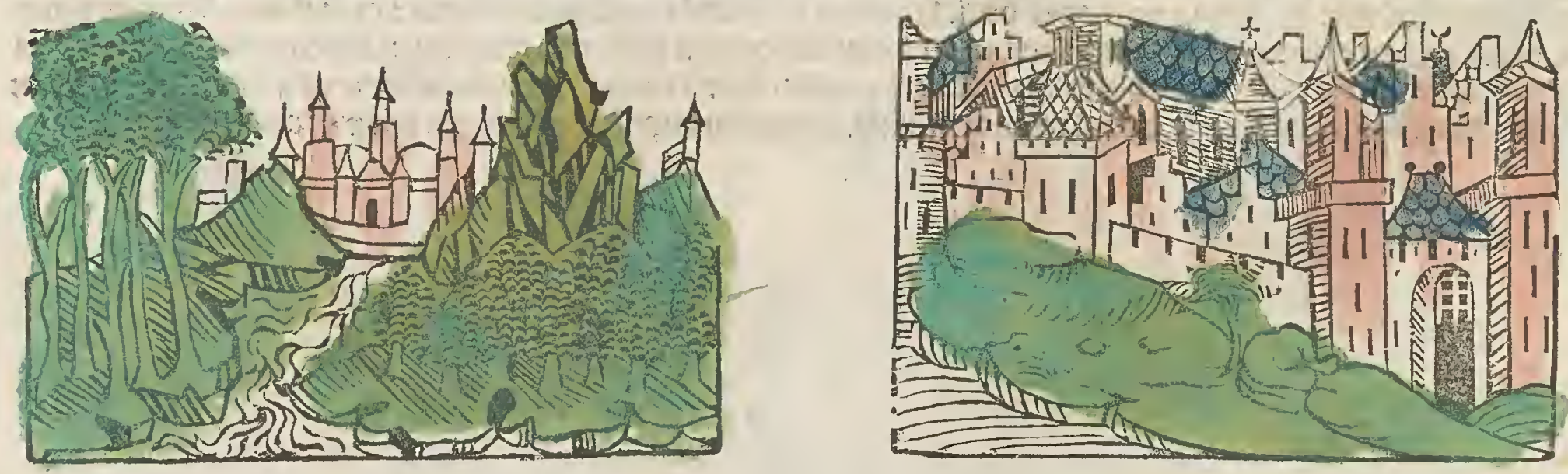


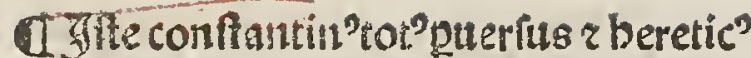
pefimus fuit:ita ut etia oemoinis imola ret:ecclefia prequebat : $\tau$ nibil oigní me. mosie egit:r fic pmittëte oeo: ecclia lögo toe afflicta é moze folito:qz in boc müdo pzeflurä babebit: z agros cu precutioib"

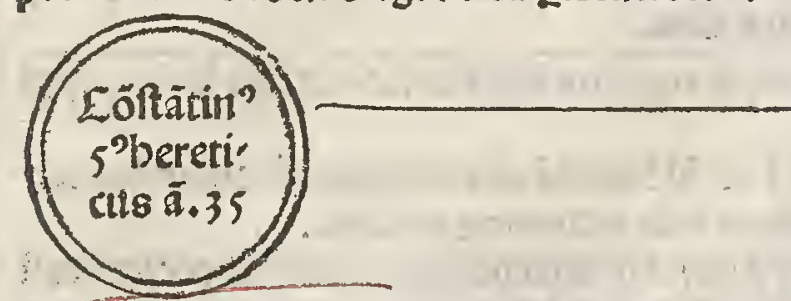

UTippin'fili"karoli marcelli fit rex frã. ciep papa çacbariã:z fuitpir valde catbo licus: $\tau p$ oia victoziofus: 2 ecclie romane fpälis defenfoz:ri i nullo oegener a pater, na ftrēnuitate.

Ukarolomãn'frater oicti pippini:oiuino ract timoze oiniffo regno:fit monacbus. TRacbis rexlongobardoze cacbariam admonit' : ut a plecutióe romano 2 ceff́ ret:equicuit.infup z mona cb"efficit (T) Bildericus rex:monacb"efficit. Fozte

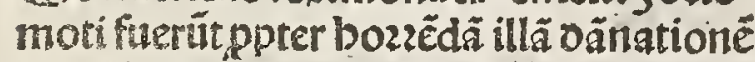

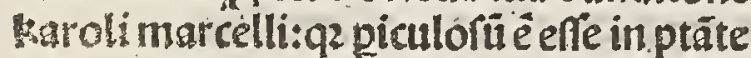

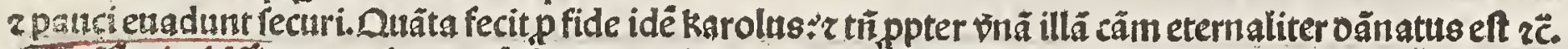

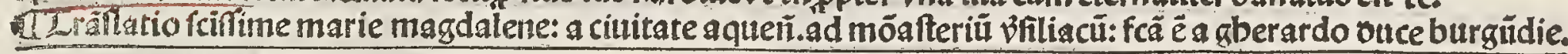

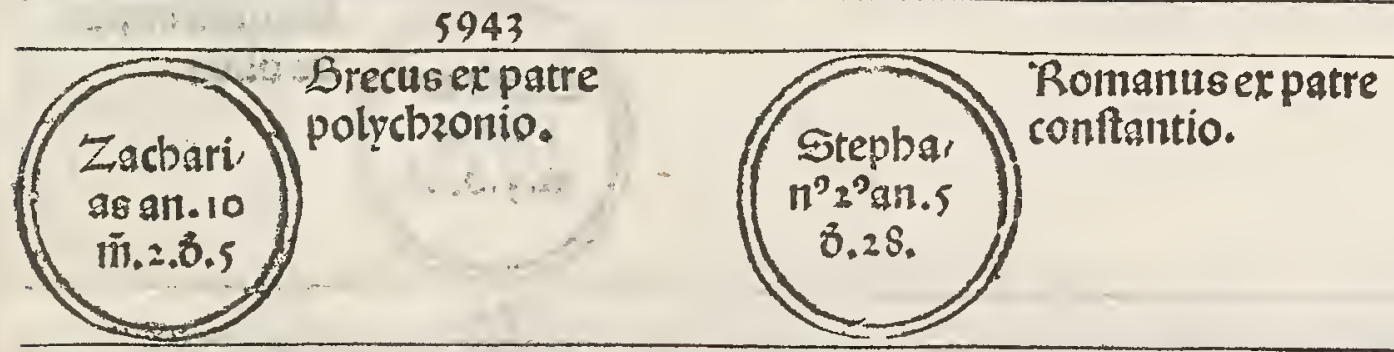

đदुłte çacbarias virfuit benign? roi virtute oznt?:oib" amabilis „ppter mititatë fuä. Ipferegë fran, cozer.bildericü oeportuit:zin locí eipoippinú inftituit:q2 vtilioz fuit Ethic p5 ptãs ecclie quanta fuerit boctpe: gregnü illid famofiffinui tranftulit oe veris beredib? ad ge nus pippinippter legittimã caufä

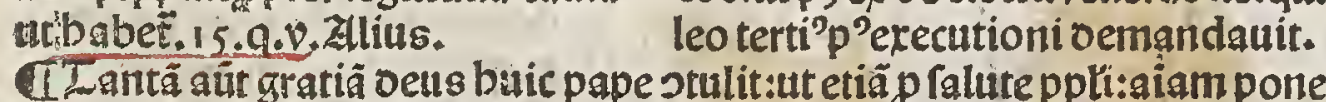

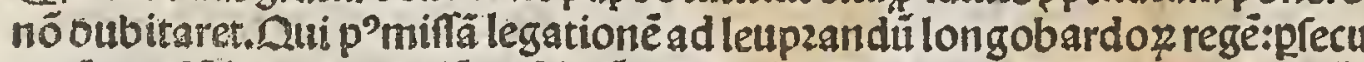

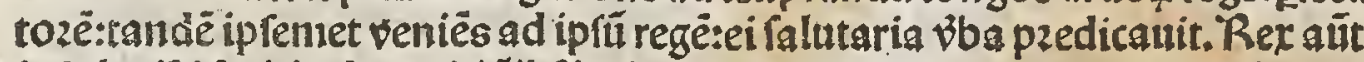

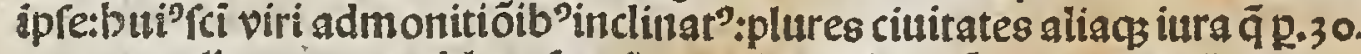
annos ecclie romane ablata fuerät:reddídtt: $z$ fact ê pax ecclie pänos.30. Qmperine trans foof ogrecis.

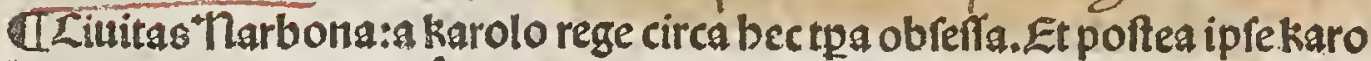
lus moztuts eft.oiuifo p̂mo regno filijs karolomanno. 2 pippino:qo fecit

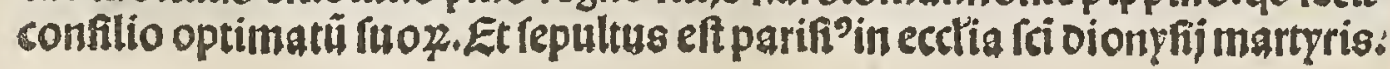

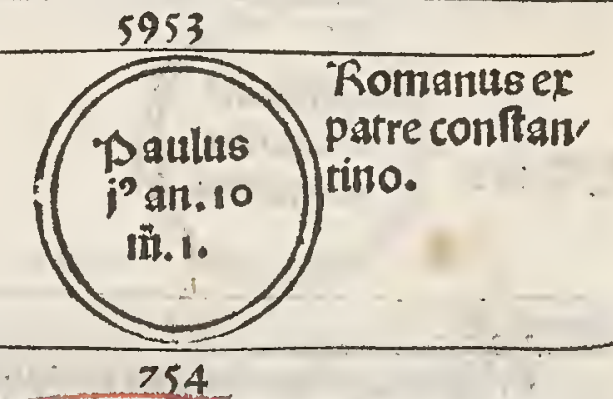

I Iffte pqulus pir fcüs fuit z mitif. fim". Secit oftitutionē de oino offi cio feruãdo iödragefima. Złpenulli malú p malo reddebat: is cii paucis familiarib'fuis oe nocte p cellas in, firmozĩ z pauperú incarceratozum circuibatt:aceis nccia miniftranda viduis r pupillis r alijs egenis pa, pale oebitü exbibuit: opem ferendo tanç⿱宀⿻三丨口 verus imitatoz rancti paulí.

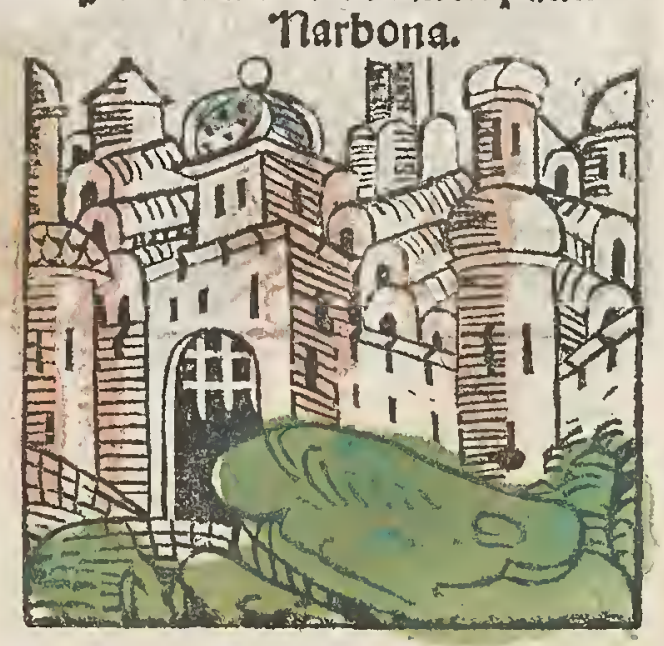




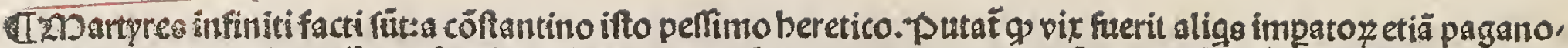

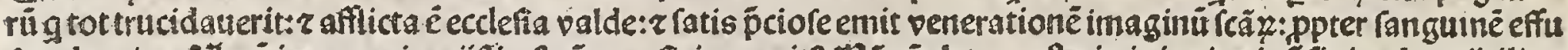

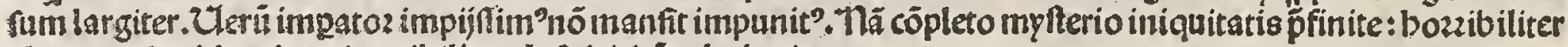
clamans.igni fum inextinguibili tradit's: ipiritüexbalatit.

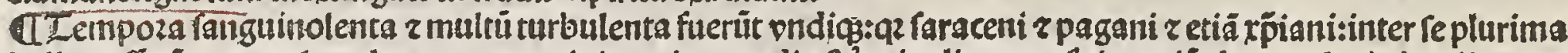

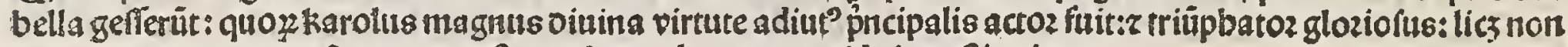
fine magna ftrage fuozp longa tpa. vide in geftis eius.

I3/mperatozes. Ckarolus adbuc iusenis:\{3 egregie indolic:incipit regnare fun francos: 2 fruit filitis pippi ni:mater eitus berta rocabatur.

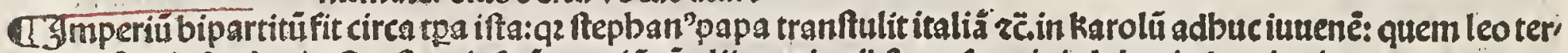
tius poftea infeudautit. Lonftanstin?aüt greciã cä alijs regionib'tranfmarinis laboziofe retintuit.

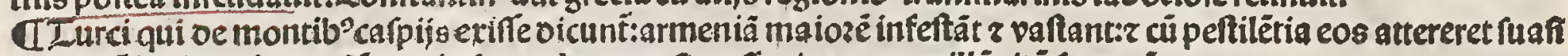

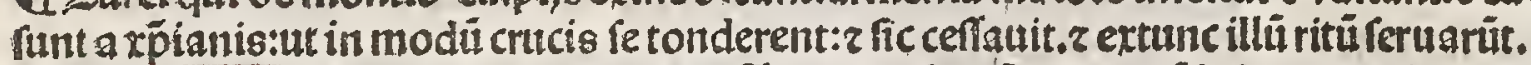

Q. Bengulpbus martyr claret miraculis. In gallia fonté emit:qué in burgundia oziri fecit. Suit itags feparat"ab Droze fua adultera:ctii? anus cantaut:eo g, oerideret miracula eitus.

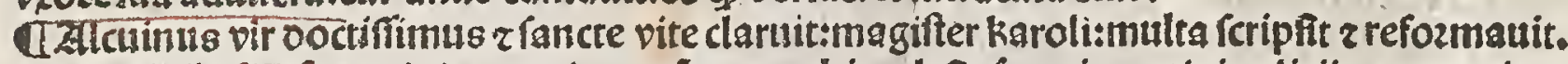

U. To 12ibile factu contigit turonis:q2 cü monacbi ecclefie fancti martini oelicijs z pompis vacarēt oës mo exce pto:ab angelis fuffocati fut: 2 Zlcuinus illud reformaut plene.

CLudgerts vir fcús: velut alter moỵfes ab vtero matris fue oño cöfecratus:inumeras gentes ad fidè contuertit:

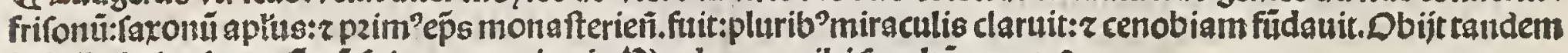
in billerbeke:(3 tranhatu fuit cospus eius in D) Jerdenam z ibi fepultü:anno.809.

TSergíus eps a oco plagatus eft:eo $q$ indignui papatui côfecrattit:q2 manus eius artuerunt.

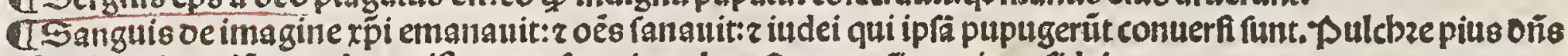
oftenditmiraculiu grande:rpe ifto p coufutatione berefis:z confirmatione fidei.

T'perronille fancte cozp' tranffert:cum titulo quem petrus fcripferat:auree petronille oulciffime fitie.

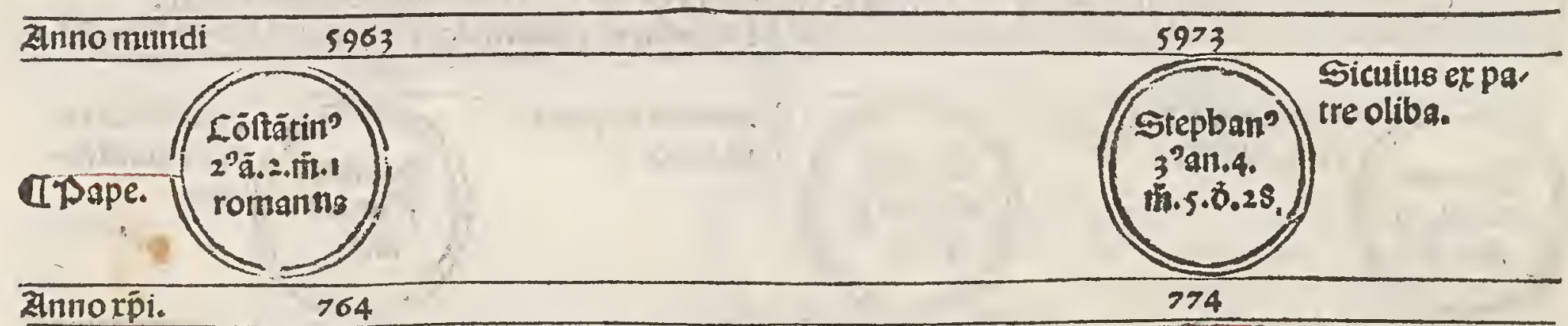

Q Jffte conltantin? fuit laicus: 2 fubito factus eft pzerbyter tyrannicepapa

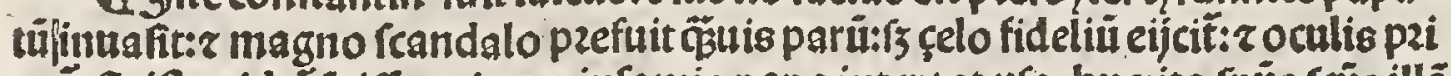

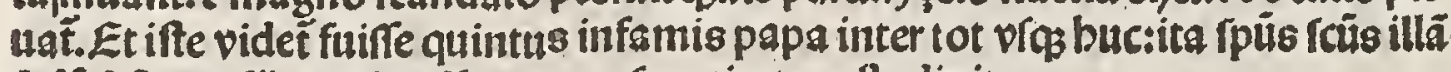
redê reãm aplicam:in oibonozer fanctitate cuftodiuit.

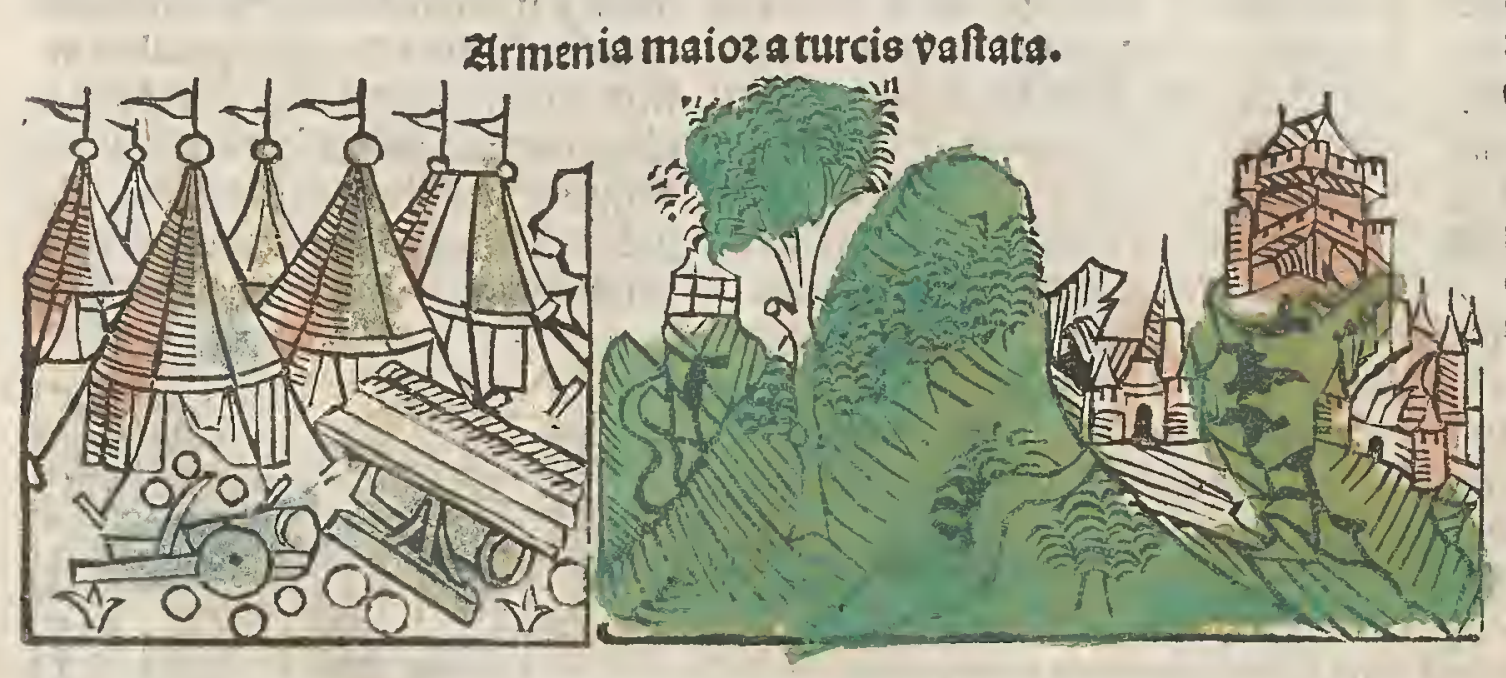

IIIItellepban'oia errata con Itantini ensersdauit:oegradat? bis ̨̊s ille ordinauit i finodo generali:repultus intaticano. bic etiä côthocauit ŕnodü:ad, iut' 'uffragio karoli regis fran cie: $r$ büit ab eo ottodeci ep̃os ooctos ac pbatiffimos in oiui nis feripturis z fancto nú cerimonije. Et in ipfá fyno, do:irritanitoia facta r celebza ta poictú conftan.papã fuú pa. decelfozem:p̄ter remin baptífma z fanctú cbzíma. Et iniuxit pe nitentiã oibus reis eiurdê facti videlicet oe vfurpatione papa tus ptyrannidē, zrecōciliauit omnes. 


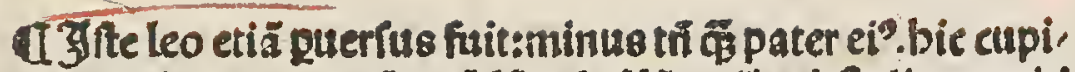
ditate victus:cozonã quãdã cuinardã ecelie abftulit z capiti fuo ip ofuit: ftatiog febre cozzipiť z fprin exbalauit. Dabuit ตrozē peffimä noie birenä:que regnanit ftati p'cú cū filio.

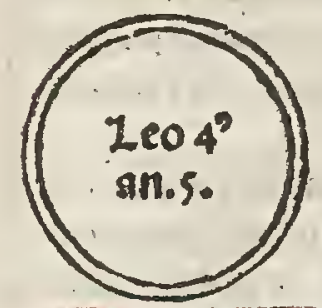

ASaroin cotiertî ad xṕm:popul'olim ourifim'z galloz inimicus ppetuus: f5 a karolo fupati: colla fubmiferüt. Et ê mirabilis oilpenfatio iudicio f oei: r infcrutabilis:quo pfer

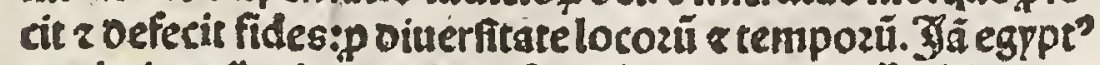
zapbzica rc̈ \& faracenis vaftate fuerunt: $z$ ecce äfi fides vo. laffer ad populï paganü puenit. $z$ bui" fimile repe reperitó.

C. Francia in fiore 2 tota gallia fimul to big triüpbatrix: ctiã oltra montes rinare:ficut olim roma ré.

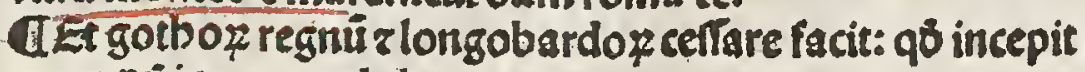
mno onitce.250.uel cirea.

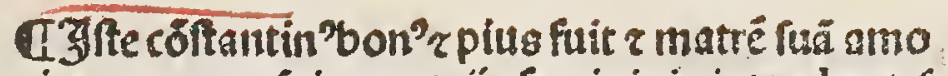
uit a regno:ut futis negociis femininis intenderer: 5 illa finula to rancoze poftea ipfí exocalauit: $z$ etias

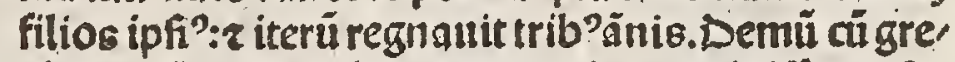

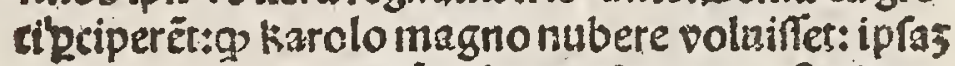

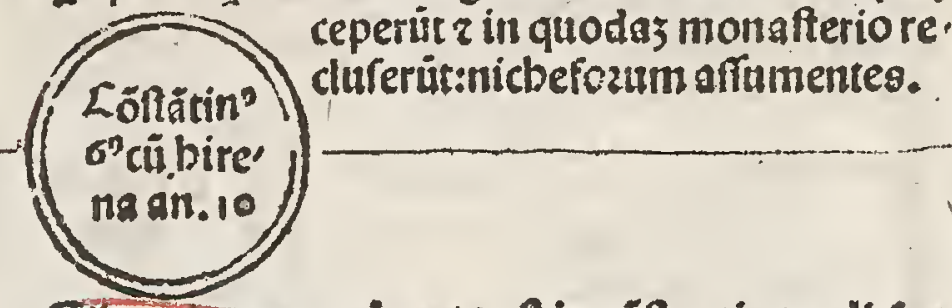
TLamuranarea iuenta eft in cöftantinopoli:fup cozp'cuiuldã oefúcti i quodả repulcbio: in qua fic erat feriptú. X̄ṕ nafcet oe vigine maria: $z$ ego cre, do i eü. D fol irerú ગidebis me: \{ub oftätino z bire "1e. Sol obrcurat"nó apparuit..17.0ieb". Signum crucis apparuit:in veftib' boins. Et fanguis dece, lo in terrä fluxit.

đSfrnodns teptima celebzấ conftantinopoli cö, tra berefim imaginú:in qua ite greci reconciliati funt poft plagas folitas:conficentes fplritum fan ctum expatre r filio pzacedere.

TStudiu vmiturfale qơ oli fuit tranthatü oe atbe. nis ad romã: circa bec cpa pkarolü trấfert parifit" UDerefis feticiana a felice auctoze códemunatur. Dicit xp̄m effe filium oei adoptitú.

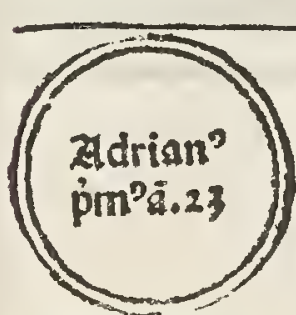

784

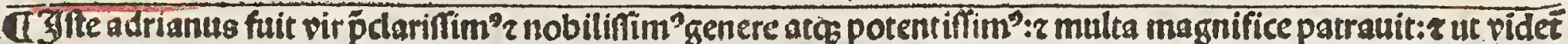

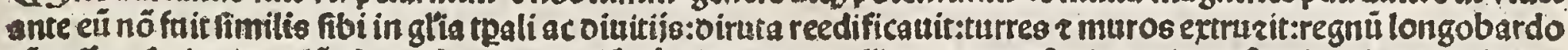
rii ceflare fecit p karolü. Spnodos ouds folénié celebzauit:eccliss z monafteria multa inftintit: z ins karolo fup ozdinatione fedis aplice: $z$ inftitutiöe ep̃o ercendas:ut p5.63.0i.g totú. Iandë bic beatus pontifer poft laudab ilè vitä:fepelít apud ́anctü perrü.

\section{Saronia.}

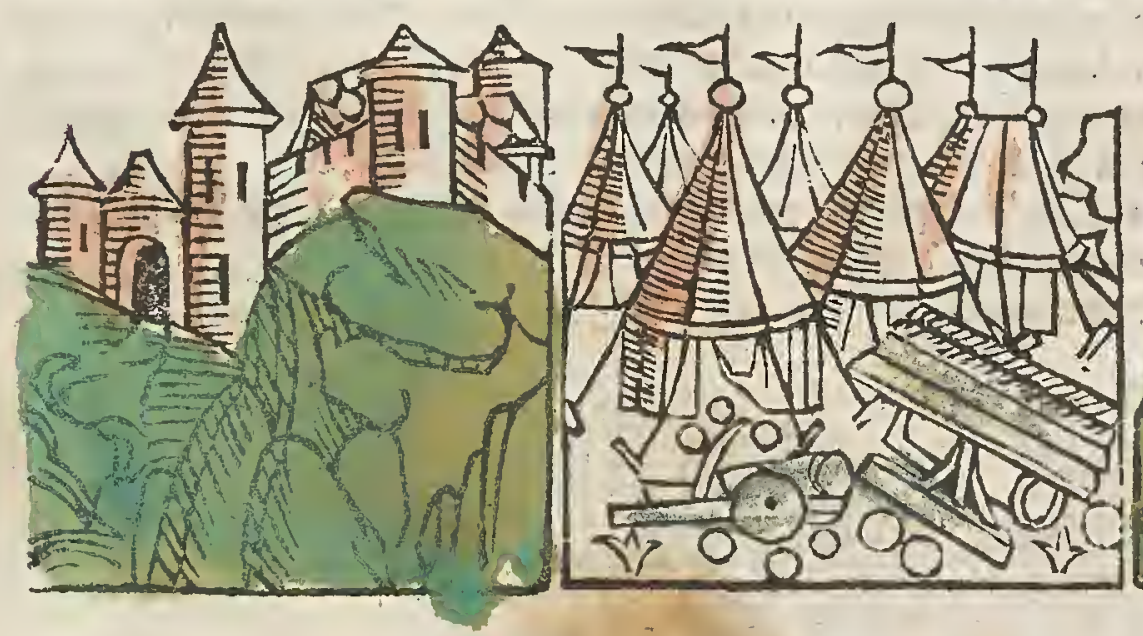

\section{Egrptus z apbzica:vaftate a faracenis.}

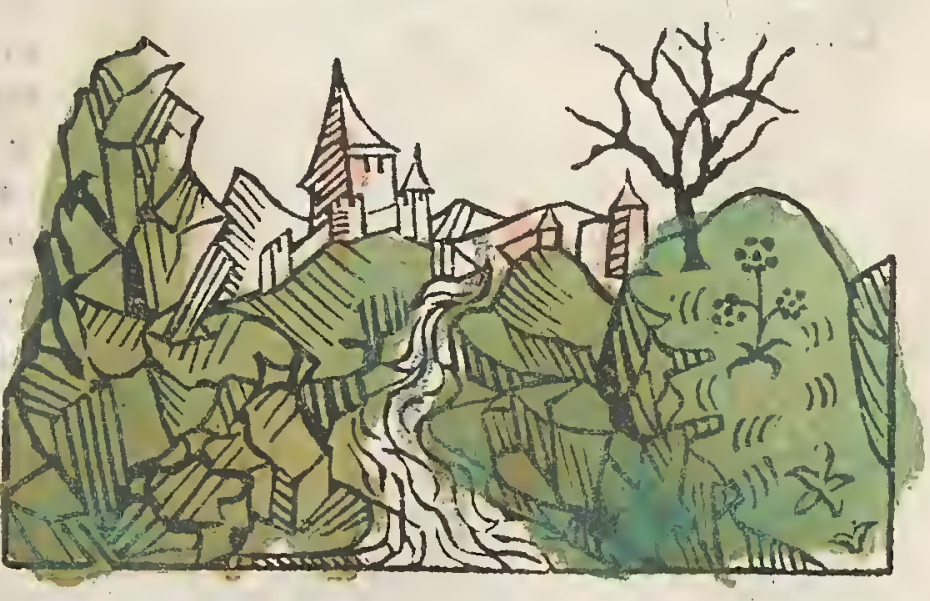


ADlemalale circe bectparecuperst Q karolic cum rots rerra reã:z rarace. nozum fectavbic peflatatrocit: $\mathrm{g}$ pós míferationí vêi

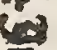
을 agftenicbe Po2"suar' fuit plefgleft:fuit asad impiū

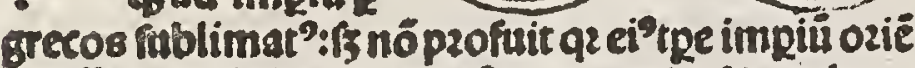
tale äfi ad ribil redactuł ef r romani ad karolum magnůfe pnanimiter contulentut.

QDgerus our oe oanamarcbia pinceps xpianiffi. mfiozut. Dic re karoli magui rṕpianitati obtinut fere oés pres tranfmarinas s bierufalem viq ad arbozes folís oeofibi propitio: 2 sptio r magnio miraculis exercitú cöforts.

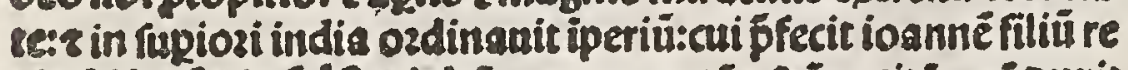

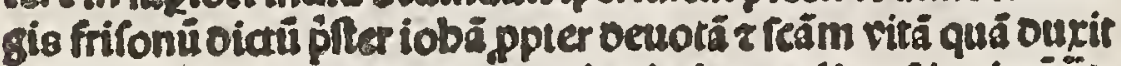

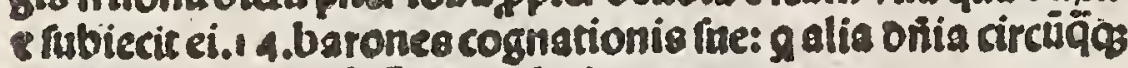

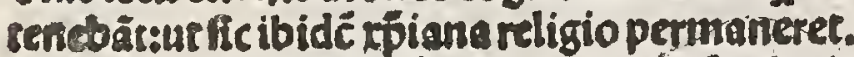

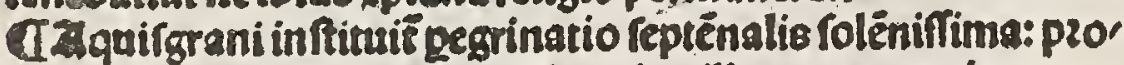
pter reliquiss pzecioras ques karolus illuc appoztauit. I Zlmelius comes aluemenfis gener karoli mertyr.

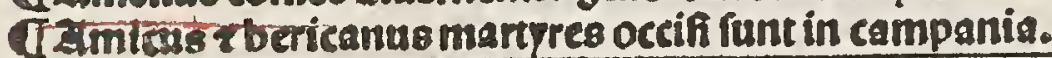
cos ci vmanimi Jenta guere ac oés ås lẹe romanozü iuftis z neceflarijo caufie rat auaritia niche. p'longä patiêtiả ecclie oei:q̄oiu gre.

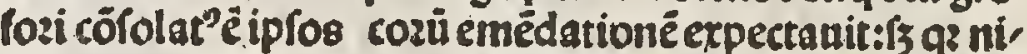
oitando. mis offeceitapmo zpietate oimiffít đÉberbard'our bataric in panno. nia cögreflus martrriçá.

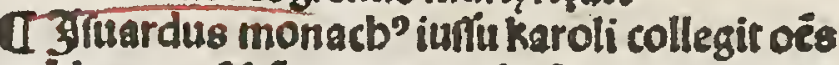
legểdse ract'fcōz oe toto ozbe i vius volumen p’bieronymü bedã z flozú: z oi oie cốcurrebant vltra.300. fefta:r ideo inftitutum eftut oicat:. 8 alioppluximax $x \tilde{c}$.

I'paul'o iacon"iuffukaroli collegit lcōes cui. libet feftinitatisueniêtes ex optis oict f frō pp prs Q Signu rubeli orice crucis: 2 multe bafte ap. parueruit. C. Sequit ftrages xṕianoz.

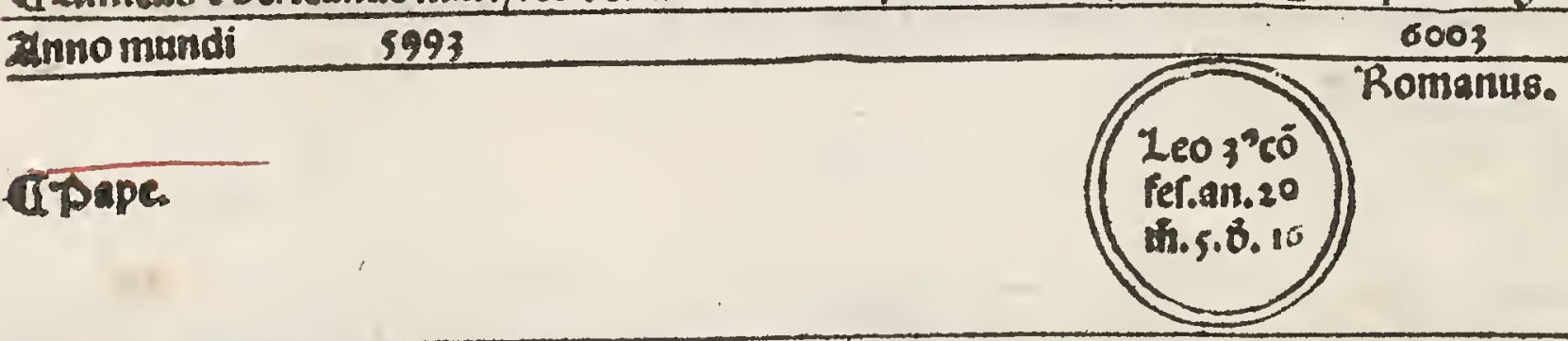

Innoxoi 294

Tharon ré plaz mifit karolo cospus fciç. oxisni gf ferati:s caput fci pantbalconis. a Spines cozons onitiforuit i manu karoli stranfiert ve confuntinopoli parifi? $s$ itrāIntióereligaz:moztu' refurcitat?ggrgrani. ICozpus rci bartbolomei trenfertur bene: netmum oebiosanis.

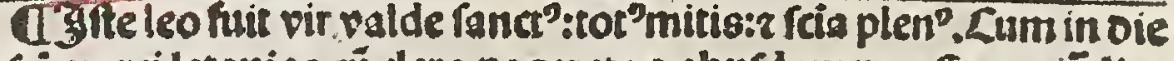
fcimarci letanias cú clero gageret : a gburdam querfis capit: lin guaq pouat? oculis effortis in carcerế mittit. 53 pius oris feruus fuin nö oereligt gnimo p ois cú fansuit:mẻbza ipfa plene reltitué do. Deinde ad karolü prexit in franciă:fingule narrans qu fibi illa. ts effent: a quo etiä bonozifice furcept' fuit: s flotim rex cū eo ro.

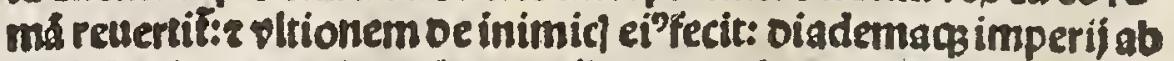
co furcepit:romanio acclamantibus:karolo augufto a oco cozo. nato vitu z victozia de celo fubminiftré. Landez poft laudabilé vith idem pantifer repelit apud fanctü petrü.

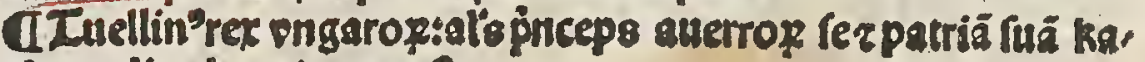
rolo oedit:s baptigatusen.

Dierufalem.

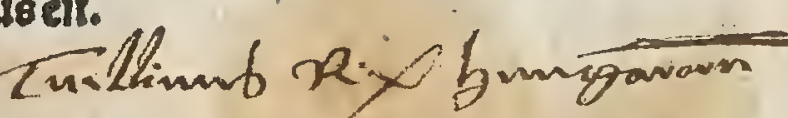

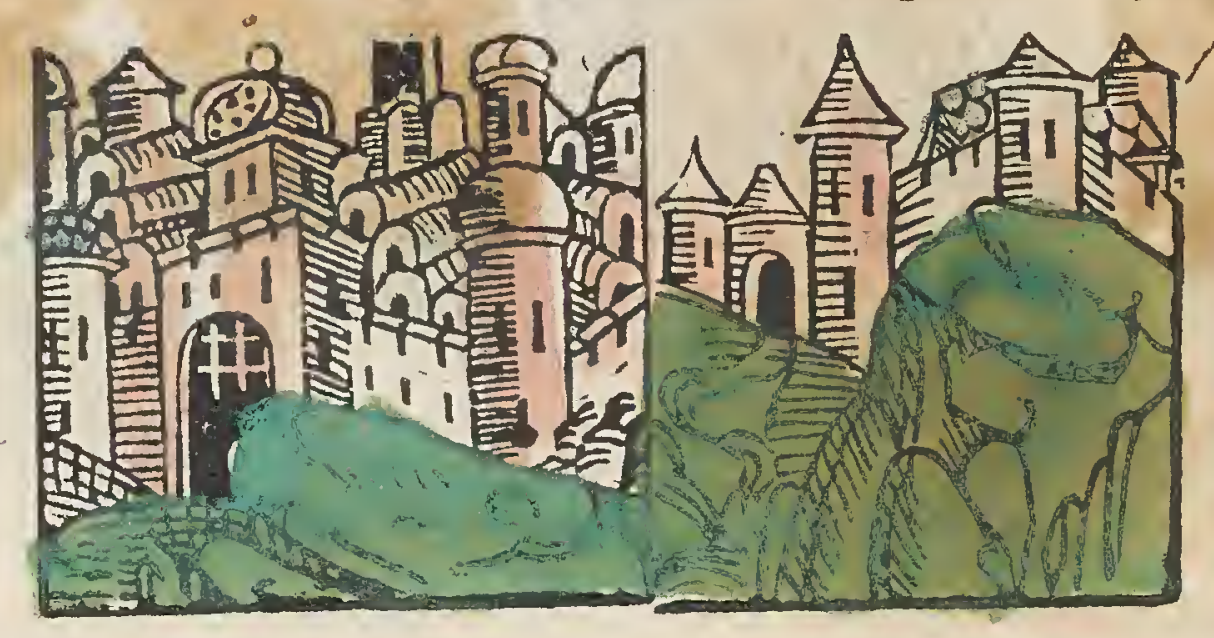




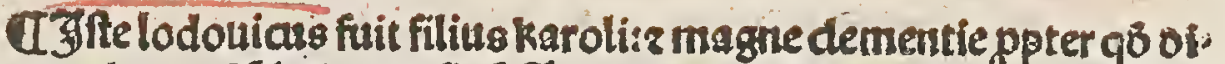
ctus eft pius. babuit duos fratres ăs lugattit: $\tau$ ambo malü babuere fine. In aduerfis patięs erat: $z$ in fine femp

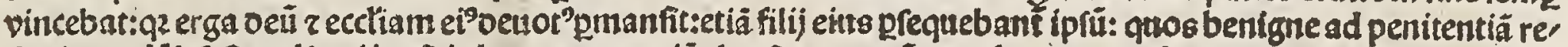
durit.tandē bri fingul is oifpofitis bona mozte oié claufit extremü: $z$ qz bumana infirmitas oelitias oiu ferre nö

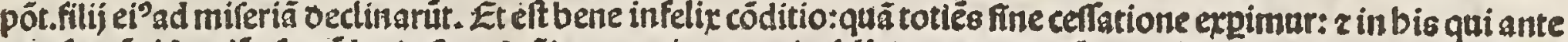

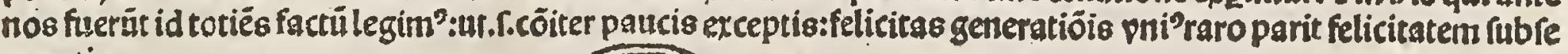
quentis.

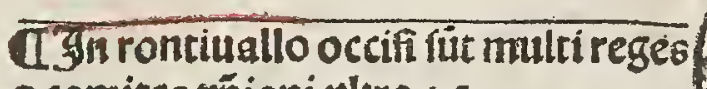
2 comites sp̄iani vltra.15.

I27bilo oe angler.our exercit' karoli pater rolandi cuz multis $x$ pianis occi. fits eff in bello ab aygolando.

US Solftetit fpacio triuz oieriiut karo Lus vinceret.

I Compeftelle ecdia $\tau$ patriarcbalis redes ordingt: rextruit ibonoze ŕi ia cobi.Et iplet petitio marie çebedei: qz ioänes a vexteris apud epbefü: riaco b'a finiftris:roms in medio pulcbze:

UEpícopat'quig ootant́pkarolūma gnifice. f.colonieñ. maguntineri.tretle

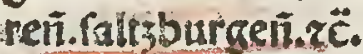

Timonafteria folemia tot fundauit quor in alpbabeto litterebabent: cuio libet vna preponebatur.

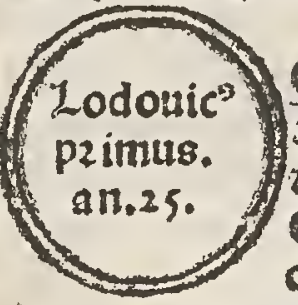

f Rabanus poets rmonacbus p'abbas vulderi. oeinde arcbiepus maguntic:Doctoz magn'claruit:z plura feripfit z ftrabus oifcipulus cius etiö notabilis.

đonoldus rex oano cirea bec tpa baptiçai maguntie cú vroze r fillije:cui impatoz frifiã oedic.

II rantatio plurimop facta eft boc toe. Sebaftiantus $\tau$

I Signa multa ṕcefferunt moztes gliofi r fci impatozis karoli:nam eclypfis folis $z$ lu ne vltra folitü fuit. apparuit p.7.0ies ma. cula nigri colozis î role. pozticus p̃ciofus agfgrani cecidit fuidit? : Pons marim" ma guntiei trib" bozis cỏbuftus é. Letnēs aüt piífimus impator moztë fibi iminere oés tbefauros futos platis cómifit eeclefije oi ftribuédos: zlodouicā p̈mogenitü sfittuit ipatozẻ:aliútbeutonic|:ttiübifpanio ṕfét.

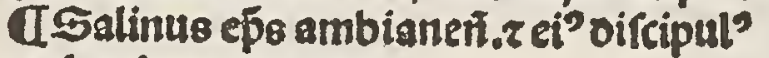
palentianus marty̧tes. gregozi? papa fueflioneri. I Scus marcellinus r pe. trus oe roma in galliätran lati funt. 2 fanctusvitus in faxoniā trautfert:t fanctus palentin'r genefius in au giam.

U. Scirma.8. erat inter et. geniaz $\tau$ fplinniúppter vis rcozdiä eligentium:red eu, genius obtinuit:quia pars maios erat áteo.

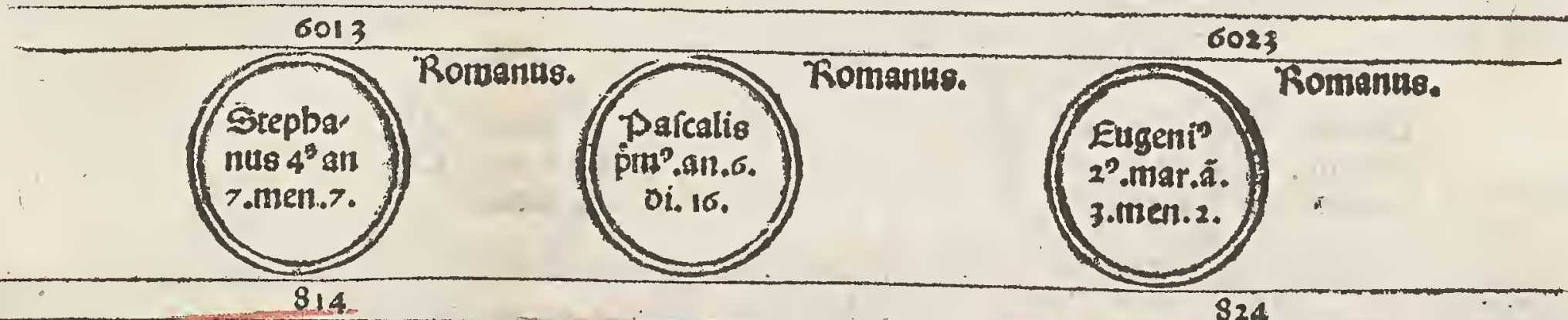

CGfteftepban'mul tos captiuos redemit: $r$ lodoui cui impatozé cozonautit. 2mozit rome:lepult'in ecctîa lcipetri.
CIfte pacalio magnāadbibuic oiligentiâ reliquijs fcöz. Ei inu, mera cozpa facra leuauit z bono rifice recondidit: ficut in pifione rcé cecilie mandatú ábi fuit.

diffe engenitus vir preclar's magief́ci. tatis fuit $z$ fimplicitan:mudi contemptoz: $z$ fola que xṕi funt:fapuit. bicmartyrio cozo. natus eff $p$ laicos romanos: feptiltus in ee, clefia fancti petri.

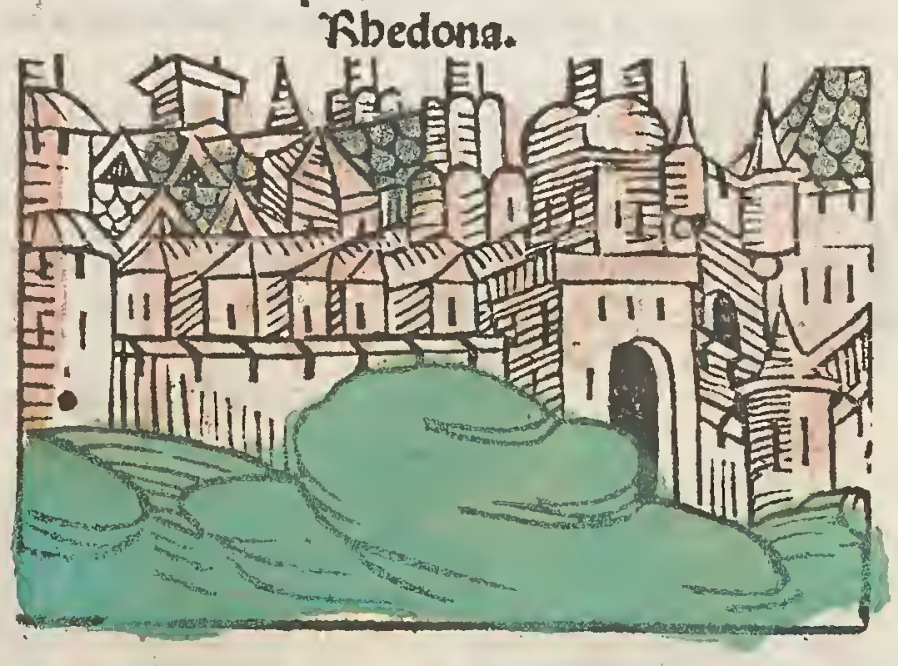
T'Rbedona ciuitas:bis tpibus a lodouico fupzadicto inatoz in eã cü multis copijs ingreffo:totã oetiaftat ferro z ignibus.

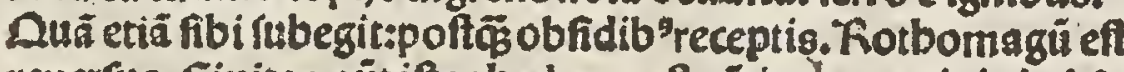 reuerfus. Eiuitas aút ifta rbedona:eft cōtigù terminis bzitā nie. Sequenti apt anno:in territorio angulti queneint:aere in

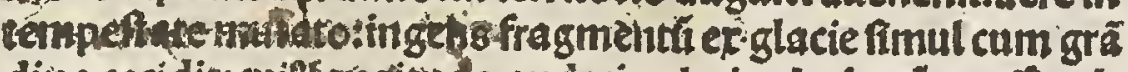 dine cecidit: cui"tongtudo gndecim:latiundo feptë:groffitudo

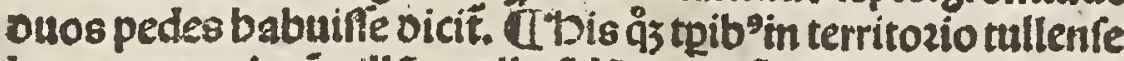 iuxta comerciacū villä:puella ădä annozū circiter. $12.9 c c e p t a$ cöione in parca pomogs abftinuit a pane: beinde oib?alifs cibis z potib?alifig nutrimetis cozpis:z fine oi victus oefiderio:ple Aur trienniú cóplenerit Dnotge engenius papa oecefrt. 


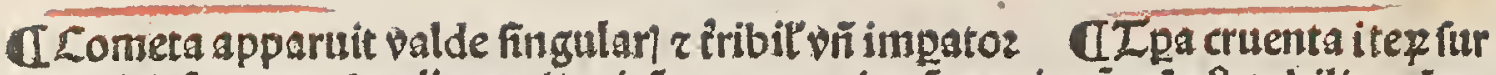

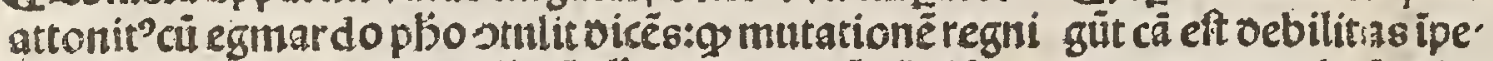

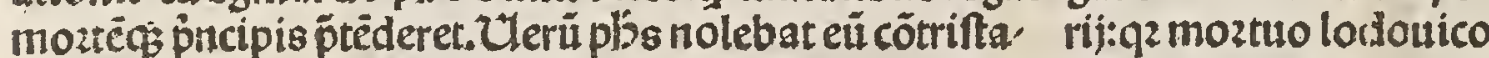

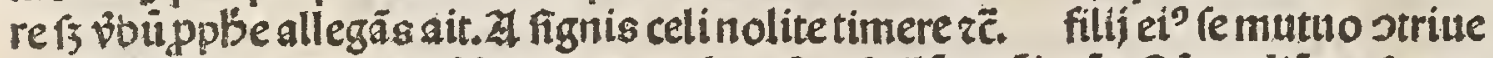

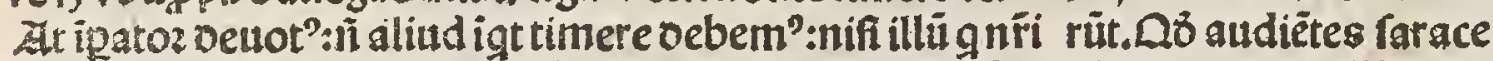

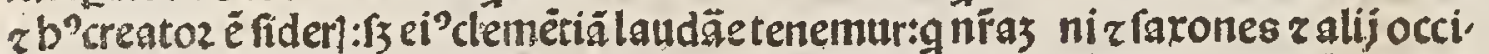

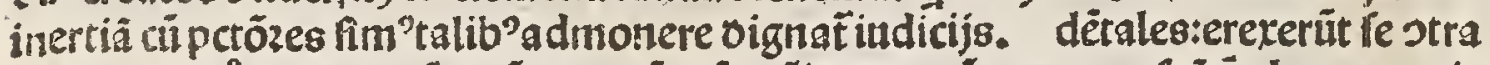

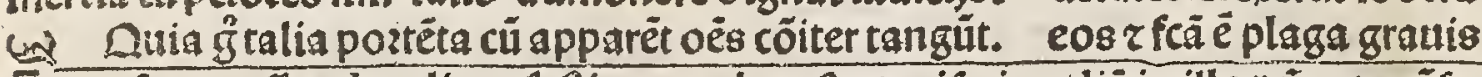
oéspoffead melioza fêtunare jebem":ut mifericozdiā in illo oñante cốre qui valeam?: $z$ pie credit $q$ bac büilitate orim placauit:qz nó fup eú tūc pla

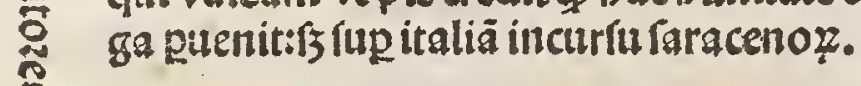

U Arnona oe celo pluit i tarconia frumê to fimilis:bis tri grana breuioza.

CIepeftas maxima ozit in gallia: $r$ ter, remor? $r$ multe ville $z$ oomus celefti igne cremāt:boies r iumẽta ictu fulminú era nimant: $z$ cü grädine lapides imeêfi ponde ris cadüt: $z$ fragmë glaciei oeicēdit cuitus latitud 0.6.pedum: lógitudo.16.altitudo ouorf fuit.z peftilentia magna fequebat. CDionyrif fei ooctozis libzi funt tranflati ve greco in latinũ:quos micbael impatoz mirit lodouico: 2.19. egroti fanati funt. 'Tnê.6.mentib'in pane zaqua ieinnauit. Deinde $p$ triennili oino abftinuit ab oi cibo r potu. Annomundi 6033

- Sape. $\left(\begin{array}{l}\text { Ualétin" } \\ \text { men.10. } \\ \text { roman" }\end{array}\right)\left(\begin{array}{l}\text { Bzegozi } \\ 4^{2} \text {.an.16. } \\ \text { roman". }\end{array}\right)$

स्यno rōi. 834

đ?fte gregozius moztuo valentino:q bzeuiter $p^{\text {? }}$ electioné e medio fublat' fuit:eligit r multa fecit viditas triftia toa, pptervarias plagas graflantes i pplo. 'bic multo 2 icö cozpa leuäs oe tra bono rifice repofuit in altaria. Ei $i^{7}$ petitióe lod ouic $c^{5} ?$ guido marcbio lombardie faracenos de italia fu garunt.

Trabozí tandê poft inumerabilia bong oga eo

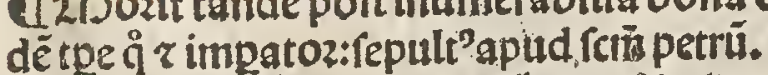

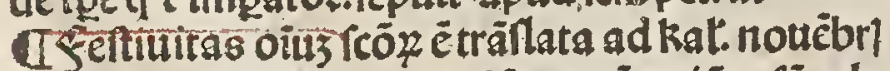
pgregl .4. z galli z germani iceperît etiä ipfä cele bzareb tpe:zbĩ frmo rabanioe codē fatl pulcber. nia:imo vltra mare ž̈. lodouici:p
monacbus.

a Gifte lotbari' moztuo pre iperituz fumpfit. büitaz ouos frē . C. lodouicuั $\tau$ karolü ẩ nitebat excludere ab beredi tate paterna: 15 illi 5 ens boc bellü mouerüt in quio tot $a b$ vtraqs pte cecideritt : $q$ file in

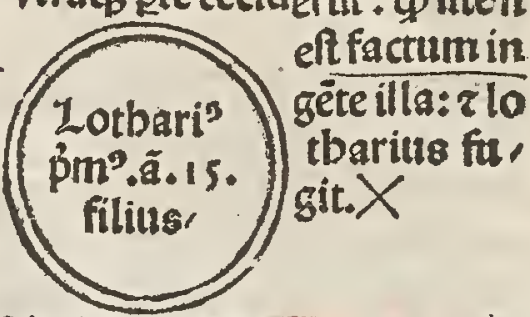
eft. Thã gdã pfidi xp̉iani míerüt clāad loldanú faracenoz:ut cito veniret. Et roma capit́:z eccle

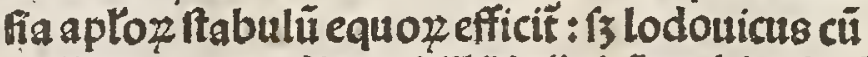
gallis z lombardis totâ illã infinitã multitudinē fugauit nö fine multa fanguinis effufione xpia no ż. Et ficiliã rapuliã etiâ boc toe faraceni va. ftarunt: $z$ tufcia in folitudinē redacta eft. đ. Slia laus a bonoz fit tibi rex xṕeréc.cóponit a quodã eṕo captiuo in fefto palmarú : pzopter

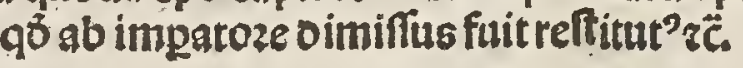

CSaracentoeat frica veniëtes irey romã inuadunt: $\tau$ eccliss aploz oe? boneftarüt f́poliä tes vndíg ré.re' deütes aût cǘpo lijs fubmerfi funt $i$ mari.

\section{IDHodeciouces}

bobcinoz rütba. ptiçatipcuratióe iodo uicifratris lotbarif.

I'Radulpbus éps biturieĩ. claper fanctitate. 6043

nomë erat inboneftú z răte oignitati incótieniens : iố inutato noie fergi? vocari elegit. Et ab ifto in antea oés ppzius nomen

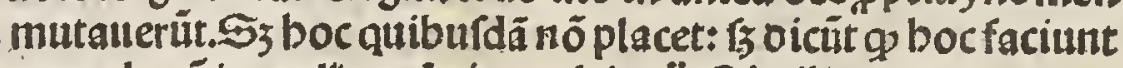
exemplo xp̆i gaplis noia impornit zc̈. Similiter $z$ oe patriar chis z bec videt melioz ró bui pariationis.

Uballia pene tota vaftat a nozmannis z frifonib": $z$ alijs cir cücirca cōcrematis ciut tatib ${ }^{9} \tau \ddot{c}$. 'Dic iterü nota mutabilitates tempo 1: q2 g longa tpa galli triúpbatozes in ozbe fuerunt:bic pfternunt: nec viö poftes ad pziftinã redeüt poteftatez $z$ glo, riam. Dominabant in italia:in germania:in bifpania:infaro

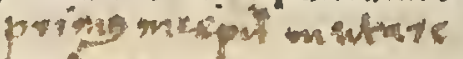
hesicy

TRoma inuadit:z oeftruit a faracenis.

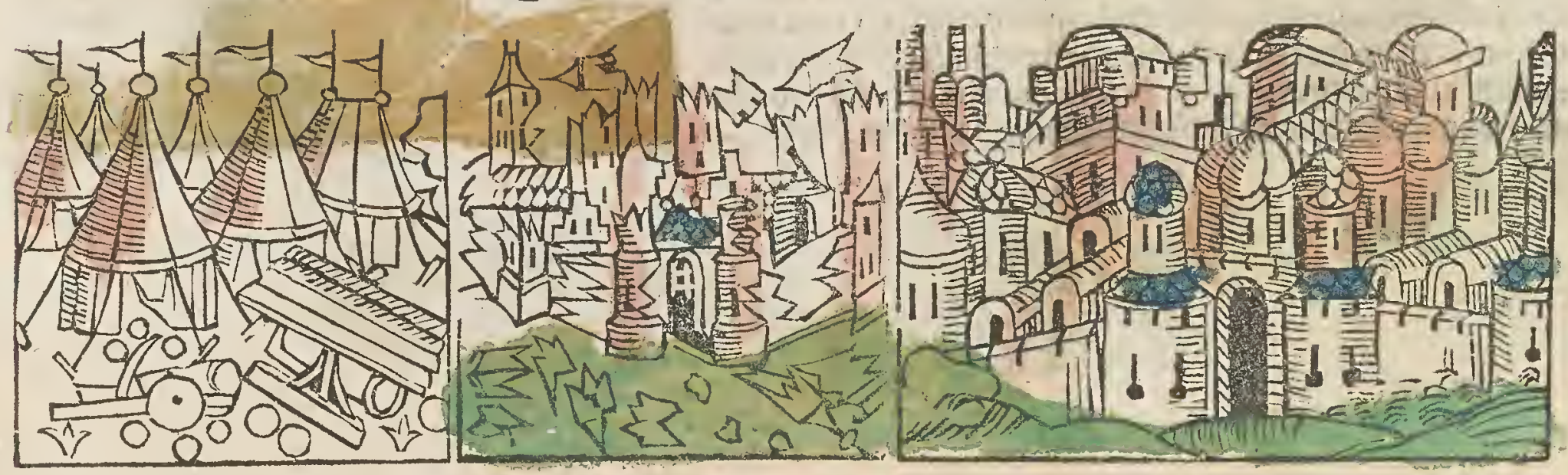


XQuidam aút magnates $\cos$ cöpoltterït regna ointdendonec valuerūt refiftere aduerfariis fuis:pzopter banc

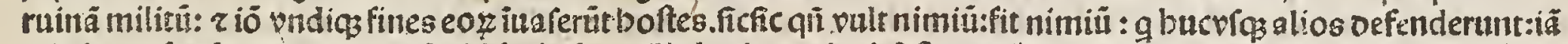
reipfos oefendere nequetunt. Quid faciet bunilis berba oeferti:fi ftarenö valet alta cedrus libani:Dia fac cui có filio:alioguin penitebis poft:\{ł tardé. bic eft grande exemplü:tandē lotbarius renücians feculo monacbus effe, ctus eft:in cui' ob itu fuit magna cöcertatio inter angelos z demones: $\{5$ ozantib' monachis oemones fugati fiit.

TLeonina ciuiras iufu leonis edificat:ad oefenfionem GJfte lodouicus filítis lotbarij fuit a fergio papa in ecclefie fancti petri pzope romam.

Concta belena impatrix tranffert a roma in franciam TDctalie gftumptionis bté marie inftituunta aleone. f Sonctus bermes tranflatus eft in galliam: ff uozare vellet.

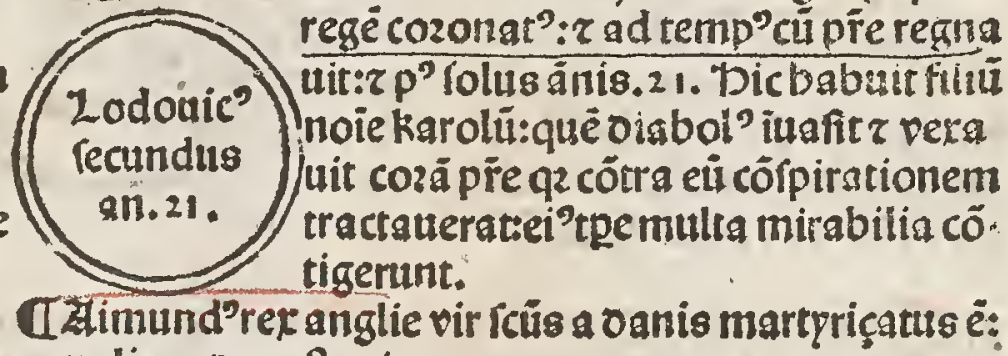
rangliam oeuaftauit.

Utzỏgntradue beremita martyriçatur.

U20Daguitia circa bec tpa in magna afflictiöe fuit per

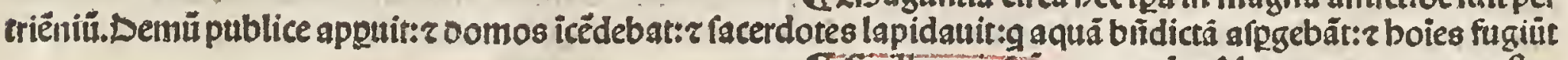

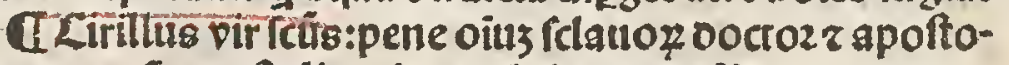
lus cozp'lci clemétis pape repperit in crifona mari exicato. $\tau$ romä tranftulit: 2 fua ecclefia reconditur.

CKozpus brï innocentij boc tpe:a valentia bifpanie ci uitate:p quendã monacbū in galliã oepoztatü ef: $r$ apud monafteriü beati benedicti in gallia:qð̋ caftrü vocatur fitū in pago albienfí z conditu. T'bocrpe etiä a btöleone pontifice fubfcripto edificata fuitrome ecclefia:que

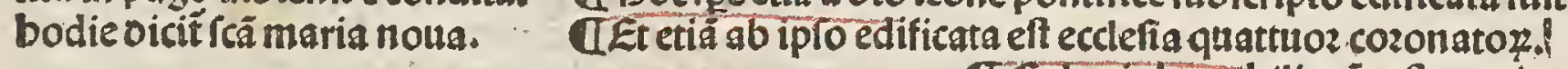

A Lolonie bozzibilis tepeftas ozitur: r fulmen ecclefiã fancti petri fcidit:z, tres interfecit boies:z fex feminiuos reliquit:babuit fozmam oraconis.

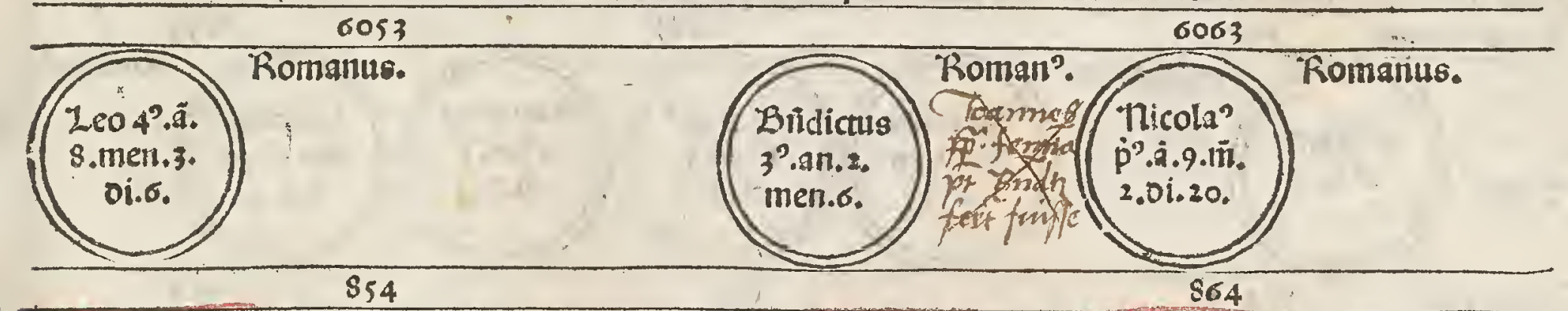

Ifytte leo vir faus fuit:in quo z ferpentina pzudentia z collumbina fimplicitas babitauerüt:in monafterio

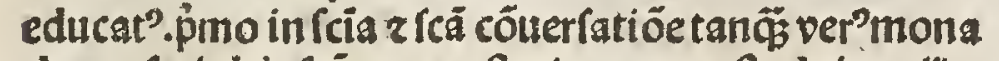
cbus pfecit:bic fcüs papa ftatim repare ftuduit ecclias

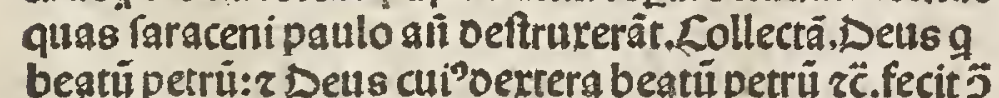

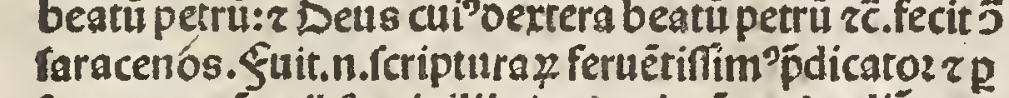

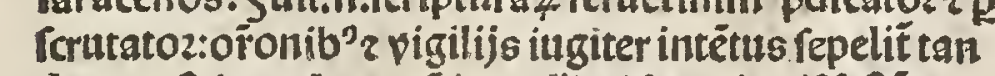
dem poft fanctã moatē in ecclia fci petri cui?feftū. I7. kalendas augufti agitur.

\section{Leonina cituitas.}

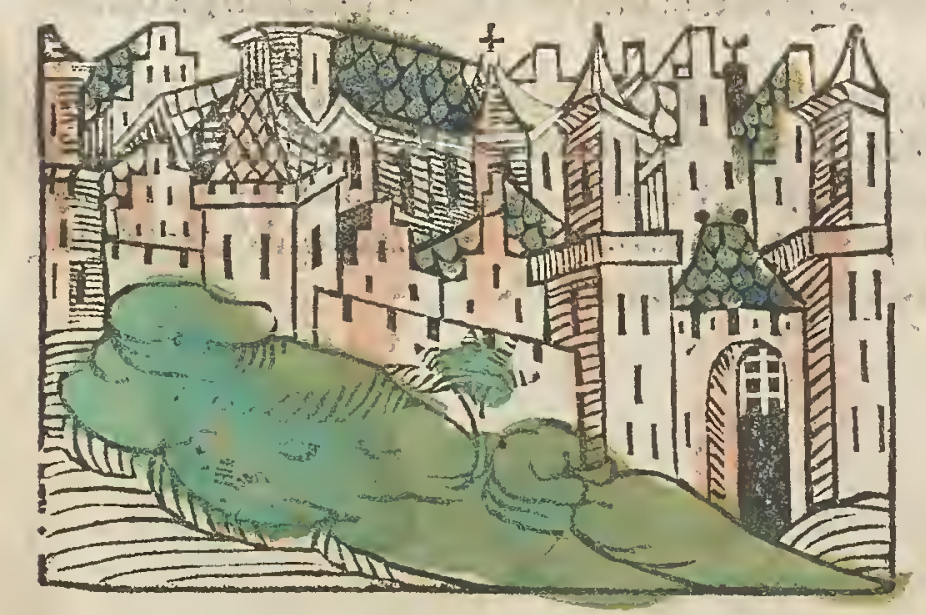

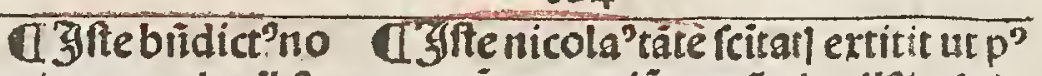

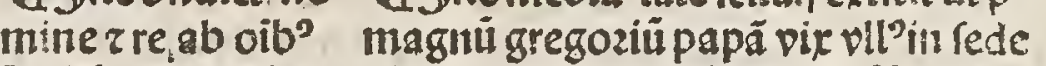
é briflim?oict?. bic röana appuit illi cöparäd?. Tn ei?or ftatuit ut clerici o2 dinatióe lodouiceprĩs fuit:tandé pon

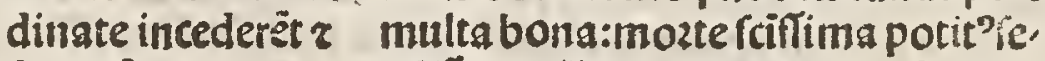
bonefte. pelit in ecctia fancti petri apoftoli.

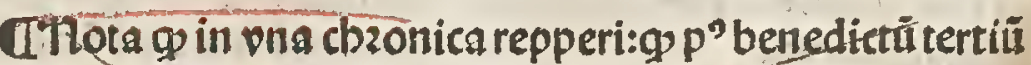
fuit quildă oicus ioannes papa:z fuil fentá z meretrix oc culta:z fuit oeanglia natione. Zhthtift alir écclefiả exiftẻs i babitu virili:pfundus tĩ̃ in cia: a legit p̉mu atbenis: De. inde rome: $z$ oemú $g$ ffumptus ad pontificatü. Landẽ:ftur pro cü amafio fino cömiffo quépzilıs babebat:peperit in.

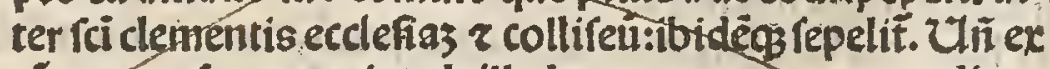
túc: papa femp oeniat ab illo loco: pzopter verecundiam ritue oeteftationem peccati. 
TIngtis pluit oe ceto i italis crib' vicb': 2 locufta galliã oe uaftat:ficut olim egrptü z fegi fames valida utpene tertia 18 boiny ibi coftipta fit $r$ fic addit Doloz finp oolozégallicis:quia

bellis laceliti 3mpatozes. iấfamectiam

xonia villa q̄dâ:cü oib'penit? abrozbet in mométo:cu ecde' fia z altari z domibuszē.

TDulgarop rer cus gentefua

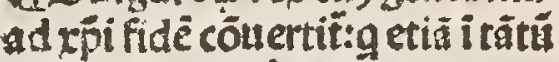
pfecit:ut oimifo regno mona. cbus efficeret. fili?aüt ei’apo faranit: quare refupto regno: ipfú cepit r ocul efforfis ipfü in carcerattit: $z$ aliú fubftituit: ac facrü bitü oib' pacat t refüp fir. IzDimen'rer baitonuma rcó inaurilione interficit: ou fran. ciam vaftaret.

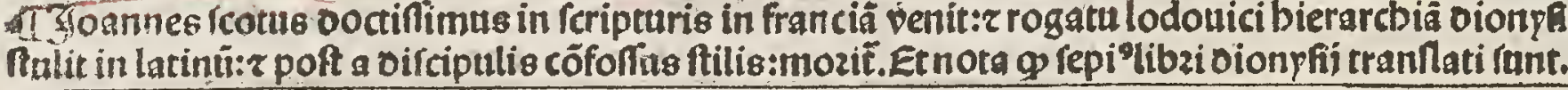

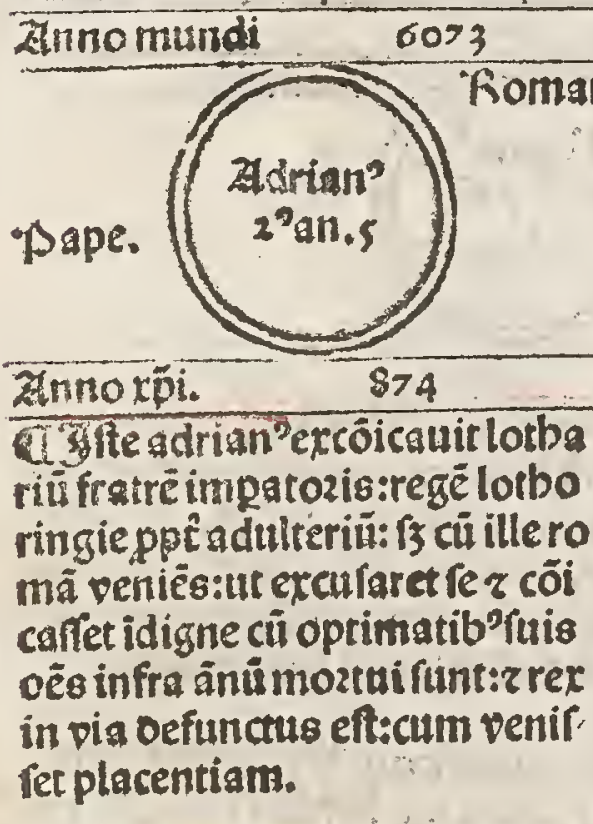

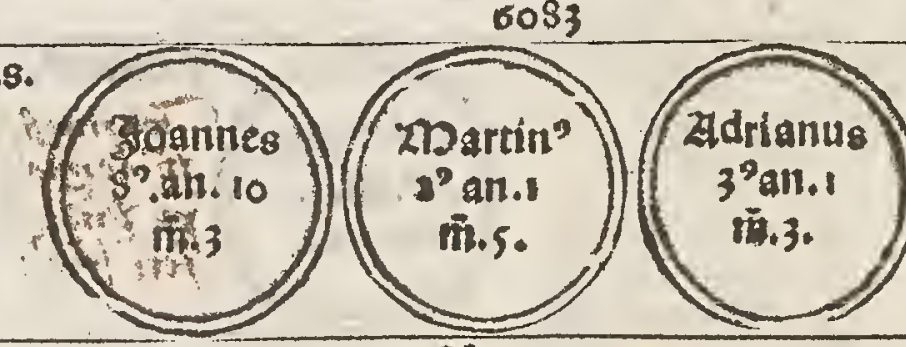

884
C.3ftekarol"oict"ë grofits

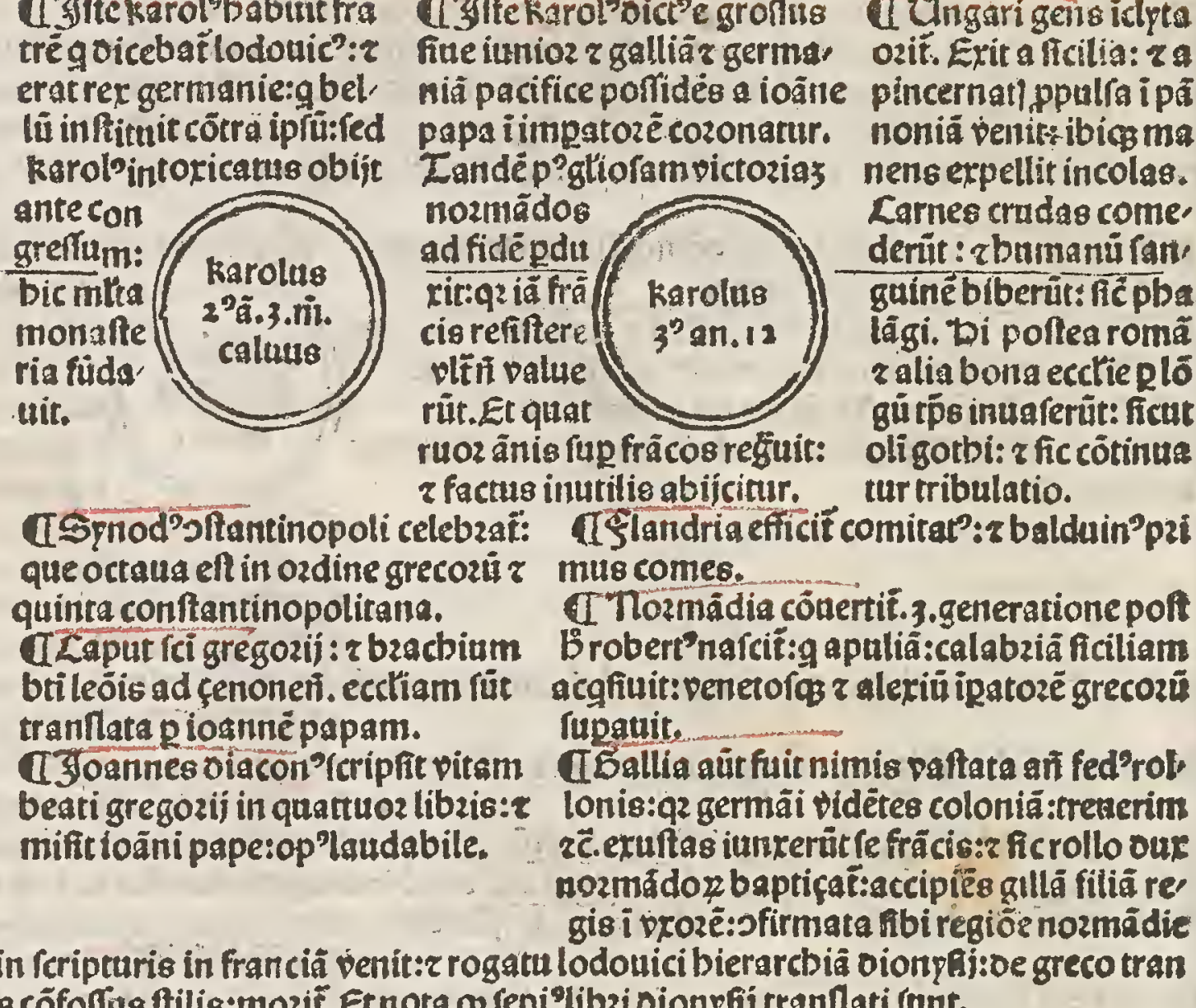

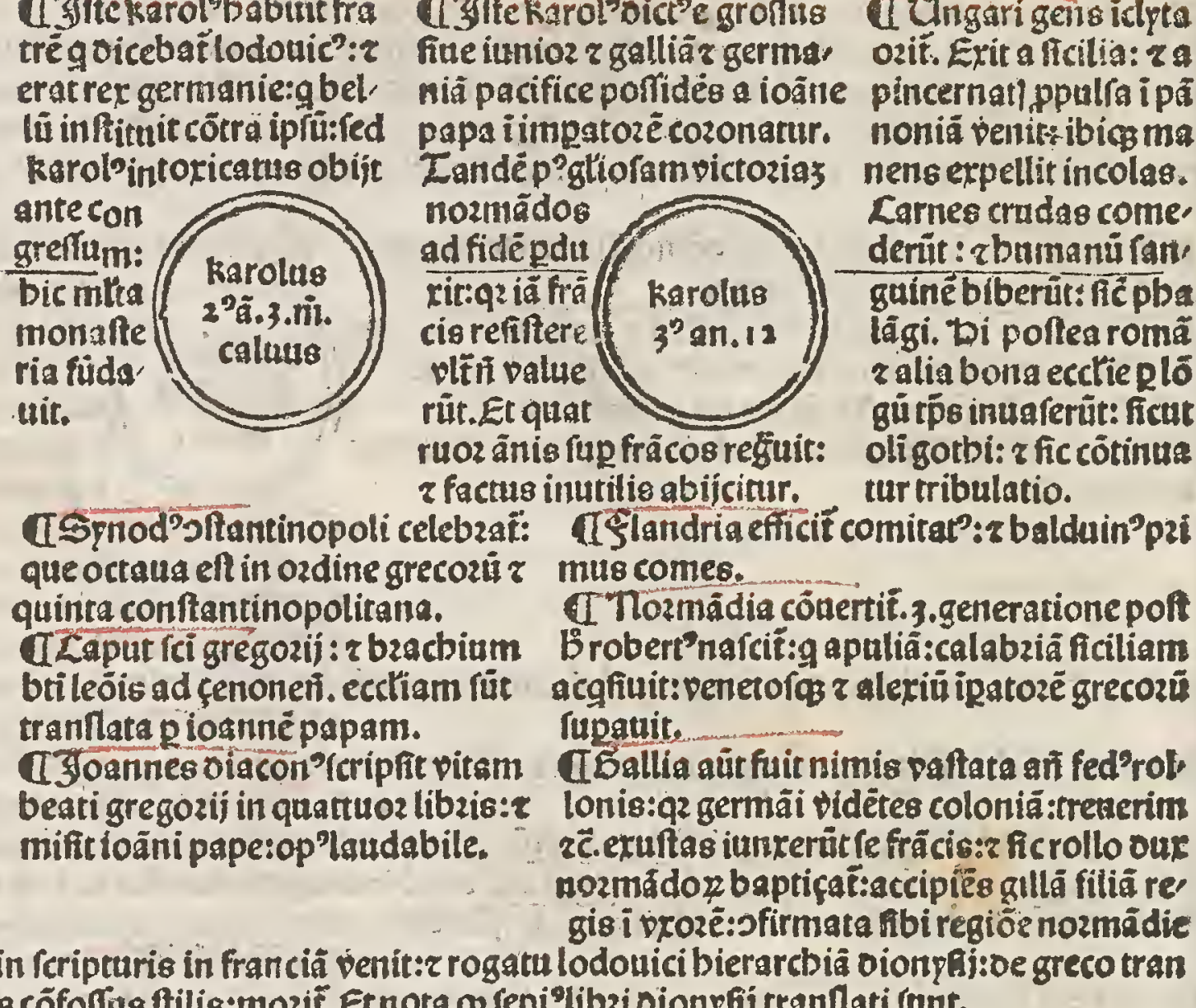

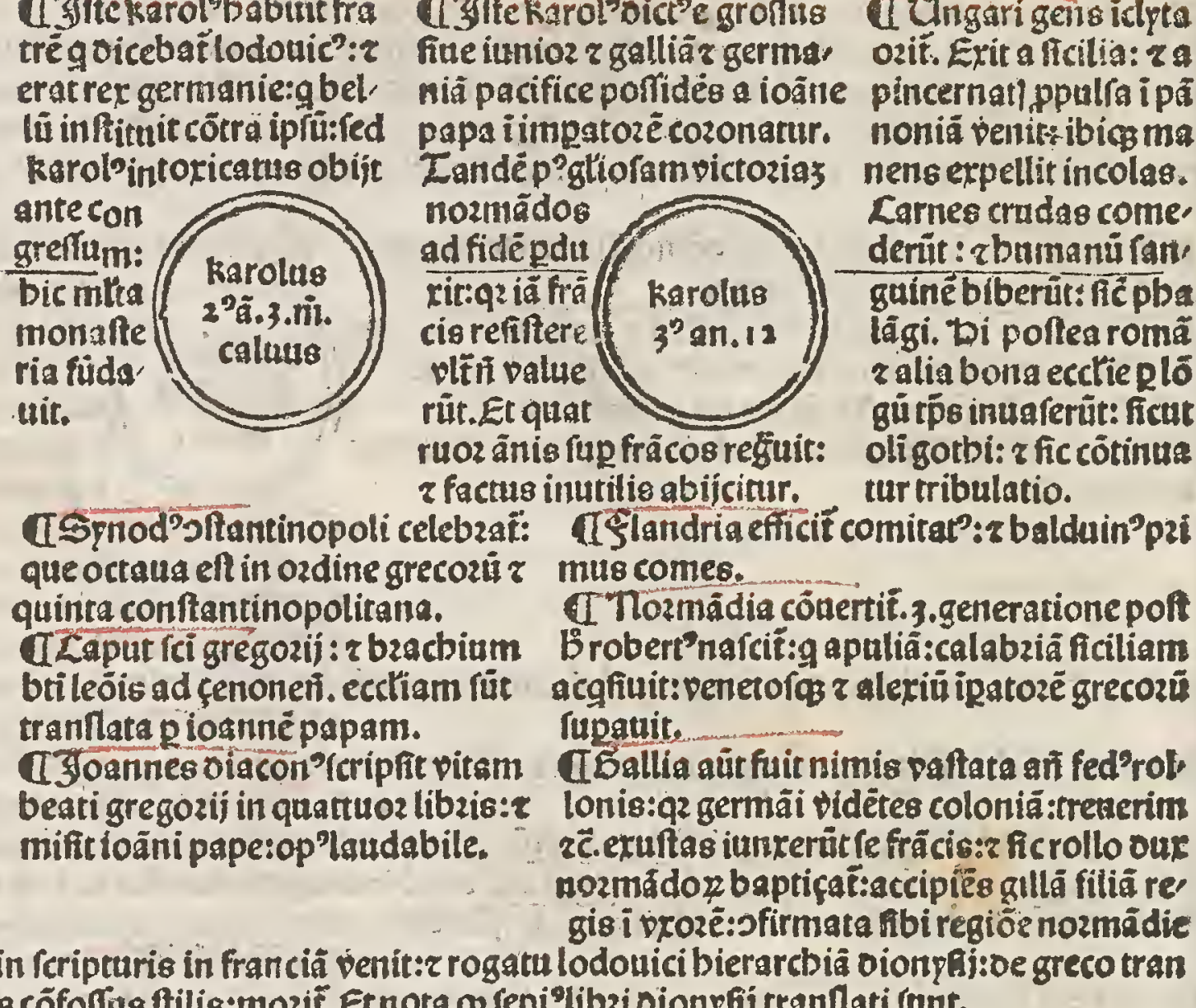

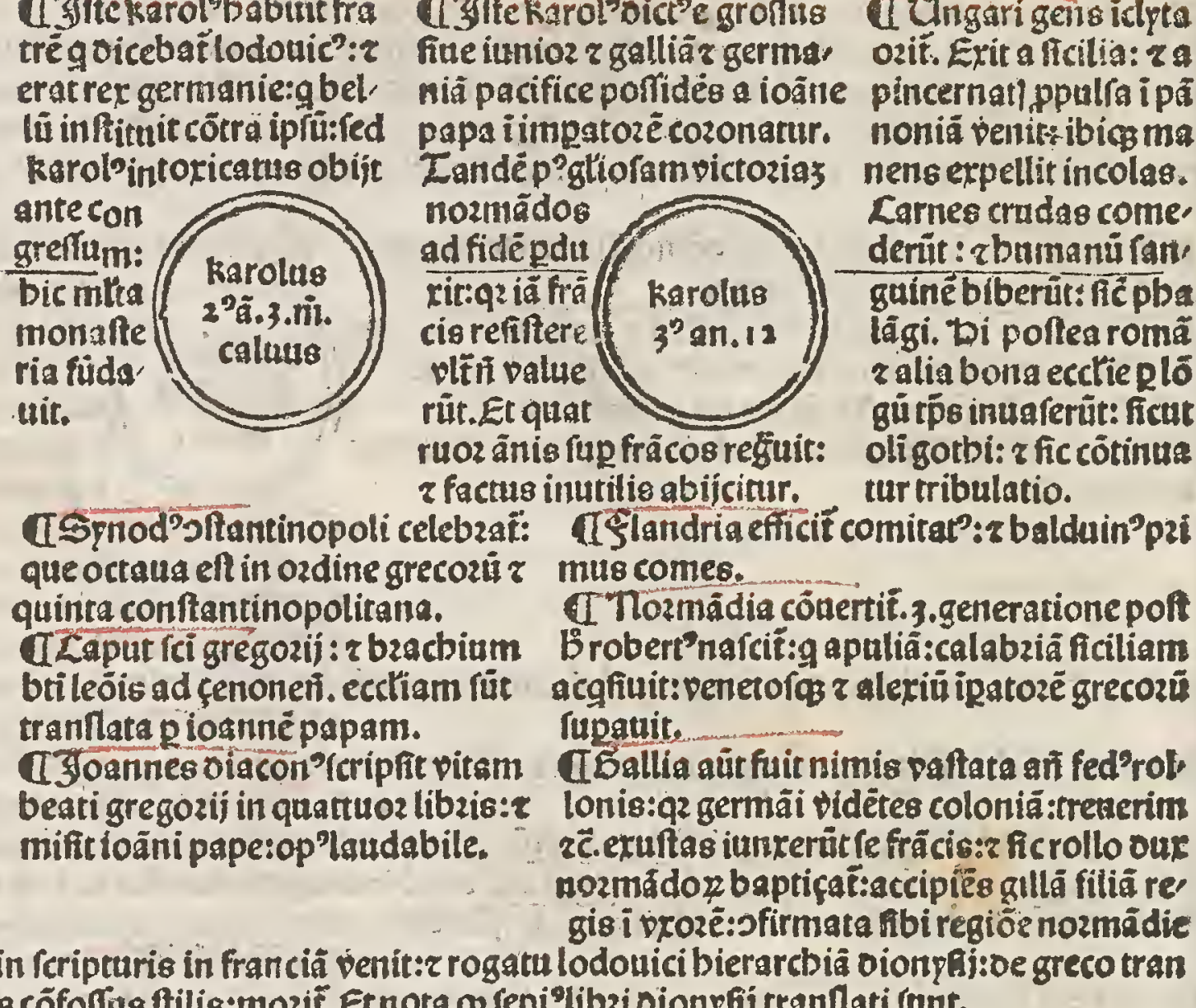

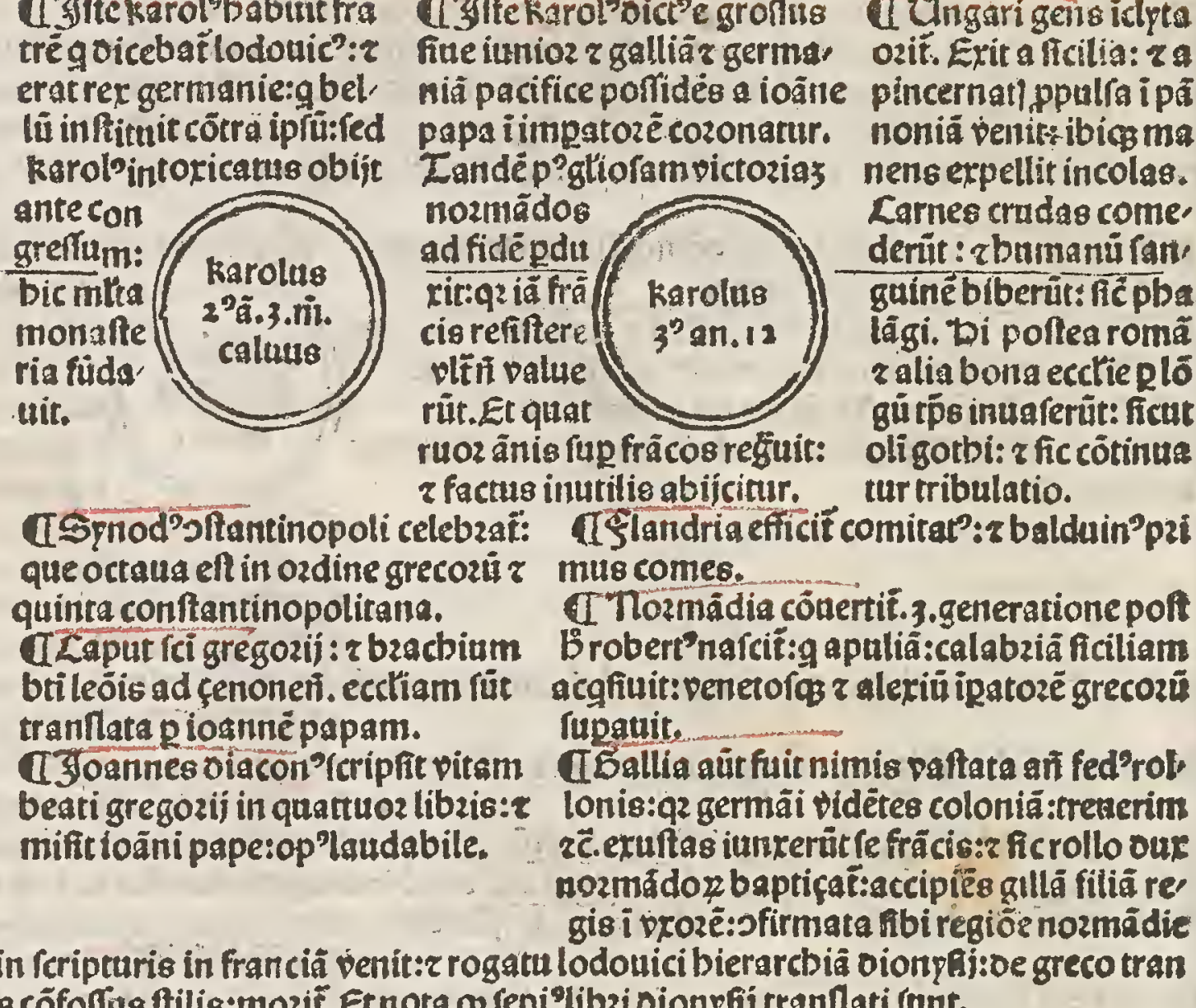

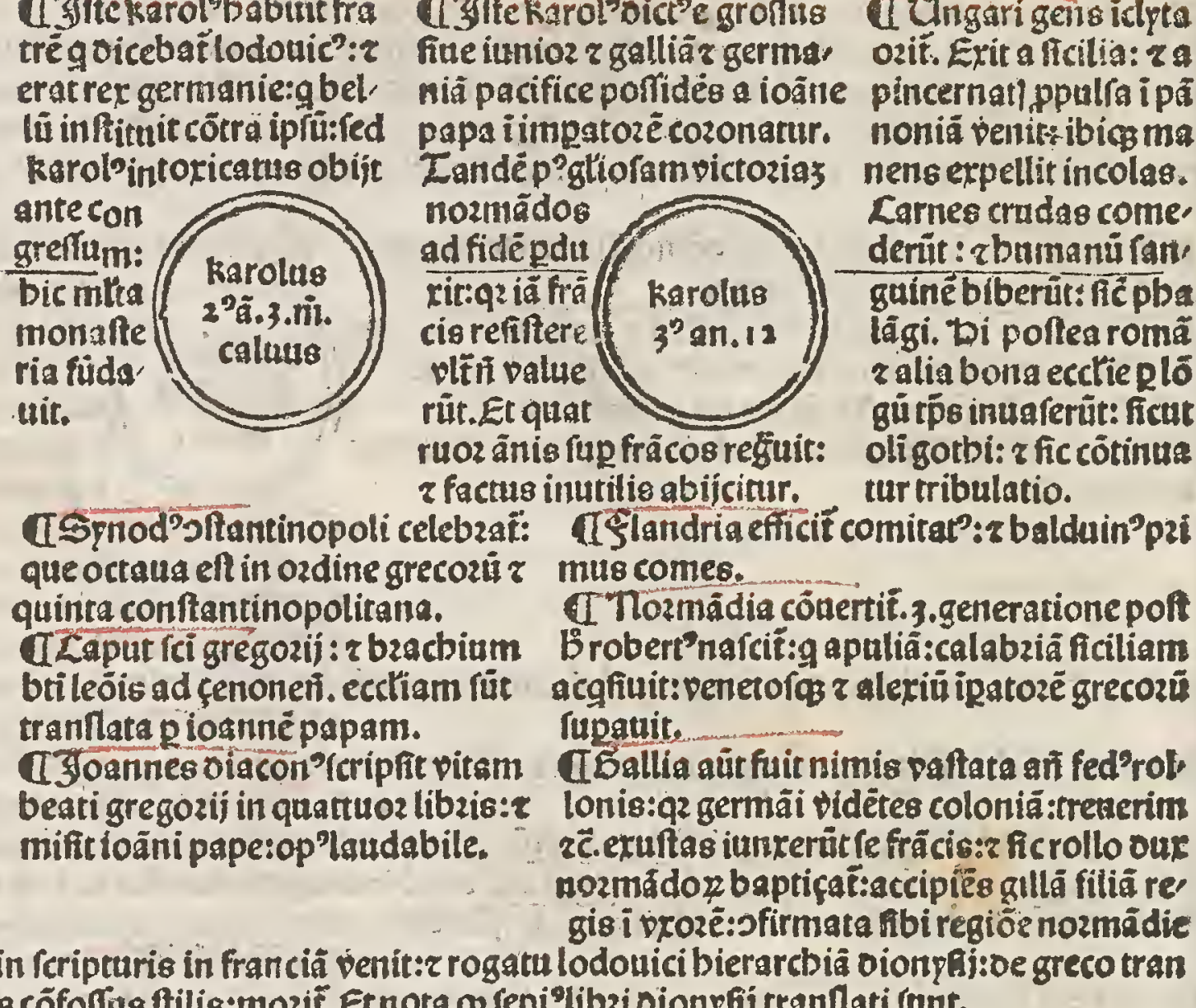

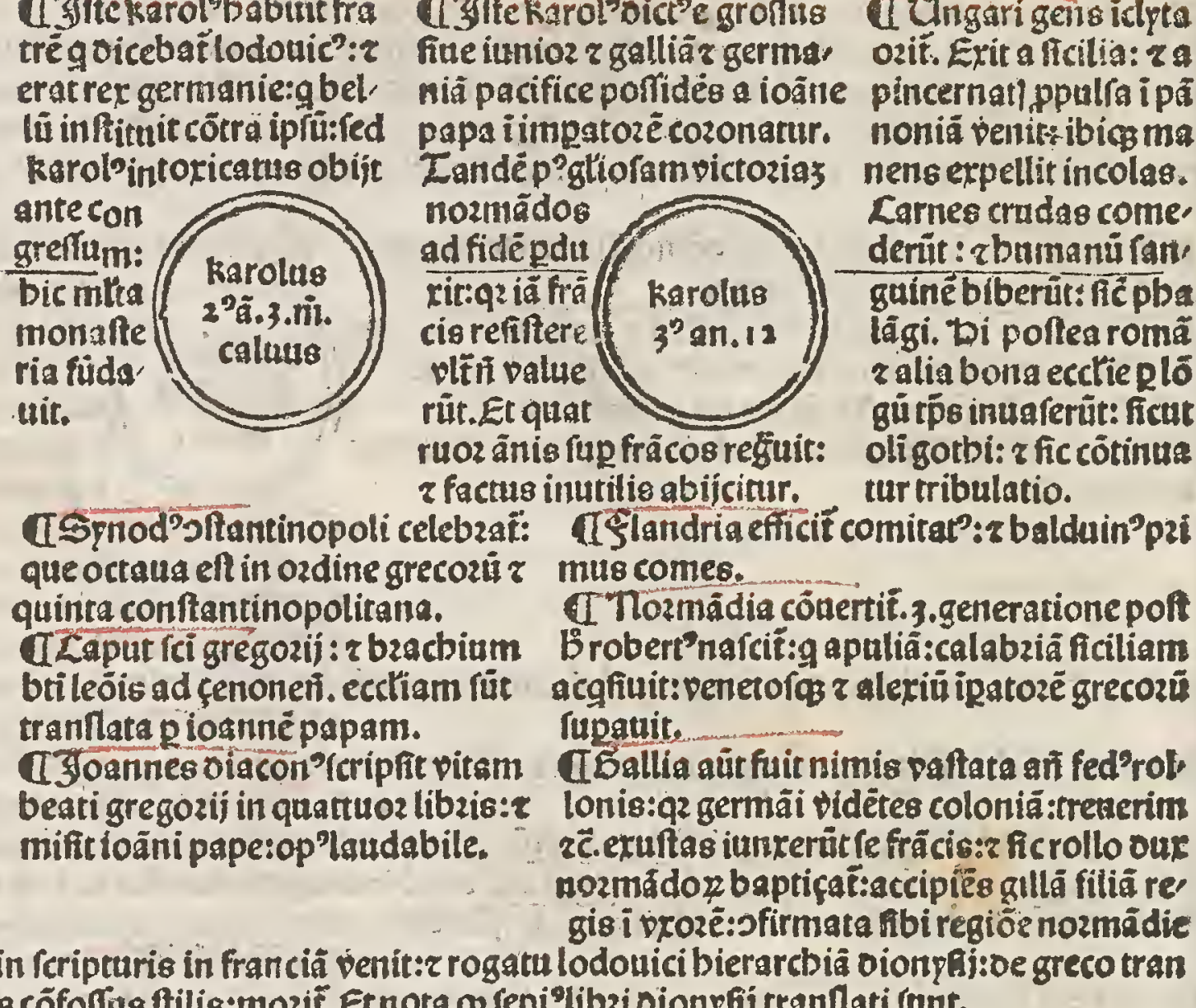

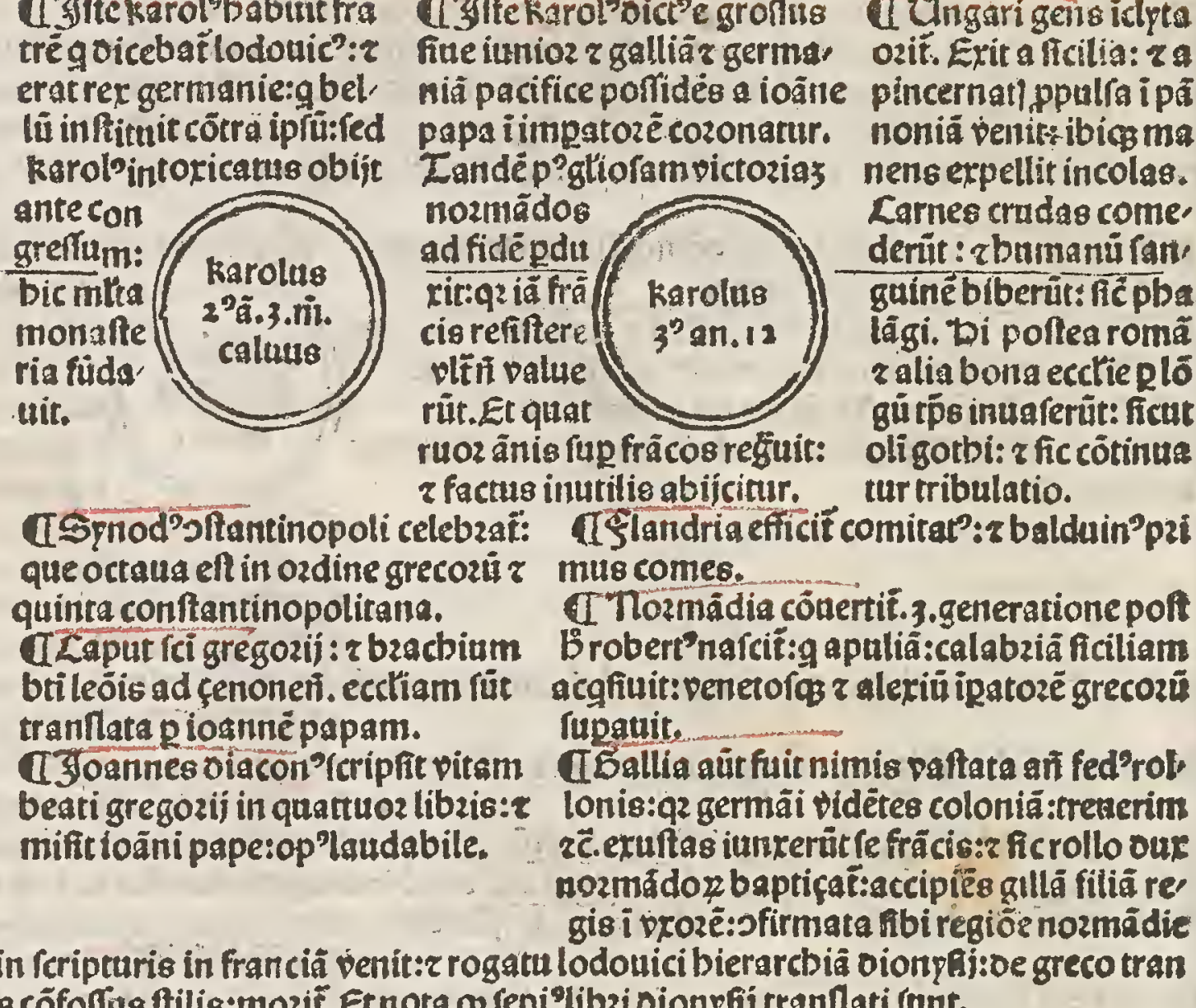

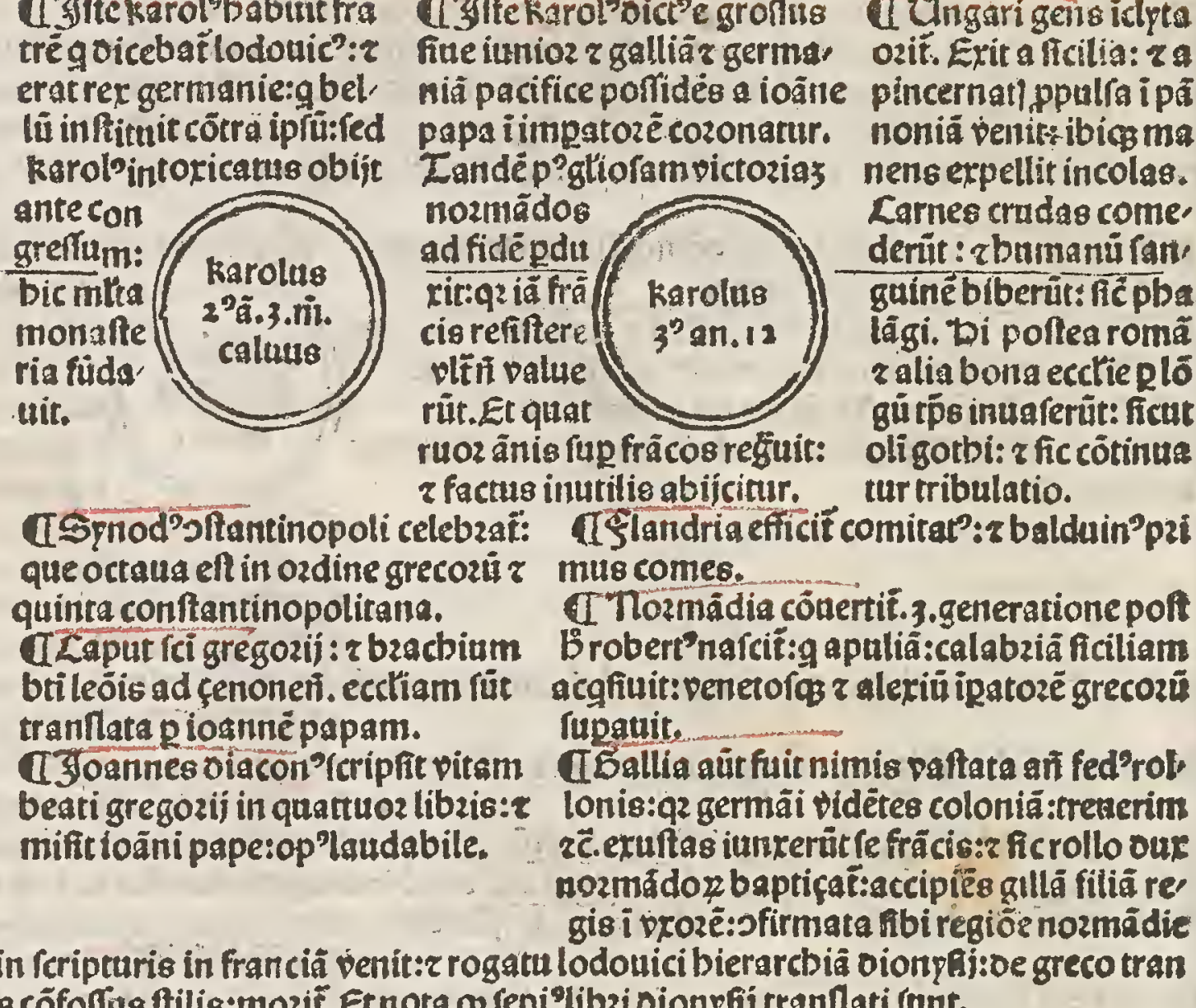

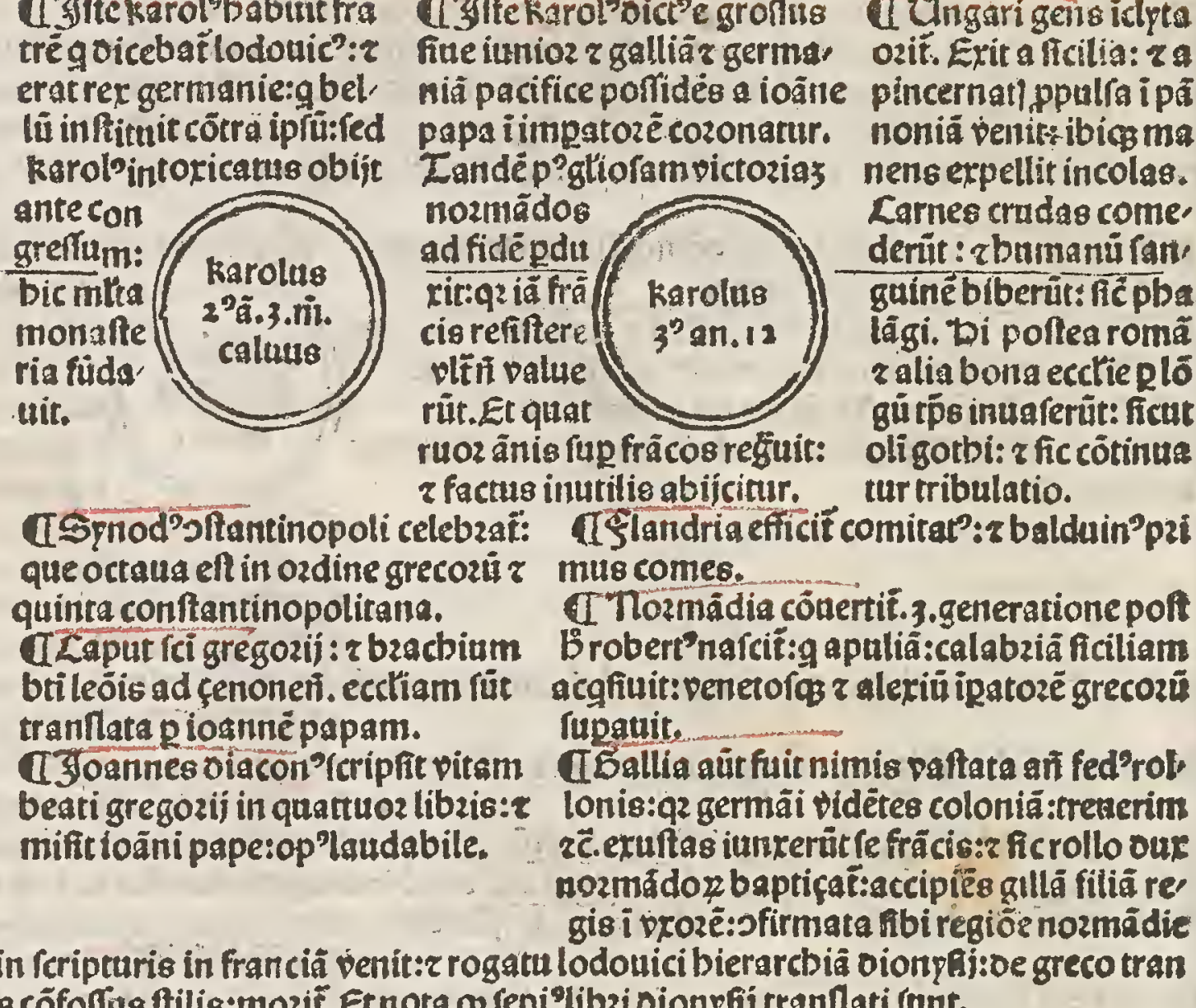

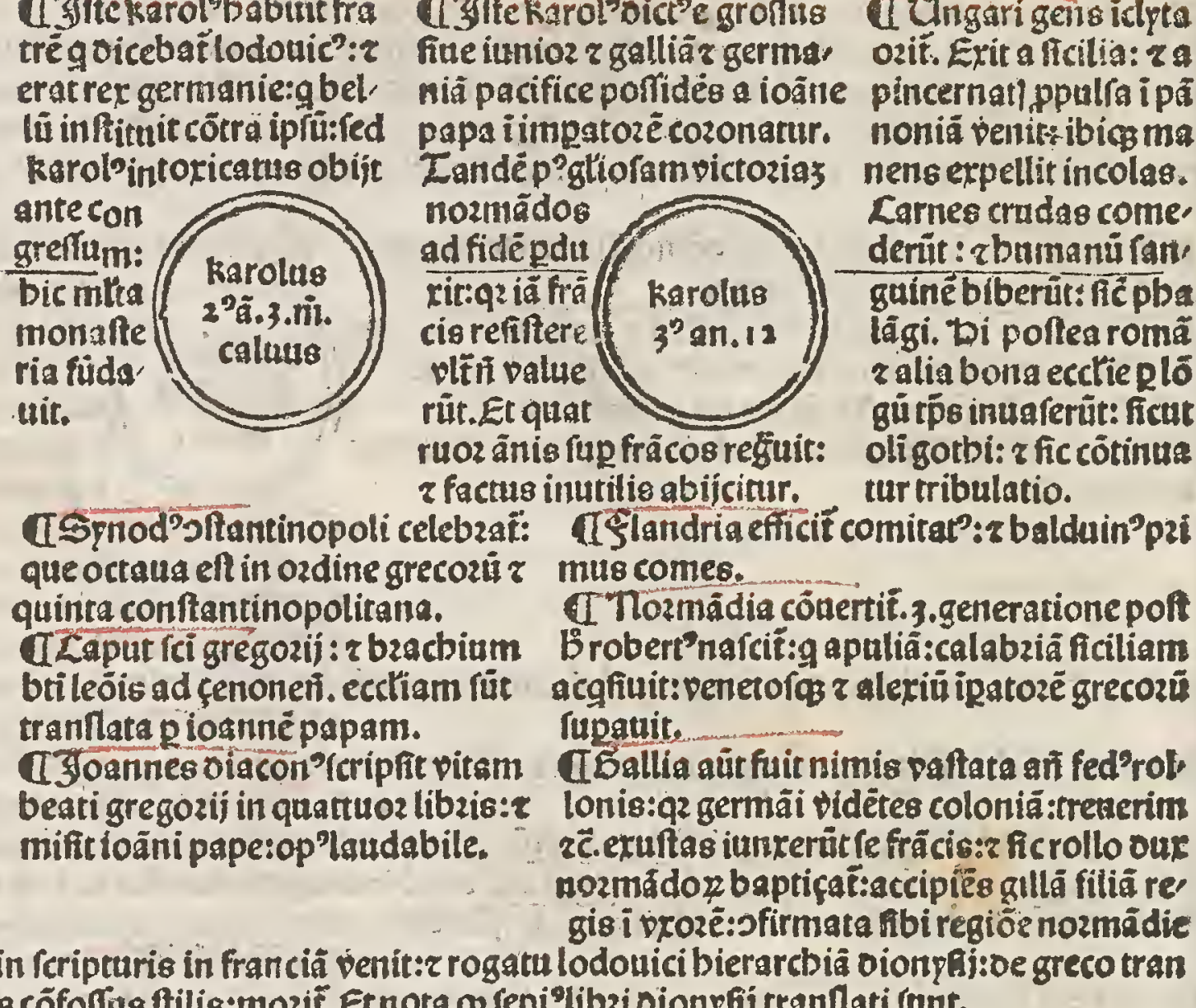

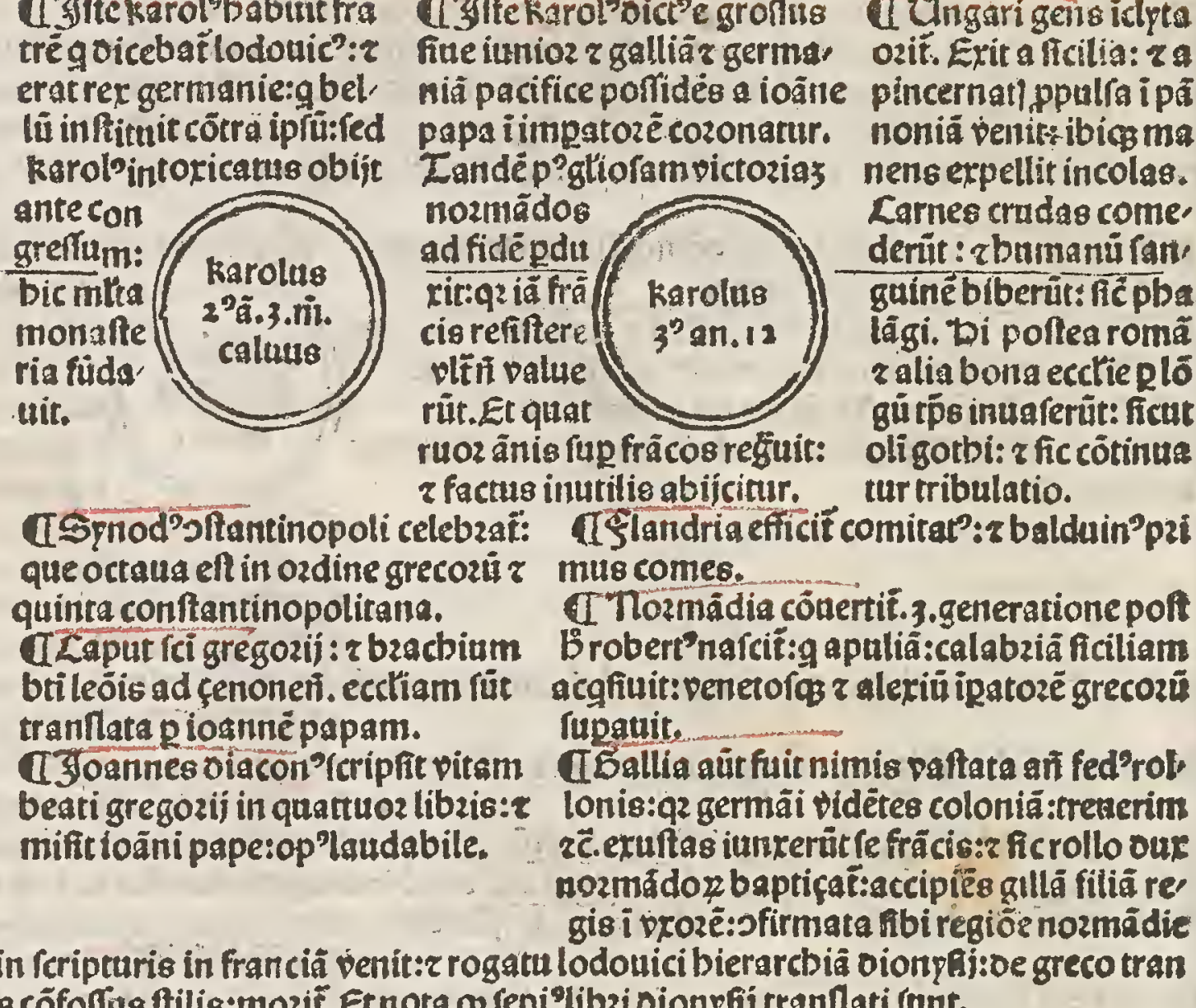

CUngarigens iclpta

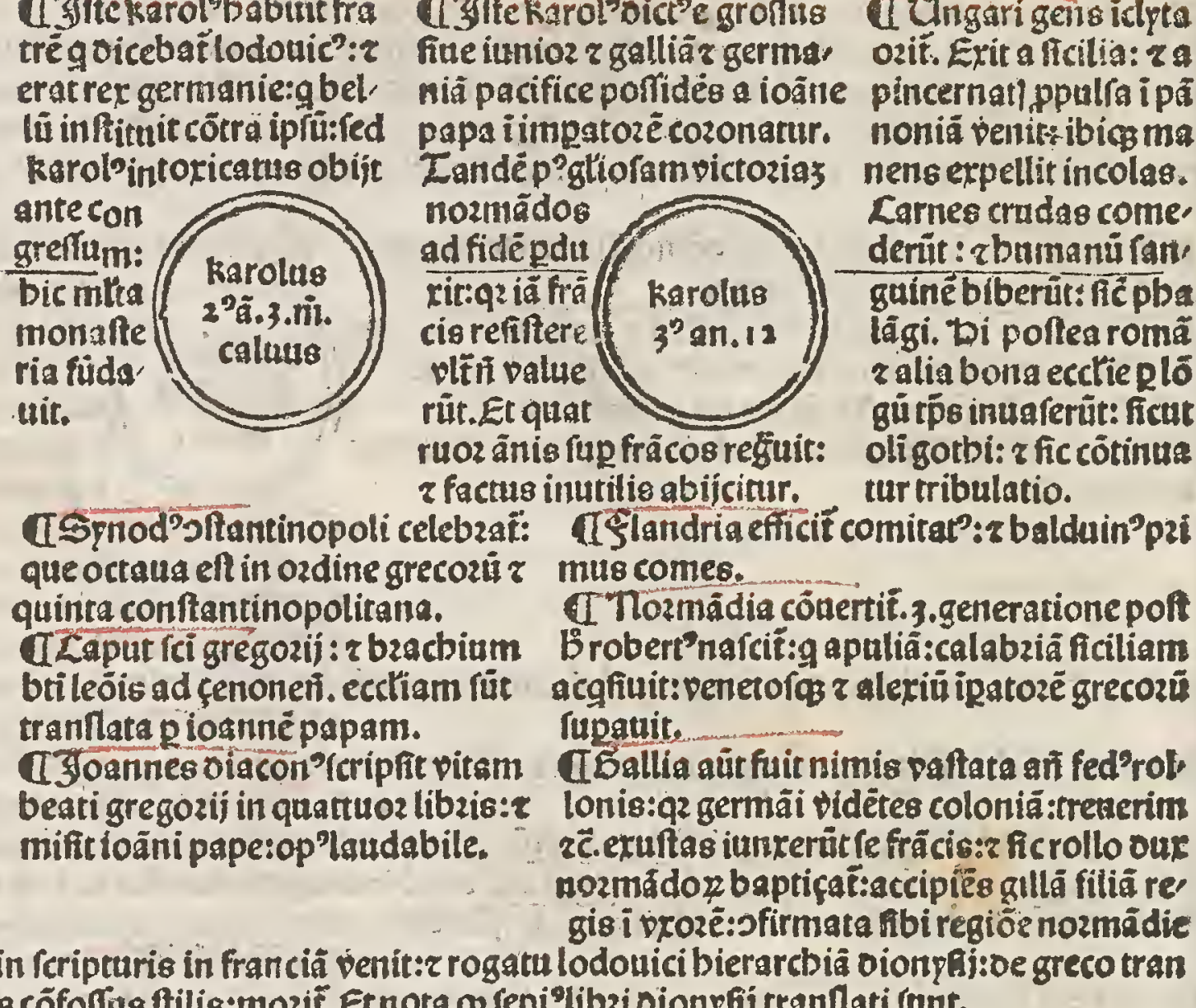

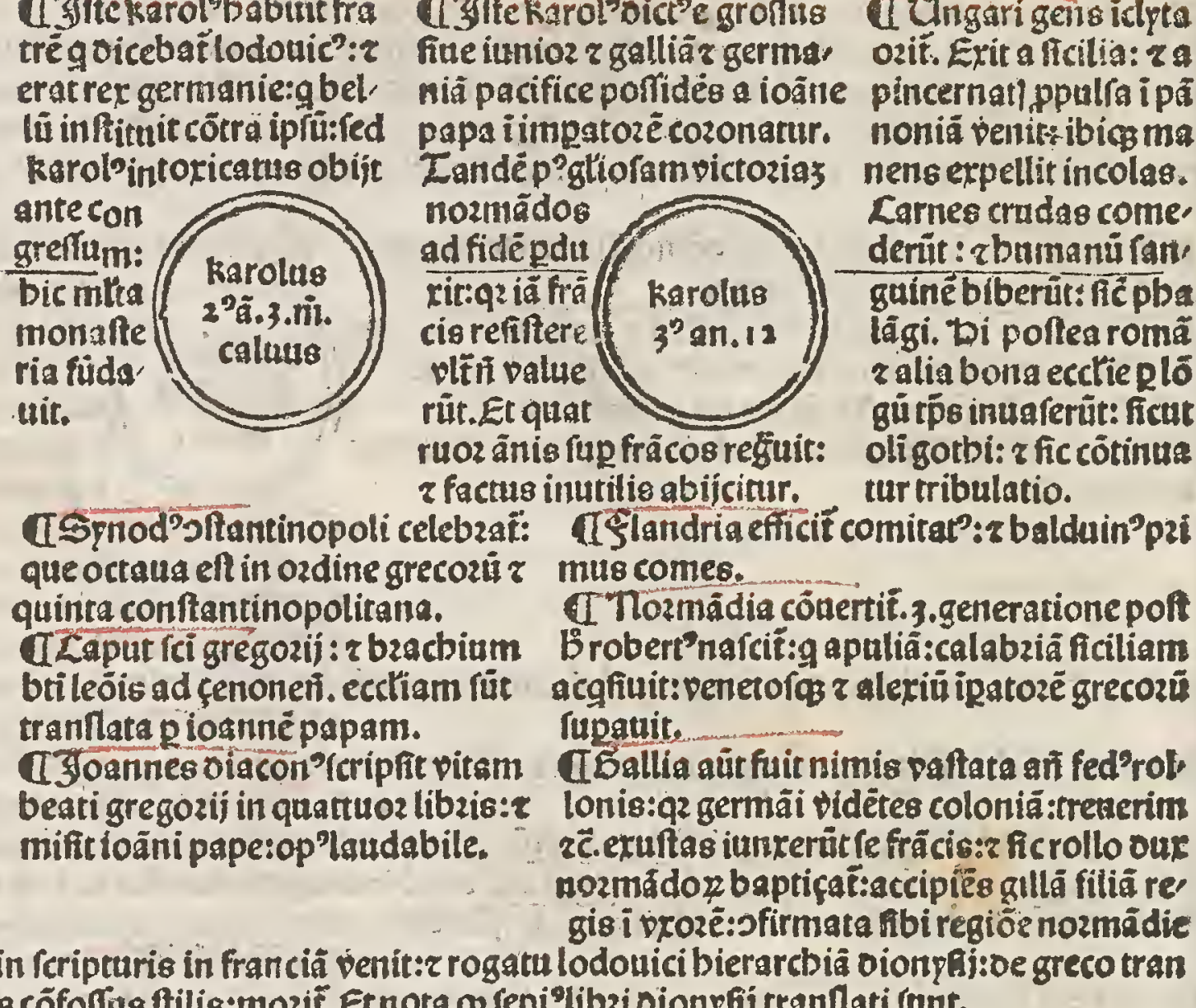

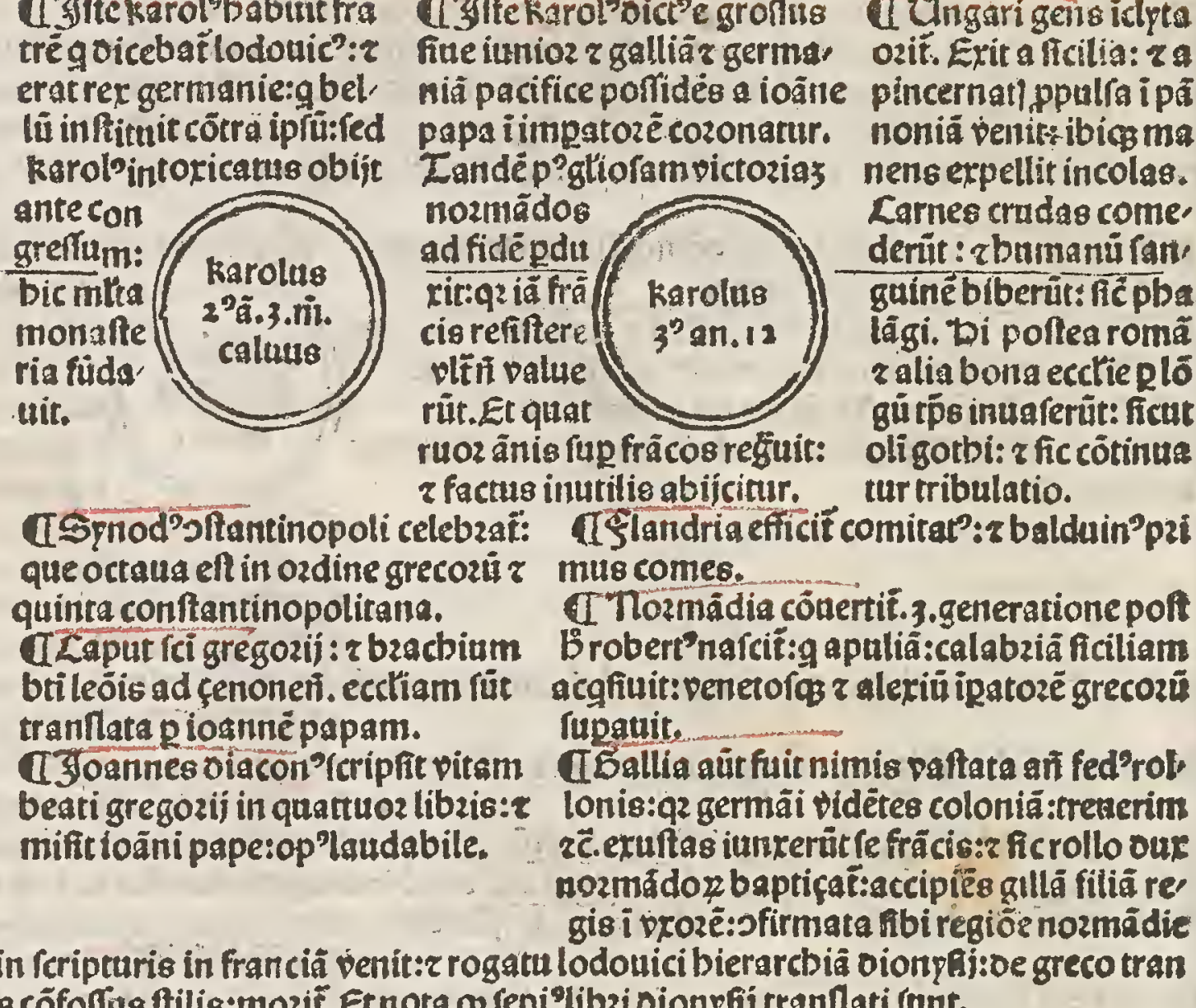

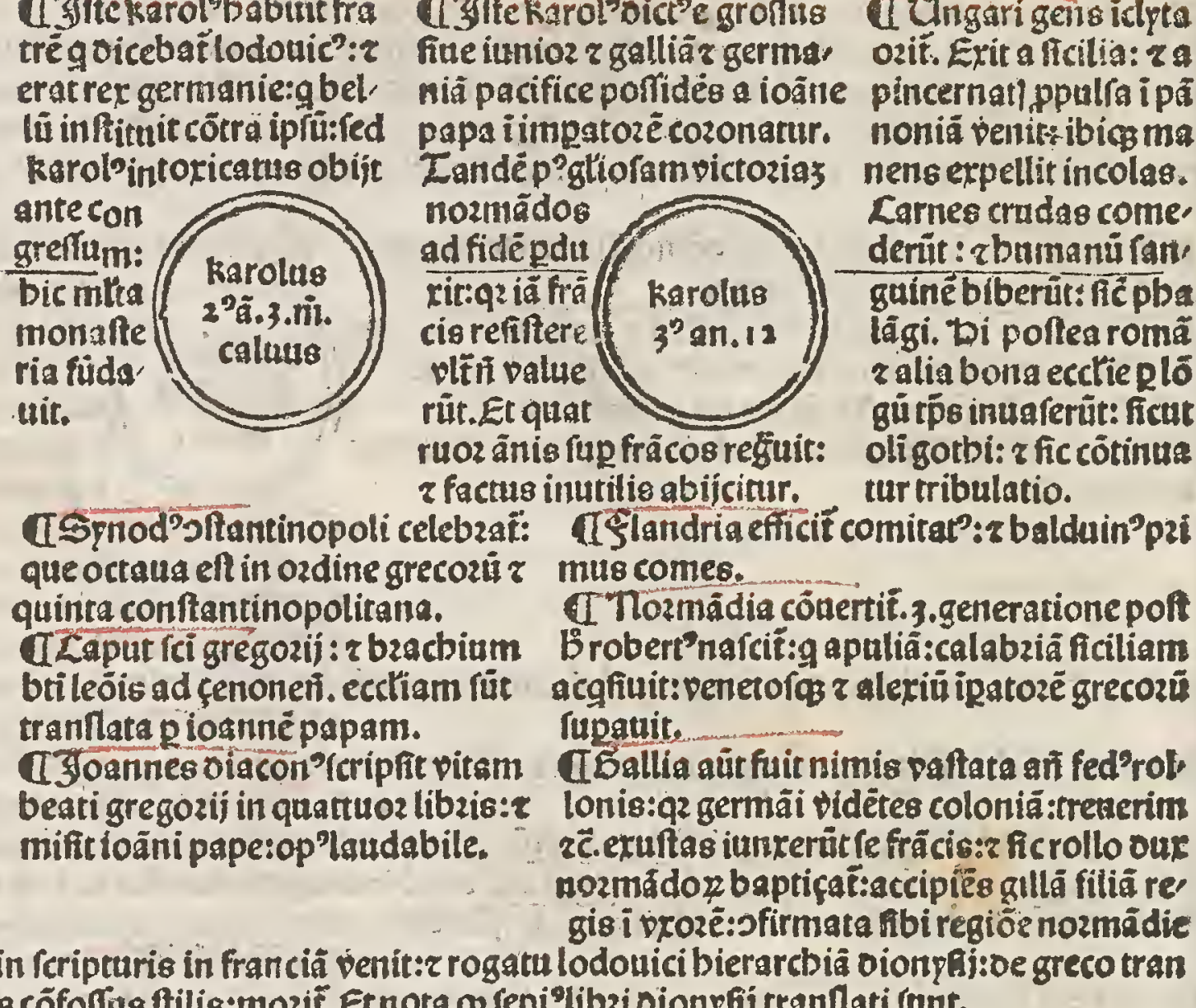

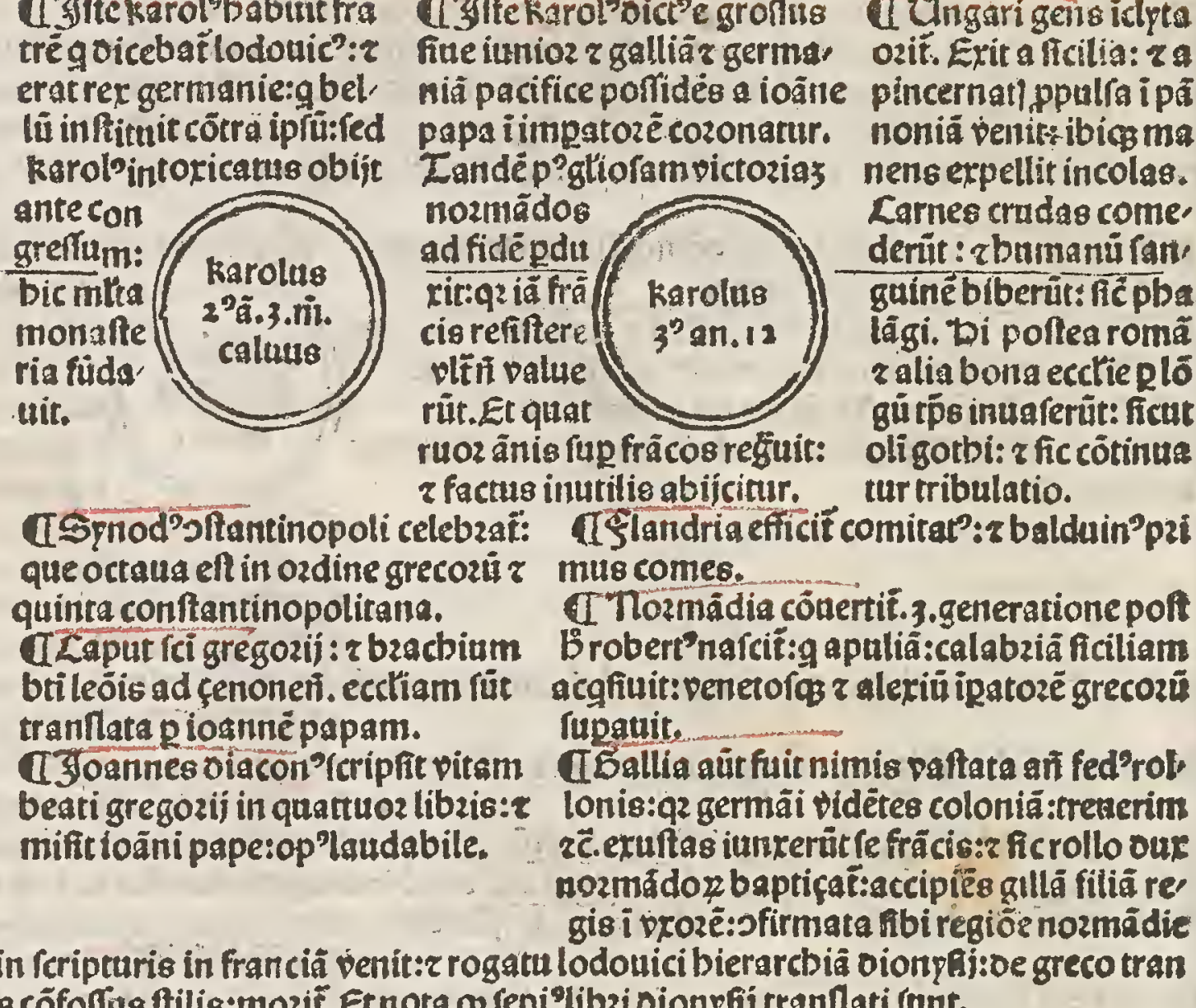

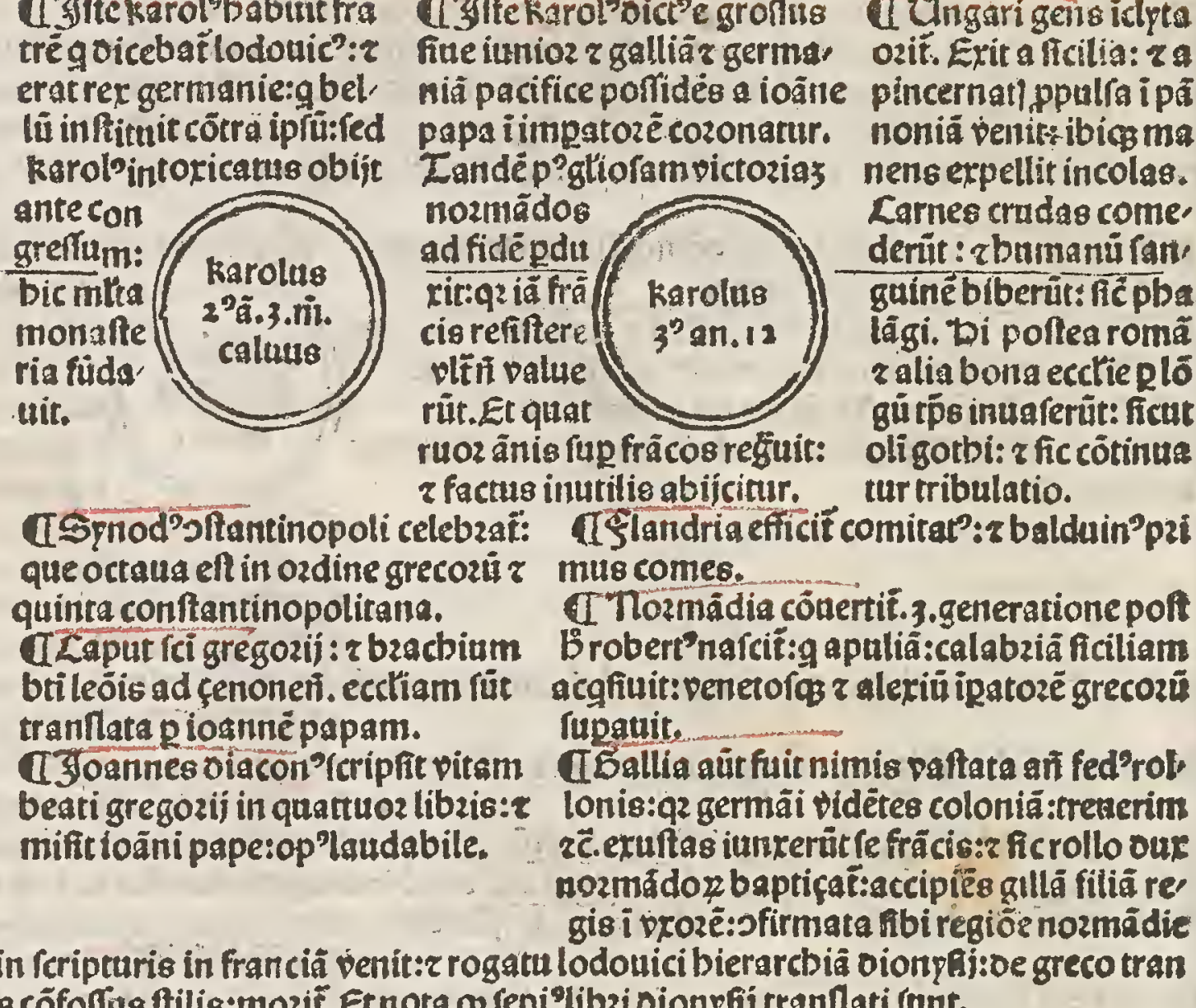

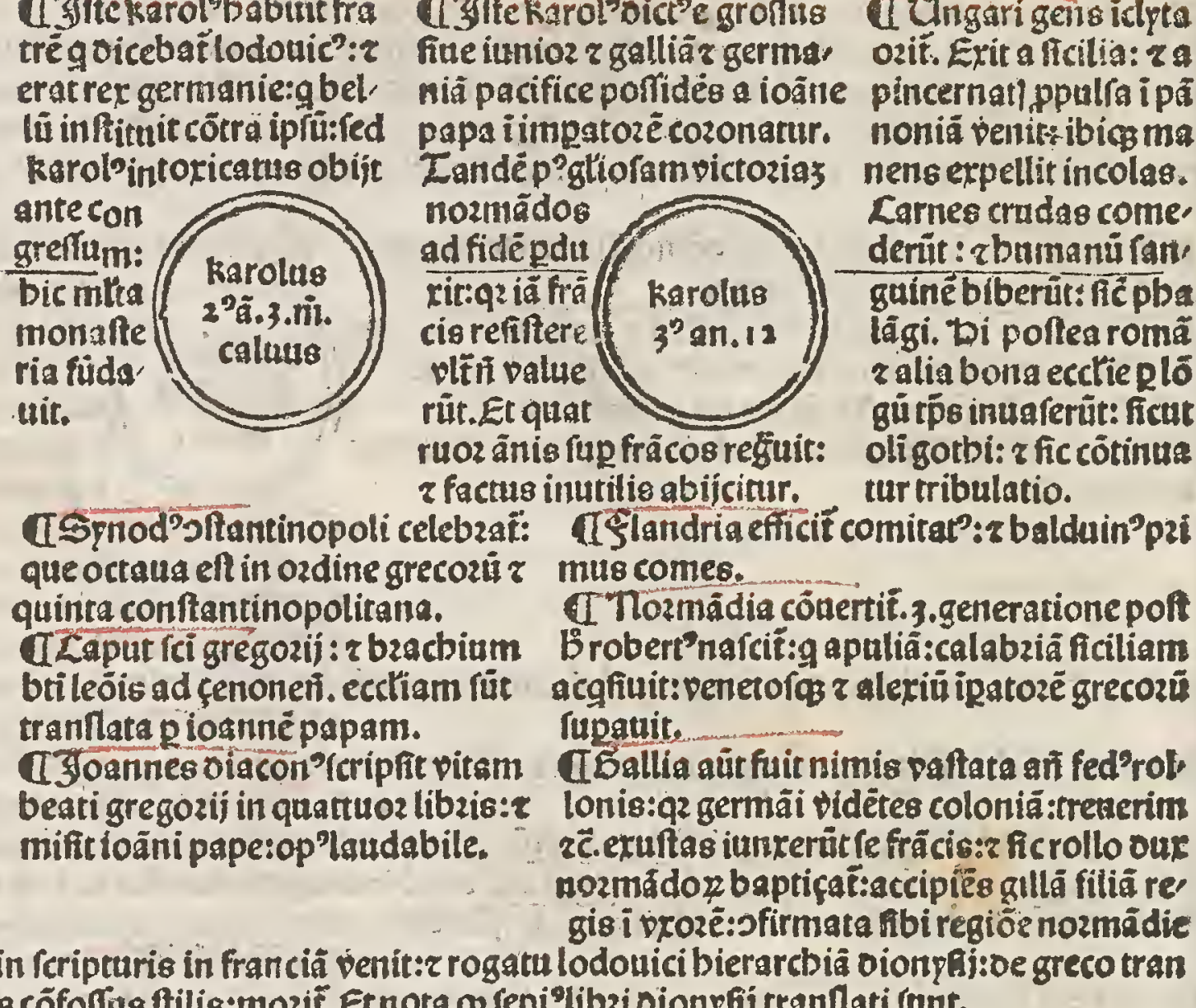

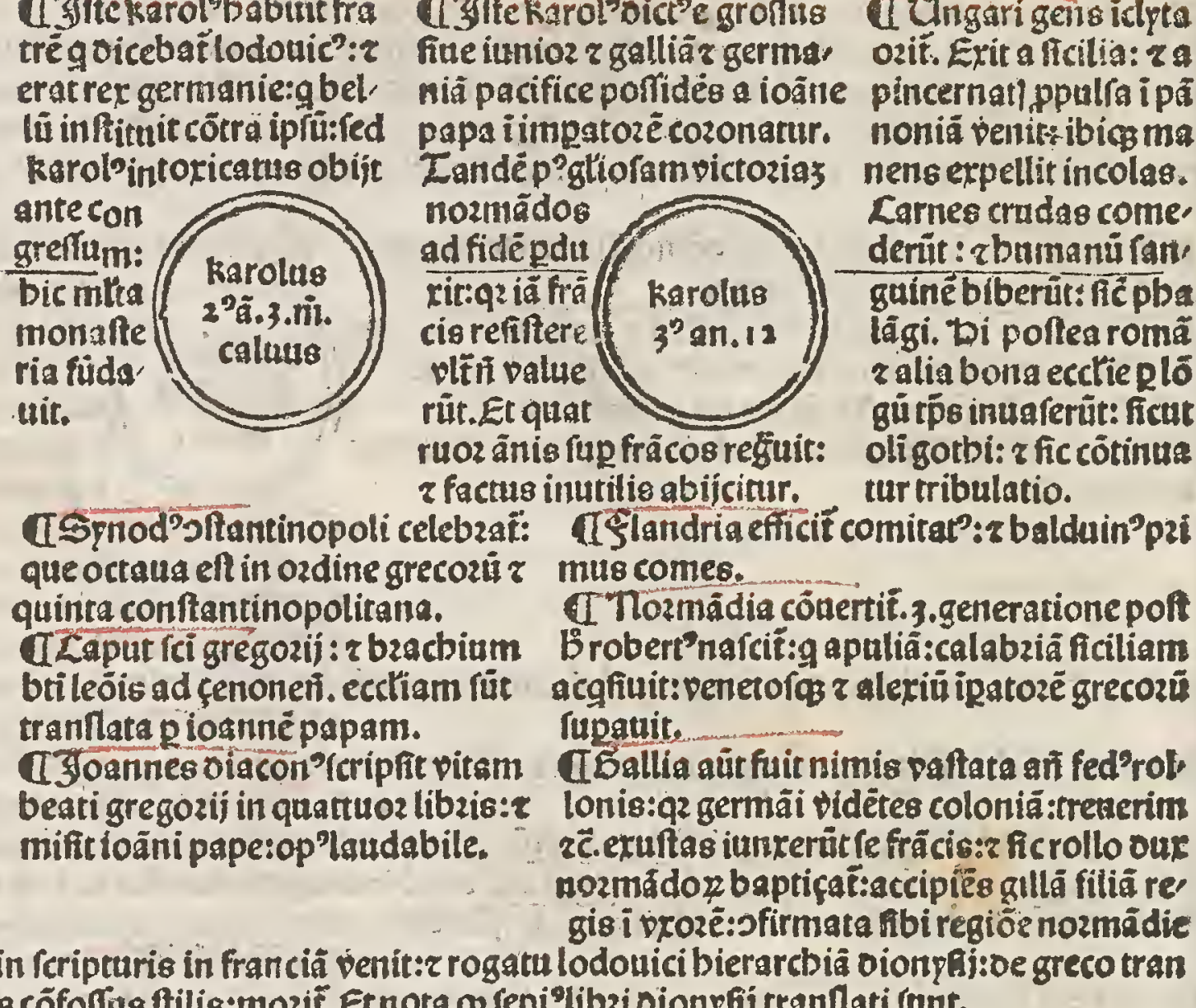

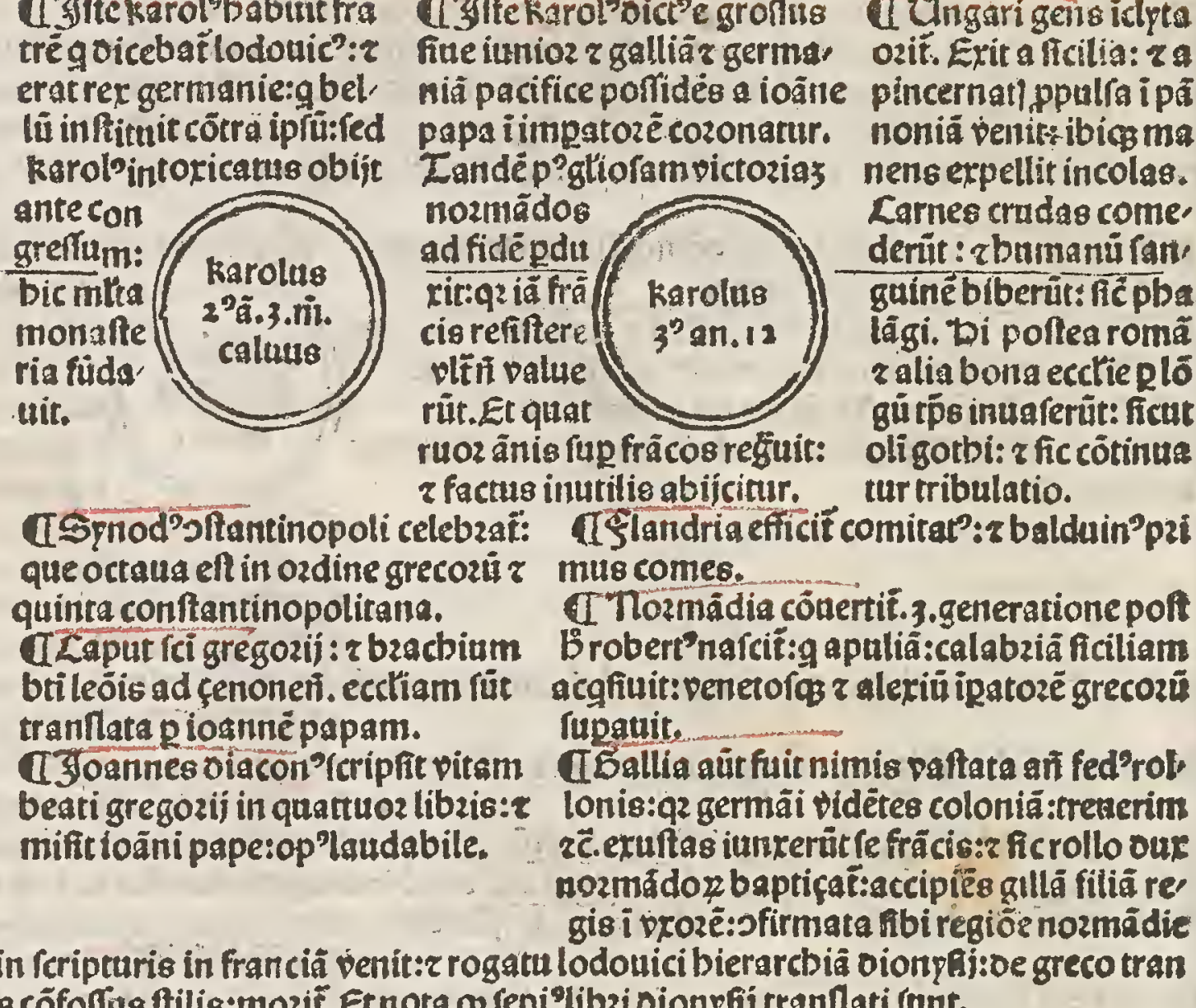

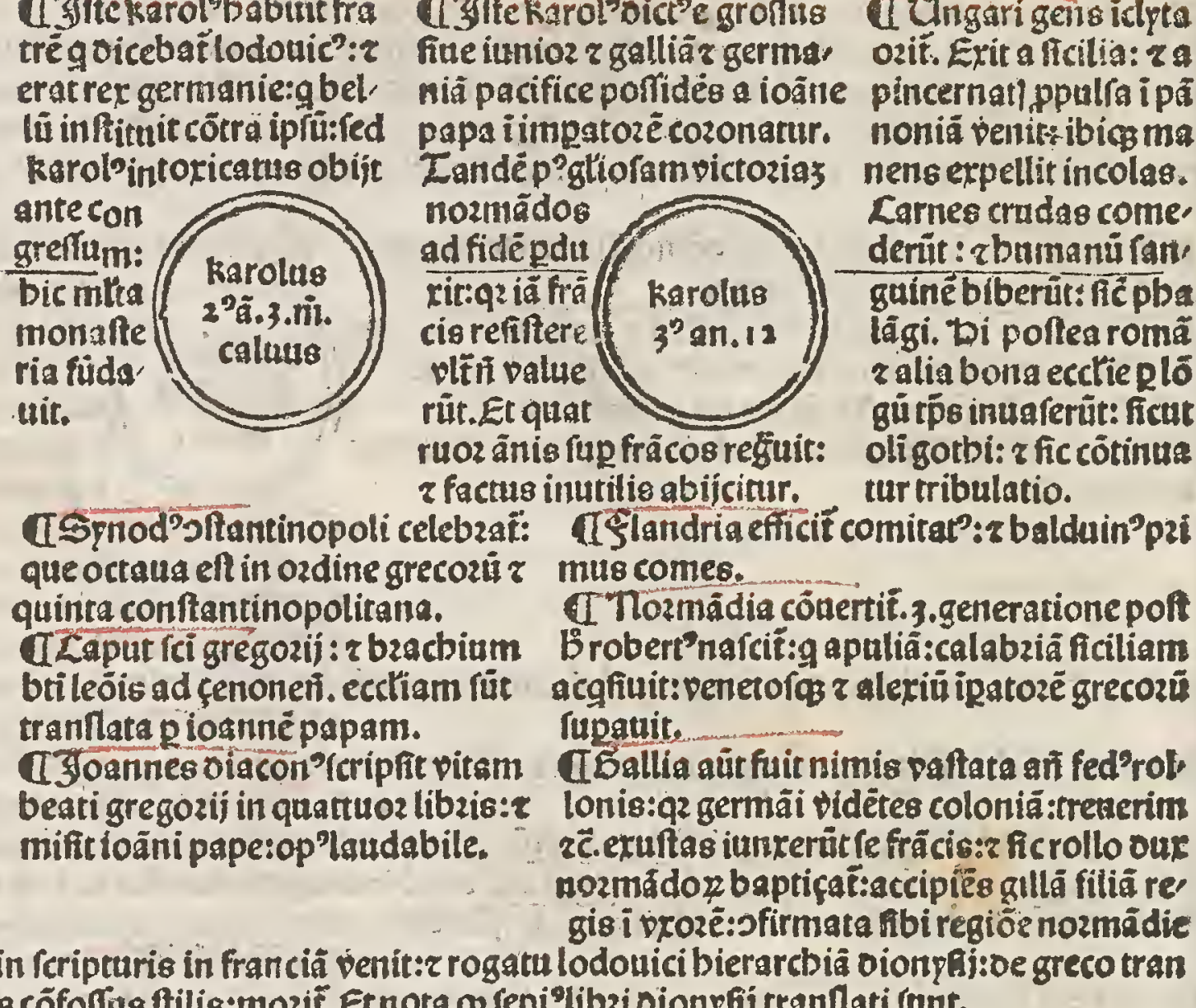

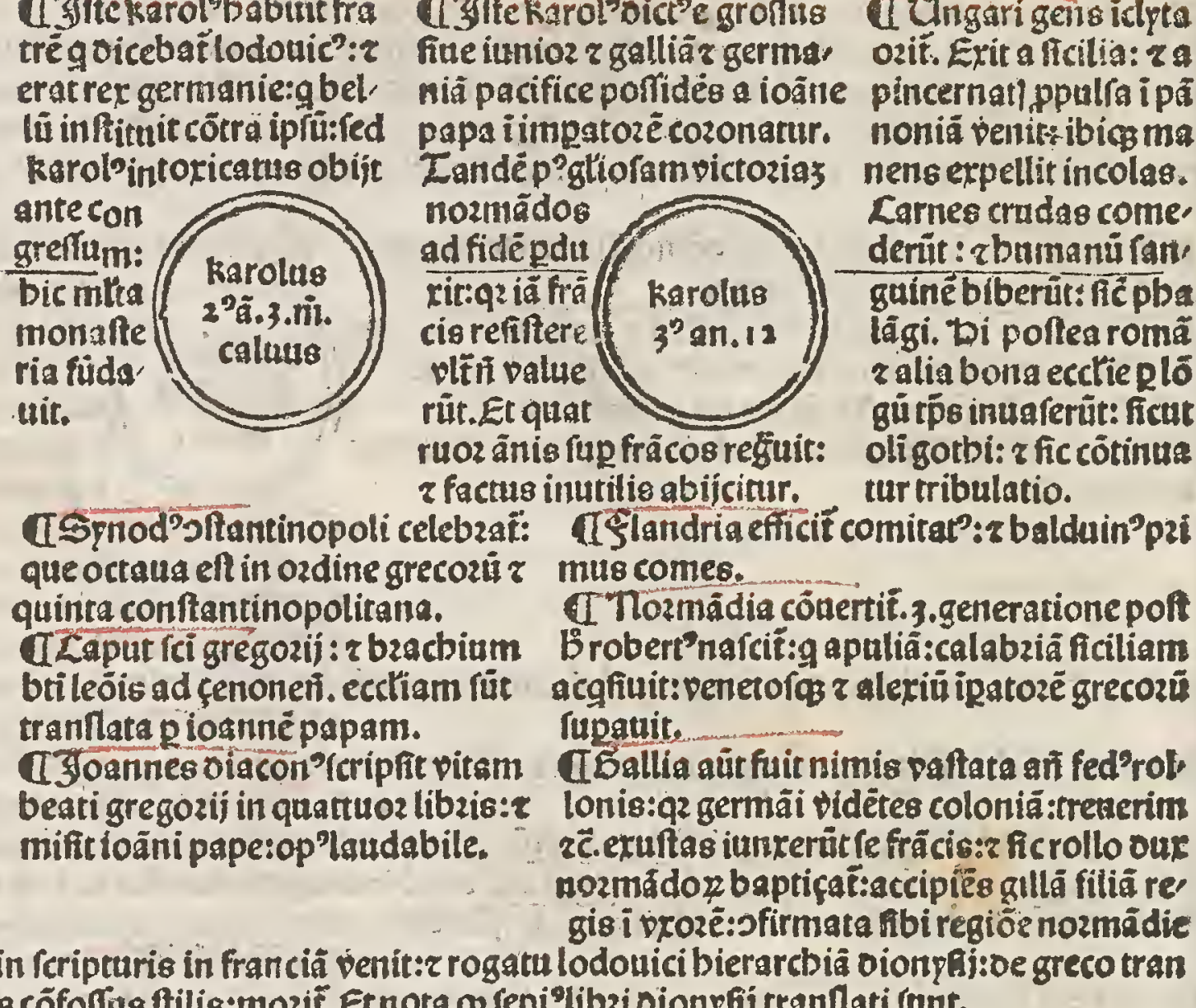

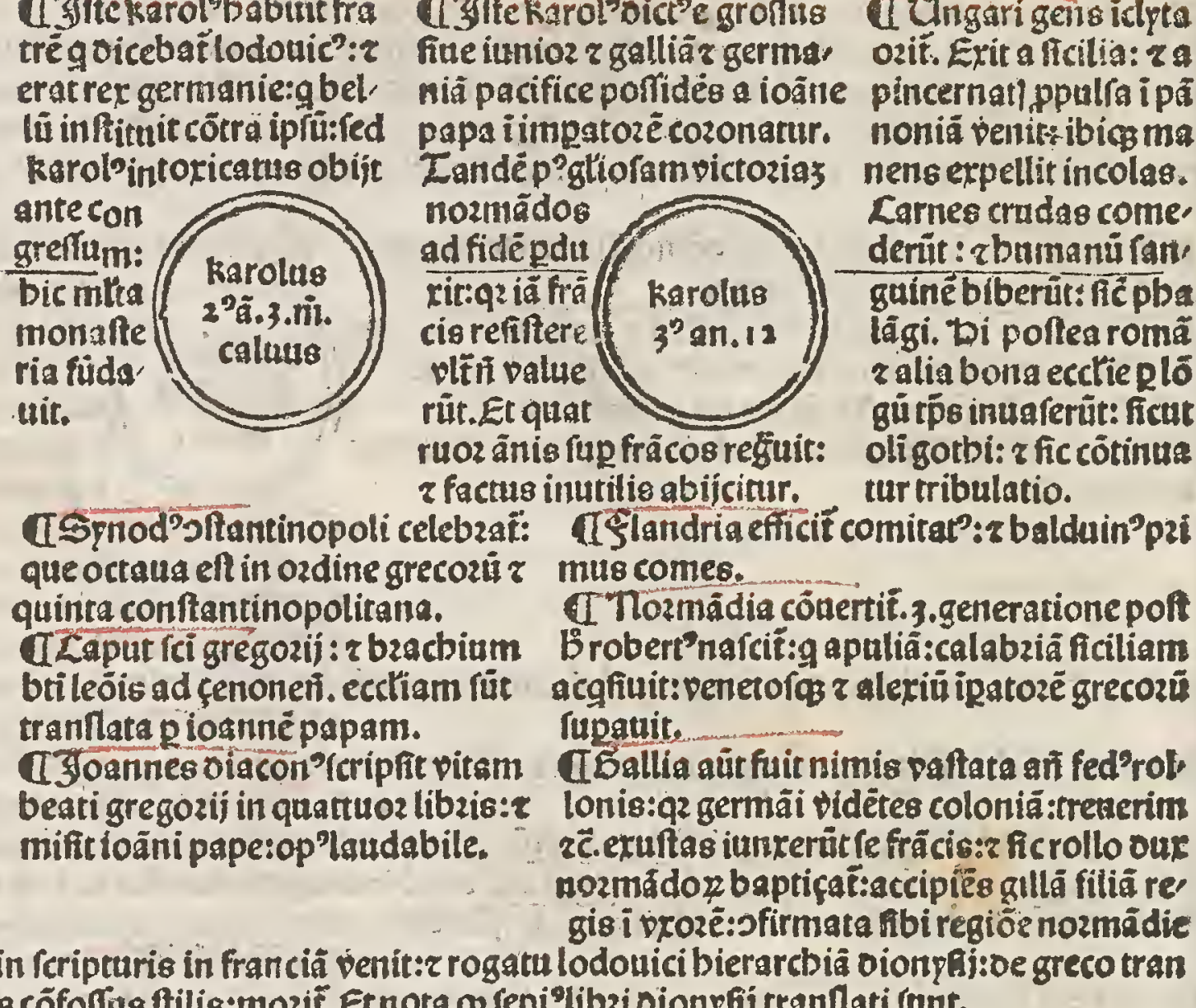

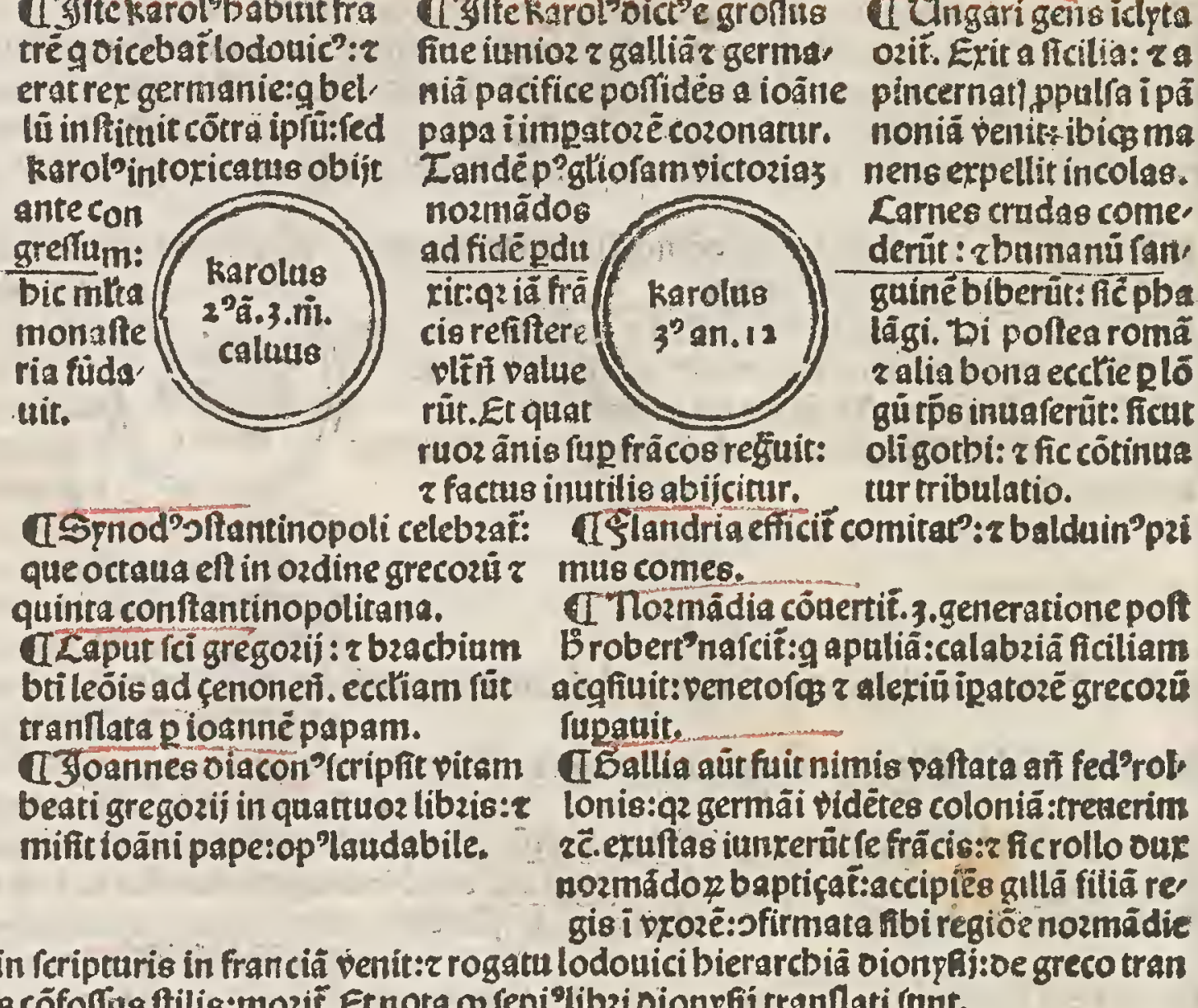

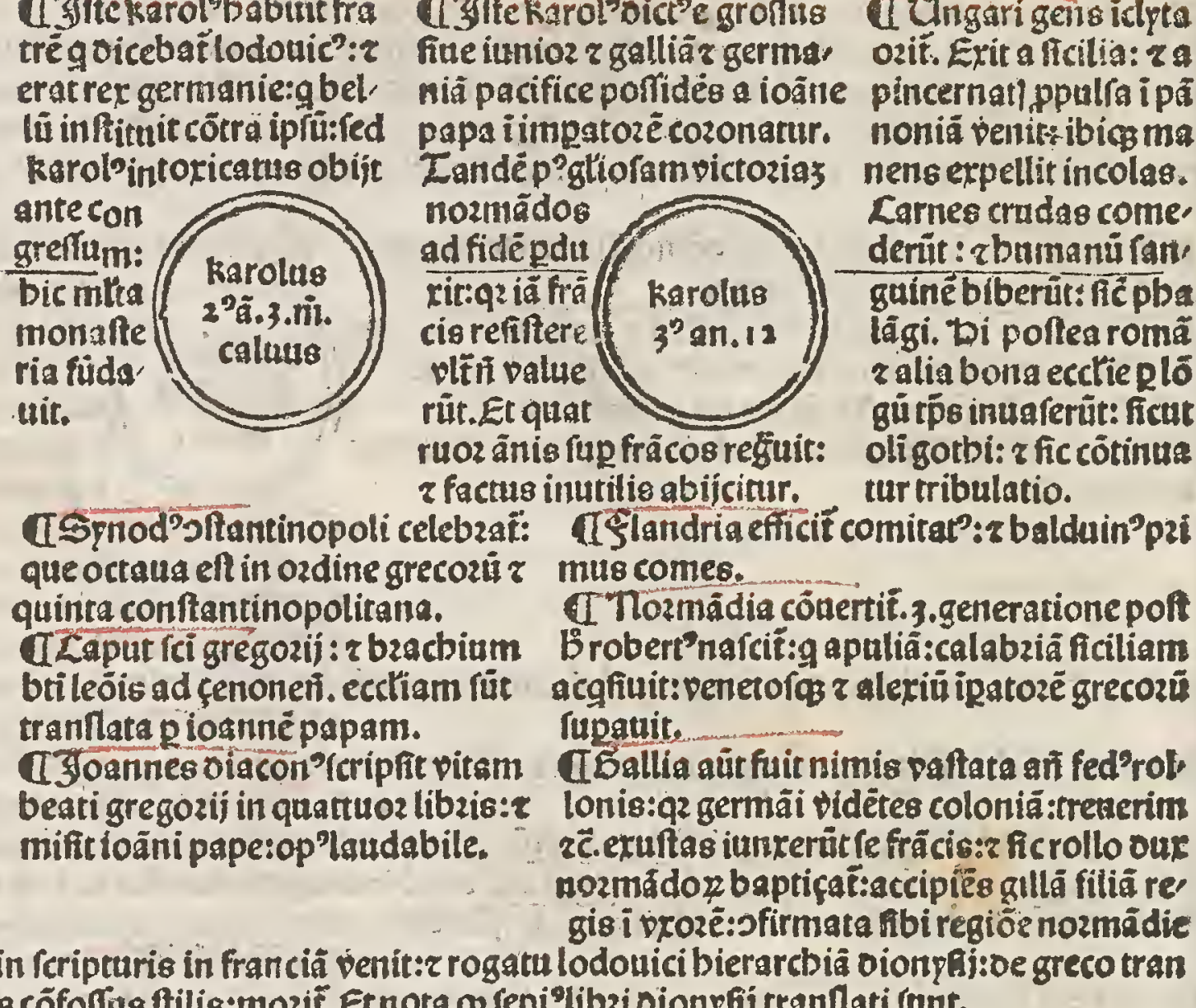

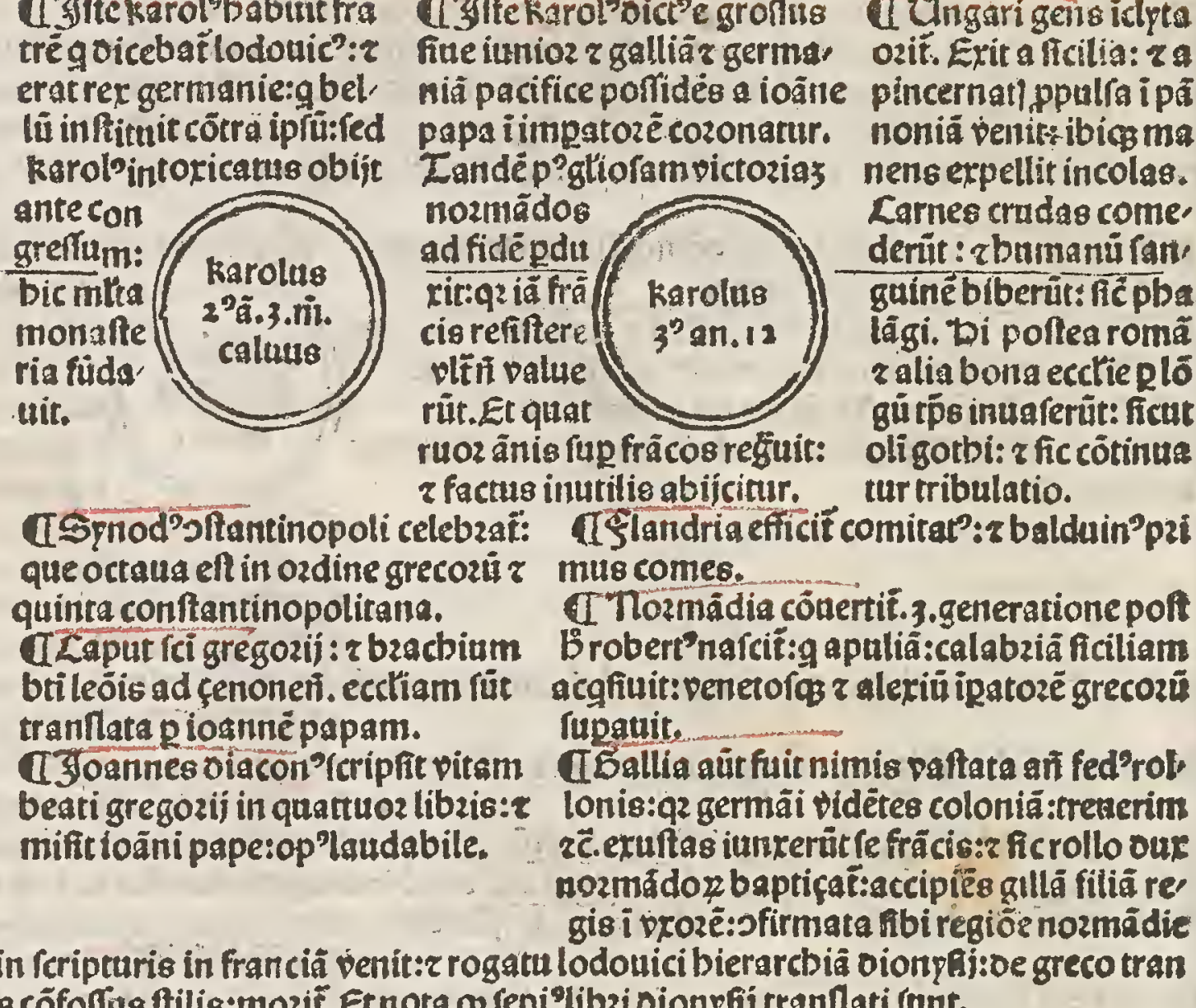

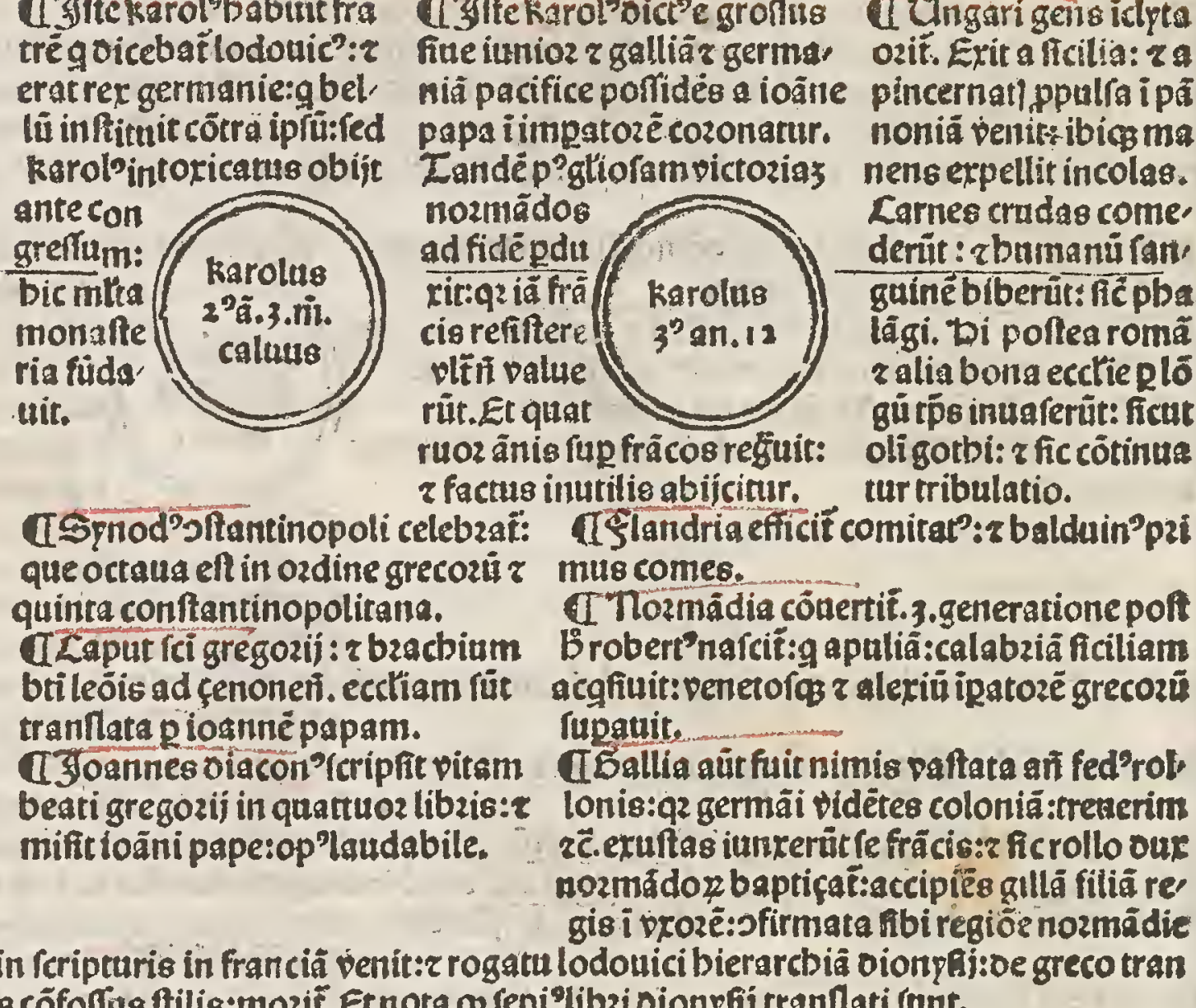

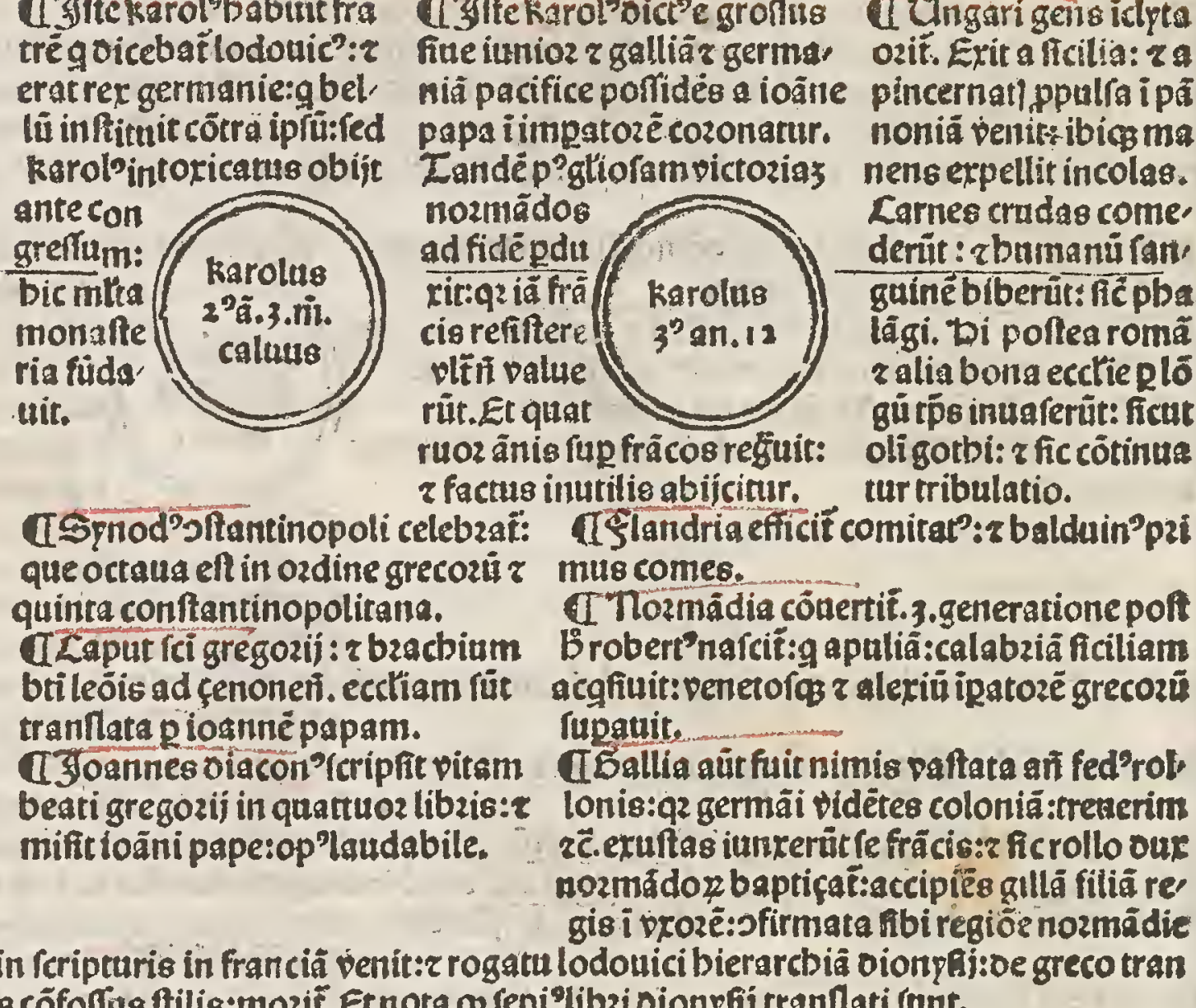

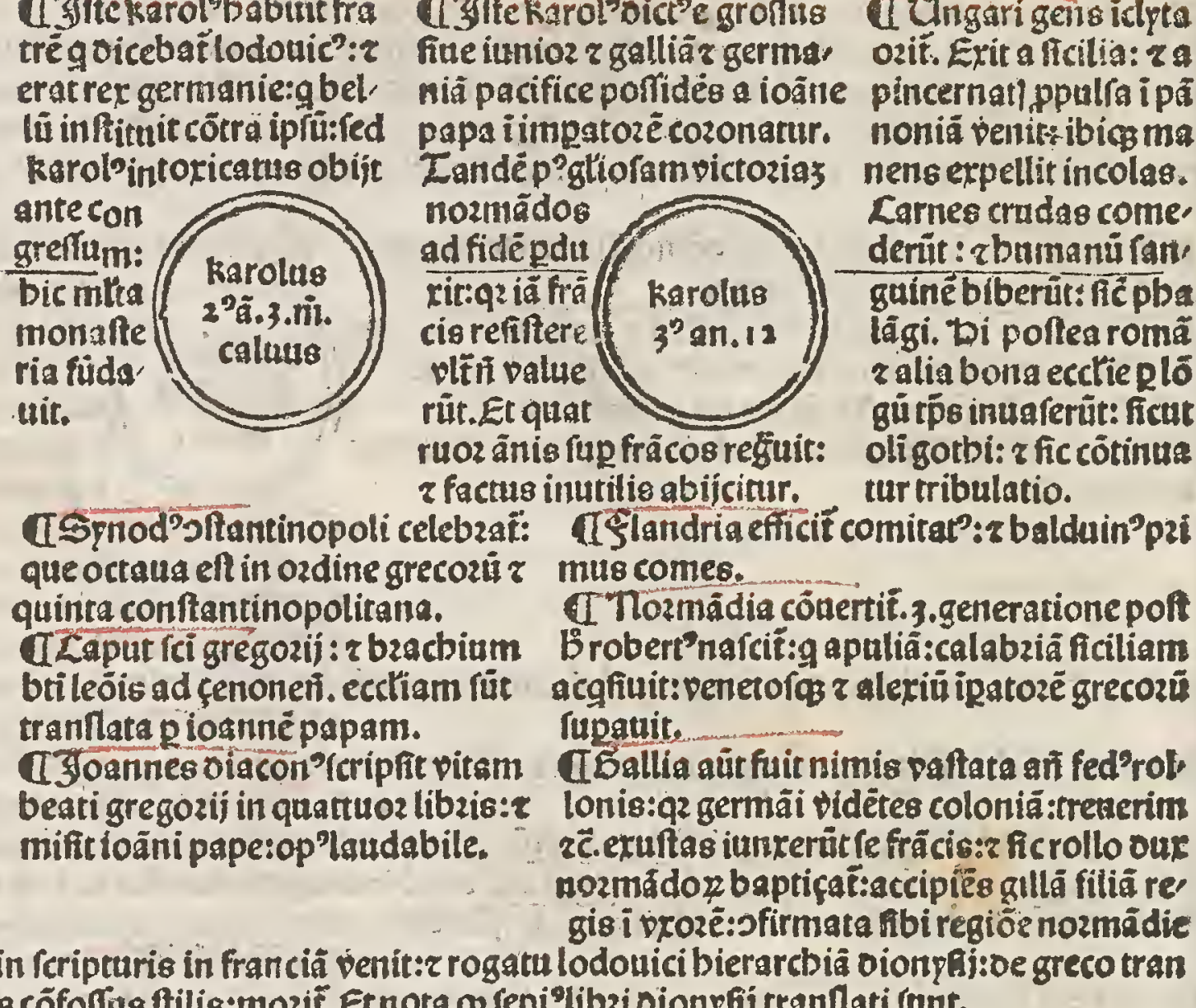

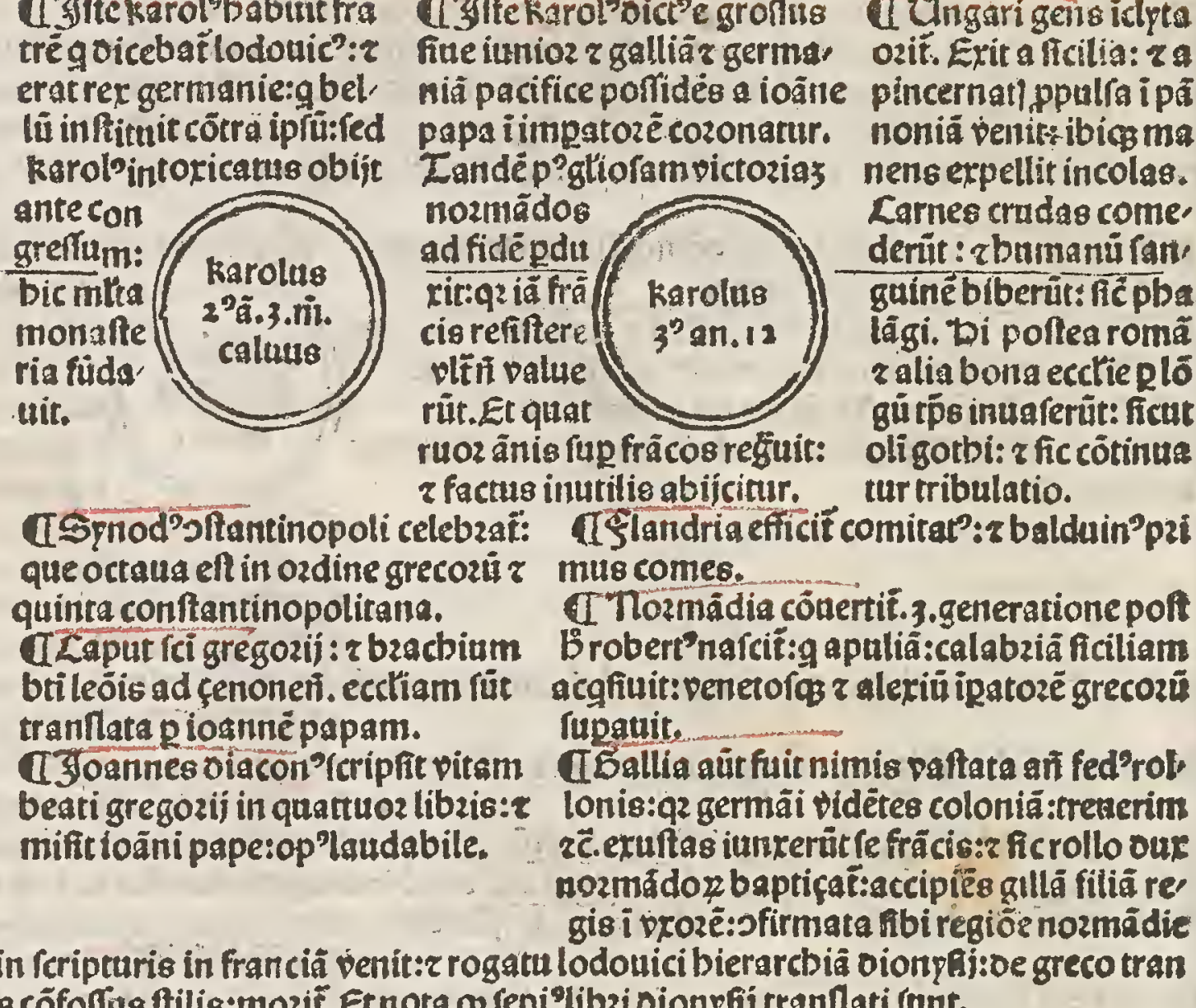

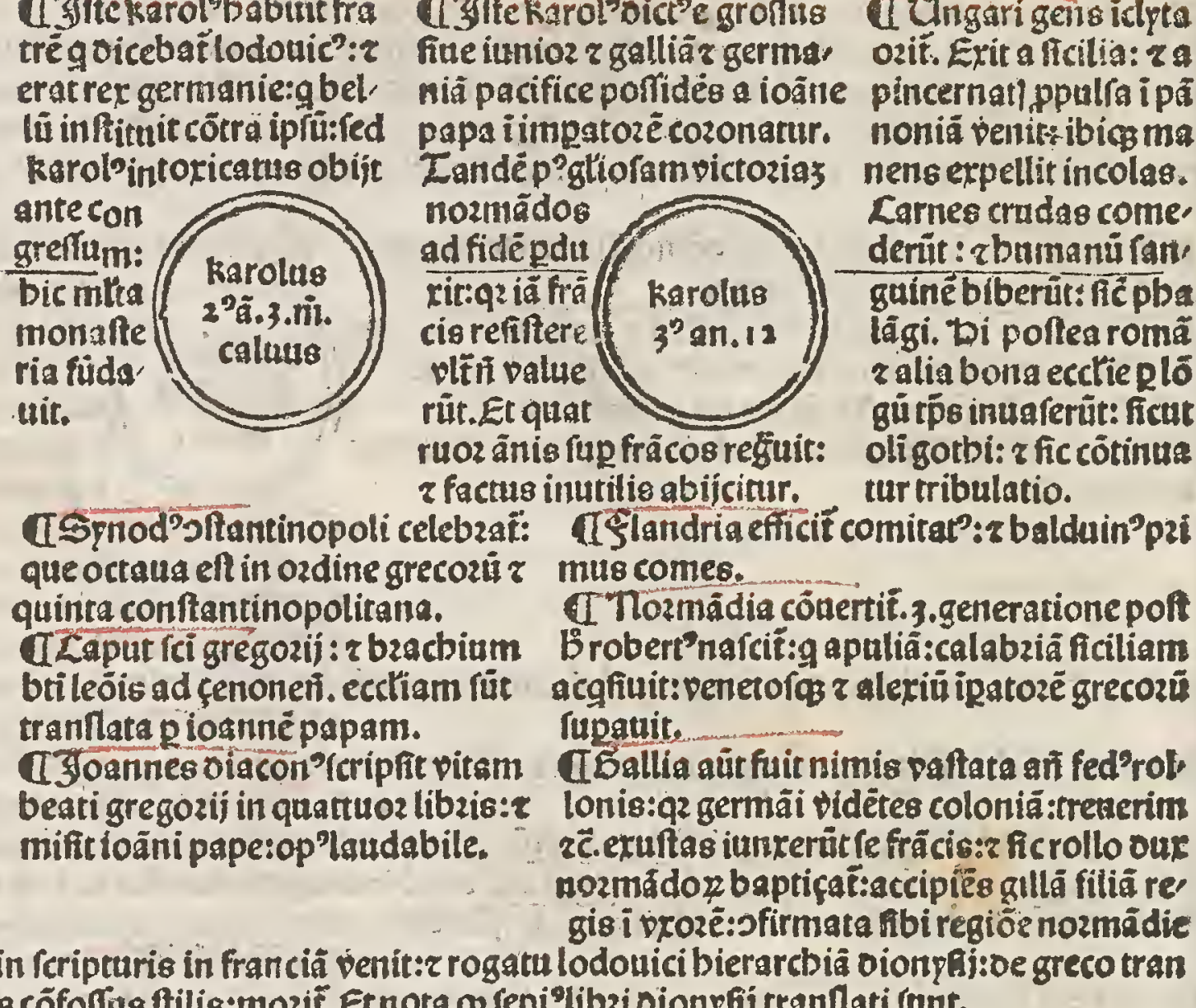

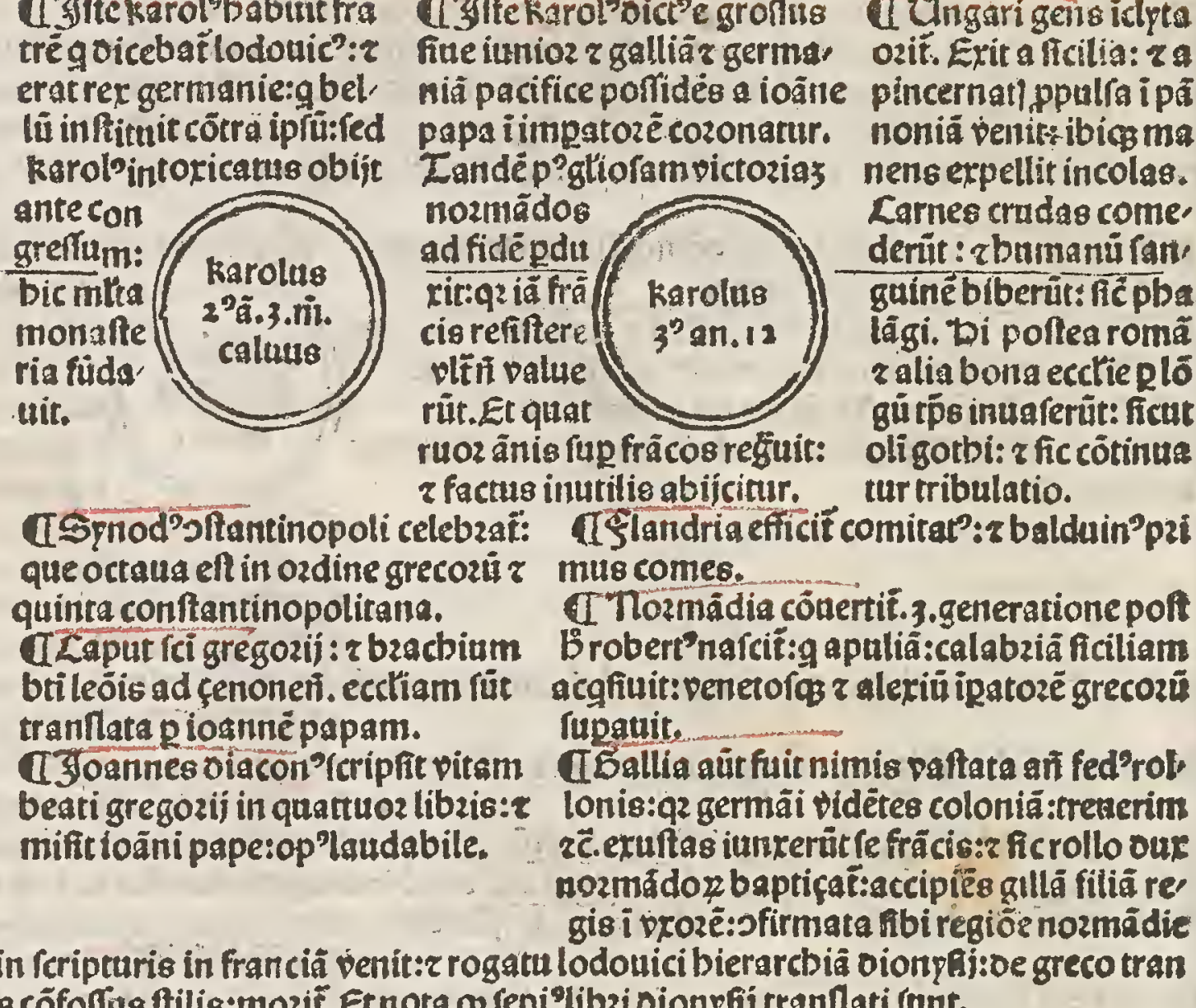

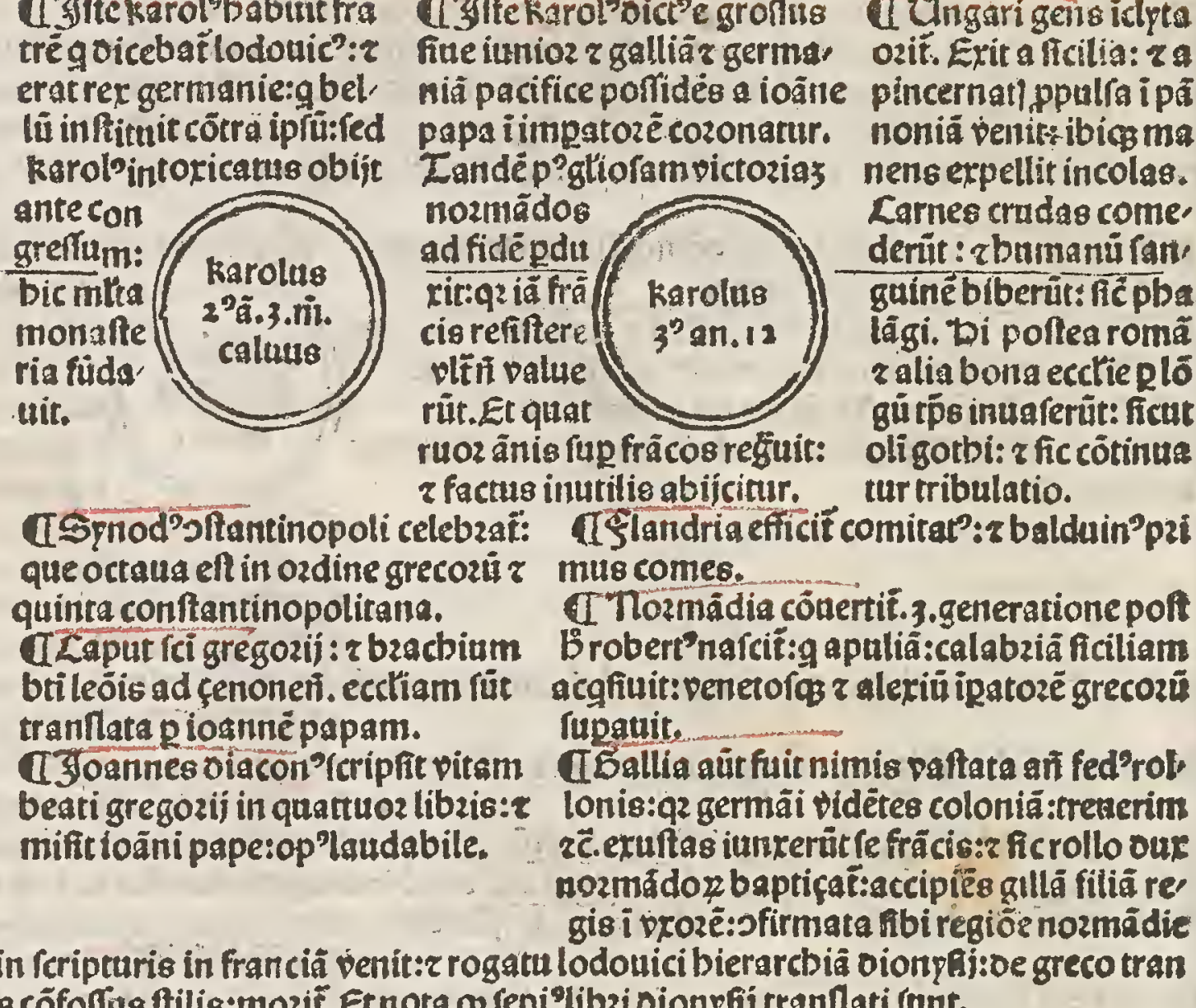

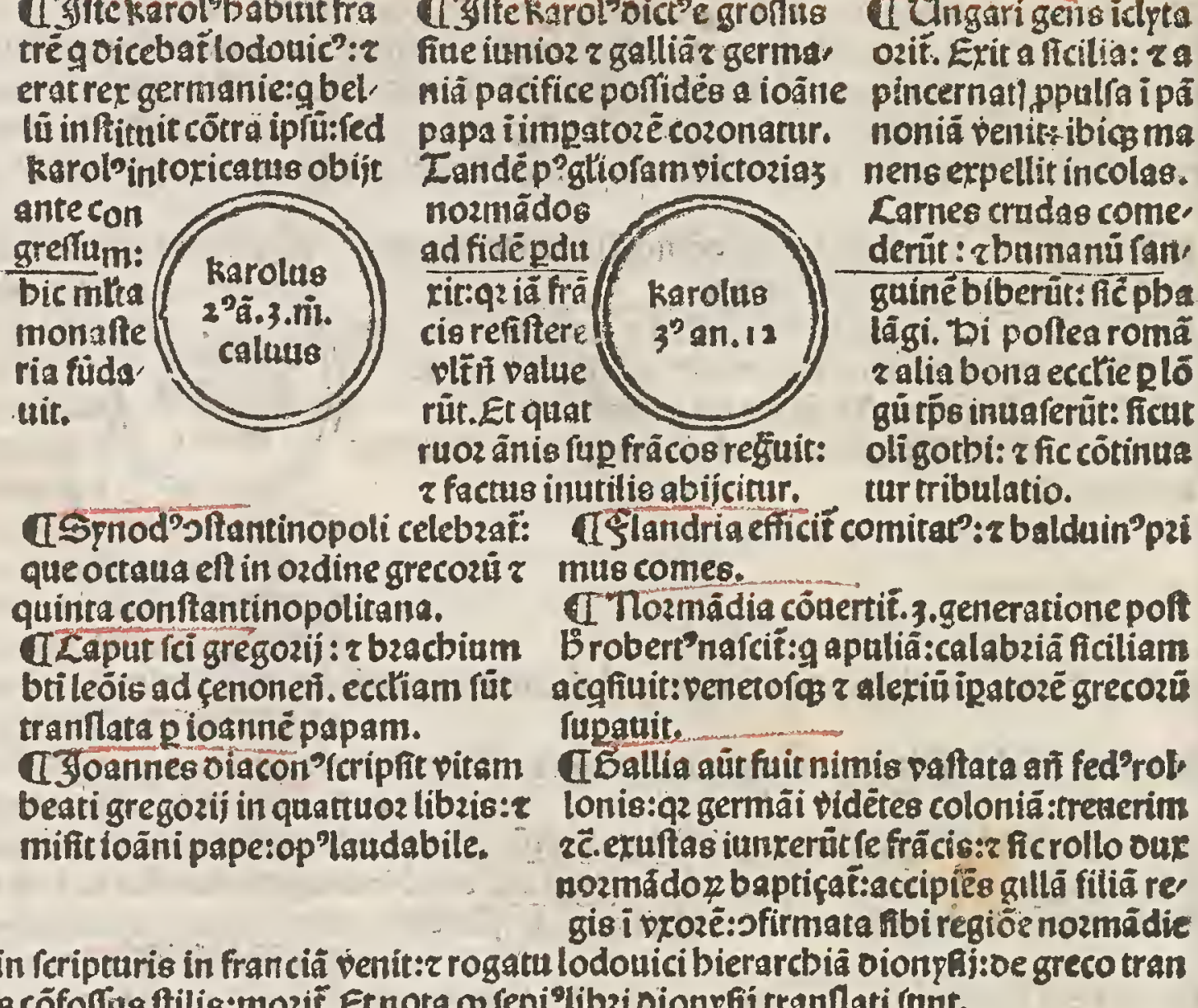

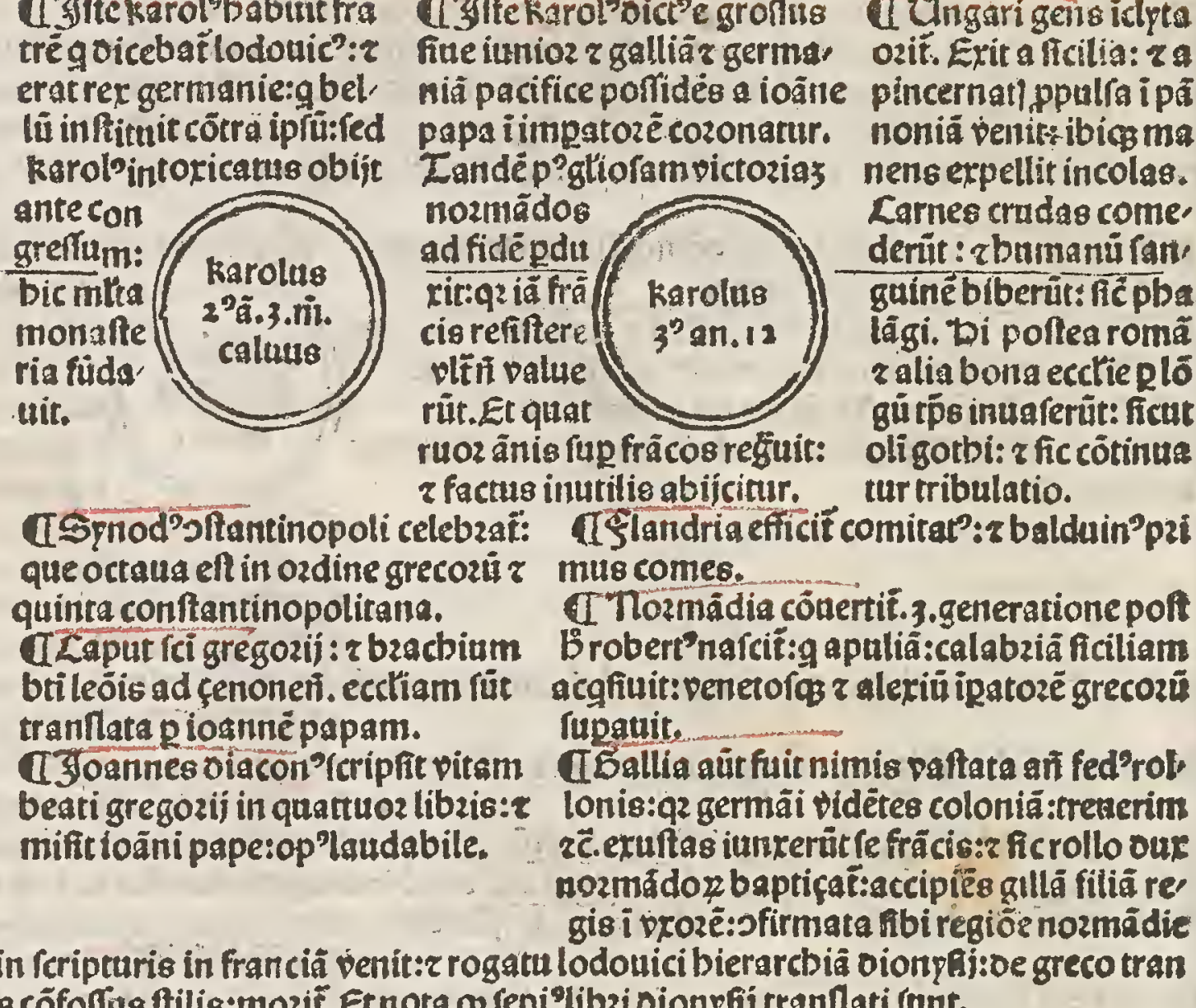

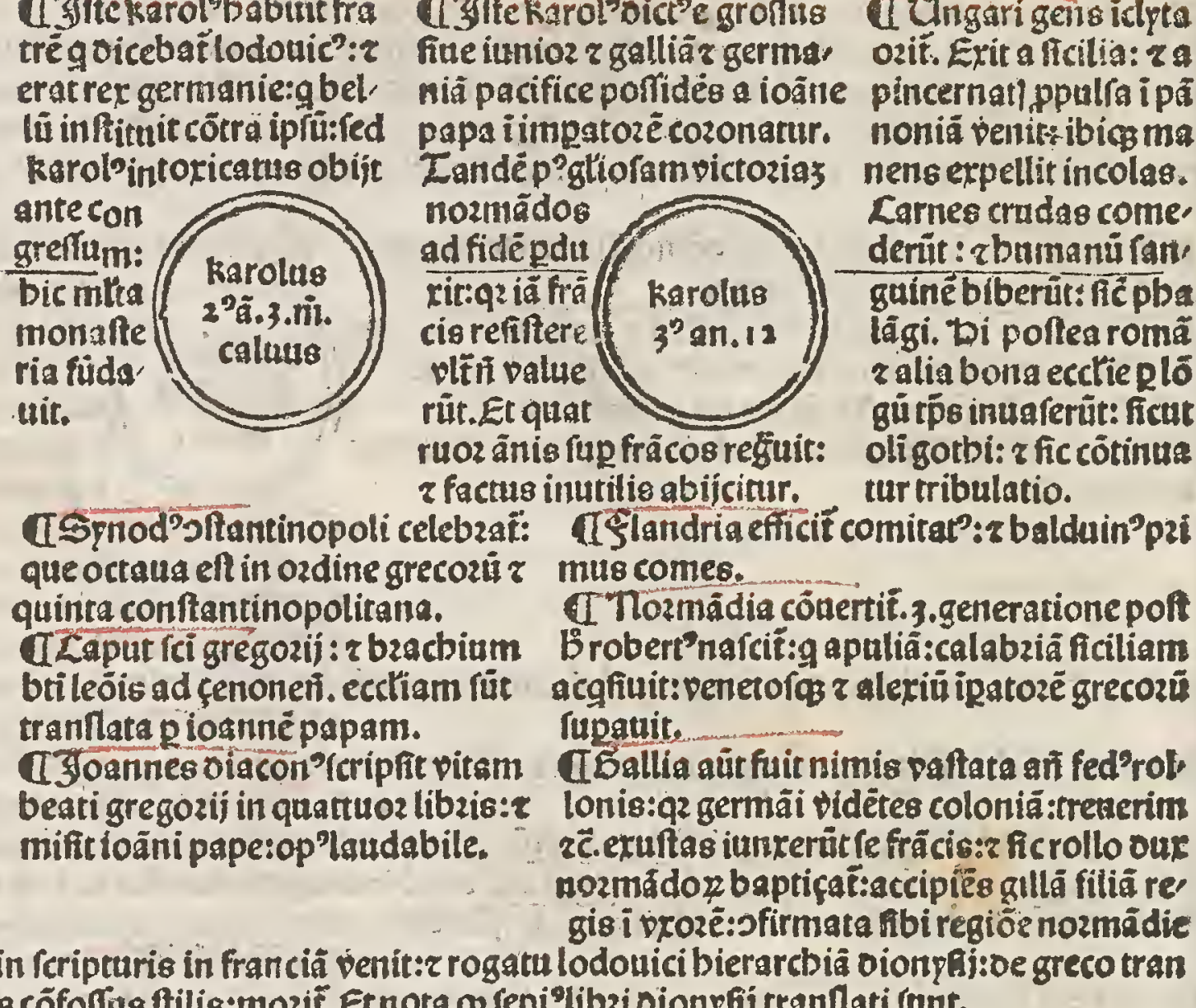

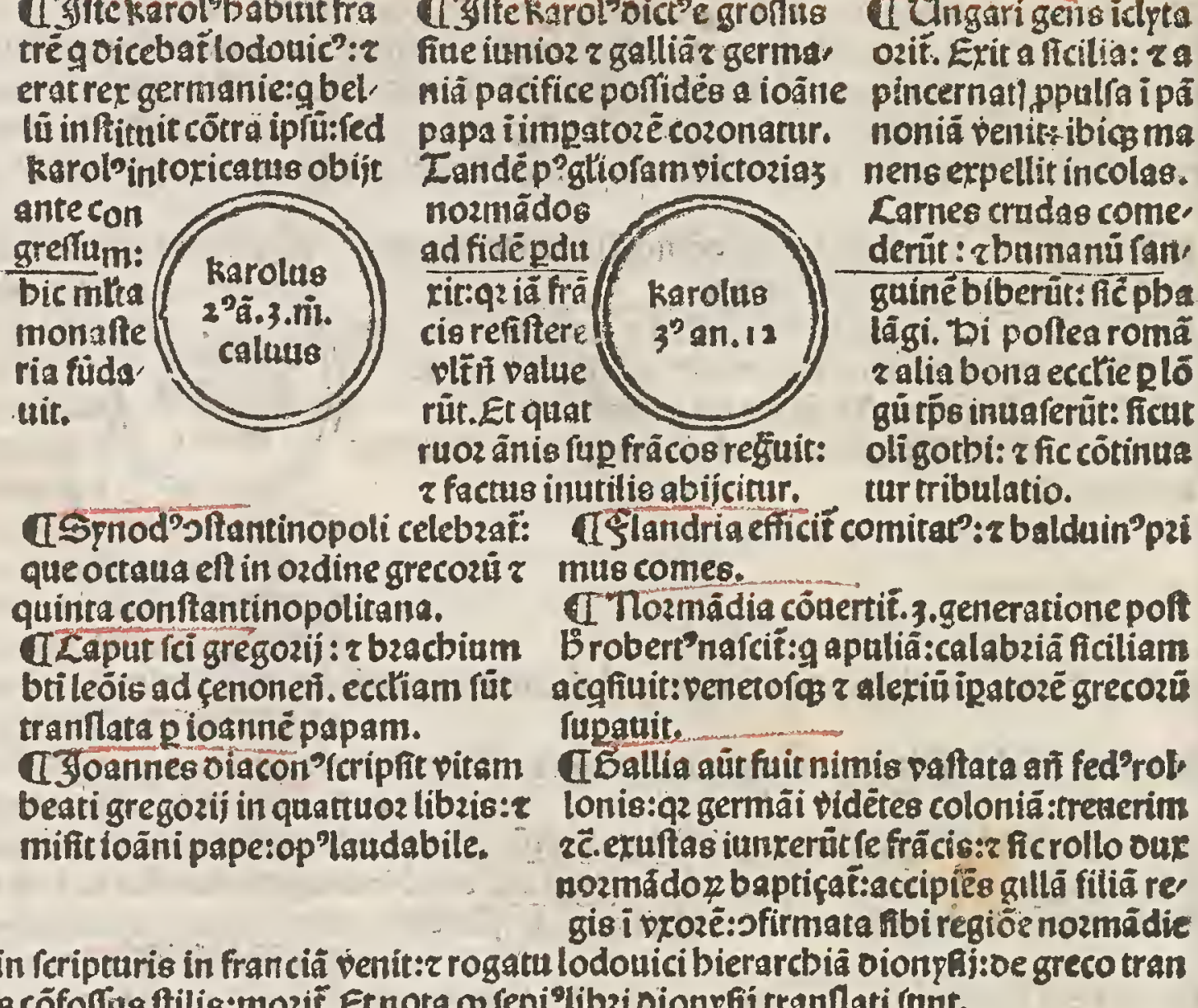

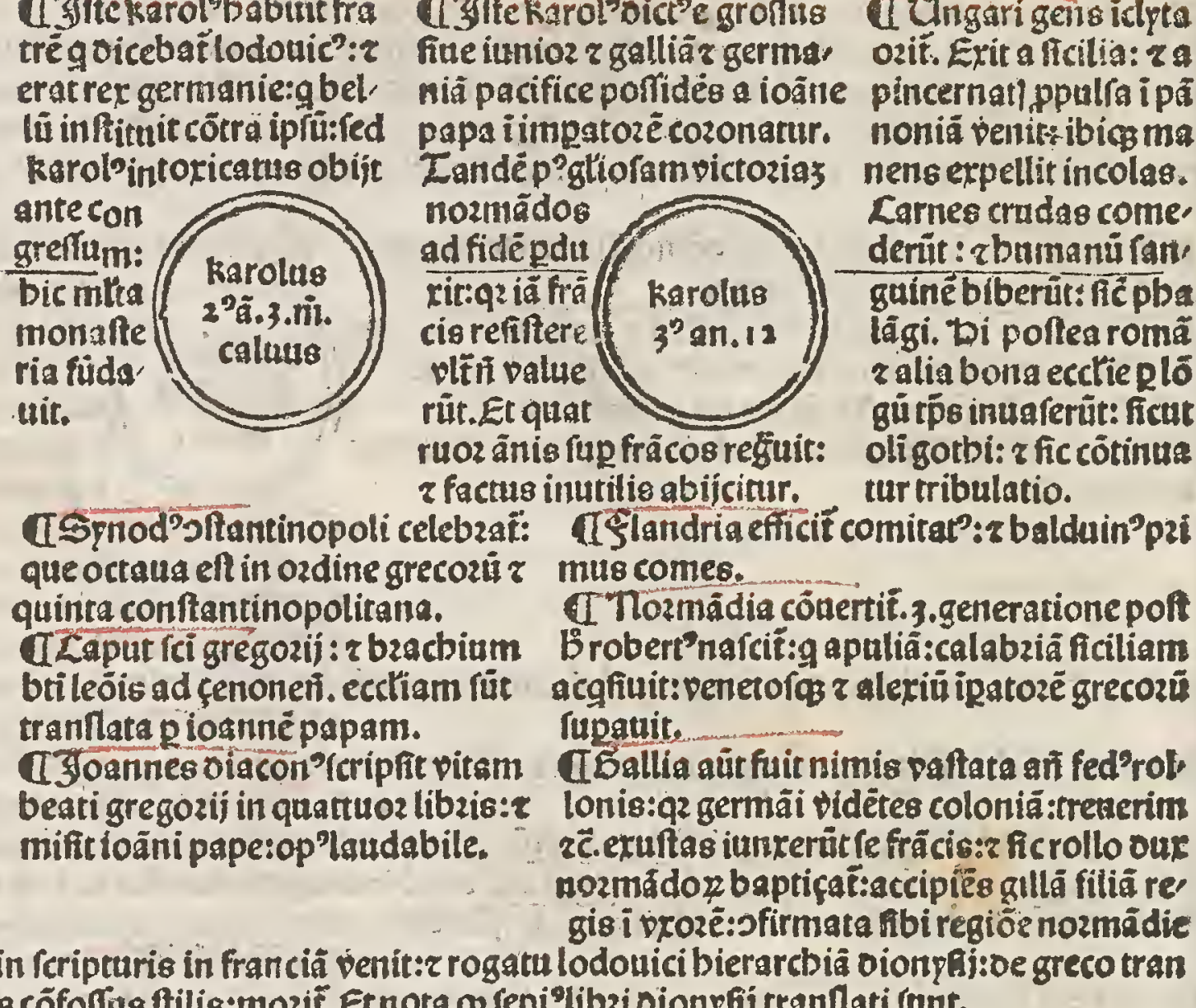

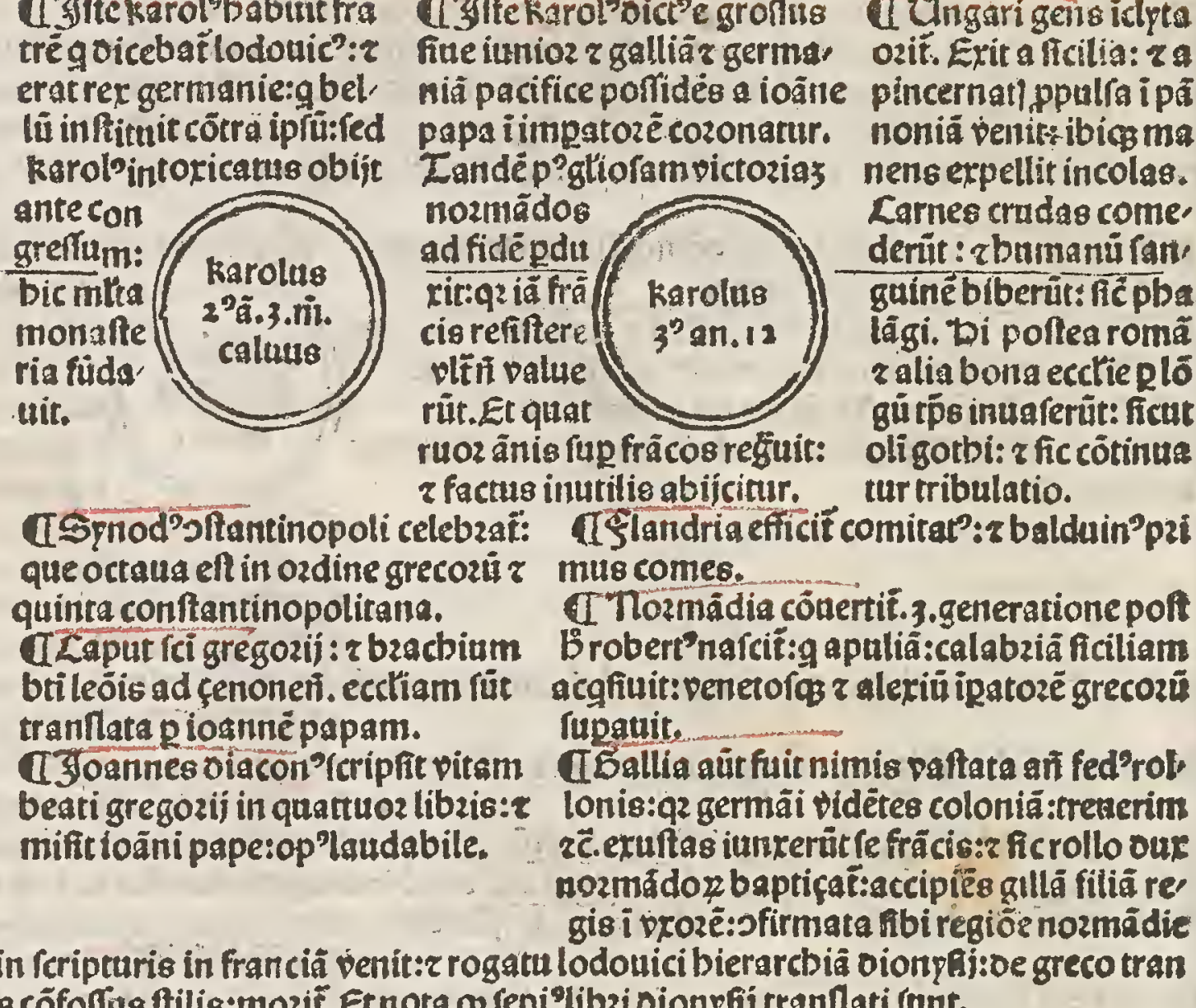
(1)

IIbaritas refriguit valde:circa lfta $1 \mathrm{~g}$ in oiftatu: $z$ ini quitas plus folito cepit babüdare. Y̧a eni gladius a bere.

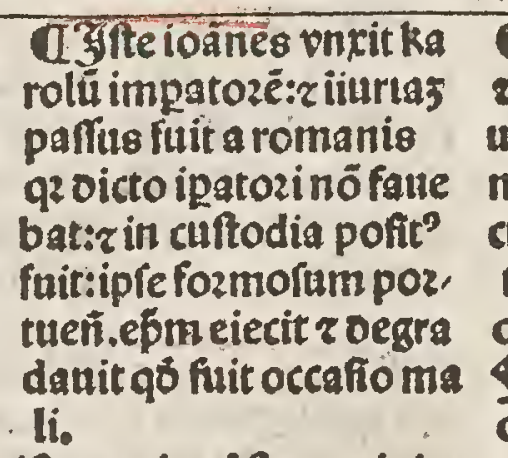
bition nes:xpianam fidem prequebant.

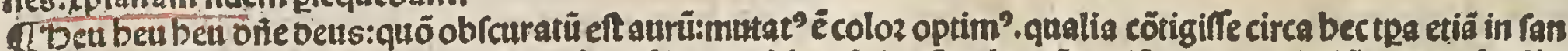

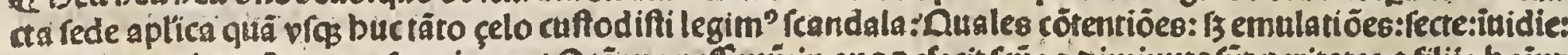

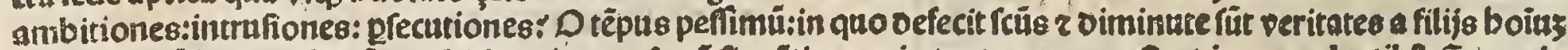

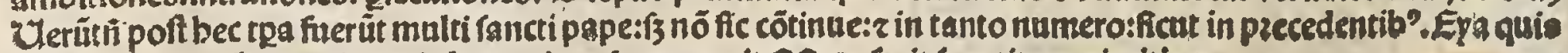
cōuentus:que cōgregatio:quis bomo iam fecurus erit:î ficoefecít fanctitas paimitiua. 


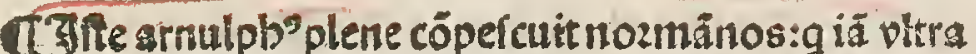
xl.ănos galliâ vaftarút.tandè r medicis:oépatus mi' rabili infirmitate:its ut a pediculis confumerễ:oefe' cit:z moztuus eft.

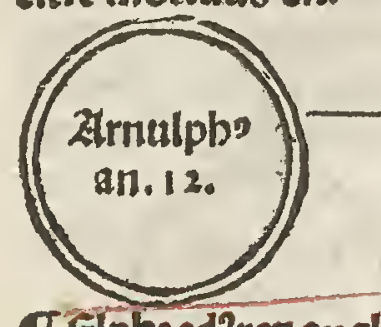

CElpbzed ${ }^{\top}$ rex anglie vir tot ${ }^{9}$ Bttuolus:octo bozis i ozãdo legédo:z freribédo expendit:octo in negocije regni:octo in cura'cozpis:redditus etiả optime oifpenfauit.

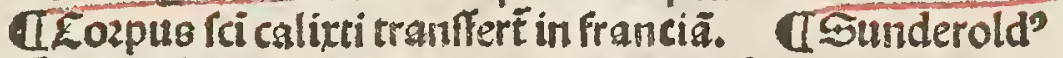
eṕs maguntie: nozmänis martyriçatus eft.

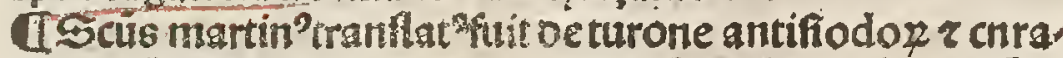

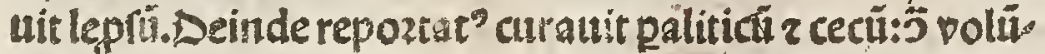
tem eo
ITeformatio ponq ozdinis fci bridicti: $q$ iam in plerifo locis cecidit : facts eft circa bectga R cluniacen. Diutrie fuerüt fepius caufa cafus bui? ozdinis facri:r pauptas re formationio.

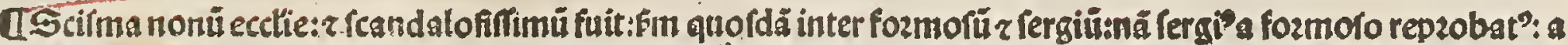

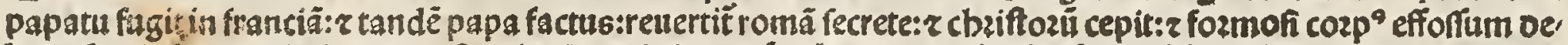

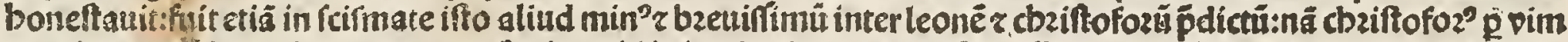

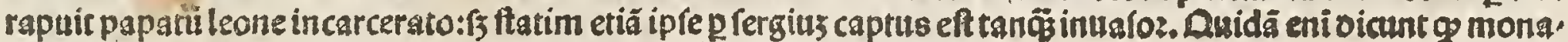
cbus effectus fit: $r$ multiplicata funt mala fup clerü $r$ ecclefiam totam.

A. Beruo abbas:0ziúdPex burgüdia:oeftirpe comi.

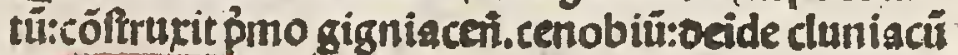

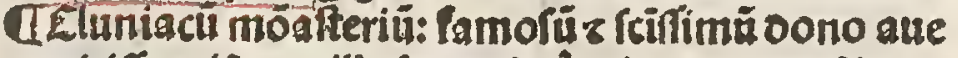
comitifle:etiâ a guilhelmo pio p̉ncipe burgundie.

T Scis odo monacbus cluniaceti. feruosé imona' fterije refufcitauit: $z$ plura feripfit: Dialogü gregozif ipfo annuente coartauit fub mo polumine.

CLomitatus blerenfie orit:er nobiliftirpenoman nozum.

TEellopimus.

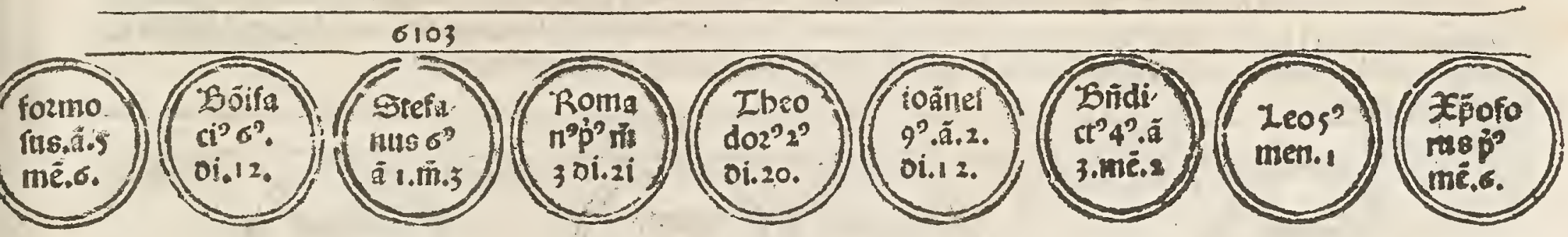

904

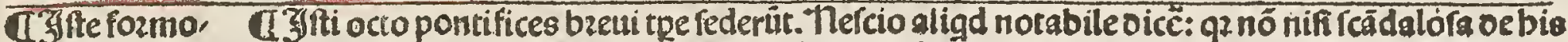

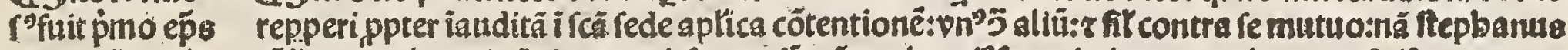

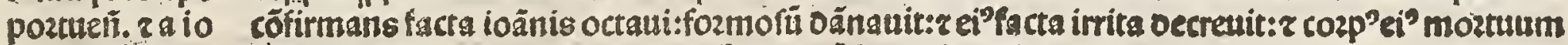

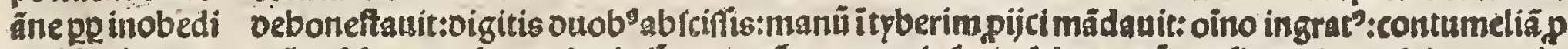

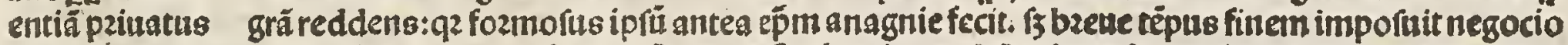
erat $r$ oeg̈dat ${ }^{3}$ rurfius tbeodoztis poft bec:oés actus ftepban i repzobäs: facta fozmofi appzobautit:filiter $r$ io.

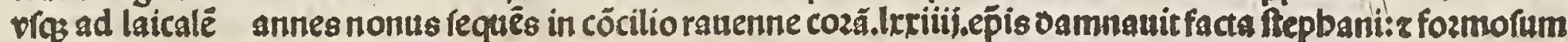

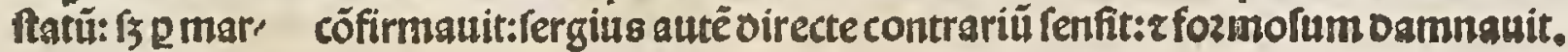

tinü reftituttıs

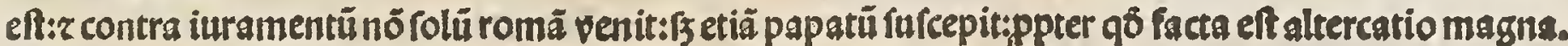

ILauromenia prbsa faracenis caota eft.

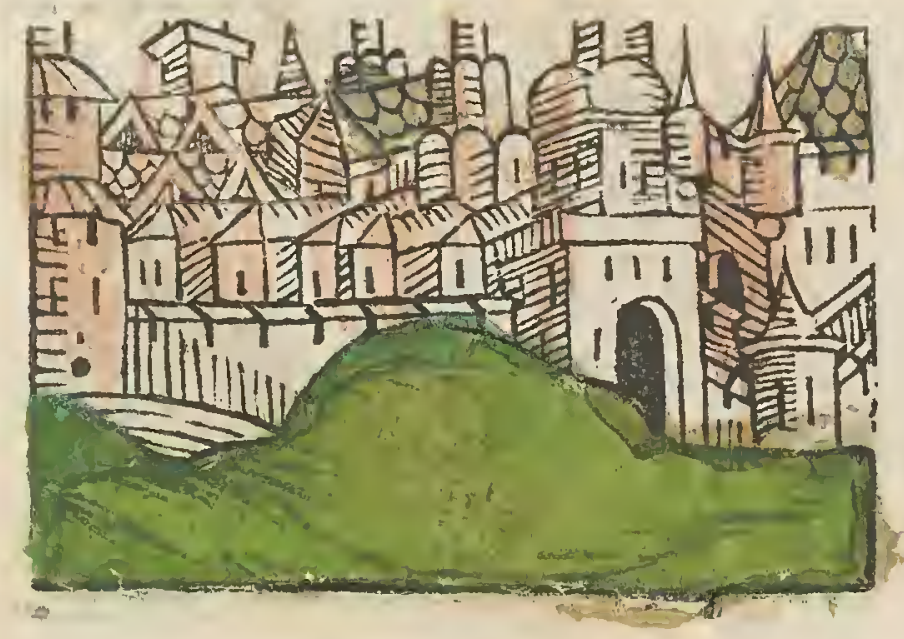

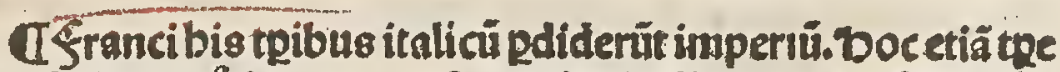
inditione. $5^{\circ}$. in nocte vifi funt igniculi in modus Rellarüp aera oifarrente8.Qua nocte rex spbzice:refidens fup co. fentiä calabzie ciuitatë: oei iudicio moztuus eft. 


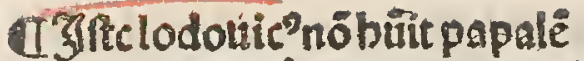

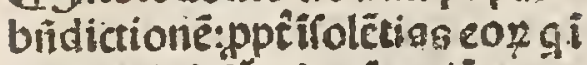
italia oliabất: $z$ berés sriú con bat expellerefs cüp ipo reğrece piffet veröe capit z excecat $z$ be rengari' reftituit. Et bic bltm? Deftirpekarolina gimperiúte, nebant.

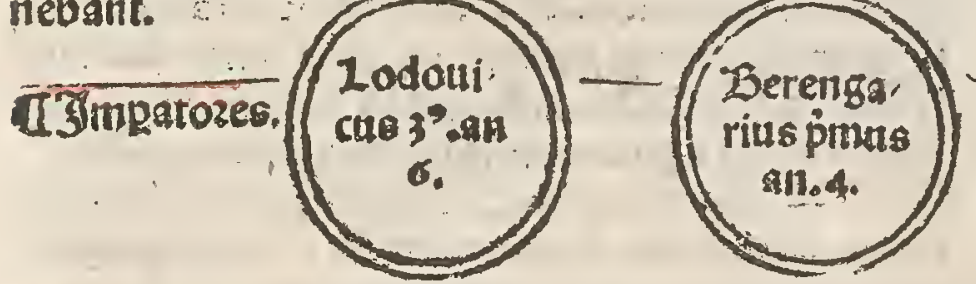

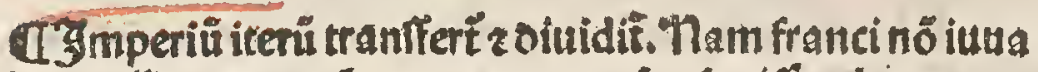

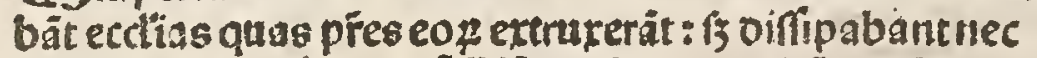

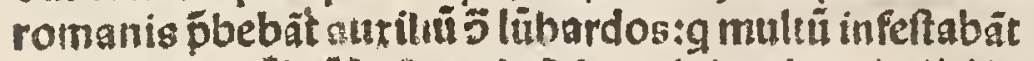
cos:ideo oe cởi côlenfu ekclû́ funt ab impio: r italici in italia: $r$ almani in almania ceperút imperare vfo ad ot. tonế:qui otrobiqgregnantit. Fräci aũt cogüî́ nüc manere in terminis rus:expientes oin jerü elle piodü: ficut alij rotain foztune af́enderit $z$ ocf́cerderút.

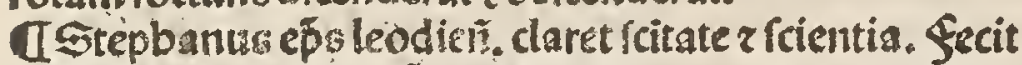
biftoziä rci lamberti cünotis z alia pitura.f. de trinitater inuentione fci fepbani.

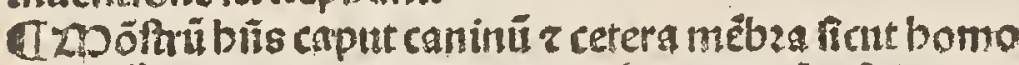

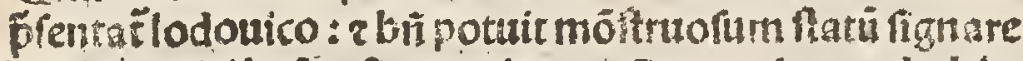
bui'rtis rbiboies fine capite quafi canes latrando binc inde vacillabant.

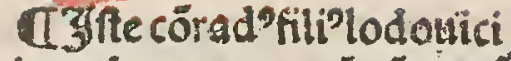
inter iperatozes nō cóputat Q2 1:ö regnatsit in itolia: fed

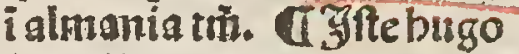
in iralia regnauit trin:nec có putat int impatozes.fuccer fit berégario:almanus.
Tseifto berégario ii é Jonâtia ilibzis qũ reğuerit. Duidâ oicüt

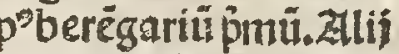
pobagonë: 5 nöeft ca rãdü. Ipa ifta fatl cö fura fuét: $\mathrm{g}$ pl'potuit

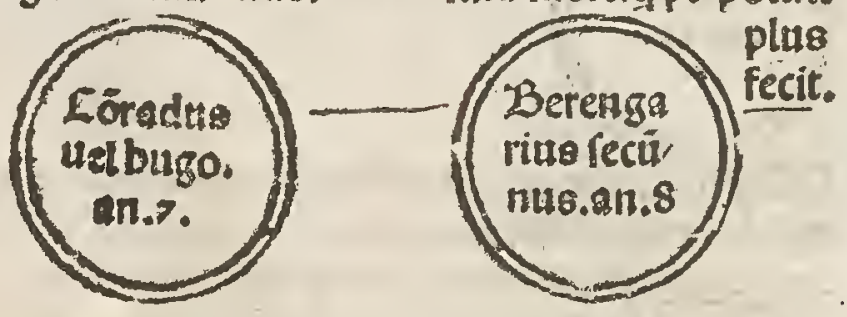

IDzdo eluniaceli.sirca bectpa incboat z pfecit ima gna bunilitste z feruoze: $z$ babet regulä rci benedicti TOdo virfeús pzimus pater eozi.

USaraceni qui oñabant circa bectea in italia: Deui crifunt sioanne papa z inarcisione alberico.

CUngeri incipint romā z ce era bona ecelie vaftare r totä tufcia oeftruút interfectis marib' $z$ feminis oia rpolia feci poztärer. Taris eo per rex fuit g oecē modios nùmozü recepic a berengario z $p^{2}$ fingulis anisredeü. tes:fines röanoz in ina dere folebãt p multa tpa. Lau. rabui ${ }^{9}$ mali fuit ingratitudo romanozü:qz pzedictum marchioné expulerüt: $z$ ideo vltuts fe fuic boc mô: too cando barbaros : ficut narfes olim fecit tre iuftinife. cundi:poftea interfectus eff.

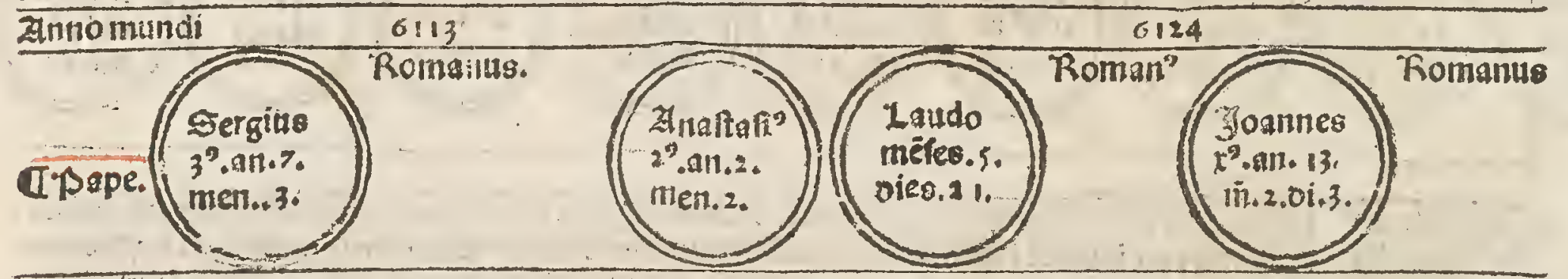

Alinorpi. 914 924

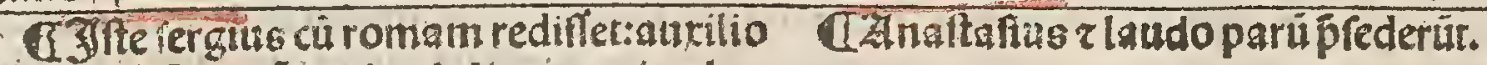
francozí xpofozi cepit:zfeditp co: $r$ in $\nu !$. tioné fue repulfe cosp' formofie estraxit oe fepulcbso:z indutum facerdotaliter:in pontificali fede occollari fecit:z i toberim $p$ ici

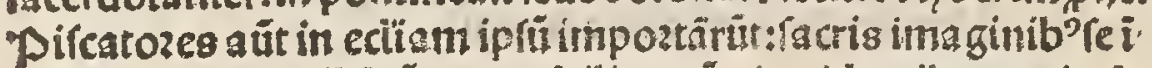
climätib' z falutâtib'cũ venerabilititer:cüctis videntibus qui ad, erât. Dia infug que ip le fozmofus fecerat irrita oecreuit.

Sipontus cituitas apulie:a iclauis ex gladio:bis tpib?paftar.

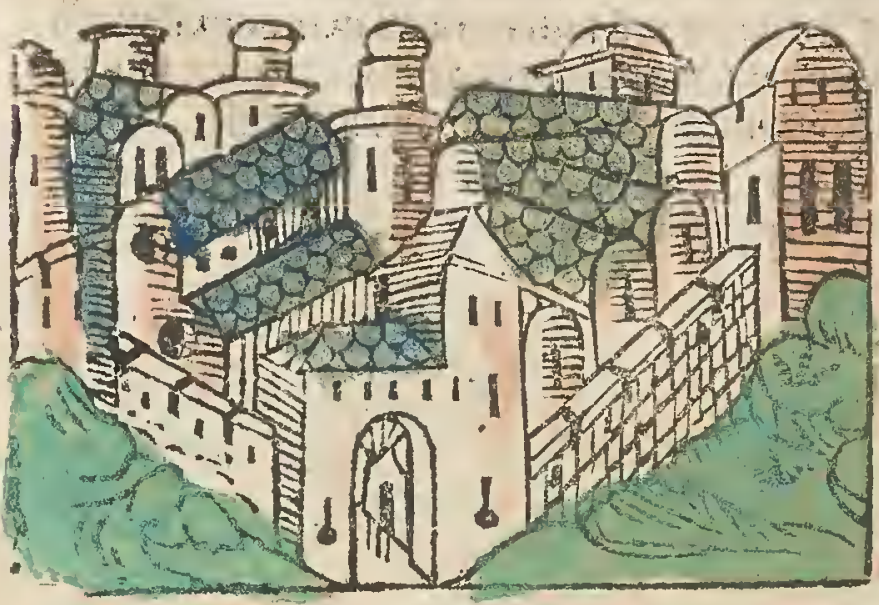
rapuit pzefulatü : tandē miferabiliter occidiêt a militib?guidonis:polito puluinari:fuper os eitıs oü in carcere tenereț. poft eú quidẫ alius ioanes intrufus fuit:5f tatim eiectus eft: rideo nö poniť in catbalogo:qz nö fuit r $r \vec{c}$.

Iarentū ciuitas apulie:ab vingaris capit̄.

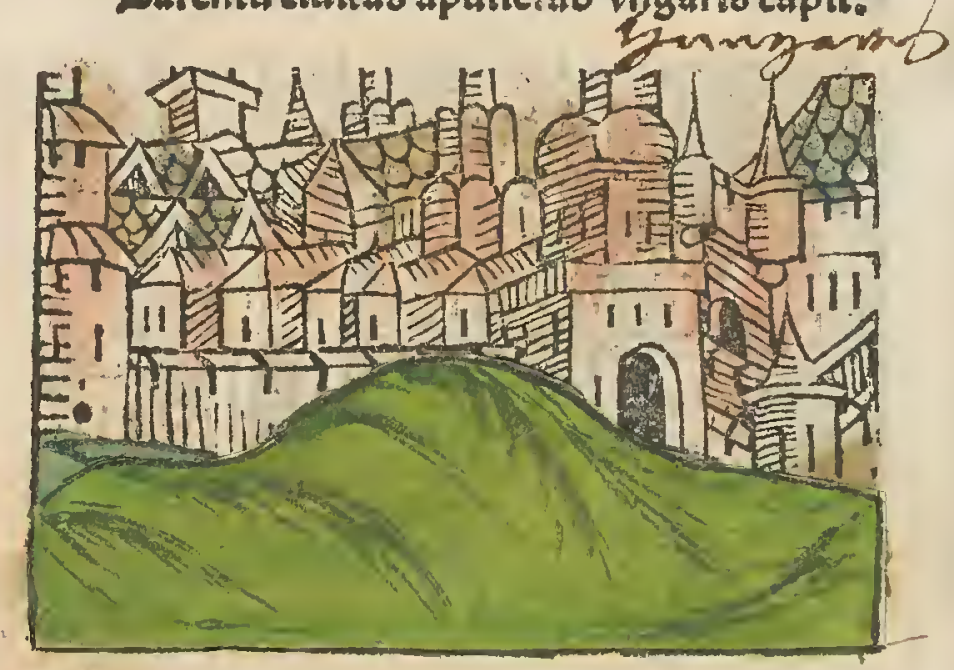




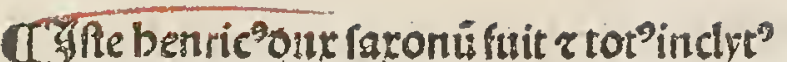
nec ipfe int impatozes cóputat: qz trīi in al

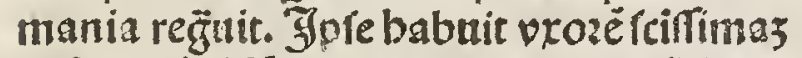
noic matbildä: er qua genuit ouns filios: ottoné $z$ benricü: $z$ otto rusceffit ei in impio z benric ${ }^{3}$ in almania büic ples terras:terriú filiú genuit noie batunone : g eriä rcús fuit.

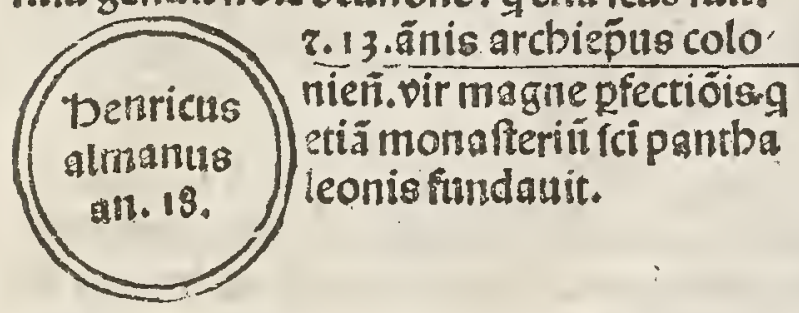

IFcüs Dibertus g cenobium gemelater. fundauit:claret in lotbotingia.

TRegino abbaspanteri.cbzonicä rcripfit

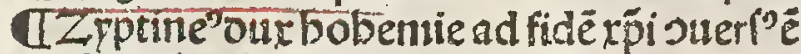

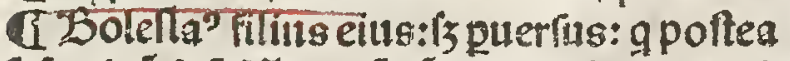

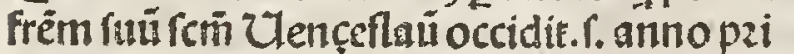
mo otronis pmi r ob boc ab ottone cun to ta bobemia fugatus fuit $r$ vaftatนs $\mathrm{g}$ ànos 14.

CFons fanguinis furtiante:lignificans cladem ftarin fequenté p faracenos g eam ceperür z occifis cücris fpoliarüt.

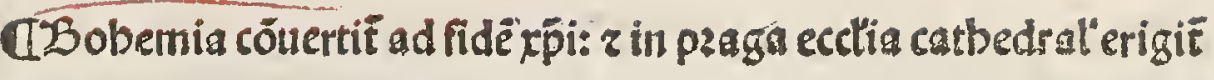

TSäcta matbildis regina vxoz benrici claret fcitate: fupza mo, dü bumilis z mifericoss : que totã firpé faronü fua nobiltauit vir, tute:becpoft obitü viri oiu in viduitate pmãfit: $z$ monafteria z bor pitalia plura fundautit: in adverfis patientiffima in ozationib' ita extitit puigil:ut totuz pralteriü ali matutinas exoluere folita fuerit: tandé Spu ppbetie mozté pzedicês:migranit ad xp̃m:Sanctam fobo lem relinquens in confolatione torius ecclefie.

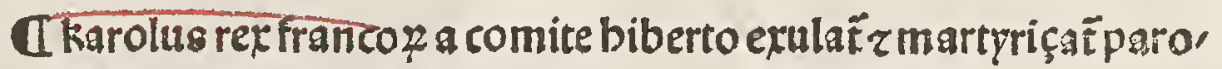
nam.

TEltbercantus rex anglie: vir mire oeuotionis flozuit ex matre bu. milis nationis.f.filia paftozis:que puidit ex fe pdire Lunam que to tam angliā illuftrabat:qo z factü eft: 'qz ifte rer tantã babuit oetuo. tioné a doiuinú cultü:ut nullī monafteriü oimitteeret indotatü.

G Zdamarus virfanctus futcelfoz rci odonis:abbas cluniaceit.

IL Leodardus abbas fci elie claret fanctitate.

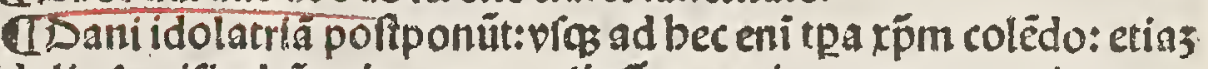
idolis facrificabãt:oicentes $q$ oij effent antigozes z potentiozes co 13 clericus quidã.f. anfgarius ว̈dicens: igniü ferrũ poztauit illefus: zfic fuerunt plene infozmati.

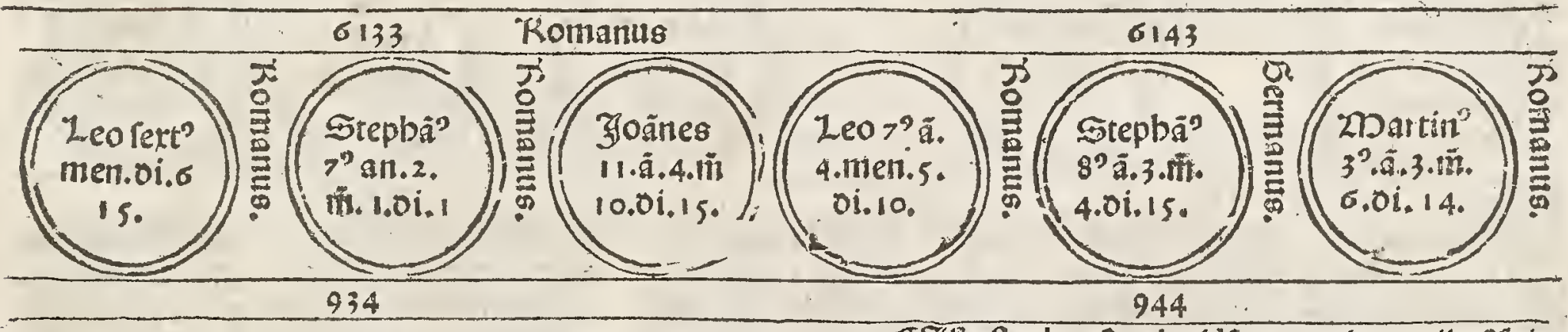

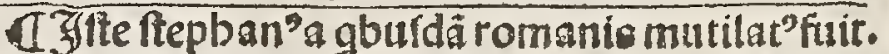

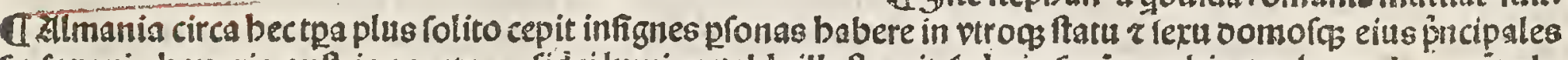
f 5 faronie:bauarie:auftrie ac ceteras fidei lumine valde illuftranit fed $z$ in fapia pzobitate plures claruerut glo riofe a naiati füt füt in ozbe. Sic fic oü vng gens cecidit altera fuccreuit ut nõ gloziét ois caro nifi i patreluminü

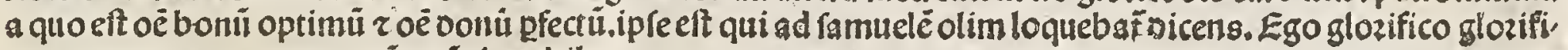
cantes me r g me contcmnuít erüt igmobiles.

Bobemia.

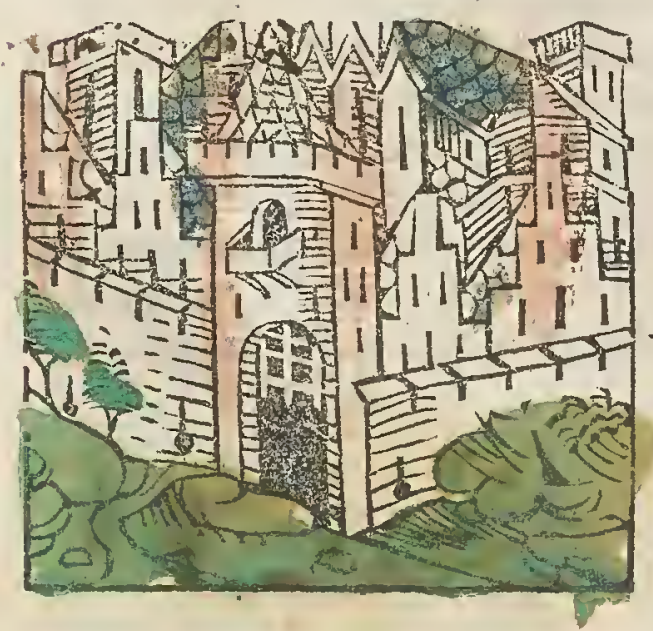

Saxonia.

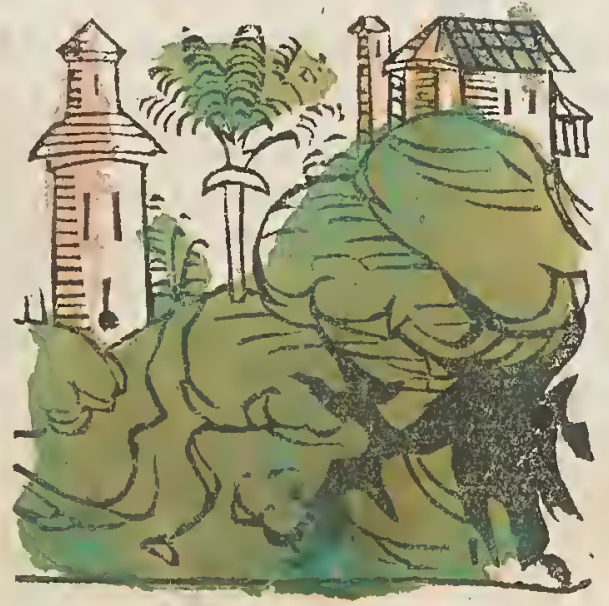

zuftria

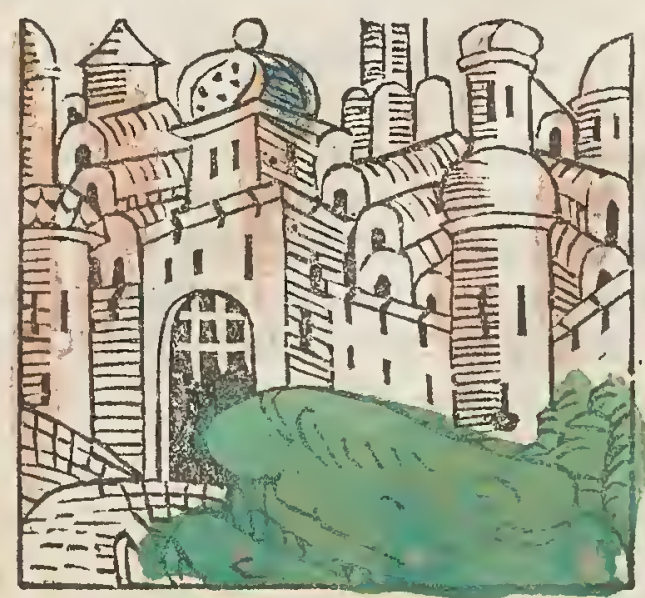


Tifteberengaripipetranit i italia: cui? toe fuit magnum fcifrns. Erbenricus mozit: $r$ otto ialmania cepit reguare.

13itelotbari? moziens qui otto regnauit:in slmania reliquit vko rem noieogluidä:quepoftea ei dem ottoni nuppit.
Q Zुfte berengaritis magns tranide pomebat italiaz quare onis papa $z$ alij romani vocaue. runt ottonem:ut liberaret, 0 os. $q \delta$ z factus eft $r$ capto $\mathrm{p}$ vim berëgario:bis exulanit elım a reli. ctam lotbarif libi brozê accepit quã tyrannus

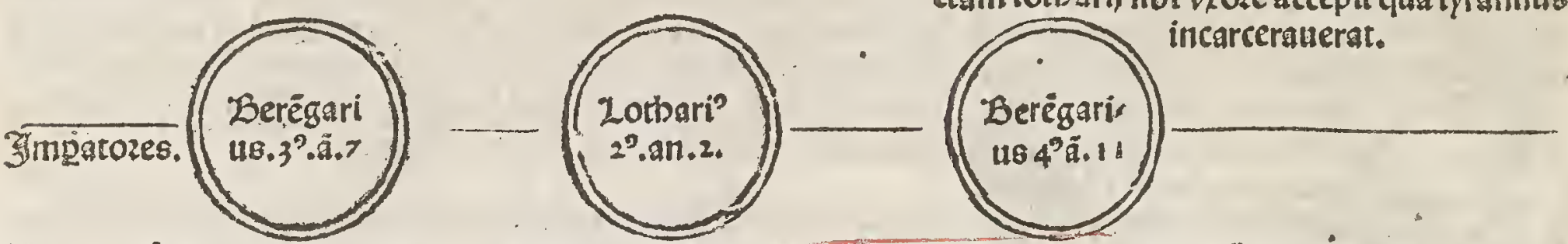

2)ençela'pinceps bobemie oe bono pïe:melioz fili" marţriçat ab iniquo frē rtio. Zfte vir fcūs fuit:bumi limus z mirericozdiffimus.

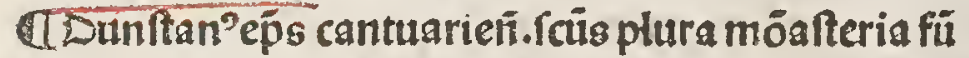
dauit 2 oidicit in oie noztis ab angelo. D rex gentiü Dinatoz oiuz $\tau$ viditueatä mariâ virginē rë.

U52uno arrbieps colonien. vir fcüs:frat ottonis $\hat{p}$. mi:claret in almania: vtrỉig gladiū ftrénue guberna do r fci pārbaleöis monafteriū in colonia füdauit:r

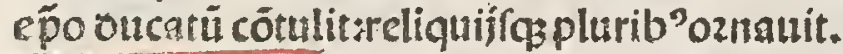

IScús odo ep̃e cantuarieñ. z cüs bzuno colonieñ.tran

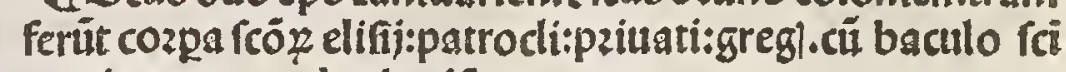
petri oe roma ad colonia.

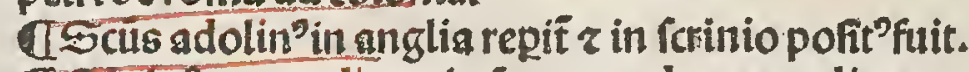

UEduin" rex anglie qui oés monacbos expulit a regno $r$ fanctü Junftanū in flandriā trufit:eiufdé fancti meritis ab inferis liberatur.

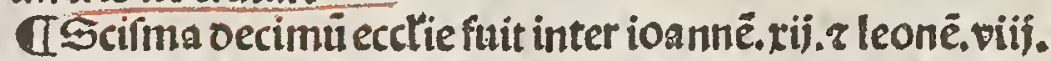
qz ioänes cü male intraffet: $r$ peilts vixiffet oepofitus futic z leo fubzogat?: \{ 5 tri leo obtinut auxilio impatozis licet iTserefis antropomozrafitaz in italia repullulat:fed bis fugatus fuiffet

parü pfecit:qz raberi" éps z ceteri extirpant eanm.

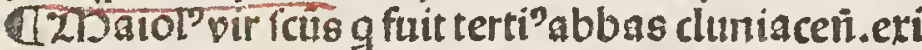

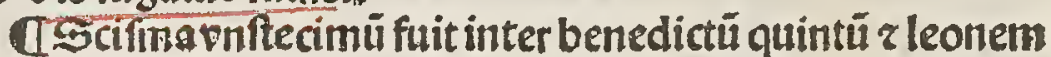

mii feruozis r abftinểie: $r$ repatoz monaftice oircipline claret.

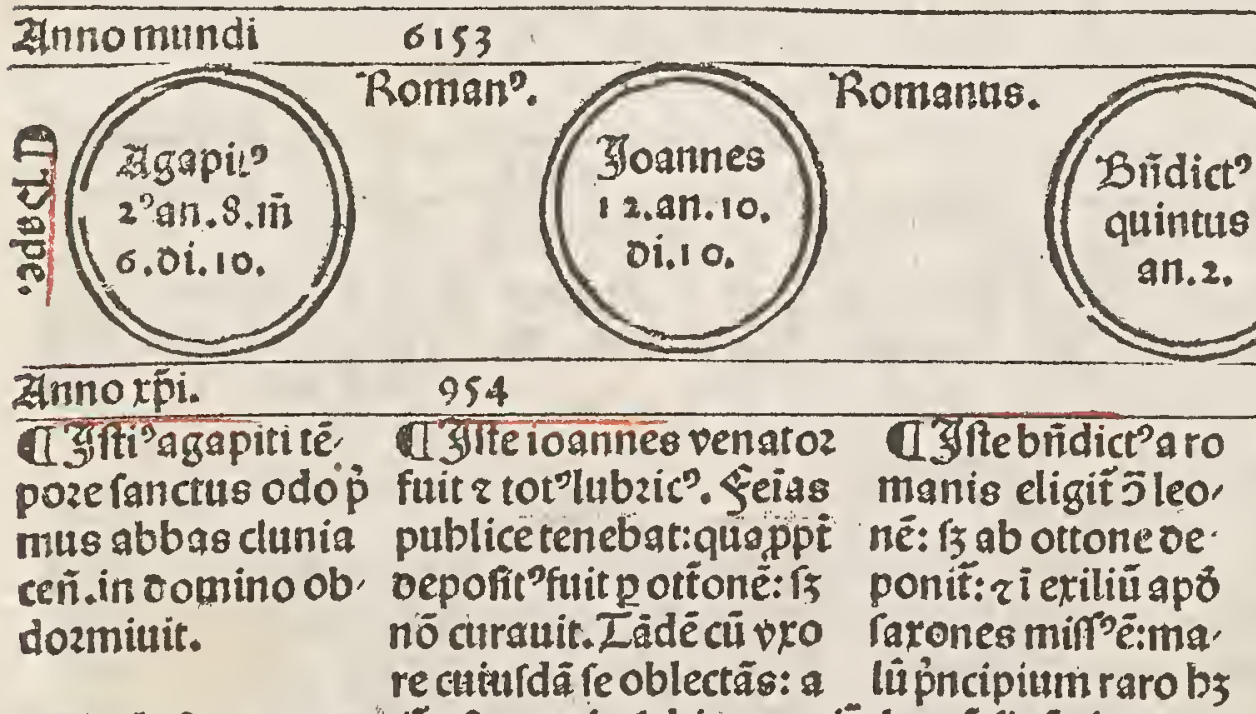

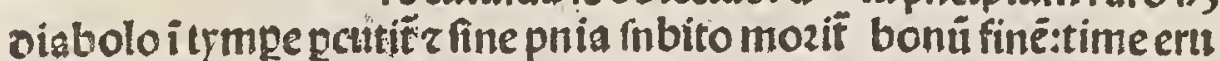
Eys ocus eterne: äs oifpares fut ifti pziozib" dit" piculo alterins

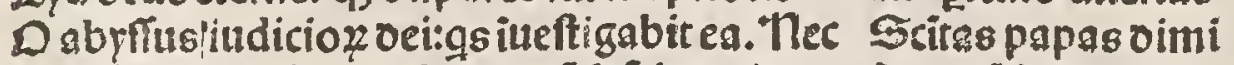
fuit ifte oigne electus: 5 p patré f́nú intrulus lit: $z$ ad impatozes quia potens erat.

acceflitboctpe ut ap paret.

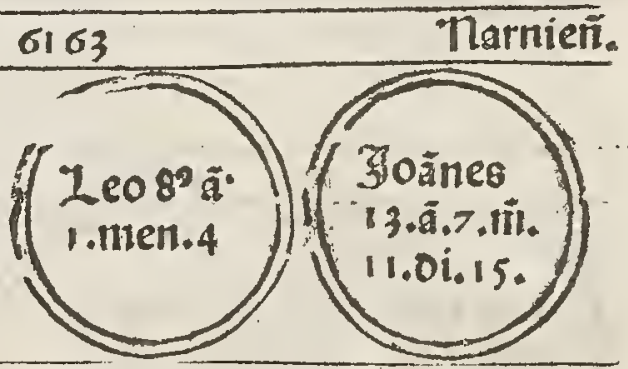

664

Q Zु̧te leo cōi poto eli git:Depofito ioāne: bic ftatuit ut null'papa fie ret fine cōrenfu ipatozis ppímalitiä röanoz:qui finos intrudebant : bic oés oonationes factas ecclie q iuftiniano $\mathrm{ka}$, rolo z alijs:ottoni con. cefitt $z$ fuisfucceffozii, bus ut italiä ab iuafo. Uyteiosnnes grauem iniurias paffus fuit a ro. manis:captus exul factus. Sed otto ourillime banc pcuffit:no. bilibus occifis zë.z quiburdam in exilitz miffis ribus offenderet.

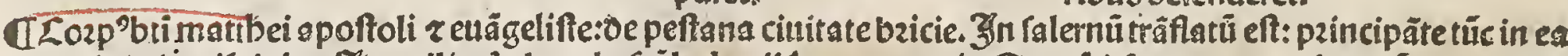

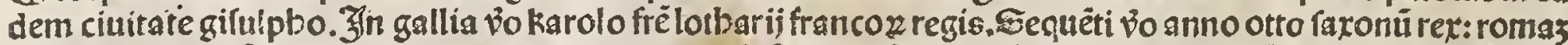

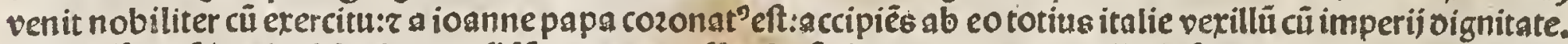

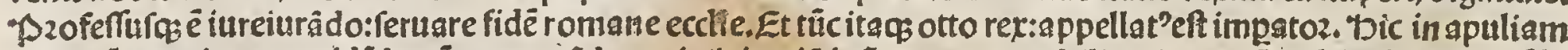

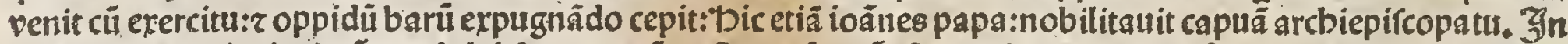
qua ciuitate pzincipabat pandulpb' cognomêto. Eaput ferreü. Eo tpe faraceni venerüt in apuliä:z expugnaue.

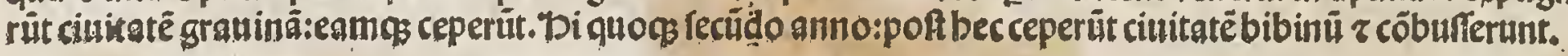




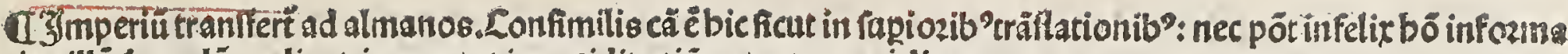
ri ut illü icopulú oeclinet:in quo tot iam vidit:etiã potentes periclitatos.

Q3ite otto pmus erat impatoz alaman?:tot?victoziofus z velut alter karol'eeclefie oei oeféroz follicit' $r$ pmotoz fingthlar|:ob qó meruit oignitaté impialē:multos infideles cöuertit:bitdictỉ pa' pã inafozểecclefie ourit fecū ad faconiā: ibig̨ in erilio mozitur.

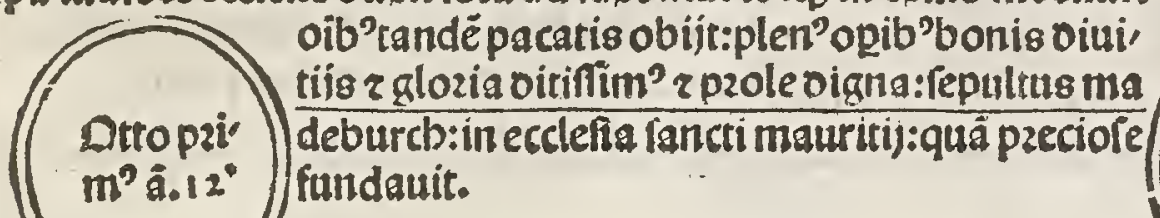

IEtgar'rex anglie:pene oi ano mo nafteriu fundauit.

4. Zlebeluoldus retrerèdus eṕs vin tonienfis:multa fecit.

Tomaldus reuetèd"vingoznie ep̃s p'ebozaci arcbieṕs : ramefie mona Tteriü fundauit.

ULbeodozic'eps meteli.claret,zre ligas de italia plures ad re träffert. Tixonity itatia:mulier bñs ouo capita: $\tau$ ceta mëbza vfos ad pmbili cü:una comedête uel oormiēte : alia quígi neutz faciebat:oiu vixerunt:? pariter tandè obierüt.

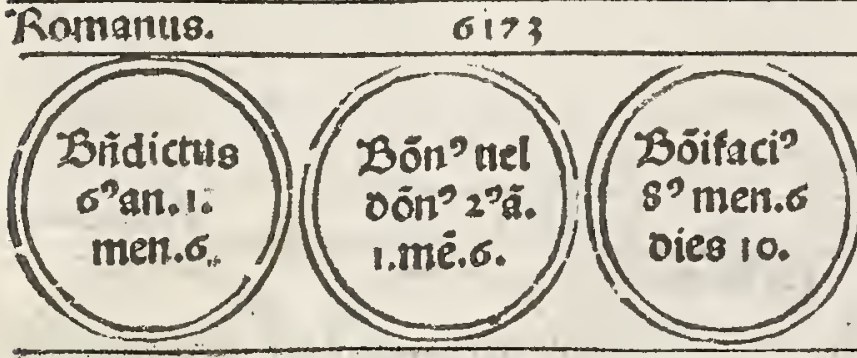

974

T3ztebridi ct? capt'fuit 8 icaftro fi angeli frä. gulatus.

(Gite bon? ueloonnus: etiaj parum redit. in papā eri, cöftantinopolim: p' reuerfus:iognni oiaco no cardinali oculos eruit:ipfe ocinde fubi to extinctusert.

fuerüt ludum almano p:vilis cōditio boiuz: ब'llota 9 bic occidunt:ficut in paimatiun ecch

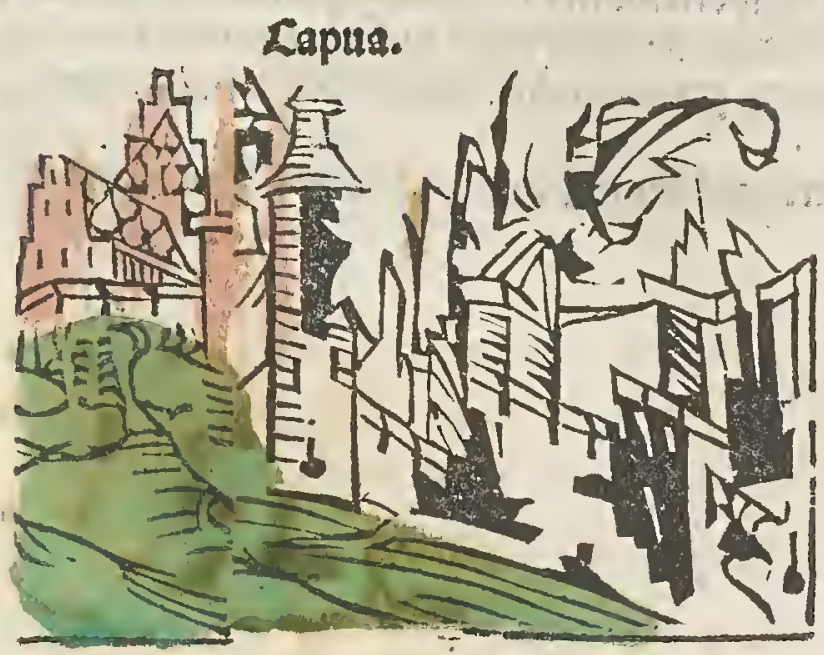

(1) Jfte otto fult filt ${ }^{\circ}$ ottonis pimi poia fidelis zftrēnu” defëfoz ecclefie:pinra bella sinfide

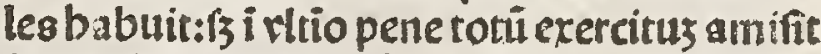
in calabzia:ipfe tri oú tota mére fanctū petruz

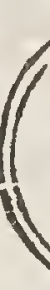

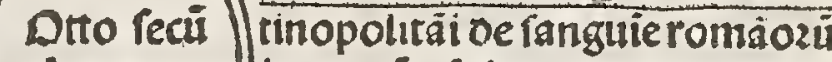
dus an.9. in vxozér fuit cozonatus a briti cto. $7^{\circ}$ mozit rome:fepult? 1 ecde' fia fancti petribonozifice.

TEduard? ret anglie bi cus claret: $q p$ ? a nouter ca lua iterficit: martyras efficitur.

ÜEctia madeburgëfis: glofe extruit z ootat́p ot, tonép̀mü z arcbiéps eius fit p̉mas almăic. Et nö tpe ottonis trij: fuit iea $g$ dā arcbié̄o noie vdo:gp

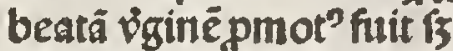
poppi malầ vitả borribi lie oänat'è. Eefla oeludo q2 fatis lufifti odo.
TAdalbert' vir fü s claruit natiöe bobemus z p̀mus eṕs pzageni. rendäte oco pãnoniam veniēs:fanctü ftep banü pzimü regē mngaroz cü multis baptiçanit: oeinde polonos in fide cōfirmauit:tandē pzutbenis p̄dicãs: ibi mar torio cozonatus fuit.

đI Lâlatio gloztola fcōæ laudoaldi:adria ni:amantiifit gandaui.

CUngaria incipit fs tpe ad fidé cöuerti vbip mo pedicauitpir oei fcus adalbert" eṕs pzageñ II Stepban" pzimus rex ongarie xpian"icus vir fuit: 2 fit gratia magna populo barbaro: $\tau$ idolatrie cultui bucurig oedito.

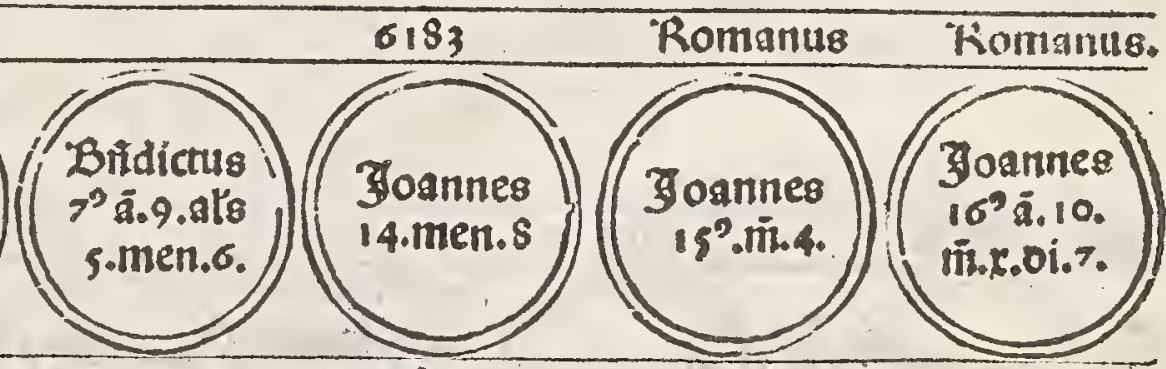

984

Tziteboni

faci?:p roma nosfrangu lato bridetō

Uß̈lte bridict ${ }^{\circ} \mathrm{co}$ ronauit ottonem recudur fecit capi ples rōanoz:con gregauit etiā cōci liüremëlés regé fräcie: ๖bi gilber tusnignmätic?oe ponit z rudolpbus reftituif́.
IISfle io. ànes.xiiii. loănes icaftrofci rv.etiä angelifa; parum meafflias pquattuo2 rit. méres oefe meresoefe

UGfte ioanes.xvi.funciar tib? entidt? : r ples libzos cópof́uit:búc crefcétip pa triti?in tãtũ afflixit $\phi$ vabe exillerit rp impatoze nun cios mitteret:qó audiētes rōani ipfū reuocāt: $\tau$ vfq ad ĉ̉ā pltrati veniā petut: tă eni aliquot annis expti

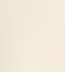




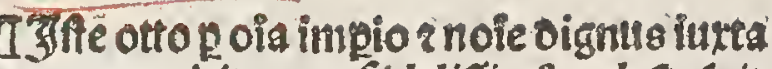
paternsm probitaten. Fidelifim ${ }^{2}$ ecclefie fuit multa bella pipegefit, Deor fcis ocuot'exti. tit. Religis foózvenerationé maximã exbibuit - loca reâ fedule vifitauit. bic cozonat ${ }^{\top} \overline{\mathrm{g}} \mathrm{g}$ gre

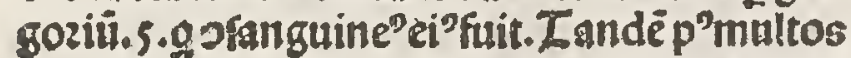

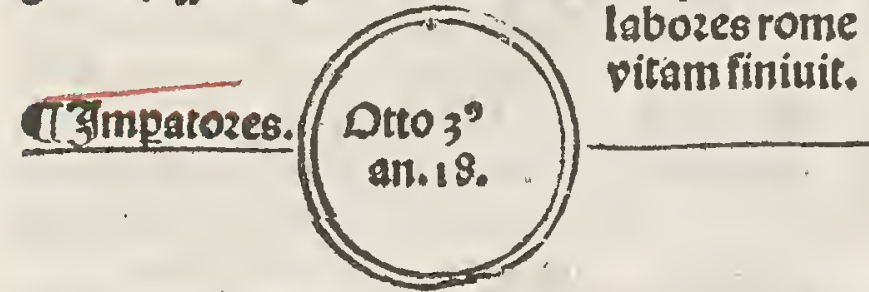

Ukarolina firps cijcit oe regno francie:comes parientis arripuit regnü circa bectpa.

Tomedericus abbas aduenf clarts baber. I Antiona pluit ó celo z pifciculi prui i albonia. TDdilo vir Icus abbas cluniaceñ. fucceffor fici

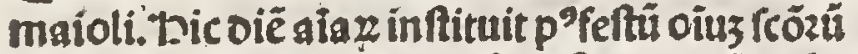
the ioänis oecimioctaui:qỏ poftea p totấ eccle. fiam appzobatum eft.

उScifna.xij.fuit int gregoziū gntü rioannem rvij. Laula fuit tyrannidis crefétiti : $₹$ ambitio ioânis:\{3 puo tpeoursuit: z gregozi? obtinuit.

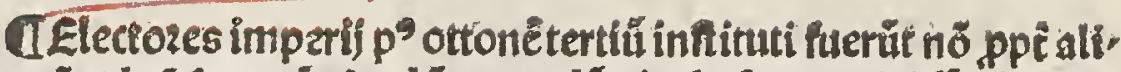
quã culpä faronü: $\mathfrak{\zeta}_{5}$ gd p̄cauendú picula futura. bi füt feptem ฟíus. DDagütineñ.treuteren.colonien. Ruilibet imperif fit can cellari'boy. Et palatin'oapifer : oux poztitoz enfis. 2narcbio

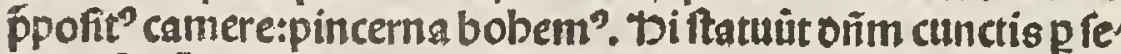

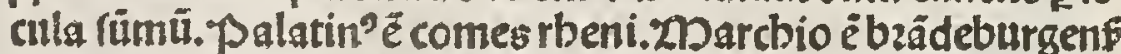
Dux faconui:z rex bobemoz. Uerü ut gdã oicit:bacoccafione aquila multas pennas amifit:z in fine totaliênudabit.
Iberibertus arcbiep̃s colonieñ. vir fcĩs clarus babetü:

İ Derigerus abbas lobieri.

TAdelboldus eps traiectei.

US altbertas eps carnoteri.

Ualloo abbastioziaceñ.

TElpbegus cantuarieñ.ep̉s:poft martpriçä a oanis. đİ̈n frid 'traiecteñ.e đIsüs gberardus eps $p^{5}$ martyriçat ab vngaris:ligatus fupet bigam $z$ oe monte currit.

IÉlla virgo pzudentiftma fozoz benrici impatozia: po R nu prit fancto ftepbano regi pngarie: 2 multú iunit ad plenã cōแe fionem vingarie.

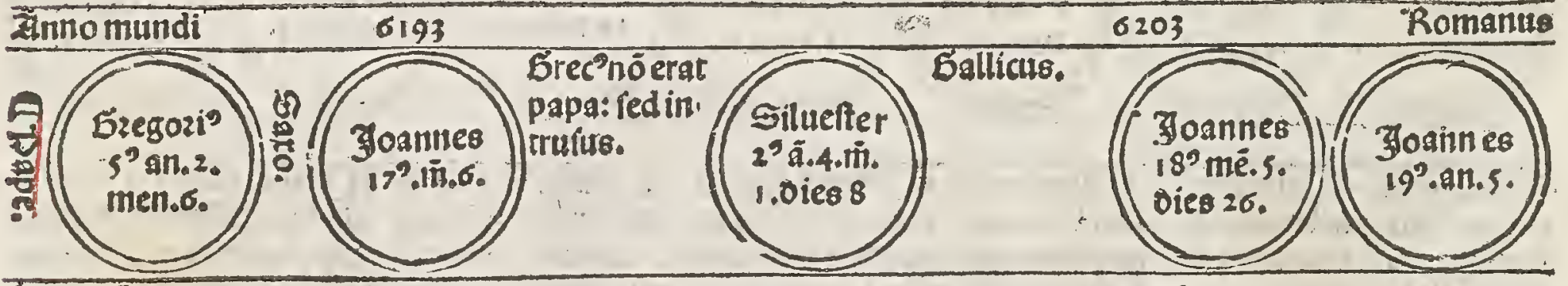

$\frac{994}{\text { Annoxpi }}$ peratozis ottonis tertij: vir venerabil:z ipfi? otronis confanguineus: dictus fuerat antea bzuno $\tau$ cũ parü fediftet: $z$ iã impatoz abvzbe recefliffet:placentin? intrudit a crefcëtio con, rale pter pecunia: $r$ ioänes lext' vocat. Et fa crüếfifma oieb²paucis. Tha impatoz retter fuz:cre fentiü cepit z capite trücautit. Joãne aût antipapã exoculari: ceter $\mathrm{mëbzis} \mathrm{mu}$ tilari fecit:nibil eü iutuntibus oucatis fuis.

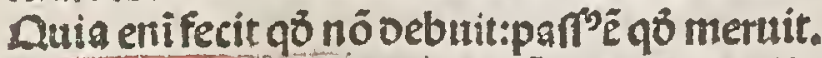
TEt nola 9 ifte gregozius cü ottone. $3^{\circ}$ ozdinauit electozes imperif:qui oeinceps pmanfertnt pfos nunc:nec pon aerunt frangi aur alij infrinzere.

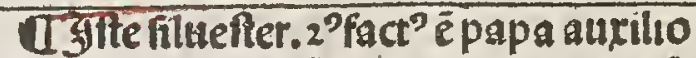
oiaboli:cui omagiũ fecit:ut cuncta ei ad votü fuccederêt: oict? fuit gilbert': r gräs regis fräcic inimic’fibi pcurault: vin fact ${ }^{2}$ eft ardbiep s remeñ.ti eiect? ftatim fuitp cöciliü:iubente brídicto reptimo. Deinde

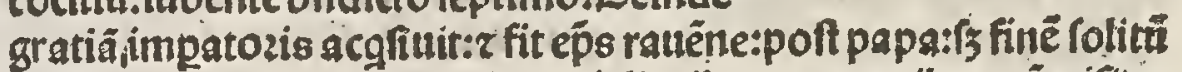
cito babuit: utputa g ́pem fuam fallscibus vemonibus cốmifit. Sperat tn oe eius falluatióe: ppter certa indicia repulcbzi ipfi? z pe

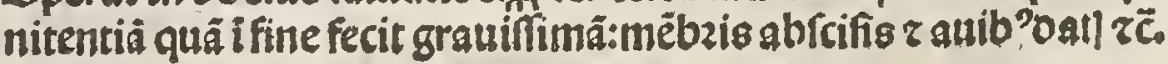
CIftiono ioanesp? fe mutuo federít r pri mus parnz ṕfuit:alter annis gnqs: Tepultus apud fanctü petrú. :

$\cdots$




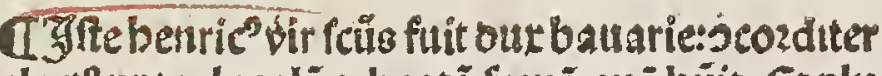
elect ${ }^{\top}$ ppter legalẽ $\tau$ beatã famã quä büit. Et plw res de oomo battarie le gim? futfen

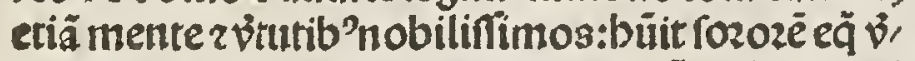
tuofã quã rcō ftepbano regi ingarozí oedít $\tau$ totã pngariã ad plenã fidē pduxit:vroz ei’fuit fãa küne

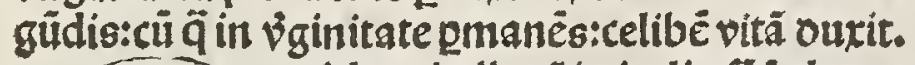

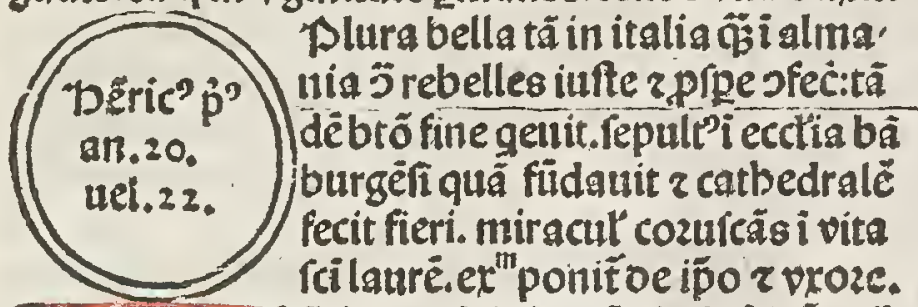
UThobert'rexträcie spoluit fequêtiä: Sci fpüs zë.

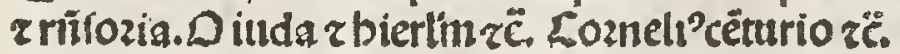
cú not $z$ alta. Eripe me zë. Jp pre fuit vir miaz.

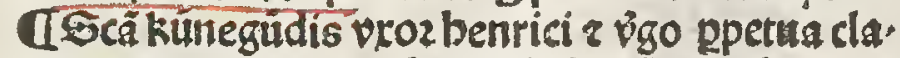
ret opibus bonis. poftea móafteriü igrefia: obijt miraculis cozurcans.

Troziçâtes gdă fueruit circa bectpg g p totũ ăniี raltabât ppter pctin infolétie:az ivigilia natiutta, tis rệi:in cimiterio quodâ cosiçando impediebăt quểả facerdoté i p̀nza miffa quä oeuote faciebat is qz nolebät cefiare maledixit cos cü imṕcatione oicés: vtinã fic p annú fáltaretis: $r$ factus é: fuerüt tandē a btō biliberto abfoluti: r quidā valde peni tuerüt:ita ut fci effecti fucrüt: $\tau$ miracul claruerùt: fm ăfdả stigit in villa faronie iecclia fci magni filia facerdotis cuitufã auulfis bzacbijs faltanit: fuerūt. 19.q̣rü tres feic erät: oés bzenif obierüt.
Ibiertfalcitex capiêtararucenis pinittente deo: 2 gliofí repulcbsit ab infidelib'por. ridet. Zudei mul tis ilocis metué' tes baptiçanti.

TLunglangai nể Ṕa apparuitz terremot ${ }^{5}$ magn? facla ardës r full gur inftar turris cecidit cúmario iplédoze:regt fa mes valida in lo tbozingia: fonti ticul"gâ ifăguine ฟैus ë:r multa fi gina curca bectpa côtigerunt.

Tisoztalitas fuit maxia pene g totü ozbë ut fe peliêtiữtedio ad buc vini ppintra bétes obzuerét cú moztris. Siccitar mağrardoz fegé.
U 3ुfe colradus nultas leges edidit pacé oiftrictifime ferture fira pena capi tis inffit : 15 comes lupoldus acculat's 0 tra fua fugit: cupiēe magis rufticane vi. uere ö folêniter mozi:cui?tri filius mir bilit ad ipiü puenit nutu oino 5 volunt té cốradi:etiã filiã eius accepit prozem. Zligetiá oicī gifte con
radus occifus fuerit anuo Löradus is.imperif́fti.

$p^{9}$ an. 20. Copmeon vir fanctus fi. if racufis monacbus : clarẹt treueris

IDurandiı eps leodiceñ,fuit:oe obrci ro senerenatus.

G'baimericus rex vngarie bjo cü fpon, fa fua obijt miraculis cozufcando: fuitcs filius fanctiftepbani regis.

A Eampanus ooctor infignis rocuots maximurca aftronom? biciuenit erroze paruú in calculatione Dtolemei quo ad mediü lune motü: videl 3 gin. 2160 . ane nis lunarib" oeficit vina oies : $\tau$ in gbur? dam alijo fimiliter. Excurat auté tantum virú $g$ boc nō puenerit ei $a b$ oefectư in genij:is ob penuriã tempozis:maxime a ad motü octaue fpbere: ad quélongúté. pus requirit eilis tbeozica z coputus fut optima

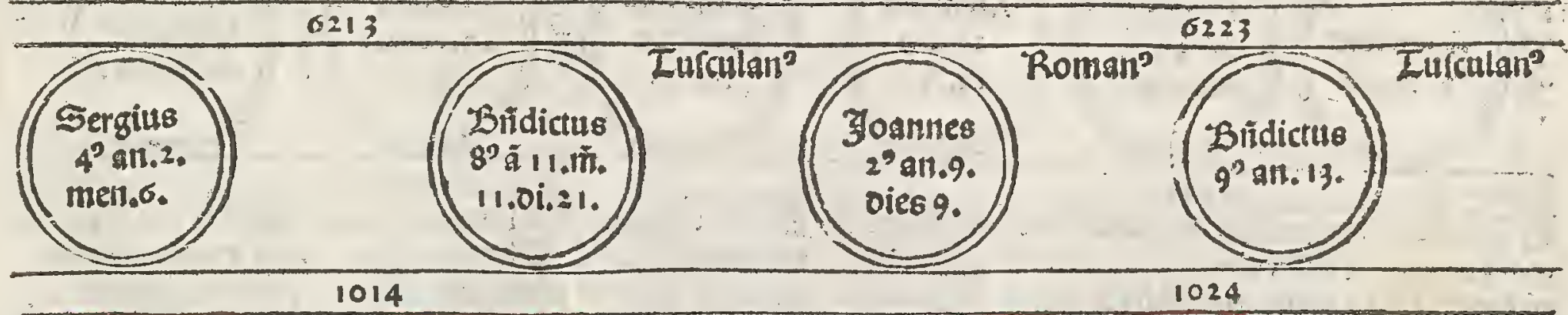

Tiglte lergius fuit fce vite r erëplaris cöuer rationis repultus in ec clefia fancti petri.

Q3/te benedict"babuit Icirma maxi muี::q2 eiect? fuit z gdã alter fubzoga" tus:búcp'mozté vidit gdã ep̄s in mi rerabili fpecie:oicentê re grauiţ affli, gi z o nibilomin 'peret ve mifericoz dia oei : rnibil frbipdefle aóple fa, ctum effet:q2 oe rapinis fuit:mifitqB eli ad ioannẽ papas ut oe tali tbeca fimä pecunieaccipet r paupibus oaret quod ipfe,fi deliter implens:epifcopatui ceffit $r$ timoze pculfus fibi puidês in futurü monafteriü intrautit.

a Rogerus éps beluacenf totus indytus claret.

IIScifma.xii).ecclelie fuit inter benedictũ octauũ $r$ quendam

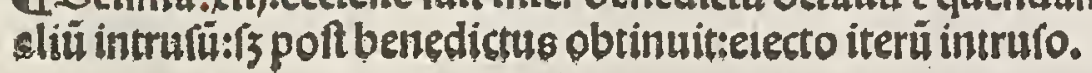

IIfte ioầne bellum ruit caidã in fpecie monltruofa z boz babuit ribili. Eaput $z$ cauda erät afinina: reli

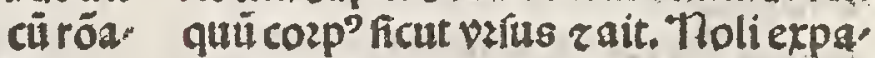
nis. : uefcere feito me boiem fuiffe ficut tu es is ficmereṕpento ficut olim exiftēs infelixpapa beftialíc vixi:tpe ei’ 'címa fâdalofin ninis fuit: qz ipfe ciect'etat zitez reftitut ${ }^{9}$ z iteri eiectus. CIscima .xiiij.eclefiefandalofun r viufione plenu fuit inter benedictü.tx. $z$ alios ut ps infra. Lã fuit mala vita buidicti:aut iniquแs introitus Dic notat Prolemens: $g$ sitt' fumozpontificit babutit femp malü exitü: z fut occafio: $\tau$ è caura multozs cirmatünotabile eft. 


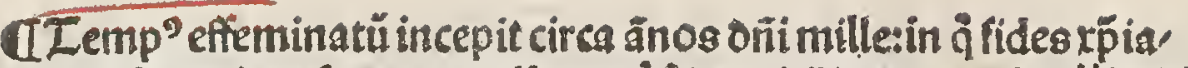
na valde cepit oeficere $z$ becliare a pitsina virilitate ut $p_{3}$ i mpia ree bildegarde: r i mulkis regiöibus xpianitar|nec facía nec eccïaftici rit’ fertubät:augarijs z maleficiis intendêtes. Et erat facerdos fié ppls:\{5 mifericozs oris ö 5 mala itez plures aplicos viros furcita. utit: $q$ bãc ariditatẽ bonis exēplisz pa dicatiöib"irrigarêt:oño coope räte Fmoné ofirmäte fequétib’ fignif. Ei multi ozdies nimio feruo

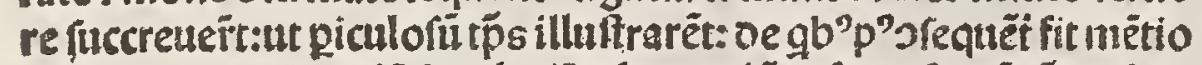

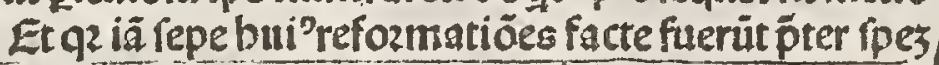
Impato2es. zi iequérib future fint: iō fatuu é oetmiare: $q$ anti tp̉s tücuel tüc ventetppí maliciả tpis: qơ pleriç at tentarüt:quos oẽs fefellit fus opinto: $r$ enägelica verifít fanctio $r$ ipfa tpis repzobaunit expientia. Doz errozu imenfusẽ numer? ASuilbetimus oimonenfis: GSulbert'carnoten. eṕs i infirmi' URichardus virdunenfis U'popoltabulenis. ELtiascotonien. Tarbertusteodiceñ. C'stepban'leodicé.qbbas

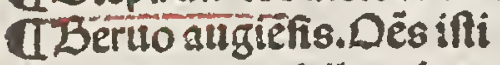
abbates venerabiles circa bectpa flozuerit.

Isado mufic i italia fuit g iuenit cãtũ manualē.r.per tatevifita a btä vigine z oe ei" เacte fanctifimo recreatus eft. đEnoto virfpü fapientie z fie da rus épsleodiceĩ.

Ibeila auguriatritin anglia fuit quà oemóo ecclia extraxit bozibiltr

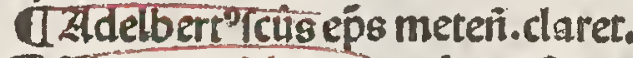
TElbermsabbas gemelatenfis.

CDardo vir fá̃s ep̃us magutie da ret.

flexuras oigito z notas oinumerädop pueris informandis.

IEgelmotus arcbieps cantuarieñ. mifit bzacbiü fancti Augurt, ni in angliam. Eius epiftolare babentr.

Zntrio xpt

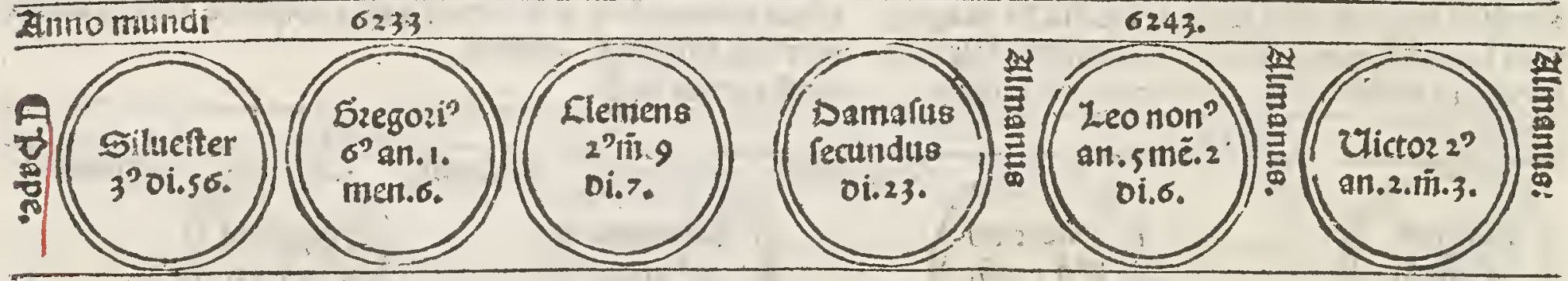

I Z̈tte benric" fuit gener côradi i filua nat? erat:z bis ad occidẽdü tradit": \{y tî̉ oeopte gëte iller" eusfit adbucpuer. Lü güt iogtos eêt effect": monafteriú edificauit iloconati uitatis fue. Üide pulcbzä biftoziāi i cronica martini z vincẽtij r $\ddot{c}$. Joic victoziofus fuit $\tau$ italiã intrãs pandulpbū cẩpa nie principé cepit. Zubbatévul denré redaut: $z$ g tüc potêtî́t

Denricus

ecundus an.17. mus fuit: oiabolo cãtäte búc oiēbellicorus feci : quens etiä increpatiat.

I Scus tbeobaldus vir nobilis ne francia reclufus beremita.

CRarolpbus mercio ap regis filius: marty. riçatus fuit a matertera

CEdmundus rex vir fcis:a oanis marţri çatus fuit.

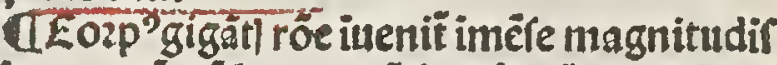
icomuptü:cú lucerna â ì poiat flatu extigui UStatua mamozed erat in apulia: cuitus caput oftendit tbefaurñ fubriliter.

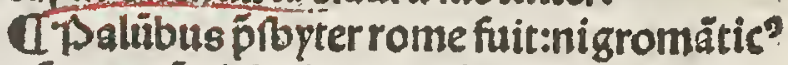
cōtra quẽ oigbolus ozauit zobijt.

(โ27Döftz:one mulierea i gallia oia mëbza finglavfó adombilicür ouiuifi opabát pna moztua alia fupuixit triẻnio moztuã poztã
A3fte filuefter elect? fuit expulfo bridi

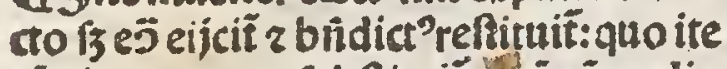
rü eiecto grego.fubftituit: g cũ eêt rudis lr̉ap:alterī papã ad ecctiaftica officia

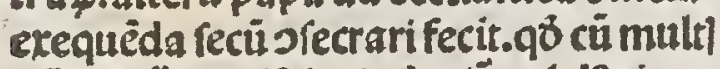

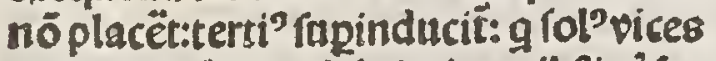
ouozs adipleret:gb"oimicantib'iné fe: benric'iggtoz fupueniēs oẽs oepofruit: $z$ clemétê. 2. fubftituit a q̊ ftatise cozona ri fecit:pmittëtib 'romäis fine ipfi " $כ$ fen

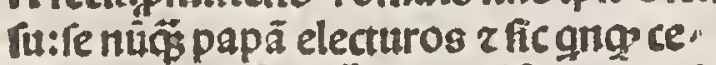
dêtib'fext'inftituit. vezz oe ifto gregorf

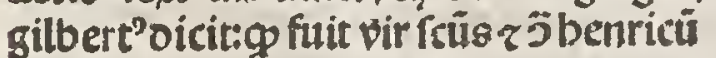
bellü babuit z raptozes fci petri extixit: scü magno miraculo fit fepultus zč. videin cbzonicis.
Oदfite cle més oict? fuit ain fin deger?bã bergenfis ep̉us:g fa. ct? frit pa papimpe ratozemp pter unio. nëreainä dam:utiã vicri eft.

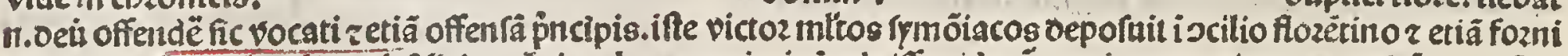

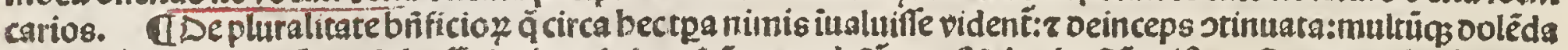

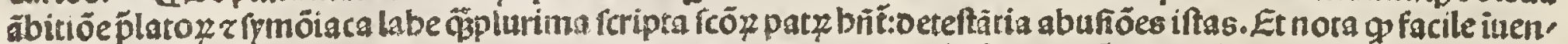

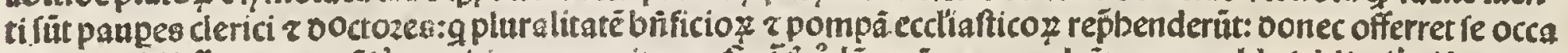

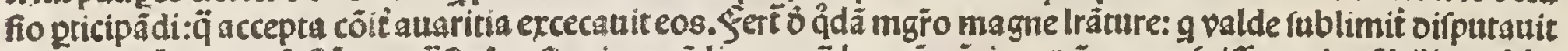

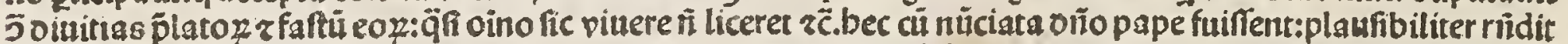

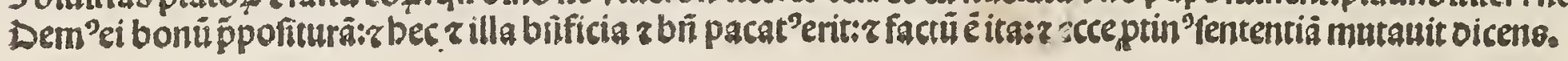

U. Ifte oamafus fuit intuafoz ecclie r ́rubito oefüct’ể. Et ftatim röani petierüt fíbi oari pốtificé: tonicii:ad boc eni nöpoterät incli nari:ex mala cốruetudie indurati. Zức iftüleoné viz fãctü ad boc in clinatuitut paparu accipet: $\left\{\mathrm{p}^{\mathrm{T}} \mathrm{ea}\right.$ fobi oe boc fecit cốlciam: ? refiğtuit

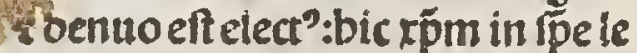
pfin nocte ilecto ituo collokãs:mane iṕuี î̉ inentit:tảdēp'taudabilế vitã [Cã nozte potit':mirarulis clars ip fe multa fcripfit 2 fecit, Erat anted eṕs tuleñ. $z$ audiuit ãgeloroicétes. ego cogito rogitatióes pacis oicit oomin?.
Gyite pictozbir bo nus z venersbit:tio re impiali factópe. pa: ficeniz oifpofita fuit aptica redeo boc tpe:p fici piri ouplici timoze le fubtraxe, rutt.f.oino z buano q2 tãto officio re idi gnos arbitrabät: $?$ tyränidèromanozã quttidie fuftinere te.

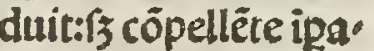
toze: gdamnibilo minuracceflerät filtr ouplici tioze: tiebãt

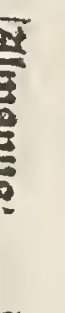
. 


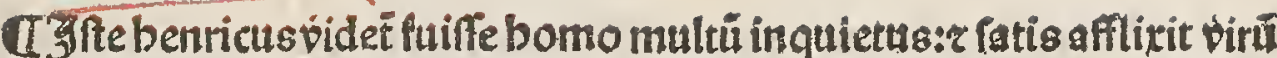

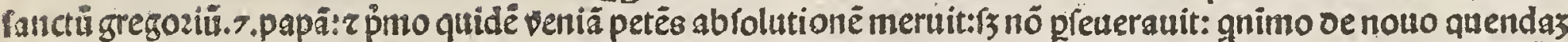

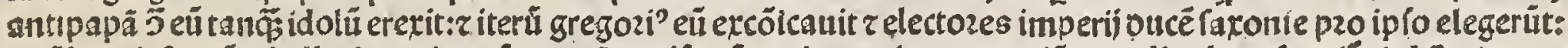

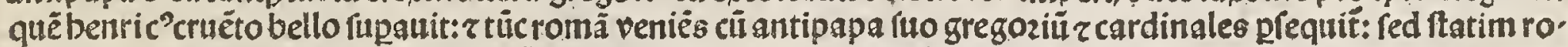

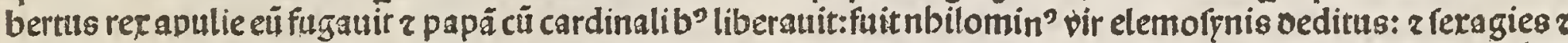

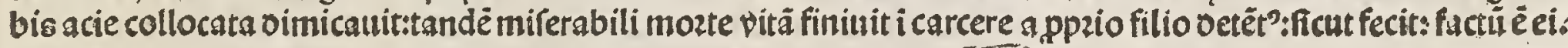

IEduardus vir fcūs rer anglie: claret Spü ppbetie:nec repperi plu res aliquos reges i aliquo regno äz in autglia.

CElburga vigo fca filia eduardi regis.

TEtgitba egdari regis filia virgo rancta claret.

TDaltburga vgo fancta $z$ abba tif́a fuit.

CBerégari?éps turoneñ.erronee oogmatiçauit ne facramèto alta ris:z poft infoumat'retractauit $z$

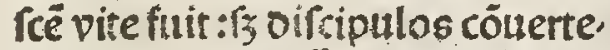
reneguit. Etregíberếs magna ă fat afflicit eccliaz lógo tpe:ip

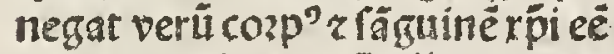

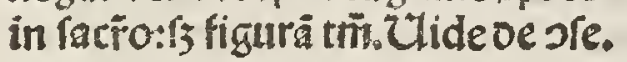
oi .ij.ego berengarills.

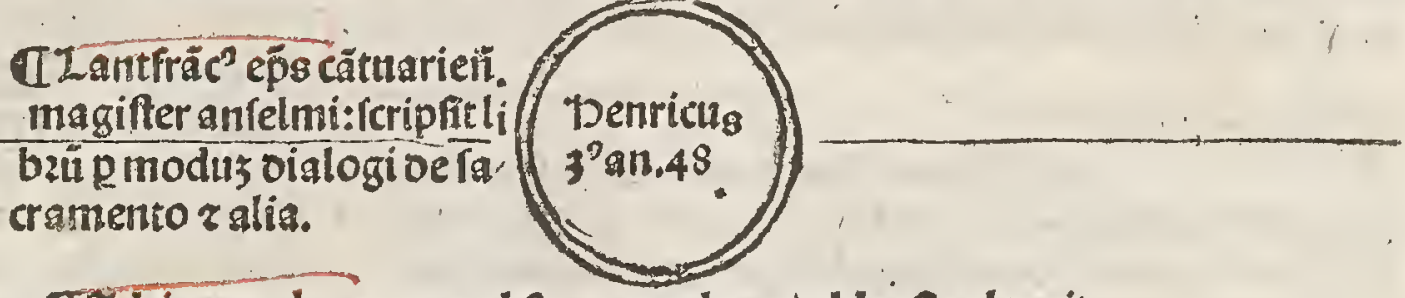

đसdrianus cbzonograpb'r monacbus vildenfis claruit.

IDerliutus abbas:monafteriü beccenfe oe fuo fundauit,

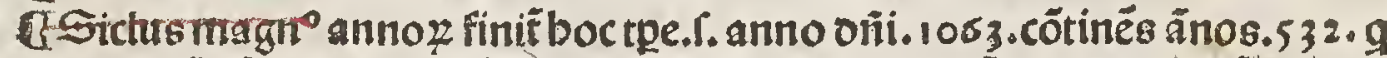

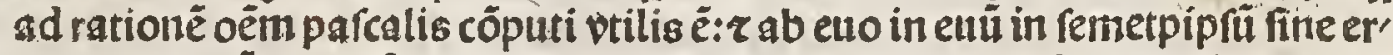
roze renoluit: $r$ fequêti âno ficlus magn?âno incepit in cui'fine erit laboz z ooloz ut gdä oicüt:terminabit̃. 1595 .

T20 atibildis comitifa triüpbatziz inclyta:nozmänos expugnar. z impato.

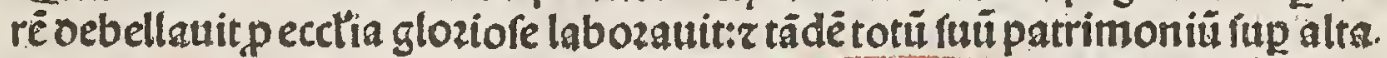
tare fi petri obtulit.

1"Detrogamian'ooctoz grauifime au

crozitatis r religiofus valde.

đScima.xp.ectie fuit inta aleran drù z codulü éprì parmeñ. 5 alexā der obtintuit:lics impatoz stradice Cद्या elmus vir fcís ep̃e cantuariein.do ret iudicio xcilij: z maioz pars fuit cto excellës z bté vigini oetrotus.

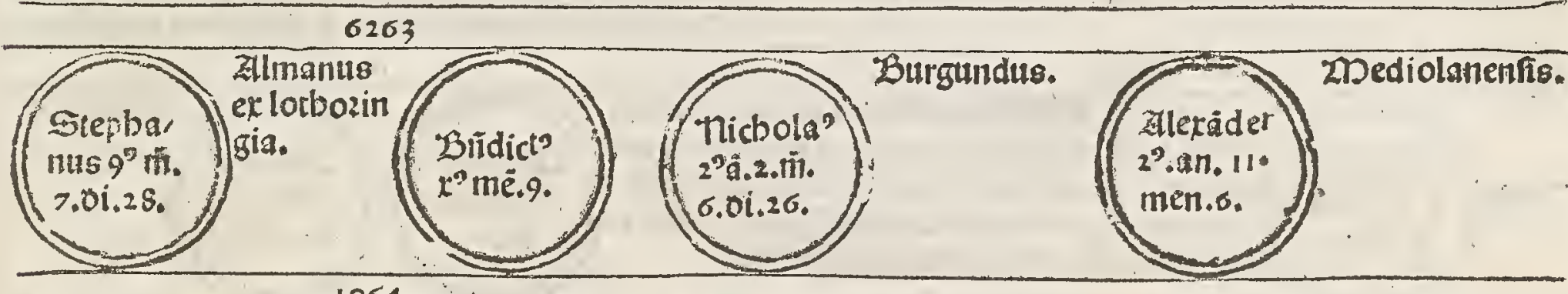

IJfte thepban'paz iupuixi. Et fequens Senedict" cü 2 vim papatü rapuiffer $\tau$ no ué menfibus fediftet celfit.

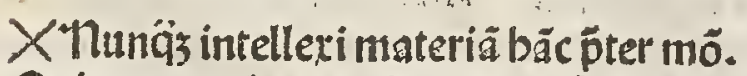
Quippeque inope oines:oe stêptibili re pétegloziolus apparuerat:bos btüs bie

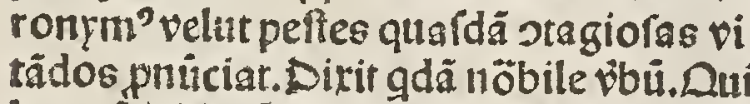

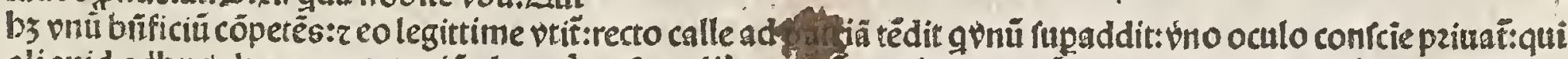
aliquid adbuc'plus acceptat:etiä altero puat’otalit excec t: $\tau$ oeinceps gcü̊s poterit coacertat:bä cmaledictio

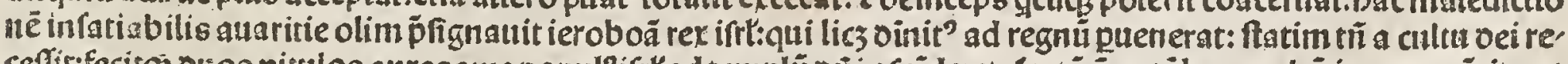
ceffir:fecitqs on os virulos aureos:ne popul'ifrt ad templü oni i afcëderet: factü é auté boc verbü in peccatü:ita ut

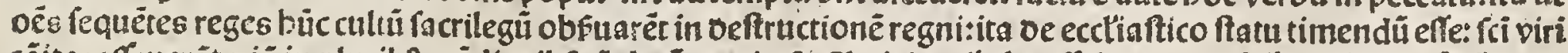

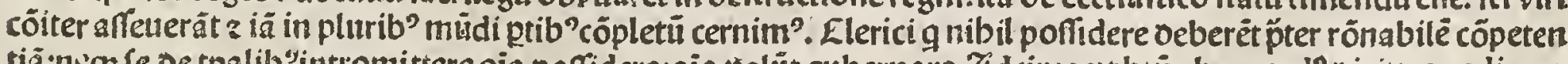

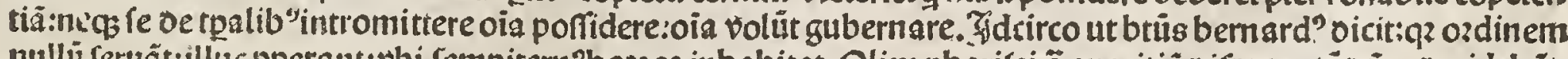

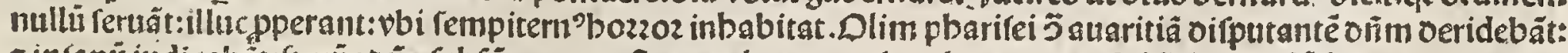

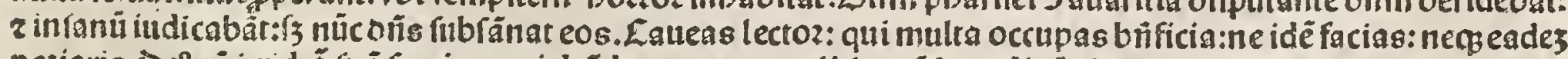

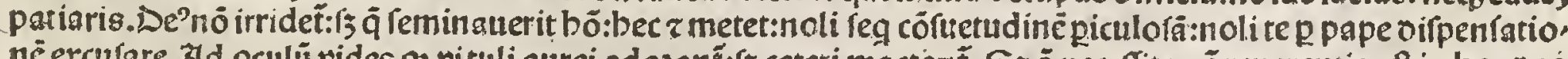

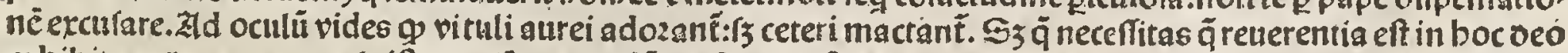

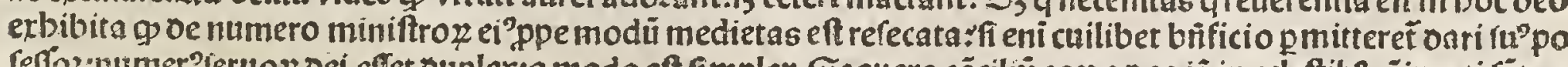

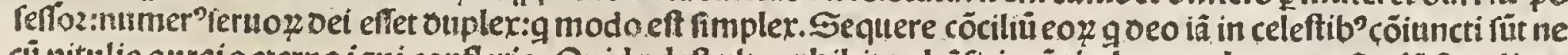
củ vitulis aurei sererno igni confleris. Quid pdeft vltra pbibitos brificiozú titulos coadunare. qũ etiä fimplices cöiter videmus in frugali boneftate amplius babundare. 
Ibodefridus bulion oux lotbozingie: victor gloziofus pecclia velut alt karolus vidiqgoimicat: g tãdēbiertm cepit:fact ${ }^{2}$ ibirer."babuit frèm eque victoziofus baldui-

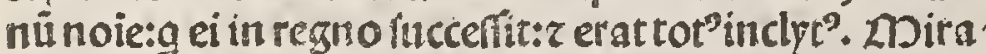
culora bella geffit 3 faracenos. Finit fuccefto regüiāglie

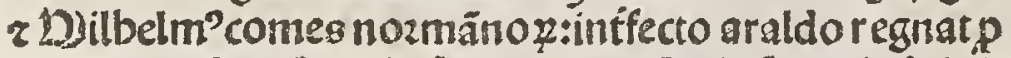
eo:oe quo fit mëtio ibiftozia xeeptiōis btë mariev̉zinis

\section{Tymperatozes.}

(1D2do grădimo ôten in choaťboctpe éfanctü virü ftepbanü nobiléguerno y ftirpite pgenitü. 120Dures infinite oueniür quëdã potentě: circüuallan, tes in quodä Juiuio:r nô poterä abigi:oonec oeuozấ renteü:idê cuidả p̉ncipi polonie cötigit:mirü palde. GSpraculans ciuitas magnü terremotú fuftinuit r ma ioz ecclia cecidit onica oie oibus oppzeffis:quattuoz ex ceptis miractulofe.

T2 Dauriliuo eṕs rotbomageri.

CEono epus treueroz:cui? tpe multa cozpoza martprí intsenitunt:quos olim rictiouarus occidit.

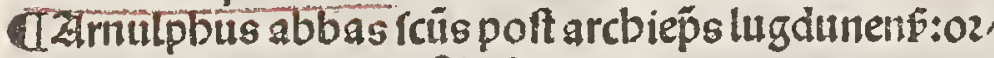
dinem regularis vite inftituit.

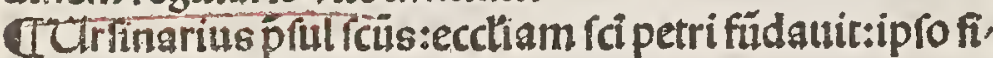
bi reuelante in fiandria.

10zdo canonicus cepitflozere in beluacenfi ecclelíg g pmo sb apoftolis:p'ea a biösuguftino regularit iftitu tus fib magiftro inone ppofito:poft carnotenfi eṕo.

CDide cartbuften f riffim incepit boctpe: g tefte brö bernardo int oës eccliafticos oidines pmatü tenet: $n$ ë röne tpis:\{3 rigozofitat): vr̃ ipfe vocat eú rpeciofiflimä colinnã ecclie. Uerü qzpptnimia abftinentiä paucl poz tabilis erat: z ne oiu pu' maneret poftea ab ecctia mo deratus fuit:nec vnä a fcóppofito cecidit:fingulariter a fpürancto pzeferuatus vfobodie.

Q23 zuno vir fäs natiōe colonieñ. $z$ magifter in tbeo logia cu fer alijs venerabilib'claret viris: $q$ cbartufien fiü ozdiné inceperüt in oiocefi gratianopolitaneñ.

Ubugo vir fifime z caftifime vire claruit:ep̉s gratia nopolitan": $q$ in. 53 .änis nulli" fentine faciē vidit:vna

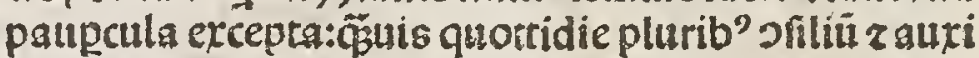
liü oederit:ofefînones etiä recipiêdo. "Dic fcicartufiani pporiti ṕ cipu? coopatoz fuit: z poftea etiä lsabitũ a fcó bzunone fumpfit:infigneogeremplï pbuit.

CLrâlatio f́ci nicbolai oe mirrea ad barenfes. Et $\mathrm{CO}_{2}$ pus f́ci clemétis pzimi épi meter in inuentüè met : qué aplí íbi ozdinarut: z oecé milia pegrini occifi tút bieru ralem per arabes.

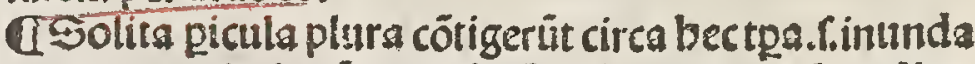
tio aquaz nimia cũ oâno inéro. Żues oomeftice filua tice fiunt:peftilêtie marie: $r$ plures facro igni confüpti füt exefis carnib'r mébzis inftar carbonu. Ierremot? i anglia:ut edificia emin' refilerent: z furoz vento zqui $600.00 m o s$ landonie côfregit. §ames ricus fulgurũ vltra modĩ zč̀.z fōs fanguis. 15 .oieb? emanauii:z oia bol'palâ locut ${ }^{2} \bar{b}$ boib?:i pago àdã vifibilit appendo.

\begin{tabular}{|c|c|}
\hline Annomundi & 6273 \\
\hline Dape $\left(\begin{array}{c}\text { Bregozin } \\
7 \% .12 .11 \\
1.0 i .4 .\end{array}\right.$ & 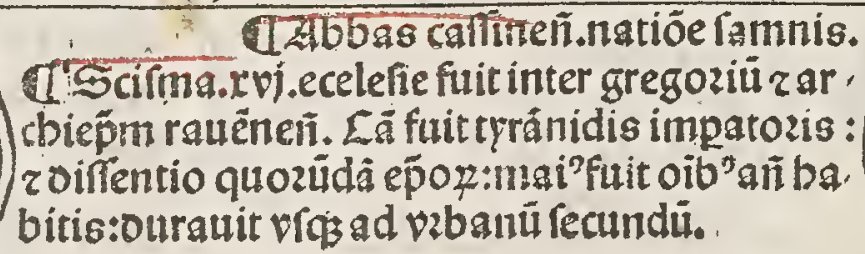 \\
\hline
\end{tabular}

Anno rṕi:

1074

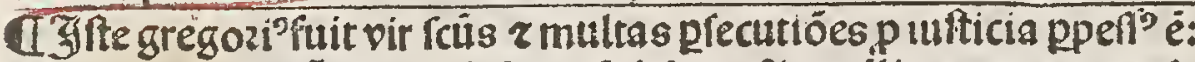
bic antea vicebat bildebzädus r fuit legat? in gallia:z oure procel.

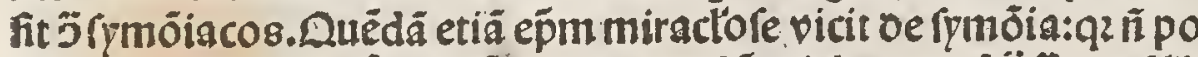

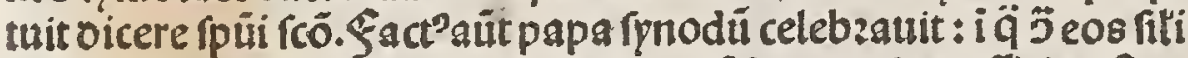

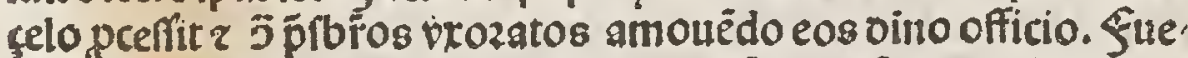
rüt eni tpa fatis arida. Et qz iufticie rigozē nifus é tenere:folito mo re כ̄ eü ınulti ifurrererüt. Et p̈mo cintbi" p̈recti fili' eủ cepit: cü p̉nä ming in nocte natiuitatis celebzaret: 2 in turri fua poftuit fo romani turri oeftruüt z papä liberāt z miferü cintbiü illü extra vabé cijciüt Deinde imperstozè excöicantitppi oifcidiü:g poft veniēs ad iplü $\tau$ plurib?oieb'nudis pedib" fuper glaciēftās vir abrolutioné ipetra uit:\{ร impatoz nó prenerauit in büili obediētia quă cepit:qnimo in

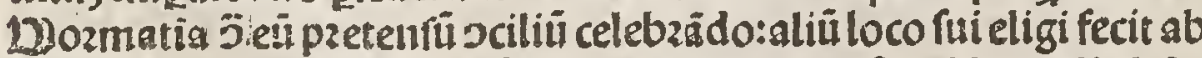
epis: $\tau$ fit foifma longo tpe. Znnfuper apbuc in caftro fci angeli ab $i$.

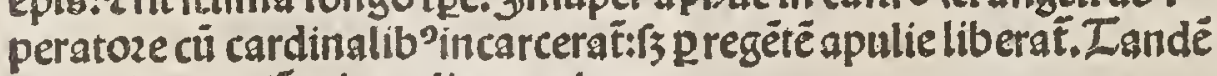
in apulia mozí̃ miraculis cozufcans. babuit magiftrü
pzioz cbartnfie:qué etiä lateri fuo fociauit in papatu z multü pfectū in ecciefia fecerüt.

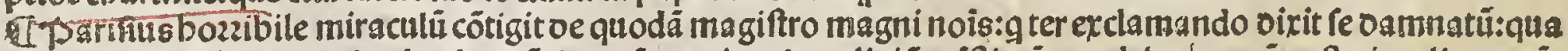

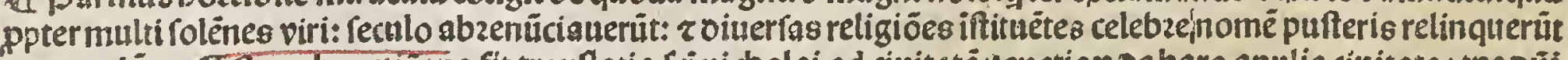
z exemplü. TLtrca bec etiá tpa fit tran円atio fci nicbolai ad ciuitaté venetiaz oe baro apulie ciuitate : tpe oni petrí patriarcbegrädeñ.z benrico cōtareno ep̄o caftellano:atą vitale micbaele venetiarü ouce. rôniü vidit oeü ctus efl odo: r fuit mona. fue oig̈tiói ifo, cbuscluniaceri. multüla. litudie cartufie labozauit in ecclia regem bitaculü jftrué francie etcöicauit pzopter

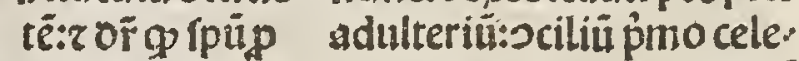
pbeticpollebat bzauit spud clarü monté fuit extinctus $\mathrm{p}$ in quo ftatuit bozas bes. venenti in cali. te marie oici quottidie $z i$ cemiflum. rabbsto folëniter officium fieri.oicit op boc beata vir go fratrib in cartufia reuelauir. Alliud concilius turonis celebzauit precupanda terra rcã zpuocanit populü occidentalé ad trant, fretandü:g tüc in lancea ouii triüpbarür:bic babuit magittrü bzunonēpedagogüg fuic

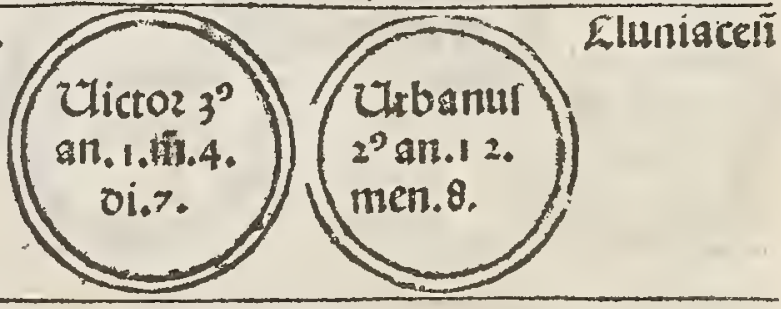

1084 , 


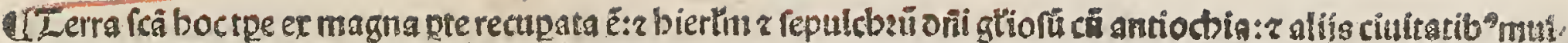

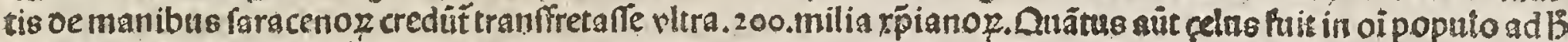

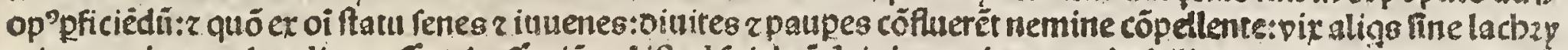
mis ant oicere uel andire pofer. paffagiū eni ifud fuit btë b̈ginis marie:que mirabiliter ouxit $z$ p oterit pzopu.

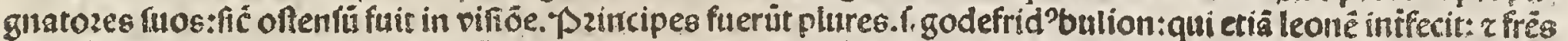

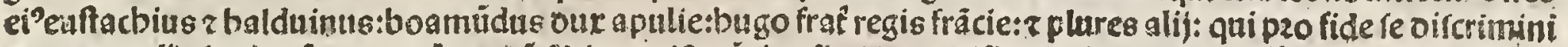

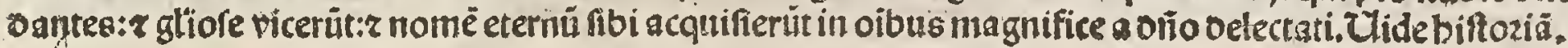

ULancea onit repta é in ancio tbia a quodã ruitico cui btīe andreas apparuit:r locũ oftendit:r quidaz parrendo iane. 13. pedü cü ea:totü erercitületifica: uit z certificanit:eo $q$ minimelederef:ficut orits fibi appurens mandaterar.

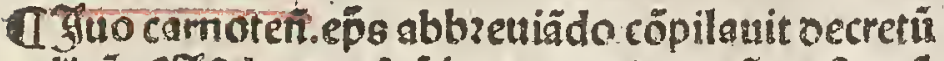

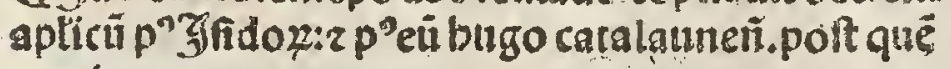
gratiantts.

CDelimand"lădaneñ.eṕs clarus babet̃. IDago claniacen,abbas vir fcüs cleruitbo the.

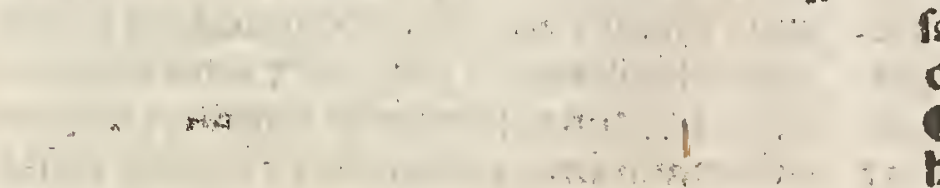

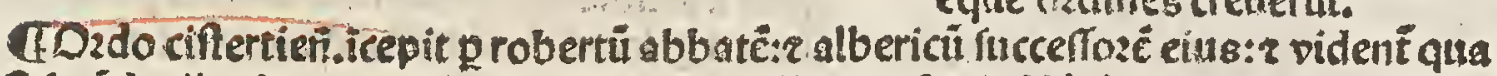

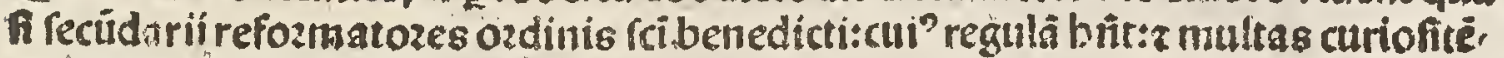

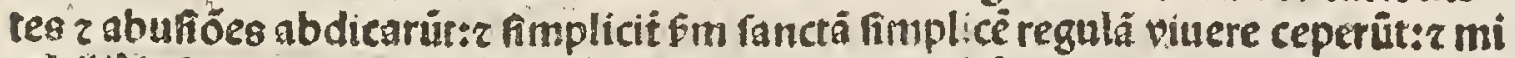
rabilit in bzeni the cretuerüt in oibus. babuit viros riffimos:z plures nuero ž̈.
IIoletủ ciuiras bifponic no'

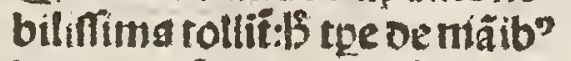
faracenozü paldefoniüregem octano anno obfeffionis.

UD2do ciftellenfis incepit fub berdingo abbare. En nota opnó eque nadines crenturt.

T3febenric \%atis excefliu' fuit quiburdã z p̉mo erga patrez

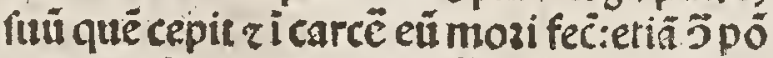
tifices rōanos:eo go debët refignare ittefti

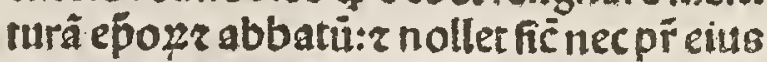
tande ad coz redičs obediut $z$ multa oãna ecclefís illat fideliter reftituit : mozî́ tandéfine pzole iurno oei itudicio:

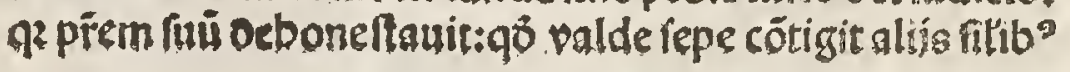

6303

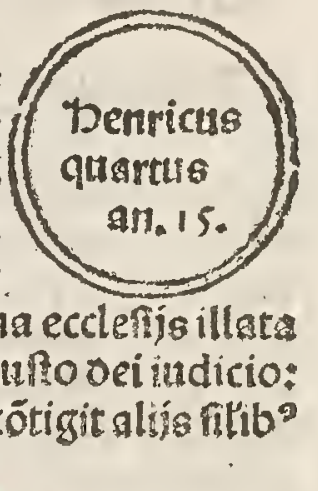

TSoles ouo appartuent terremot magn? Fuit: Aclla poiem fulguratit: in italia pluitranguis : in antiocbia terra abfozbait plura edificia:z pozcellus narcit ci ca pite bumano:pullne nafic quadrupes:z mulier quedã enira fuit monftrü: an fictu bomo:retro facies canis: $\tau$ cetera mébza.

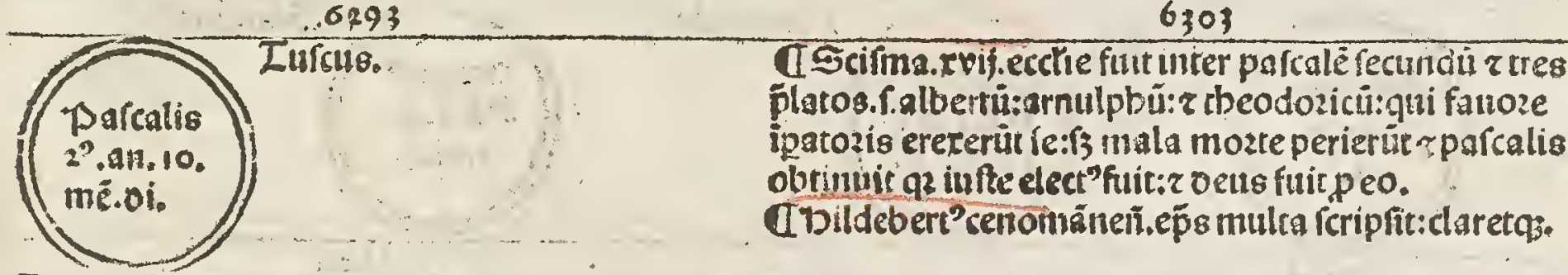

1094

1104

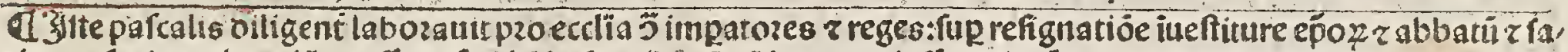
tis pzofecit:multa etiã gpeffis eft a falfis fratrib". Etiã inpator iprü cepit cü cardinalib": z gouos menfes in vin

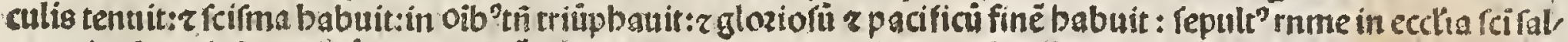

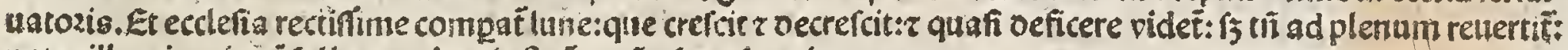
ppter illuminationé folis eterni:qui eft xṕs oñs fponfus eitus.

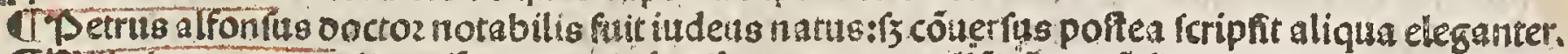

aDithelmus rex anglie pefimus obijt:parfis a 0.80:q2 nullú cótuentü fieri pmifit.

Ioletui citiitas bifpanie

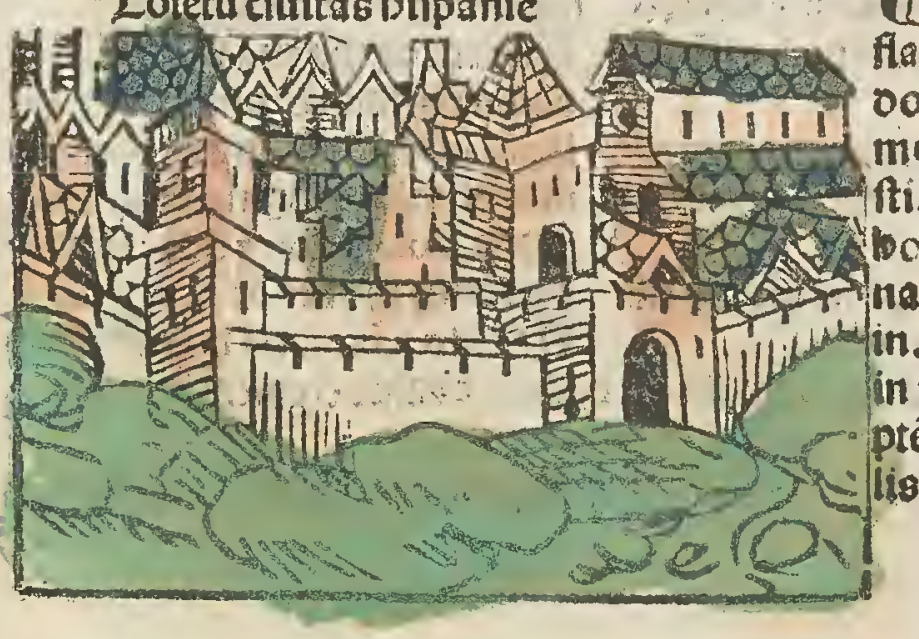

CLirca bectpa o menfe apzilis:in venetia lyguria:enulia atos fla minia: italie prouincijs:in gallia quoqs tran ralpina:multorn̆ oom'cōtritis boibus:plura edificia fimul $\tau$ eectie : ingenti terre

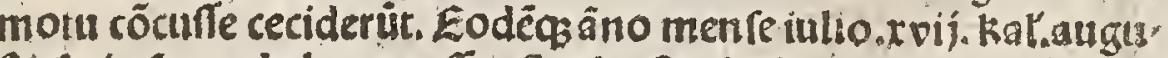
Ati.feria fecunda luna paffa eft eclypfim in figro aquari.ab.viij. cza noctis b/ag matutinu. Tertio idus oecébzis feria quarta lia

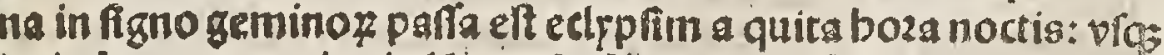
in. ix. bozam noctis eiuldem. Eodẽ menfe poft folis oćcafit: víg in tertiä bo?ă noctis:cetum rubeú quafi ignis apparnit:a tota fer ptêtrionali pre:vfqg ad arcron. Sequëti po menfe ianuarí parca lis papa rome of functuseft. 
TSemard'incipit clarefcere adbuciuuenis: $Q \mathrm{p}$ in trauit ozdine ciftertiê. oeinde fact"abbas: clarãual lem fundaut. biccreucioocroze magni $z$ aplici vi rì. Lor miracus fecit z tantu bonozé büit at fitis ei in bis nüră creditur fuife: videvitam zé. pater.160.

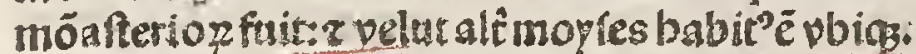

Tozdoteplarioz incepit bostpe:g pai albis vfi rür man

I. Tmpatozes tellis: pof rubeà cru ceinfup pofitä poutar ueruit. Etbugo r ganfredus fuerüpmi fundatozes ei": z btüs bernardus regu lam compofuit.

Cordopzemonttraterit.incepit p vi rum Dei notbertum.

TStepbanus virvenerabilis abbas ciftertii terti" claret: $g$ bearü bernardí cü fratrib'fuis ad ozdinē ftrfcepit.

TExtra romã in monafterio fi lau. rentí:monacb"gdä admiräs quō zč. cigulo foltuto audiuit. Sic potuic xps claufo.pdire fepulcbzo.

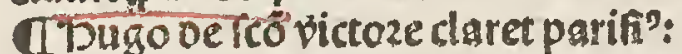
natione faxo:00cto2 magnts: galter suguftinus oicebat tpe fus.

\section{0alacbias virfuib ar, \\ cbiepus bibernie claret:a \\ totã illa genté refozmauit \\ Ei vita bernard? fcripfic. \\ GRichardus oereó victo \\ repietate plenue z $00 \mathrm{crO} 2$ \\ flozidiffinus claret.}

ULYr'capit́a xṕanis z leodiú mltis plagis atte rï:tremotu $z \vec{c} . \tau$ baldui nus rex bierlim capit. dAcies icelo sppuerit U2Dora fupedit: $z$ alia nilta móftra fuerütá foz te tartaroptyränidépxi. me futurâ fignarüt. Zlen tus maxim? futit:turres $r$ edificia frtbzuit. aftaddria ex ptefabmer gitur. Tocis gberardus bitureit. é̆us.
ULartari pmifiōe oiuina circa bectpa mötë exiffe putät in ả elaufi faerüt i magna mileria

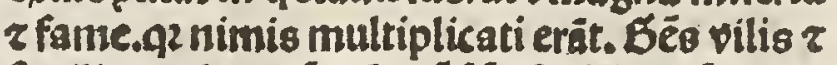
fterilis: 2 plaganüt $p^{9}$ müdū oia fub ijciêtes iu. rta illud mopf. In gente ftults irritaboillos. mirü valde quồ illi $q$ in maria fuitute fuerüt iä nö armis 13 pellirijs $r$ baculis oia profter' nut r oñant pniuerfis. beciudicia tua orie. fíc olim affyrif:medi:z pri: greci $z$ romani:gotbi: buni: $z$ D) andali: faraceni: $z$ arabeg:,bulgari: affricani:franci: almani:turci: bifpani rê.,fla gella iracidie tue fuerunt quilibet expti in tpe fuo:eo g bomo noluerit obedire tibi ż̃. z'anctus anfeinmus laudunice ciutratisep̃ 6 :qui glofas interliniares in pralmis ozdinauit.

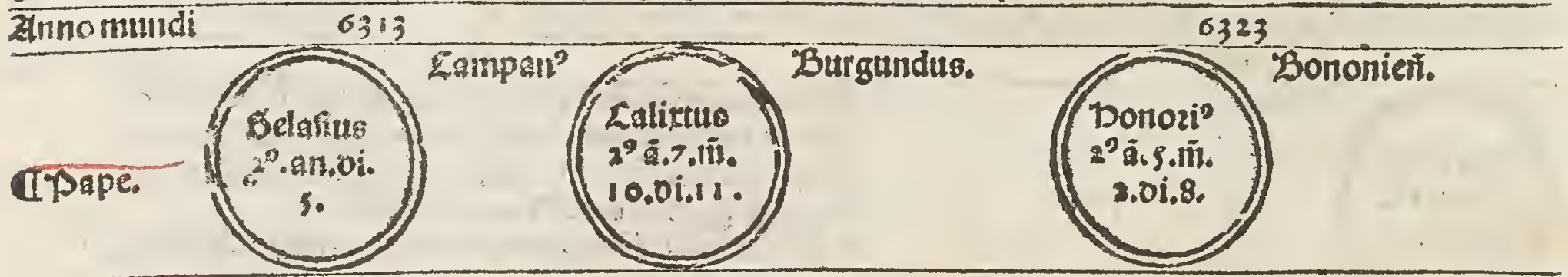

Anno xpi.

$$
1114
$$

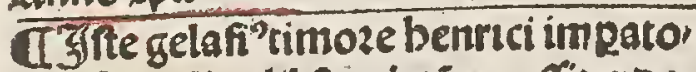
ris cü cardinalib' gaietä acceffit:z oe inde $\mathrm{e}$ mare venies in burgandiä:aps cluniacú moztu'eft r repult?:idēimg toz ́címa côtra eǘtecit:erigèdo quen. dä benedictuz bifpanui:qỏ etiä pofter cü calixto continuatĩ eft.

dü celebzanit:i qua oănanit fictos quordä religiofos: g plures berefes fecrete zublice feminabät 5 faça z bona eccliaz. Secit libellü oe niraculis fci iaco

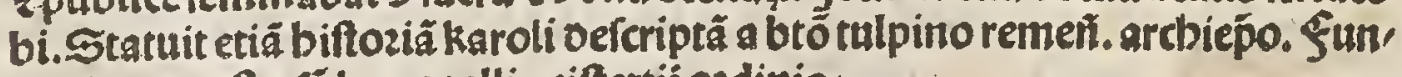
dauit monafterfü boneuallis ciftertij 0zdintis.

đScíma.xviii.ecctie fuit boc tpe:qz benedict? quidă fauoze impatozio erexit re contra gelafiû: $\tau$ etiẩ contra calixtü cṓequêter:fed miferabiliter perift: $r$ qui iufte electi fuerüt obtinuerüt moze folito.

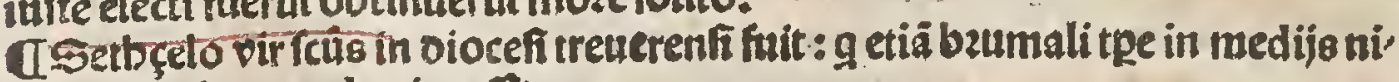

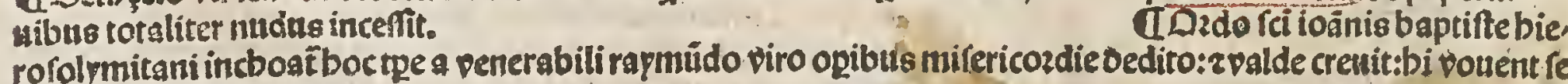
pauperibus fertituros.

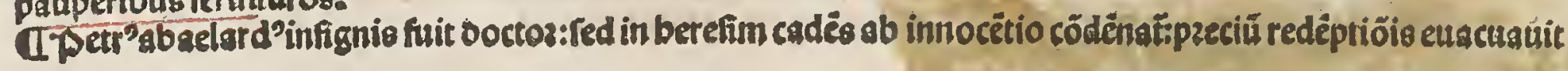

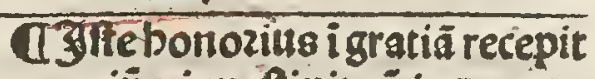
rogeriū r inueftiuit eư in oucatu apulie facto bomagio $g$ fuit rex ficilie. r magna p'p fide fecit.bic ou0s priarcbas oeportuit: agle.

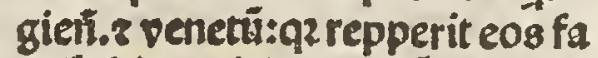
uiffécímaticis: mozit́ tandē ro me: fepalt? in ecclia lateraneñ. $z$ idc rogerius $p^{2}$ ab innocentio re moutet:qz fibi côtrarius fuit.

Q Siccitas magna fuit:ut flumi ns:lscus:fontes: putei ficcarent ignis in terrã frubinträs biennio non potuit extingui aqua: $r$ fuit plaga bozzibilio: z q̊daz mulier quattuo mafculor peperit.

IDzdo fei toänis baptiftebie. edito: 2 valde crenit:bi vounent re 


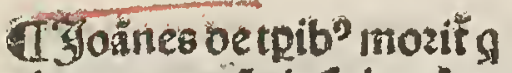
vixeral. 36 1.änis fuit eni ar migerkaroli: $z \forall$ fq ad bee tempoza ourauit.

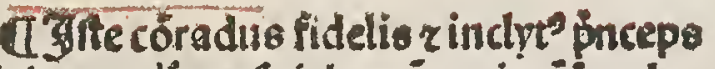
fuit: $z$ qz B tpe fuit bonü regimé iecele. fiafticoftaru: ió p̉ncipee prompre obe diebăt ppter exêplaritatē p̆latozũ: vnde ifterer crttce fignarus erat $\$$ btö benar,

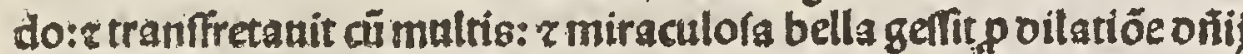

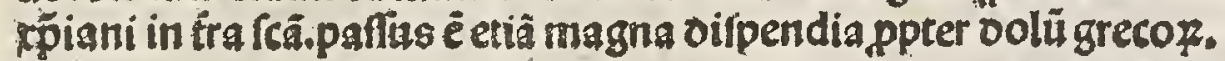

A paf́agiĭ magnú cōtra faracenos fa cti eft: 2 lotberius r lodoulcus crucem fu icepentut : $r$ btüs bernardus vinino oo. ctus f́pú:crucé ṕdicando pluresptrocaut

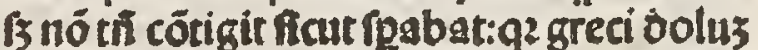
magnú fecerant cú calce farine mixta in toxicantes exercirñ.

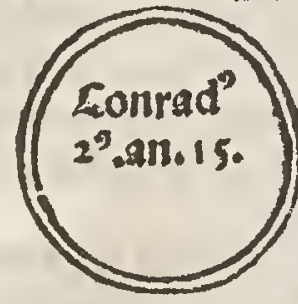

I Ditus lodouicus res francie clartuit g magna p fide fecit 2 a btō bernardo cruce fignat: $₹$ vitra mare tranfitês capt' fuit $\tau$ multa oäna paffus eft:z multa pzelia gloziofe geffit. Et benri cus frater ei monacbus efficit:poft ēs.

Uथiffones tondali facte füt in bibernia boz ribiles ż̈.

तulifoes ree elíabetb bocrpe facte fuerüt. वUTifones Kë bildegardis r voginis:ppbetie plurime apud trenerim facte fuerunt. U Scifma decimünoni ecclie fuit inter inno centiä recüdü: $r$ petrü leonis:ppter oircozdias eligëtiü:z innocentip obtinuit: qz maioz pars etat fecü: 2 btüs bernardis p peptëannos la bozaut p vnione foztiter $r \vec{c}$.
1Comes muriếfis fact'ë bumilim? conuerfus in cartufia.

aLbeobaldus comes campanie: vir totusmifericozs. I'bugo folieti ferip fitlibzả oe clanftro arvime.

đÉratianus monacbus decretū cōpilauir: $₹$ ab eugentio appzo bat̃:z és fit in turcia inclufiua: vnde oziundus fuit.

U' Petrus lumbard'ep̄e parifien. frater gräni:libzü iniax edidit. a 'Setrus comeft o frater gratiani z petri lumbardi biftoziä ico lafticam cöp ofuit $z$ allia.

đIEdîfa que olim oicebai rageomedorü:femp innicta z fancta: boctempoze peftruit.

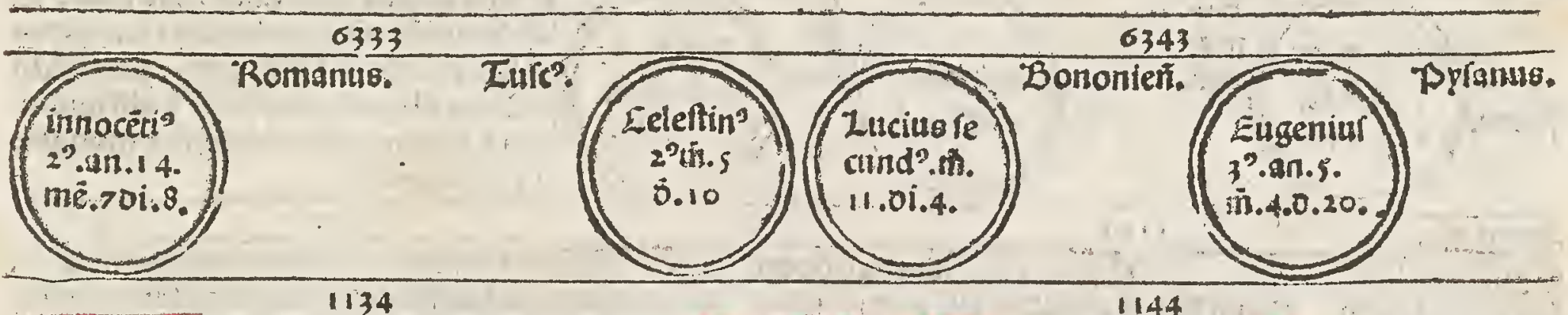

Ifyite innocenti? fuit vir nalde oenot?: 2 tales fuo lateri focianit:bic babuit fcifma p reptë an nos cõtra pstrü leonis: g fe anactecumnoiauit:

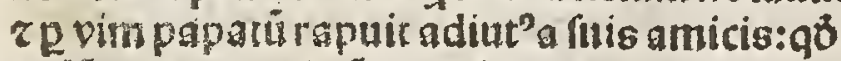
vidẽ innocenti?: cü ouab? galleis fugit i galliä vbi fut gloziore furcept ${ }^{9}$ a f́có bernardo: $\mathrm{q}$ tüc puocauit eos ut reducerēt oñu papä ad ledes itann z plura oe eo narrant $i$ vita bti bernardi tandé pacatls oïb": 2 bozzibilit oiuino iudicio aduerfarifs confüptis:pacifice $\tau$ vtiliter eccle. fie pzeledit:fepelit in laterano gloziafe. oés regé, 2 pzincipes in manib'fuis babuit:r

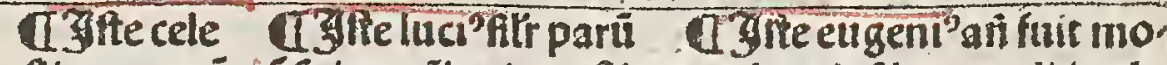
finus parú "̄ruit:qza äbo in pefti nacbus bi ber zardi in cla redit:fepelit lentia bzeuit obierüt raualle: $z$ mifiusab eo ro. inlaterano sepult'inlatersno. mä cü alijs pinftaurariöe monafterif f́cianaftafij : $\tau$ ibi sbbas efficit̃:z nö longe poft: ex infpersto i papä clect" ê:bic cü eẽt fímplex:De'eü nirabili grä z eloquentia pfudit: btüs etia bemard'illũ folëné libzú oe cōfideratióe ad eü feripfit. Roinani aút folito moze feruefcétes feditioné fgciüt. Quzapzopter vir fcüs oedit locü ire: $z$ in gallijo veniens p̈pinülocü vilecte clarauallis büiliter benigneq vifitauit:alloquit frës nö fine lacbzy̆nis: me mo: pltine z ram palcb ze quietis iam pdite tnircës fermonibu

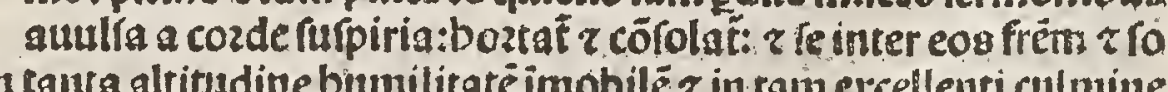

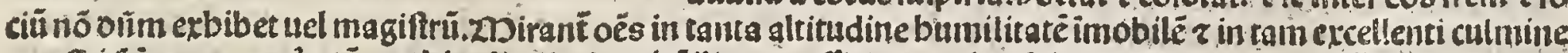

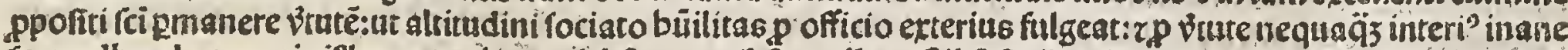
reat:adberebat carni ei"lanes tunica: 2 vieb" ac noctib"cuculla veltib": fic ibat fic cubabst:inus monacbi babi

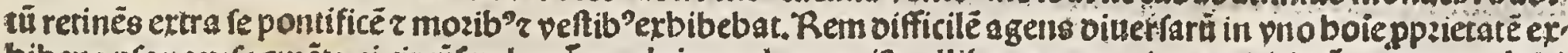

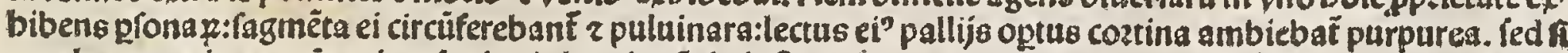
retsolueres opimenta iuenires fupiectio laneis cöplofa ftramina z paleas cöglobatas. Dö in facie:osus videt in

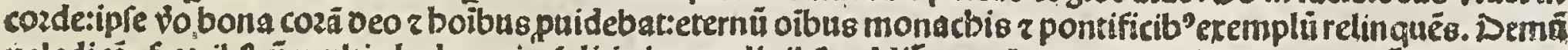
valedicés fratrib"cī multis lacbzymis: folitis ingetudinib" reddit: romäq reuerfus gloziofe furciput clamantib" vniuerfis. Benedictus g venit in noie onit: obijt tandé in magns fcitate fuis meritis illuftrando romä miraculis

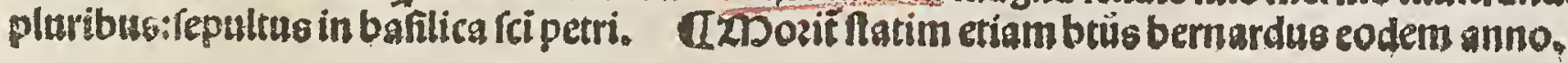




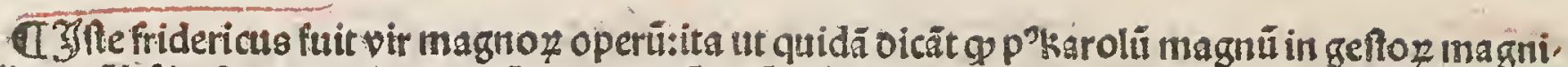

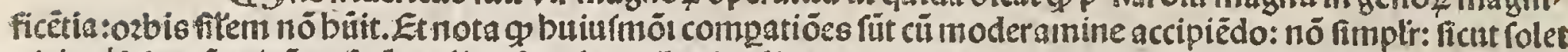
oici oelralomöe. po öt ent eé $q$ alige fimpler miles in aliquo negocio ita magnifice fe bëat: $q$ vere oici poterit oe

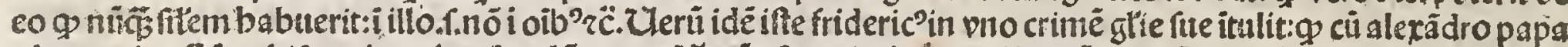

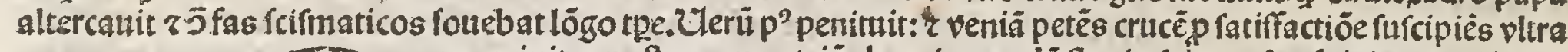
3inuatozes. (frideric" mare iuit: z poft magnos triūpbos:in quodā futuio fubmerfus fuit inipzouife.

(1) ilbelmus beremita fciflim ${ }^{9}$ claruit:olim oux 1 Lozpa fcồz triü regültranfferüt oe mediolano ad coloniä aquitanie: $z$ comes pictauienf. bic p̉mú totus oi rcolıs fuit:zppífcíma a btö bernardo cü venera bili facraméto trit? fait:p' lozica fup nudo veftiť. Ubuilelmpuer iăglig crucifigit a iudeis:i oie rä cto parceues. Et erat tüe puer ibidềg viditiferni.

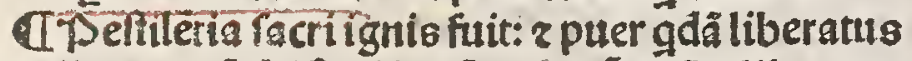

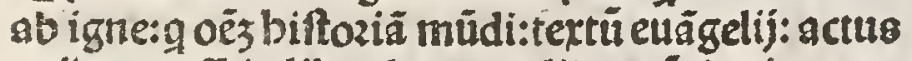
aplo z tanö in libzo legeret a lijs pniciauit. I'Petr?barätafieñ.eps: vir itegerrime relegiöis IT Tlozuegia cōuertit ad fidê: vbi pzimù ṕdicauit cardinalis albaneĩ. poftea papa.

p rainoldü arcbiépm colonieĩ. $z$ extü colonia flozuit.

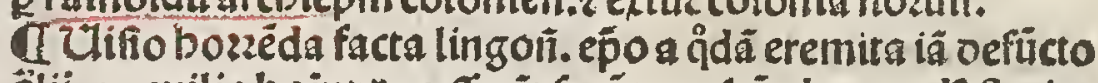

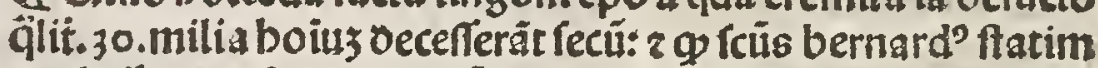
euolaffet:tres i purgatoziū oécenderầt:oés alij i inferno ppe tuo cruciandi oimerfi fuerunt.

TScis tbomas cắtuarieñ.arcbiep̌s marţ̨riçat b tpe in an glia:multis clar"miraculis:z benric' rex anglie mifit folênes ambafiatozes: z excufauit fe oe nece eis: z crucé furcepit polt trienniü zë Eanoniçat ab alexandro.

II Scus bernard"canoniçat p alexandrü tertiū: zppter scur fum ppli pbibuit eí abbas:ne plura miracula faceret: $z$ obe dint moztuus.

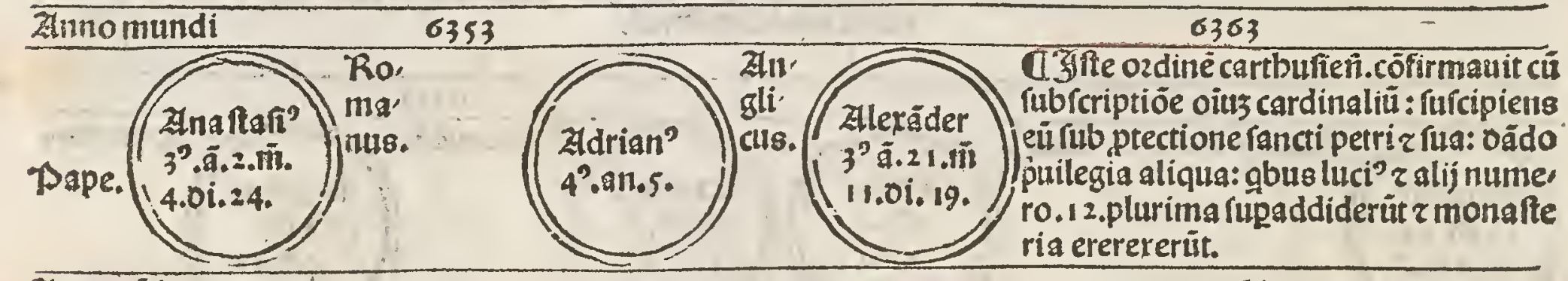

Anno xṕi.

dite analtafi? fuit abbas firt. fi valétinieñ.oio cef. $z$ oeide i car dinglem $z$ poft in papã affunitur. oic fecit palatiú nouน̃ eptad rām imariā rotundas mosit repelitos in laterano:

1154

Uद̧fte adrianus natióe an glicus fuit:epus albaneri. vir magnani mus: $r 2^{2}$ bi oei cü çelo pzedicatozegre. gius: 'Regé ficilie z romanos côpef́cuit cú cenfuris. Zlpreante legat? fuit in noz แtegia: $z$ gentê illă barbaricã cöuertit $r$ inftituit:poft elect'i papã:officiū fum bonosificautit. Et or $q$ p̀mus papa fuit g cú curia i vabe veteri mozá cötraxerit bic fecit girone in radicofano : $z$ turri bus minuit: $z$ multa comparauit a co, mitib'. circa locú fcẻ cbaiftine fepult'el in vaticano.
1164

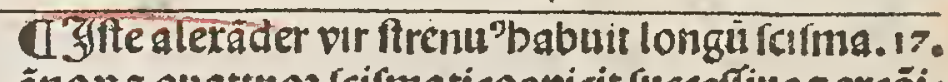
âno 2 q quattuoz fcifmaticos bicit fucceftiue z excōi. caut: g oés mala mozte perierüt:pzeuglùt etiä 5 im patozé: $z$ ad unioné renocauit. Duo cócilia celebza, uit vnüturonis:aliud i vabe:tandé oib’nó fine gra ui laboze cōpofití: puta gaduerius talëregẽ oimi. cauit gloziofe romã reuertit z eos gppter pleueran'

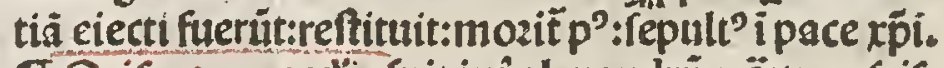
II Scínsa. 10.ecelic fuit incalexandrü z ättuoz fcis, maticos:\{5 alexāder obtinuit:gräde fuit änox. 17.

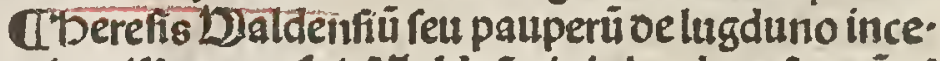

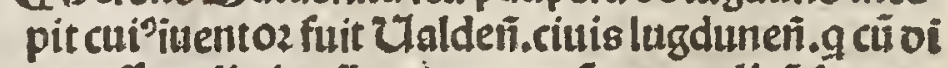
ue\& effet relictis oibus pauptatēeuangelicã feruare

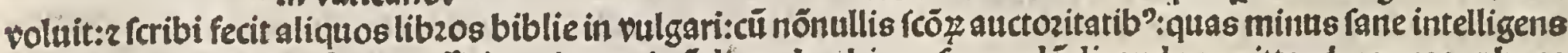

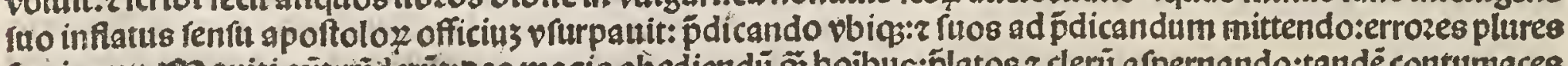

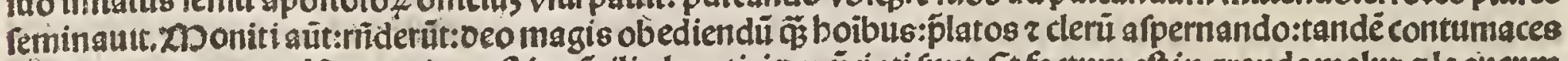
ex cöicati funt: $r$ expulfi a patria.poft in cócilio beretici oenūciati funt. Et factum eft in grande malus z laqueum

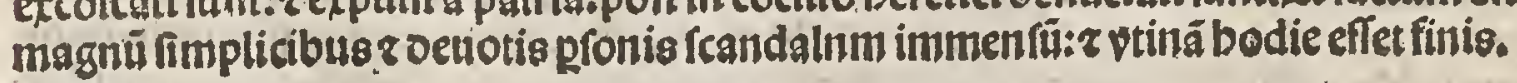


đSanctus ricbardus fuitg a itudeis marty riçatus fuit parifin: : r iudei expellút a regno ISctre petr'montocul'abbas clareuall fuit đDzdo gutilb elmitar a icõ guilbelmo be remita olim ouce aquilegieñ nomé z ozigi nètraxit: eius oifcipulus fuit feùs albertus beremits:g ozdinem ifum educaut. a Scá alpiadie virgo fcifim claret q̊bumiliser nata:fubul ca erat: in terra fenonerí. cibo fpüali ptebaí: multıs babédo retuelatiōes is nullo cozpozali tamen venufta facie.

đ Sctisbugoeps lincolnieri. ozdinis cartbutien. i anglia in numerts claret miraculis.
G. z sccepit cōttãtiā filiä regis ficilic in prozez occafione cuius fubiuga uit fibi totü regnũ apulie: fugatio illis qui illnd tenebant.

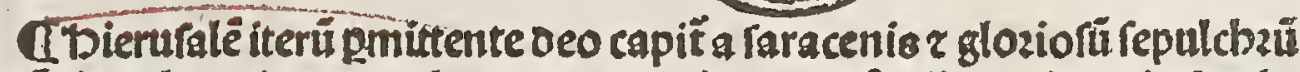

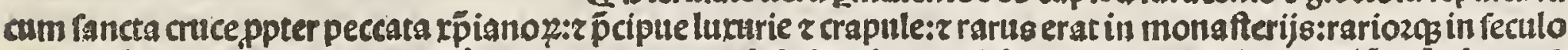

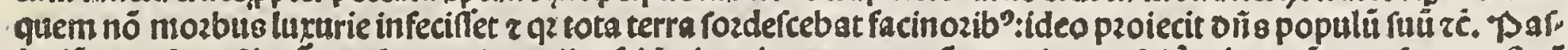

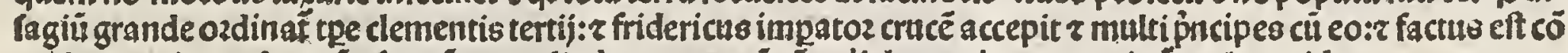
curfis maximus:5 parü pfecerüt:nec aligd recupauceüt:pter'folam acbos:que oicit ptolomaida.

¿Sanctus anfbelmus eṕs blefineri.ozdinis cartbufieri.claret bona vita.

dद्Abbas ioacbimf fuit g plura ditit z fcripfit. Et in gbưdä erra. uit. ut $p 3$ in pincipio oecretalinm. Scifitantib" etià pincipib? an ire oeberēt ad cerrã reãum rĩudit nõ: tempus nödum adueniffet.
A Leodiú capitioepdat: vaftatiz mu lieres ac vigines oppzimutt. Religiore tin actimozate:mirabiliter liberate fu erút:nec alicui` poillutiōis òtagiú par re rüt:fíc oñ onidit reẽ marie oe ogni. e8: vide in vita ipfus.
ARegnutartarozicepit $z$ creuir val de z vígbodie émagis i ozbe r fece runt plagã in mido maximã.

A $D_{2}$ do orioptbeatonicozi incepit circa bectpa íub celeftino papa. $3^{\circ}$ oz tum babuit er ozdine fei ionnis ba ptiftebierorolpmitani.

$6374 \quad 6354$ Lufaus de luca Lombard" Eeneuétan' Roman"

\section{4}

TDlin reá fides catbolica p potétes pucipes:p arguros pbos:p rubtiles be reticos: ac cetos viros Ipectabiles ipu gnata fuerat:oiebus aút iftis 2 viliffi. mos idiotas:ac laicos paugrimos $\mathrm{ex}^{\prime}$ ritic nó modice tribulata. Duafi oicat

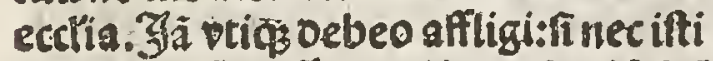
a tribulatióe ceffant:gvita ipfa videbã

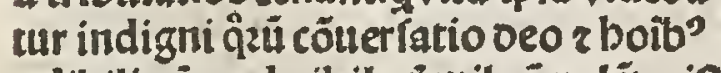
odibilise qad nibil qỏotile é valêt:nîn o re métiút me çelare ut ficefficacinno, ceăt:fuerüt nibilomin'poftea gdä fub tiliffimi beretici: $g$ iftã berefim Djaldennis oefendere conabant: rplia re gana z populos oeceperït:cii gbus tan dem milerabiliter exterminati pierút.

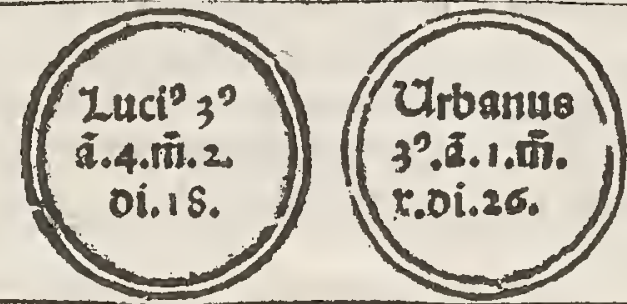

1184

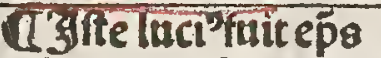
oftieñ.gpoft verone mozit bris tale epita. pbiú. Luca dedit lacé tibiluci pontificatü. Dftia papatũ roma: verona mozi. imo ve rone oedit verú tibi viuereroma.Exilius curas:oftia:luca mo ri.pulcbzi verfus ärt qớdä apologeticü.
(13) fuit oriüd? oe ci uitate mediola nêfiad eú venit ioacbi decala. bria: bै cü audif ret captí bieru. faléa faracenis nimio ooloze ta ct?:obijt: fepul tus in ferrarla: fecit pacēe inter piranda. Et

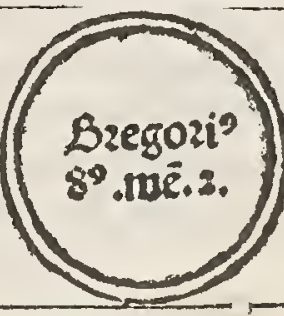

Wiftegre digfte clemens gozi'magnú ozdiatuitmona çelübüitp $\hat{t}^{\prime}$ fteriü ext̃ murü ra fancta:r qoboiciéfcilaurē cepit practi tij: zquedãalia care oe mó edificia: ei’tége recupädi eã factü épaftagiú pfect' iturciã mağni stradi. ad oiluerías centeabbate io puicias lräs acbim:q2 nödü imifitpartuce ventifet têpus.

fecit pacẻ inter piranos r ianuểes, Qua facta:pi fis moztuls elt:z bonozifice ibidé fepultus.

đIsanct bertold carmeliti mötis bermicolis ab aymerico antiocbeno patriarcha in pziozé affignattus fama celebziozi multis inotercit. "Dic iné

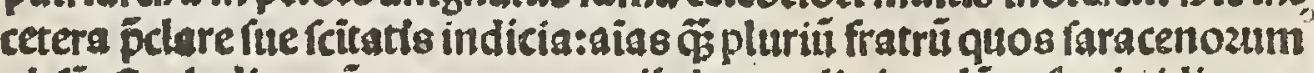
abfüprit gladius:cü cozona martyrij ab angelis in celü oeferri vidit.

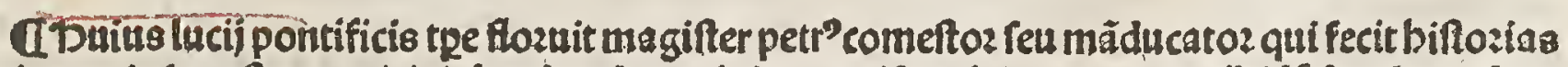
feolafticse.i.biftozias vtriufq; teftamenti. toic lombardus ozigine:parifus fuic canonicus:ibidé fepultus. Sup

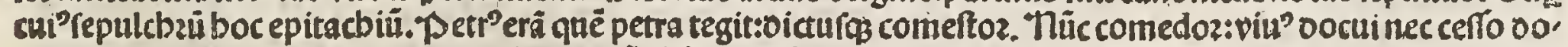

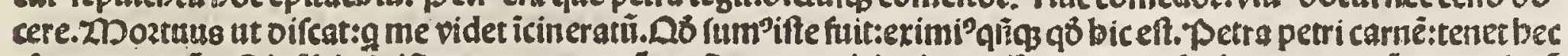

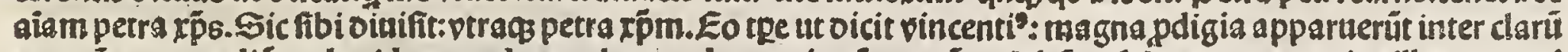
montē $r$ compediü:qz lapides quadrangulares ad quantitaté ouozü cadebät:z fulgura cremantia villą: $r$ cozú in roftris carbones ignitos portantes:incendëtes 00 mos ac villas:r multi ictibus fuluninis pierüt. 


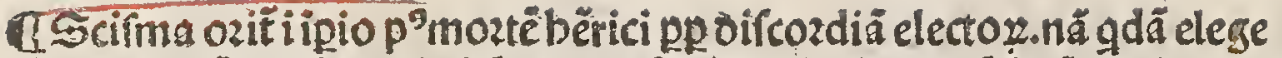

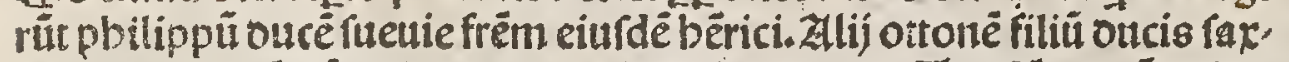
onie. Et facta é alítcatio magna $r$ bella i almania. Iandē otto pualuit

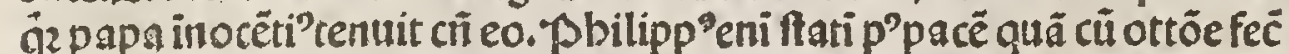
ințfectus é oolofe a lätgrauio: $z$ fic otto obtinuit $z$ romä veniēs: $a b$ in

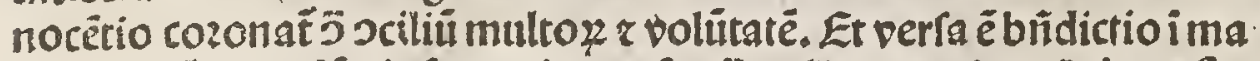

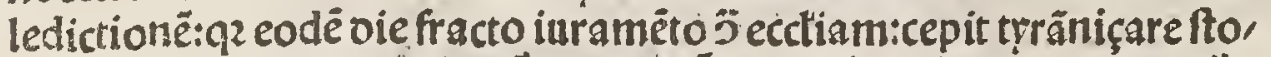

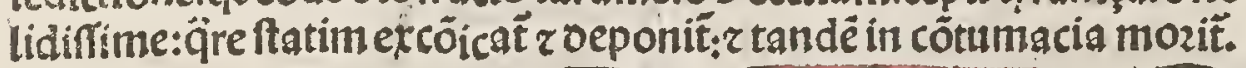

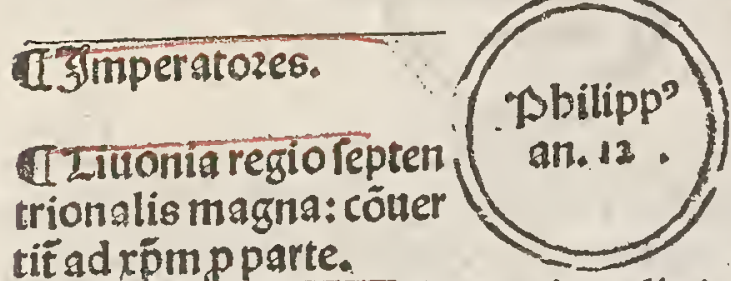

tî́ $\mathrm{ad}$ xṕmp parte.

a toaria de ognies claret miraculis in oiocefi leodieñ. Dbijt. 121 3.circa annus etatis fuc. 37. Etmultealie virgines r vi due z rcé maritate fuerüt ibidem.

CDilicus bilpan' vir feils ac aplice pfe, ctiôis emulatoz:mirabili çelo pregt bere ticos:miraculis claret:z ozdinê iacobita rîfitue pdicato ż in Rituit:

Thelinandus monacb'belueceĩ.säcte vite:fcripfít cbzonicâ ab ozigine mundi: ze veparatione lapfi $r$ alia.

TFräcicus italicus vir incópabilis fer, uozis ac fíme pfectióis pauptatis etuan' gelice ä́s qődä exēplar plucidum:multis claret niraculis r ozdiné minozz iftituit. IElectio intpatozis pédet ex iudicio fü: mi pötificis: $q^{0}$ p 5 p oecre. YInnocen.3.
IEonitantino.

polis recupata

rpianiszbaldui / Dtto 4?â. nuts comes flan drie ipatoz ibi efficitur.

1D)ilfelmus parilientin cepic ozdinem auguftineñ. qui etiä oicūt mendicätes.

TLrax pdicat quincs bici bus: z boc in gere oftenfur fuit:quia cruces oitueriozú colozum quinqs numero: in aere patēter réplendue runt.

aद्याbert? patriarcbabic rofolymitanus:ozdinécar melitarũ inftituit in monte carmeli.

đScîs petr"mediolaneĩ.poftea martyr clar"babet adbucpuer. COIncta clarafulget virtutibius.

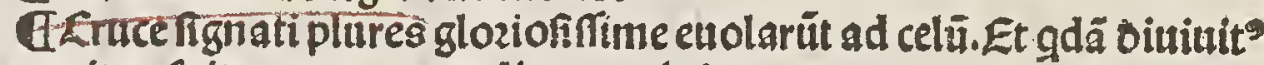
punitus fuit $g$ crucem pzedicare noluit.

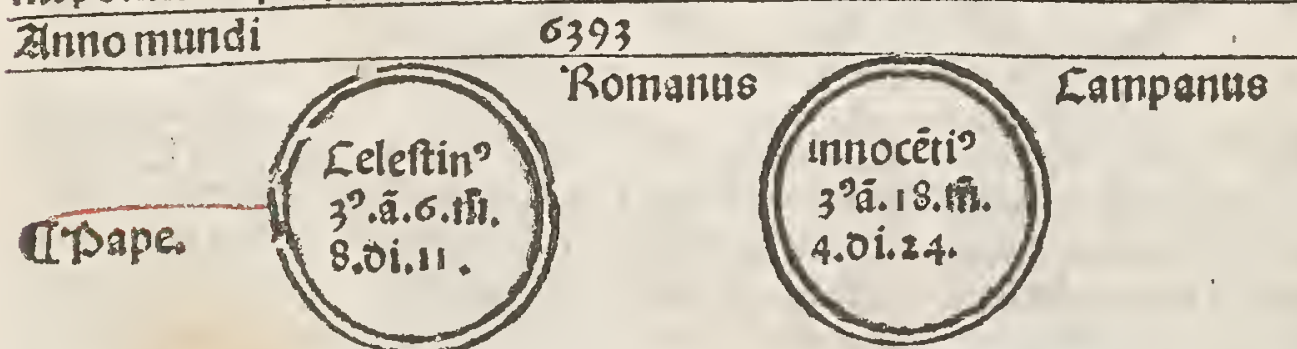

Anno rōi.
IPtieri oe almanta.20.milia z amplis oiabolica macbinatiōe pecepti cruce $\mathfrak{f}$. gnant äfi oeus peos vellet recupari ter,

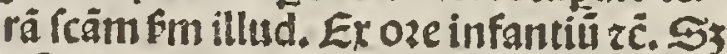
ci ad mare veniffent a pyrratis oolofe i naub' rapiunt: äfi cos ad bier ufalēou. cere pmittentib?. Uez multos fubmerfe rüt alios vendiderunt faracenis: $z$ fic $p$ tet gd oe fimilibus in futuz faciendü fit: fi fimilis cafus occurreret.

UTaftozes peco o filr oe bifpania cóue inientes cú turba graui parifi? venerüt ? oia bona cleri vaftarút intuidis plebib? gratulantib": Yz cü etiä laicozú bona ce. piffent oetuozare ftati expugnati fuerunt z pempti: z fic patet quõ oiabolus etiam ruas craces ṕdicautit.

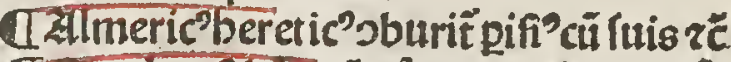
CStepban'Tctis pr r p̉oz oom poztarẗ. ozdinis cartbufieñ.z poft ep̃s oigenfis. 15spmo comes mótiffozt) velutalt karo Lus mirabilit triüpbautit ว̈ bereticos:bris fecú ep̃os z abbatę fcōs: ₹ ṕcipue fãctū oñici. Sugaut aliqui centünilia bereticopt ci paucis puto otto milib'catbolic

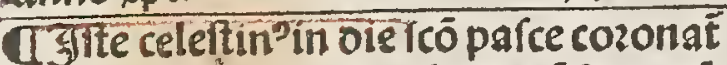
z oie fequéti cozonauit benricū ipatozé Z̄pe etiâ fecis fieri pallatiũ apo fañ pety A' Jacobus oe vitríaco feripfit multa vti tia zp̃cipue de f́cis mulierib'ḡ tüc fuerüt ples i viocefi leodieti. Et fuerüt tpa fatis

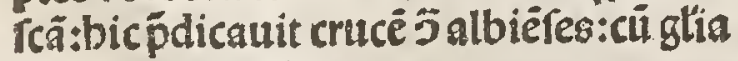
miraculozmultox.
1204

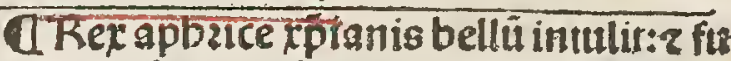

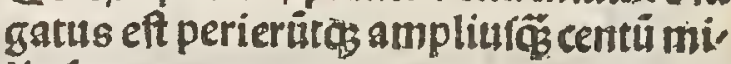
lia faracenoy.

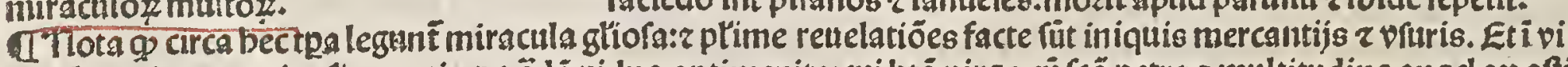

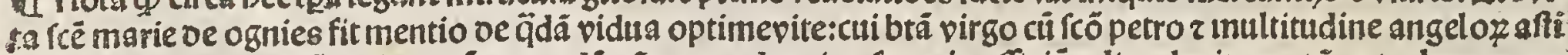
tit i ggonia $z$ vix oemóes abegerüt:z tandé oñs met aduenit: $r$ funeris officiü adimpleuit: nec tri ppter bec penas purgatozij euafit:maritus eni eius mercatoz fuit: $z$ quedä p fraudēacglierat:å̂fdas etiä oe familia oucis lousnie

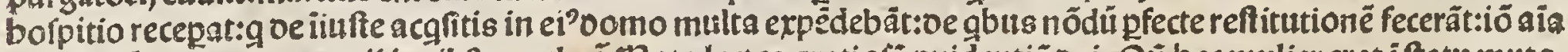

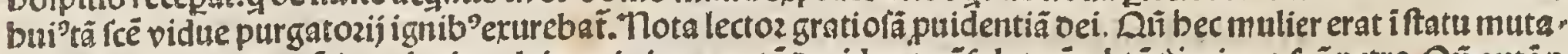

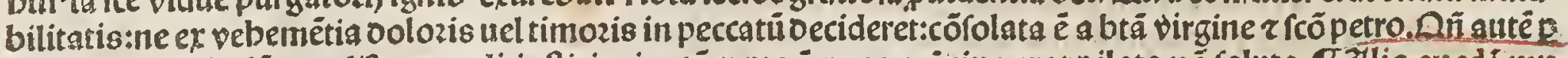

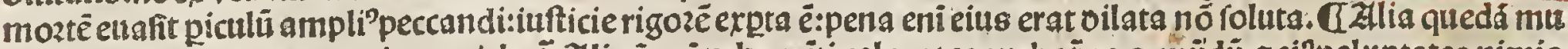
lier boc ozdine in purgatozio cruciebat̃. Alliqui eni vebeméti caloze tozquebat̃ eo g müdü zeip voluptates nimis ardenter oileriffet. Zlligñ frigoze maximo:q2 pigra ad bonü fuerat z maxime: q2 filio s zppziä familiā nimis ne. gligenter cozzexerat:fiti aruit:ppter potatiöes:nuditate cōfundebat:ppter veftes fupfluss.

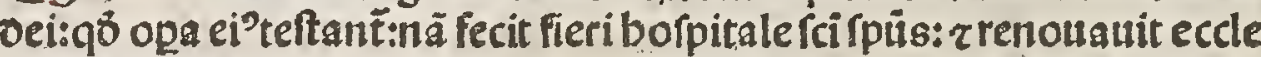

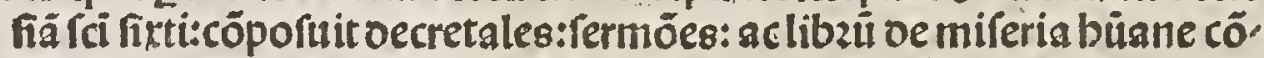

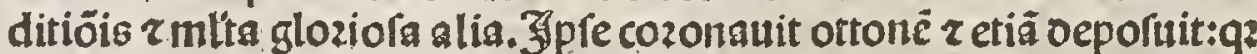
nō feruauit fidelitatė:berefes ples oangait.f.albiêfiú 5 ås crucép̄dica

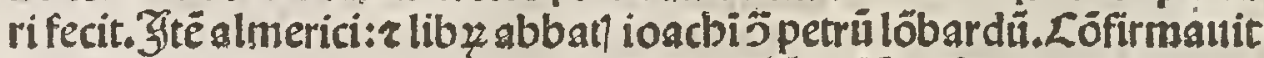
f́rī bugonè linconieñé cartbufieit.ozdis. Iandē poft plá bona paces

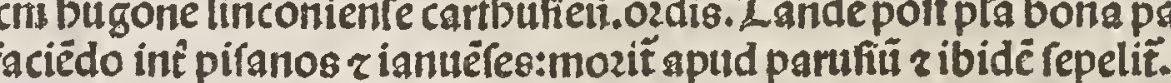

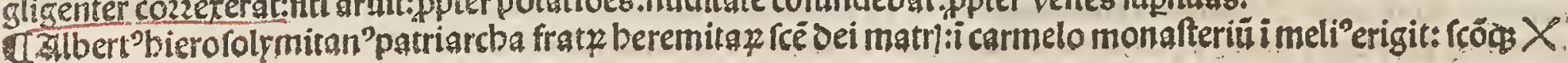




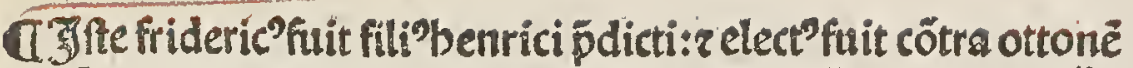
ut ei expugnaret: go r fecit. Et extüc icepit eccliam laniare:äre

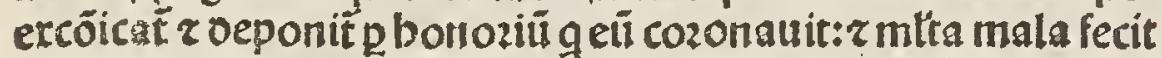
z stumax oit pmâfit: $r$ mozte pzenent’fine facramêtis a ppzio filio fuffocat:fic irez:multa erêpla bic fiut oe precutozib"ecctie äs miferabiliter peunt.ipfe etiã filiü fuü benricü fuffocauit:qua pzopter ab alio filio fuo cuz egrotaret fuffocatus fuit tempoze Zुnnocentij pape guarti.

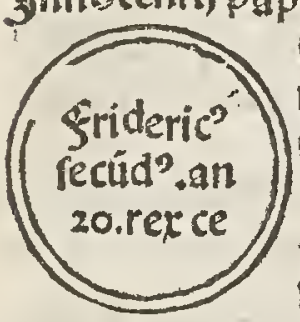

1215.

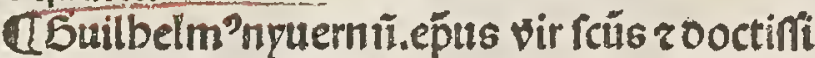
mus claret:q ouo milia pauperü tpe famis q̉' tidieparcebat.

TSca elifabetbfilia regis vingarle cilievixit vidua:omni virtute pleniffima cla 15, p̃tüax. ret fancta vita.

QLodouicts fititis regis ficilie fra ter minoz: vir fcïs clarus babet.

đEoncilium lateraneñ. Thiertiaté oeftruí vfás ad folü:ex celebzat in v2be.1315.p. cepto téplo $r$ cinitate oauid a coza latozz füna fuit ibidê có, dino filioftapbadim.

gregatozü:factum apud Touattrozozdines mendicätîn ps fcith ioanne in laterano. ṕdicatozes:minozes:anguftinêfes: z carmelite ofirmant ab bonozio.
I Lapis gräđis cecidit imonafterio '́ci gab:iel

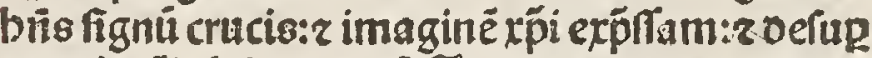

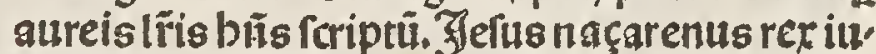
deozun. $r$ cecú illuminatit.

1 Srilia tota perte fubmergit fluctib?marinis iä perierüt boinz plur äs centú milia ppter irreue' reutiã factä facraméto a quodã pugile: fícat po. ftea reuelauit btã ť̉go maria:z cöftructa é eccliq i codéloco vbi boftie ceciderür: z ceffauit äflatio đUacat impil mito tpep"ospofitioné friderici zetiā p'ei'moztê:z iō plures âni ấcribunt fride rico:licz pancis intre i obediëria ecctie regnaue rit: q2 nô ftatim alius in locī ei electus fuit.

C Lartarí tratetítmōtes ripbeos g oituidüt afia maiozé ab europa : ac totã vngariã $\tau$ poloniam q̈í vaftãt nulli parcêtes rextui uel etati:z fit ingēs terroz ixṕianitate: f̧ pzecibus fcóy impediti fiit nepzocederent.

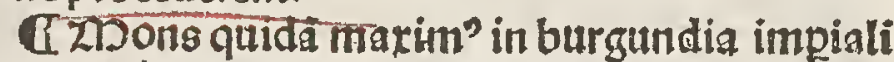
Ditudiț: $r$ cucurrit p multa miliaria: $z$ gnç milia boilz fuffocauit: $z$ tandéad alios montes accer. fit mirabiliter.

IDecretales côpitañ̄ praymũdú ozdinis p̃di. catoz:oemådato gregozij noni:z ad ftudia mit 102docrucifero 2 circa bec tpa renouat ${ }^{\prime} \tilde{e}$ p innocentiin tertii anno pötificatus rui. 1 s. iä oenicta berefi albiéfiù p cruce figna tos. Fert́ beatü quiriacü bierololymo epm olim buius ozdinis

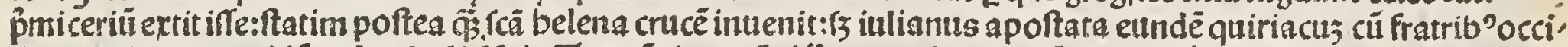

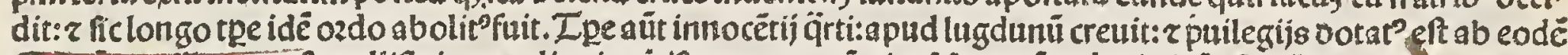

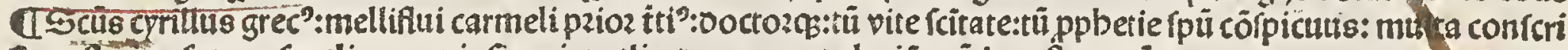
fit pofteris pfutura feculis: z copiofis miraculis: oeo pcurat gloziā müdoq; ftupozé.

6413

\begin{tabular}{|c|c|c|}
\hline 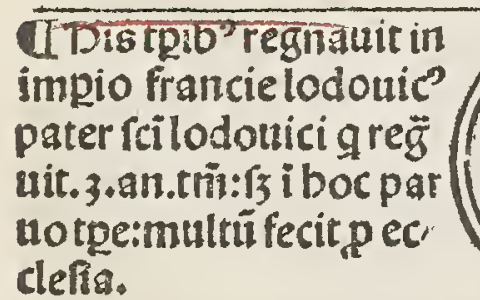 & 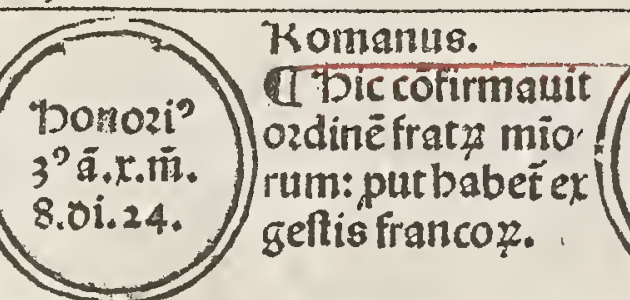 & $\begin{array}{l}\text { Siegori" } \\
9^{2} . \text { an. } 14\end{array}$ \\
\hline
\end{tabular}

1214
6423

Eampanus oe arania.

CEulbelm? altifiodozeñ., bis tpibus flozuit q rümä in tbeologia cōpofutt $r$ laurenti? ac vincenti? bifpani ooc.ü. canonici flozuerüt grome aucrozi. fue ooctri.allegant.

Timebonozi?multos bonozanit: canoni. çauit ples fcōs : Sridericü cozonauit: z etiá oe pofuit ppi rebellionē. Eccliaz fil laurëtí extra

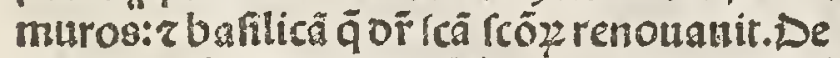
cretales cöpofuit ozdine pa dicato 2 mio

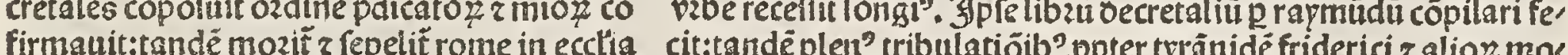

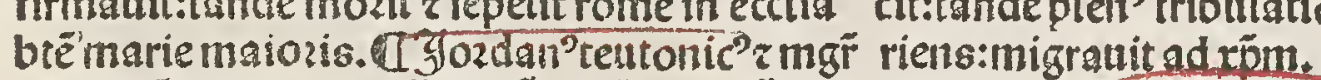

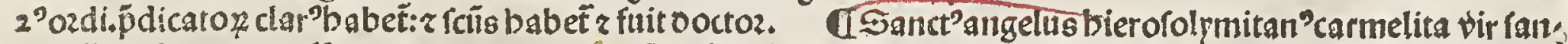

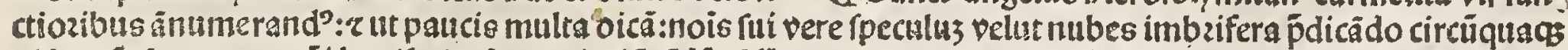

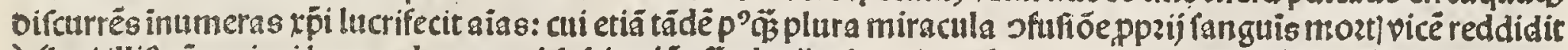

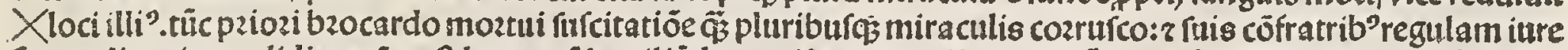

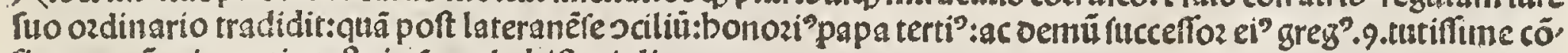
firmauerit vincentio telte in fpeculo biftoriali.

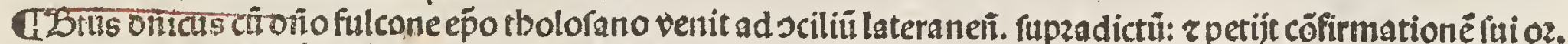

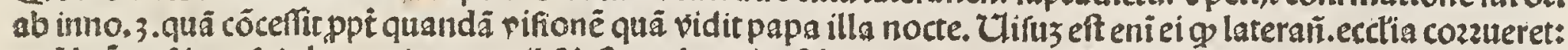
quã beüs onicus ftuis bumeris z manib'fuftentabat. Doft bec oe mädato ipfîpape redijt tbolofä pregula eligë.

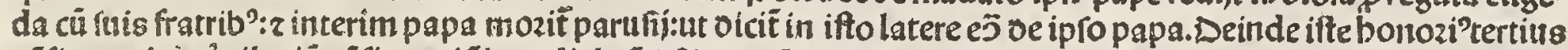

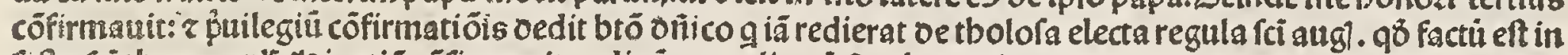
fefto fei tbome apli.. bic etiä cöfirmauit ozdine carmelitarü fiue beremita montis carmeli: ut oicit vincentius.

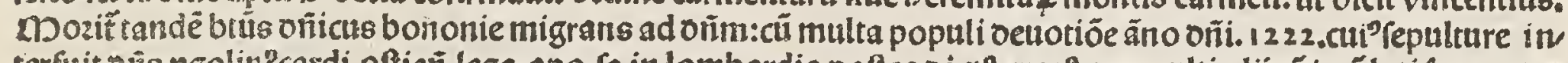

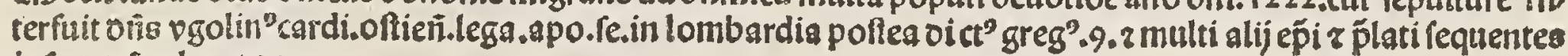
iprum orim legatum. 


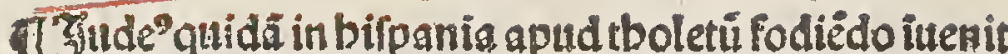
lapidé in quo crat liber vetuftifim": in quo fic icriptĩ erat inter cetera. In tertio mido:fill? osi nafcet oe ţ gine maria zp falnte boius patiet. Et $q$ liber oeberet iueniri ifto tpe.f ferădi ฟ̧aginis caftelle. Et ftatim iudes baptiçat ci oi oomo rua. Et bic rex aggreffus faracenos puinciä nüdalie:fibrillä uel bifpalä: z plura loca cepit: raracenis bincinde fugaris.

Tismperatoze6.

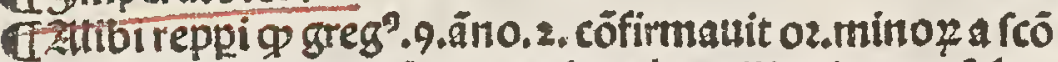
frãcifco: viro eximie fcitatis z pfecte bumilitatis:g eriā fuit magnoz patratoz miraculoz̧: pide cius vitã.

CLboms8 oesquino doctor fcus.

T. दोibertus magnus ratifponenfis eps.

TEutachins qui $z$ bonguërura oocto oetıonis.

CLiterander oe balis ooctoz irrefragabilis.

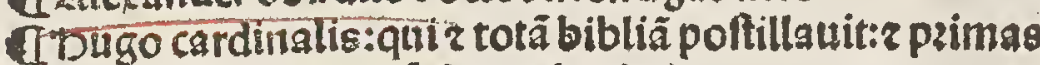
cõcozdan. ́úp bibliả cü fratre fư fecit.

đUUnincentipípeculatoz oẽm materiä fcibilê collegit.

dimagiffer iozdan'fcile z doctoz slaret.

G'Dagifter riricis oifcipulus alberti.

TPetroetbaräbafia poftea papa. Etplures alii fir zlit'

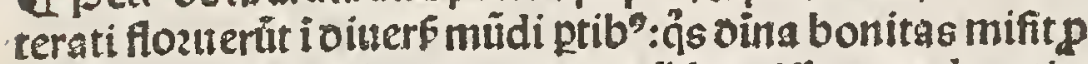
fidei oefenfiōe: alıoquin tota peoe fides piffetppter bereti coz multipliciraté r fubrilitaté: finmal z potentiā.

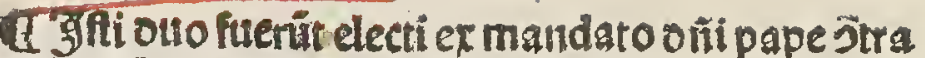
fridericü fuccefliue: \{ nó pzeualuerüt ţrannidé eiur fupare: oz potens nimis erat : nec fuerunt cozonati moztepzeueniente.

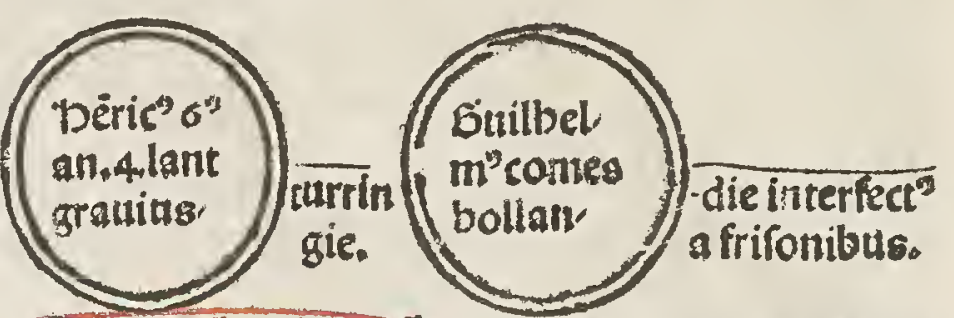

Q'bon "xpian'mozit in urcbia miraculis clarens. CEdmudus arcbiep̄s cantuarieni.canoniçat ab in nocentio.

TL Lodouicus rex frãcie vir fcüs:crucẽ accepit $z$ tră' fiut mare $z$ capit:z multa oe ipfo laude oigna inue nies.

Tpetr" non'martyr or.p dicat7.ab beretic occidit: multis clarue miraculis can oniçat.

IIStanitaus epse cracouteñ. ab iniquo p̉ncipe in. terfectus eft:x canonicat,

1 Uaticiniú qỏdam facrilegũ os ceffatiös euägelii

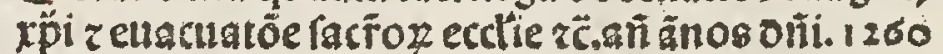
Do expientia tpis exfuflatit. Plura talia totalit më dofa repies facta $z$ oicta.

Annomuri 6433

\begin{tabular}{|c|c|c|}
\hline & \\
\hline & & \\
\hline \multicolumn{3}{|c|}{ 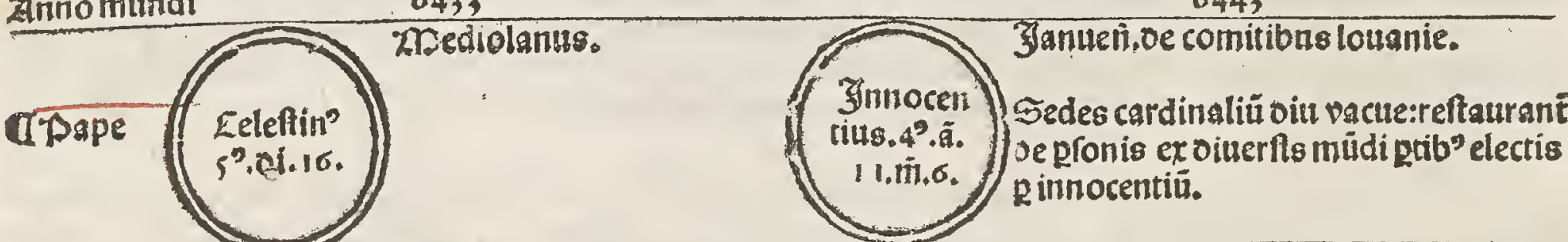 } \\
\hline
\end{tabular}

Anno xṕi.

1234

1244

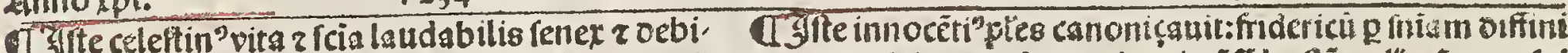

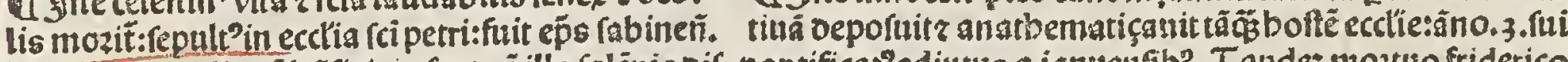

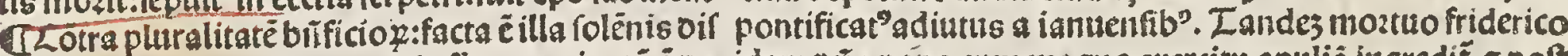

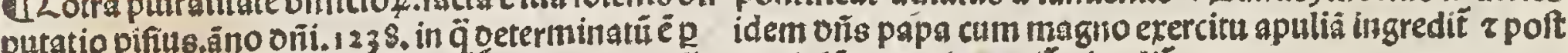
f́ôs voctozs:s: $q$ nemo fine piculó peccati moztaĺ paululü neapoli moziť z fepelit,

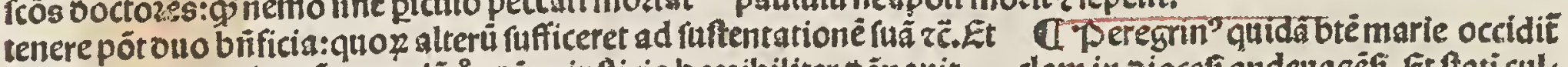

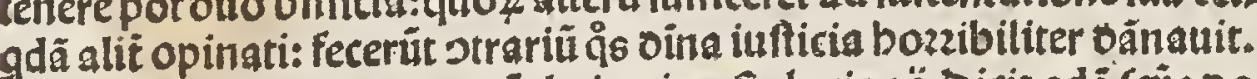

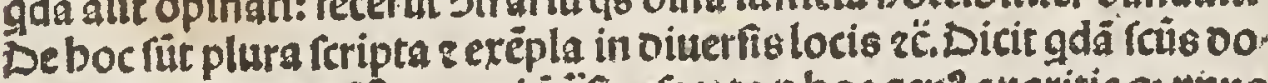

cto? $q$ medietas miftroz oei ê äfi refecata qboc gen" auaritie $q$ thus

plura bificia gmittit babere. 55 ge pix vumu pöt oigneadminiftrare:

clamn in oiocéri andenagéfi. Er ftati cul. tellus bomicide nó ceffauit ftillare fan. guinēoonec fripéderễ intfectoz iple të sutppaijs p peccatis fatiffacere.

¿Db frequenteg Taracenoz infultus: frës ozdinis oeifere marie oe carmelo a tranimarinis ptibus: wbi in plurio bus lócio multiplicati fuerant:in cimsrinis venerunt paulatiue oiuerfas 02 bis regiones incoluerüt: tefte vincé orio in speculo biftoziali.

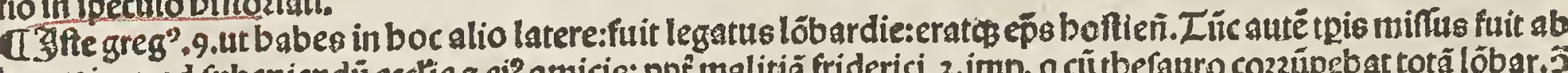

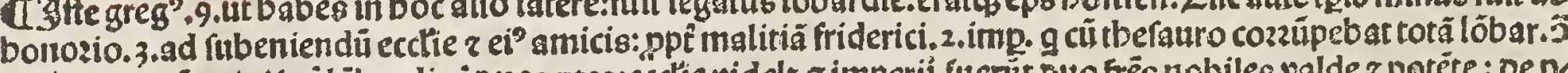
eccliam. Er tüc oituifa è löbardia i ouas ptes:ecclie videl; z imperij. fuenút suo frēs nobiles valde z potéte : oe p

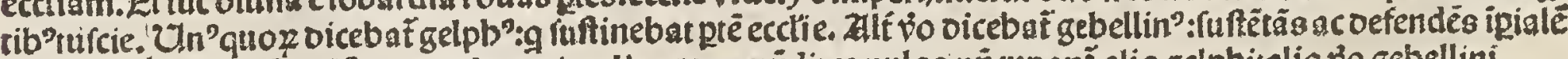
ptê:äpoftea noia füt trällata $z$ vulgata:iı alias ptes müdi:qz vulgo nücupaní alig gelpbi:alig vo gebellini.

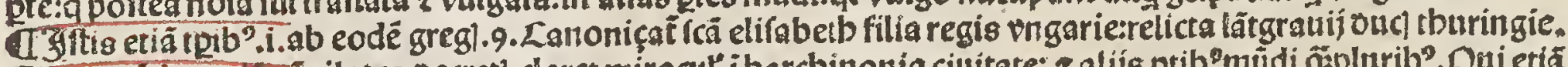

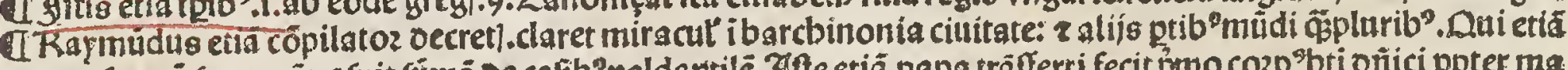

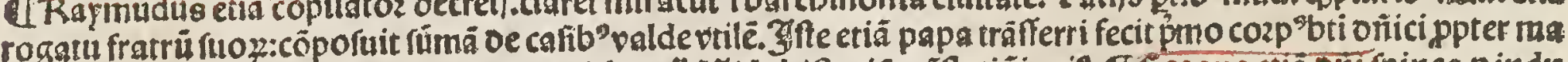

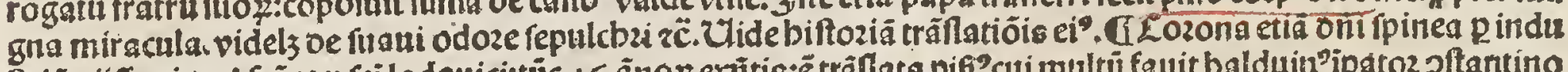

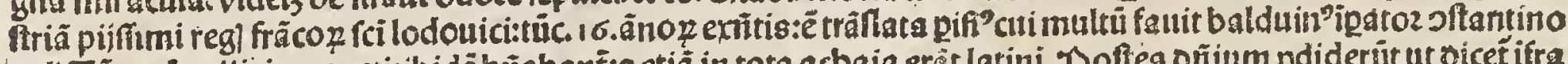

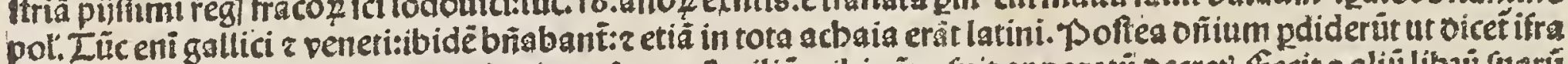

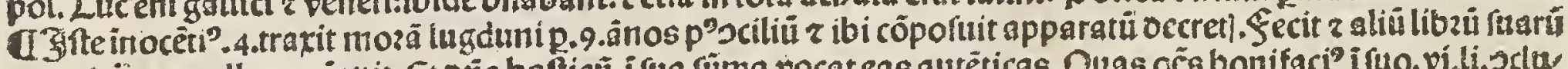

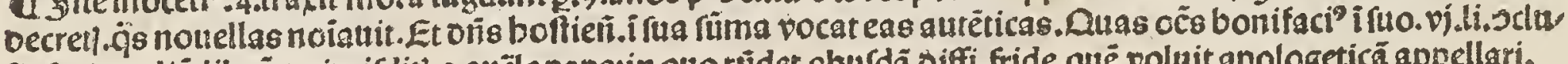

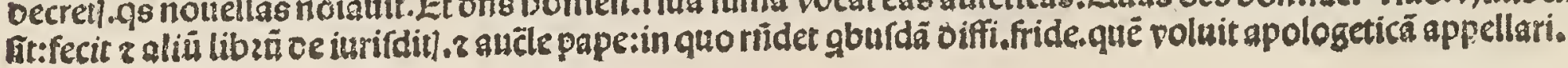




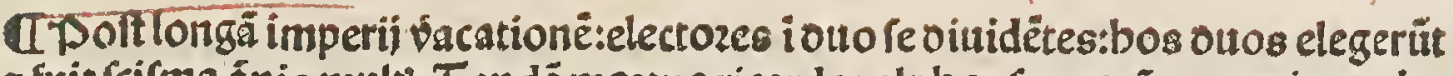

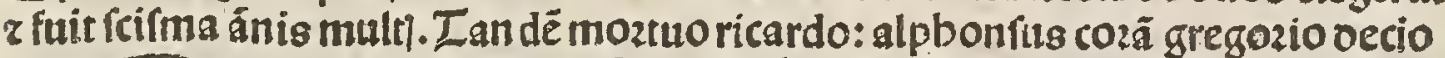

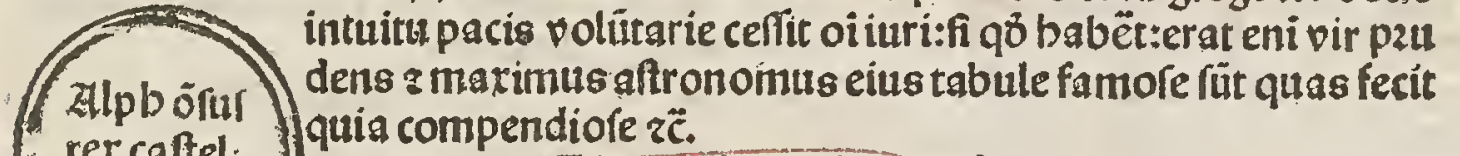

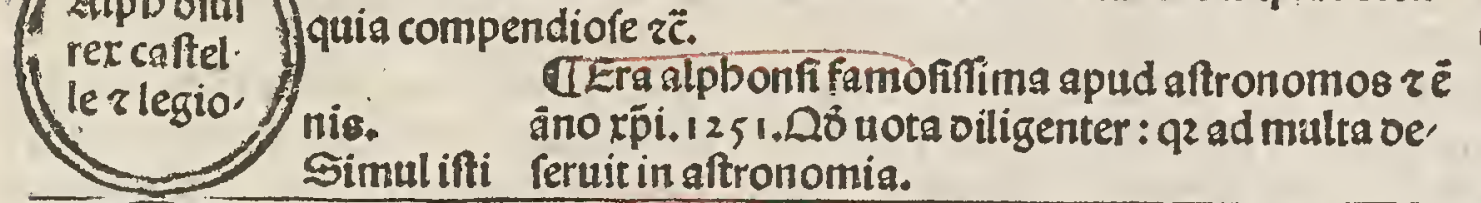

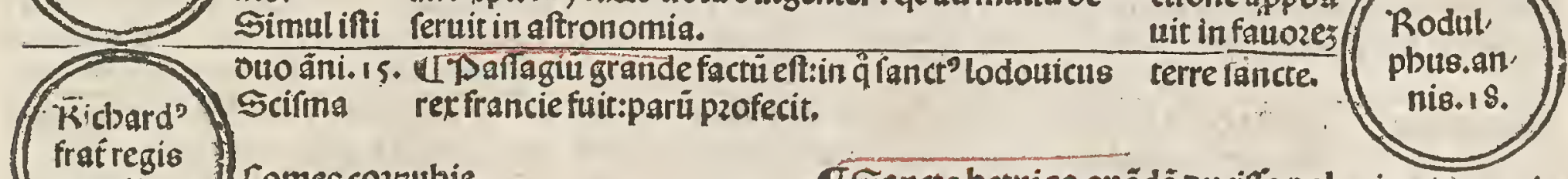
$\left.\begin{array}{c}\text { frat regis } \\ \text { anglie }\end{array}\right)$ Lomes connubie.

CŚftü venerabilis facĩi infti. đ2martin'cardinalis ruit $\mathrm{p}$ v2banü.4.cum indulgen. g cronicå abbzeuiauit tijs. Et oemandato iftip onii pa Callexäder $\delta$ villa oei pe fcús tbomas oe agno cöpor ozdis mio ż gooctria fuit totĩ eiurdé oiei officiü cum le compilauit:vir reús pzofa zoibus:q̈ oicunt in ipro tbeologie facre pfeffor officio.

UScâ clara canoniçat ab alexädro. 1254.

cispectitubiftoric vin centií bic finiț.
II Sancta betuiga qũõdã oucifị polonic:vidug mire fanctitatis canoniçat p clementem.

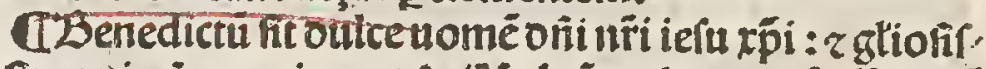
fime virgis marie matr\} ei ${ }^{p}$ i énü $z$ vltra.ané. Tlos cii ple pia biidicat virgo maria amen. Quicung; bec lege rit totiens quotiens: babet tres annos indalgentiaru: quos clemens cóceffit ob roganù lodoutici fancti regis francie folêniter.

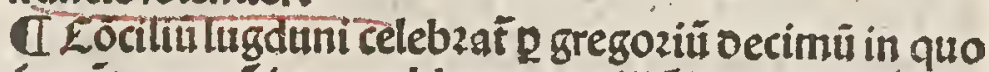
fuerüt.500.epi.z.40.abbates: $₹$ alij plati circa mille: $శ$ greci:z quidã tartari folēnes ibi fuerüt baptiçati. gauéf burcb:pb?in armis ftré,

(pudés elect' apud baifi dictionétñ ipialểnó büit: oĩs

tĩ papa ele. ctione appiba

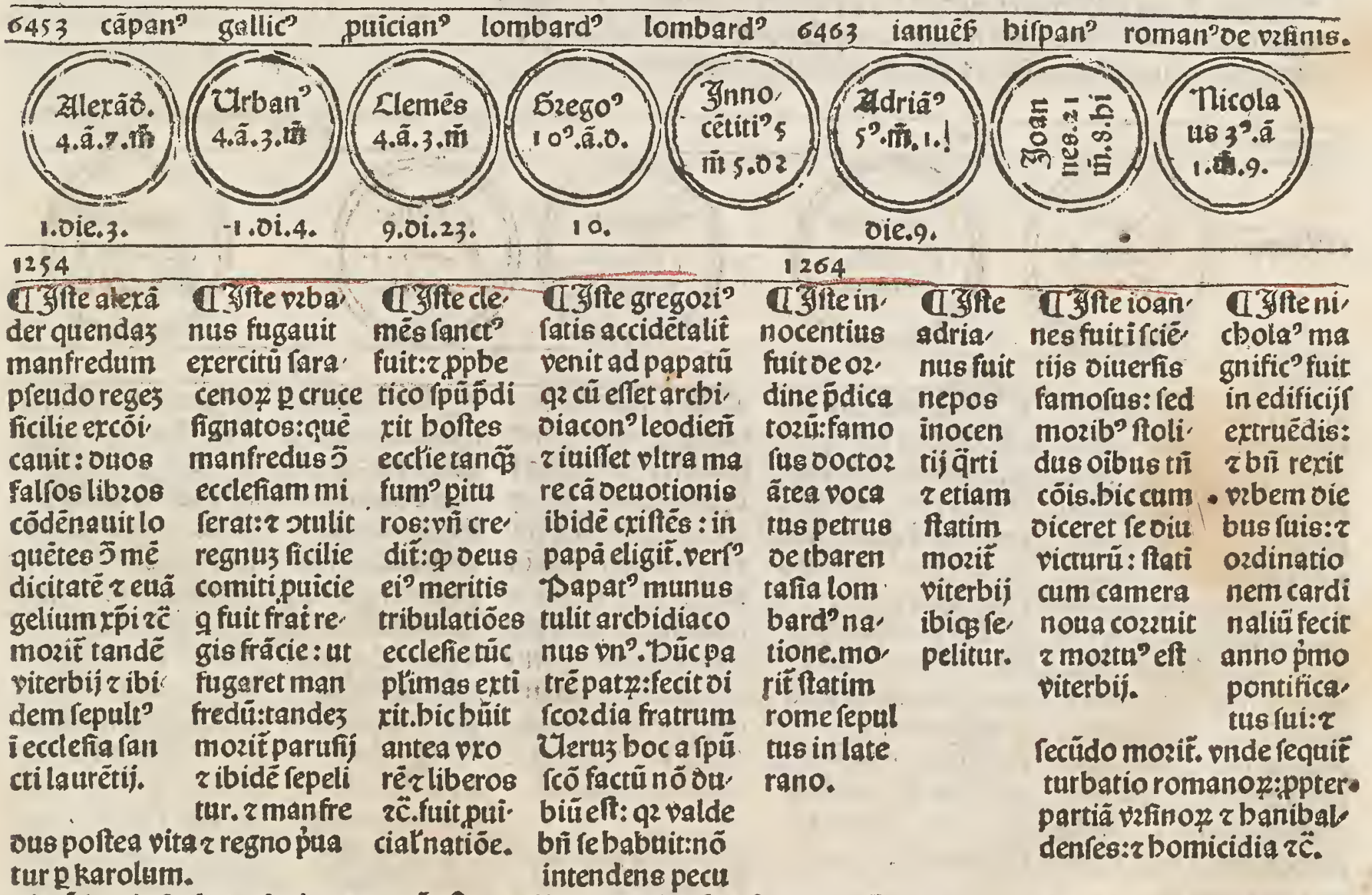
tur pkaroltim. intendens pecu

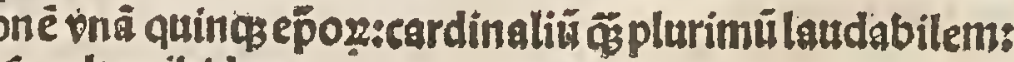
q2 bonefta 8 valentes pronas affumpfit. Xnosit aretij::epultus ibidem. 


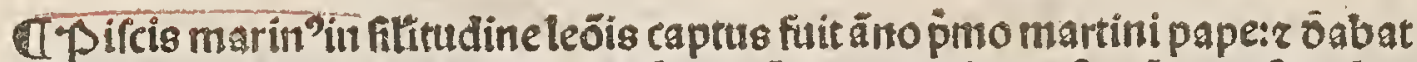

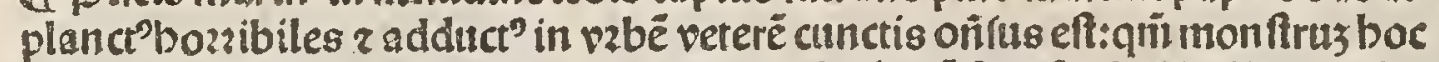

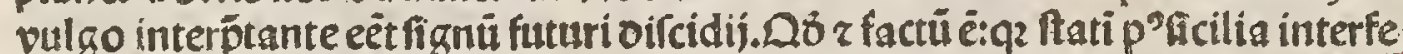

TDernber'puer făs ruftican" martpriçat a ildeis:requiefcit

ctis alienigenis r fetib? imaterno vtero occifis crudelit ab obedientia

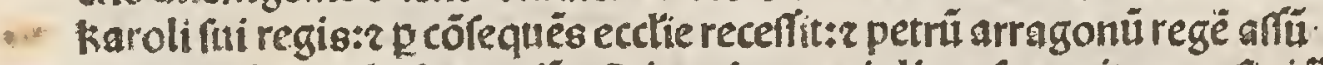

pfit: $r$ multa mala fecuta für, Et in vzbe partialitas furrerit: q2 vifini banibaldos cü mul!a fanguiluis effufione pugnarunt. Gtem r int fara cenos multa milia occífa fuerü. Et iônon mirü 9 patrímoniü ecclefie perit folito moze:qz temp"é ut indiciú incipiat ab ec

Inngatozes. clefra oei. Zerikarol'non longeante martiniz obijt bene oifpofitis fingulisz oeuote facramentat". petr" bo inobedientie fili? infeliciter moztu'eft:ex vulnere qo i bello fufcepir ficut folent mozi pfecutozes ecclefie: q2 ourü eft fragili bomini contra ftimulü recalcitrare.

Afrancilcus petrarcba poeta z beremita feripfit plura ftilo eleganti. CTartari inuadüt regnü cöftantinopolitanú:multafósterras imperij occupant:ftragem indicibilem oe bominib'facienteg.

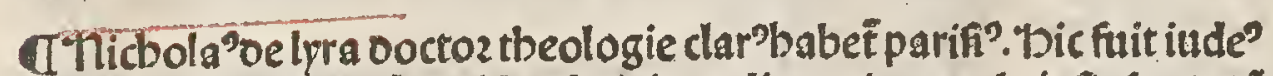
matione. Eónerfus aút valdepfecit in ozdine minow $r$ fcripfit fup totä

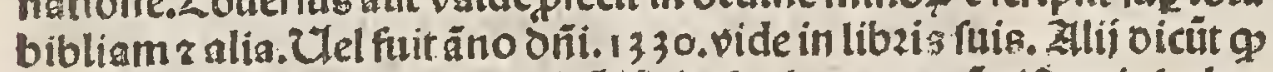

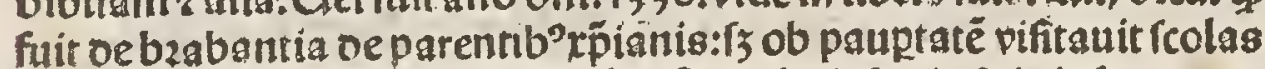
atideožr: fic oidicit linguâ illä. Uel ifte nicbola" $*$ iudeis informatus eft in pueritia.

Thoc tpe rpiani pdiderür ci acbone. 15.citutates nobiles:2.12.caftra

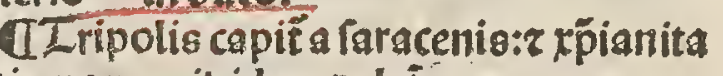
tis nomen ibidem oclet.

A Acbon illa fortiflima: 2 iexpugnabil" cinitas:capit a foldano r faracenis:ppi oifcozdiã vitisą̧ nationú i ea cōnozan tiin $r$ seleta fuit: $z$ côlequenter tora fimul tra feà occupat a faracenis ppternimia pctá xṕianoz:qubidé tücmozabanț.

CD2do celeftino 2 icbogí $p$ virü fanctü

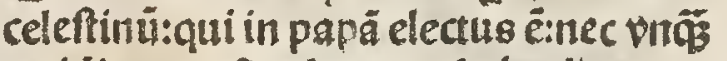
cecidit a ppofito fancto vrabodie.

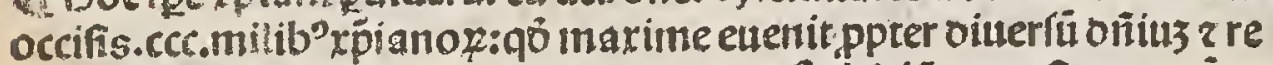
gentes cituitatë:

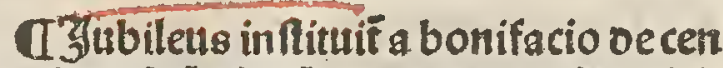
tefímo i cëtefíni femp ouratur". Et fuit pzim?iubile?anno onit. 1300.

CLiber rent? oecretaliu publicat : $z$ fuit miffus ad ftudia pniuerfalia perbonifa cium octanü.

ISefta quattuoz enangelifta r $r$ ăttuoz ooctozin inftituutêt:bieronymi: auguftini ambzolij:gregozin.

QTape $\left(\begin{array}{c}\text { martin } \\ 4 \text { ânio.8. } \\ \text { mề. 1.gal. }\end{array}\right)$

Anno toi.

I Zite martums fuic re ligiofoz amator: 2 pijs opib" valde inteni". bic ercöicautî impatozécó, fatutinopolitantizeog nó redierat ad fidé:ficut pmifit ii röcilio lugduti. ppt qo tuulta paffis fuic rota ectia fimul : filit z petrú regé arrogonie nafozé regni ficilie excöi coluit.tanden $p^{\circ}$ mulra bella ảinftruxit contra pfidosiudeos z tribula tiones:mozif parufij:mi raculis clarens.

\section{3.}

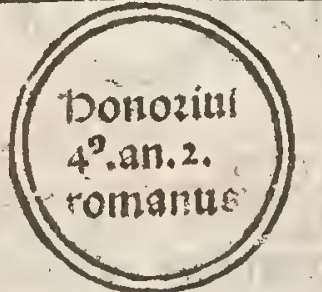

1274

I Gite bonorills fuit bó têpatus $\tau$ magne oifcretionis:libenter bäbés pacē nulli lefi uts, bic podicarifecit crucē วั petruz inuafo rem regni ficilie.

C Earmelite butus tpe oimifis mätellis varijs:cappas albas fumplerunt.

UEcmeta vilus eft:fi gnum mali: az pla re cura funt afflictiua xṕianitatio.

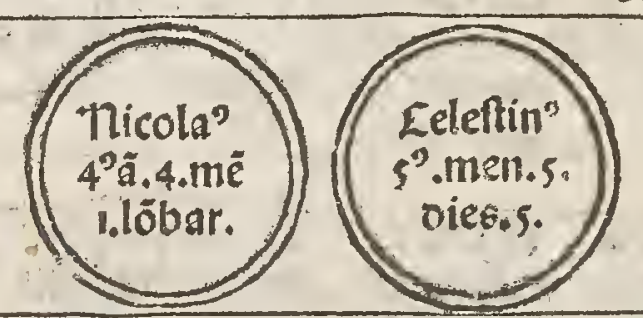

1284

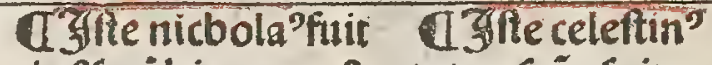
oict'frat bieronym? minifter generalis $i$ ozdineminoz:glic5 bonus bomo ife fue rat:tñ mlta infelicia ecclie fuo tpe accide rüt.nam multa bella orta fuerunt in vabe ipfioccafione: arni mis adbefit vni pti. pof búc vacatit fe des änis.2.men.6. totus feñs fuit:? obboccuj pan. nosousos cü me dio cardinales concozdarinon poffent:iprútan dẻ oe beremo vo cantes clegerüt. Et ftatipptonus papatui refigua uit. Et ob co oi ctus ef ozdo ce' leftinoz.canoni çatus eft $\mathrm{p}^{\circ} \mathrm{p}$ clemēté: fub noie fci petri ofellozis:cui’feltú eft,xiiij.kal.iunij.
483

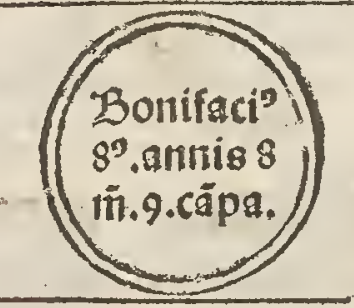

C'Gltebonifact' fuit vir in bisã ad curiaz ptinèt expiëtiflim?: q2 pacénon büit pa dêtie rue modü i tan tã arrogantiaz ererit reipfi:ut onim totius mundi fe oiceret tā î tpalib’ô" in fpüalib? Etmlta magnifice fe cit:ăin fine mîerabi lít oefecerüt oeditos exemplũ cüctis p̂lat? ne alta faperèt: is foz ma facti gregl mag? fuderēt amari a fub ditis öttimeri. bic $\overline{\mathrm{e}}$

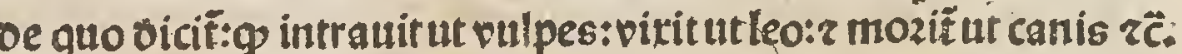

ITutus bon02i. 4.tpe:fait bellü maximü zraue inter ianuenfes $\tau$ pifanos:occafiōe

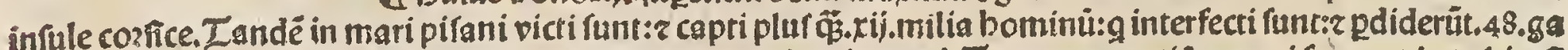
leas:exceptis alije nanigijs z pzeter illas que fubmerfe funt in mari. Terremotus etiā magni fuerunt in turcis:f gngntes mala multa que fecuta funt ibidem. 
aftesdulp' fuit comes oe anarone: rnö fuit cozo natus p papä:q2 obijt i bel lo qó cü alberto ouce au. Atriebabuit.

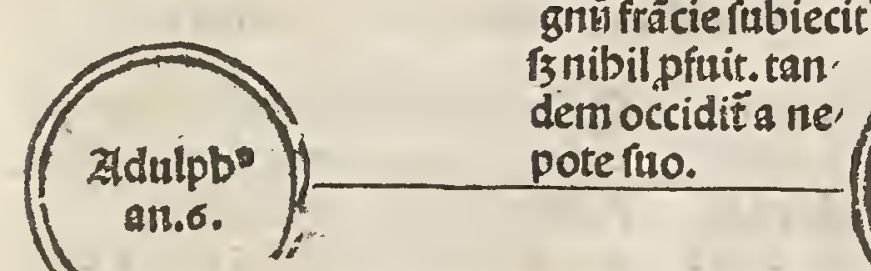

đEometa apparuit. 2 regêftati bellü flandrëre: vbi cecidit flos militie galicane. 1302 .

Q Lerremot'magni fuertit: nec anf fuerü bo mines manere in ciutatib': 2 papa bonifacits fimiliter in pzato quiefcebat.

QLodonic'oli rer frãcie canoniçã p bonifa.8. Iद्alanus oocto onituerfalis.

ff Joanties fortus oocto2 fubtilis.

I 3 oones andree iturifta maxim":claret bono, nie:plura feriphitit folêriter.
13) 3 fte albert?fuit our aufrie filitis rodulpbi ṕdicti. bic pzimú a boni facio repzobat ${ }^{\circ}$. Deinde $a b$ eodẻ có firmat'ppîregé fräcie: túc inimicá ecclie. cui etiâ alberto idé papa ré gni fräcie rubiecit : fič $₹$ alia regna

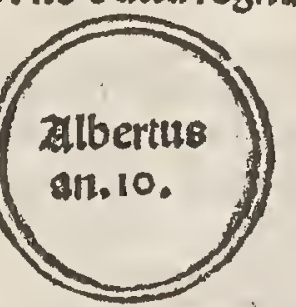

A Fffe benricus fuit comes lutzenburgeri.in militarib' actib ftểnuiffim" : pacem p terrä r aquä tenere cōcupiuit: victoz gliofus: 2 bella. toz iuict? extitit:cozona t'fuit a clemente gnto. tandé itoricat" fumëdo etucbariftiā. beclegüé ilibzis:z fama ferunt́ $q$ quendã oe ozdine p̃ di catou feã:fed mibi prittate fute, runt lî́ teftinoniales : i gbus excufat ozdo oe bis : $z$ os falle becimpofita fuerútpenerabili viro oño bernardino de mon te politiauo: $g$ erat frater eiuf

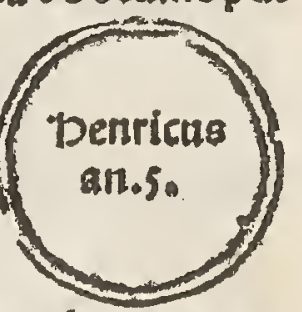

dem ozdinis bó pzudens z religiorus facerdos oe claro genere nat": in curia impiali p̉ncipib' eälis. Dbtulit etiā fe in ciutatê aretij inter amicos impatozis ftare iuri:z ad oèm øbiectionem fiducialitriñdere : cui placet regrat buiufmodi apud pfeffozes eiufdé ordinis:z plene informabié oe bis ad oém copian.

ITRbodus infula capit̃o manib'tburco z:p orios ozdinis lci ioannis bierofolymitani cü quings adiacentib?. Et fut bella tum annis quattu $02: 2 x$ p̆iani finaliter obtinuterút.

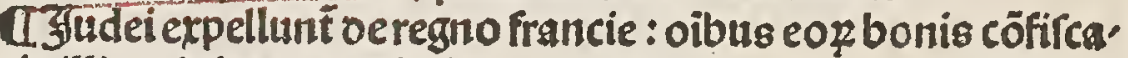
tis illic minime retuerturi.

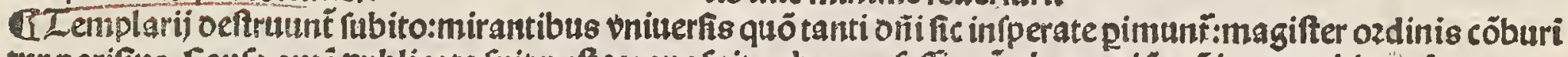
tur parifus. Laufa auté publicata fuit poftea:que fuitppbana pfeflio cü abnegatiöexpi: $z$ expuitionefupza cru. cem in oppzobziñ crucifixi:put plures eo w confeffi fuerüt. Et ftetit ordo ifte annis.1 84.

C. Sulcinus berefiarcha nouarieti. cü margaretba vroze fua beretica:z complicibus fuis combufti fuerunt: fed pritus membzatim concifi fuerüt crux ṕdicata fuit.

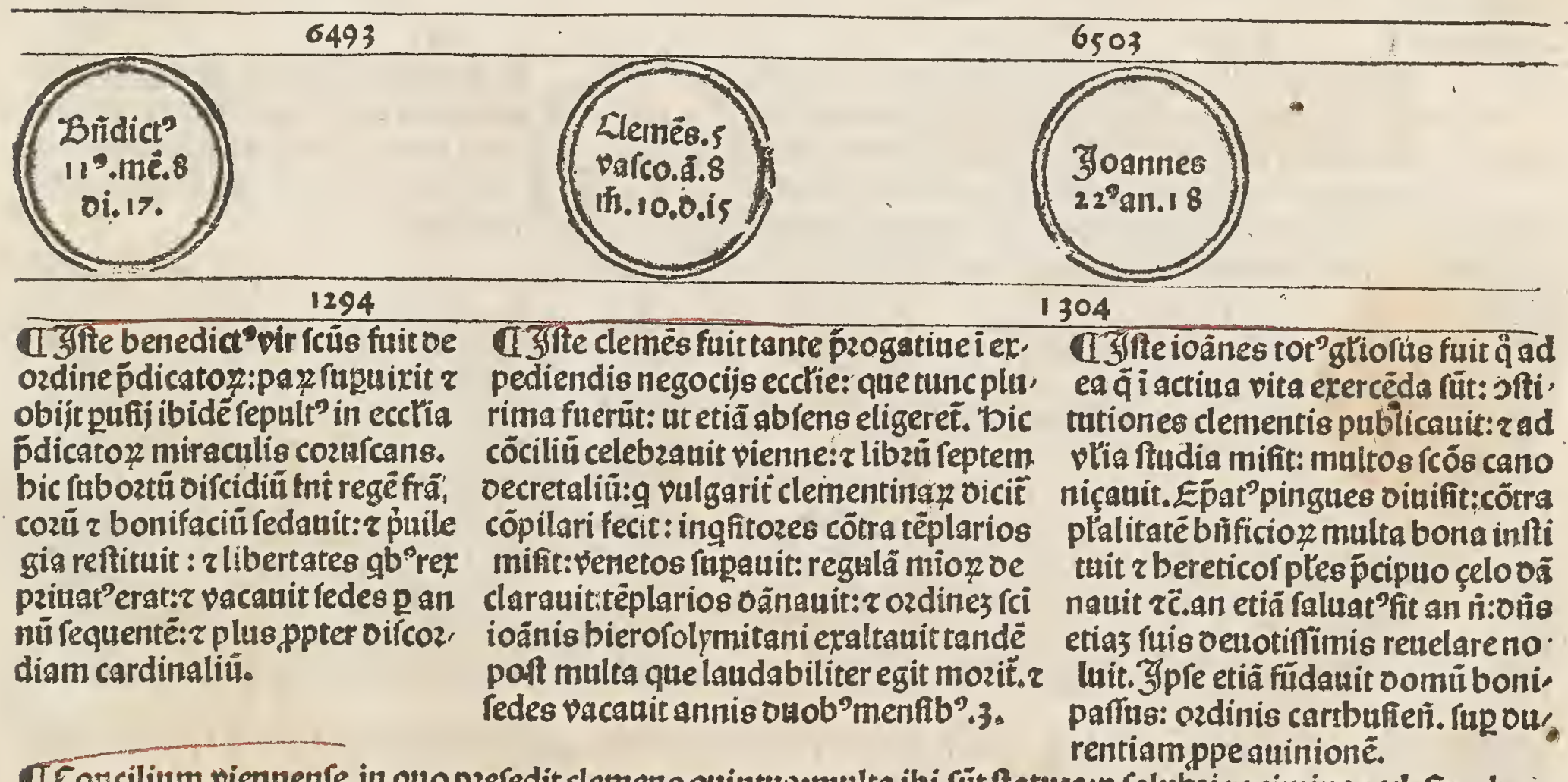

CEoncilium viennenfe in quo prefedit clemens quintus:multa ibi füt ftatura:p faltubzi regimine ecclefie:z bere

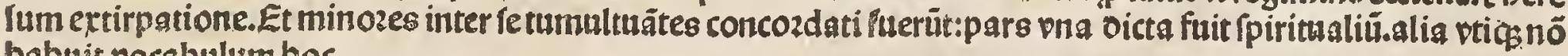
babuit vocabulumboc.

đTlobiliffima cittitas aconenfis a faracenis oeftuit: ac oemus beifere nnarie in carmelo monafteriä ad ättuoz miliaria ciuitati vicinú:ab eis igne cremat̃:fratribus inuêtia in eo:pfidosü gladijs trucidatis: z tuncpzocbdoloz ozdo carmelitus mellifutu locum ex toto pdidit:in quo'a tempoze belie: z belifeippbetarü:ouob"milibus oucen tis viginti z pno anmis pftiterat.

ITsanctus albert oe trapano carmelita ficulus: Dir meritis:infignis ooctrinsq clarus:actorius pfectiöis exem plar.7.idus augufi migrauit ad oominu. 


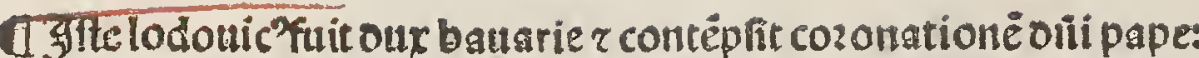

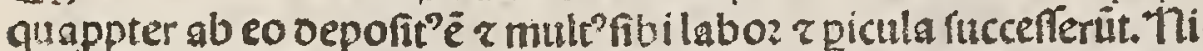
fus eft etiā fcindere vnitatẽ ecclis. Et fridericii oucé guftrie contra fe electî vicit. Intribulatióe $z$ côtumacia vfq ad Finem our ${ }^{9}$ pmanfit ģrande picalù aie fue repoztãdo. Iandē karolus côtra eủ elígit qui pualuit.zlodouicus oe equo cadēs fubito moziť.

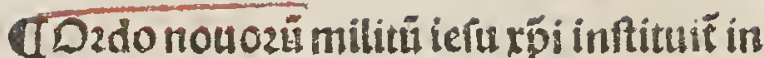
pozrigelia piosnnê.22.3 faracenos.

C Aftronomt maximi fuerit parifus b boc the videls:ioãnes de lineriis: i oấnes de fa. ronia: ioannes de muris z buridan' maxi. mus plis g inuenit viả nodernoṛ.

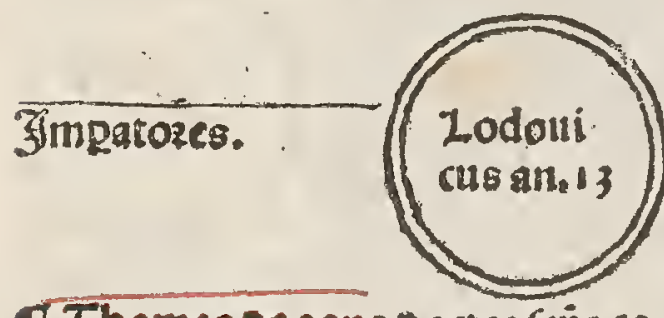

Tlbomas oe agno doctoz reis ca

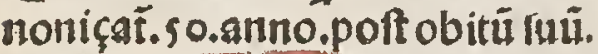
LLbonas epserfordeñ. canoniçat. At todoutictooloran? eṕs canoniçat filius regis ficilic ozdinis minoz:

d Elementinarúliber publicať 3 ad fludia vlia oírigif́ p ioannê. 22.

AT paupes oelugduno $g$ fe oixerunt oe ttia regula francifci:tanç beretici -ãnati fü r cốbufti:pluribus locis r Dicib":cī fuis articulis erroneis. Ün" articulus fuit: $Q$ xp̉s z apli nibilba.

buerît in ppzio uel côi:z ợ nullù itts

babuerut in bis que fcriptura vicit

eos babuiffe.

Zninomund 6513
C3oânes mandeuil:ooctoz imedi. cina z miles in armis:natiōe anglic? fuit circa bectpa. Etmirabilê pegrinatione qैi toti" midi pfecit. Et feri pirt eà tribus linguis.

CDderic vir [cüs oe ozdine minozu in afia zindia euâgeliçando bifcurrit miraculis clar'. Et qüttuoz fcốn ntarty rii cozpa fui ozdinis oe kcuitate boz. mes tranftulit e mare:ad fupiozé iu diam i ciuitatê carrä nó fine miracul: Et oefcripfit pegrinationem fuã. Lee

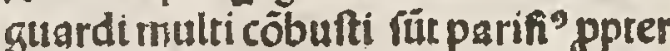
berefim pauperï : q2 fub fpecie boni mala fufcitare conabant́. Ermicbael generalis minon: fuit cũ fibi adberē tibus declaratus bereticus. 'Tumer? conbuftoz tam oe ozdine eadem ต̈ alioy.114.
(I) Spus guidonis multa retelat î cillitate alexiippe romã: 2 be boc pulcberlibellus eft rcripens.

a Cent ${ }^{2}$ magn ${ }^{2}$ tut:gterras mo. uit z ondas: $r$ edificia fubzuit.

đUitioltebilis fcâ ctidã bëmite in pittia onìi innocentij pape fexti oú adbuc cardinalif cêt. stu aiebat Ulidi gias i infernü oefcëdere: fie uiueg oéffrimas : ipurgatoziú fic niuē rarifimã:\{y ad paradíu trĭ tres vidi introire fec illius eppi acil lius pidue romane: zillip pziozis cartufieñ.q̆oia ficpoft repperitve ra. Et maximã ouotioné ad facrü ozdiné cartufeñ .oeinceps bũit.

Q Ludolphus cartbufien. pozar. gentinêfis: $g$ vitā iefu compilauit egregie zalte.

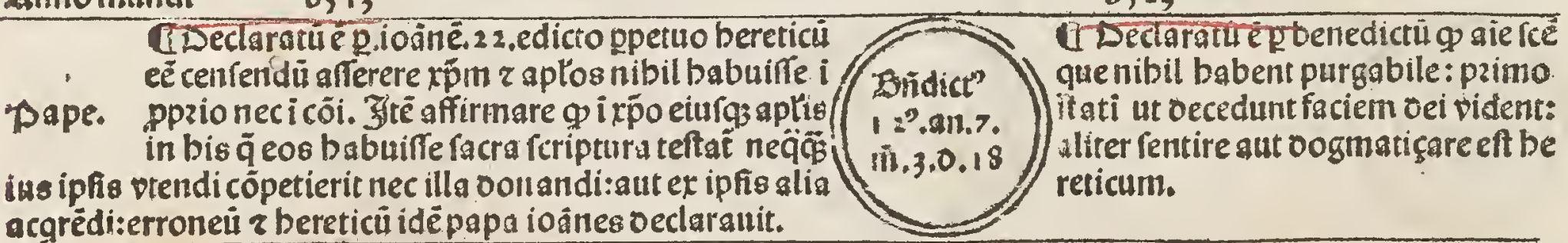
acgrédi:erroneu z bereticü idépapa ioânes oeclaralut.

żnno rṕi. 1314

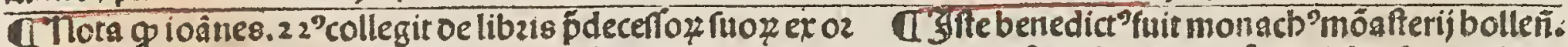
dine btibnidicti rumos pontifices.24. fuiffe. Lardinales. 183.

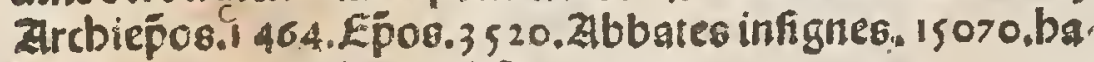
buit qüog canoniçalos ficōs. 5555 .

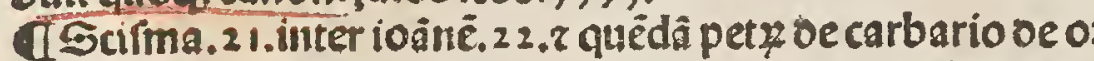
dine minoz. Là fuit trãnidis lodonici:g fcinderenitebalur

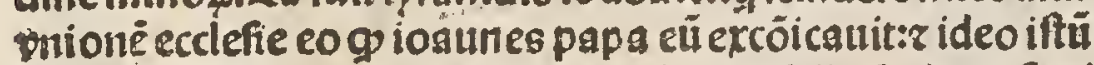
petriu in idolî erexit z venerat"eft eü red nibil pfecit: qz ftat Tuccifüeft: $r$ petrus venit ad pedes ioânis veniā petés r obri nuit:tî fuit côfรtuat'ut boftis oibus oieb? vite rue. ozdinio ciftercij: $r$ rocabai iacob' oe furno ab in' fantia bone vite z mgr̃ i tbeologia. Sact?aút papa

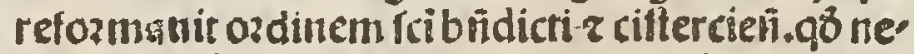
ceffe fuit. In largsëdis brificijs ourus fuit:z ne in

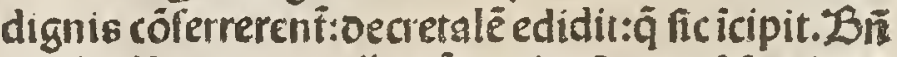
dict'oe $e^{3}$ vonis:z mltos püuatit. Erat eni fermid? fi dei cil futucritate çclator:z ob bocmultis min"ch its. ante rigoz of tatis fuit : $q$ vix cognofcere vor: luit cốangumeos:dicês papã côfanguieos ñ bĩe.

(CDEerardus oe bononia: ozdinis magne marie oe carmelo ooctor parifij: fapientie z ooctrine opinione cele bzis:poft pluriūlibzozù editione in auinione vitä exiuit.

đSibertus oe bëre almanus:z ioganes valfigrã anglicus cameliti ozdinis:D octozes illuftribus cönumerandis

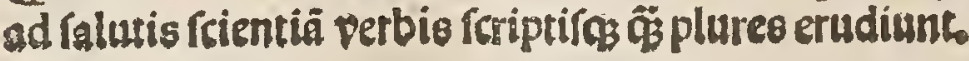




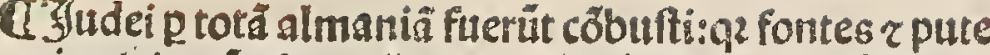
os intoricarüt:ficut pleses eoz côfefli futerü id effe verü. mut

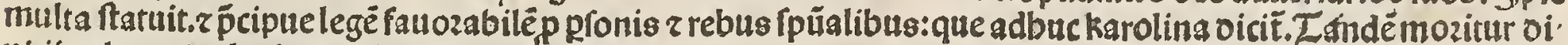
titijo plenus r glozia:repultus pagge.

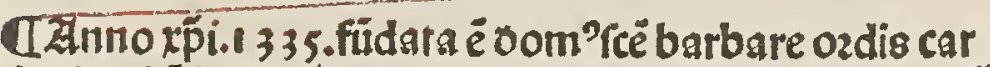
tbutientiü in colonis agrippina :illo i loco ut pie credit vbi olim btüs fenerin" fci martini animã in celü offerri cöfpexit:angelico cĩ cốcentn.

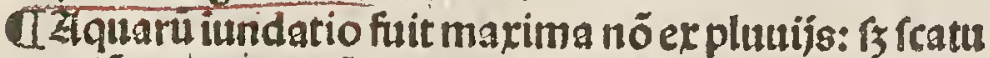
rientiú terre venarüioanma fecit infinita to to $02 \mathrm{bi}$.

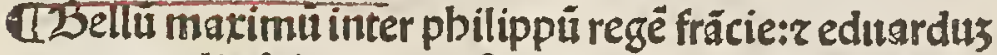
regem anglie fuit: $z$ tanta ftrages ut mare flandrëre ali, quot oiebus tinctü fanguine videret̃.

Opettilentig grauifima fuit:ita $Q$ vix viui rufficiebàt ad fepeliendú moztrsos.

ब. jtern multe ville oeferte oiu manierunt.

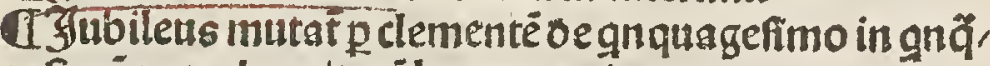
gef̂mü ppter bzenitaté bumane vite.

USclis illo bzito ooctoz iuris canoniçat: qz fuit aduo, catus pauperî r fcé vite: bic folus inter oés iuriftas mo dernos fanctus reputat.

Q Leliarandrus cardinalis fci petri ad vincula:p̆latus oenotus: $₹$ amicus religiolozü zpmotoz bono 2 fuit.

đPortentú ignis in celo vifü eft:quod a phis vocá̃ cädela rotūda. Et rodé gnino

karolus

$4^{3} .911 .31$. lecta peftifera furrexit i fupiozi almania: zad inferiosem oefcendit: oemü ad ptes gallicanas. Eonftuebät buitumodi ex oiueris: ooctis r indoctis: nobilibus r ignobilius: flagellabant aute recuz flagellis nodofis acubus infutis zê. r nifipapa pbibuiffet:multa mala attentafient.

1350

đIectoz quidā pautus noie:negãdo btãm virginè cö ceptã fuiffe fine peccato oziginali:cozā toto clero r po pulo in cracouia cecidit: zexpirauit: fermone nōdum

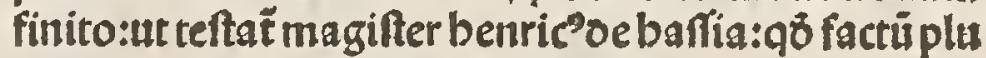
res termit in bac materia feribentes.

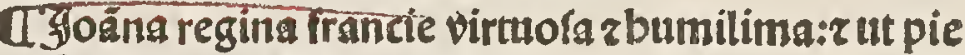
creditur fancta obijt. 1349. iurrexerunt. 135 1.cruciflagellatoze8. Dec

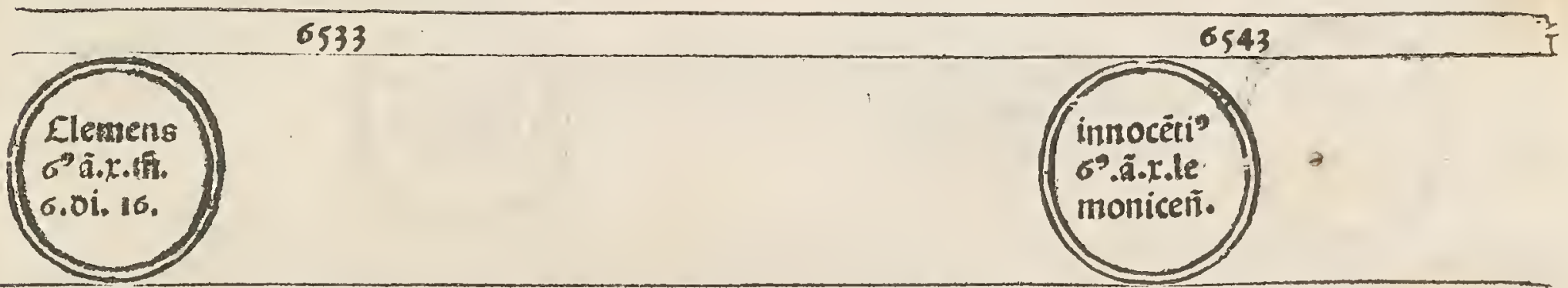

1334

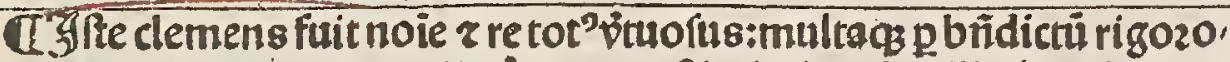
fe facta mitigauit:z quofdä puatos reft tutut. Laudabilis fuit rigoz fe.

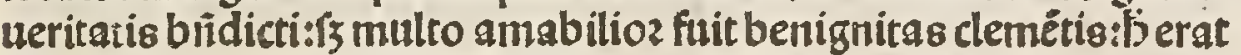
rermocinatoz egregi $\imath^{\text {? }}$ z rermóes multos collegit." 'nullü incölolatum

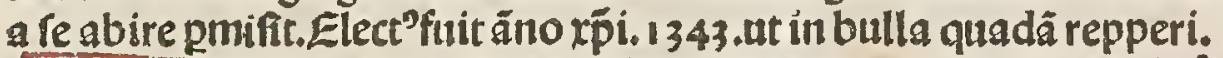

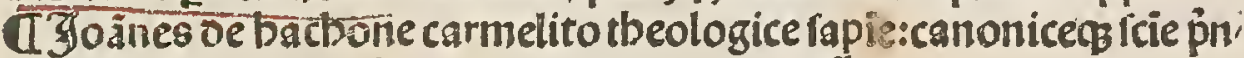
ceps parifius:z oemü pangliä clarme cogno iciť.

đÉ ioziceri.ac oemú clueñ. pötifer ooctoz inter ṕcipuos cổmédatus ₹ ut alter elias p omo oñi feriofius poft cozzectozi⿱艹 iuris: $z$ alia ö pluri ma volumina pcômédata:libau 5 oés berefes feribit quẽ oño gancelli no cardinali albaĩ. ptitulauit z multozü actuú fuozum clariflime ge Ptozú magnitudine rp̄ianū ozbem celebzi rumoze clarificat. d'ffte innocenti? amatoz fuit religiolo: 2 fecit fabzicari in regno francieppe ran. ctum andreã ex oppofito atuinionis mor. nafteriī ozdinis cartbufieñ.z aulra pzi,

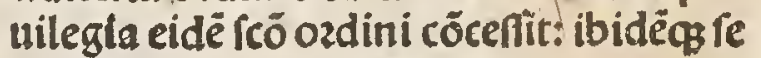
peliť:fuit etiä canonifta maximus.

f- seirusorectrex prioze generali car, melitarĩ ep̃s vafionenfie ac bierofolymi tanus patriarcba virtutis fozma: ooctri. nec; fpeculum clarus babet: quë ä:plura miracula oeo conregnare pzedicant. 
U Lerremot ${ }^{9}$ maximi fuerüt per oiner a loca: $z$ bafilea tota cecidit cii multis caftris i circuitu. Iücboies ve. lut beftie in filtuis cómozât:nec cittitates intrare audêt Bella etiã pltura z peftilêtic z famés fuerìr. Lerraqzi i multis locis aquam albã z fetenté euomutt:ä caftra loca foztia calui oedit. Ipa pniciola ppt berefes r re. ctas plures r fupbia:z inigras nimis inualuit: vi ili.

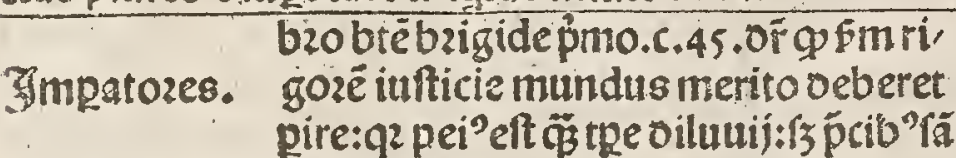
ctozmifericozdia parcit ei.

15zigida vidua fciflima oe regno ftetie clara babet multas retélatiōes babiuit infozmatinas ad oém fia tü ecclefie: $r$ ordiné inftituit ati ${ }^{9}$ ipfa patrona è: feftú eitrs agiť. 23. Tlulií.

Co2doraluatozis g vulgariter oicif ozdo bzigide:cir ca bectpa icboat cuipregulä iṕe faluator met oictauit

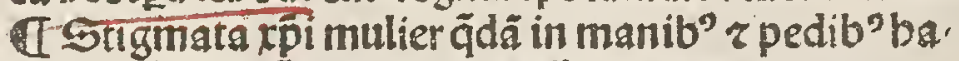
buit $z$ mozabat in oppido oslfft in ptib'solandie. CStıdiu p2age inftituit. Et puilegiis dotat ab inno centio fexto intuitu karoli.

\section{Tognes oe rupercifta oe oz die minoy multa ṕdixit}

mor futura de ouob'antixpis:z oefolatione terraz $\tau$

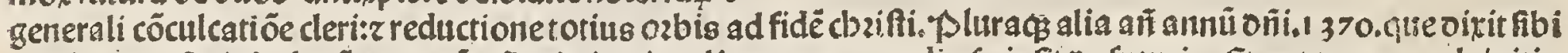
retuelata 9 oño iefu:\{ร nố euenerüt. Et oiu in vinculis tentus:grandia fcripfit oe futuris. Et nota 9 pene ab initio

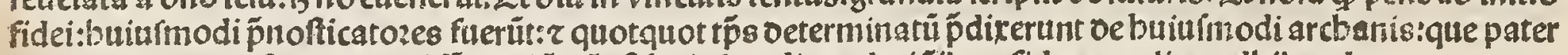
pofuit in fina poteftste oecepti füt. Et ió nó eft buiufmodi reuelatiöibus:fides amplitts adbibenda.

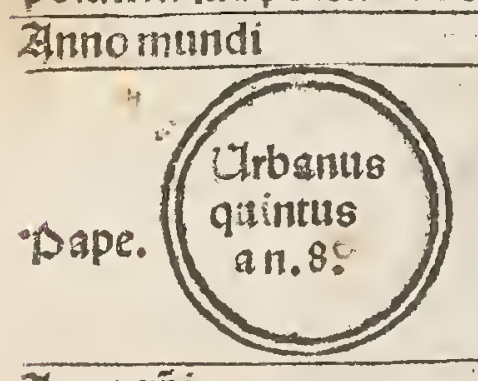
6553

Q Lonftitutio in vinea:publicatur contra fy. moniacápzautitaté p̉mo anno vzbanti: in pr. be apud fartctü pertī. Cipio martijzoursutet âf ougbus bo:is.

IIpa multurupitiora ? cariofa:r popul' leuis ni mis.

akatberinaterenis vigo incóparabilis fcitatis fuir cui? vitam fcriphing dan'ozdinis ṕdicatozú có felTor el?: obijt rino.1 380 . moltui uftificauit partes vabani fexti: oicendo ipfí efleverú papã roefcíma teppbetautit r $\vec{c}$.

Q Q̉abuit fecü viginé râm katberinã filiã beate b ziğ de: $z$ alias plares trrituras ferus prongs venerabiles.
Tanta bimane malitie ooctis viris multipler sfí, gna ṫinter çnóminima é:q parentes filios nó educât o: fciplinate: fed pmittunt eos ad placitum delitís affiuere perulâtia igit cú er confue. tudine in naturâ tranfiterit: nec erubercë nec timere por fit. Sitoz certix oura oonec paupertate bellis: labozib" z aliis tribulationib'molle

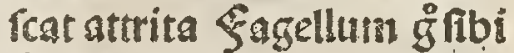
prerat 9 filios nó caftigat.

1. Zlerãdria egrpri ciuitas opulentifina a petro bierts ralē cypziqa rege capiț. Dea. to petro thome o?dinis car, meli patriarcba cöftantinopolitano ac redie aplice p ran cto paffagio legato multú coopante. 1364 6563

Anno xp̃i. 1354

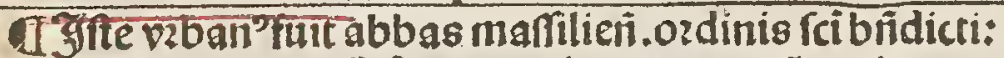
decreto z ooctoz z fé̉s reputat. Secit crucé pzedicari cötra tburcos z paffagiü ozdinautit:intoricatus obijt $z \ddot{c}$. żd ipłus beata brigída fuit mifịa a xṕo pzo confirmatióeregule. .

$$
\epsilon
$$

4Lira bec tpa pmifit karolus.4.electozibus thelonea r vectigalia imperialia:que fita fuerát in terris ipfoy. Et

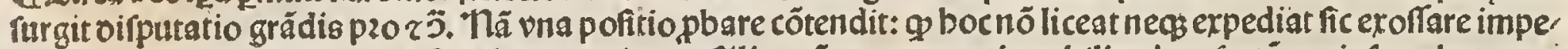
rium:ut nullas vires contra aduerfantes retineat. Zllia ecôtra putat rationabiliter boc factú: ne ipfoł electop re

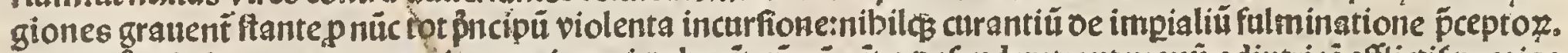
Quare ğ ipfi el ectozeo pze ceteris exactionari oeberẻt:cü nö eẻt $q$ oefenderet:aut manù adiutricēafflictí pozzige

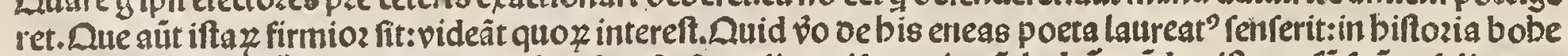

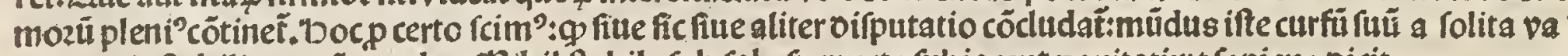
nitate z inftabilitate nô retrabet. Thibil ftabile fub fole:fy cuncta fubiacent panitati:ut fapiens oicit.

z patriarcba côftantinop olitan': Doctoz pecelebzis fümig regis fignifer bellicofus. "Poft inumeras quas babuit

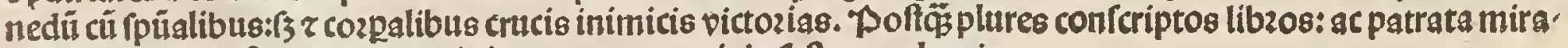
cula in famaugufta regni copzi ciutateicozpus exuit in fefto epppbanie. 


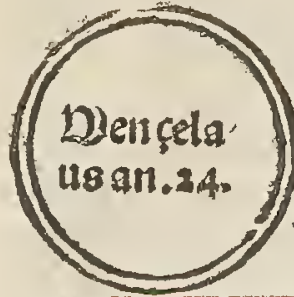

đSsecta choziçantiü träfituit:anno. oñi.1 373.Et fuit rbenus magn? in comparabiliter.

\section{A3artbolus: \\ TSaldis:fuerüboctpemaximi legifte.}

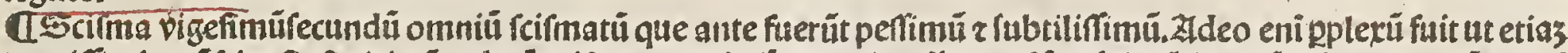

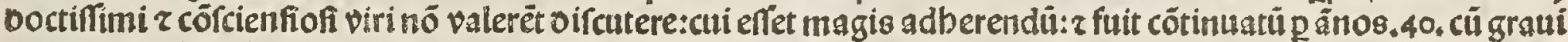
fcandalo totius cleri: $\tau$ grandi iactura giazppter berefes: $z$ gliq oeuia:que tunc pullularüt:eo 9 nó effet oif́cipli na in ecclefia contra buinímodi.Er ió ab ifto vabano fexto:

1'Zुoannes baleftari carmelita ooctoz:inter ooctozes ingenti babitus glozia:poft editioné multo zo voluminü:in cöuentu fuo maiozitarü mozitur.
Qदुfte bonifactus eligit rome loco vabani:oi cºfuit petrovetbomacellis: $\tau$ cótinuat fcima.

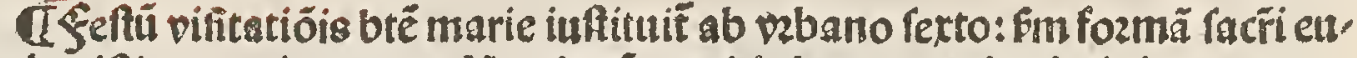
cbariftie ppter impetrandã bnioné:meritis beate marie virginis.

C Cincentius oe balentia al's oe ferra: vir fcus ozdinis pzedicatozil claret miraculis multis: canoniçatus eft poft a calixto tertio anno olii. 1455 . qơ z fibi rpüppbetico ṕdixit bernardns oifcipulus eius.

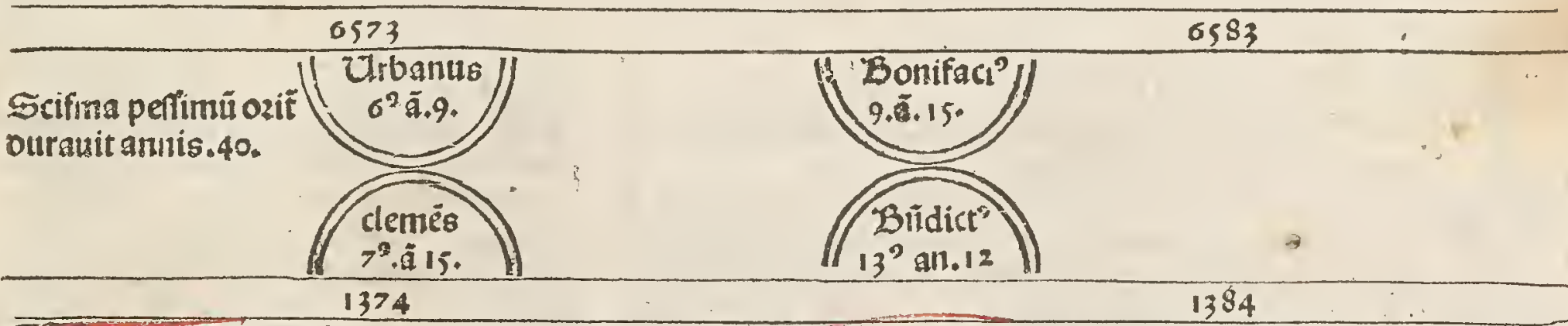

Cद्lte vrbanus elect?fuit in vabe ppter vim romano rü is cardinales boc metu fecerit z nö ex aio. Duappt fugiêtes ad ciuitaté fundop̣:oixerút eü nö effe papam z elegerunt loco cius orim robertū oe gebennis eodē äno:qui oictus eft clemës feptim": z bic ozit fcífms.

ISctis andreas ex pzioze carmelitarüflozentini ce nobii:piul feftilan' odoze virtutifero: löge latega ful, gurante fplenderés:in oño genit:cui ${ }^{\circ}$ cozpus flozen, tie tranflatu:magna miraculozi illuftrat glozia.

I Lirca bectpa moatuus eft illuftriffim'oris ioan. nes galeaceus oe vicecomitibus:our medilani. Duo tpe obtenta fuit ciuitas vincentie. Spontere, cömendata $z$ oedit illuftrifimo oominio vene. tiarum.
đIJfte benedict 'fuit elect? in altinione in locū clemêtis:

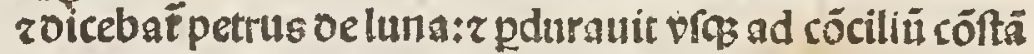
tienfe: fs nectunc quidem obedirevoluit:\{ femig pmanfit ptinax. 2noziế tandê in regno aragonie iuffit cardinali bus fuis: $q$ ftatim aliü loco fui eligerêt: $₫ 8 z$ fecerüt: $z$ ido

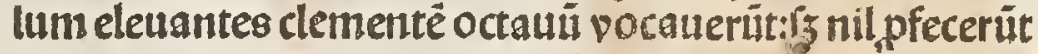

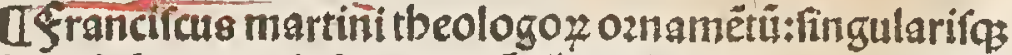
fui tpis lucerna: in bonozes pgliofe fui carmeliti ozdinis patrone:libaũ oefcã conceptióe inatula e oe gentricis marie cốfcribit:cúctis virginis çelatozibuts gratifimu. Ulincentia.

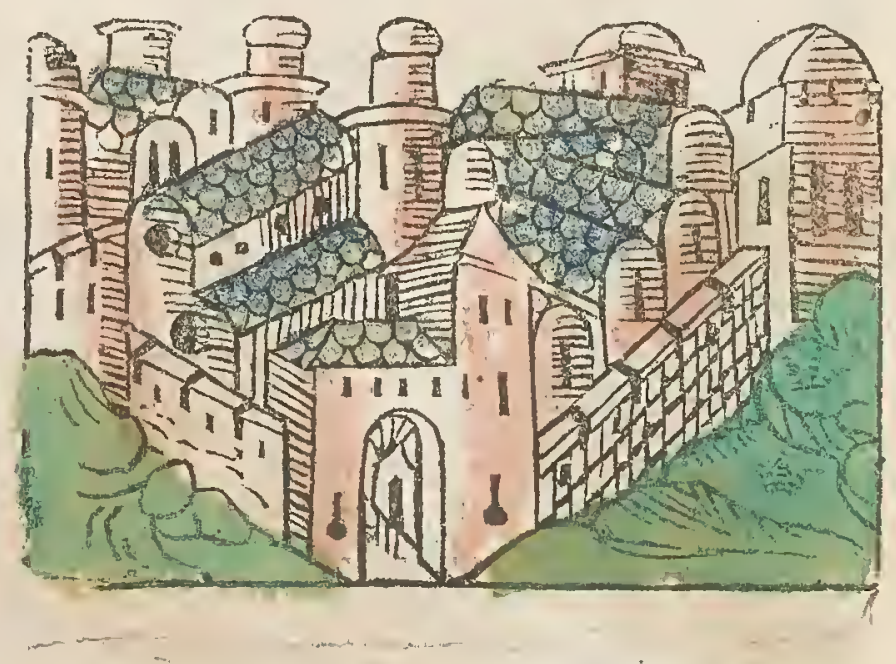


Gदुfterupertus fuit oux bauariez comes palatinus rbeni:vir iuftus r catbolicus cozonatus a bonifacio nono. bic cü grandi exercitu almanoz intrautit italiä contra ioanne oucé ga-

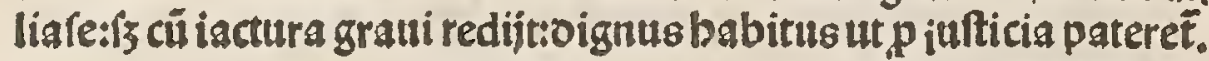

Timperatozes.

TБberbardas groet claret fcitate vite $z$ fcia. $z$ ince pít cōgregationé fratrũ i oauãtria: z plura fcripfit.

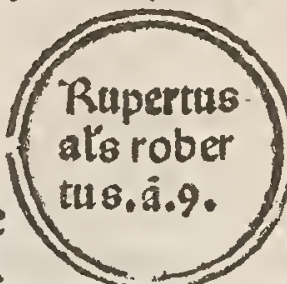

T'7oânes rubzocb clarus babet: vir admodü oeuot'r illuming, tus. Etiā multa fcripta in tbeatonico reliquit.

Thenricus opta:tacre tbeologiepfefoz famofus.

CDenricus de bafta etiã ooctoz tbeologie: fuerüt in Diena ouo luminaria ecclefie.

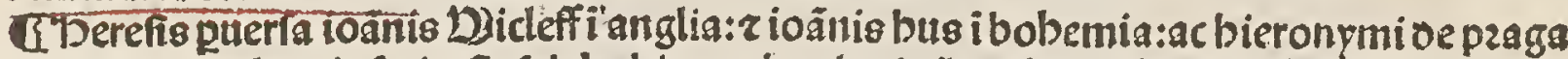
pullauit $\tau$ multos infecit. Et fub babitu ouino: Ispinä crudelitatē ab/ códentes:totû́eccle.

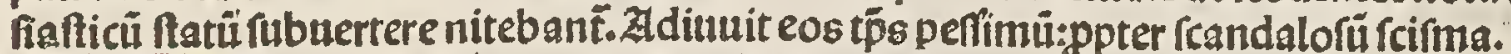

Iberefis adamita 2 pullulare cepit ibobemia: Is ftati extincta ab bereticis fuit.f. buffitis Erat eninimis grof́a : iuerecüda. Tã nudi incedebãt: 2 indifferéter cú feninis luxuriabã

Znno mundi

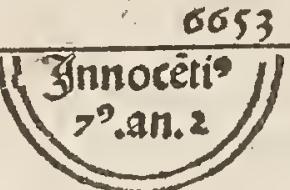

occafio infinitorma

6603
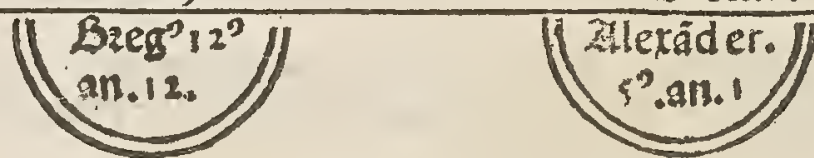

apape.

CEometa appuit. Et ftatim poft leodiũ ce . Milib?interfectio. Et oriti pautbeni Jrege poloniebellantes fupati funt occifis 10g48. Toannes ger ooctor tbeologie cla rent parifius. nó pualuit ereg bo. ní qơ ozcreuit. 1407. relianeni. frater regf räcie: occifus eft ps cócilio cóftantien.
Cipetroecliaco the ioz fciftura fcã elt:qz

ILodouteontes. rifius ifidiore. Et fuit Znnorp̄i. 1394 1404 nifacij:oicebatur colmarus oe parufio.

II rifarius curfus tempo z repit: $q$ fe nuiro ozdine alternat: $\mathrm{gm}$ bũc

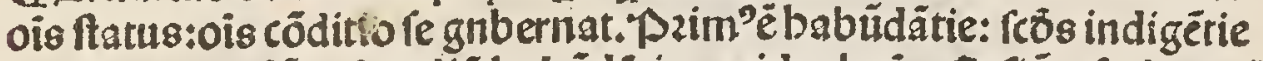
terti"tpantic. Lü eni tpaliã babüdätia arrider:boies fic fiūt aiofi z grä dia attentãt:pléą relut futuri fublimes: oelicate z pompofe educất. Sequiť ex bis faciliter oifcozdia qũ mnllus alteri cedere oidicit:oonec apta bella cuncta ad pauptatē oeducät. Indigētes igif effecti:pzudentiä
IIgite gregori? fuit elect? rome loco in nocentif:vocabatur aĩ angel' ${ }^{20}$ arius ceflit in concilio cō fantieit.
ICōcilíü pirantù incboata fuit matia oemó faeiēdevniöis ouos.n. Depoluit $z \hat{E}$ tiü fubftituit qfic pe

$$
\text { . }
$$

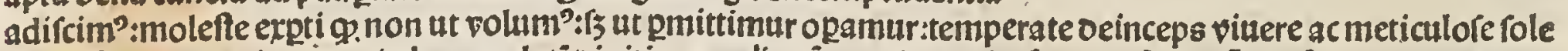
mus. Senerat oeniq tpantia bec paulati oiuitias:queliterü ut pzius animü tumidü reddüt:z eü in circuitu lempi terne infabilitat] ambulare cogüt. Zuxta cöe igit puerbiü:oiutie pariüt aiofitates:aiofitates bella:bella paup

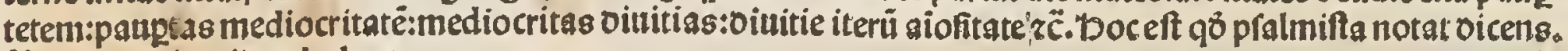
In circuitu impij ambulant.
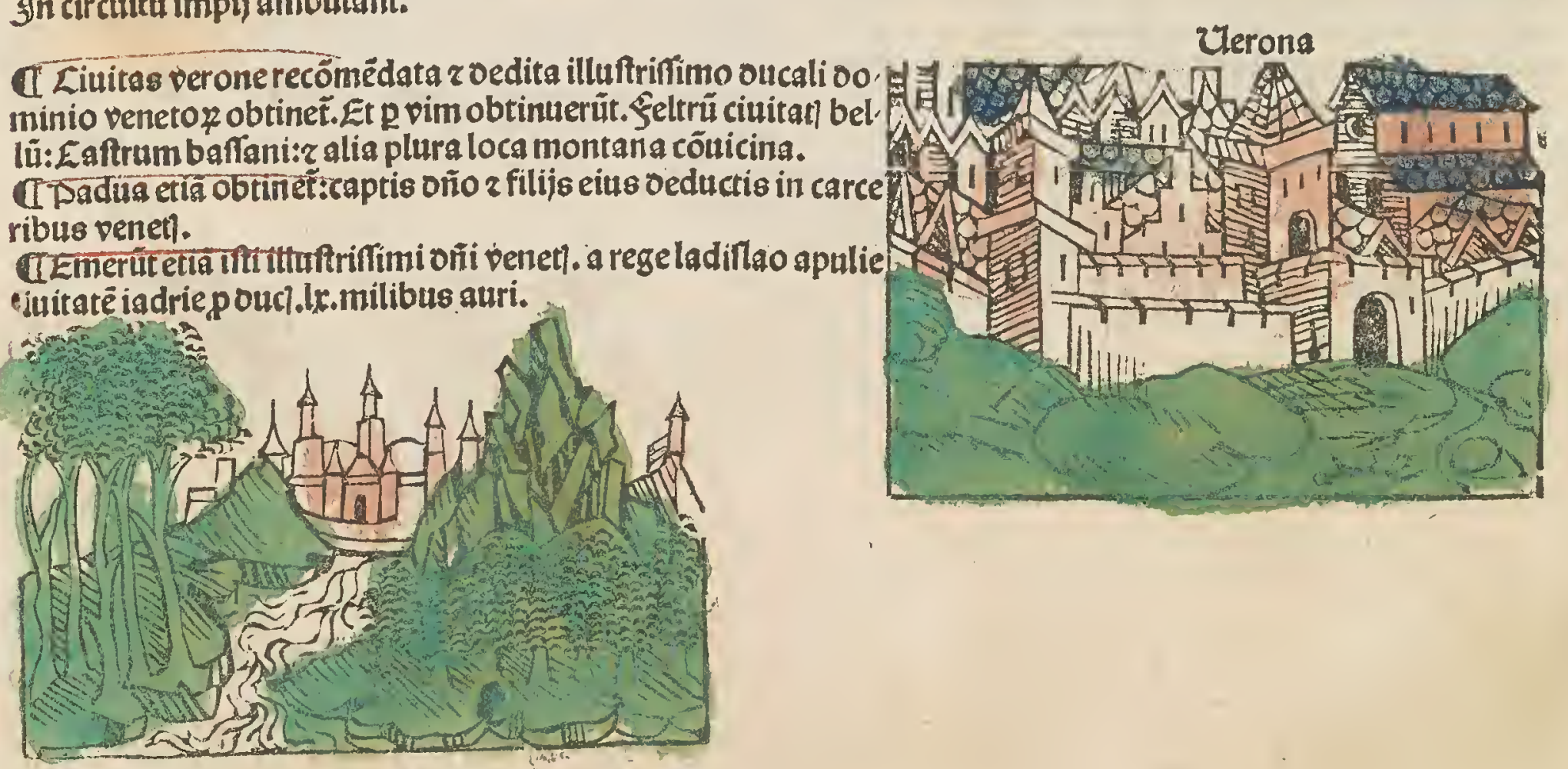


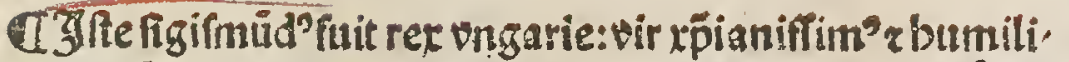
mus:ad eo oesrot?at merito canöiçari o ébuifet iturta årúdã pioz vota. Dic afficte ecclie r pene oefolate : fua mirabili fa piêria r induftria fttccurrit:nec in aliå fibi ac fuis pepcit:oo.

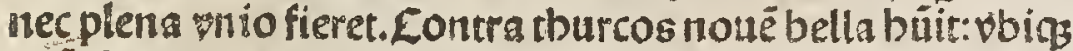
triupbådo. Qusid p!rra:å oe oftâtino:tbeodofio karolo:ot

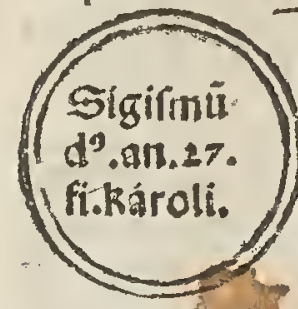
tone:ceterifos impatozib?laude oigna fcri bunt́:buic fecure pint applicari:eligit anno 1409. cui iä.23.ãnis regnaffet in pngaria co onat́ab eugenio.

a Bobemia vaftatafrociter p figínundi z pincipes almanie ppéberefim bufitaz. Et

fuit crur oata z p dicata contra 208.

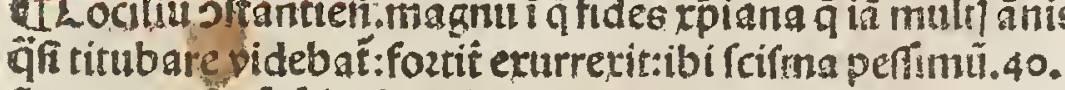

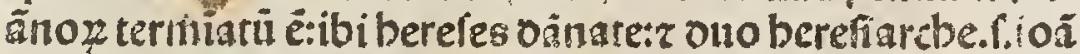
nes bus z bieronym" cöbuft fuerür: $z$ plia bona iltituta. De

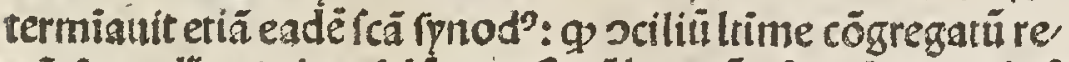

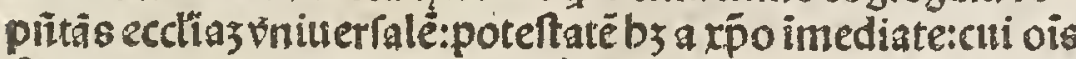
'tat"etiä papalis obediretenet: in bis ä fü ad generalê re"

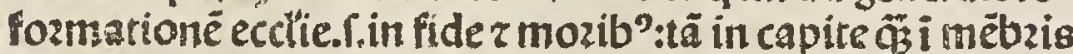
Z̈rē q oeinceps cốciliủ oe oecẻnio i oecēniü oebët celebzai. đ Sräcia añ becrea oiu ifloze: bic in merose z cö culcatione fuit : iucra moze pariabilitatis tpatium Etnota op fräci etiā extra patriä fua. . .i turcbia mirerabilifime ceciderút ibello: q2 nollienunt audire cöfiliū figifnūdizcapt'fuit our burgüdie: alijs in. terfectis.

Q Regnu frãcie flozédiflimü mi erabiliti lupza 1110 dü paftá p benricĩ regë anglie: g etiā nó valés ge, tos vies in velitifs fufferre:poftö alios afflixir non fine grîdi iactura fuoz: infelicifime mozbo peffi. mo vitä finiuir.

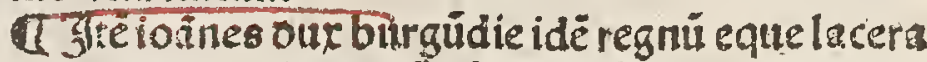
uit:r ipfe etiã p occidiť̃: $q \delta$ fuit infinito $z$ malozum occofio. Lández onis cardinalis reé cricis ozdinis certbufieñ.pacis modui ini eos repperit:fed anglici noluertít recipere: f́s bugrîdi tini.

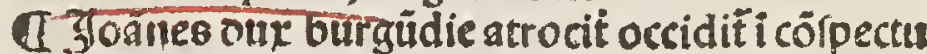

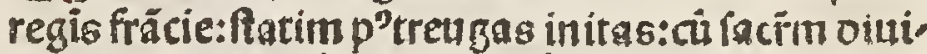
fím ambo füpfiffent: z fequút multo mala lōgo toe U1 $\sqrt{110}$ amătes in prĩtia figímūdi fatuo anoze cō. globati: cî fe ad tibitü frui nó poffent: bozzibili in, firmitate peuffi füt:ita us mulier etpirgrer:vir etiä .

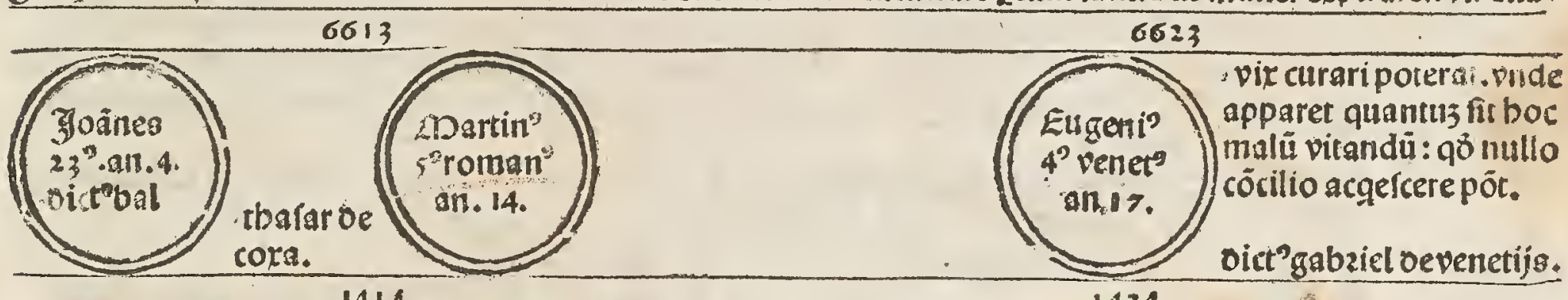
1414

1424

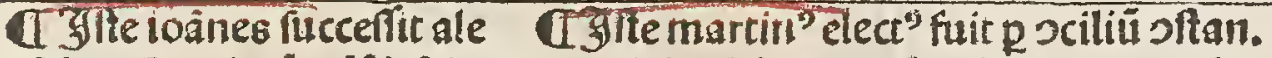
rảdro.Et pzimü gdé bri in oepofitisalijs stendẻribs g oiu fcimaba cboaut p vtióe: $\tau$ fut $i$ cö buerunt: $\tau$ fic redije vnio oiu oefiderata $\tau$ lio cöftain. z obtullit celtio. nē papat?: fed p’oepzauat? latenter fugit: $r$ tri nil pficit ci:capit tandé:x fic ceflatuit coactns:fact?"etiã iterü car dinalis:lepnlt'thozentie.

\section{neceffaria p fidei oefenfione. bic fuit $\mathrm{papa}$} potentifim"fup oēs: Diues $z$ iufticiarins magn': plateas z ftratas publicas fect' ras reddidit:bereticos oeleuit:mlta bona patrauti:adiuuãte fibi inclyto pzincipe fí, gifmüdo. \20 tra reä recupanda:multos thefauros agregauit:\{s mozte puent" res impedita fuit:z cōciliū bzeuit añ moztê cōgregari iufft in bafilea.

o iuno indicio relinquo. Ip fe etiã romä recupauít adint"
Uदुfte eugeni? fuit elect ${ }^{9}$ pacifice i vabe mortuo ma: tino:zidubitat" papa babi tus: $\{$ poftea bzeuiter erpulius oe roma fuit:ita ut nud?fugët. Ttè a cỏcilio bafn

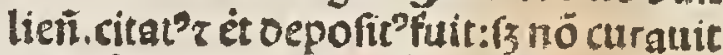

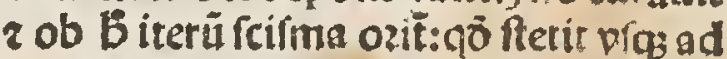
moztē ei ${ }^{2} \mathrm{~g}$ fanebär fibi multa laude oi gna oe co vixerunt. Econtrag aduerfa. bantiplura enozmia fibi impoluerüt z $\overrightarrow{r_{0}}$ ut mozis é. Iñ quicgd é: ali fufceptä oi gnitatē fuit virabftràcte vite:puta frati. cella $z$ bone fame. Qó poftea fert feciffe

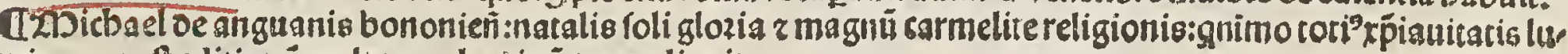
minare:poft editioné multo voluninü terras liquit.

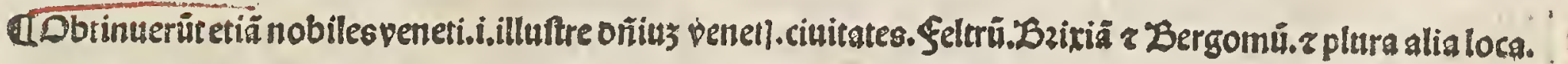
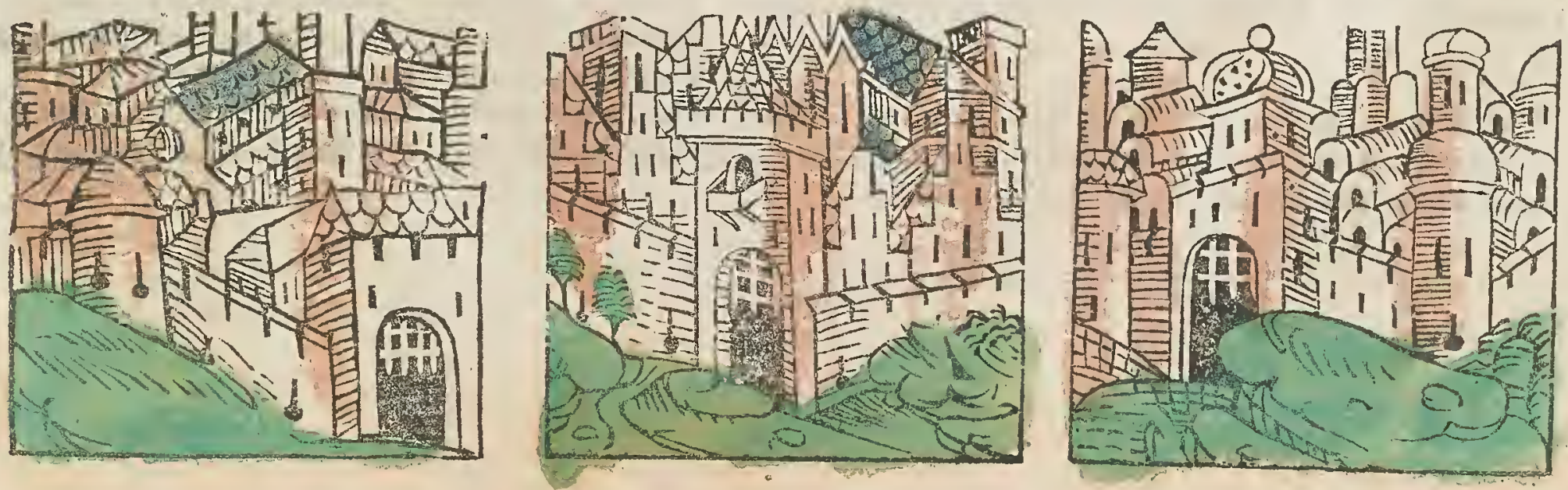
Q Zffe alber" fuit our auftrie z gener figifmúdi:z ideo aftumpt fuit i regēbobemie r vngarie:ppter filiä fcz ei" $q 2$ aliï beredẽ nö religt, "Dic elect' fuit i regez slmanie:\{y ftatim intorieat'obiit. Allijoicuit op pzofuutio ventris. Cirvtiós totalitervirtuofus r adeo pius ut tota plebs oiceret $q$ müd'ei ${ }^{\circ}$ fiden, tia nö effer oign?. Keligt unü filiu partuliu cui fite contigit $z$ ouas filias. Zmpatozes. Elect'ë franckfordie

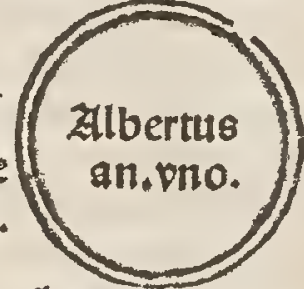

QIres roles vif füt in celo. Et regét ftati triplex re' gimé i ecclia.f.engenij:cócilij: z neutralital.2m Dul

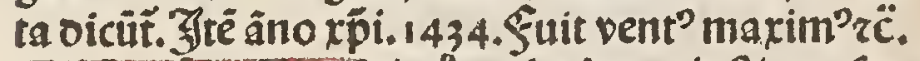
TLocitiu balitien e in â multa bong inftituta fue runt prefozmatiōe ecclie in capite $r$ in mêbzis.ba buit p̉ncipin ghofü: Is finē bumilê ac tribulatione plenü ppi fcirma. 2Dirabilis rerü enent". "ßzena,

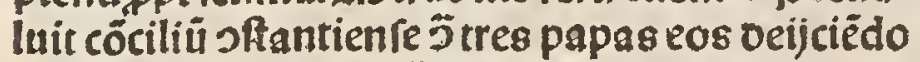
z quartū inftituēdo:cũ tot baberet aduerfitates: $\tau$ a nullo cöfirmatum fuiffet. Fffud aùt tanta auc̈te collectii z firmatii: nec vnii potuit uel i modico re. ducere ad nozmâ fui ppofíti : imo ecötra pcen' $X$
(1) Jfte fridericoux suftrie clect? fuit in rege almanie: $r$ oiu oiftulit cozonari a papa ppt fcirma. Iandé facta vniöe ani cbolao cĩ magna glia impiali oiademate extitit i vzbeco. ronat?: vir vtiq pacific' $r$ get? $z$ patiētie fingulam nec odiē cleruy. Siliã quogregis poztigalie funtpfit in vxozê. Anno aût. 147 I. magnä fecit suocationé pzincipü i ratífpona:ppí incurfü thurco z.pponés eis go iã infra. 20.annos kṕianitas

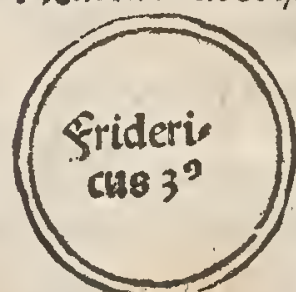
oiminuta eêt ad cenus leucas uel quafi. Et monuit at ad refiftendü le pararent. (15onitatinopolis cititas impialts capit $a b$ infinelib?tburcis tradita qianuenfem $q$ p triduū a turco cōftituit rex iurca pmifú: $r$ oie ärto oecollat́. Et fit plante tota rṕiar Q Lrduit p̉go nitate ztimoz grandis.20 Dulti ypiani trucifeâ in bolàdia dati für zinumerabiles vendit gmpatozis fuli imirabili cozp iã moztuú. oecapitatum fuit ex liuoze ifirmitate oiu tburci. Et perijt pene totaliter fides i grecia. oetenta pbics Lodouic"aretateñ.éps: cardinalis mozit̃ patiț.i.in toto vir reé vite ac mire patiêtie:miraculis cozzu cozpe iuxta no icans: fingularis colüna concilii bafilieî. men fuã. cui oiu pzefedit.

CĹcrnardinus frater minoz g nouã refozmationẽ incboa uerar:mozit miraculis fulgens:ctius feltú agit. 20.maii.

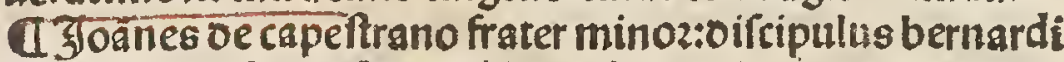
ni:ftatim poft obitui eills pofuit reformationi none:clares:

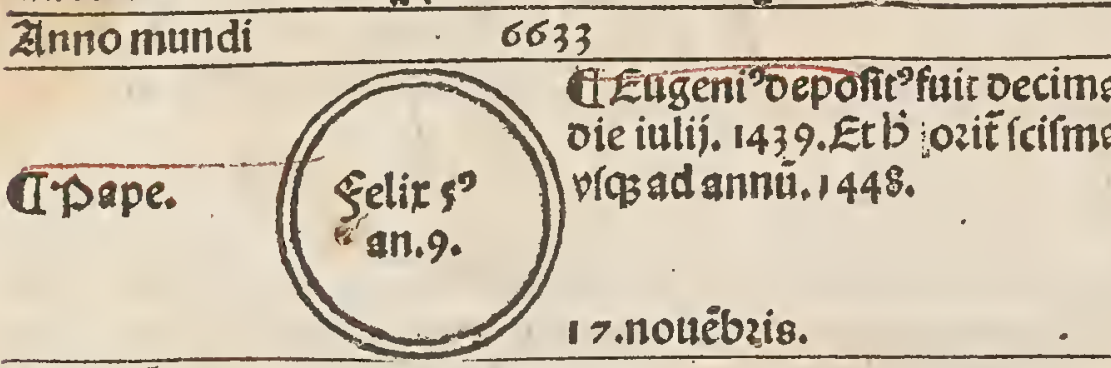

Anno rp̄i. 1434

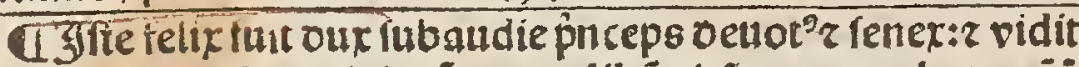

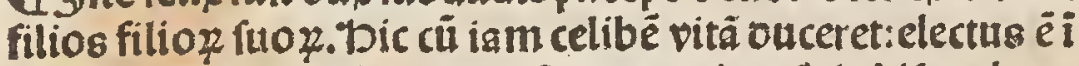
papã a cốcilia bafilieti. oepofito eugenio:z fuit f́írma lon. go tpe r non babuit magnä obedientiā: qz neutralitas fub intrauit. Tündé oefücto engenio:ceffit nicholso ppter fauo rem unionis: fact? legat' francie 2 cardinalis fabinian tus.

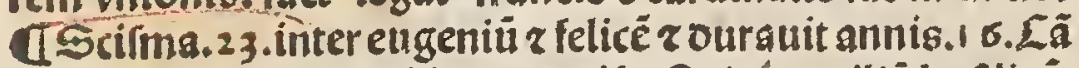
fuit fatis noua neqs añ bec tea vía. Quia'conciliü bafilieú.

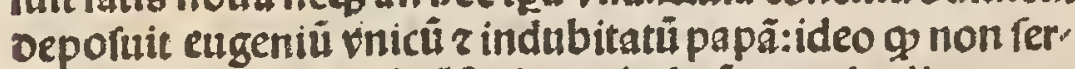
uaret oecreta concilij cóftañ.ut oicebat̃: nec obedire curar uit cöcilio bafilieñ. afferens magis ecötra oebere fieri. Ùĩ ozit grandis altercatio feribentiú Je bacmateria p z כ̃ nec poterant cōcozdari pfab bodie. ZIng gs vicit cōciliū ê fupza

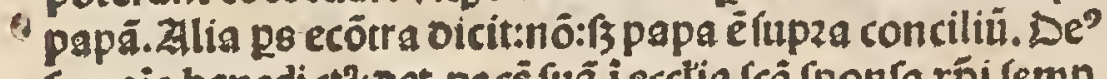

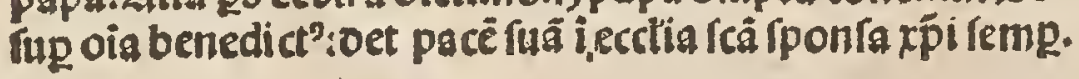
6643

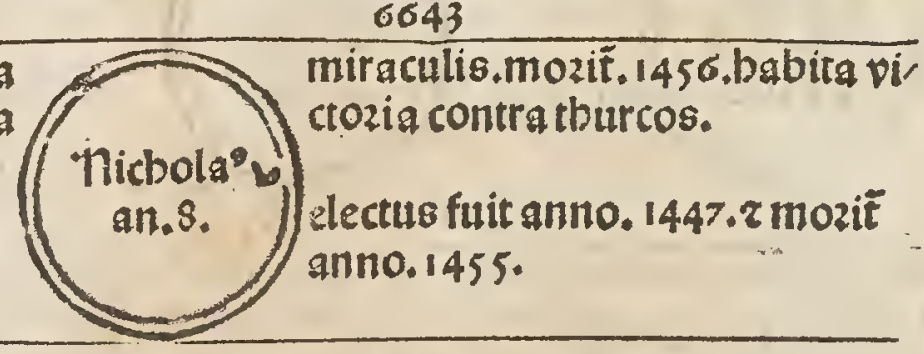

Q Ẏtenicbola?elèct?i vzbe loco eugenijadbucpé dente feímate: paulati vbiqz obtinuit obedientia5 mirantib? $0^{\circ} b^{\text {: }}$ quvir bumilime natiöis fic pualeret côtra oucé fubaudie: qui fuit ăfí affinis cüctis p̉nci. pib'rpianitatis:z ni oimifius ab oib?. Ss ftatim fe quenti anno vnio redijt cedente felice:quia placuit Qño pabiecta müdi glozificare nomé fuú. Dic fuit magifter in tbeologis tot ${ }^{2}$ actiu ${ }^{2} z$ in cóceptib'locu pler:multa diruta reedificauit:z grãdē murü rome in circuitu palatij côftruxit: $r$ totū murüromanum reintegrantit ppter timozëtburco z. Ztem verfus oe trione in vabe publicat". " ur fulfit müdo:ceffit fe lixnicbolao. pranno.1449.

QBella plura io oinerfís pribo oiu côtinuata.iD en pbalia in paufcia in flandria ianglia in romania in

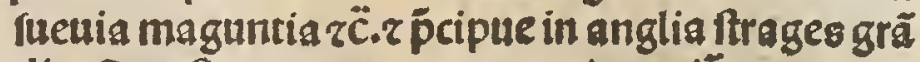
dis.Etpoft anno.1461.maguntia capit.

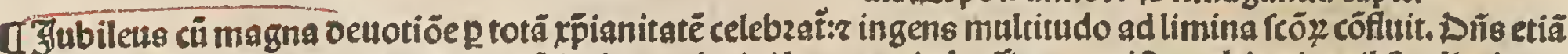
papa:rofam in onica letare confecratä:inclyto pzincipi lantgrauio baffie tranmifit multis virtutib’redimito: $g$ a elifabetb fancta matre fing fuit pzoles fexta. 
doptteri fi micbaelis pegrinant củ magno ferttosep

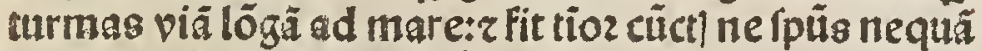

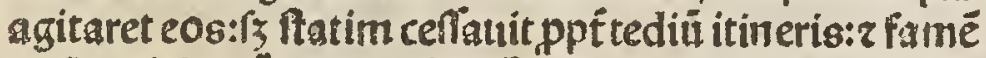
qua patiebant. 1457 . $\tau$ âno pecdenti fait maxim?terre motus in neapoli zperiertir multi.40.milia.

Q Ifrifices mira celeritate fubriliozes folito fiunt. Et impzeffozes lib:oz multiplicant in terra.

ItReformatio magna plurimoz monafterioz i situer fis müdiptibus fit. Et nota op buiurimöi reformatióes crebzo legunt facte:F 3 penentulla remãfit: gn folito mo rep puccenti tpis ad pziftinuz relaberet languozépoft venerabiliii patrú moztē.

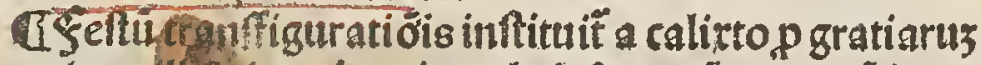
actione lil victozie:miraculofe facte cötra turcü in von garia code ole fítancti fixti. $145 \%$.

đClictozia miraculofa celit? oat xp̉ianis i ungaria trär oanubiü 5 turcä magnii: $z$ gdidit multosz fugit turpit timoze boftiü pculfus:cĩ nemo eü prequêt. rola man"

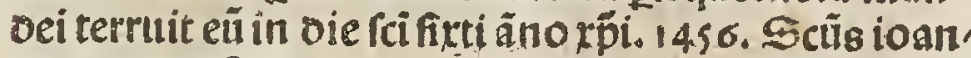
nes de capeftrano pris fuit ibi: zpuocauit pplin trepi danté ad prequendü infideles fugiètes : $z$ facta é vltio magna. Dixerüt eni turci: $q$ tä imenfus numer? armi ' geroz infequebat cos: 9 vir aufi fuerut répicere: $z$ iō fugiffent relictis oibus. Zp fi fuerüt fci angeli.
UTuella noieftina in ptib'Deftphalie ioppido qó b?

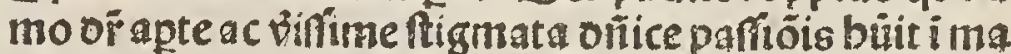

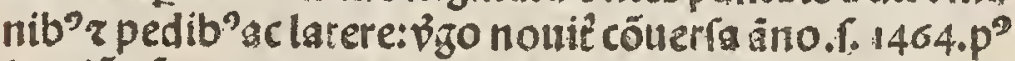
Ipaciü ait. 15. ebdomadarz circa feftú venerabil facti co

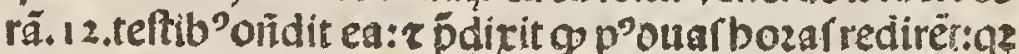

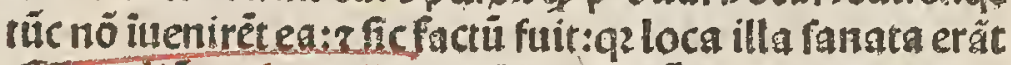

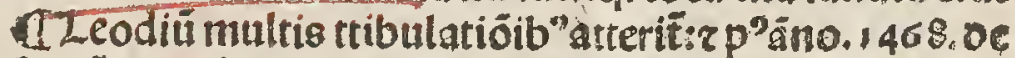

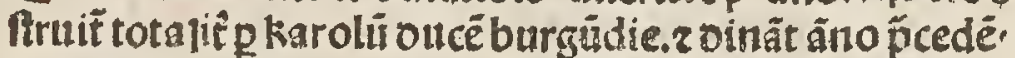
ti.etiâ idēäno.73.intraut terrä gel rie:z obtinut Łã.

Q Jubile mutat in fa dLometa apparuit in pripio แozẽaiarü p paulī oe äni.147ะ. Lireg feftus fci agner vicefimo gnto i.25.an tis trâfutut fup coloniā is oppo nũ ut'qz abüdat iniq' fíto libze: $r$ caudâ longaz quăfí tas fupbabuidet z grä. gradui. 30 . mifit ad occidentes in fefto fci blafij fetit in aricte: z mifit caudã ç̆́ ad pliades verfus ozientế: paga nimio

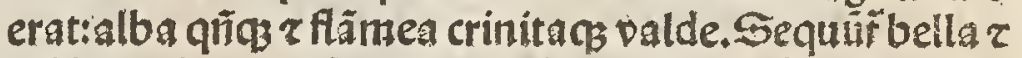
epidimie in oituerfis ptib? Et ãno.73. fuit eftas fertuentif fima z ficcitas inaudita:z i gbufdã terris ignis fub terra fitcceníus bía ad arenã fuit.

a Joannes lozetb poz generalis ac refozmatoz carme.

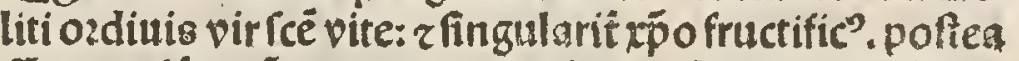
ğ carmelủ totĩ. 20 .rererat annis: andegauis obijt 25 .

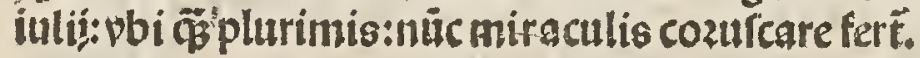

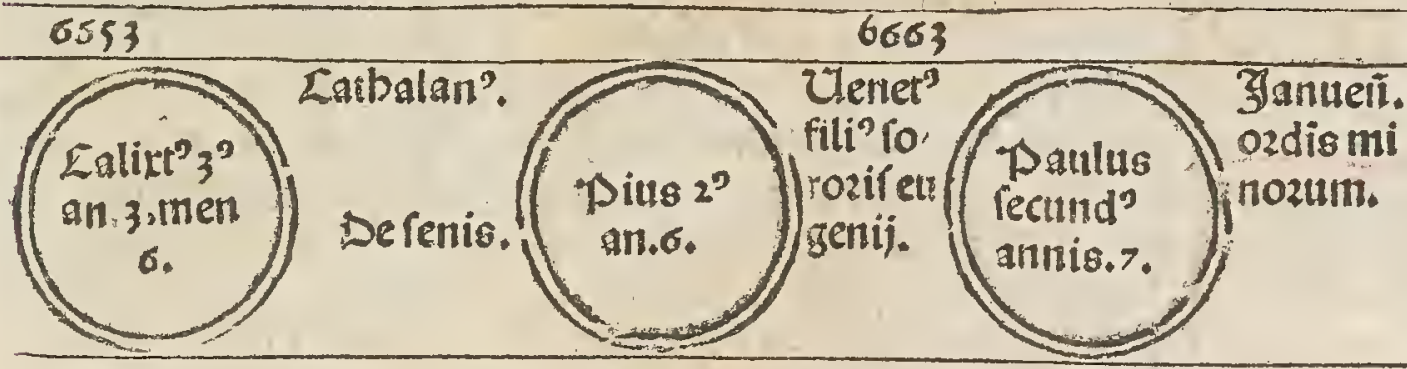

1454

agte calictopir valde fener elect'fuit $r$ otinue infirm?:nec potuit çelii ruu pficere qué oira tur cos côcepitipediente fe nio mozteq puentente elect?tuis.1 4.55.mo:itur 145 s. ipfo oie fil fixti in quo feftü trâffiguratiōis inftituit ãno vno slap fo

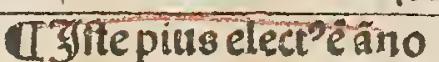
oñi.1458.2vocabat ene as: vir eloquēs r ozator magn":poetaqglaurear tus:impatozis ambaria 102 ai fuit: $z$ in concilio bafilienfin notabiles tra ctatus fcripfit pzo aučte eitirdẽ. Jpre etiā canoni çautit făm katberinã oe fentis, 1461 , bic paftagiú o2dinare cupiens:cuz plures ex aimania veniffent romä:iplos cü bñdictiöe remifit ad ppzia:eo $q$ nó fufficiffent:s frati ipfe p'moziẗ. 1 464, oie.1 4, ment attgufi.

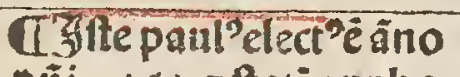
oni. 1464.z ftatiappba. tuit celebzationé fefti pñ tatiōis btè v̧ginis gliofe ficut pi":bic îfignàdis pe titionib' maturus fuit $z$ iufticie tenar: ̧ैfi melins fozet pautra códonare: $\tau$ ea firmiter fertuare ổ pla fignarez ftati renocare. Erande palatiú oftruxit apud fañ marcü:añ cu. itus côpletioné moziť an no.1471,0ie, 21 , iulijo.

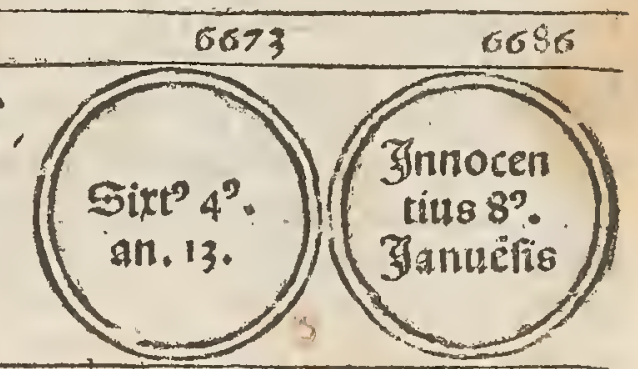

$1471 \ldots$

1485
Ibic ante cardinalatuz fuit ge? neralis in ozdine minoz:electus anno. 1471. vocabat aú franci faus de fanonia ppe ianuã: bone fame r mozu. Suit etiā vocat?ad cardinalatú abŕácicito rito. Eodë anno ozatoz bernard luftinian? veneto recitatuit cozä co:g tur cus abftuliff xp̆ianitati buo im peria:äituoz regna, 20.puincias خ.200. Vzbes:populügabras nu mero vtriufa lexus. boztabat ås ư ad refiftendú fe oifponeret.

U. Anno oñi. 1475 . Karolus bur gur

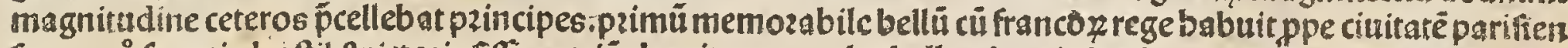

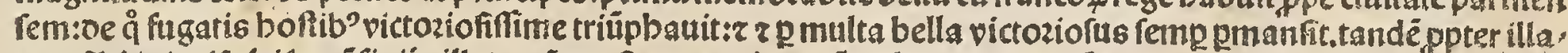

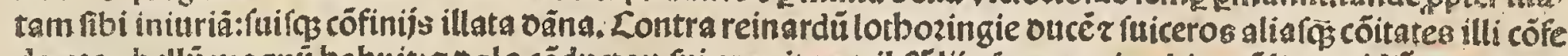

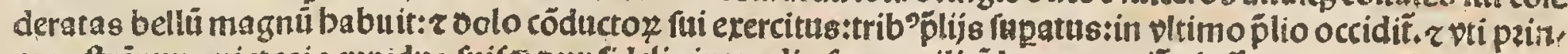
ceps ftrēnuแs victozie cupidus fuif́: oux fidelis in medio fuo z militü lancea repié pfoffus.

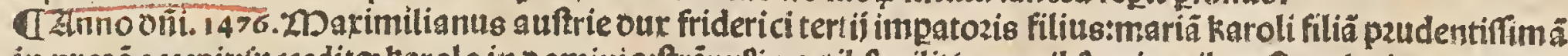
in vrozé accepit:fucceditç karolo in o ominio:Atrẻnu'in actib?militie:mozib' r virtutibus fingulariter oznatus, Lui fecundo anno fui oominij:pzope flandriã cum gallis maximú babuit bellü memozia oignü:in quo magna cum victozia franco potentiä ruperauit. 
đIempoze illuftrifimi oucis oñi francifci folcari oucis venetiaz. Slozęia zei’ptes liberate fuerüt ab ob fidio, ne illuftriffimi pbilippi maria oucis mediolain. ppter quä liberanioné ozta eft guerra inter ipfü z oominiii vene:

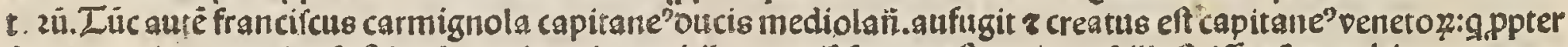

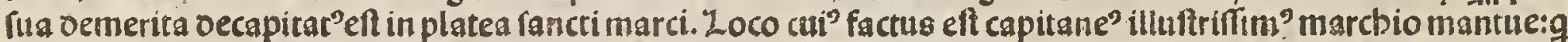

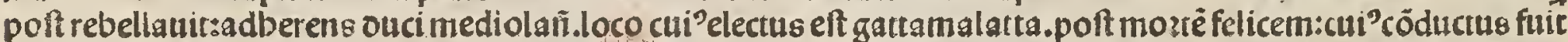
comes francircus ffozcie.tan ڤ̈̈ generalis capitane colligationis vtdeiz oucis fauoie. cốitatis flozeñ. nuarchionis ferrarte z marcbionis mantue. Et ipfe oins marcbio ferrarie oedit paffas ferrarievi. ob qua caufam oominiü illu

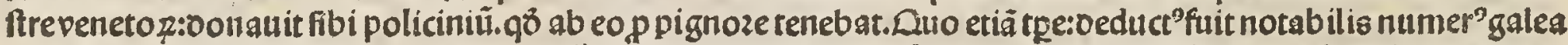
rù in lacu garde: a venetis $\mathrm{p}$ montes altiffimos côtra nauale bellü oucis mediolani. Et victoziä obtinuerunt:ca' pientes inumera loca vz caftrü riperie tridenti:z multa alia.

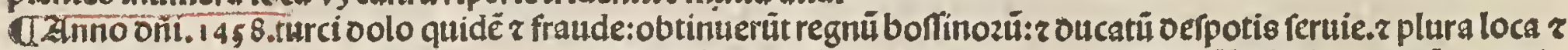
regna in ptib? ozientis acbaiã puinciẫ zinfulä mibỵlene. Eo etiã tpe dominiü venetozü babuit ciutatē cernie in romandiola.

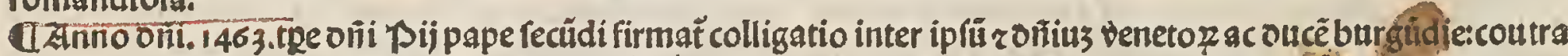

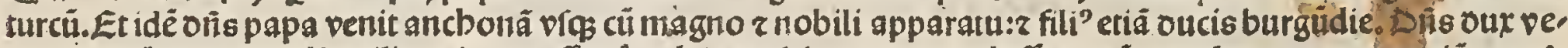

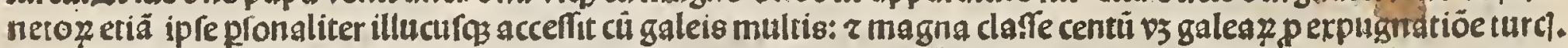
Rex aüt vngarie veniebat cu marimo z potenti exercitu terreftri. Iandem paratis oibus: ibi in ancbonna papa mozif̃:z nibil pen it"actü eft:oës reuertunt ad ppzia. Bellü poftea oiu ourauit in peloponeffo. Et oris lodouicus lauredano tũc capil] claffis maritime penet|.ibidé exiften \&:fieri fecit murü longiffimü:oe lapidib? fine calce qui murus fuit fact'in loco oicto eximili z tunc infulam ftalimine obtinucrüt: oetuaftantes locs multa turcozü: terra

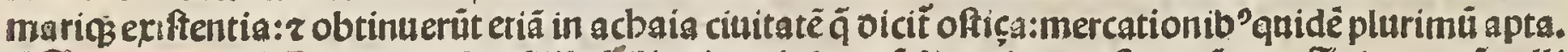

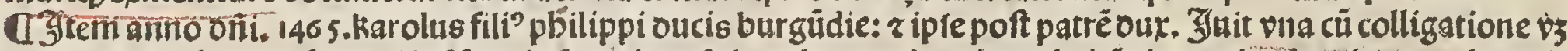
oés barones francie. frater.f.ipfi ${ }^{2}$ regis francie noie karolus oux barri.oux bzitänie.oux bozbonticcmes karmi, gnatb.ac etiam oux ioannes:z multi alij onces z oñi. Et in loco oicto amolieri:rumpit̃ ipfe rex francie:aufugiţ;

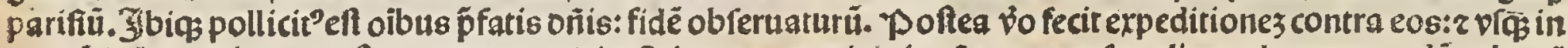

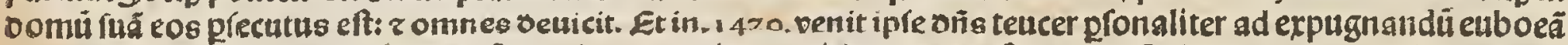
ciutatè oictä pulgo nigro ponte cũ maximo exercitu maritimo z equeftri z oemü cú maxims occifióez fangui,

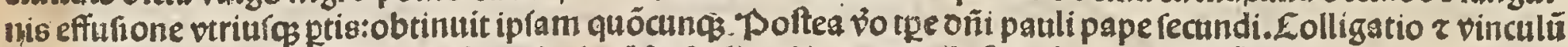

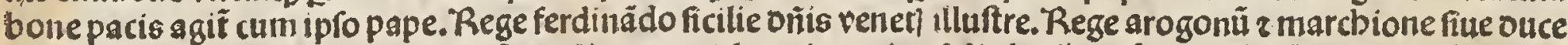
ferrarie. Et tüc poftea venit ad illuftre oñiuz venet). legatio regis gfidis buffucaflani petës cü magna inftantia a oñio ṕ faro fubfídiü contra turcüp mare tıñ: qz intendebat oino ad oeftructioné impatozis buitus ottomanozum

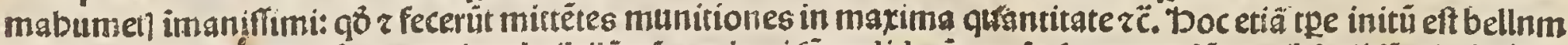

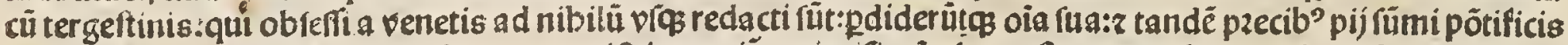

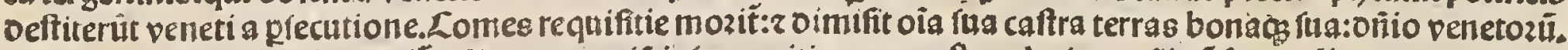

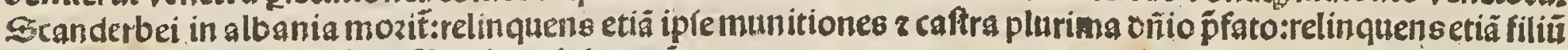
futu ipfi oñio in adoptiuũ:québenigne lütceperüt.

Qस सnno oni. 1477. Sur mediolani rediens ab ecclefia fancti ftepbani in oie fue feftuitatis occifus fuit:cũ pluri

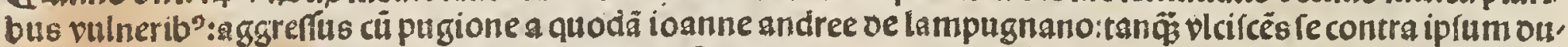
cem ee iniurijs fibi źfuis illatis ab codem ouce. Quare tumultus magn"fuit in populo. Iandem redato populo omnes redierüt ad fua. paulopoft ozta féditione:iulianus quondā cofmemedicis: in ecclefia fancte reparare flo rentie cü pugione vulnerat inter miffarü folénia quodam francifcbino oepactis victo:ciuenobili flozeñ. $z$ moz tuus efi, La urentı ${ }^{9}$ etiã cofme frater ei ${ }^{9}$ pitali vulnere vulnerat z euadit incolumis. Lua oe caufa oris. 11. cardina lis tituli fáncti gregozij nëpos oñi comitis bieronymi oetinet flozentie in cuftodia fecreta: z oris francifcus fal

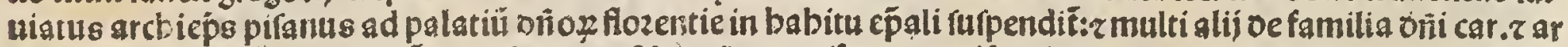

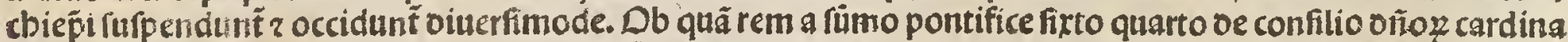

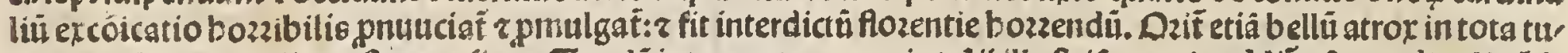

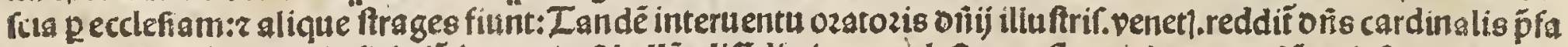

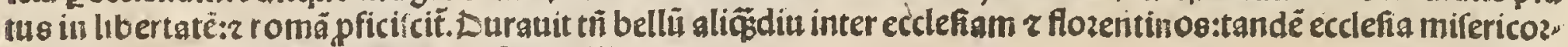
diter verfa eft cum ipfis.z placata eft cum illis.

- CIurci etia pauloghte venerunt in confinijs fozliuij:z tranfierüt aliqua flumina videlz illad qó vulgo oŕ lifon, zo r taiamento z plures ais captius 8 ouxerüt oe rṕianis: $r$ impie oepzedati funt nö fine fanguinis effufione $z$ mulro of ftrage:randem repulfi funt a oñio illuftri venet).

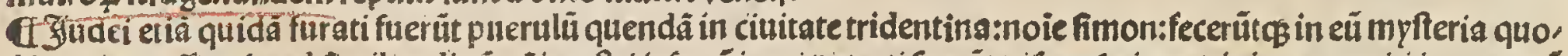

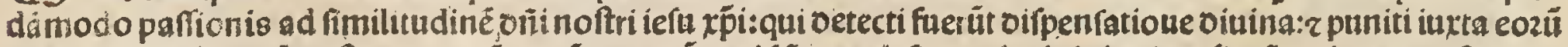

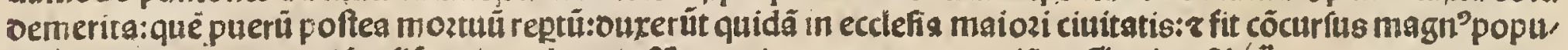

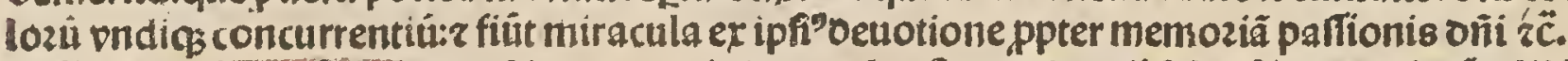

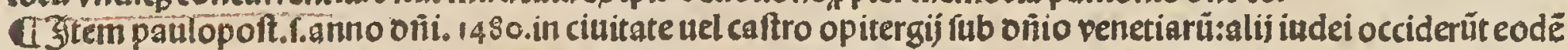

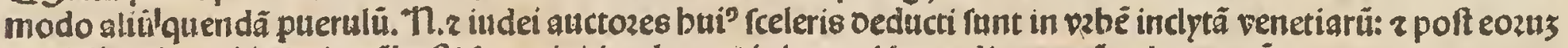
confefficnë pacti íceleris:cöbufti funt viui in platea oiui marci in medio ouarü columnarī.

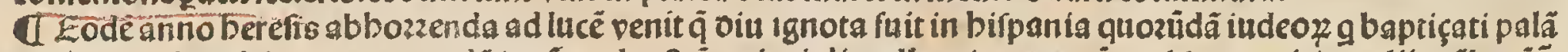

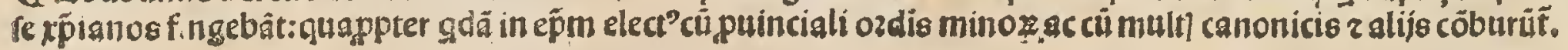




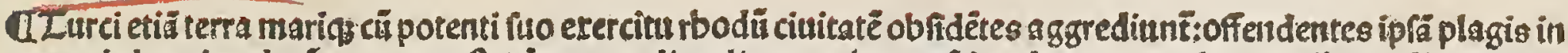
numeris bombardarú:muros oeftrnètes: $z$ vndíç alias muri ptes cörcendentes:z multos varís modis occiden

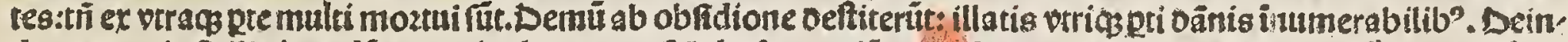

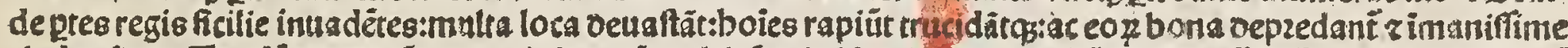

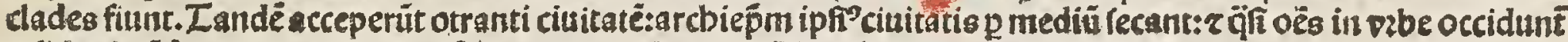

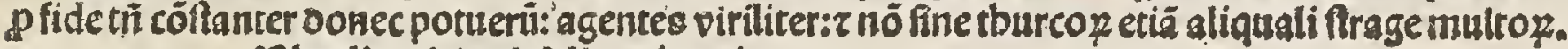

Kbodie vabis obfidio a tburcis.

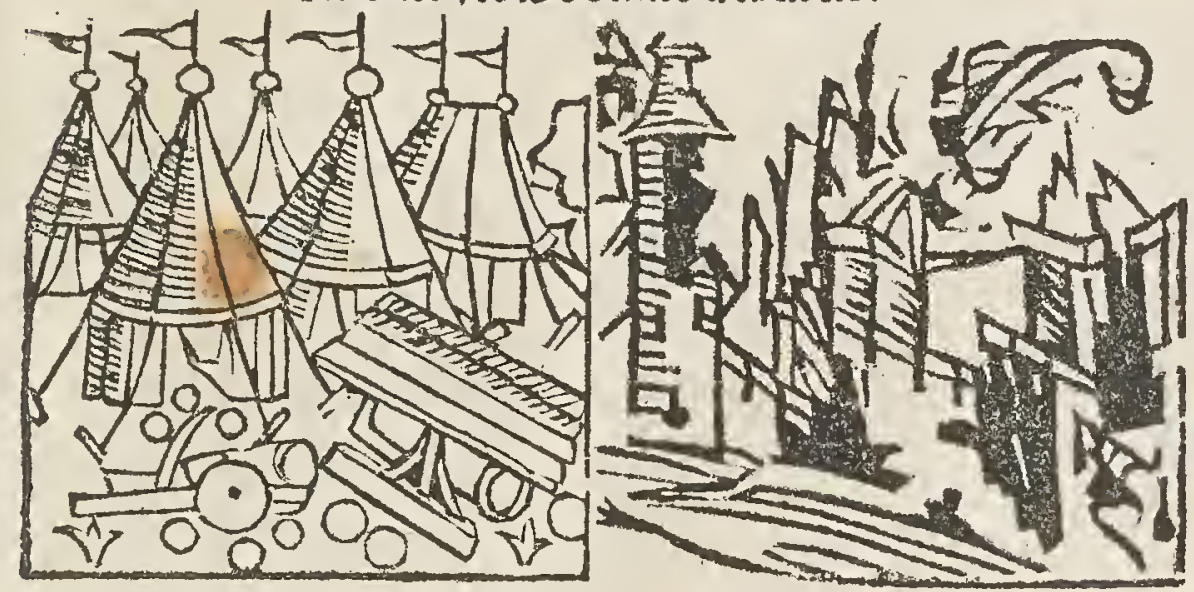

IAnno oñi. 1481. Dotumetus ottonianus g iam p.30. ãnos infeftifime xṕifideles pre. cut? fuerat multif terris xpe ianitatis fute oi tioni fubiagatis atrociffimis bellis: tandem oefendit ad inferos:tertia diemaij.

TEodéanno quo moztẻobijtmaumetus tumultus magn'oztus eft côftantinopoli. Dopul'enipofcebut 'Baif

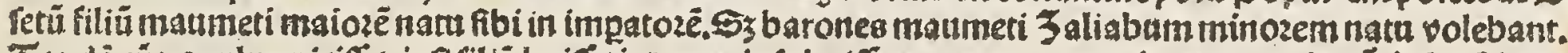

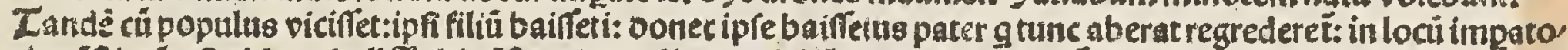

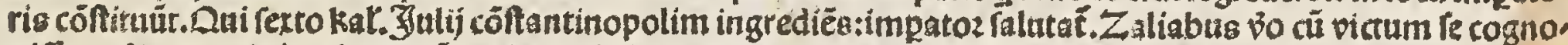
uiffet rediens ex fýria z imperiú cąiens obtinere afie:pzufas accepit. Qué poftea impatoz teucroz baifetus fú

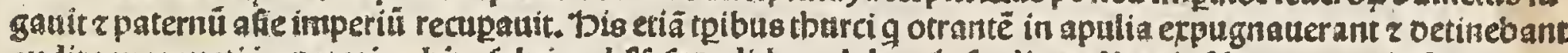
audito maumeti impatosis obitu faluis reb' fefe oedidere alpbonto ferdinandi regis filio:quos oeinde in man.

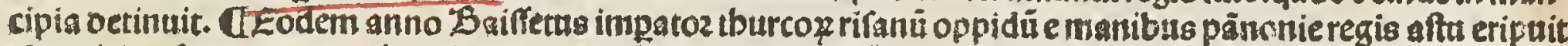

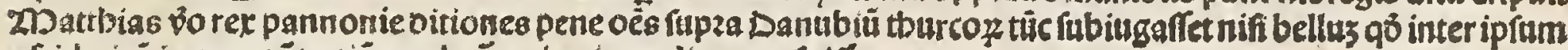
s fridericü intgatozẽ tertiü gerebă̈ acriter impedimento fuiffet.

\section{Erbardus Katdolt Fugultenfis impzelfioni parauit:

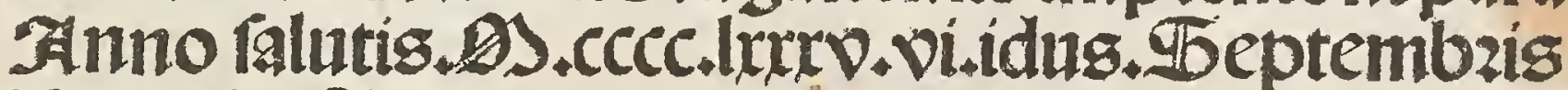 Eenetiis 3 Incly to pzincipe Zobanne Dsocenico.}




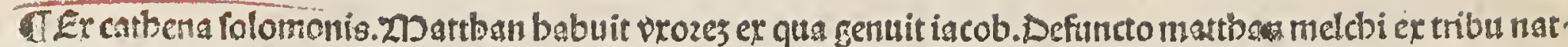
the: g films fuit quidem teui:frater aü pantberis nupfit vrozi mattbä:mattban vo iacob:z er ea genuit beli:z fic

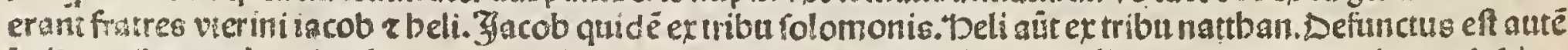
beli ex rribu nattban fine liberio: $z$ iacob ex tribu folomonis frater eius carnalis accepit vrozem eits : $r$ fufcita uic femen fratri fuo belı z gentuit iofepb virü marie. ZJ ofepb igit natura:elt fili? iacob ex linea folomonis: fed fuit

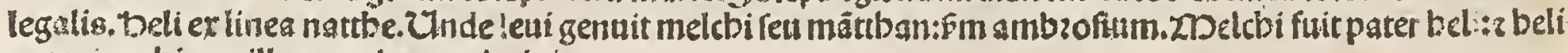
pater ioucbim:t ille pater beate virginis.

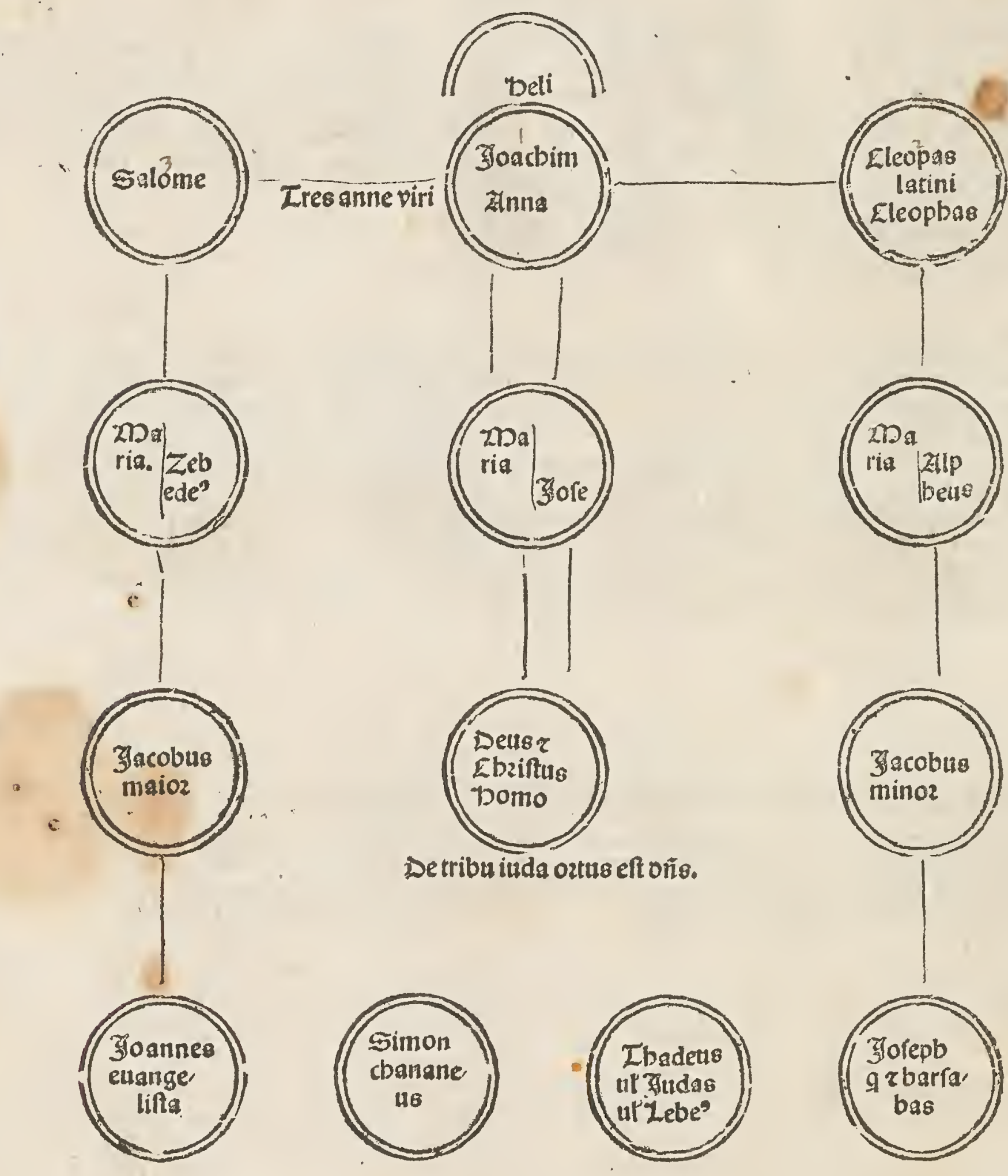

đ'Tn enangelio beati mattbei:in poncipio oicit. Liber generationis iefli xp̉ filij oatuid:filij ababam. Et beatus

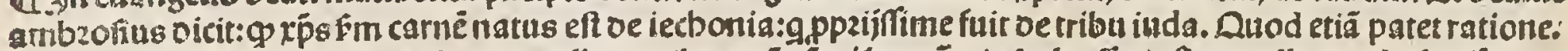
Lum eni pceptum fit numeri vltimo caplo.gp tribus nó cômi ceant: z iofepb effet iuftus:nullo modo feciffet con

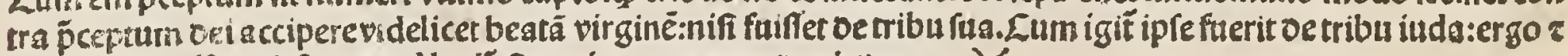
beata pirgo. Thec obfat quod legit Ero.vi.ca.gagaron ouxit vrozem X 
Xelifabetb:filiäaminadab fozozẻ naafon:g fuit oe tribu iuda:qz adbuc nö erat oatum illud pzeceptú oe nö cómifcendis tribubus. "Nec obftat $\phi$ anna mater beate virginis zifmeria oe qua nata eft elifabetb: fuerint fozozes:z; 9 elifabetb nupferit i o omo leui:côceflü eni futrat il ge $\phi$ fümus facerdos poffet accipe vrozé oe populo futo: oümó effet virgo z bone fame. Unde ifmeria $z$ anna fuerü oe tribu iada. Sร elíabetb filia ifmerie:nupta fuit çacbarie qui erat fa. cerdos in, vice fua:liç fueric oe tribu leui. Quidä vo oicüt ifmeriam fuiffe oe tribu beniamis.

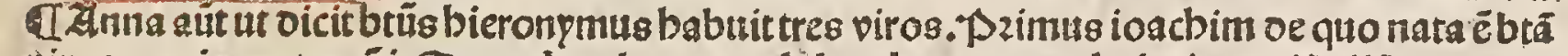
virgo maria mater xp̄i. Secundus cleopas uel eleopbas:oe quo babuit mariã aliã que nup fît

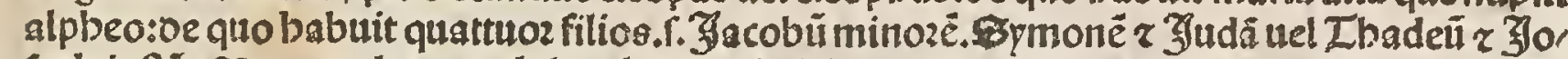
reph iuftü. DDozttio sleopg uel cleopba:nupfit falome:De quo genutit aliã mariam:que nup fit sebeddeo:oe quo babuit ouos filios. T.ioannēeusngeliftä:riacobü maioze. Unde veríns, Ex ioacbin cleopa falome:tres anna marias.

Qlsas peperit iunxit:iofepb alpbeo çebedeo.

'prima oeum iofe iacobum indam frmonég fecunda.

zaltera que requitur:iacobum pariter ato ioannem.

Ztem verfits.

Anna viro ioacbim peperit te virgo naria.

Dequa p:oceffit:fine femine tera fopbia.

polt bǘc cleopba gennit tibi virgo fozozem.

Que parit alpbeo:f́pmo, iud iofe iacobüg minozé.

boc quoq o efuncto:cuidan falome copulatur.

Dequo natop̧:çebedei genitrix generatur.

Sic tribus via viris genuit tres anna marias.

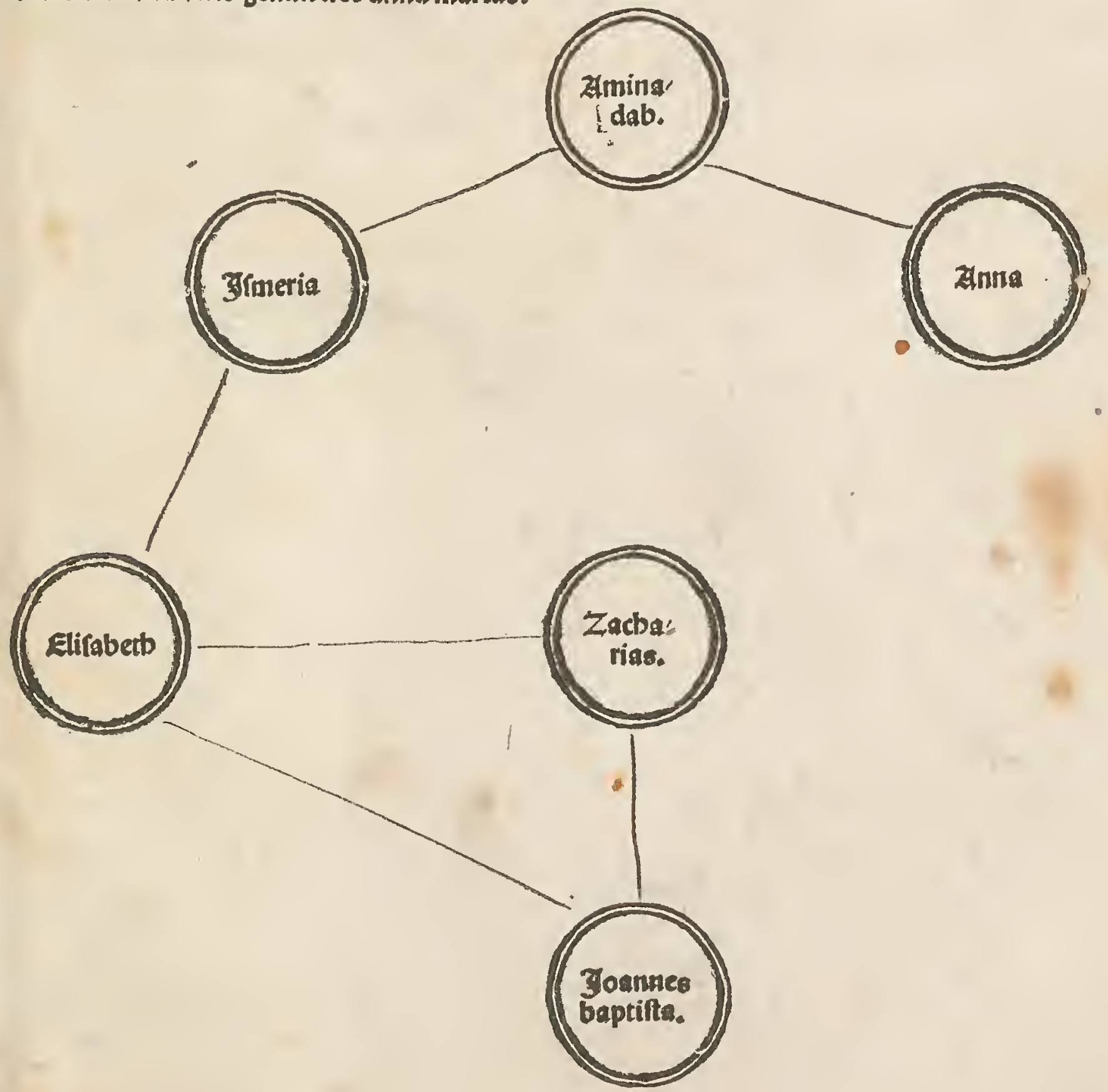




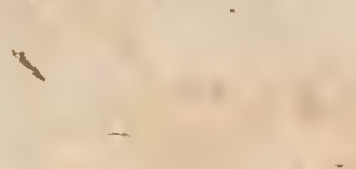

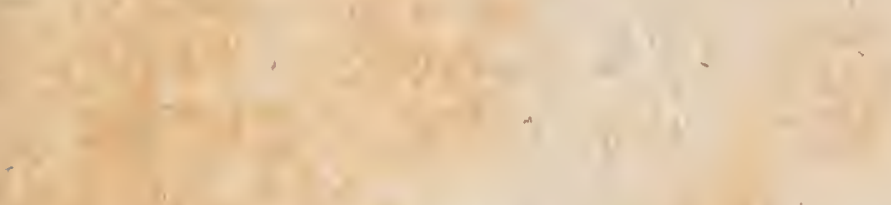

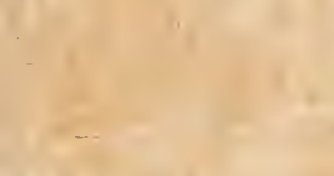

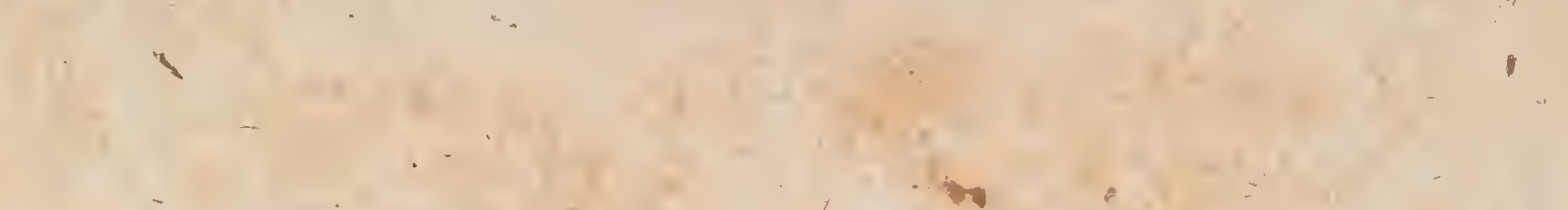

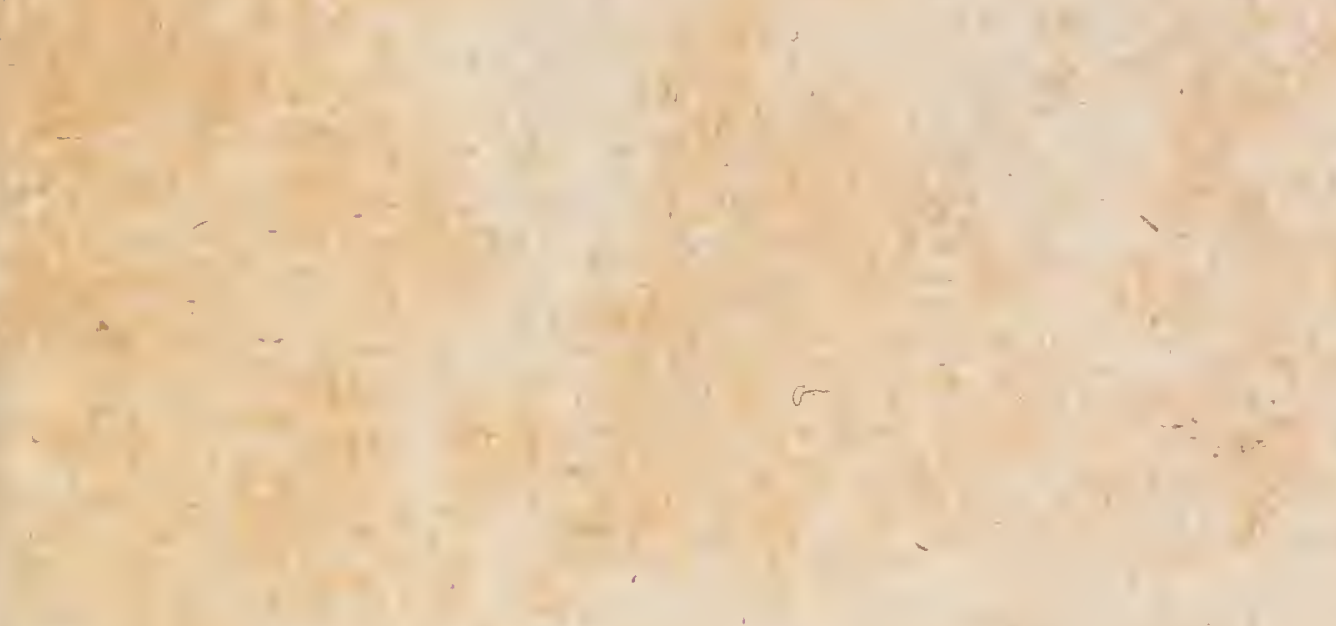

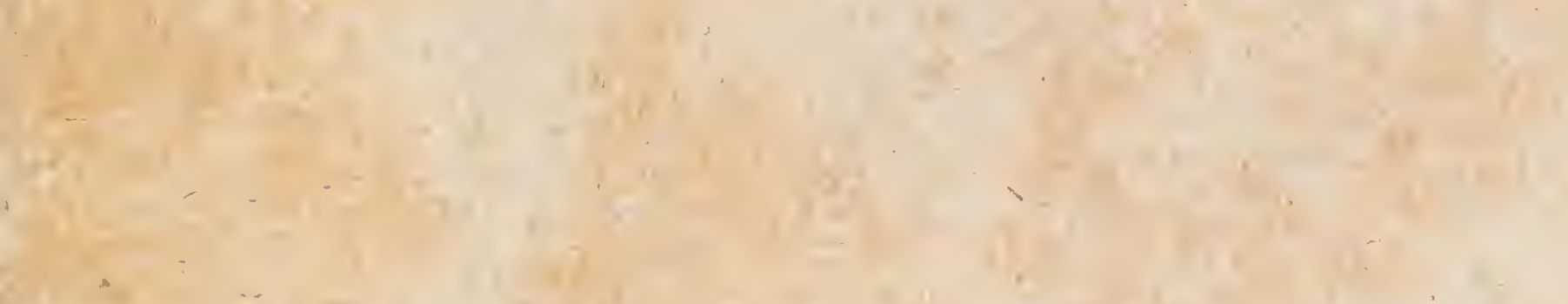

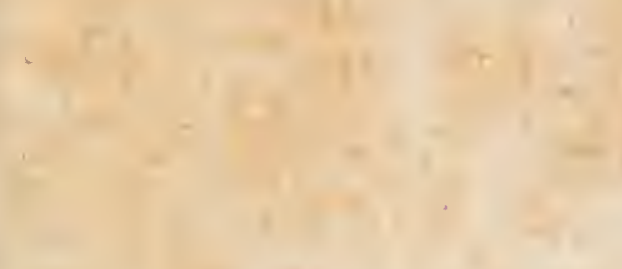

$-1$

:

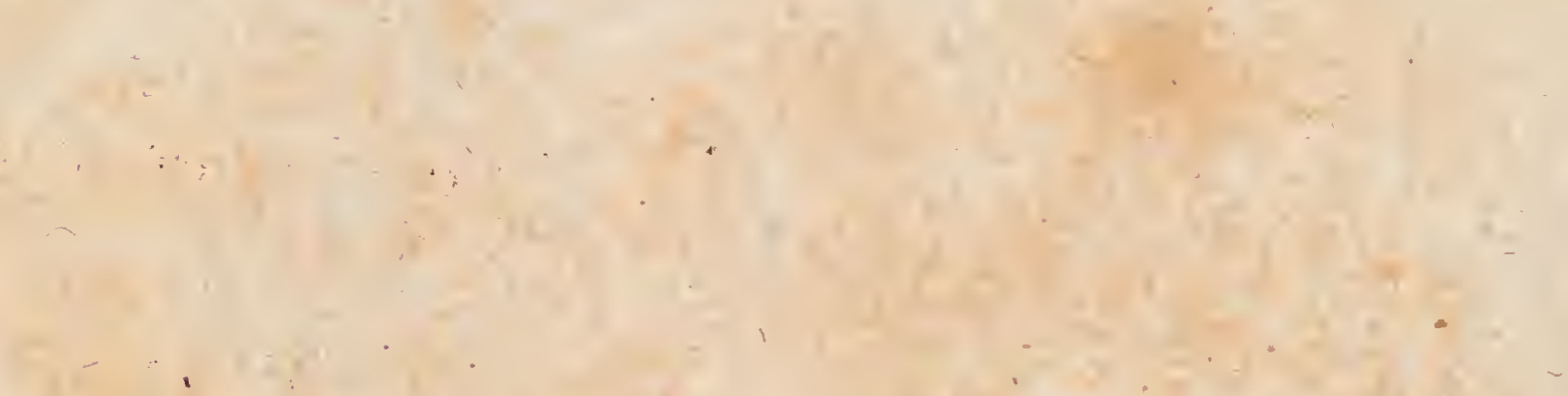

$-8$

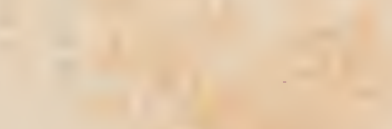

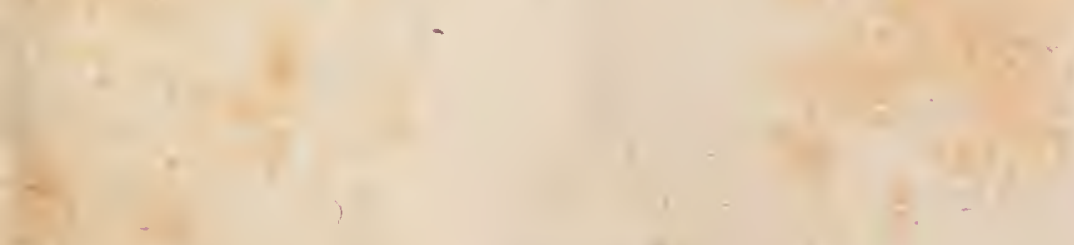

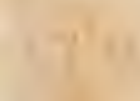

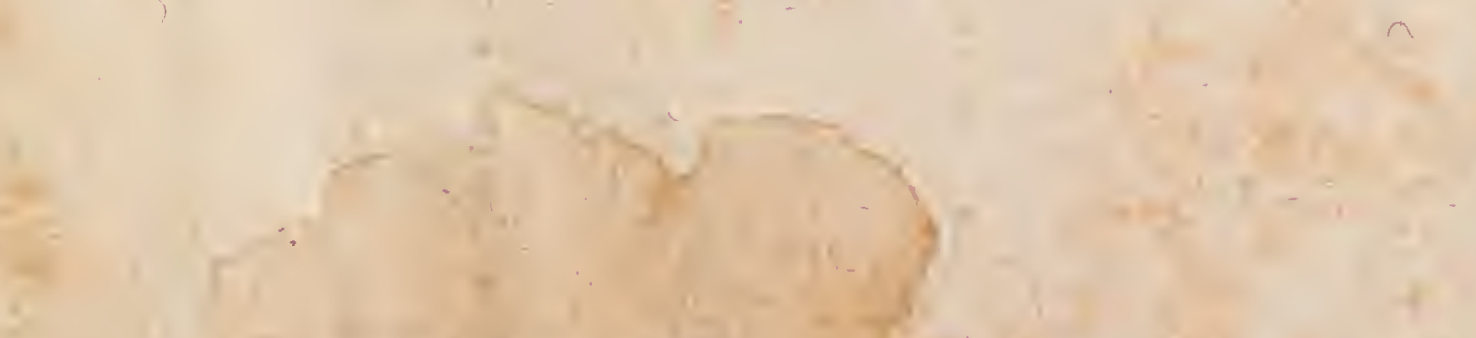




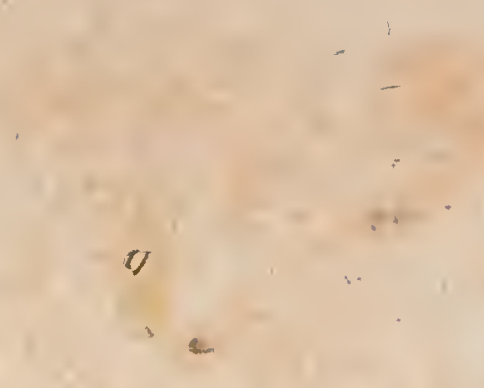

$$
\text { , , , }
$$

.

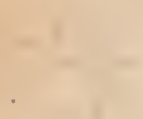

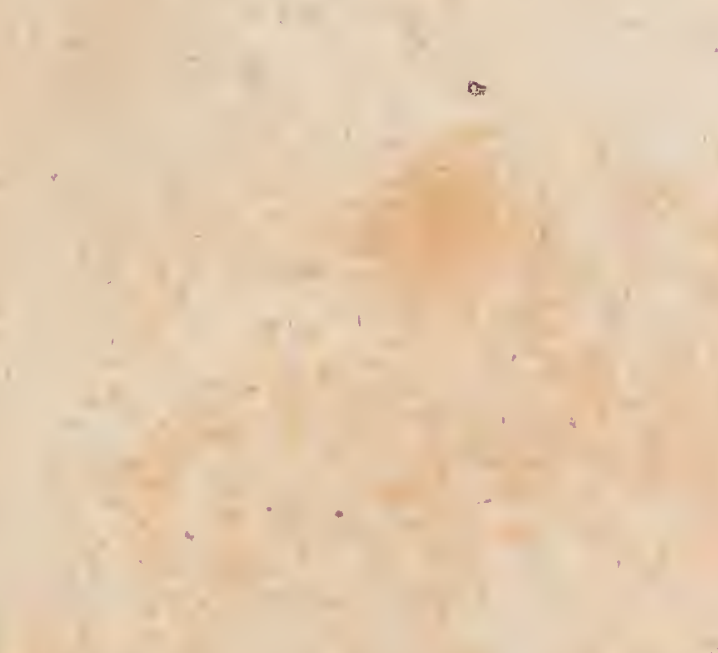



